\title{
Evaluation of Transport and Dispersion Models: A Controlled Comparison of HPAC and NARAC Predictions
}

S. Warner, J. F. Heagy, N. Platt, D. Larson, G. Sugiyama, J. S. Nasstrom, K. T. Foster, S. Bradley, G. Bieberbach

This article was submitted to

$5^{\text {th }}$ Annual George Mason University Transport and Dispersion

U.S. Department of Energy

Modeling Workshop, Fairfax, Virginia, July 18-19, 2001

Lawrence

Livermore

National

Laboratory

May 1, 2001 


\section{DISCLAIMER}

This document was prepared as an account of work sponsored by an agency of the United States Government. Neither the United States Government nor the University of California nor any of their employees, makes any warranty, express or implied, or assumes any legal liability or responsibility for the accuracy, completeness, or usefulness of any information, apparatus, product, or process disclosed, or represents that its use would not infringe privately owned rights. Reference herein to any specific commercial product, process, or service by trade name, trademark, manufacturer, or otherwise, does not necessarily constitute or imply its endorsement, recommendation, or favoring by the United States Government or the University of California. The views and opinions of authors expressed herein do not necessarily state or reflect those of the United States Government or the University of California, and shall not be used for advertising or product endorsement purposes.

This is a preprint of a paper intended for publication in a journal or proceedings. Since changes may be made before publication, this preprint is made available with the understanding that it will not be cited or reproduced without the permission of the author.

This report has been reproduced directly from the best available copy.

Available electronically at http://www.doc.gov/bridge

Available for a processing fee to U.S. Department of Energy

And its contractors in paper from

U.S. Department of Energy

Office of Scientific and Technical Information

P.O. Box 62

Oak Ridge, TN 37831-0062

Telephone: (865) 576-8401

Facsimile: (865) 576-5728

E-mail: reports@adonis.osti.gov

Available for the sale to the public from

U.S. Department of Commerce

National Technical Information Service

5285 Port Royal Road

Springfield, VA 22161

Telephone: (800) 553-6847

Facsimile: (703) 605-6900

E-mail: orders@ntis.fedworld.gov

Online ordering: http:/ / www.ntis.gov/ordering.htm

\section{OR}

Lawrence Livermore National Laboratory

Technical Information Department's Digital Library

http: / / www.llnl.gov/tid/Library.html 
IDA PAPER P-3555

\title{
EVALUATION OF TRANSPORT AND DISPERSION MODELS: A CONTROLLED COMPARISON OF HPAC AND NARAC PREDICTIONS
}

\author{
Steve Warner, IDA Project Leader \\ James F. Heagy \\ Nathan Platt \\ Institute for Defense Analyses \\ Alexandria, VA \\ David Larson \\ Gayle Sugiyama \\ John S. Nasstrom \\ Kevin T. Foster \\ Atmospheric Sciences Division
}

Lawrence Livermore National Laboratory

Livermore, CA

Scott Bradley

George Bieberbach

Logicon Advanced Technology

Alexandria, VA

14 May 2001

Copy

IDA Log No. H00-002143/1

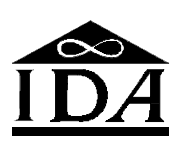

INSTITUTE FOR DEFENSE ANALYSES

Contract DASW01-98-C-0067

Task no. DC-9-1797 


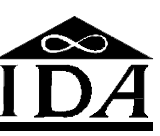

INSTITUTE FOR DEFENSE ANALYSES

Contract DASW01-98-C-0067

Task no. DC-9-1797 
IDA PAPER P-3555

\title{
EVALUATION OF TRANSPORT AND DISPERSION MODELS: A CONTROLLED COMPARISON OF HPAC AND NARAC PREDICTIONS
}

\author{
Steve Warner, IDA Project Leader \\ James F. Heagy \\ Nathan Platt \\ Institute for Defense Analyses \\ Alexandria, VA \\ David Larson \\ Gayle Sugiyama \\ John S. Nasstrom \\ Kevin T. Foster \\ Atmospheric Sciences Division
}

Lawrence Livermore National Laboratory

Livermore, CA

Scott Bradley

George Bieberbach

Logicon Advanced Technology

Alexandria, VA

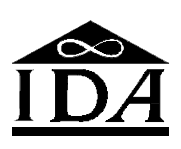

INSTITUTE FOR DEFENSE ANALYSES

Contract DASW01-98-C-0067

Task no. DC-9-1797 


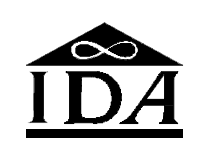

INSTITUTE FOR DEFENSE ANALYSES

Contract DASW01-98-C-0067

Task no. DC-9-1797 


\section{PREFACE}

The Institute for Defense Analyses (IDA) prepared this paper for the Defense Threat Reduction Agency (DTRA), in partial fulfillment of the task "Support for DTRA in the Validation Analysis of Hazardous Material Transport and Dispersion Prediction Models." The objective of this effort was to conduct analyses and special studies associated with the verification, validation, and accreditation of hazardous transport and dispersion prediction models. This task involves the comparison of two models: DTRA's Hazard Prediction and Assessment Capability (HPAC) and Lawrence Livermore National Laboratory's (LLNL) National Atmospheric Release Advisory Center (NARAC) modeling system.

The IDA Technical Review Committee was chaired by Thomas P. Christie and consisted of Arthur Fries, Jeffrey H. Grotte, Ira Kohlberg, David A. McWhorter, and Jozsef A. Toth. The authors would like to thank Allan Reiter (DTRA), Leon Wittwer (DTRA), and Don Ermak (LLNL) for their comments, critiques, and support throughout this effort.

The LLNL work was performed under the auspices of the U.S. Department of Energy by University of California Lawrence Livermore National Laboratory under contract No. W-7405-Eng-48. 


\section{EVALUATION OF TRANSPORT AND DISPERSION MODELS: \\ A CONTROLLED COMPARISON OF HPAC AND NARAC PREDICTIONS}

\section{TABLE OF CONTENTS}

SUMMARY

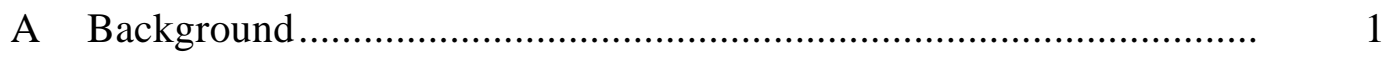

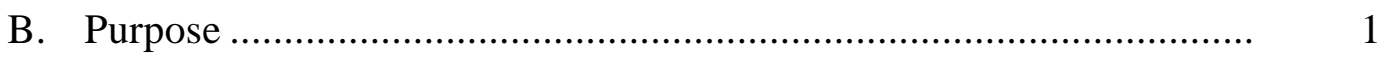

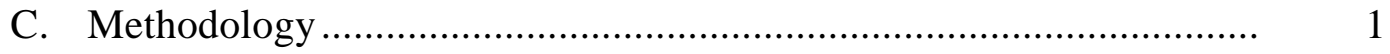

1. Compared Releases ................................................................ 1

2. Measures Used for These Comparisons ........................................ 3

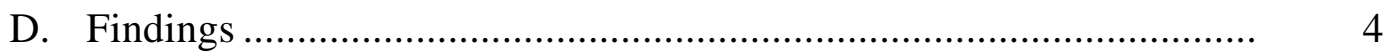

1. Model Intercomparisons.............................................................. 4

a. Influence of Release Height on Comparisons ......................... 6

b. Influence of Atmospheric Stability on Gas Release Comparisons ................................................................. 9

c. Influence of Particle Size on Comparisons ............................ 12

2. HPAC Prediction Excursions: Resolution Issues .......................... 12

a. Vertical Resolution .......................................................... 13

b. Horizontal Resolution ....................................................... 15

c. Time-Step Resolution ..................................................... 15

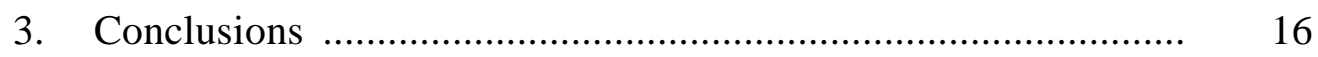

E. Outline of This Paper ........................................................................ 17

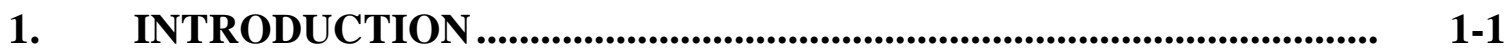

A. Background ................................................................................. 1-1

B. Brief HPAC Description................................................................ $1-3$

C. Brief NARAC Description ........................................................... 1-3

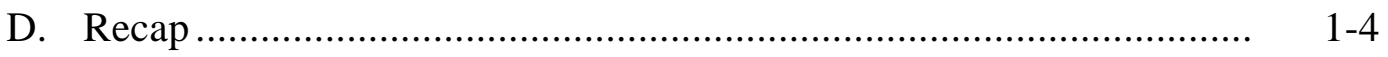

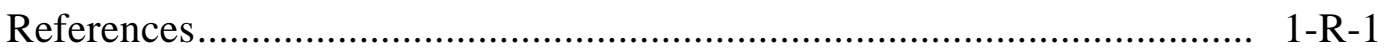

2. COMPARED RELEASES .................................................................... 2-1

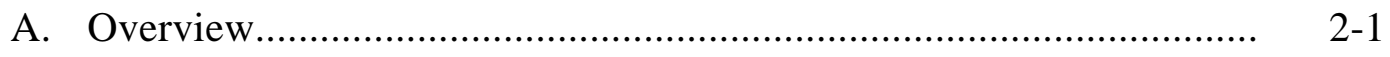

B. Model Specifics....................................................................... 2-3

1. Meteorology: Vertical Wind Profiles............................................ 2-3

2. HPAC Computational Details .................................................... 2-4 
a. HPAC Parameters and Settings ………………………......... 2-4

b. HPAC Surface Observation Files .......................................... 2-6

c. HPAC Output and Dosage Calculation.................................... 2- 2-7

3. NARAC Computational Details ................................................. 2-8

a. NARAC Meteorological Grids, Parameters, and Settings ...... 2- 2-8

b. NARAC Dosage Calculation................................................. 2-. 2-9

4. NARAC and HPAC Output Comparison Grids ........................... 2- 2-9

a. NARAC Grids ………………..................................... 2-10

b. HPAC Grids..................................................................... 2-11

C. Comparison Measures .................................................................... 2-13

1. Dosage Contours ................................................................... 2-13

2. Downwind Contour Distances................................................... 2-14

3. Crosswind Dosage Plume Widths ............................................. 2-14

4. Crosswind Maximum Dosages .................................................... 2- 2-15

5. Area-Based MOE ............................................................... 2-15

References............................................................................ 2-R-1

3. RESULTS OF COMPARISONS ......................................................... 3-1

A. Neutrally-Buoyant Gas Releases .................................................... 3-1

1. Representative Contour Plots .................................................... 3-1

2. Scatter Plot Comparison of Downwind Contour Distances ........... 3- 3-4

3. Scatter Plot Comparison of Crosswind Dosage Plume Widths...... 3-6

4. Scatter Plot Comparison of Crosswind Maximum Dosages .......... 3-11

5. Area-Based MOE.................................................................. 3-16

B. Particle Releases.................................................................... 3-19

1. Influence of Particle Size on Comparisons ................................ 3- 3-20

2. Influence of Release Height on Comparisons ............................. 3-27

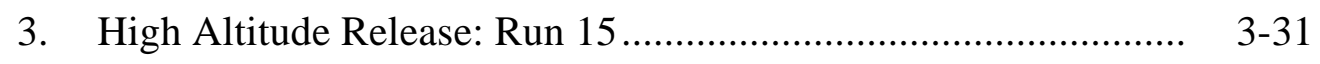

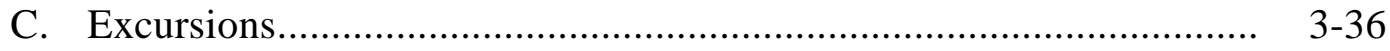

1. HPAC Vertical Resolution ................................................. 3-37

2. HPAC Horizontal Resolution .................................................... 3-40

3. HPAC Time-Step Resolution …………….......................... 3-42

References.............................................................................. 3-R-1

Appendix A - Acronyms

Appendix B - Initial Conditions for HPAC and NARAC Predictions

Appendix C - Gas Release Comparison Plots

Appendix D - Particle Release Comparison Plots 
Appendix E - Task Order Extract

\section{LIST OF FIGURES}

1. Results for Three Nominal Gas Release Scenarios as a Function of Meteorological Stability Category: at 60 Minutes with NARAC (Red -) and HPAC (Blue - -) Dosage Contours .

2. Results for Two Nominal Particle Release Scenarios as a Function of Particle Size (5 and $50 \mu$ ): at 60 Minutes with NARAC (Red -) and HPAC (Blue - -) Dosage Contours.

3. Results for Two "Higher" Altitude Release Scenarios: MvM 3 at 30 and 60 Minutes and MvM 15 at 120 and 240 Minutes with NARAC (Red -) and HPAC (Blue - -) Dosage Contours

4. Area-Based MOE for All Gas and Particle Releases. Red Circles Denote Releases at 2-Meter Height (Lowest Height Considered) and Blue Triangles Denote Releases At All Other Heights. MOE Values Separate as a Function of Height. $A_{O L}=$ the Area of Overlap, $A_{\mathrm{NARAC}}=$ the Area of the NARAC Prediction, and $\mathrm{A}_{\mathrm{HPAC}}=$ the Area of the HPAC Prediction All at a Specific Contour Level.

5. Scatter Plot Comparison of Downwind Contour Distances at 60 Minutes for All Gas Runs: Colors Indicate Meteorological Stability Categories and Dashed Lines are 15\% Overprediction Limits....

6. Dosage Contours at 30 Minutes and $1 \mathrm{~km}$ Downwind for Three 2-Meter Height Neutrally-Buoyant Gas Releases: MvM 1 (Stable), MvM 4 (NearNeutral), and MvM 7 (Unstable). Of the Seventeen Releases Studied, These Are Considered the Most Similar to the Previously Examined Prairie Grass Field Trials.

7. Scatter Plot Comparison of Downwind Contour Distances at 30 Minutes for Particle Runs MvM 10 through 14, 16, and 17: Colors Indicate Particle Size and Dashed Lines are 20\% Overprediction Limits.

8. MvM 1 at 60 Minutes with Upper: Dosage Contours for HPAC (Blue - -) and NARAC (Red -); Lower: Dosage on Downwind Symmetry Axis. HPAC Runs Are Done at Coarse and Fine Vertical Resolution Values of 40 and 10 Meters as Noted.

9. HPAC Dosage Along Downwind Symmetry Axis for MvM 4 at 30

Minutes. Blue Trace Is for 60 Second Time-Step (Baseline Value) and Red Trace Is for 30 Second Time-Step. The Magnitude of the Dosage Oscillations Decreases Substantially by Decreasing the Time-Step.

2-1. Vertical Wind Profiles for Model-Versus-Model Runs

2-2. Surface Observation File for Stable Releases (MvM 1 through 3)

2-3. Surface Observation File for Neutral Releases (MvM 4-6, 10-17)

2-4. Surface Observation File for Unstable Releases (MvM 7-9)

2-5. Grid Points for Grid 1: Blue Points Denote Those Retained for HPAC Sampler File 
2-6. Grid Points for Grid 2: Blue Points Denote Those Retained for HPAC

Sampler File.

$2-12$

2-7. Illustration of Three Regions for Two Model Predictions $\mathrm{M}_{1}$ and $\mathrm{M}_{2}$

$2-15$

2-8. Illustration of Area-Based MOE

$2-16$

3-1. MvM 1 (Stable) at 60 Minutes: Histogram of NARAC (Red -) and HPAC (Blue - -) Dosages with Lower and Upper Contours at $10^{-10} \mathrm{~kg}-\mathrm{s} / \mathrm{m}^{3}$ and $10^{-5} \mathrm{~kg}-\mathrm{s} / \mathrm{m}^{3}$, Respectively

3-2. MvM 1 (Stable) at 60 Minutes with Upper: NARAC (Red -) and HPAC (Blue - -) Dosage Contours; Lower: Log Dosages on Downwind Symmetry Axis.

3-3. MvM 4 (Near-Neutral) at 60 Minutes with Upper: NARAC (Red -) and HPAC (Blue - -) Dosage Contours; Lower: Log Dosages on Downwind Symmetry Axis.

3-4. MvM 7 (Unstable) at 60 Minutes with Upper: NARAC (Red -) and HPAC (BLUE - -) Dosage Contours; Lower: Log Dosages on Downwind Symmetry Axis.

3-5. Scatter Plot Comparison of Downwind Contour Distances at 30 Minutes for All Gas Runs: Colors Indicate Meteorological Stability Categories and Dashed Lines are 20\% Overprediction Limits.

3-6. Scatter Plot Comparison of Downwind Contour Distances at 60 Minutes for All Gas Runs: Colors Indicate Meteorological Stability Categories and Dashed Lines are 15\% Overprediction Limits.

3-7. MvM 1 at 60 Minutes with Crosswind Plume Profiles at Selected Downwind Distances: NARAC (Red -) and HPAC (Blue - -).

3-8. MvM 4 at 60 Minutes with Crosswind Plume Profiles at Selected Downwind Distances: NARAC (Red -) and HPAC (Blue - -)

3-9. MvM 7 at 60 Minutes with Crosswind Plume Profiles at Selected Downwind Distances: NARAC (Red -) and HPAC (Blue - -)

3-10. Scatter Plot Comparison of Crosswind Plume Widths at 30 Minutes for All Gas Runs: Colors Indicate Meteorological Stability Categories and Dashed Lines Show 20\% and 50\% Overprediction Limits

3-11. Scatter Plot Comparison of Crosswind Plume Widths at 60 Minutes for All Gas Runs: Colors Indicate Meteorological Stability Categories and Dashed Lines Show 20\% and 50\% Overprediction Limits

3-12. Scatter Plot Comparison of Maximum Crosswind Dosage at 30 Minutes for All Gas Runs: Colors Indicate Meteorological Stability Categories, Marker Size is Proportional to Downwind Distance, Dashed Lines Show 10x, 100x, and 1000x HPAC Overprediction Limits and 10x NARAC Overprediction Limit, and Indicated Outliers Are from Stable Run 3

3-13. Scatter Plot Comparison of Maximum Crosswind Dosage at 60 Minutes for All Gas Runs: Colors Indicate Meteorological Stability Categories, Marker Size is Proportional to Downwind Distance, Dashed Lines Show 10x, 100x, and 1000x HPAC Overprediction Limits and 10x NARAC Overprediction Limit, and Indicated Outliers Are from Stable Run 3.

3-14. MvM 3 at 30 Minutes with Upper: NARAC (Red -) and HPAC (Blue - -) Dosage Contours; Lower: Log Dosages on Downwind Symmetry Axis 
3-15. MvM 3 at 30 Minutes with Crosswind Plume Profiles at Selected Downwind Distances: NARAC (Red -) and HPAC (Blue - -) (Note Log Dosage on Vertical Axis).

3-16. MvM 3 at 60 Minutes with Upper: NARAC (Red -) and HPAC (Blue - -) Dosage Contours; Lower: Log Dosages on Downwind Symmetry Axis......

3-17. MvM 3 at 60 Minutes with Crosswind Plume Profiles at Selected Downwind Distances: NARAC (Red -) and HPAC (Blue - -) (Note Log Dosage on Vertical Axis)

3-18. Dosage Contours for MvM 1 at 30 Minutes: Contour Levels Are Indicated on the Left, Red (Blue) Lines Denote NARAC (HPAC) Contours, and Red (Blue) Circles Denote Boundary of Overlap Region Belonging to NARAC (HPAC) Contours.

3-19. Area-Based MOE for All Gas Runs at 30 Minutes. Colors Denote Stability: Red $=$ Stable, Blue $=$ Neutral, and Green $=$ Unstable. Circle Sizes are Proportional to Dosage Contour Level. By Stability Type, Unstable Cases Show Best Model Agreement. MvM 3 Points are Indicated, Showing Extreme HPAC Overprediction.

3-20. Area-Based MOE for All Gas Runs at 60 Minutes. Colors Denote Stability: Red $=$ Stable, Blue $=$ Neutral, and Green $=$ Unstable. Circle Sizes are Proportional to Dosage Contour Level. By Stability Type, Unstable Cases Show Best Model Agreement. MvM 3 Points are Indicated, Showing Extreme HPAC Overprediction.

3-21. MvM 10 at 60 Minutes with Upper: NARAC (Red -) and HPAC (Blue - -) Dosage Contours; Lower: Log Dosages on Downwind Symmetry Axis. Particle Diameter is $5 \mu$, Release Height is $2 \mathrm{~m}$, and Release Duration is $15 \mathrm{~min}$.

3-22. MvM 13 at 60 Minutes with Upper: NARAC (Red -) and HPAC (Blue - -) Dosage Contours; Lower: Log Dosages on Downwind Symmetry Axis. Particle Diameter is $50 \mu$, Release Height is $2 \mathrm{~m}$, and Release Duration is "Instantaneous."

3-23. MvM 16 at 60 Minutes with Upper: NARAC (Red -) and HPAC (Blue - -) Dosage Contours; Lower: Log Dosages on Downwind Symmetry Axis. Particle Diameter (Mass Median Diameter) is $500 \mu$, Release Height is 2 $\mathrm{m}$, and Release Duration is "Instantaneous."

3-24. Area-Based MOE for Particle Runs 10, 13, and 16 at 30 and 60 Minutes. Colors Indicate Particle Size and Circle Size is Proportional to Dosage Contour Level.

3-25. Scatter Plot Comparison of Downwind Contour Distances at 30 Minutes for Particle Runs MvM 10 through 14, 16, and 17: Colors Indicate Particle Size and Dashed Lines are 20\% Overprediction Limits.

3-26. Scatter Plot Comparison of Downwind Contour Distances at 60 Minutes for Particle Runs MvM 10 through 14, 16, and 17: Colors Indicate Particle Size and Dashed Lines are 20\% Overprediction Limits.

3-27. MvM 10 at 60 Minutes with Upper: NARAC (Red -) and HPAC (Blue - -) Dosage Contours; Lower: Log Dosages on Downwind Symmetry Axis. 
Particle Diameter is $5 \mu$, Release Height is $2 \mathrm{~m}$, and Release Duration is $15 \mathrm{~min}$

3-28. MvM 11 at 60 Minutes with Upper: NARAC (Red -) and HPAC (Blue - -) Dosage Contours; Lower: Log Dosages on Downwind Symmetry Axis. Particle Diameter is $5 \mu$, Release Height is $250 \mathrm{~m}$, and Release Duration is $15 \mathrm{~min}$.

3-29. MvM 12 at 60 Minutes with Upper: NARAC (Red -) and HPAC (Blue - -) Dosage Contours; Lower: Log Dosages on Downwind Symmetry Axis. Particle Diameter is $5 \mu$, Release Height is $400 \mathrm{~m}$, and Release Duration is $15 \mathrm{~min}$.

3-30. Area-Based MOE for Particle Runs 10, 11, and 12 at 30 and 60 Minutes. Colors Indicate Release Height and Circle Size is Proportional to Dosage Contour Level.

3-31. MvM 15 at 120 Minutes with Upper: Dosage Contours for HPAC (Blue - -) and NARAC (Red -); Lower: Dosage on Downwind Symmetry Axis

3-32. MvM 15 at 240 Minutes with Upper: Dosage Contours for HPAC (Blue - -) and NARAC (Red -); Lower: Dosage on Downwind Symmetry Axis.

3-33. Area-Based MOE for Particle MvM 15: Colors Indicate Time After Release and Circle Size is Proportional to Dosage Contour Level. Agreement is Better for Later Times and Higher Dosages.

3-34. NARAC and HPAC Instantaneous Concentrations $\left(1.0 \times 10^{-9} \mathrm{~kg} / \mathrm{m}^{3}\right)$ for MvM 3 at $\mathrm{t}=10,20,30,40,50$, and 60 Minutes The Material is Moving from Right to Left. The HPAC Contours Show Much Greater Vertical Diffusion and Descend at a Greater Rate.

3-35. MvM 1 at 60 Minutes with Upper: Dosage Contours for HPAC (Blue - -) and NARAC (Red -); Lower: Dosage on Downwind Symmetry Axis. HPAC Run Done at Coarse Vertical Resolution Value of 40 Meters (Default HPAC Value). Note Extended HPAC Plume in Downwind Direction.

3-36. MvM 1 at 60 Minutes with Upper: Dosage Contours for HPAC (Blue - -) and NARAC (Red -); Lower: Dosage on Downwind Symmetry Axis. HPAC Run Done at Fine Vertical Resolution Value of 10 Meters (Adopted Baseline HPAC Value). Effective Transport Speed of HPAC Plume is Lower With Finer Vertical Sampling.

3-37. Vertical Wind Profile for MvM 1 (Blue -) and 40-Meter Sampling Height (Red - -). Coarse Vertical Sampling Artificially Inflates the Effective Transport Speed.

3-38. HPAC Surface Dosage Contours for MvM 1 at 60 Minutes. Color-Filled Contours Are For 0.4 km Horizontal Resolution and Solid Black Contours (at Same Contour Levels) Are For $1 \mathrm{~km}$ Horizontal Resolution. Note High-Frequency Distortions Introduced in Color Contours, Believed to Be an Artifact of "Puff-Splitting" Routines in SCIPUFF.

3-39. HPAC Dosage Along Downwind Symmetry Axis for MvM 4 at 30 Minutes. Blue Trace Is for 60 Second Time-Step (Baseline Value) and 
Red Trace Is for 30 Second Time-Step. The Magnitude of the Dosage

Oscillations Decreases Substantially by Decreasing the Time-Step.

\section{LIST OF TABLES}

1. Key Input Conditions for the Model-to Model Comparisons........................ 3

2-1. Input Conditions for the Model-to Model Comparisons ………………...... 2-2

3-1. MOE Areas for MvM 1 at 30 Minutes .................................................... 3-17

3-2. Maximum Dosages for MvM 15 at a Sampling Height of 10 Meters.......... 3-31 



\section{SUMMARY}

\section{A. BACKGROUND}

During fiscal year 2000, a series of studies in support of the Defense Threat Reduction Agency (DTRA) was begun. The goal of these studies is to improve the verification, validation, and accreditation (VV\&A) of hazard prediction and assessment models and capabilities. These studies are part of a larger joint VV\&A collaborative effort that DTRA and the Department of Energy (DOE), via the Lawrence Livermore National Laboratory (LLNL), are conducting. This joint effort includes comparisons of the LLNL and DTRA transport and dispersion (T\&D) modeling systems, NARAC and HPAC, respectively. ${ }^{1}$

\section{B. PURPOSE}

The purpose of this work is to compare, in a systematic way, HPAC and NARAC model predictions for a set of controlled hypothetical release scenarios. Only "modelversus-model" comparisons are addressed in this work. Model-to-field trial comparisons for HPAC and NARAC have been addressed in a recent companion study, ${ }^{2}$ in support of the same joint VV\&A effort.

\section{METHODOLOGY}

\section{Compared Releases}

In January 2000, members of the joint collaboration met at LLNL to establish a set of release scenarios for this model-to-model study. Seventeen scenarios were agreed upon based on several selection criteria.

$1 \quad$ NARAC $=$ National Atmospheric Release Advisory Center and HPAC $=$ Hazard Prediction and Assessment Capability.

2 Warner S., Platt, N., Heagy, J. F., Bradley, S., Bieberbach, G., Sugiyama, G., Nasstrom, J. S., Foster, K. T, and Larson, D., User-Oriented Measures of Effectiveness for the Evaluation of Transport and Dispersion Models, IDA Paper P-3554, 8 January 2001. 
First and foremost was the desire for simplicity so that the scenarios would test only the core transport and dispersion algorithms within each model. Consequently, all releases were chosen to have idealized weather - a defined single unidirectional vertical wind speed profile. ${ }^{3}$ Terrain was similarly elementary - flat terrain with a constant surface roughness of $0.008 \mathrm{~m}$. Downwind transport distances of $40 \mathrm{~km}$ were used for all but one "high altitude" release. Initial source geometries were also kept simple spherical sources (Gaussian with standard deviation $=1 \mathrm{~m}$ in all directions) for 16 of the 17 releases and a $500 \mathrm{~m}$ line source in the remaining release.

A mix of atmospheric conditions - stable, near-neutral, and unstable - were chosen through suitable choices of the atmospheric boundary layer height, $\mathrm{z}_{\mathrm{i}}$, and MoninObukhov length, L. A range of release heights (relative to the boundary layer height) was also chosen. ${ }^{4}$

Two agent types were considered: "neutrally-buoyant gas" (9 releases) and "particles" ( 8 releases). Particle runs were carried out for three particle size distributions, two using fixed diameter particles of 5 microns $(\mu)$ and $50 \mu$, and the third with a log-normal distribution with a mass median diameter (MMD) of $500 \mu$ and a geometric standard deviation $(\sigma)$ of 2 . Releases were chosen to be either instantaneous or continuous, and in all cases the mass of released agent was $1 \mathrm{~kg} .^{5}$

The chosen comparison scenarios do not represent an exhaustive set of potential cases and should not be considered as the basis for a complete statistical analysis of model comparisons. Rather, the trials were chosen to examine the impact of critical transport and dispersion parameters on relative model behavior. Specifically, the 17 trials

3 Vertical wind speed variations were inferred from a $5 \mathrm{~m} / \mathrm{s}$ wind speed observation at 10 meters. See Chapter 2, Section B.1 for additional details.

4 The Monin-Obukhov length, L, is a length scale determined from the surface heat and momentum fluxes, and is a fundamental scaling parameter for boundary layer turbulence. The boundary layer height defines the depth of the turbulent layer generated by the surface, and is another fundamental turbulence scaling parameter. See, Pasquill, F., Atmospheric Diffusion, The Dispersion of Windborne Material from Industrial and other Sources, Second Edition, Wiley, 1974.

5 Additional details associated with the examined releases are provided in Chapter 2. Note that these releases were not intended to represent actual or hypothetical accidents or attacks. 
allowed for the comparison of model predictions as a function of atmospheric stability condition, source type (gas or particle), release duration, release height, and particle size. ${ }^{6}$

Table 1 presents the key input conditions for the seventeen runs that were examined. The first column denotes the run number and the second column identifies the source type (neutrally-buoyant gas or particles). The next two columns present the values used for two critical dimensionless input parameters - the ratio of release height to boundary layer height $\left(\mathrm{z}_{\mathrm{r}} / \mathrm{z}_{\mathrm{i}}\right)$ and the ratio of boundary layer height to Monin-Obukhov length $\left(\mathrm{z}_{\mathrm{i}} / \mathrm{L}\right)$.

Table 1. Key Input Conditions for the Model-to Model Comparisons

\begin{tabular}{|c|c|c|c|}
\hline Run & Source & $\begin{array}{c}\text { Release Height } / \\
\text { Boundary Layer } \\
\text { Height }\left(\mathrm{z}_{\mathrm{r}} / \mathrm{z}_{\mathrm{i}}\right)^{\mathrm{a}}\end{array}$ & 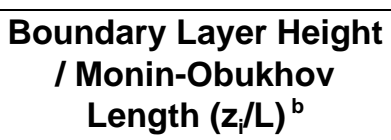 \\
\hline 1 & neutrally-buoyant gas & 0.02 & 4 (stable) \\
\hline 2 & neutrally-buoyant gas & 0.50 & 4 (stable) \\
\hline 3 & neutrally-buoyant gas & 0.80 & 4 (stable) \\
\hline 4 & neutrally-buoyant gas & 0.004 & -1 (near-neutral) \\
\hline 5 & neutrally-buoyant gas & 0.50 & -1 (near-neutral) \\
\hline 6 & neutrally-buoyant gas & 0.80 & -1 (near-neutral) \\
\hline 7 & neutrally-buoyant gas & 0.004 & -10 (Unstable) \\
\hline 8 & neutrally-buoyant gas & 0.50 & -10 (Unstable) \\
\hline 9 & neutrally-buoyant gas & 0.80 & -10 (Unstable) \\
\hline 10 & $5 \mu$ & 0.004 & -1 (near-neutral) \\
\hline 11 & $5 \mu$ & 0.50 & -1 (near-neutral) \\
\hline 12 & $5 \mu$ & 0.80 & -1 (near-neutral) \\
\hline 13 & $50 \mu$ & 0.004 & -1 (near-neutral) \\
\hline 14 & $50 \mu$ & 0.004 & -1 (near-neutral) \\
\hline 15 & $50 \mu$ & 1.50 & -1 (near-neutral) \\
\hline 16 & $\log$ normalc $^{c}$ & 0.004 & -1 (near-neutral) \\
\hline 17 & log normal & 0.004 & -1 (near-neutral) \\
\hline
\end{tabular}

a $\quad \mathrm{z}_{\mathrm{r}}=$ release height, $\mathrm{z}_{\mathrm{i}}=$ boundary layer height

b $\quad \mathrm{L}=$ Monin-Obukhov length. For this study, atmospheric stability categories were defined as follows: stable runs $\mathrm{z}_{\mathrm{i}} / \mathrm{L}=4$, near-neutral runs $\mathrm{z}_{\mathrm{i}} / \mathrm{L}=-1$, and unstable runs $\mathrm{z}_{\mathrm{i}} / \mathrm{L}=-10$.

c For the log-normal particle distribution, the $\mathrm{MMD}=500 \mu$ and the geometric standard deviation $=\sigma=$ 2.

6 In order to manage the size and scope of this study, only a limited range of values were chosen for several of these variables. 


\section{Measures Used for These Comparisons}

For each run, we compared contoured regions at three to seven dosage levels. Dosage contours provide immediate graphical information about the relative performance of model-to-model results; model agreement or lack thereof can be quickly assessed. The following quantitative measures were also used for comparisons of model outputs. ${ }^{7}$

- Downwind Contour Distances: For a given near-surface (10m) dosage value, the downwind distance (along the symmetry axis) to that dosage was computed for both models. This metric, in particular, addresses the relative transport characteristics of the model predictions.

- Crosswind Dosage Plume Widths: For these comparisons, we used a doseweighted width (described in Chapter 2). This metric allows for direct comparisons of model crosswind dispersion features.

- Area-Based Measure of Effectiveness (MOE): This measure considers three regions of interest: 1) HPAC and NARAC predictions agree (overlap), 2) HPAC predicts a larger region for a given dosage than NARAC, and 3) NARAC predicts a larger region for a given dosage than HPAC. ${ }^{8}$ A twodimensional vector composed of the fraction of the NARAC prediction that corresponds to overlap and the fraction of the HPAC prediction that corresponds to overlap represents the area-based MOE. ${ }^{9}$ The MOE provides information associated with both transport (direction and downwind distance) and dispersion.

\section{FINDINGS}

\section{Model Intercomparisons}

One of the chief findings of this study was that, with the selection of consistent input parameters (see Section D.2), the predictions of HPAC and NARAC for many of these simple scenarios agreed quite well. Figure 1 displays three such cases. Shown in the figure are the predicted HPAC (blue) and NARAC (red) near-surface (10m) dosage

7 In addition, to the metrics described here, we examined the crosswind maximum dosages (i.e., the maximum predicted dosages of each model, at several downwind distances) and the dosage along the downwind symmetry axis.

8 For simplicity when discussing the area-based MOE, we will use the terminology "overprediction/underprediction" when one model predicts a larger/smaller area for a specified contour level.

9 Chapter 2, Section C.5 provides additional discussion. 
contours for three neutrally-buoyant gas release runs: Model versus Model run 1 (MvM 1), MvM 4, and MvM 7. These three runs, each with release height 2 meters (m), correspond to three meteorological stability categories, stable, near-neutral, and unstable, respectively.

Stable

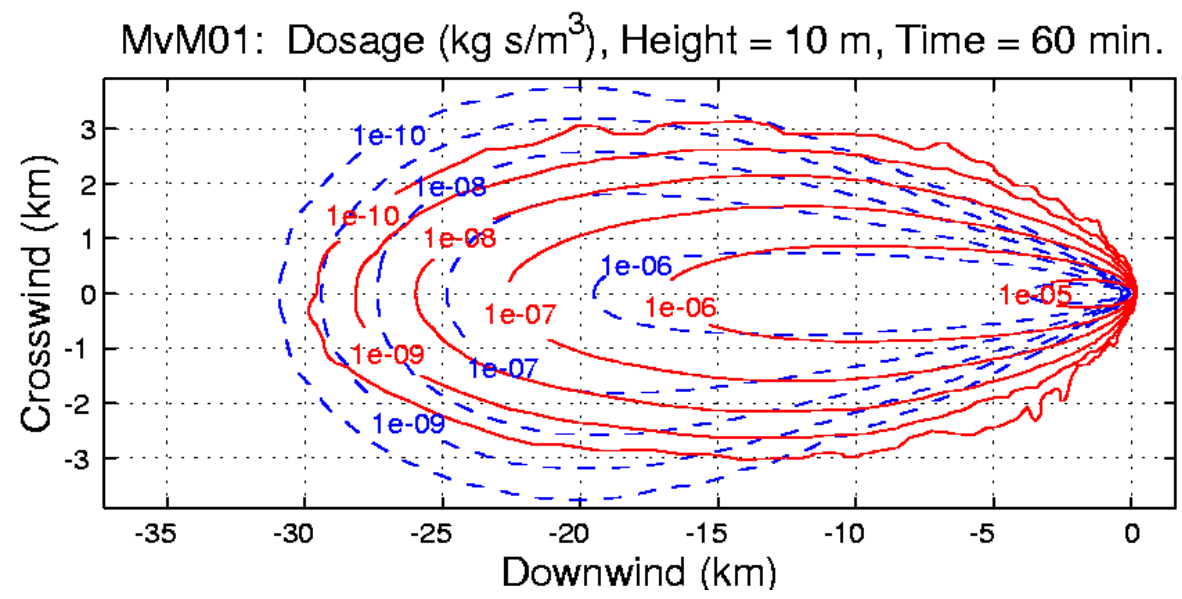

NearNeutral
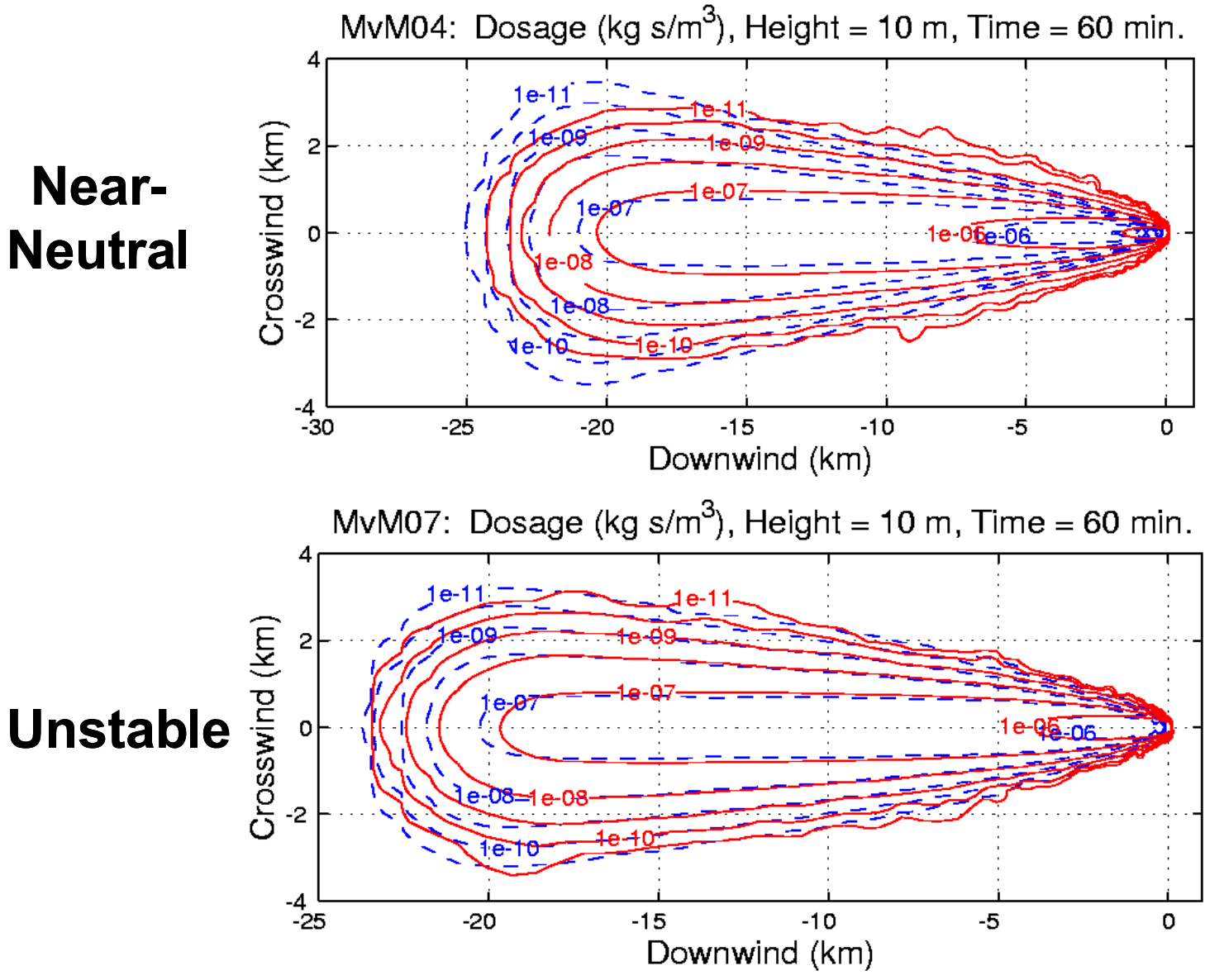
Figure 1. Results for Three Nominal Gas Release Scenarios as a Function of Meteorological Stability Category: at 60 Minutes with NARAC (Red -) and HPAC (Blue - -) Dosage Contours

Close agreement could also be found in many of the particle releases. Figure 2 shows near-surface $(10 \mathrm{~m})$ dosage contours for two particle releases, one with $5 \mu$ particles and the other with $50 \mu$ particles. Each release occurred at a height of 2 meters. Good agreement is seen in both cases, with better agreement for the $5 \mu$ particle release (relative to the $50 \mu$ particle release) at least at the higher dosages
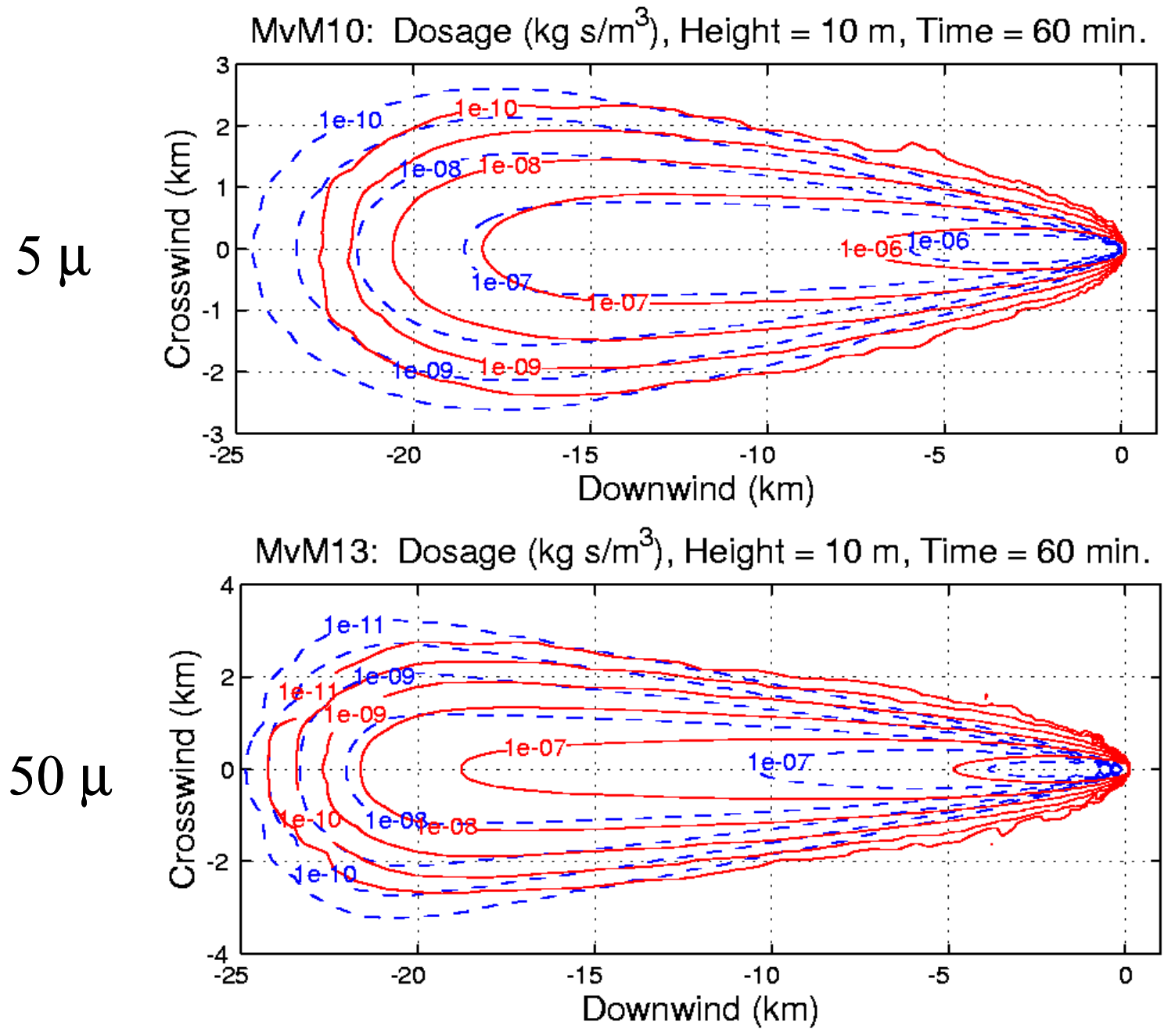

Figure 2. Results for Two Nominal Particle Release Scenarios as a Function of Particle Size (5 and $50 \mu$ ): at 60 Minutes with NARAC (Red -) and HPAC (Blue - -) Dosage Contours 


\section{a. Influence of Release Height on Comparisons}

A major finding of this study was that release height (relative to boundary layer height) had dramatic effects on model agreement, with a clear trend for better model agreement with lower release heights. The highest height releases displayed marked differences between model predictions. Figure 3 compares HPAC and NARAC surface dosage contours for MvM 3 at 30 and 60 minutes after the release (80 meter gas release height with a boundary layer height of 100 meters) and for MvM 15 at 120 and 240 minutes (750 meter release height with a boundary layer height of 500 meters).

For MvM 3, the HPAC $10^{-10} \mathrm{~kg}-\mathrm{s} / \mathrm{m}^{3}$ 30-minute dosage contour completely encloses the NARAC $10^{-13} \mathrm{~kg}-\mathrm{s} / \mathrm{m}^{3}$ contour, indicating relative overprediction by HPAC. 10 This trend continues at 60 minutes. Similar conclusions are seen for MvM 15 at 120 and 240 minutes.
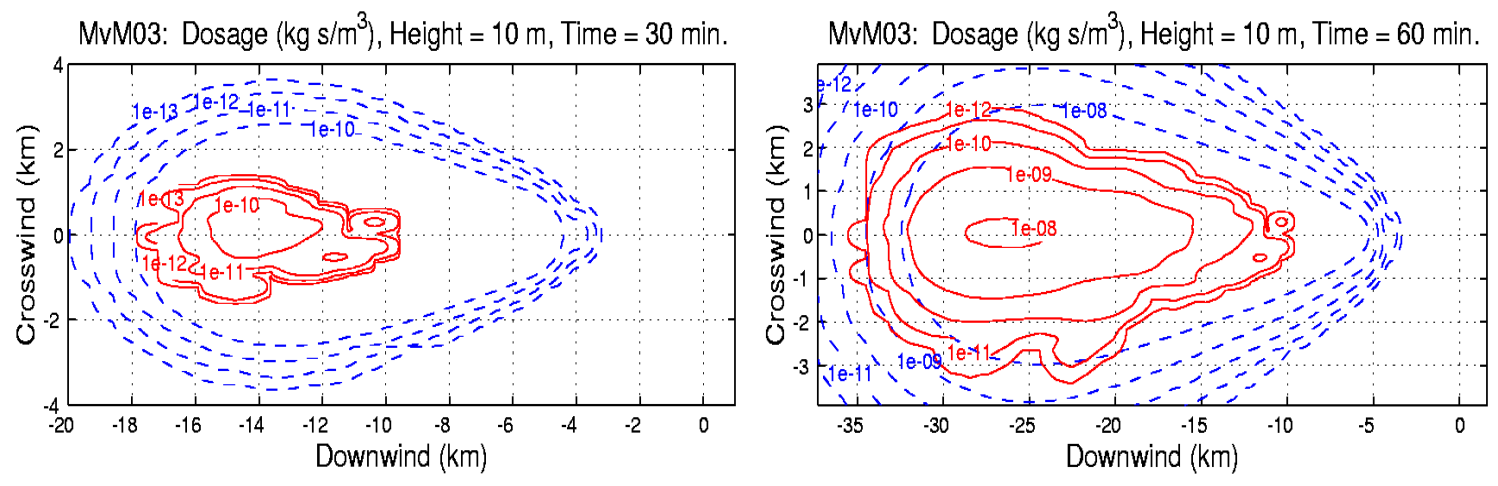

MvM15: Dosage $\left(\mathrm{kg} \mathrm{s} / \mathrm{m}^{3}\right)$, Height $=10 \mathrm{~m}$, Time $=120 \mathrm{~min}$.
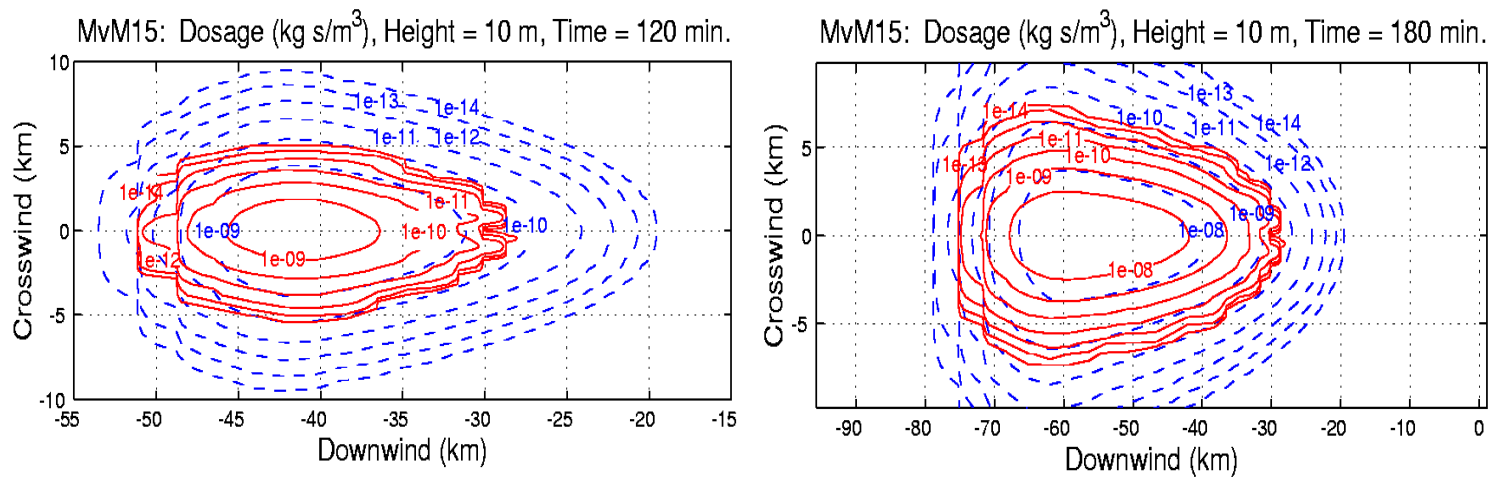

10 Equivalently, NARAC underpredicts HPAC. Throughout this study when drawing comparisons we adopt the nomenclature that one model overpredicts the other. This terminology is not to be construed as a statement about the essential correctness or incorrectness of either model. 
Figure 3. Results for Two "Higher" Altitude Release Scenarios: MvM 3 at $\mathbf{3 0}$ and $\mathbf{6 0}$ Minutes and MvM 15 at 120 and 240 Minutes with NARAC (Red -) and HPAC (Blue - -) Dosage Contours

Differences in the vertical diffusivity models used, as well as in the blending of the diffusivity across the boundary layer, are likely contributors to the marked differences in the predictions for these higher altitude releases.

Figure 4 displays the area-based MOE for all 17 compared releases for various contour levels. In the figure, the red circles denote releases with 2-meter release heights (the lowest release height considered), and blue triangles denote all other releases (with release heights ranging from 50 to 750 meters). Each symbol is associated with a single near-surface $(10 \mathrm{~m})$ contour level region (therefore, there are more symbols than runs). For each run, between three and seven contour levels were examined. 


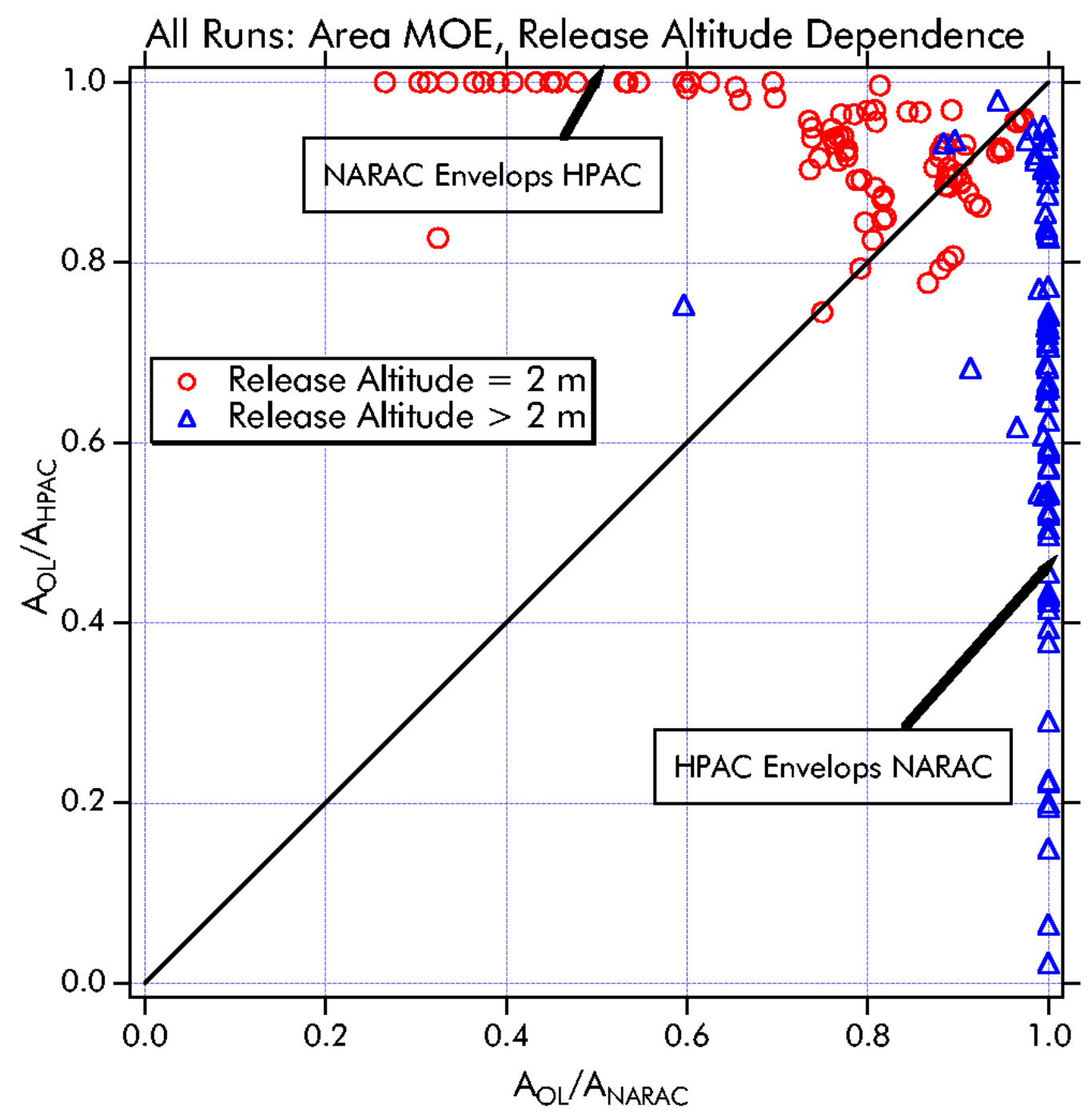

Figure 4. Area-Based MOE for All Gas and Particle Releases. Red Circles Denote Releases at 2-Meter Height (Lowest Height Considered) and Blue Triangles Denote Releases At All Other Heights. MOE Values Separate as a Function of Height. $A_{O L}=$ the Area of Overlap, $A_{\text {NARAC }}=$ the Area of the NARAC Prediction, and $A_{\text {HPAC }}=$ the Area of the HPAC Prediction All at a Specific Contour Level.

The symbols in this plot show a very definite separation, with the 2-meter releases falling mainly above the diagonal (NARAC overprediction relative to HPAC) and the higher altitude releases falling mainly below the diagonal (HPAC overprediction relative to NARAC). Extreme regions where NARAC contours enclose HPAC contours $(y=1)$ and where HPAC contours enclose NARAC contours $(x=1)$ are marked. There are a number of points that lie close to the diagonal and near the point $x=y=1$ (the point of "perfect" model agreement, with respect to this measure). These MOE comparisons are 
consistent with the conclusions drawn from the graphical comparisons discussed previously.

\section{b. Influence of Atmospheric Stability on Gas Release Comparisons}

Closer inspection of the three contour plots for neutrally-buoyant gas releases shown in Figure 1 reveals that model agreement improves slightly with decreasing meteorological stability. Contour differences are also most pronounced at the longer ranges, where the trend is for longer (downwind) and wider (crosswind) HPAC contours. Figure 5 shows a scatter plot of the near-surface downwind contour distances for the gas releases at 60 minutes, with color indicating stability condition (blue $=$ stable, red $=$ neutral, and green $=$ unstable).

Overall, agreement is good, with the bulk of the points falling within the 15 percent overprediction limits. Taken by groups, the unstable (green) points are closest to the diagonal line, followed by the neutral (red) points, then the stable (blue) points, reflecting the graphical differences displayed in Figure 1. Other comparison metrics (e.g., crosswind plume widths and area-based MOEs) show a similar trend.

For the three gas cases examined with a source release height of 2 meters, the relative $1 \mathrm{~km}$ downwind crosswind plume widths for the HPAC and NARAC predictions are shown in Figure 6. NARAC relatively overpredicts HPAC crosswind plume width for stable and near-neutral conditions. For the unstable case, MvM 7, the $1 \mathrm{~km}$ crosswind dosage plume widths are similar. This is consistent with the conclusions drawn from the Prairie Grass comparisons that involved similar downwind distances. ${ }^{11}$

Differences between models for the runs done with stable meteorological conditions may not be too surprising, since it is for these conditions, relative to neutral and unstable, that the understanding of transport and dispersion phenomena is least complete.

11 Warner S., Platt, N., Heagy, J. F., Bradley, S., Bieberbach, G., Sugiyama, G., Nasstrom, J. S., Foster, K. T, and Larson, D., User-Oriented Measures of Effectiveness for the Evaluation of Transport and Dispersion Models, IDA Paper P-3554, 8 January 2001, pp. 3-31 and pp. I-18, Figure I-18, e.g., see the "800 meter arc, 95\%" chart. 


\section{Gas Runs: Downwind Contour Distances, 60 Minutes}

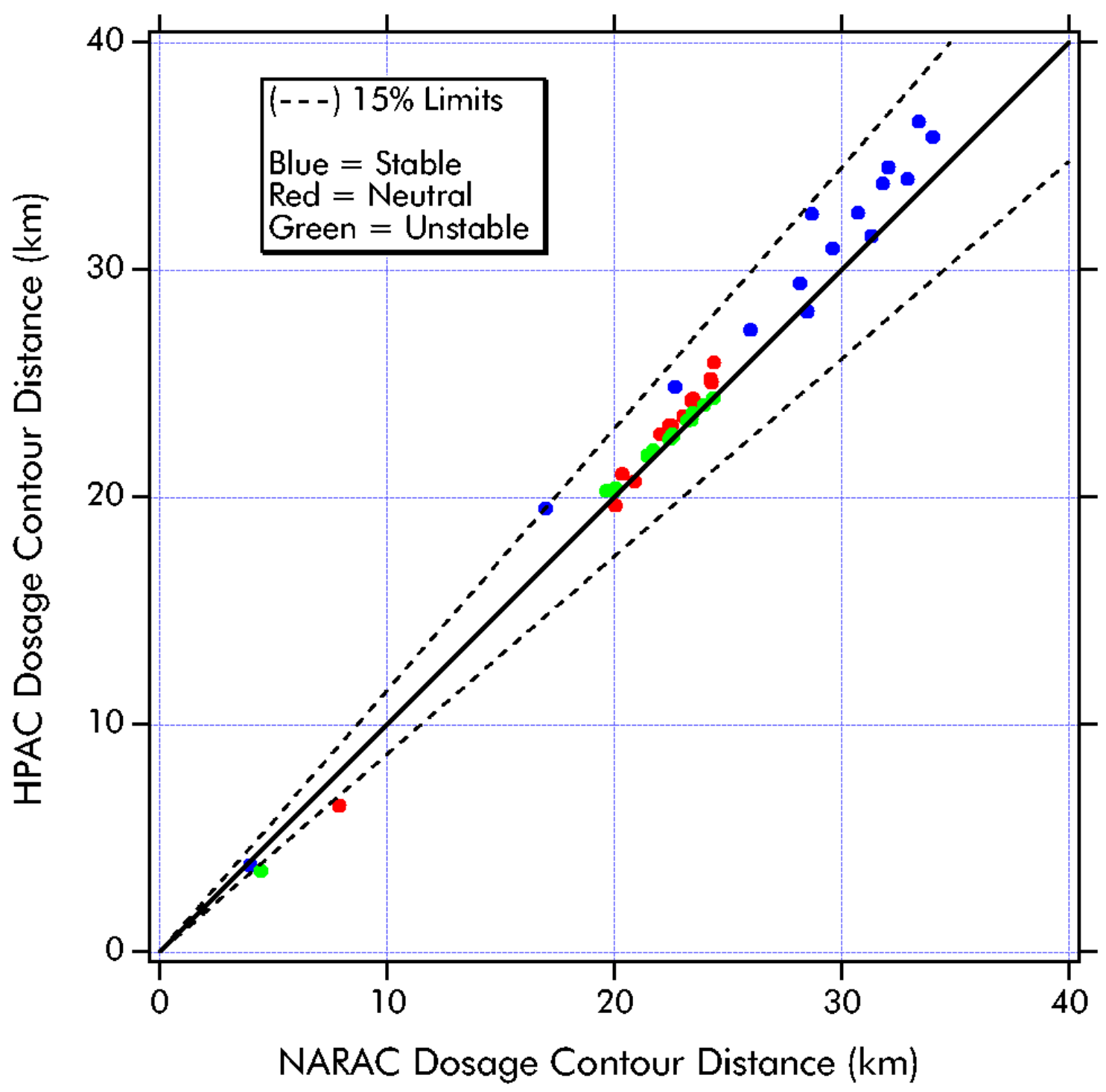

Figure 5. Scatter Plot Comparison of Downwind Contour Distances at 60 Minutes for All Gas Runs: Colors Indicate Meteorological Stability Categories and Dashed Lines are 15\% Overprediction Limits 

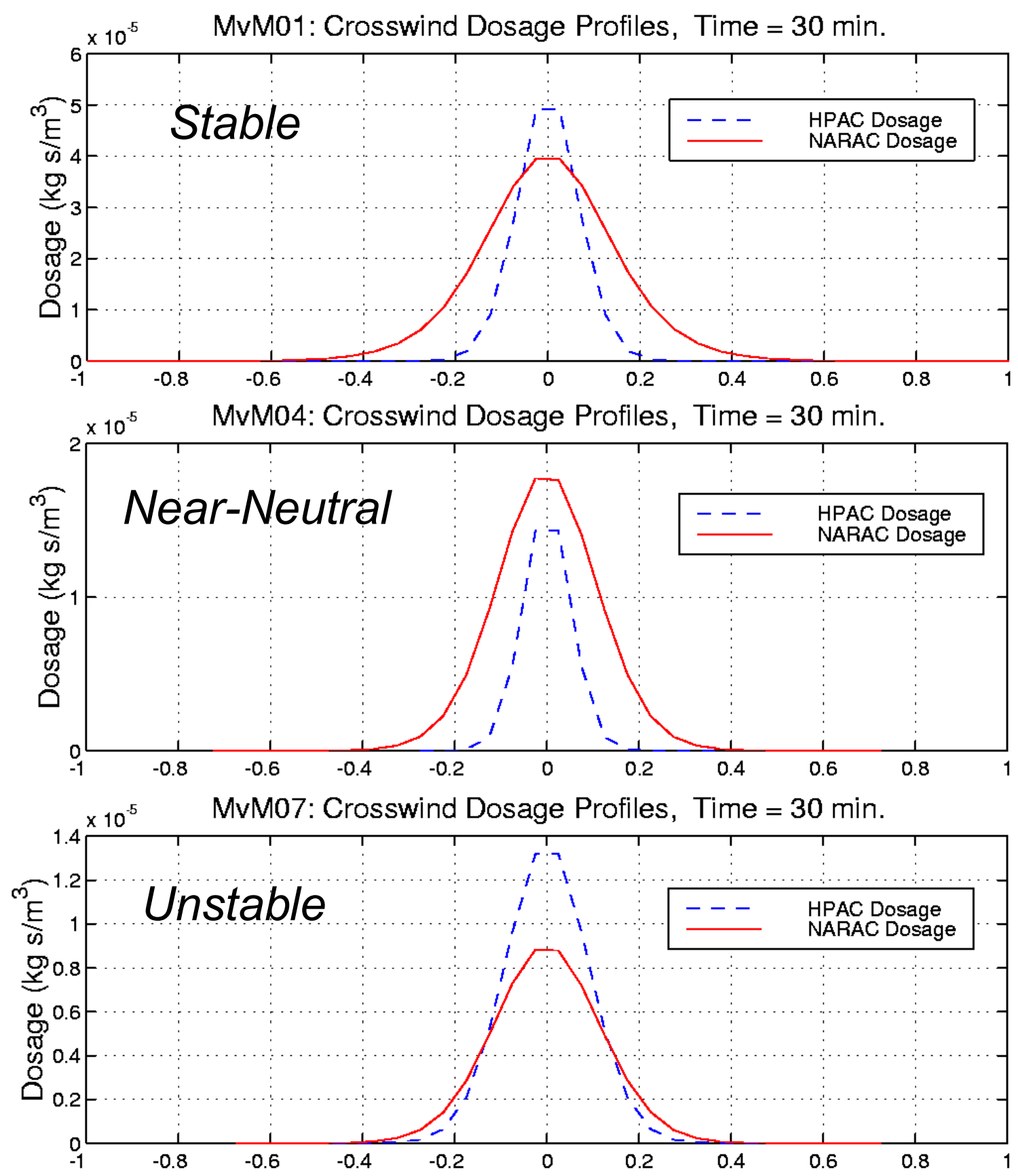

Figure 6. Dosage Contours at 30 Minutes and $1 \mathrm{~km}$ Downwind for Three 2-Meter Height Neutrally-Buoyant Gas Releases: MvM 1 (Stable), MvM 4 (Near-Neutral), and MvM 7 (Unstable). Of the Seventeen Releases Studied, These Are Considered the Most Similar to the Previously Examined Prairie Grass Field Trials. 


\section{c. Influence of Particle Size on Comparisons}

Figure 7 presents a scatter plot of HPAC and NARAC near-surface downwind contour distances ( 60 minutes after the release) with particle size indicated by color (blue $=5 \mu$, red $=50 \mu$, and green $=500 \mu$ ). Generally, HPAC and NARAC downwind contour distances agree to within 20 percent. HPAC slightly overpredicts NARAC for this measure at the longer ranges/lower dosages. If all distance/dosages are considered, the $5 \mu$ particle results show the fewest large differences. For the shorter ranges/higher dosages (inside $20 \mathrm{~km}$ ) the $5 \mu$ points show the best agreement.

For the $50 \mu$ (red) and $500 \mu$ (green) particles, the disagreement between the two models is greatest for the shorter distances (higher dosages) with NARAC relatively overpredicting HPAC (e.g., see the $10^{-7}$ dosage contours for MvM 13 in Figure 2). For longer distances (lower dosages), there is a slight opposite trend, with the $500 \mu$ points (green) lying closest to the diagonal and the $5 \mu$ points (blue) lying farthest from the diagonal.

The particle settling models employed by HPAC and NARAC are somewhat different (there are several approaches to the settling of particles in the transport and dispersion literature). It is therefore reasonable to expect some differences in model performance as a function of particle size, such as those observed in this study.

\section{HPAC Prediction Excursions: Resolution Issues}

In the initial stages of this study, a set of "baseline" parameters that control spatial and temporal resolution was agreed to after a series of test comparisons. During these explorations, some significant resolution-dependent effects were noted. These effects were used to guide the final choice for the baseline resolution settings. Choice of proper resolution is always critical to model simulations. The discussion in this section is intended to underscore the need to thoroughly understand and account for the intrinsic computational framework of the models in a model-to-model comparison. Three main effects were observed, two concerning HPAC spatial resolution and one concerning HPAC temporal resolution. ${ }^{12}$

12 Related considerations apply to setting up NARAC meteorological and concentration grids but are not discussed here. (See Chapter 2 for additional discussion.) 


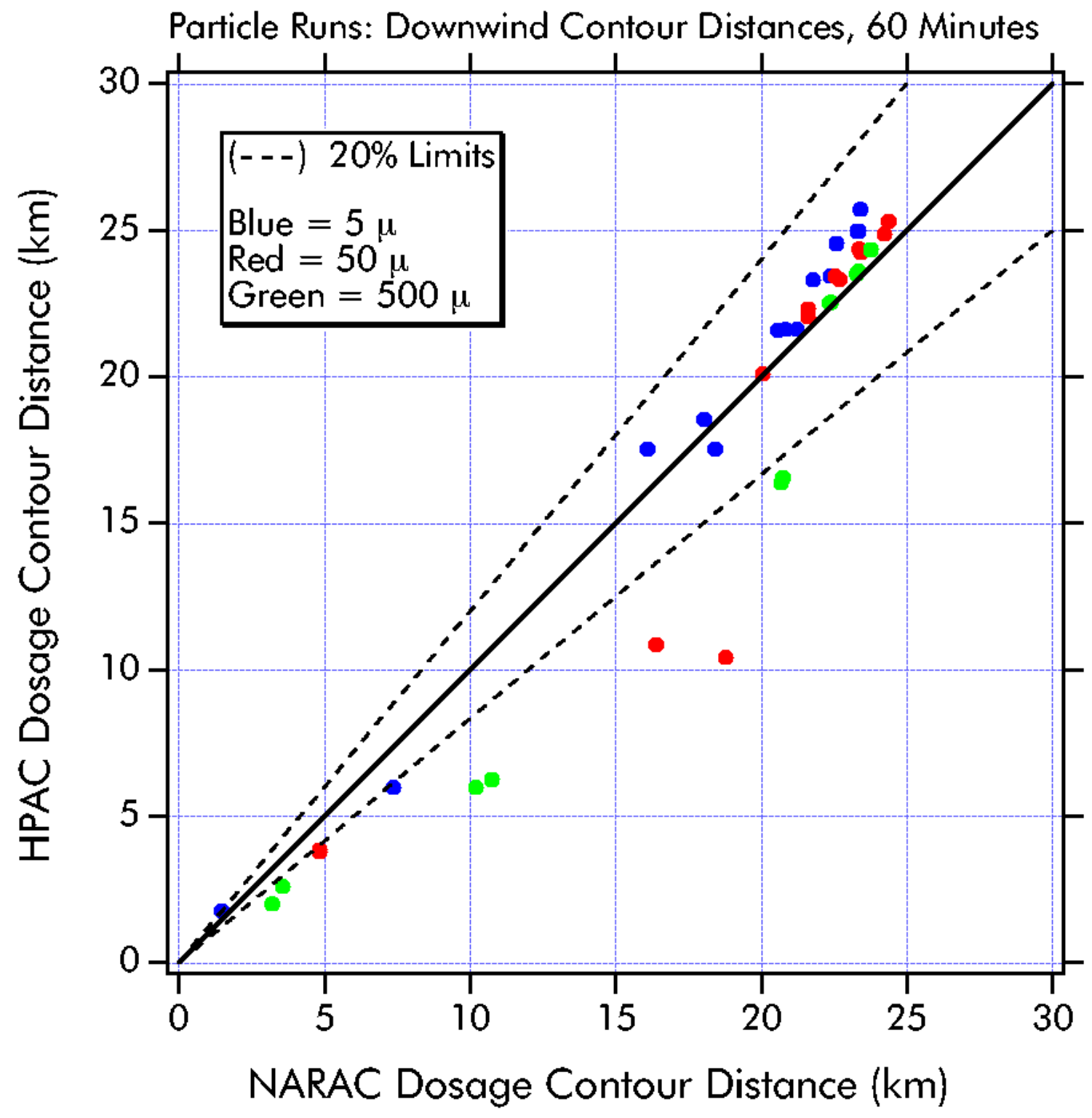

Figure 7. Scatter Plot Comparison of Downwind Contour Distances at 60 Minutes for Particle Runs MvM 10 through 14, 16, and 17: Colors Indicate Particle Size and Dashed Lines are $20 \%$ Overprediction Limits

\section{a. Vertical Resolution}

Substantial changes in HPAC downwind plume transport were observed when the HPAC vertical resolution was changed. This effect was most prominent in the 2-meter stable gas release, MvM 1. Figure 8 shows dosage contour comparisons with two values of the HPAC vertical resolution: a "coarse" value of 40 meters (the default HPAC value for a grid top height of 2,000 meters) and a "fine" value of 10 meters (the adopted 
baseline setting). The coarse resolution HPAC plume (blue) propagates much farther downwind than the fine resolution HPAC plume.

This effect is caused by the relative under-sampling of the vertical wind profile for the coarse resolution case, resulting in an artificially high transport speed at elevations near the release height of 2 meters. This effect motivated the choice to adopt the finer vertical resolution value of 10 meters for all of the releases. Retention of the default HPAC resolution value of 40 meters would have clearly (and inappropriately) skewed the conclusions of this study

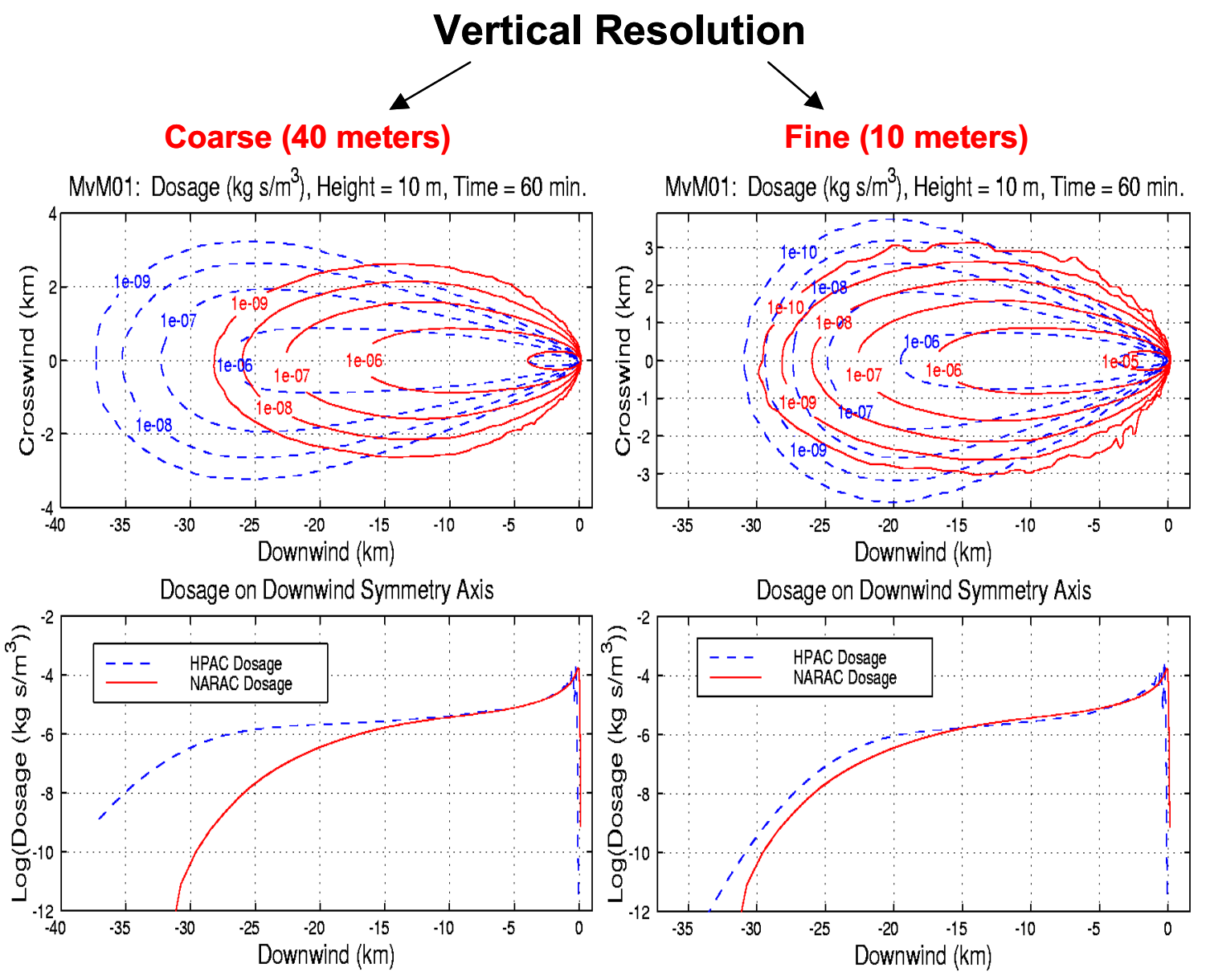

Figure 8. MvM 1 at 60 Minutes with Upper: Dosage Contours for HPAC (Blue - -) and NARAC (Red -); Lower: Dosage on Downwind Symmetry Axis. HPAC Runs Are Done at Coarse and Fine Vertical Resolution Values of 40 and 10 Meters as Noted. 


\section{b. Horizontal Resolution}

A second resolution-induced effect was observed in HPAC dosage output, when the horizontal resolution was changed from the default value of approximately $1 \mathrm{~km}$ to the finer value of $0.4 \mathrm{~km} .{ }^{13}$ Two differences between the contour sets done with different horizontal resolution were apparent. First, the downwind plume extent for the fine (i.e., higher resolution) contours was somewhat reduced. Next, the finer resolution setting also had the undesirable effect of introducing high-frequency spatial modulation in the contours that distorted the plume shape, particularly at larger dosages. We hypothesize that, computational artifacts introduced by "puff-splitting" routines in SCIPUFF" ${ }^{14}$ that control the creation of new Gaussian concentration puffs when plumes cross resolution cells, cause these modulations.

We adopted the default HPAC horizontal resolution value of $1 \mathrm{~km}$ as the baseline value in all model-to-model comparisons. This choice, combined with the 10-meter vertical resolution choice, produced HPAC contours that had comparable transport speeds and acceptable (i.e., sensible) smoothness properties. Contrary to the vertical resolution case, retention of the default HPAC resolution value in the horizontal case was required to ensure a reasonable comparison.

\section{c. Time-Step Resolution}

Significant spatial oscillations in the HPAC dosage were observed near the release for all of the 2-meter instantaneous releases ( 6 out of the 17 releases). These oscillations eventually decay with downwind distance ( 1 to $3 \mathrm{~km}$ downwind). While the precise cause for the oscillations is unclear (as is their absence in the 11 other releases), we have demonstrated that the magnitude of the oscillations is related to the output time-step. Figure 9 shows the symmetry axis dosage for MvM 4 at 30 minutes, computed with two time-steps: 60 seconds (the baseline value, in blue) and 30 seconds (in red). Decreasing the time-step by a factor of two diminishes the magnitude of the oscillations by as much as a factor of 100.15

13 It was initially thought that finer horizontal resolution would result in more favorable comparisons.

14 SCIPUFF = Second-Order Closure Integrated Puff. SCIPUFF is the set of transport and dispersion algorithms used in the version of HPAC that we examined.

15 A possible explanation for this effect is given in Chapter 3, Section C.3. 
Because we did not focus on short-range dosage comparisons, the presence of the dosage oscillations did not adversely affect the comparisons. Future model-to-model studies that involve comparisons of short-range HPAC dosages would likely benefit from further reductions in the time-step.

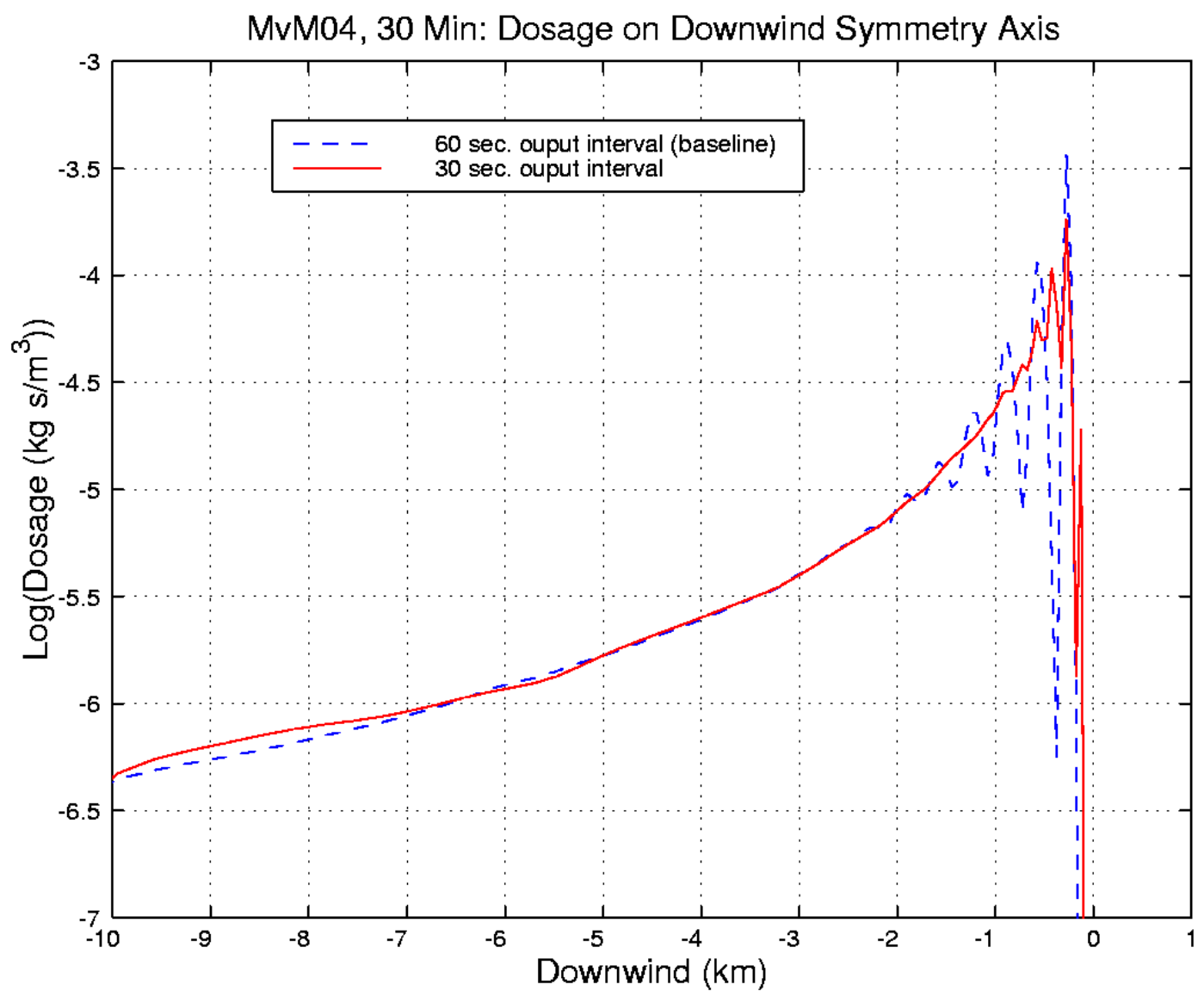

Figure 9. HPAC Dosage Along Downwind Symmetry Axis for MvM 4 at 30 Minutes. Blue Trace Is for 60 Second Time-Step (Baseline Value) and Red Trace Is for $\mathbf{3 0}$ Second TimeStep. The Magnitude of the Dosage Oscillations Decreases Substantially by Decreasing the Time-Step.

\section{Conclusions}

Controlled comparisons of HPAC and NARAC predictions of 17 notional releases were completed. In general, good agreement was obtained between the models, with the majority of comparisons resulting in predicted downwind contour distances and crosswind plume widths within 15 percent and 50 percent of each other, respectively. 
To achieve close agreement between many of the HPAC and NARAC runs, we implemented a stringent protocol for this exercise (e.g., identical fixed wind profiles, careful control of all physical input parameters and model-specific parameters controlling various resolution aspects). Close agreement also required several iterations of model predictions in order to arrive at a set of baseline input parameter settings for all of the runs. These baseline settings were adopted and agreed to by all members of the collaboration.

HPAC and NARAC take substantially different mathematical and numerical approaches to transport and dispersion of material: HPAC uses a second-order closure equation set and a Gaussian puff method, while NARAC uses the diffusion equation and a Lagrangian, Monte Carlo particle method. Thus, the fact that the core transport and dispersion subsystems of HPAC and NARAC agree closely on a range of releases should inspire users with a certain degree of confidence in physical validity of both of these models.

The scenario releases that we examined allowed us to probe the effects on differences between model predictions of release height, particle size, meteorological stability category, and to a lesser degree, source term geometry and duration of the release ("instantaneous" versus "continuous"). We found that major differences between model predictions occurred for greater release heights with increasing atmospheric stability and larger particle size contributing as secondary factors. In particular, runs 3 and 15 (Table 1), with $\mathrm{z}_{\mathrm{r}} / \mathrm{z}_{\mathrm{i}}$ values of 0.80 and 1.50 , demonstrated dramatic differences in model predictions (due to vertical diffusivity differences, which were associated with release height and boundary layer changes). Runs 1 through 9 were used to explore differences in model predictions as a function of atmospheric stability. Runs 10 through 14, 16, and 17 allowed for the examination of model prediction differences related to particle size.

\section{E. OUTLINE OF THIS PAPER}

This paper is organized as follows. Chapter 1 describes the goals of the overall VV\&A comparison effort. Brief descriptions of the HPAC and NARAC modeling systems are given. Chapter 2 gives detailed descriptions of 17 baseline release scenarios that make up the core of the model-to-model comparison. Comparison metrics are introduced and illustrated in some detail. Chapter 3 reviews the results of the comparisons, including graphical comparisons. Excursions from the baseline model 
parameters and settings (e.g., spatial and temporal resolution) for HPAC are also considered.

In addition to the main body of this paper, there are five appendices, A through E. Appendix A provides an acronym list, and Appendix B presents details associated with the model predictions that were used for this study's comparisons. Appendices C and D provide plots and graphical displays that describe the comparisons of the specific gas release and particle release predictions, respectively. Finally, Appendix E includes an extract from the pertinent task order. 


\section{CHAPTER 1}

\section{INTRODUCTION}





\section{INTRODUCTION}

For fiscal year 2000, The Institute for Defense Analyses (IDA) began a series of studies in support of the Defense Threat Reduction Agency (DTRA). The goal of these studies is to improve the verification, validation, and accreditation (VV\&A) of hazard prediction and assessment models and capabilities (e.g., HPAC and NARAC). ${ }^{1}$ These studies are part of a larger joint VV\&A effort that DTRA and the Department of Energy (DOE), via Lawrence Livermore National Laboratory (LLNL), are conducting. This joint effort includes comparisons of LLNL and DTRA transport and dispersion (T\&D) modeling systems, NARAC and HPAC, respectively, and their predictions.

IDA's role is to conduct independent analysis and special studies associated with this VV\&A effort. This role includes conducting comparisons between the models, providing analysis and discussions associated with these examinations, and exploring and developing measures of effectiveness (MOE) that can aid hazard prediction model validation and accreditation. ${ }^{2}$

The focus of this paper is on model-to-model comparisons for a collection of relatively simple release scenarios. ${ }^{3}$ Comparison metrics that have been developed in the course of this work are also discussed in some detail.

\section{A. BACKGROUND}

This VV\&A effort represents a cooperative comparison in that DTRA and LLNL have set up a team that works closely together to provide comparable model runs and analysis. The two models were developed independently and against different requirements. The purpose of this cooperative program is to leverage resources and expertise for the goal of developing better modeling and simulation tools. This

$1 \quad$ HPAC $=$ Hazard Prediction and Assessment Capability and NARAC $=$ National Atmospheric Release Advisory Center.

2 Appendix $\mathrm{E}$ of this document contains an extract from the pertinent fiscal year 2000 task order.

3 Seventeen release scenarios are considered. These scenarios were defined in a joint effort at the outset of this study. 
cooperative spirit is consistent with recent newsletter articles suggesting that the challenges of hazard prediction model VV\&A [Ref. 1-1] are better addressed through joint efforts. These joint efforts are expected to bring a certain synergy to the Chemical and Biological (CB) warfare modeling and simulation community [Ref. 1-2].

Model-to-model parametric studies can lead to the elucidation of model performance and quantification of relative model differences. Previous comparisons of the predictions of transport and dispersion model outputs demonstrated the potential for parametric sensitivity studies to identify, clarify, and communicate performance differences, including differences arising from operational assumptions used in each of the models [Ref. 1-3].

The paper focuses on model-to-model comparisons, and represents a portion of a larger three-year program. Recent related analyses include a careful comparison of HPAC and NARAC predictions of short-range, well-characterized field trial data (i.e., the Prairie Grass field trials). These results were completed and documented elsewhere [Ref. 1-4]. These initial first-year studies are expected to serve as a basis for future, more complex comparisons (e.g., complex terrain and weather, longer transport ranges).

For this study, we adopt Department of Defense definitions for VV\&A [Ref. 1-5]:

- Verification - The process of determining the degree to which a model or simulation implementation accurately represents the developer's conceptual description and specification. Verification also evaluates the extent to which the model or simulation has been developed using sound and established software engineering techniques. ${ }^{4}$ [Department of Defense (DOD) Directive 5000.59]

- Validation - The process of determining the degree to which a model or simulation is an accurate representation of the real world from the perspective of the intended uses of the model or simulation. [DOD directive 5000.59]

- Accreditation - The official certification that a model or simulation is acceptable for use for a specific purpose. [DOD Directives 5000.59 and 5000.59-P].

Model-to-model comparison studies can only address VV\&A in a limited sense. For instance, it is quite possible that two models agree perfectly with one another, yet; perhaps due to deficiencies in understanding of the relevant phenomenology, disagree with real-world observations. However, agreement between models, when one of the 
models has already been validated against field trial data, can improve the case for validation. In addition, even without specific field trial data, agreement between two models can boost confidence in both models' ability to adequately predict observations. This is particularly so in the case of HPAC and NARAC, whose transport and dispersion methodologies (described below) differ distinctly. Further, identification of model discrepancies serves a valuable purpose. Such identifications can clarify limitations of a model, direct more appropriate parameter settings for a particular class of releases, or point to the need for new modeling techniques and/or new phenomenological investigations.

\section{B. BRIEF HPAC DESCRIPTION}

HPAC is composed of a suite of software modules that generate source terms for hazardous releases, retrieve and prepare meteorological information for use in a prediction, model the T\&D of the hazardous release over time, and plot and report the results of these calculations. HPAC has been applied to various national defense problems including military studies and operational planning.

For hazardous material T\&D, HPAC uses the Second-Order Closure Integrated Puff (SCIPUFF) model and an associated wind field model. SCIPUFF is a Lagrangian model for atmospheric dispersion that uses the Gaussian puff numerical method - an arbitrary time-dependent concentration field is represented by a superposition of threedimensional Gaussian distributions. The downwind concentration is calculated from a turbulent diffusion parameterization based on second-order closure theory. This methodology provides a link between measurable wind-flow field velocity statistics and predicted dispersion rates. The "second-order" feature allows concentration variance to be estimated (in addition to mean concentration), and this uncertainty estimate can be used as the basis for a probabilistic description of the dispersion prediction. ${ }^{5}$

This model-to-model study uses HPAC software version 3.2 [Ref. 1-7].

5 See Reference 1-6 for details of HPAC design, functionality, capabilities, and V\&V. 


\section{BRIEF NARAC DESCRIPTION}

The ADAPT/LODI 6 modeling system, within NARAC, is used for both real-time operational applications and detailed assessments of events involving atmospheric releases of hazardous material.

The ADAPT meteorological data assimilation model constructs fields of such variables as the mean winds, pressure, precipitation, temperature, and turbulence, using a variety of interpolation methods and atmospheric parameterizations [Ref. 1-8]. Nondivergent wind fields are produced by an adjustment procedure based on the variational principle and a finite-element discretization.

The LODI dispersion model solves the 3-D advection-diffusion equation by integrating a stochastic differential equation (SDE) for many (typically hundreds of thousands) particle trajectories in a Lagrangian Monte Carlo method [Ref. 1-9]. LODI includes methods for simulating the processes of mean wind advection, turbulent diffusion, radioactive decay and production, first-order chemical reactions, wet deposition, gravitational settling, dry deposition, and buoyant/momentum plume rise.

The ADAPT/LODI models are coupled to NARAC databases providing topography, geographical data, chemical-biological-nuclear agent properties and health effects, real-time meteorological observational data, and global and mesoscale forecast model predictions. Graphical output is typically constructed by first smoothing raw LODI output with the NARAC system tool, smoothBinDat, and then plotting.

This model-to-model study used version 2.9 of ADAPT and version 9k of LODI within the NARAC software.

\section{RECAP}

This work is part of a larger VV\&A effort comparing two widely used transport and dispersion model systems, HPAC and NARAC. The focus of this work is model-tomodel comparisons for a set of relatively simple releases (discussed in detail in the following chapter). The modeling architectures of HPAC and NARAC are quite distinct. HPAC treats the concentration field as a continuum (represented as a sum of Gaussian "puffs") and propagates these puffs in time, while NARAC treats the concentration field as a collection of particles and propagates each particle in time. It is shown below that

6 ADAPT $=$ Atmospheric Data Assimilation and Parameterization Techniques. LODI = Lagrangian Operational Dispersion Integrator. 
HPAC and NARAC predictions can be brought into general agreement, but only after full consideration of wind profile parameterizations, spatial and temporal resolution issues, and other internal model-dependent parameters. ${ }^{7}$

7 Comparing the outputs of two codes is not necessarily a straightforward procedure. Ensuring that both codes' methodologies and performance are fairly applied and assessed across any set of input conditions is typically a challenge. The seemingly straightforward task of comparing model outputs is fraught with traps that the analyst must guard against. 



\section{REFERENCES}

1-1. Merkle, P. B., "Analysis and Validation: A Perspective for Hazard Models," Chemical and Biological Defense Information Analysis Center (CBIAC) Newsletter, Spring 1998, Vol. 4, No. 2.

1-2. Gibbs, R. L., "Improving the Development Process for Chemical and Biological Warfare Modeling and Simulation," CBIAC Newsletter, Fall 1999, Vol. 5, No. 4.

1-3. Warner, S., Carpenter, J. N., Cook, J. M., Miller, R. S., and Hegemann, B. E., NBC Hazard Prediction Model Capability Analysis, IDA Document D-2245, September 1999.

1-4. Warner S., Platt, N., Heagy, J. F., Bradley, S., Bieberbach, G., Sugiyama, G., Nasstrom, J. S., Foster, K. T, and Larson, D., User-Oriented Measures of Effectiveness for the Evaluation of Transport and Dispersion Models, IDA Paper P-3554, 8 January 2001.

1-5. Director, Operational Test and Evaluation and Director, Test, Systems Engineering and Evaluation OUSD(A\&T), Simulation, Test and Evaluation Process: STEP Guidelines, 4 December 1997.

1-6. Bradley, S., Mazzola, T., Ross, R., Srinivasa, D., Fry, R., and Bacon, D., Verification and Validation of HPAC 3.0, for Defense Special Weapons Agency, June 1998, and references therein; Sykes, R. I., "HPAC/SCIPUFF: Kamisiyah Modeling Issues," 3rd Annual GMU/DTRA Transport and Dispersion Modeling Workshop, Fairfax, VA, 28-29 July 1999; and Nappo, C. J., Eckman, R. M., Shankar Rao, K., Herwehe, J. A., and Gunter, L., Second Order Closure Integrated Puff (SCIPUFF) Model Verification and Evaluation Study, Air Resources Laboratory, NOAA, May 1998.

1-7. DTRA, The HPAC User's Guide: Version 3.2, October 1999.

1-8. Sugiyama, G. and Chan, S. T., "A New Meteorological Data Assimilation Model for Real-Time Emergency Response," 10th Joint Conference on the Applications of Air Pollution Meteorology, Phoenix, AZ (11-16 January 1998), Am. Met. Soc., Boston, MA, 285-289.

1-9. Ermak, D. L. and Nasstrom, J. S., "A Lagrangian Stochastic Diffusion Method for Inhomogeneous Turbulence," Atmospheric Environment, 2000 and Nasstrom, J. S., Sugiyama, G., Leone, J. M. Jr., and Ermak, D. L., "A Real-Time Atmospheric Dispersion Modeling System," American Meteorological Society's 11th Joint Conference on the Applications of Air Pollution Meteorology, Long Beach, CA, 9-14 January 2000. 

CHAPTER 2

\section{COMPARED RELEASES}





\section{COMPARED RELEASES}

In this chapter, the release scenarios and the underlying rationale for their selection are discussed. HPAC and NARAC model specifics, including wind profile parameterization and grid selection, are also discussed. Several comparison measures are also introduced and illustrated.

\section{A. OVERVIEW}

In January 2000, members of the joint collaboration met at LLNL to establish a set of release scenarios for this model-to-model study. The joint collaboration agreed to seventeen releases based upon several selection criteria.

First and foremost was the desire for simplicity so that the scenarios would test only the core transport and dispersion algorithms within each model. Consequently, all releases were chosen to have idealized weather - a defined single unidirectional vertical wind speed profile. Terrain was similarly elementary - flat terrain with a constant surface roughness of $0.008 \mathrm{~m}$. Downwind transport distances of $40 \mathrm{~km}$ were used for all but one "high altitude" release. Initial source geometries were also kept simple spherical sources (Gaussian with standard deviation $=1 \mathrm{~m}$ in all directions) for 16 of the 17 releases and a $500 \mathrm{~m}$ line source in the remaining release.

A mix of stable, near-neutral, and unstable atmospheric stability conditions was chosen through suitable choices of the atmospheric boundary layer height, $\mathrm{z}_{\mathrm{i}}$, and MoninObukhov length, L. Stable, "neutral," and unstable conditions were chosen to have $\mathrm{z}_{\mathrm{i}} / \mathrm{L}=$ $4, \mathrm{z}_{\mathrm{i}} / \mathrm{L}=-1^{1}, \mathrm{z}_{\mathrm{i}} / \mathrm{L}=-10$, respectively. A range of release heights (relative to boundary layer height) was also chosen.

Two agent types were considered: "neutrally-buoyant gas" (9 releases) and "particles" ( 8 releases). Particle runs were carried out for three particle size distributions, two using fixed diameter particles of 5 microns $(\mu)$ and $50 \mu$, and the third with a lognormal distribution with a mass median diameter (MMD) of $500 \mu$ and a geometric

1 Theoretically, neutral stability corresponds to $\mathrm{z}_{\mathrm{i}} / \mathrm{L}=0$, but this case was not computationally accessible by HPAC. 
standard deviation $(\sigma)$ of 2 . Releases were chosen to be either instantaneous or continuous, and in all cases the mass of released agent was $1 \mathrm{~kg}$. Continuous sources assumed a constant dissemination rate for 15 minutes for a total $1 \mathrm{~kg}$ release. Table 2-1 summarizes the conditions for the 17 runs that were examined.

Table 2-1. Input Conditions for the Model-to Model Comparisons

\begin{tabular}{|c|c|c|c|c|c|c|c|}
\hline Run & Source & $\begin{array}{l}\text { Source } \\
\text { Geometry }\end{array}$ & $\begin{array}{c}\text { Release } \\
\text { Height } \\
\text { (m) }\end{array}$ & $\begin{array}{c}\text { Boundary } \\
\text { Layer } \\
\text { Height (m) }\end{array}$ & $\begin{array}{l}\mathrm{L}^{\mathrm{c}} \\
(\mathrm{m})\end{array}$ & Stabilityd & $\begin{array}{c}\text { Duration } \\
\text { of } \\
\text { Release }\end{array}$ \\
\hline 1 & NB gas ${ }^{a}$ & sphere $^{b}$ & 2 & 100 & 25 & stable & instant $^{e}$ \\
\hline 2 & NB gas & sphere & 50 & 100 & 25 & stable & instant \\
\hline 3 & NB gas & sphere & 80 & 100 & 25 & stable & instant \\
\hline 4 & NB gas & sphere & 2 & 500 & -500 & "neutral" & instant \\
\hline 5 & NB gas & sphere & 250 & 500 & -500 & "neutral" & instant \\
\hline 6 & NB gas & sphere & 400 & 500 & -500 & "neutral" & instant \\
\hline 7 & NB gas & sphere & 2 & 500 & -50 & unstable & instant \\
\hline 8 & NB gas & sphere & 250 & 500 & -50 & unstable & instant \\
\hline 9 & NB gas & sphere & 400 & 500 & -50 & unstable & instant \\
\hline 10 & $5 \mu$ particles & sphere & 2 & 500 & -500 & "neutral" & $\begin{array}{c}\text { continuous } \\
\text { (15 min) }\end{array}$ \\
\hline 11 & $5 \mu$ particles & sphere & 250 & 500 & -500 & "neutral" & $\begin{array}{c}\text { continuous } \\
\text { (15 min) }\end{array}$ \\
\hline 12 & $5 \mu$ particles & sphere & 400 & 500 & -500 & "neutral" & $\begin{array}{c}\text { continuous } \\
\text { (15 min) }\end{array}$ \\
\hline 13 & $50 \mu$ particles & sphere & 2 & 500 & -500 & "neutral" & instant \\
\hline 14 & $50 \mu$ particles & sphere & 2 & 500 & -500 & "neutral" & $\begin{array}{c}\text { continuous } \\
\text { (15 min) }\end{array}$ \\
\hline 15 & $50 \mu$ particles & sphere & 750 & 500 & -500 & "neutral" & instant \\
\hline 16 & Log normal $^{f}$ & sphere & 2 & 500 & -500 & "neutral" & instant \\
\hline 17 & Log normal & $\begin{array}{c}\text { Line } \\
\text { source }^{g}\end{array}$ & 2 & 500 & -500 & "neutral" & instant \\
\hline
\end{tabular}

a $\mathrm{NB}=$ neutrally-buoyant. The gas considered was sulfur hexafluoride $\left(\mathrm{SF}_{6}\right)$, albeit with some of the actual material characteristics suppressed.

b The initial sphere contains $1 \mathrm{~kg}$ of material and has a Gaussian density distribution with $\sigma_{\mathrm{x}}=\sigma_{\mathrm{y}}=\sigma_{\mathrm{z}}=$ $1 \mathrm{~m}$.

c $\quad \mathrm{L}=$ Monin-Obukhov length.

d $\quad z_{i}=$ boundary layer height. For stable runs $z_{i} / L=4$, for near-neutral runs $z_{i} / L=-1$, and for unstable runs $\mathrm{z}_{\mathrm{i}} / \mathrm{L}=-10$.

e Instant $=$ instantaneous. 
f For the log-normal particle distribution, $\mathrm{MMD}=500 \mu$ and the geometric standard deviation $(\sigma) 2$.

$\mathrm{g} \quad$ The initial line source contains $1 \mathrm{~kg}$ of material and is $500 \mathrm{~m}$ long.

\section{B. MODEL SPECIFICS}

In this section, we review the parameter settings and input values used by the HPAC and NARAC models for the predictions examined in this study. Specific attention is given to spatial and temporal resolution, meteorological settings, and vertical wind profiles.

\section{Meteorology: Vertical Wind Profiles}

Preliminary model-versus-model (MvM) runs revealed differences in output concentrations that could be attributed to differences in vertical wind profile parameterizations between the two models. For this reason, it was agreed to specify the user-controlled NARAC vertical wind profile for each run, according to the documented HPAC vertical wind profile parameterization, given by [Ref. 2-1].

$$
u(z)=\begin{aligned}
& u_{s} \frac{\ln \left(z / z_{0}\right)-\psi_{m}(z, L)}{\ln \left(z_{s} / z_{0}\right)-\psi_{m}\left(z_{s}, L\right)} ; z<z_{s}, \\
& u_{s} ; z ? z_{s}
\end{aligned}
$$

with the following identifications:

- $u$ : wind speed $(\mathrm{m} / \mathrm{s})$

- $z$ : height $(\mathrm{m})$

- $z_{0}$ : surface roughness $(\mathrm{m}) ; 0.008 \mathrm{~m}$ for all runs

- $z_{s}:$ surface layer height $(\mathrm{m})$

- $\quad L$ : Monin-Obukhov length (m)

- $u_{s}:$ wind speed $(\mathrm{m} / \mathrm{s})$ at the surface layer height $z_{s}$

- $\psi_{m}$ : stability correction.

The functional form of the stability correction and the value of the surface layer height depend on the Monin-Obukhov length used; details are provided in Reference 2-1. The seventeen MvM runs used three distinct vertical wind profiles:

- Profile 1: Stable runs (1 through 3) 
- Profile 2: Near-neutral runs (4 through 6, 10 through 17)

- Profile 3: Unstable runs (7 through 9).

For all runs, the surface layer height is $z_{S}=50 \mathrm{~m}$, above which the wind speed is constant. This consistent value of $50 \mathrm{~m}$ was essentially a coincidence, resulting from the particular parameter set chosen. The three profiles are illustrated in Figure 2-1 below. Note that all three wind profiles pass through the observation point, $u=5 \mathrm{~m} / \mathrm{s}$ at $z=10 \mathrm{~m}$, as required.

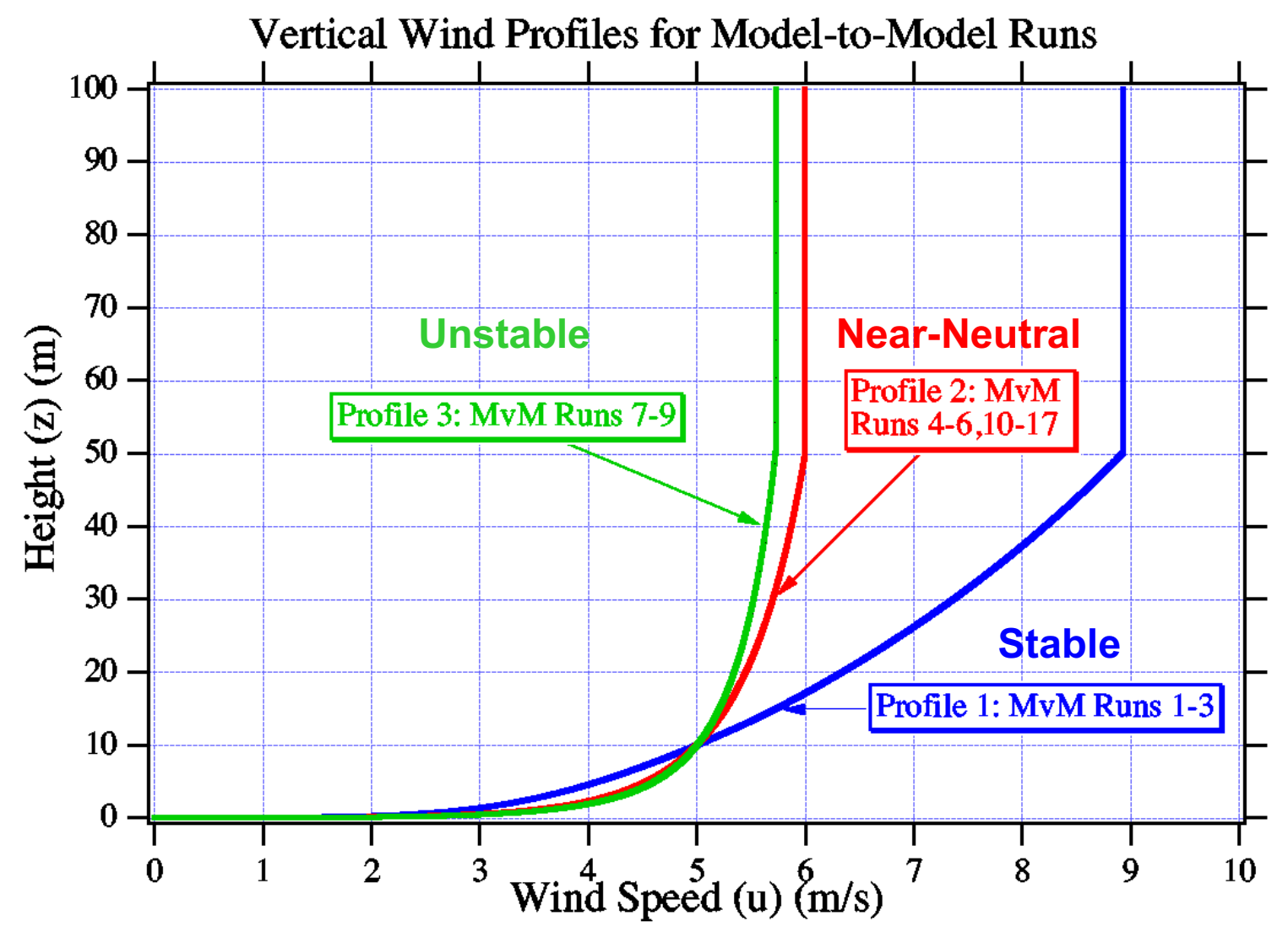

Figure 2-1. Vertical Wind Profiles for Model-Versus-Model Runs

\section{HPAC Computational Details}

\section{a. HPAC Parameters and Settings}

HPAC has several user-controlled parameters that define specifics of the release, meteorological conditions, and spatial and temporal resolutions in internal computations and external output. For the model-to-model comparisons conducted in this study, it was agreed to define baseline parameter settings. Four key HPAC parameters in the baseline set are vertical resolution, horizontal resolution, maximum time step, and conditional 
averaging time, discussed separately below. Other baseline HPAC parameters are discussed in Appendix B.

\section{i. Vertical Resolution}

Vertical resolution for HPAC runs is set within the Domain Editor in the Project Editor. For all MvM runs, with the exception of MvM 15, the baseline vertical resolution was set to $10 \mathrm{~m}$. This value was found to be a reasonable compromise between adequate sampling of the vertical wind profile and the extent of the vertical computational domain. $^{2}$ The vertical resolution setting limits the maximum height of the vertical domain (also set in the Domain Editor) to be less than or equal to 50 times the resolution value. The $10 \mathrm{~m}$ value therefore restricts the domain height to be no greater than $500 \mathrm{~m}$. A vertical domain height of $500 \mathrm{~m}$ was selected for all runs except MvM 15 (note that maximum release height for these runs is $400 \mathrm{~m}$ ). For MvM 15, vertical resolution was set to $20 \mathrm{~m}$ and the vertical domain height was set to $1,000 \mathrm{~m}$.

\section{ii. Horizontal Resolution}

Horizontal resolution for HPAC runs is set within the Domain Editor in the Project Editor. For all MvM runs, the horizontal resolution was set to the default value. Fine horizontal resolution values (e.g., $200 \mathrm{~m}$ ) were found to give rise to high frequency spatial oscillations in the HPAC dosage plumes that may be connected with SCIPUFF puff-splitting algorithms used in HPAC (discussed in more detail in Section C of Chapter 3). Note that horizontal resolution is an internal parameter, in that it affects only the internal representation of the plume and its evolution. The horizontal resolution does not affect the spatial locations of HPAC output values; these are set via the sampler locations within the sampler files.

\section{iii. Maximum Time Step}

The Maximum Time step for HPAC runs is set within the Time Editor in the Project Editor. For all runs, the value was set to 60 seconds. This parameter determines the time step used in the output sampler (.smp) file. Excursions from the 60-second baseline value are taken up in Section $\mathrm{C}$ of Chapter 3.

2 Section $\mathrm{C}$ in Chapter 3 addresses excursions from the baseline vertical resolution. 


\section{iv. Conditional Averaging Time}

The conditional averaging time for HPAC runs is set within the Options Editor in the Project Editor. Conditional averaging is used by HPAC to incorporate large-scale uncertainties in meteorological conditions (turbulent velocity fluctuations) into output concentration estimates [Ref. 2-2]. The conditional averaging time controls the extent to which the large-scale (meandering) components are included in the concentration estimates. Larger conditional averaging times typically produce larger plumes. For all runs, the conditional averaging time was set to 1 hour.

\section{b. HPAC Surface Observation Files}

In order to specify the meteorological quantities listed in Table 2-1, it was necessary to create HPAC surface observation files [Ref. 2-3] for the three stability classes considered. ${ }^{3}$ Each file specifies a single wind observation of $5 \mathrm{~m} / \mathrm{s}$ in the negative $x$ direction (90 degrees) at a height of $10 \mathrm{~m}$, geo-location of $45^{\circ} \mathrm{N}$ latitude and $0^{\circ} \mathrm{E}$ longitude, and local time of 0:00 hours. ${ }^{4}$ Also specified are the boundary layer heights $\left(z_{\mathrm{i}}\right)$ and Monin-Obukhov lengths $(\mathrm{L})$ for the runs. The three surface observation files are displayed in Figures 2-2 through 2-4.

3 For example, the boundary layer height and the Monin-Obukhov length cannot be directly specified via the HPAC user interface.

$4 \quad 45^{\circ} \mathrm{N}$ latitude and $0^{\circ} \mathrm{E}$ longitude is the release point for all HPAC releases. The time for all releases is 0 hours local time. Both geo-location and time of the release are arbitrary choices and do not influence the HPAC results. This would not be the case, however, if real terrain was added (depends on geolocation) or agent decay effects were included (depends on time of day). 


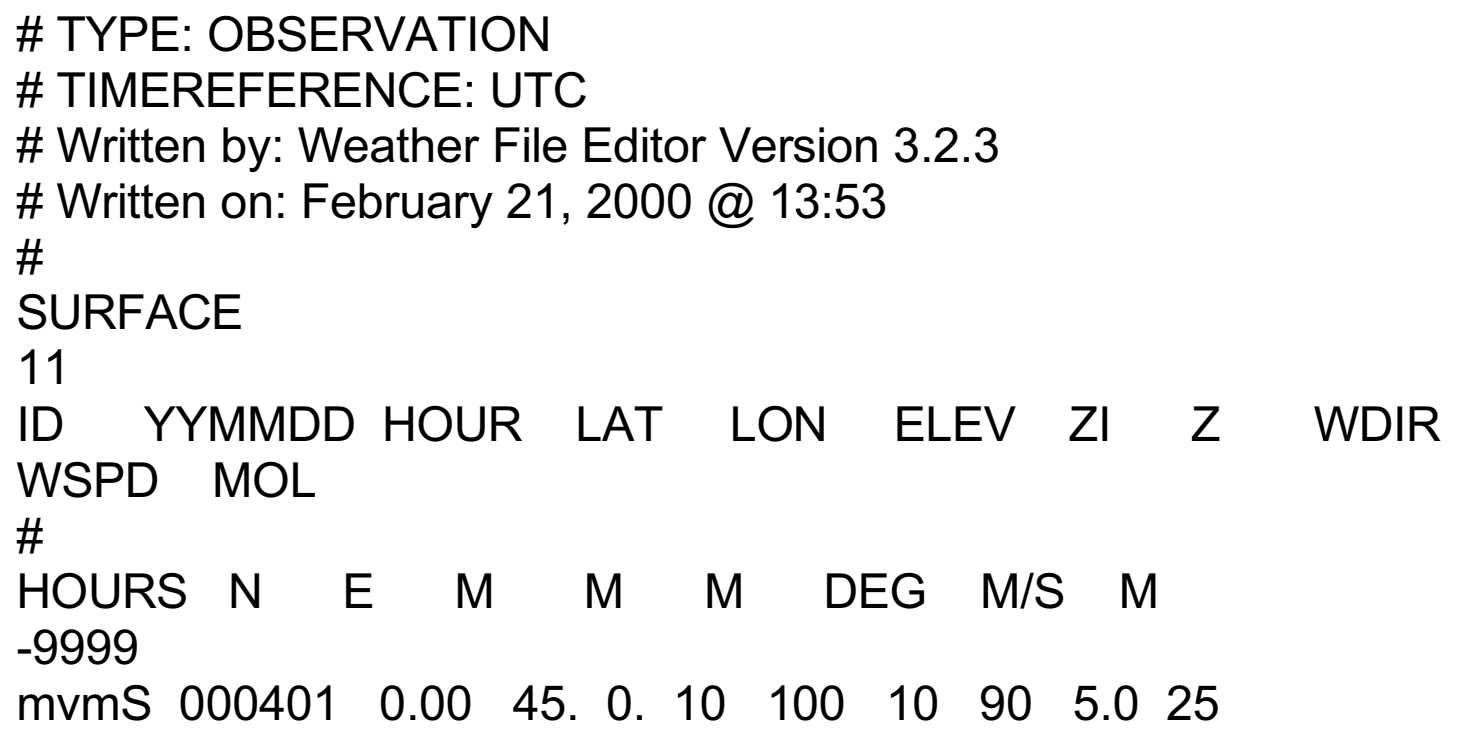

Figure 2-2. Surface Observation File for Stable Releases (MvM 1 through 3)

\# TYPE: OBSERVATION

\# TIMEREFERENCE: UTC

\# Written by: Weather File Editor Version 3.2.3

\# Written on: February 21, 2000 @ 13:53

\#

SURFACE

11

ID YYMMDD HOUR LAT LON ELEV ZI Z WSPD MOL

\#

HOURS $N \quad E \quad M \quad M \quad M \quad$ DEG $\quad M / S \quad M$ $-9999$

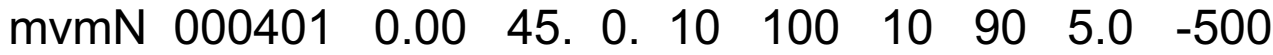

Figure 2-3. Surface Observation File for Neutral Releases (MvM 4-6, 10-17) 
\# TYPE: OBSERVATION

\# TIMEREFERENCE: UTC

\# Written by: Weather File Editor Version 3.2.3

\# Written on: February 21, 2000 @ 13:53

\#

SURFACE

11

ID YYMMDD HOUR LAT LON ELEV ZI $Z$ W WDIR WSPD MOL

\#

HOURS $N$ E $M \quad M \quad M \quad M \quad$ DEG $M / S$ M

$-9999$

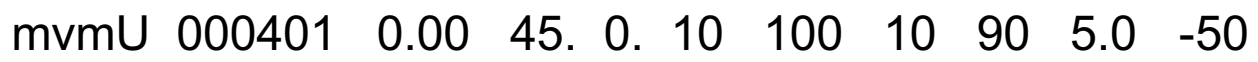

Figure 2-4. Surface Observation File for Unstable Releases (MvM 7-9)

\section{c. HPAC Output and Dosage Calculation}

At the outset of this study, it was agreed that the model-to-model comparison would focus on comparisons of dosage, sometimes referred to as (time) integrated concentration. HPAC output is held in a sampler output file (.smp file) [Ref. 2-4] that contains the concentration $c\left(\mathbf{r}_{\mathrm{i}}, t_{\mathrm{k}}\right)$ at each sampler location $\mathbf{r}_{\mathrm{i}}$ and time step $t_{\mathrm{k}}$. For the purposes of this study, the dosage at a sampler point $\mathbf{r}_{\mathrm{i}}$ is defined to be the time integral (sum) of the concentration at that point from the time of the release, $t=0$, to the current time $t$,

$$
d\left(\mathbf{r}_{i}, t\right)=\Delta t \sum_{k=0}^{N} c\left(\mathbf{r}_{i}, t_{k}\right)
$$

where $\Delta t$ is the output time step (typically $60 \mathrm{sec}$ ), $t=N \Delta t$ is the current time, and $N$ is the number of time steps (in MKS units, dosage has units of $\mathrm{kg}-\mathrm{s} / \mathrm{m}^{3}$ ). A routine to read HPAC sampler output files and compute dosages for all sampler locations was written in MATLAB. Dosages for all runs were computed at $t=30 \mathrm{~min}$ and $t=60 \mathrm{~min}$. Dosages for MvM run 15 were computed at the additional times $t=120,180$, and $240 \mathrm{~min}$, because of the longer run duration. 


\section{NARAC Computational Details 5}

\section{a. NARAC Meteorological Grids, Parameters, and Settings}

NARAC meteorological fields including mean winds and turbulence were generated by $\mathrm{ADAPT}^{6}$ on a user-specified meteorological data grid generated by the Gridgen utility with flat topography specified. For MvM runs 1 through 14, 16, and 17 the meteorological data grid was constructed with $0.5 \mathrm{~km}$ horizontal resolution covering an area $40 \mathrm{~km}$ in the downwind direction $(x)$ and $8 \mathrm{~km}$ in the transverse $(y)$ direction. For the high altitude run, MvM 15, the meteorological grid was again constructed with 0.5 $\mathrm{km}$ resolution, but covered an area $100 \mathrm{~km}$ by $20 \mathrm{~km}$ in $x$ and $y$, respectively. The horizontal resolution is unimportant, since there is no horizontal variation of the meteorology in these simulations. For all runs, a 26-level graded vertical grid was used with levels at $0.0,10.0,21.6,35.1,50.7,68.8,89.9,114.2,142.6,175.3,213.4,257.6$, $308.9,368.4,437.4,517.4,610.3,718.1,843.2,988.2,1156.5,1351.8,1578.4,1841.2$, 2156.2, and $2500.0 \mathrm{~m}$.

The HPAC vertical wind profile was input to ADAPT via a NARAC standard format observational file. The main input file to ADAPT is a namelist specifying information about the grid, the meteorological data, and the choice of assimilation methods used to generate the 3D meteorological fields used by LODI. The critical parameters for this study are the surface roughness, surface layer depth, boundary layer depth, and the inverse Monin-Obukhov length. ADAPT also generates eddy diffusivities based on similarity theory parameterizations.

A 2-meter cutoff distance was selected for all runs using a spherical Gaussian source. This is the distance at which the Gaussian distribution is cut off, yielding a finite area over which to initialize source particles. (Several runs done with a cutoff of $5 \mathrm{~m}$ displayed only minor differences in the results.)

All sources were initialized with 500,000 particles. $^{7}$ This allowed convergence in the concentration field to roughly three significant figures along the downwind axis.

5 See Reference 2-5 for additional details associated with the NARAC modeling system.

6 See Chapter 1, Section C and Reference 2-6.

7 The 500,000 particles used in the NARAC calculation do not correspond to individual molecules. Rather, they represent computational constructs that have the appropriate properties for the material being modeled. 
Name lists (input files) for all of the NARAC predictions can be found in Appendix B.

\section{b. NARAC Dosage Calculation}

Integrated air concentration (i.e., dosage) is defined by:

$$
\overline{I C}(x, y, z, t)=\int_{t-\Delta t}^{t} \bar{C}\left(x, y, z, t^{\prime}\right) d t^{\prime}
$$

where $t$ is the output time and $\Delta t$ is the sampling period. NARAC integrated air concentrations in the xy plane at $\mathrm{z}=10 \mathrm{~m}^{8}$ were computed every 30 and 60 minutes, using a 30- or 60-minute sampling period, respectively. (Note that MvM 15 also produced integrated concentrations using 120-, 180-, and 240-minute sampling periods.) Air concentrations were also calculated in the $\mathrm{xz}$ plane at $\mathrm{y}=0 \mathrm{~m}$ at particular times every 30 minutes. Runs with particle sources also computed instantaneous surface deposition every 30 minutes.

\section{NARAC and HPAC Output Comparison Grids}

For each MvM run, HPAC and NARAC output data (typically concentration data) were generated on spatial grids. Grids were chosen to respect the spatial extent of the plume for the duration of the release. Two grids were adopted:

- Grid 1: used for all MvM runs except MvM run 15 (high altitude release)

- Grid 2: used for MvM run 15.

Specifics on the construction of the grids and their conversion to sampler files follow.

\section{a. NARAC Grids}

The NARAC suite of modeling tools includes the utility Gridgen, which is used to generate variable-resolution concentration grids. The grids are constructed to resolve the spatial distribution of plume concentration as a function of downwind distance from the release point. This is achieved by satisfying the relationship $\Delta x=\sigma_{x} / n$ for $n \geq 2$, where $\Delta x$ is the grid spacing (or resolution) and $\sigma_{x}(t)$ is the standard deviation of the plume concentration distribution and $n$ determines the desired resolution. Using this relationship and the approximations that $\sigma_{x}$ grows linearly with time,

8 The concentration, $\bar{C}$, is determined using a sampling depth of 20 meters. See Section 4 below. 


$$
\sigma_{x}(t)=\sigma_{x}(0)+\sigma_{u} t
$$

we can define a grading factor, $f_{\mathrm{x}}=\Delta x / x$ such that

$$
f_{x}=\frac{\sigma_{u}}{\bar{u} n}
$$

where $\bar{u}$ is the mean wind speed, $x$ is the downwind distance, $t=x / \bar{u}$, and $\sigma_{u}$ is the standard deviation of the $x$ component of the wind velocity. This assumes that $\sigma_{x}(0)$ is much less than $\sigma_{u} t$ (which is valid for small source sizes or for sufficiently large $t$ ).

Typical one-hour-average values of $\sigma_{u}$ are 0.5 to $1.0 \mathrm{~m} / \mathrm{s}$. For the runs we have defined, $\bar{u}=5 \mathrm{~m} / \mathrm{s}$, so using $n=2$ and Equation $2-5, f_{x}=(0.5 \mathrm{~m} / \mathrm{s}) /[(5 \mathrm{~m} / \mathrm{s})(2)]=0.05$. For example, at a downwind distance corresponding to one hour after the release, this grading factor leads to a grid spacing of $\Delta x=f_{x} \bar{u} t=(0.05)(5 \mathrm{~m} / \mathrm{s})(3600 \mathrm{~s})=900 \mathrm{~m}$. The same grading factor was used for both the downwind $(x)$ and the crosswind $(y)$ directions.

Grid 1 has a downwind $(x)$ extent of $\sim 40 \mathrm{~km}$ and transverse $(y)$ extent of $\sim 8 \mathrm{~km}$. The grid was constructed with $50 \mathrm{~m}$ resolution out to a distance of $1 \mathrm{~km}$ in both the downwind and transverse dimensions. This grid was then graded outward with a grading factor of 0.05, yielding a mesh with 130 (96) points in the $x(y)$ direction, for a total of 12,480 grid points. The maximum cell size in the $x$ direction is $1,435 \mathrm{~m}$ and in the $y$ direction it is $189 \mathrm{~m}$. This resolution is sufficient to resolve the plume at all distances greater than $1 \mathrm{~km}$ in both the downwind and transverse dimensions.

MvM run 15 requires a larger concentration grid, due to the height of the release and the longer duration. The grid for this run, grid 2 , has a downwind $(x)$ extent of $\sim 90$ $\mathrm{km}$ and a transverse $(y)$ extent of $\sim 18 \mathrm{~km}$. The grid uses the same base grid and grading factor as defined above, but the resulting mesh is 116 points by 136 points in the $x$ and $y$ directions, respectively, giving a total of 15,776 grid points. The maximum cell size in the $x$ direction is $4,607 \mathrm{~m}$ and in the $y$ direction it is $455 \mathrm{~m}$.

Because LODI is a Lagrangian particle code, a sampling volume must be defined in order to calculate concentrations. This volume is defined by specifying a sampling depth perpendicular to the two-dimensional bin already defined. We chose a sampling depth of 20 meters implying that the volume used to calculate the air concentrations at 10 -meter height extends from $\mathrm{z}=0$ to $\mathrm{z}=20 \mathrm{~m}$.

The NARAC smoothBinData utility was used to smooth the concentration field prior to plotting. This utility uses an area-weighted filter to smooth the data on the graded concentration grid. For concentration grids with constant spacing the filter 
reduces to a 1-2-1 filter along each dimension [Ref. 2-7]. Use of smoothing is desirable due to the rapid fall-off in particle number as the edge of the plume is approached.

\section{b. HPAC Grids}

All HPAC results in this comparison were generated using HPAC version 3.2 operated in the Extended Mode. In order to compute HPAC concentration values on the NARAC-defined grid points, it was first necessary to convert grids 1 and 2 to HPAC sampler (.sam) files [Ref. 2-8]. HPAC sampler files are limited to 10,000 grid points. This limitation required the NARAC grids to be suitably reduced before conversion to sampler files. Point reduction was done by eliminating every other row of downwind points, starting near the edges in the crosswind direction and working inward, symmetrically about the centerline. This process was continued until the remaining number of grid points dropped below 10,000. After reduction, the grid sizes were:

- Grid 1: (130 downwind) x (76 crosswind) for a total of 9,880 points

- Grid 2: (116 downwind) x (86 crosswind) for a total of 9,976 points.

Figures 2-5 and 2-6 show the two grids, before and after reducing the number of points. Throughout this study, output was compared only on those points common to the HPAC and NARAC grids, that is, only on the reduced grids. Unless otherwise mentioned, the sampler height was chosen to be $10 \mathrm{~m}$ for all samplers for all runs. This value coincides with the height used in the NARAC runs for integrated concentrations. 
Grid 1 for MvM Runs 1-14,16,17

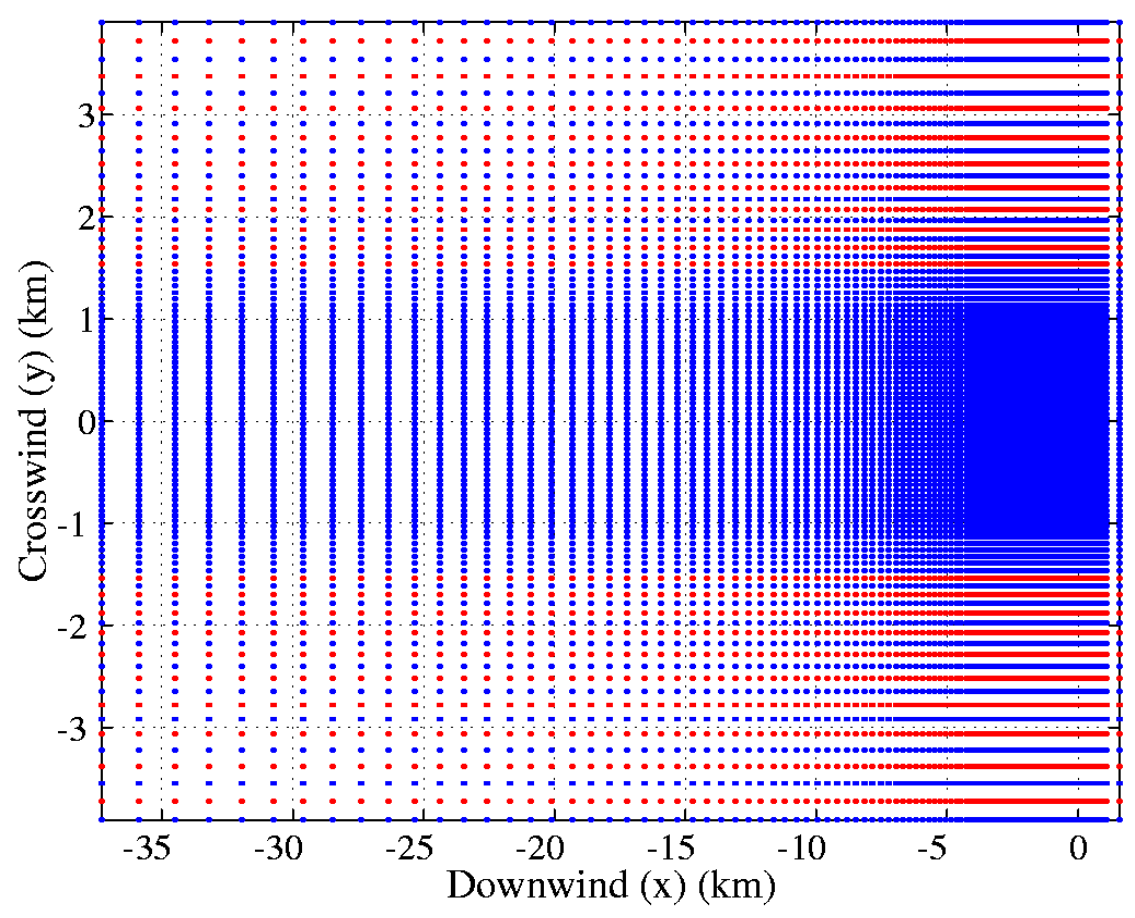

Figure 2-5. Grid Points for Grid 1:

Blue Points Denote Those Retained for HPAC Sampler File




Figure 2-6. Grid Points for Grid 2:

\section{Blue Points Denote Those Retained for HPAC Sampler File}

\section{COMPARISON MEASURES}

In this section, we discuss the measures used to compare the HPAC and NARAC output dosages. In selecting comparison measures, we decided to adopt measures that answer basic questions about the dosage plumes:

- How far downwind is the plume?

- How wide is the plume?

- What is the maximum dosage at a given downwind distance?

- To what extent do the two model plumes overlap?

For this purpose, four quantitative measures were adopted: downwind contour distances for selected dosages, crosswind dosage plume widths, crosswind maximum dosages, and an area-based measure of effectiveness (MOE). These measures are easily computed and communicate in a quantitative fashion much of the information one learns from simple graphical comparisons of output dosages. For the high altitude release (MvM 15), vertical plume structure was also investigated. Details are provided in Chapter 3.

\section{Dosage Contours}

Dosage contours provide immediate graphical information about the relative performance of model-to-model results; model agreement or lack thereof can be quickly assessed. Within a single run, the dosage can span a large range of values (for the scenarios that we examined, typically $\left.10^{-12}-10^{-6} \mathrm{~kg}-\mathrm{s} / \mathrm{m}^{3}\right)$. Because of the wide dynamic range, contours are usually spaced at powers of 10 (or the $\log _{10}$ of the dosage is viewed). To avoid processing extremely small or zero dosage values, all dosage data for both models were truncated at a minimum threshold value of $10^{-15} \mathrm{~kg}-\mathrm{s} / \mathrm{m}^{3}$. A MATLAB routine was written to process the dosage data for both models and construct the contour plots. Contours were computed using the built-in MATLAB contouring algorithm, contour. Contour values were selected by first viewing the histogram of the log of the dosage values for the run, then choosing upper and lower contours at powers of 10 near the tails of the histogram, and filling in with intermediate powers of 10. This technique takes much of the guesswork out of contour value selection. 


\section{Downwind Contour Distances}

Dosages along the centerline ( $x$ axis) for both models are computed by interpolating ${ }^{9}$ two-dimensional dosage data onto the centerline. For a given dosage value the downwind distance to that dosage is computed for both models.

\section{Crosswind Dosage Plume Widths}

There are many ways to define the plume width. The width used in this comparison is a dose-weighted width, defined as follows. Let the dosage values at a given crosswind slice be denoted by $d_{\mathrm{i}}, i=1,2, \ldots, n$, with corresponding crosswind positions $y_{\mathrm{i}}$. Then the dose-weighted mean location is given by

$$
\langle y\rangle=\sum_{i=1}^{n} \alpha_{i} y_{i},
$$

where the weights $\alpha_{\mathrm{i}}$ are given by

$$
\alpha_{i}=\frac{d_{i}}{\sum_{j=1}^{n} d_{j}} .
$$

Similarly, the dose-weighted mean square position is

$$
\left\langle y^{2}\right\rangle=\sum_{i=1}^{n} \alpha_{i} y_{i}^{2} .
$$

The dose-weighted width is then taken to be

$$
W=2 \sqrt{\left\langle y^{2}\right\rangle-\langle y\rangle^{2}}
$$

Dosage plumes are frequently approximated by a Gaussian in the crosswind direction. ${ }^{10}$ If the points $\left(y_{\mathrm{i}}, d_{\mathrm{i}}\right)$ describe a Gaussian, then the mean position (2-6) and width (2-9) correspond to the mean, $\mu$, and twice the standard deviation, $2 \sigma$, respectively for the Gaussian. Crosswind dosage plume widths are compared for several downwind locations for each run.

9 Interpolation was carried out with the MATLAB routine interpl.

10 This is no surprise in the case of HPAC, since the HPAC plume is represented as a superposition of Gaussian distributions. 


\section{Crosswind Maximum Dosages}

Using the same crosswind dosage values as in the plume width calculation above, the maximum dosage, $d_{\max }=\max _{i}\left(d_{i}\right)$, is found for both models at each downwind location.

\section{Area-Based MOE}

The area-based MOE was introduced in Reference 2-9, where it was used to compare model predictions against field trial data. With a minor change in interpretation, this MOE can be applied to model-to-model only (i.e., no field trial data) comparisons. A description of the MOE as it applies to model comparisons follows.

In any comparison of two model predictions, there are three regions of interest:

- Model 1 and Model 2 predictions agree (e.g., overlap for some dosage contour)

- Model 1 overpredicts Model 2 (Model 1 predicts a larger area at the specified contour level than Model 2)

- Model 1 underpredicts Model 2 (Model 1 predicts a smaller area at the specified contour level than Model 2).

Figure 2-7 illustrates dosage contours, $\mathrm{M}_{1}$ and $\mathrm{M}_{2}$, for two models at the same contour level. The green (solid) overlap area, $\mathrm{A}_{\mathrm{OL}}$, represents the region where the model predictions agree. The blue (cross-hatched) region, $\mathrm{A}_{\mathrm{OP}}$, represents the region where model 1 overpredicts model 2. The red (diagonal lined) region, $A_{U P}$, represents the region where model 1 underpredicts model 2.

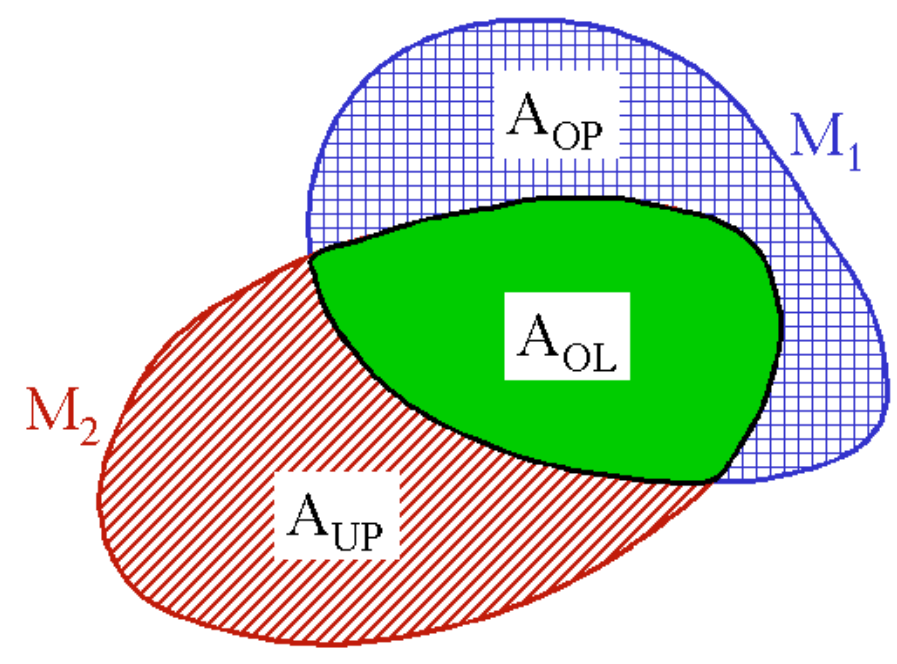


Figure 2-7. Illustration of Three Regions for Two Model Predictions $M_{1}$ and $M_{2}$

The area-based MOE is a two-dimensional quantity, defined in terms of the three areas, $\mathrm{A}_{\mathrm{OL}}, \mathrm{A}_{\mathrm{UP}}, \mathrm{A}_{\mathrm{OP}}$, as follows:

$$
\mathrm{MOE}=\left(1-\frac{A_{U P}}{A_{U P}+A_{O L}}, 1-\frac{A_{O P}}{A_{O P}+A_{O L}}\right) .
$$

Noting that the areas inside contours $M_{1}$ and $M_{2}$ can be expressed as $A_{M 1}=A_{O P}+A_{O L}$ and $\mathrm{A}_{\mathrm{M} 2}=\mathrm{A}_{\mathrm{UP}}+\mathrm{A}_{\mathrm{OL}}$, respectively, the MOE can be equivalently expressed as

$$
\mathrm{MOE}=\left(1-\frac{A_{U P}}{A_{M 2}}, 1-\frac{A_{O P}}{A_{M 1}}\right)=\left(\frac{A_{O L}}{A_{M 2}}, \frac{A_{O L}}{A_{M 1}}\right) .
$$

Geometrically, the MOE occupies a point in the two-dimensional region shown in Figure 2-8. If the model predictions agree perfectly, then $\mathrm{A}_{\mathrm{M} 1}=\mathrm{A}_{\mathrm{M} 2}=\mathrm{A}_{\mathrm{OL}}$, and the $\mathrm{MOE}$ takes on the value $(1,1)$. Alternatively, if the model predictions disagree completely, then there is no overlap region; in this case $\mathrm{A}_{\mathrm{OL}}=0$ and the MOE is $(0,0)$. Models that are in close agreement will have MOE values concentrated in the vicinity of the $(1,1)$ point.

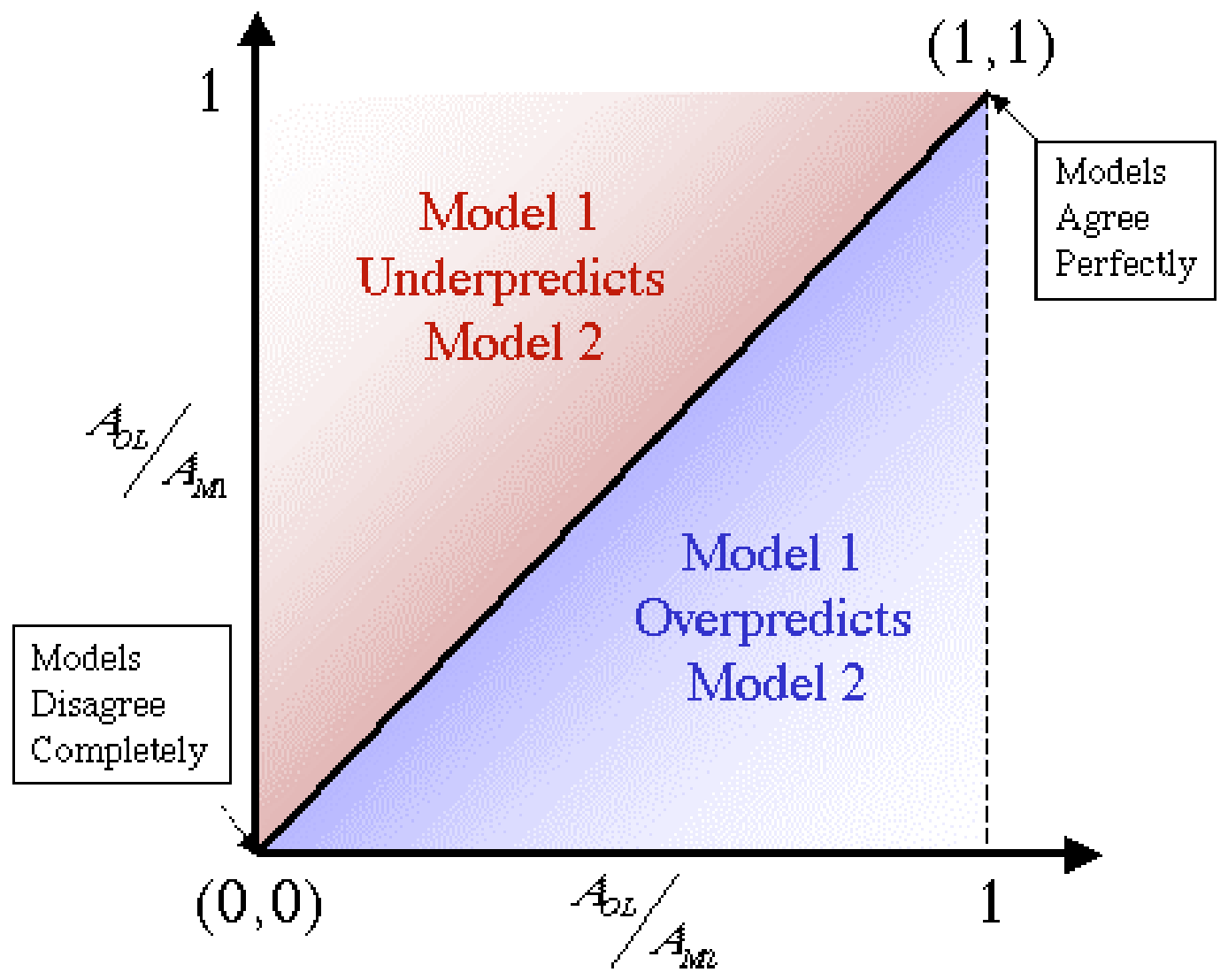

Figure 2-8. Illustration of Area-Based MOE 
A model that consistently overpredicts or underpredicts the other can be easily diagnosed from MOE behavior. Consider the diagonal line in Figure 2-8. On this line, the areas $A_{M 1}$ and $A_{M 2}$ are the same. This in turn implies that the areas $A_{U P}$ and $A_{O P}$ are the same. In other words, underprediction and overprediction are equally likely. Below the diagonal, $A_{M 1}>A_{M 2}$ or $A_{O P}>A_{U P}$, represents the region of consistent overprediction of model 1 when compared to model 2. Above the diagonal, $A_{M 1}<A_{M 2}$ or $A_{O P}<A_{U P}$, corresponds to consistent underprediction of model 1 relative to model 2.

In practice, the contours for HPAC and NARAC, generated using the MATLAB routine contour, are polygons. Contour areas are computed using the MATLAB routine polyarea. Without loss of generality, we choose model 1 to be HPAC and model 2 to be NARAC throughout this work; therefore $A_{M 1}=A_{H P A C}$ and $A_{M 2}=A_{N A R A C}$. MOEs for all runs and several contour levels are computed once the basic areas $A_{\mathrm{OL}}, \mathrm{A}_{\mathrm{HPAC}}$, and $\mathrm{A}_{\mathrm{NARAC}}$ are found. 


\section{REFERENCES}

2-1. Sykes, R. I., et. al., PC-SCIPUFF Version 1.0 Technical Documentation (DRAFT), A.R.A.P. Report 717, Titan Research and Technology Division, Princeton, 1998, pp 133-135.

2-2. ibid, pp. 23-24.

2-3. ibid, pp. 110-114.

2-4. ibid, pp. 180-181.

2-5. Nasstrom, J. S., Sugiyama, G., Leone, J. M. Jr., and Ermak, D. L., “A Real-Time Atmospheric Dispersion Modeling System," American Meteorological Society's 11th Joint Conference on the Applications of Air Pollution Meteorology, Long Beach, CA, 9-14 January 2000 and references cited therein.

2-6. Sugiyama, G. and Chan, S. T., "A New Meteorological Data Assimilation Model for Real-Time Emergency Response," 10th Joint Conference on the Applications of Air Pollution Meteorology, Phoenix, AZ (11-16 January 1998), Am. Met. Soc., Boston, MA, 285-289.

2-7. Ermak, D., personal communication.

2-8. Sykes, R. I., et. al., PC-SCIPUFF Version 1.0 Technical Documentation (DRAFT), A.R.A.P. Report 717, Titan Research and Technology Division, Princeton, 1998, pp 159-160.

2-9. Warner S., Platt, N., Heagy, J. F., Bradley, S., Bieberbach, G., Sugiyama, G., Nasstrom, J. S., Foster, K. T, and Larson, D., User-Oriented Measures of Effectiveness for the Evaluation of Transport and Dispersion Models, IDA Paper P-3554, January 2001. 



\section{CHAPTER 3}

RESULTS OF COMPARISONS 



\section{RESULTS OF COMPARISONS}

In this chapter, results of the model-to-model comparison are presented. Gas releases (runs 1 through 9) are discussed first, followed by the particle releases (runs 10 through 14, 16, and 17). The high altitude particle release, run 15, is considered separately. This chapter concludes with a discussion of excursions from the baseline HPAC resolution settings.

\section{A. NEUTRALLY-BUOYANT GAS RELEASES}

Nine neutrally-buoyant gas releases were compared: three stable cases (runs 1 through 3), three near-neutral cases (runs 4 through 6), and three unstable cases (runs 7 through 9). Overall agreement between the HPAC and NARAC gas release predictions was good, and in some cases excellent, with the exception of run 3, which had the highest release height of all the stable releases. In general, agreement for the stable releases was less favorable than for the near-neutral and unstable releases. Also, there was generally better agreement for low altitude releases than for higher altitude releases. Details are presented below.

\section{Representative Contour Plots}

Comparative dosage contour plots form a mainstay of this comparison effort, and examples are discussed below. The full collection of contour plots can be found in Appendix C. Contour plots were constructed for all gas runs at 30 minutes and 60 minutes after the release. Contour values were chosen by first viewing histograms of HPAC and NARAC dosages (after taking the logarithm), then selecting contours that cover the bulk of the overlap region of the two histograms. Figure 3-1 shows the dosage histogram for run 1 (stable atmospheric conditions) at 60 minutes. ${ }^{1}$ The lower and upper contours are selected at $10^{-10} \mathrm{~kg}-\mathrm{s} / \mathrm{m}^{3}$ and $10^{-5} \mathrm{~kg}-\mathrm{s} / \mathrm{m}^{3}$, respectively, with intermediate contours spaced in powers of 10. Figure 3-2 shows the corresponding contour plot; the

1 This histogram is based on all dosages in the output domain (that is, dosages at each output grid point are considered). Throughout this comparison solid red lines denote NARAC quantities, while dashed blue lines denote HPAC quantities. 
lower portion of the figure shows the dosage along the downwind symmetry axis. The release location for all runs is at $(x, y)=(0,0)$ and the downwind direction is the negative $x$ direction. Unless otherwise stated, dosages are computed $10 \mathrm{~m}$ above the surface.

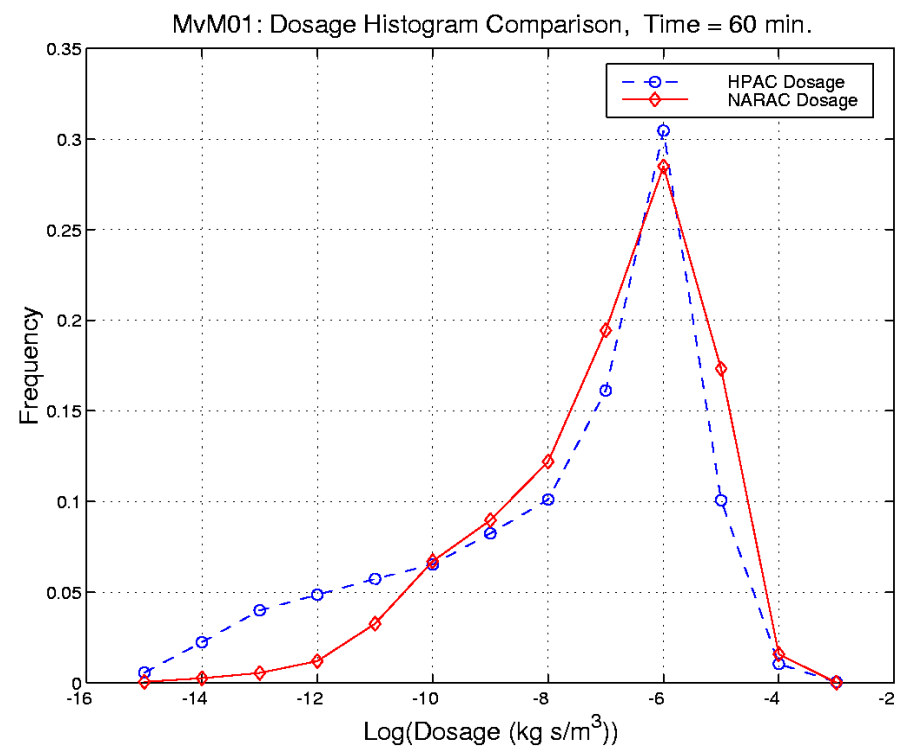

Figure 3-1. MvM 1 (Stable) at 60 Minutes: Histogram of NARAC (Red -) and HPAC (Blue - -) Dosages with Lower and Upper Contours at $10^{-10} \mathrm{~kg}-\mathrm{s} / \mathrm{m}^{3}$ and $10^{-5} \mathrm{~kg}-\mathrm{s} / \mathrm{m}^{3}$, Respectively

MvM01: Dosage $\left(\mathrm{kg} \mathrm{s}^{2} \mathrm{~m}^{3}\right)$, Height $=10 \mathrm{~m}$, Time $=60 \mathrm{~min}$.

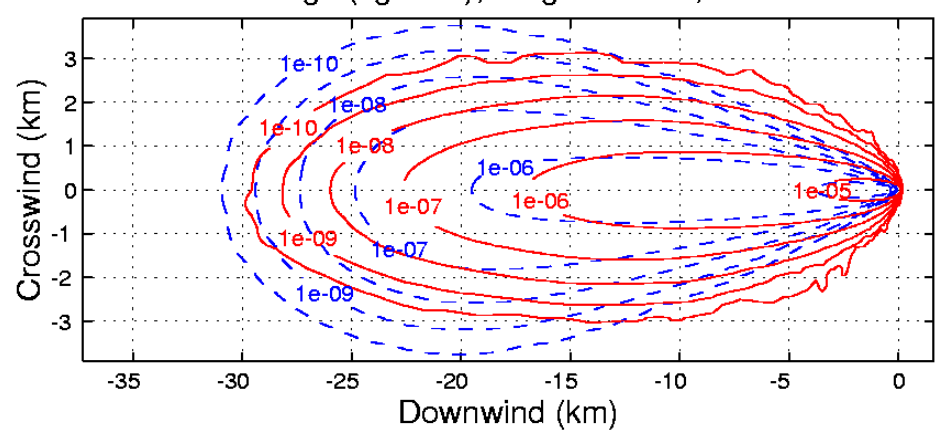

Dosage on Downwind Symmetry Axis

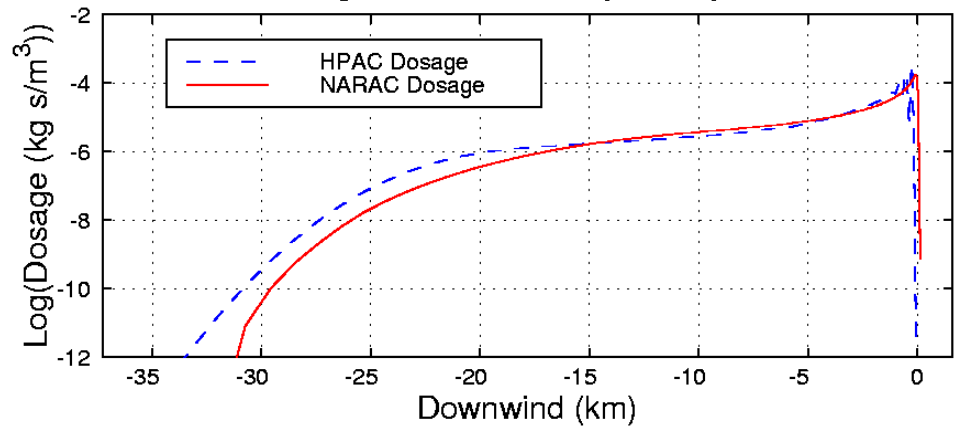

Figure 3-2. MvM 1 (Stable) at 60 Minutes with Upper: NARAC (Red -) and HPAC (Blue - -) Dosage Contours; Lower: Log Dosages on Downwind Symmetry Axis 
Figures 3-3 and 3-4 show similar dosage contour plots for runs 4 (near-neutral) and 7 (unstable) at 60 minutes, respectively. ${ }^{2}$ These three figures point to a general trend in the results of this comparison: model agreement improves as atmospheric conditions become increasingly unstable. ${ }^{3}$ This and other trends are substantiated in the following sections.
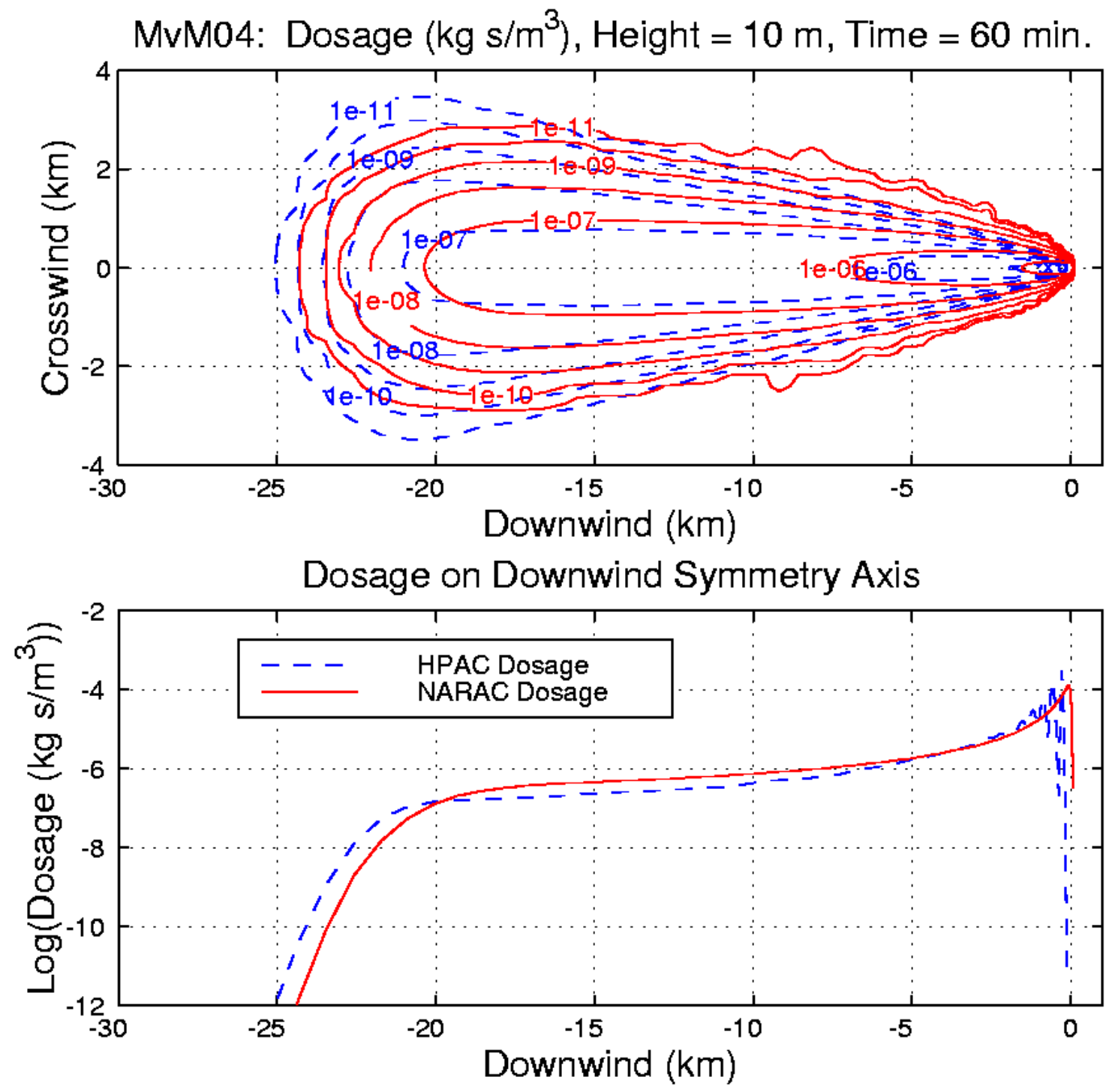

Figure 3-3. MvM 4 (Near-Neutral) at 60 Minutes with Upper: NARAC (Red -) and HPAC (Blue - -) Dosage Contours; Lower: Log Dosages on Downwind Symmetry Axis

2 The HPAC dosage oscillations near the origin are discussed in Section C.3 below. These oscillations do not affect the conclusions drawn in this Chapter.

3 Note that the release height for runs 1,4 , and 7 is $2 \mathrm{~m}$. Other than atmospheric stability, all other parameters are the same. 


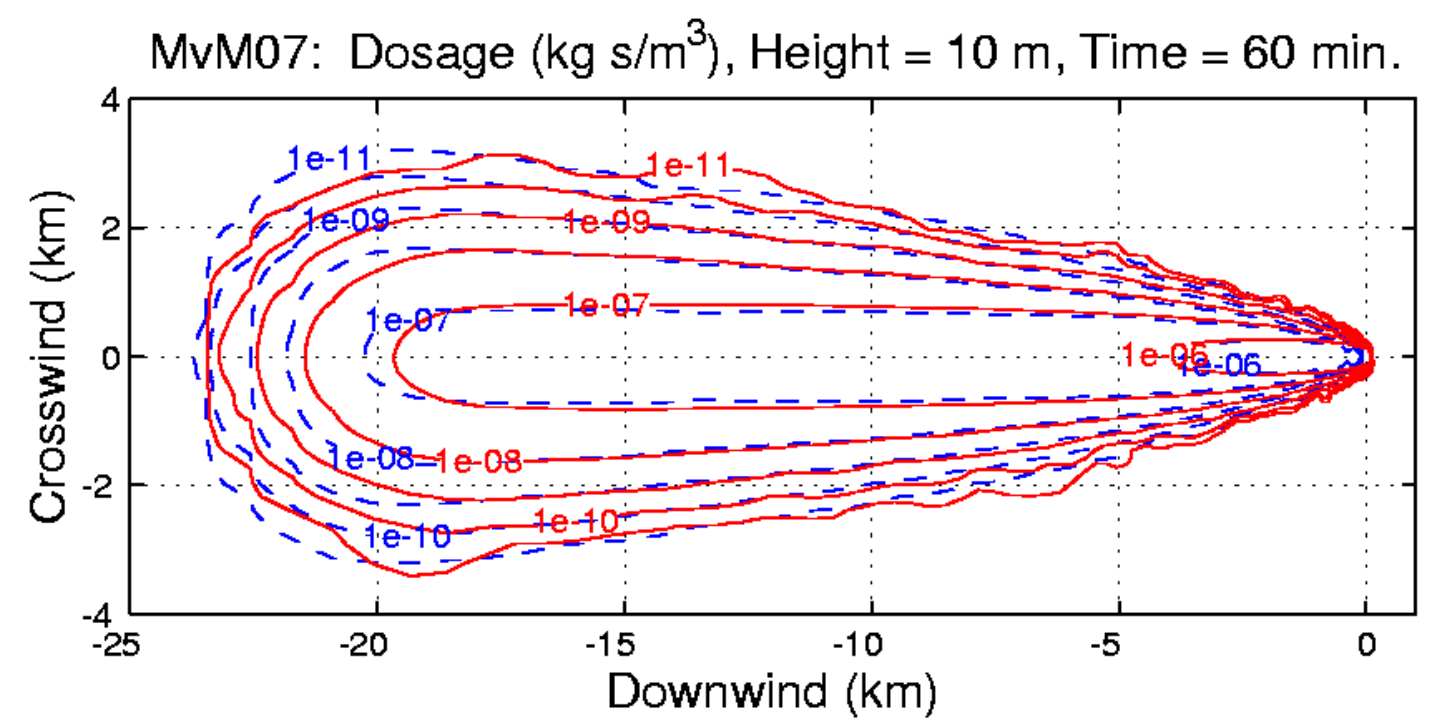

Dosage on Downwind Symmetry Axis

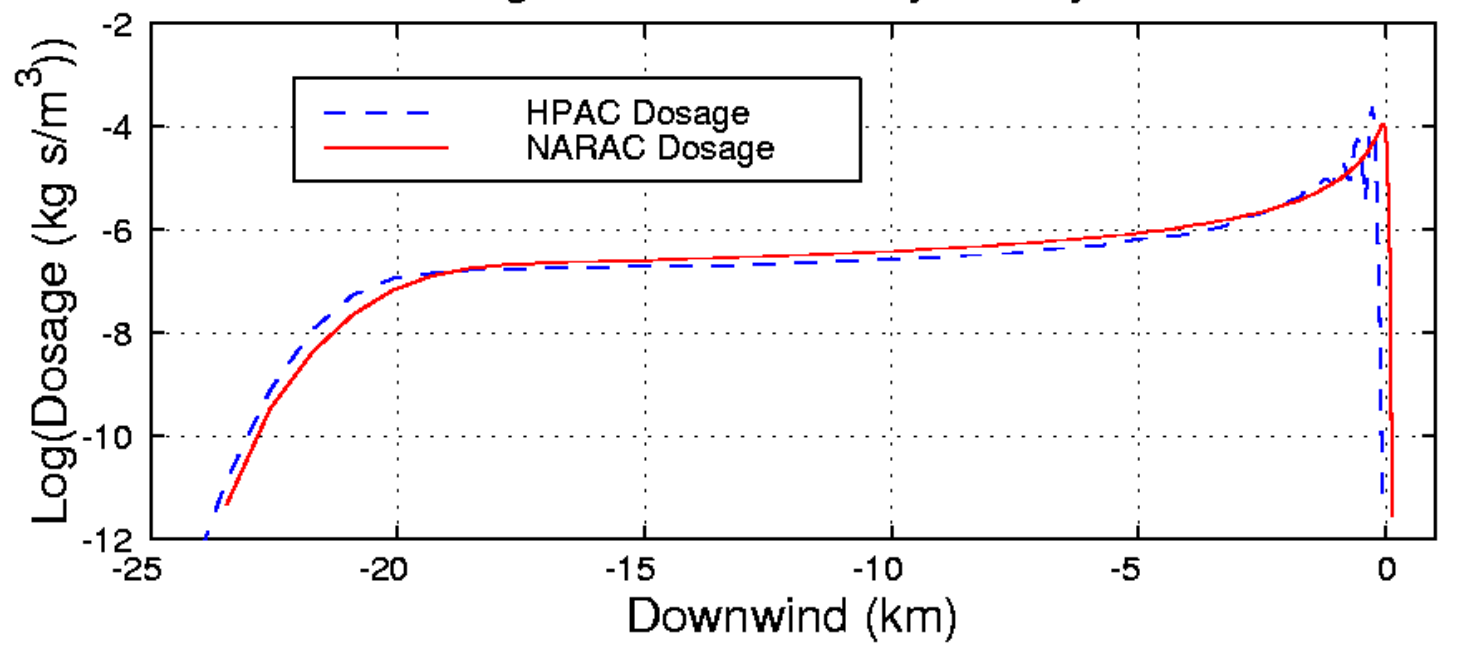

Figure 3-4. MvM 7 (Unstable) at 60 Minutes with Upper: NARAC (Red -) and HPAC (BLUE - -) Dosage Contours; Lower: Log Dosages on Downwind Symmetry Axis

\section{Scatter Plot Comparison of Downwind Contour Distances}

Transport (and downwind diffusion) of the plume between HPAC and NARAC was quantified by comparing the downwind distances to given dosage contours along the symmetry axis. The contour distances were computed by first interpolating dosages onto the symmetry axis using the MATLAB interpolation routine interp1. A bisection algorithm was then used to find the distances where the dosages crossed the given contour values. Figures 3-5 and 3-6 show scatter plots of HPAC versus NARAC contour distances at 30 minutes and 60 minutes, respectively. Colors indicate stability category: 
blue $=$ stable, red $=$ near-neutral, and green $=$ unstable. ${ }^{4}$ The dashed lines above and below the diagonal correspond to fixed overprediction limits. For example, in the 30minute case (Figure 3-5), the upper dashed line represents the HPAC distance exceeding the corresponding NARAC distance by 20 percent. Similarly, the lower dashed line corresponds to the NARAC distance exceeding the corresponding HPAC distance by 20 percent. In general, the HPAC contours tend to overpredict ${ }^{5}$ (extend farther than) corresponding NARAC contours, but by no more than $\sim 20$ percent at 30 minutes and by no more than $\sim 15$ percent at 60 minutes. Agreement between the models is seen to improve with decreasing stability; that is, the green $=$ unstable points are closest to the diagonal, while the blue $=$ stable dots are the farthest.

\section{Gas Runs: Downwind Contour Distances, 30 Minutes}

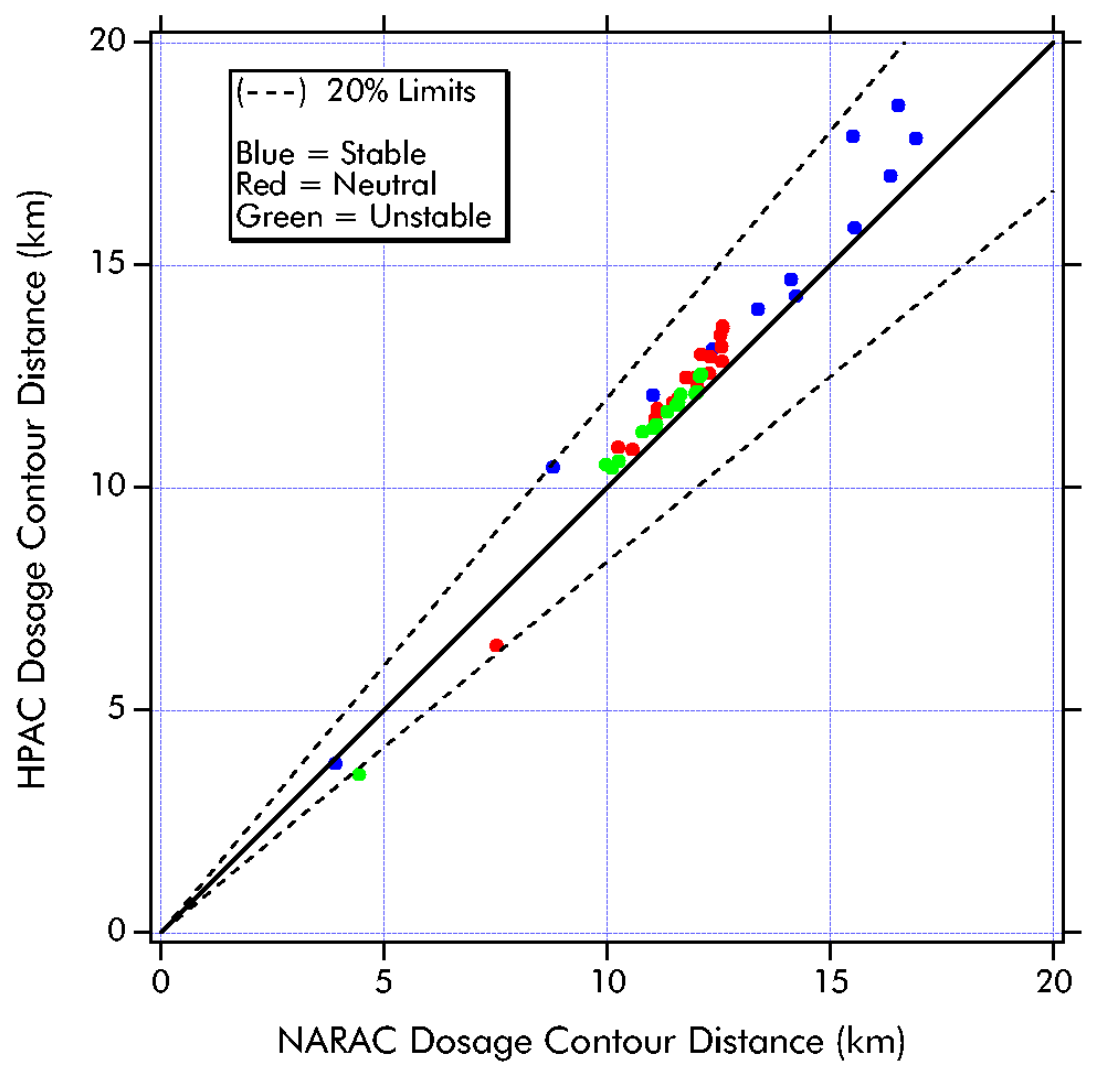

4 This color convention is used throughout this chapter.

5 Equivalently, NARAC underpredicts HPAC. Throughout this study when drawing comparisons we adopt the nomenclature that one model overpredicts the other. This terminology is not to be construed as a statement about the essential correctness or incorrectness of either model. 
Figure 3-5. Scatter Plot Comparison of Downwind Contour Distances at 30 Minutes for All Gas Runs: Colors Indicate Meteorological Stability Categories and Dashed Lines are 20\% Overprediction Limits

Gas Runs: Downwind Contour Distances, 60 Minutes

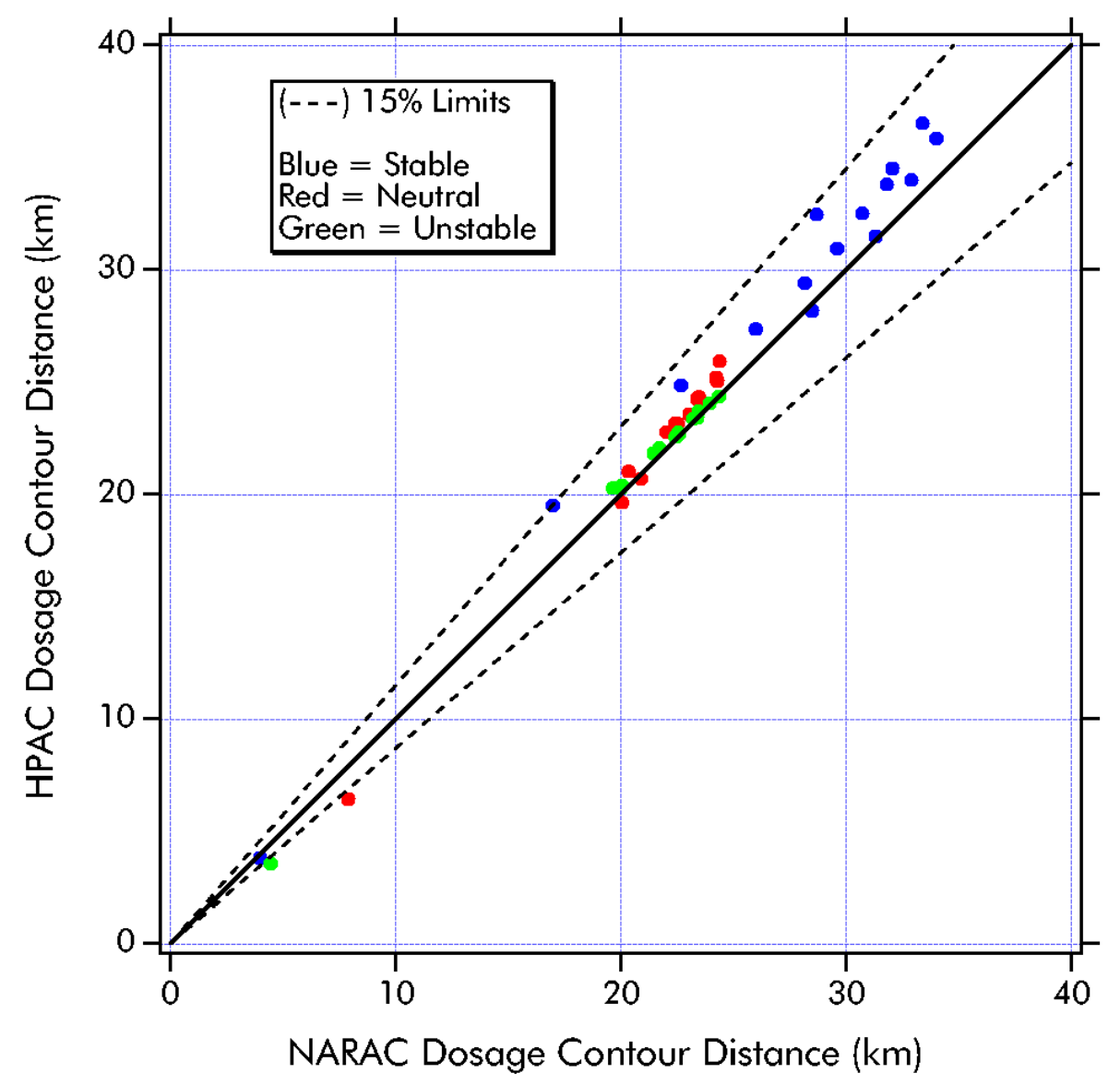

Figure 3-6. Scatter Plot Comparison of Downwind Contour Distances at 60 Minutes for All Gas Runs: Colors Indicate Meteorological Stability Categories and Dashed Lines are 15\% Overprediction Limits

Based on the above results, it appears that the transport (and downwind diffusion) components of the two modeling systems for neutrally-buoyant gases compare favorably.

\section{Scatter Plot Comparison of Crosswind Dosage Plume Widths}

Figures 3-7, 3-8, and 3-9 show crosswind plume profiles at four selected downwind distances for runs 1,4 , and 7, respectively; the time after release in all plots is 
60 minutes. These figures are representative of the crosswind plume profiles for all gas runs (with the exception of run 3, which is considered separately below). Appendix C contains crosswind plume profiles for all gas runs. Dose-weighted plume widths were computed from expression (2-9) at four downwind distances for the 30-minute and 60-minute plumes for all gas runs. For the 30- (60-) minute plume, the downwind distances were typically: $1 \mathrm{~km}, 3 \mathrm{~km}, 5 \mathrm{~km}$, and $10 \mathrm{~km}(5 \mathrm{~km}, 10 \mathrm{~km}, 15 \mathrm{~km}$, and $20 \mathrm{~km})$. At shorter distances, the NARAC plume is wider than the HPAC plume. Further downwind, HPAC begins to, and then increasingly, overpredicts NARAC plume widths.
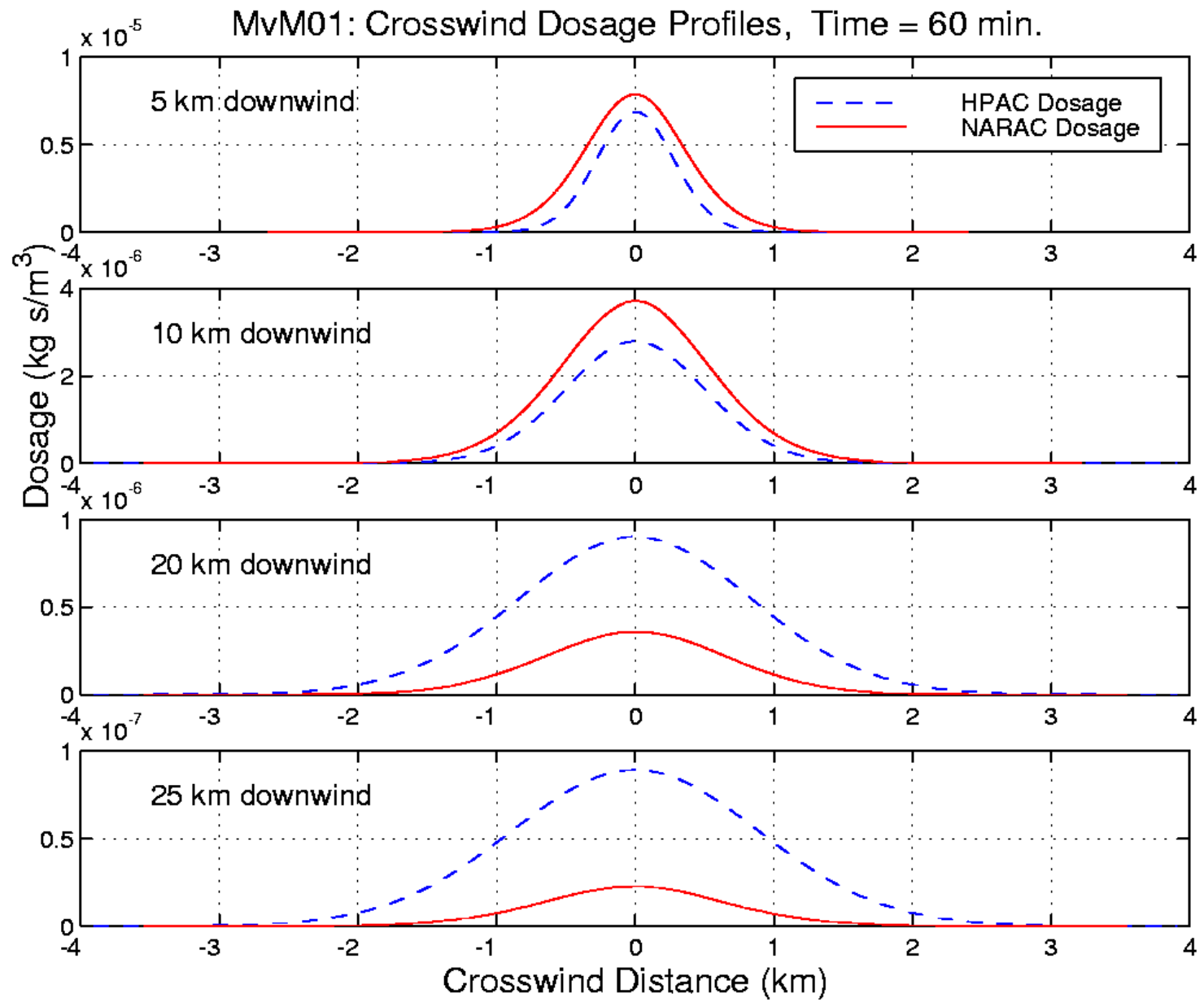

Figure 3-7. MvM 1 at 60 Minutes with Crosswind Plume Profiles at Selected Downwind Distances: NARAC (Red -) and HPAC (Blue - -) 
Figures 3-10 and 3-11 show scatter plot comparisons of the HPAC and NARAC plume widths at 30 minutes and 60 minutes, respectively. Agreement for the unstable cases is best, with the bulk of the unstable (green) points falling within the 20 percent limits. The stable and neutral cases show greater differences, with the bulk of the points (blue and red) falling outside the 20 percent limits, and a few points falling outside the 50 percent limits.

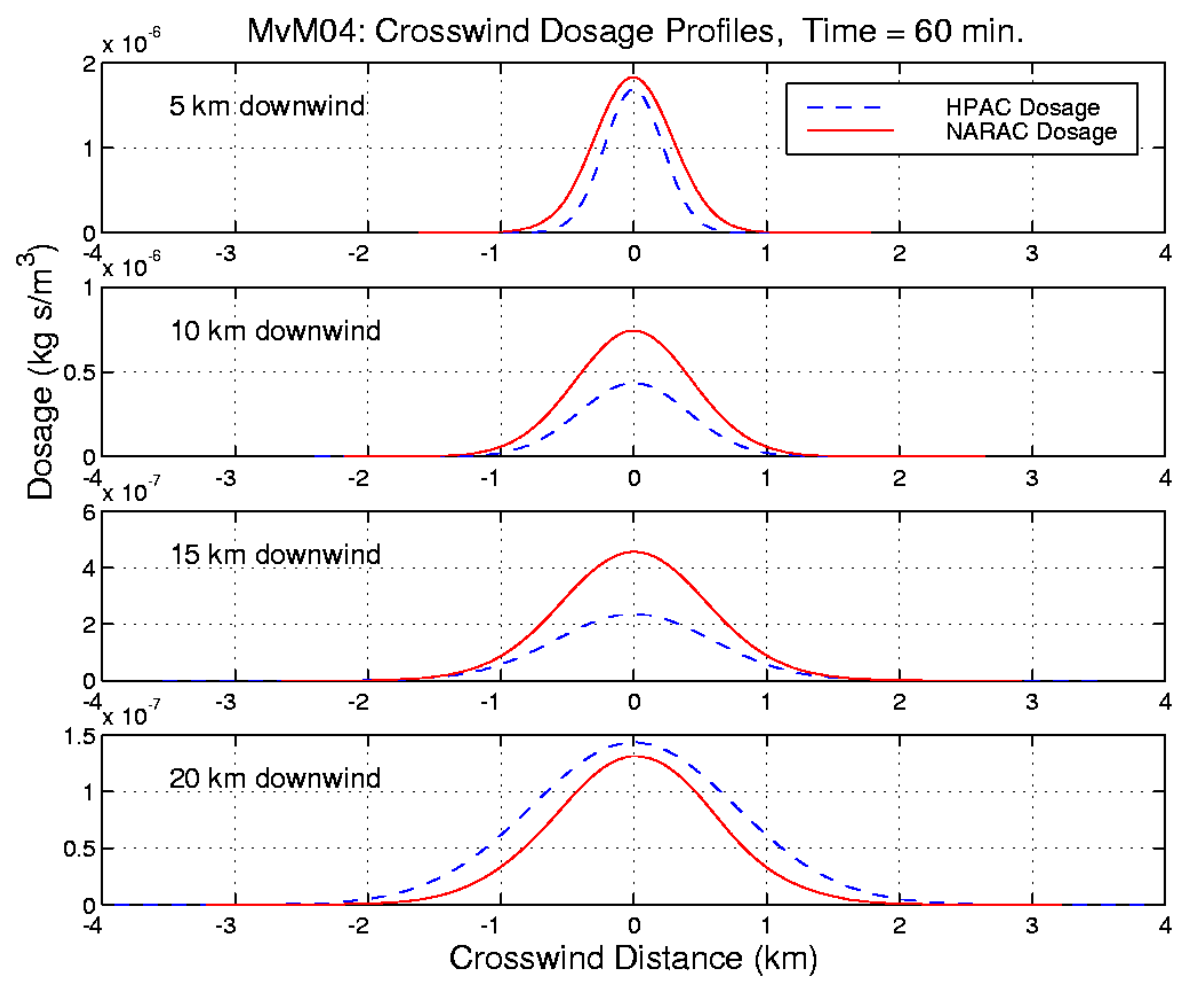

Figure 3-8. MvM 4 at 60 Minutes with Crosswind Plume Profiles at Selected Downwind Distances: NARAC (Red -) and HPAC (Blue - -) 

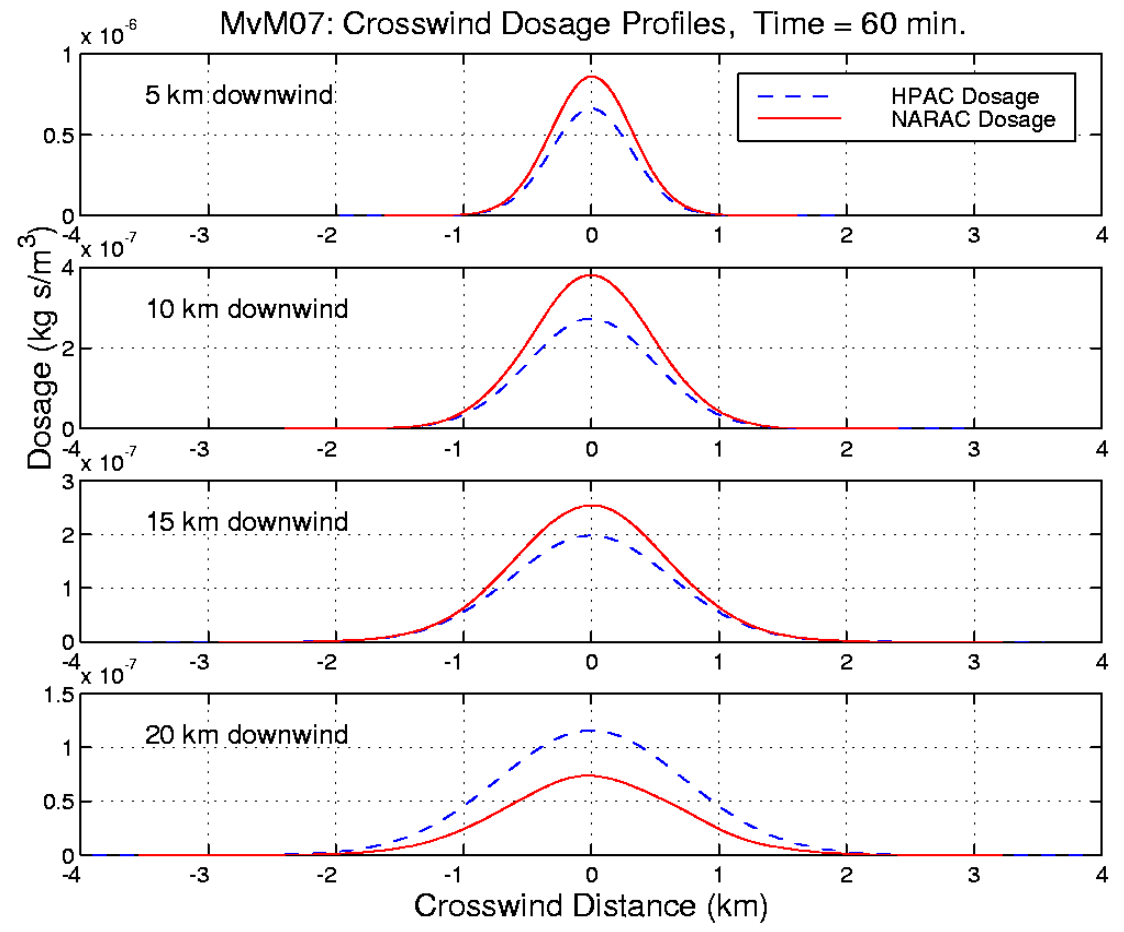

Figure 3-9. MvM 7 at 60 Minutes with Crosswind Plume Profiles at Selected Downwind Distances: NARAC (Red -) and HPAC (Blue - -)

The trend for NARAC plumes to be wider than HPAC plumes at the smaller downwind distances $(1 \mathrm{~km})$, but narrower at the larger downwind distances at $30 \mathrm{~min}$ is clearly seen in Figure 3-10. This observation is consistent with the results from comparisons of HPAC and NARAC predictions of the Prairie Grass field trials, which incorporated a maximum downwind range of 800 meters [Ref. 3-1]. 


\section{Gas Runs: Crosswind Plume Widths, 30 Minutes}

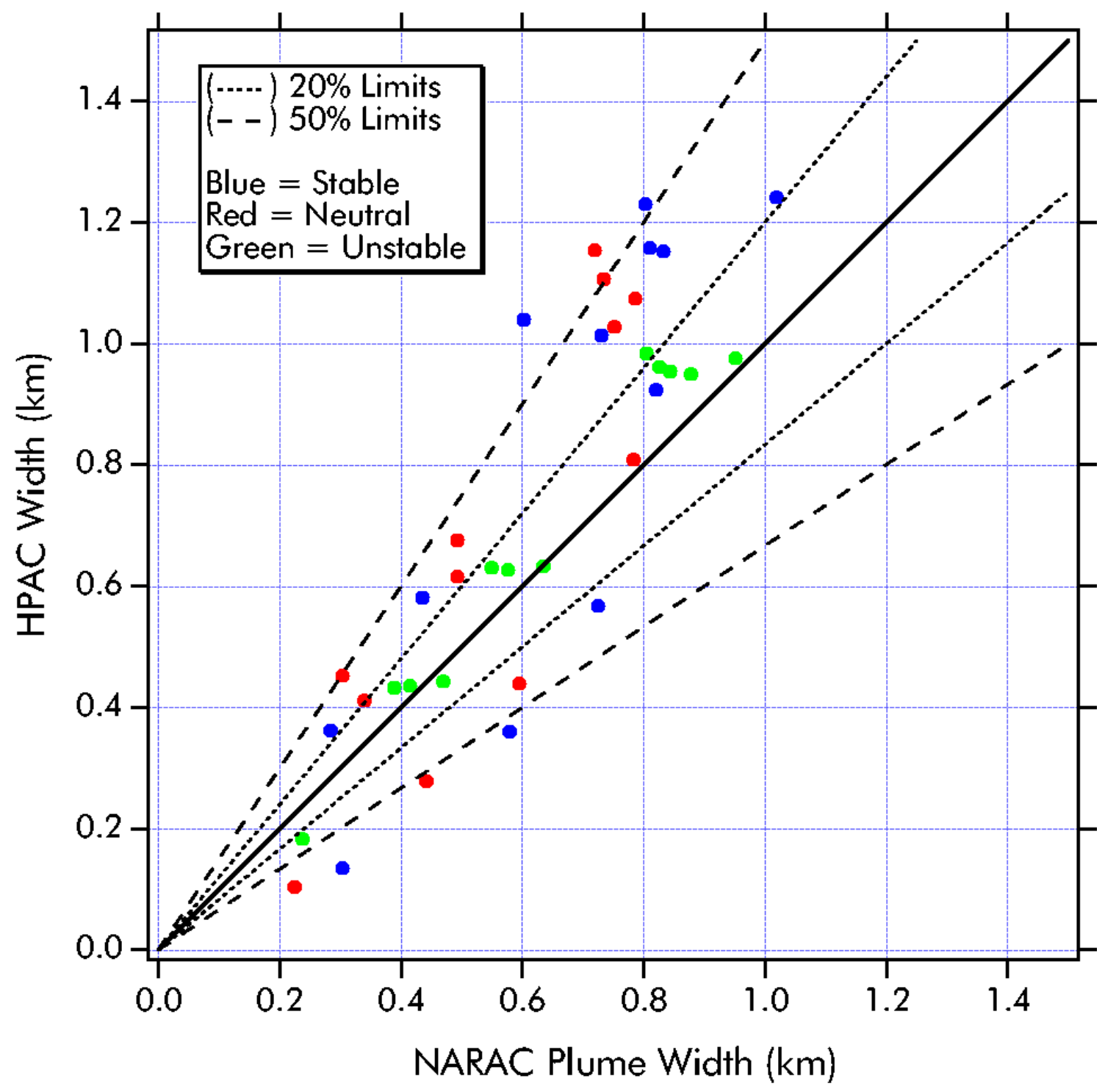

Figure 3-10. Scatter Plot Comparison of Crosswind Plume Widths at 30 Minutes for All Gas Runs: Colors Indicate Meteorological Stability Categories and Dashed Lines Show $20 \%$ and $50 \%$ Overprediction Limits

For the three gas release cases examined with a source release height of 2 meters (which was most consistent with the near-surface Prairie Grass field trials), the crosswind plume widths for the HPAC and NARAC predictions $1 \mathrm{~km}$ downwind are shown in Figures C-2 (MvM 1, stable), C-20 (MvM 4, neutral), and C-38 (MvM 7, unstable). Consistent with the comparative Prairie Grass results, NARAC's largest 
overpredictions of HPAC (crosswind plume width) occur for the stable and neutral conditions [Ref. 3-2]. For the unstable case, MvM 7 (Figure C-38), the $1 \mathrm{~km}$ crosswind dosage plume widths are similar (as was true for the Prairie Grass comparisons).

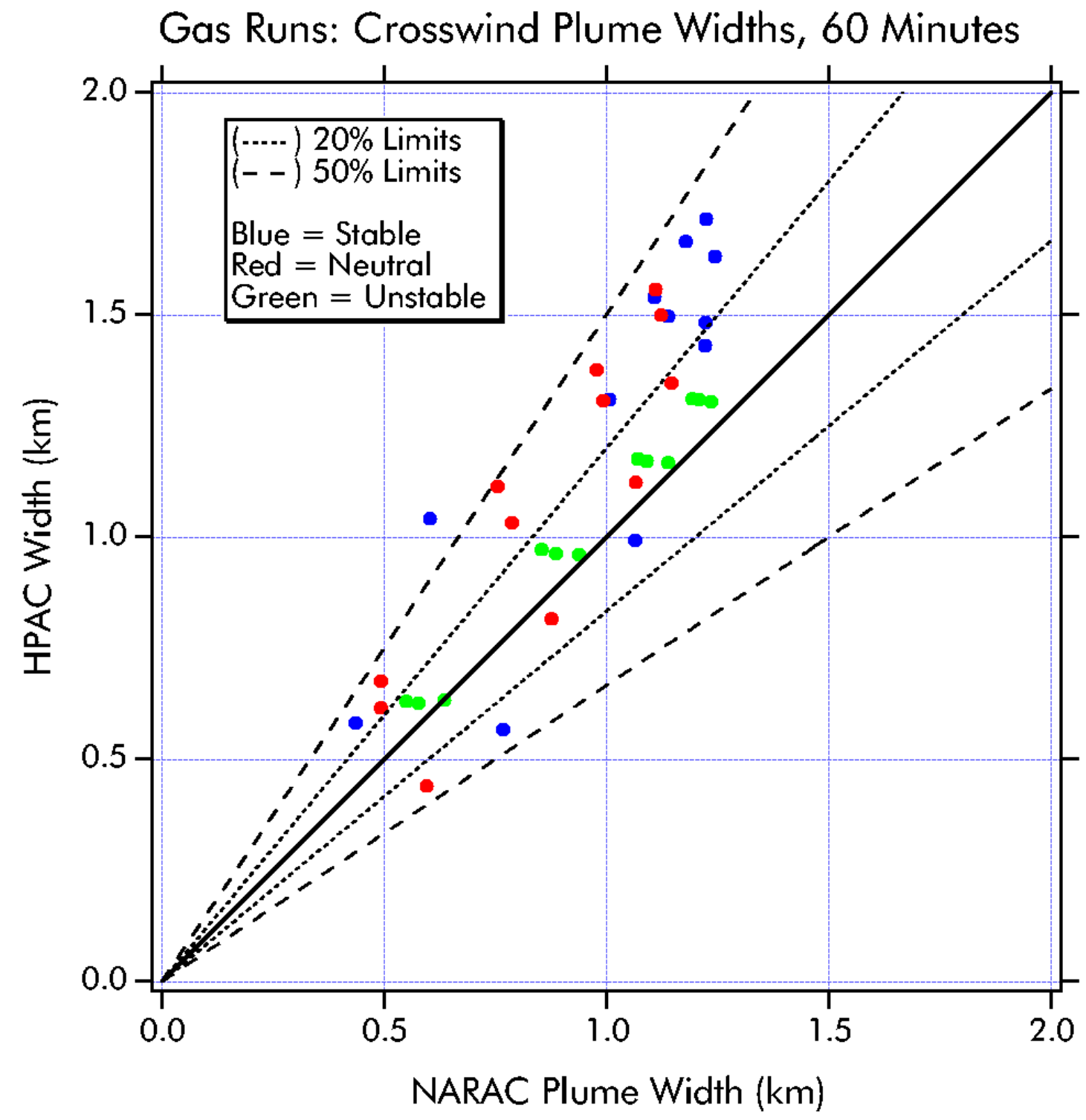

Figure 3-11. Scatter Plot Comparison of Crosswind Plume Widths at 60 Minutes for All Gas Runs: Colors Indicate Meteorological Stability Categories and Dashed Lines Show $20 \%$ and $50 \%$ Overprediction Limits

\section{Scatter Plot Comparison of Crosswind Maximum Dosages}

Maximum crosswind dosages were computed at the downwind plume locations used in the plume width calculations above. HPAC versus NARAC dosage data for all 
gas runs at 30 minutes and 60 minutes are displayed in Figures 3-12 and 3-13, respectively. In each plot, the size of the markers is proportional to the downwind distance. Colors indicate the meteorological stability categories. Also shown on the plots are three HPAC overprediction limits: 10 times, 100 times, and 1,000 times the NARAC dosage, and 1 NARAC overprediction limit, 10 times the HPAC dosage.

Several general trends can be gleaned from the two plots. There is reasonable agreement for the unstable (green) and neutral (red) cases at both times, with a slight tendency for HPAC to overpredict NARAC at 30 minutes and for NARAC to overpredict HPAC at 60 minutes. For all stability categories, there is a tendency for closer agreement at shorter downwind distances

The large HPAC overpredictions for the stable (blue) cases are primarily due to run 3; these points are noted in the figures. Run 3 is problematic. Dosage contours and crosswind profiles for this run are shown in Figures 3-14 through 3-17. There is substantial disagreement between the predictions at both 30 and 60 minutes. The height of this release plays an important role in the model differences. The release height for run 3 is the highest of the stable runs $-80 \mathrm{~m}$ - versus $2 \mathrm{~m}$ for run 1 and $50 \mathrm{~m}$ for run 2 . The boundary layer height for all three stable runs is $100 \mathrm{~m}$. Since the $80 \mathrm{~m}$-release height is near the boundary layer, it is reasonable to ask to what extent the vertical diffusivity parameterizations and blending above and below the boundary layer height affect the HPAC and NARAC results. The resolution of this discrepancy, which is a topic of ongoing investigations, is discussed in more detail in Section B.3 of this chapter. 


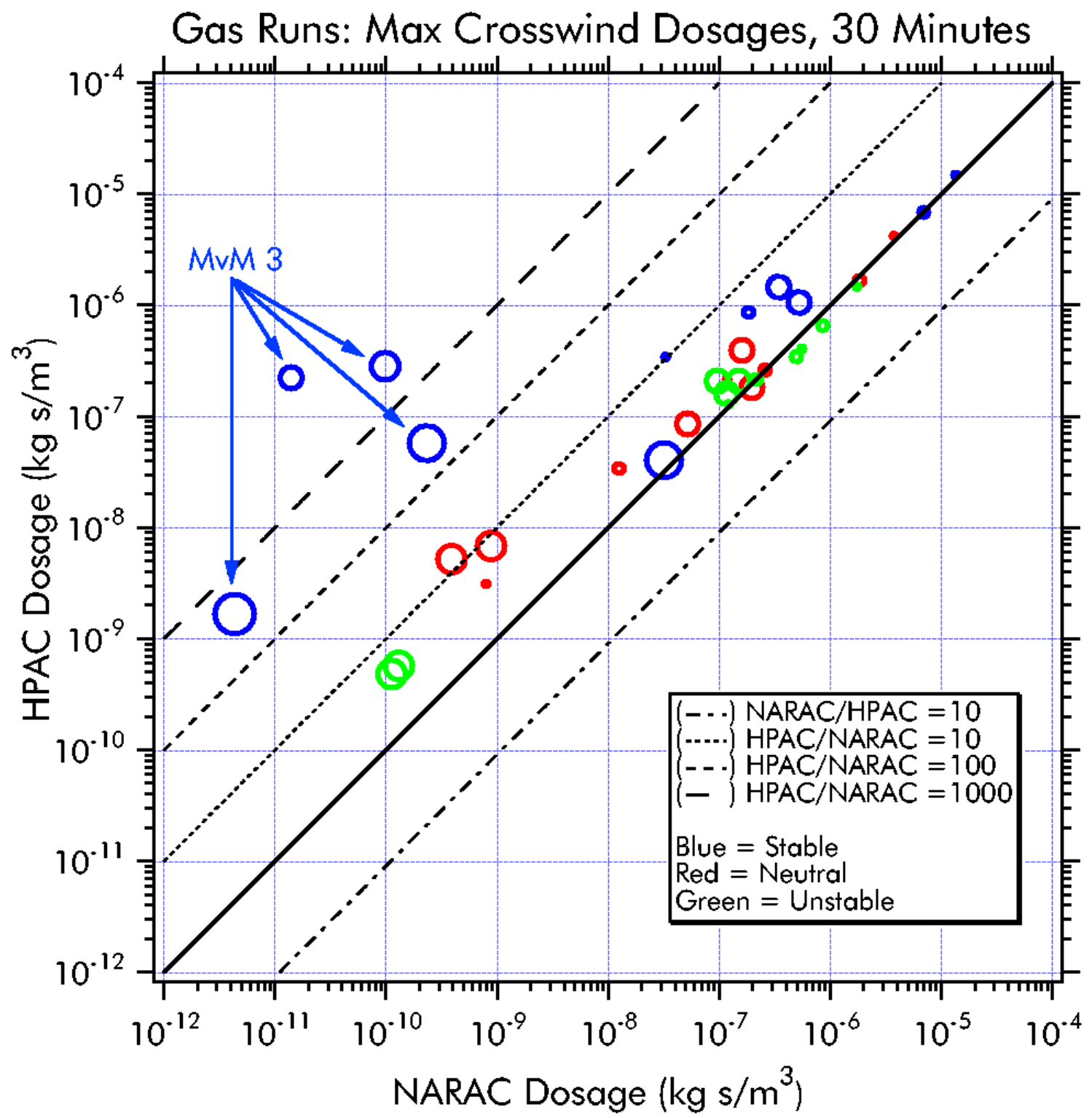

Figure 3-12. Scatter Plot Comparison of Maximum Crosswind Dosage at 30 Minutes for All Gas Runs: Colors Indicate Meteorological Stability Categories, Marker Size is Proportional to Downwind Distance,

Dashed Lines Show 10x, 100x, and 1000x HPAC Overprediction Limits and 10x NARAC Overprediction Limit, and Indicated Outliers Are from Stable Run 3 


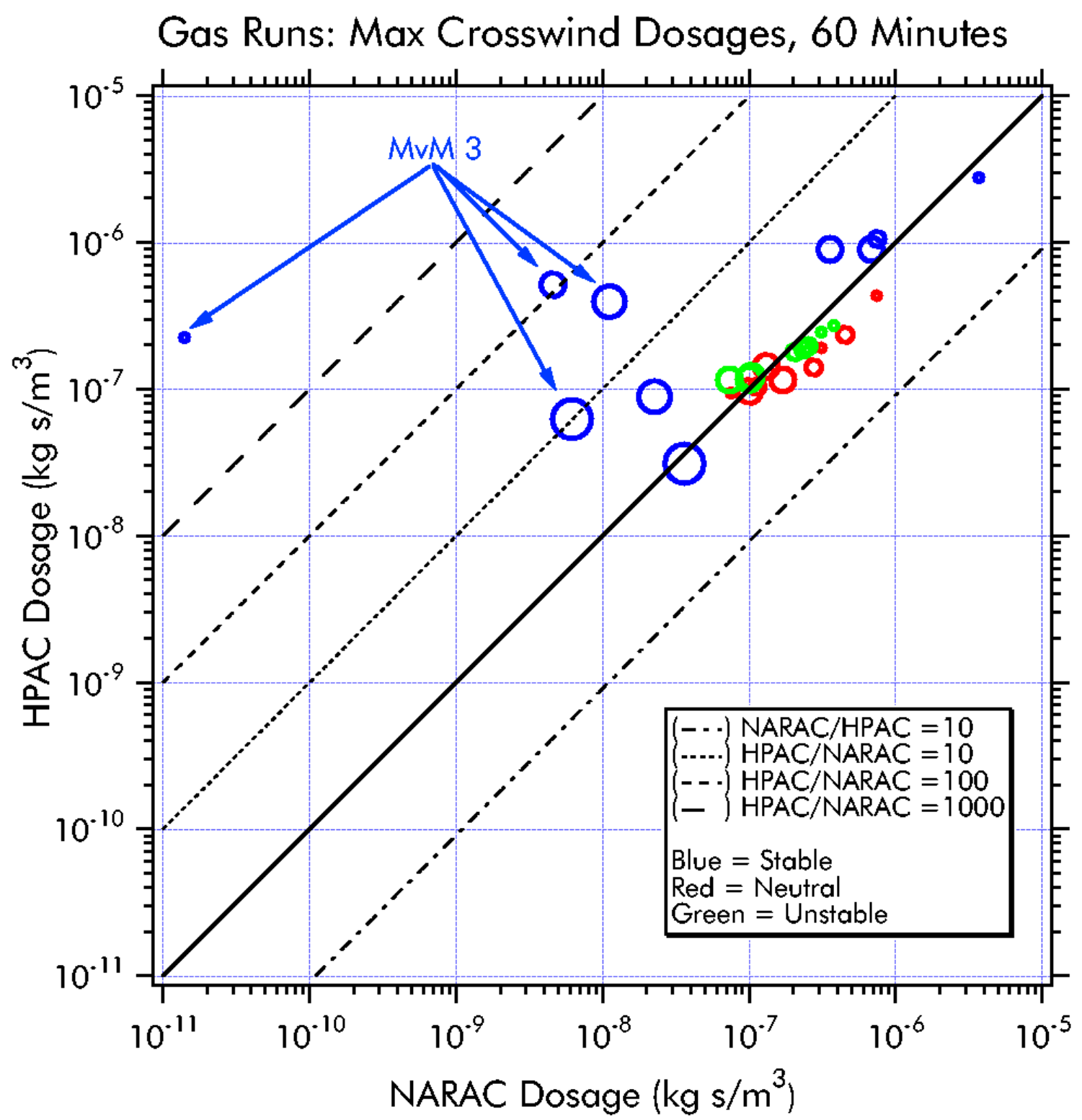

Figure 3-13. Scatter Plot Comparison of Maximum Crosswind Dosage at 60 Minutes for All Gas Runs: Colors Indicate Meteorological Stability Categories,

Marker Size is Proportional to Downwind Distance,

Dashed Lines Show 10x, 100x, and 1000x HPAC Overprediction Limits and 10x NARAC Overprediction Limit, and Indicated Outliers Are from Stable Run 3 


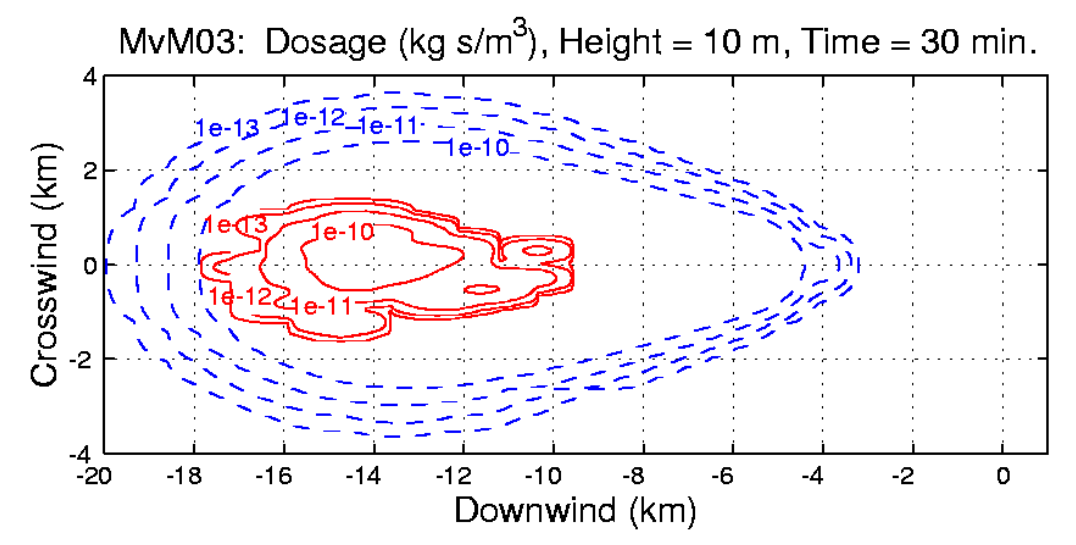

Dosage on Downwind Symmetry Axis

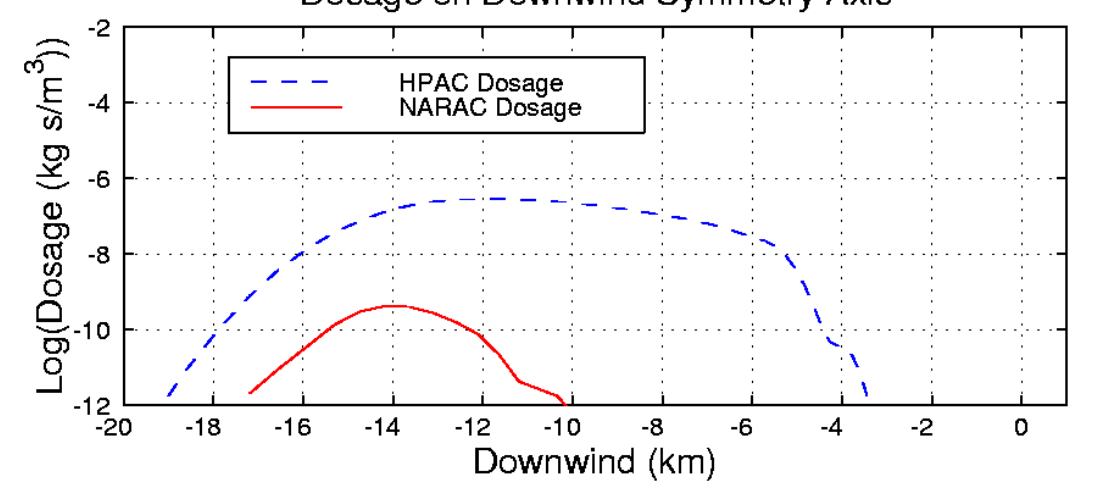

Figure 3-14. MvM 3 at 30 Minutes with Upper: NARAC (Red -) and HPAC (Blue - -) Dosage Contours; Lower: Log Dosages on Downwind Symmetry Axis 
MvM03: Crosswind Dosage Profiles, Time $=30 \mathrm{~min}$.
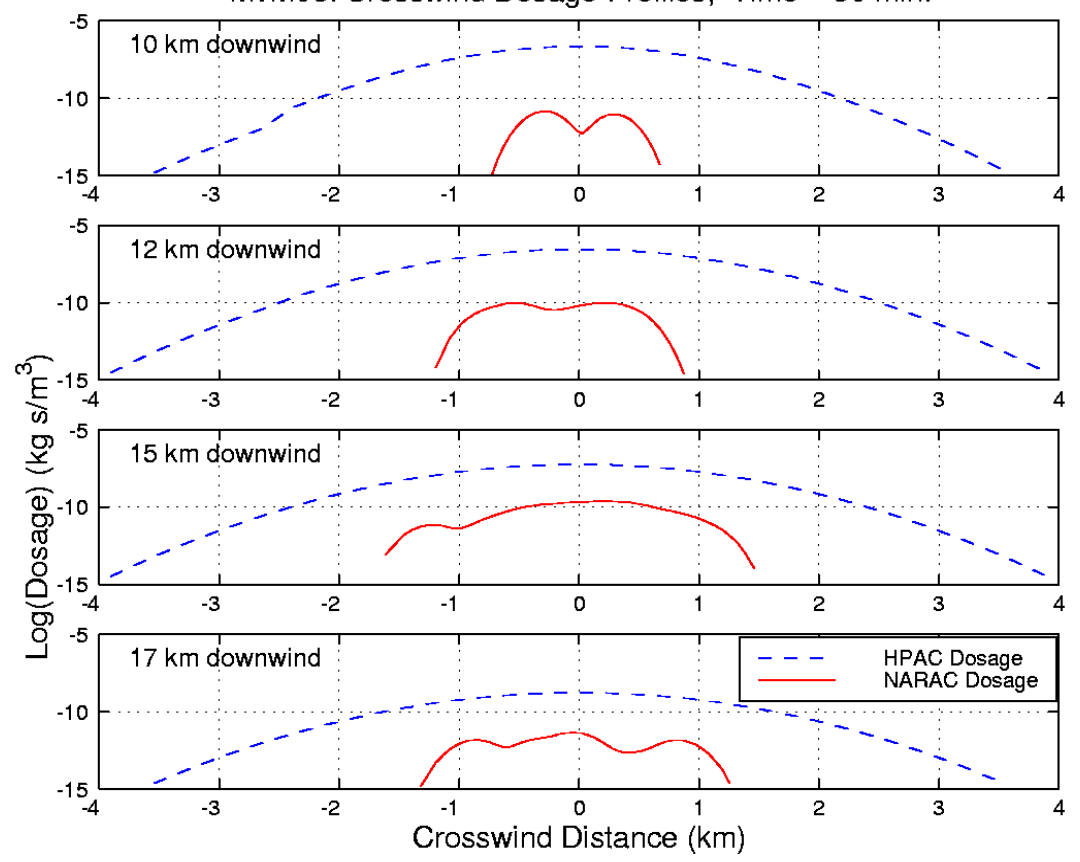

Figure 3-15. MvM 3 at $\mathbf{3 0}$ Minutes with Crosswind Plume Profiles at Selected Downwind Distances: NARAC (Red -) and HPAC (Blue - -) (Note Log Dosage on Vertical Axis) 
MvM03: Dosage $\left(\mathrm{kg} \mathrm{s}^{3} \mathrm{~m}^{3}\right)$, Height $=10 \mathrm{~m}$, Time $=60 \mathrm{~min}$.

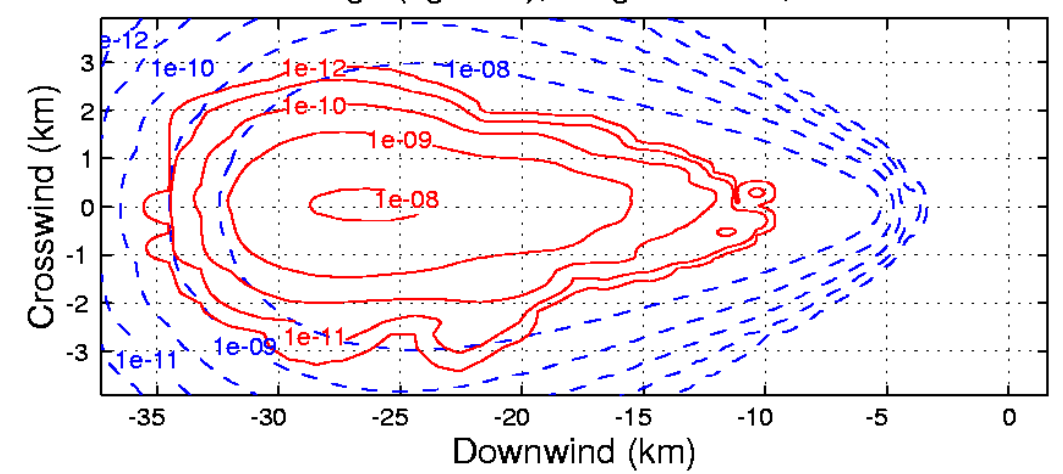

Dosage on Downwind Symmetry Axis

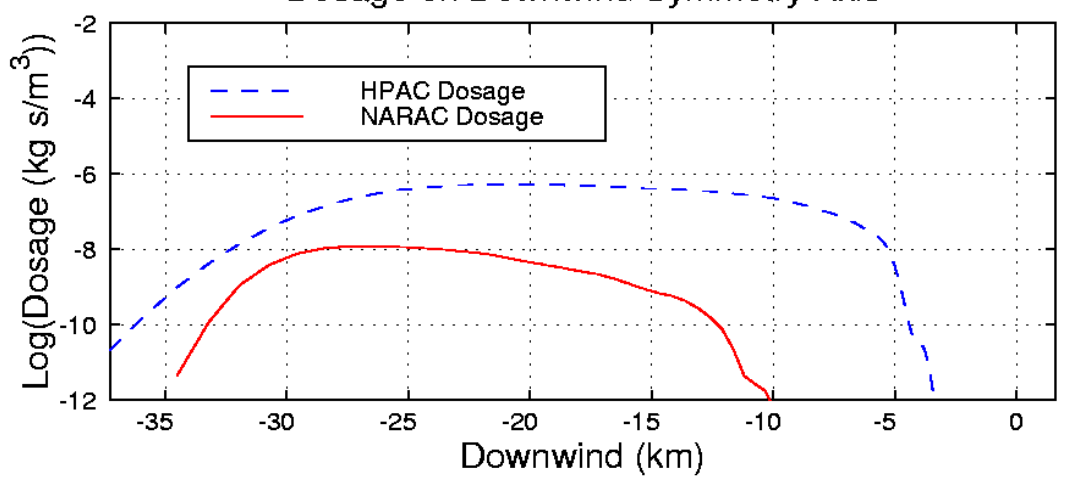

Figure 3-16. MvM 3 at 60 Minutes with Upper: NARAC (Red -) and HPAC (Blue - -) Dosage Contours; Lower: Log Dosages on Downwind Symmetry Axis 
MvM03: Crosswind Dosage Profiles, Time $=60 \mathrm{~min}$.
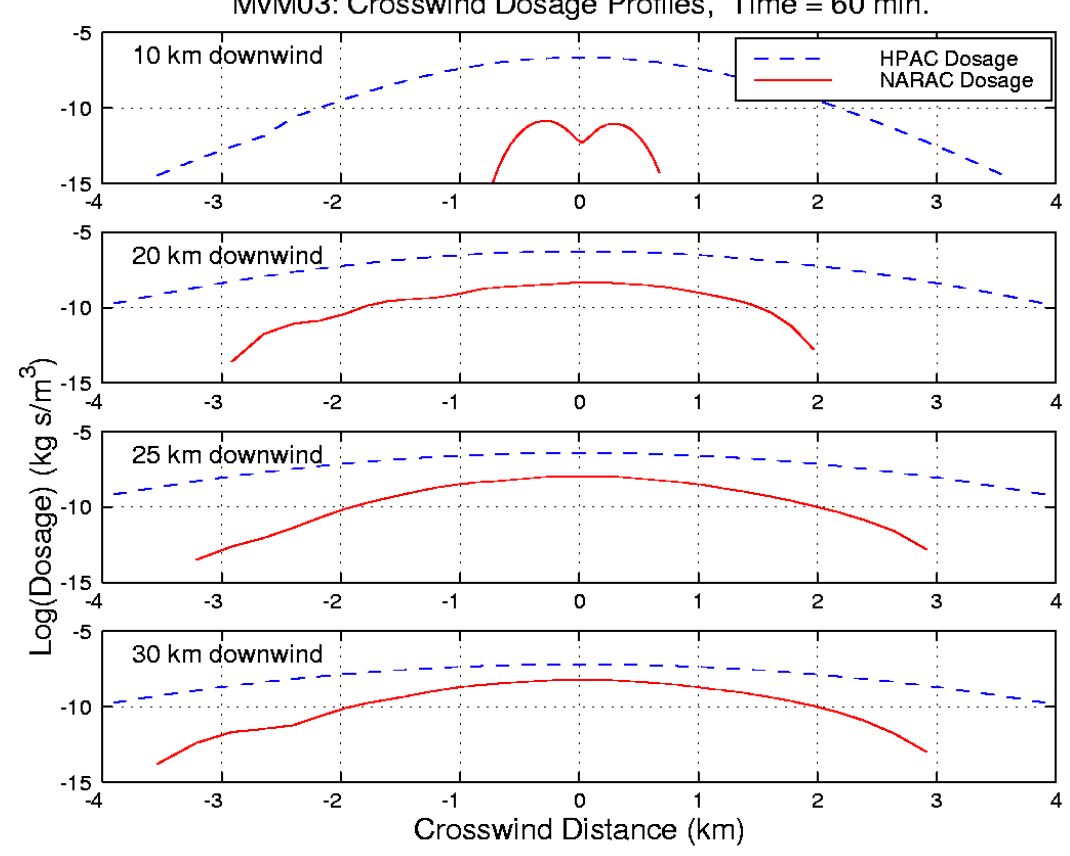

Figure 3-17. MvM 3 at 60 Minutes with Crosswind Plume Profiles at Selected Downwind Distances: NARAC (Red -) and HPAC (Blue - -) (Note Log Dosage on Vertical Axis)

\section{Area-Based MOE}

The final comparison measure applied to the neutrally-buoyant gas runs is the area-based MOE introduced in Chapter 2. For a given contour level, the calculation of the area-based MOE requires three areas: the HPAC contour area, $\mathrm{A}_{\mathrm{HPAC}}$; the NARAC contour area, $A_{\text {NARAC; }}$ and the area of the overlap region, $A_{O L}$. In MATLAB, the dosage contours and overlap region are represented as polygons, whose vertices are stored in user-accessible arrays (see Figure 3-18). The three areas are estimated by computing the enclosed areas of the polygons via the MATLAB routine polyarea. ${ }^{6}$ Here, and throughout, we take the $x$-axis of the two-dimensional MOE to be $\mathrm{A}_{\mathrm{OL}} / \mathrm{A}_{\mathrm{NARAC}}$ and the $y$ axis to be $\mathrm{A}_{\mathrm{OL}} / \mathrm{A}_{\mathrm{HPAC}}$. Perfect model agreement then corresponds to the point $(x, y)=$ $\left(\mathrm{A}_{\mathrm{OL}} / \mathrm{A}_{\mathrm{NARAC}}, \mathrm{A}_{\mathrm{OL}} / \mathrm{A}_{\mathrm{HPAC}}\right)=(1,1)$, while "perfect" model disagreement corresponds to the point $(x, y)=(0,0)$. The diagonal line from $(0,0)$ to $(1,1)$ divides the MOE space into two regions: a region of HPAC overprediction, occurring below the diagonal, and a region of NARAC overprediction, occurring above the diagonal. Points on the line $x=1$ represent cases in which the HPAC contour envelops the corresponding NARAC contour, while

6 Proper ordering of the polygon vertices is crucial for this routine to give sensible answers. Ordering is checked before submitting the vertices to polyarea. 
points on the line $y=1$ represent cases in which the NARAC contour envelops the corresponding HPAC contour.

Figure 3-18 shows an example set of contours and overlap regions for four contour levels from run 1 at 30 minutes. The color convention for the contours is as before: solid red denotes NARAC contours and dashed blue denotes HPAC contours. The circles represent the boundary of the overlap region; red circles denote boundary points belonging to the NARAC contour, and blue circles denote boundary points belonging to the HPAC contour. Table 3-1 gives the contour areas, overlap areas, and the $x$ and $y$ components of the MOE for the four contours. 

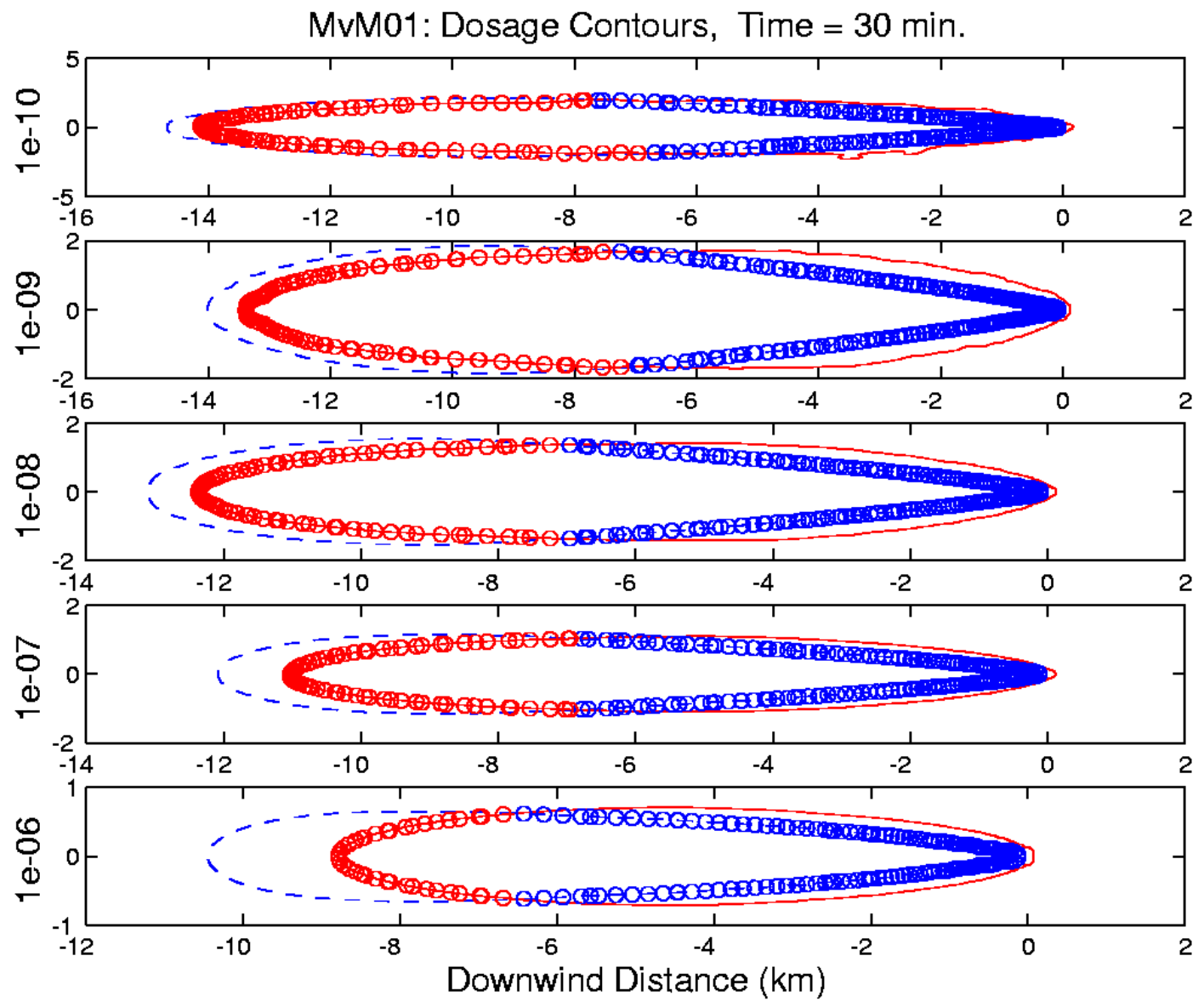

Figure 3-18. Dosage Contours for MvM 1 at 30 Minutes: Contour Levels Are Indicated on the Left, Red (Blue) Lines Denote NARAC (HPAC) Contours, and Red (Blue) Circles Denote Boundary of Overlap Region Belonging to NARAC (HPAC) Contours

Table 3-1. MOE Areas for MvM 1 at 30 Minutes 


\begin{tabular}{|c|c|l|l|c|c|}
\hline $\begin{array}{l}\text { Contour Level } \\
\left(\mathbf{k g ~ s} \mathbf{~ m}^{3}\right)\end{array}$ & $\begin{array}{l}\text { HPAC } \\
\text { Area } \\
\left(\mathbf{k m}^{2}\right)\end{array}$ & $\begin{array}{l}\text { NARAC } \\
\text { Area } \\
\left(\mathbf{k m}^{2}\right)\end{array}$ & $\begin{array}{l}\text { Overlap } \\
\text { Area } \\
\left(\mathbf{k m}^{2}\right)\end{array}$ & MOE (x) & MOE (y) \\
\hline $1.00 \mathrm{E}-10$ & 42.53 & 44.05 & 36.13 & 0.820 & 0.850 \\
\hline $1.00 \mathrm{E}-09$ & 34.79 & 36.10 & 29.47 & 0.816 & 0.847 \\
\hline $1.00 \mathrm{E}-08$ & 26.90 & 27.55 & 22.19 & 0.806 & 0.825 \\
\hline $1.00 \mathrm{E}-07$ & 18.74 & 18.77 & 14.86 & 0.792 & 0.793 \\
\hline $1.00 \mathrm{E}-06$ & 9.75 & 9.68 & 7.26 & 0.750 & 0.745 \\
\hline
\end{tabular}

Figures 3-19 and 3-20 are plots of the area-based MOE for all gas runs at 30 and 60 minutes, respectively. The marker size is proportional to the contour level. Grouped by stability class, the unstable points (green) are closest to the $(1,1)$ point, again showing the best model agreement. HPAC contours tend to envelop NARAC contours at both times, particularly for the smaller dosages. NARAC contours envelop HPAC contours for some of the larger dosages. Points belonging to run 3 are indicated, and show extreme HPAC overprediction, as evidenced in the plots shown in Figures 3-14 through 3-17. Omitting the results associated with the MvM 3 case, the remaining stable and neutral cases show a similar level of agreement, with somewhat better agreement for the neutral runs at 60 minutes. 


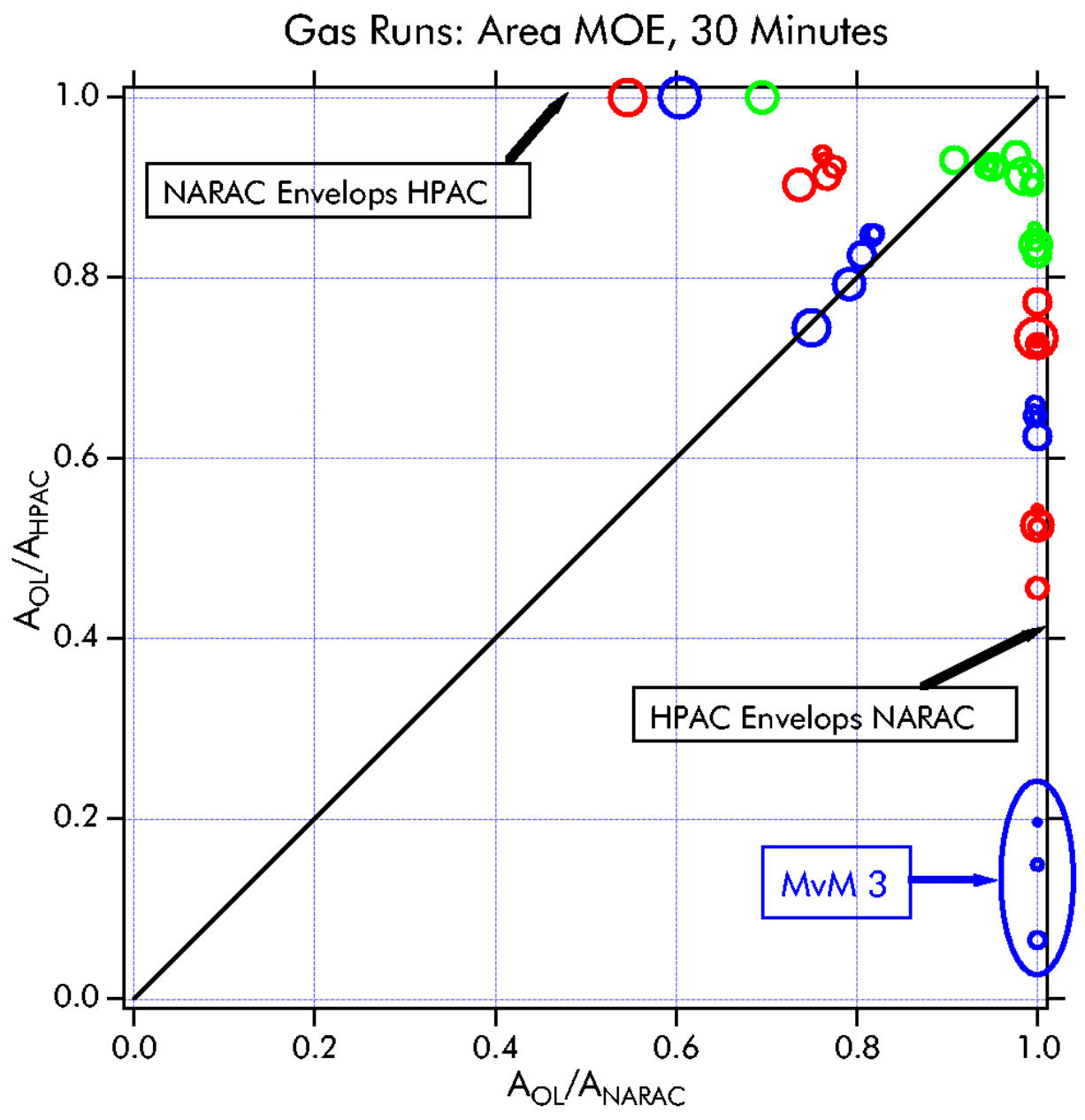

Figure 3-19. Area-Based MOE for All Gas Runs at 30 Minutes. Colors Denote Stability: Red $=$ Stable, Blue $=$ Neutral, and Green $=$ Unstable. Circle Sizes are Proportional to Dosage Contour Level. By Stability Type, Unstable Cases Show Best Model Agreement. MvM 3 Points are Indicated, Showing Extreme HPAC Overprediction. 


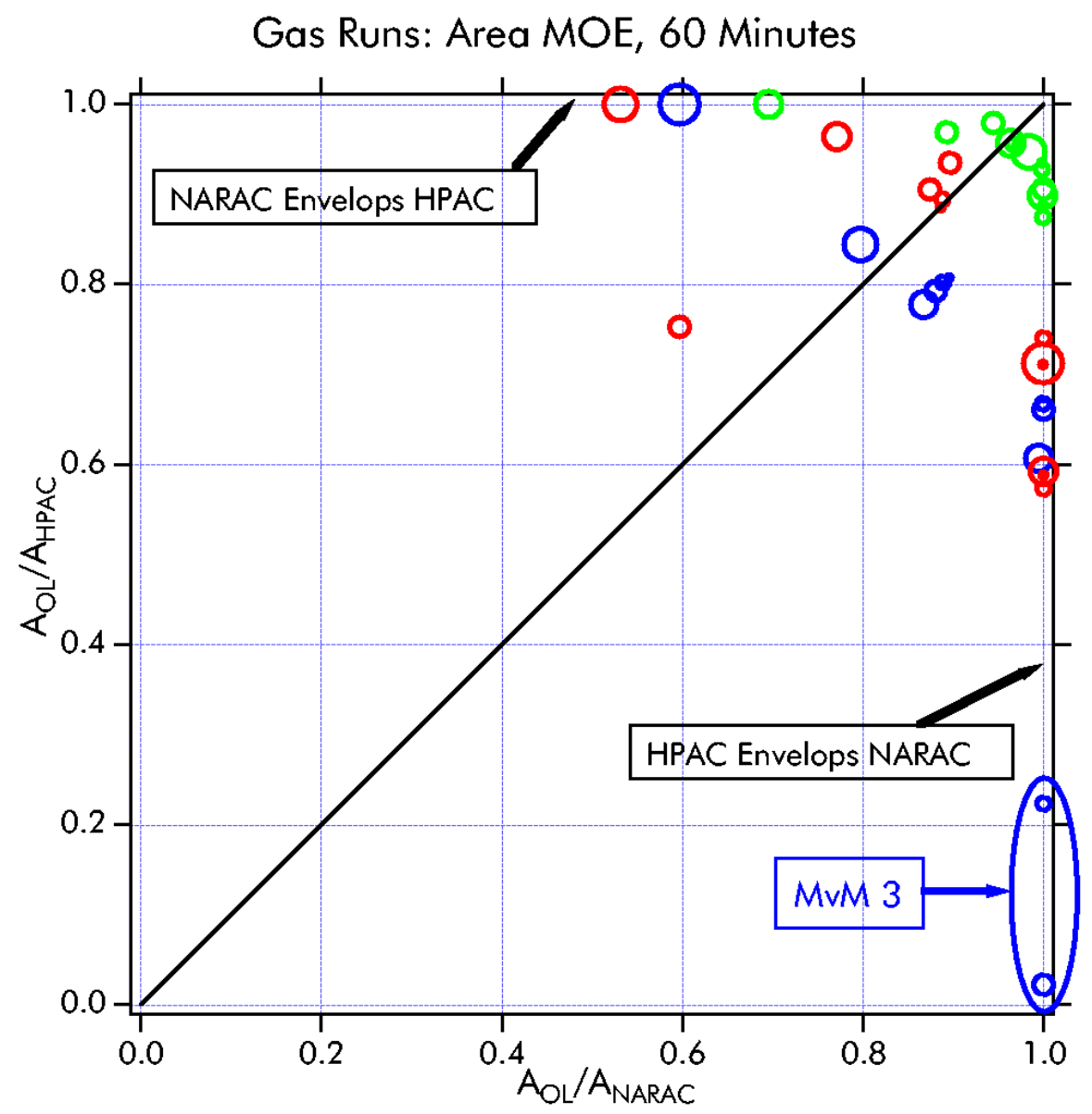

Figure 3-20. Area-Based MOE for All Gas Runs at 60 Minutes. Colors Denote Stability: Red $=$ Stable, Blue $=$ Neutral, and Green $=$ Unstable. Circle Sizes are Proportional to Dosage Contour Level. By Stability Type, Unstable Cases Show Best Model Agreement. MvM 3 Points are Indicated, Showing Extreme HPAC Overprediction.

\section{B. PARTICLE RELEASES}

Eight particle releases were compared, all for near-neutral atmospheric stability. Particle size, release height, release duration, and release geometry were varied (see Table 2-1). Of these four variables, release height had the most dramatic effect on model agreement, with better agreement for lower height releases. The "very high" altitude release at $750 \mathrm{~m}$ (MvM 15) is considered separately from the other particle runs. Particle size has a moderate effect on model agreement, with smaller particles yielding somewhat 
better agreement. Release duration and release geometry did not induce major trends in model agreement.

\section{Influence of Particle Size on Comparisons}

Figures 3-21, 3-22, and 3-23 show dosage contours at 60 minutes for particle runs 10,13 , and 16 respectively. ${ }^{7}$
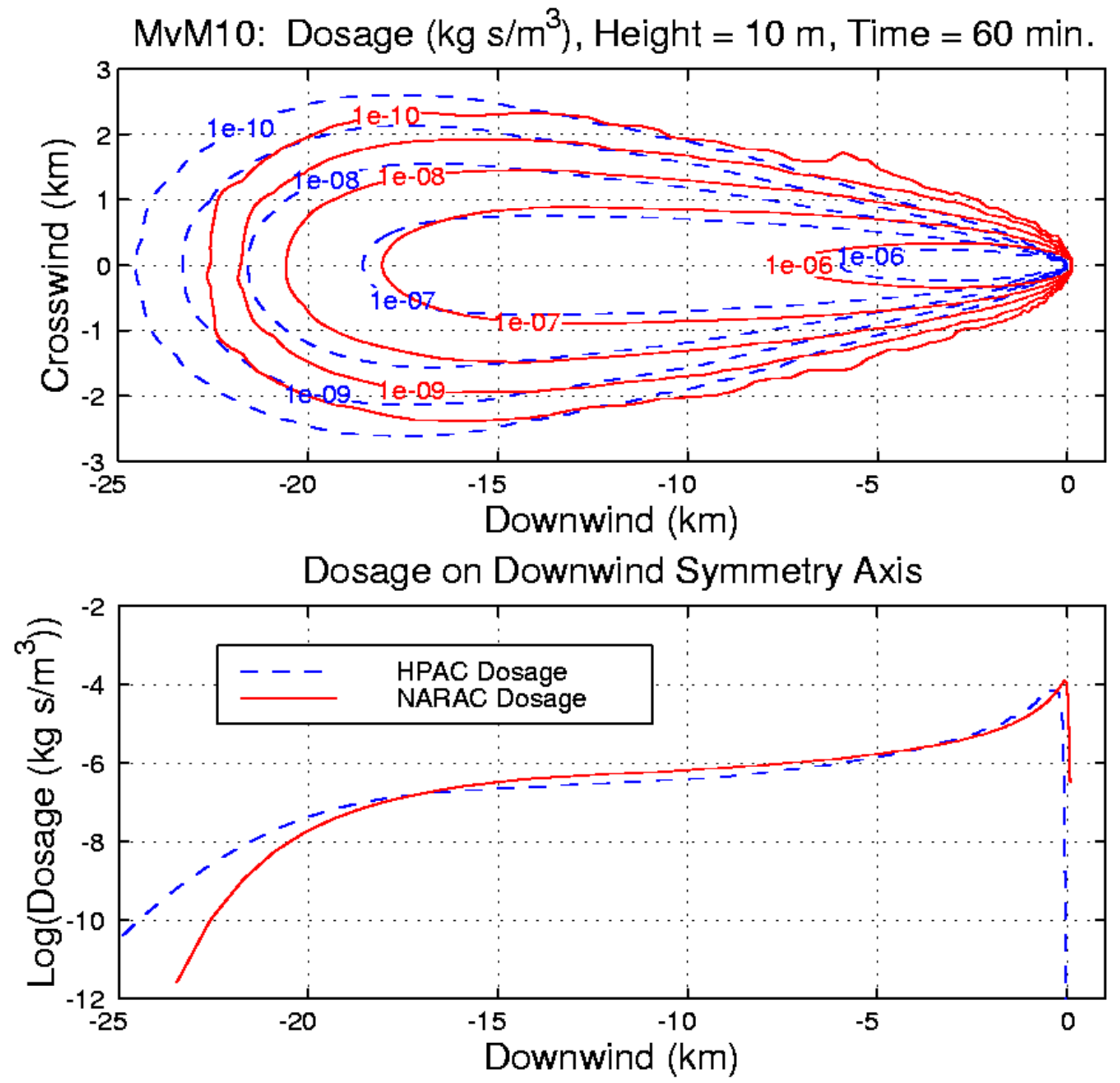

Figure 3-21. MvM 10 at 60 Minutes with Upper: NARAC (Red -) and HPAC (Blue - -) Dosage Contours; Lower: Log Dosages on Downwind Symmetry Axis. Particle Diameter is $5 \mu$, Release Height is $\mathbf{2} \mathbf{~ m}$, and Release Duration is $15 \mathrm{~min}$.

7 The full collection of particle run plots can be found in Appendix D. 

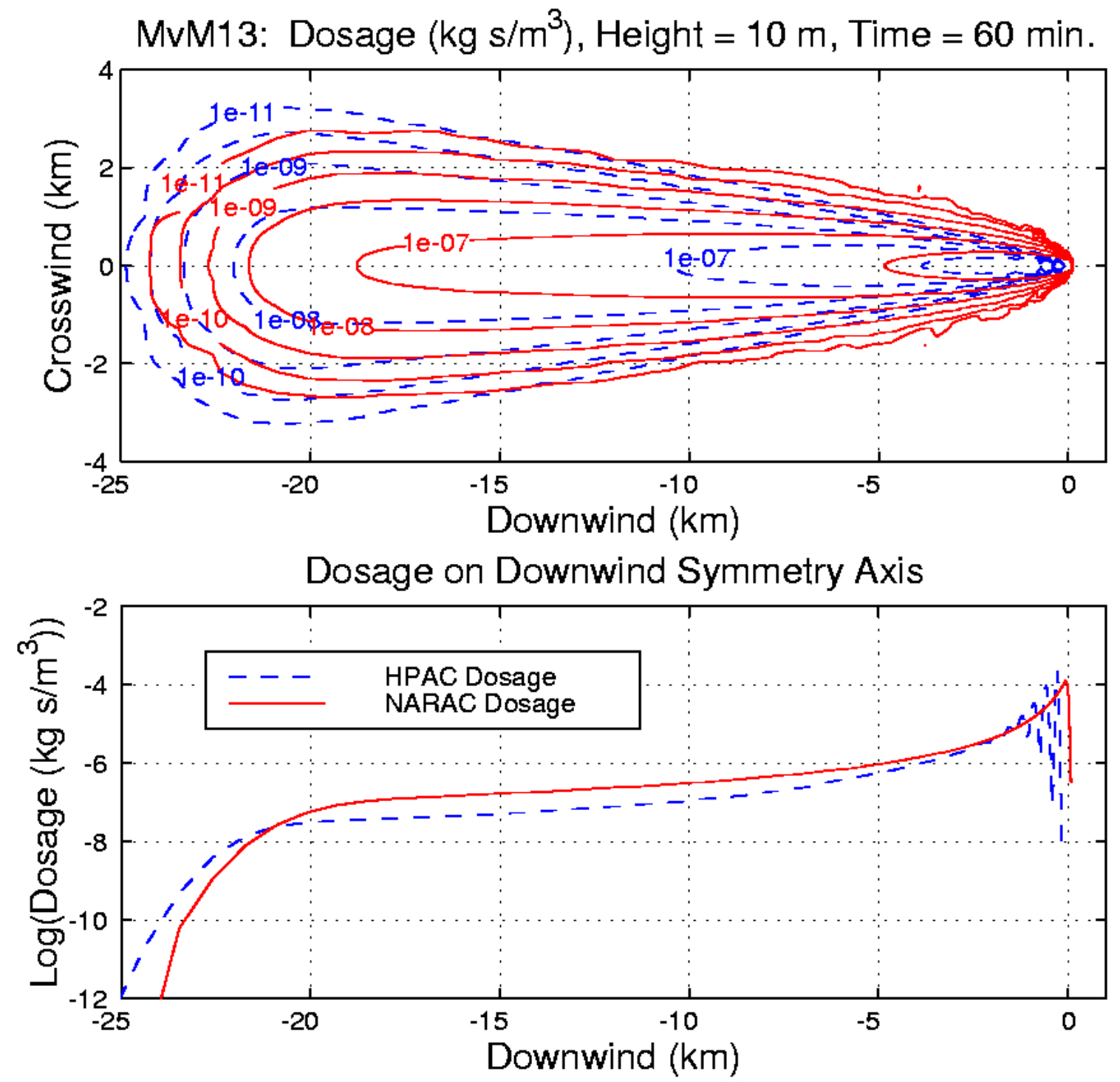

Figure 3-22. MvM 13 at 60 Minutes with Upper: NARAC (Red -) and HPAC (Blue - -) Dosage Contours; Lower: Log Dosages on Downwind Symmetry Axis. Particle Diameter is $50 \mu$, Release Height is $\mathbf{2} \mathbf{m}$, and Release Duration is "Instantaneous." 

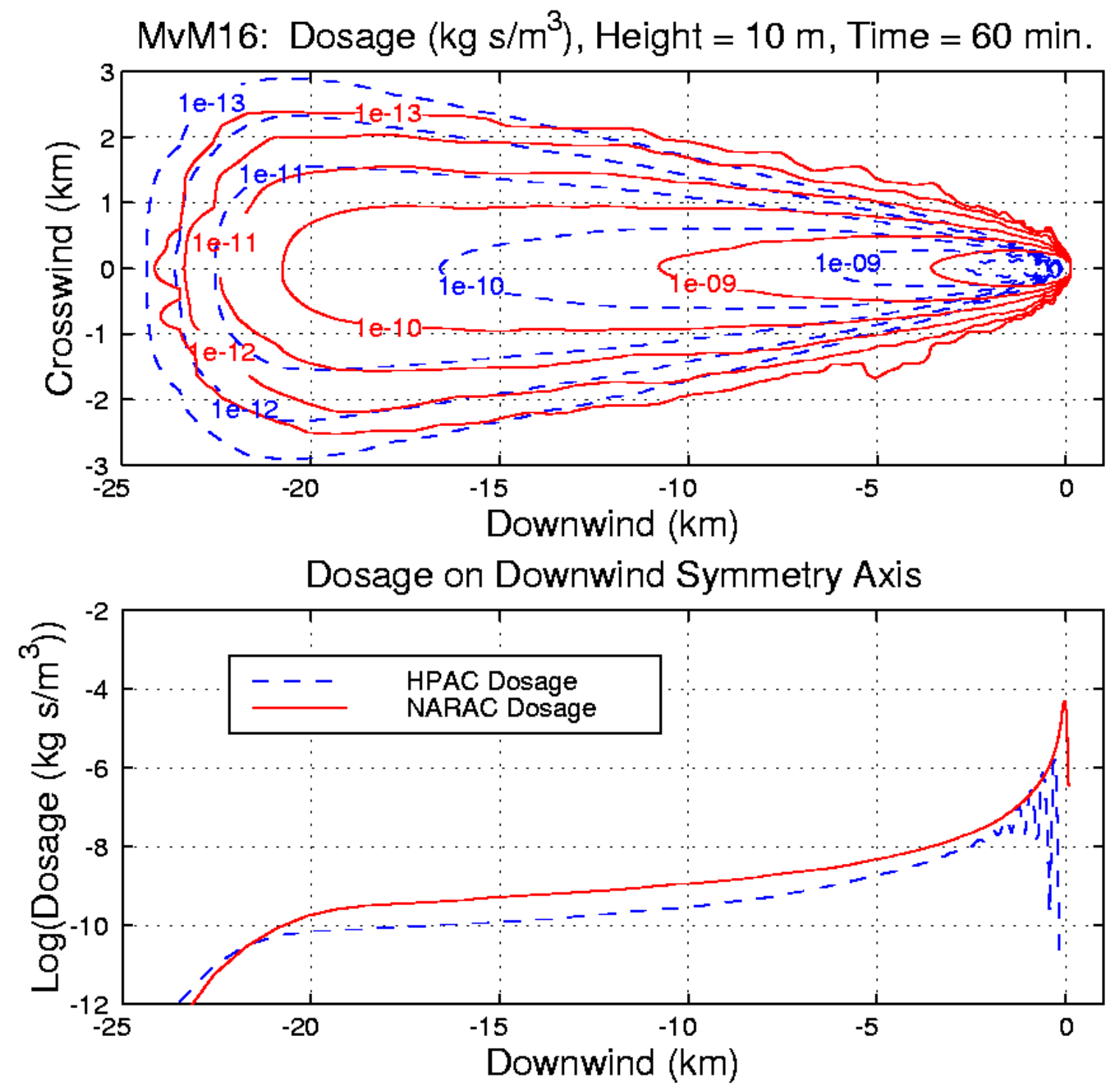

Figure 3-23. MvM 16 at 60 Minutes with Upper: NARAC (Red -) and HPAC (Blue - -) Dosage Contours; Lower: Log Dosages on Downwind Symmetry Axis. Particle Diameter (Mass Median Diameter) is $500 \mu$, Release Height is $\mathbf{2}$, and Release Duration is "Instantaneous." 
The particle size for these three releases was $5 \mu$ for MvM 10, $50 \mu$ for MvM 13, and $500 \mu$ for MvM 16. ${ }^{8}$ The release height for all three runs was 2 meters. MvM 10 was a continuous release (15 min, constant rate), while the other two releases were instantaneous. ${ }^{9}$ All other input parameters for the three runs were the same. Overall agreement for the thee runs is very good; however, a close examination of the figures, particularly the symmetry axis dosage plots, shows that model agreement is best for the 5 $\mu$ release (Figure 3-21). This is further supported by Figure 3-24, which shows the areabased MOE values for runs 10, 13, and 16 colored by particle size (with the symbol size proportional to dosage contour value). It is apparent from this figure that the $5 \mu$ (blue) circles, as a group, are closest to the diagonal line; the $50 \mu$ (red) and $500 \mu$ (green) circles are progressively farther away. ${ }^{10}$ The bulk of the circles are above the diagonal line, i.e., in the NARAC overprediction region; this is consistent with the contour plots shown in Figures 3-21 through 3-23.

8 For MvM 16, a log-normal particle distribution with mass median diameter (MMD) $=500 \mu$ and geometric standard deviation $=\sigma=2$ was used.

9 Note the appearance of spatial oscillations in the HPAC dosage along the downwind symmetry axis for the instantaneous releases (Figures 3-22 and 3-23) and the absence of oscillations in the continuous release (Figure 3-21). This is discussed in more detail in Section C.3 below.

10 We acknowledge that these trends could be an artifact of the small sample size examined. 


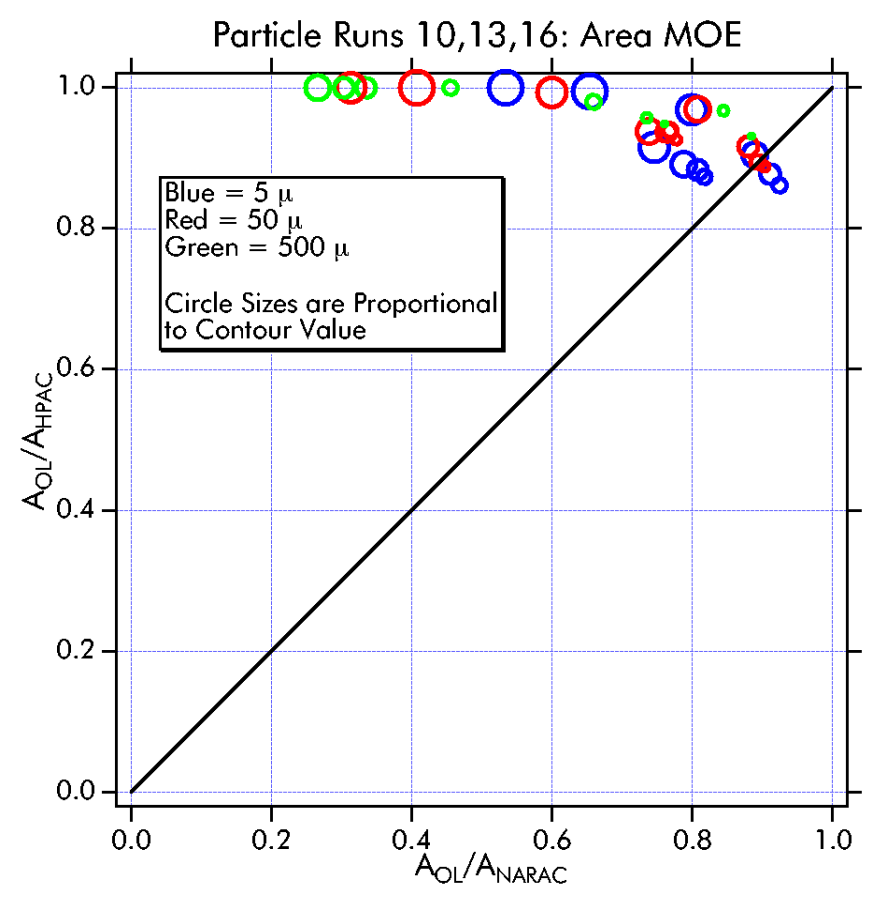

Figure 3-24. Area-Based MOE for Particle Runs 10, 13, and 16 at 30 and 60 Minutes. Colors Indicate Particle Size and Circle Size is Proportional to Dosage Contour Level.

Figure 3-25 and 3-26 present scatter plots of HPAC and NARAC downwind contour distances as a function of particle size for 30 and 60 minutes, respectively. At both times, the plots show that HPAC and NARAC downwind contour distances agree to within 20 percent. In general, HPAC overpredicts NARAC for this measure, with the results matching more closely with increasing downwind distance (decreasing dosage levels).

For the higher dosages (shortest downwind distances) the $5-\mu$ points show the best agreement. All of the $165-\mu$ points (blue) shown in Figure 3-25 indicate HPAC/NARAC model agreement to within 20 percent (for this measure). At 60 minutes, 2 of $155-\mu$ points indicate differences larger than 20 percent. These two points are associated with higher dosage contours (i.e., shorter downwind distances). For the $50 \mu$ particle runs, differences larger than 20 percent are indicated for 3 of 14 and 3 of 13 dosage contours at 30 and 60 minutes, respectively. For the largest particles, the disagreement between the two models is greater, with the biggest differences reflecting NARAC overpredictions of HPAC at shorter distances and hence larger dosages (e.g., see the $10^{-9}$ and $10^{-10}$ dosage contours for MvM 16 in Figure 3-23). Differences larger than 20 percent (for the $500 \mu$ particles) are shown for 4 of 11 and 5 of 11 dosage contours at 30 and 60 minutes, respectively. 
At the longer downwind distances (i.e., lower dosage contours), the relative model behavior is similar for all particle sizes - HPAC slightly (within 20 percent) overpredicts NARAC with respect to downwind contour distance. In fact, for downwind distances $>10 \mathrm{~km}$, the $500 \mu$ data show the best match (closest to the diagonal line) between HPAC and NARAC results. This result is true at both 30 and 60 minutes after the release.

Further investigation is needed to determine the most important causes of the differences shown by the particle scenario comparisons. The observation that the greatest differences are seen in comparisons involving the largest particle sizes is consistent with the hypothesis that the differences are due to the algorithms used by NARAC and HPAC to compute settling velocity. The two models use different algorithms for determining the Reynolds number of the falling particle. HPAC computes the local air density, while NARAC uses a constant value of $1.225 \mathrm{~kg} / \mathrm{m}^{3}$. NARAC uses a constant value of 1.225 
3-30 


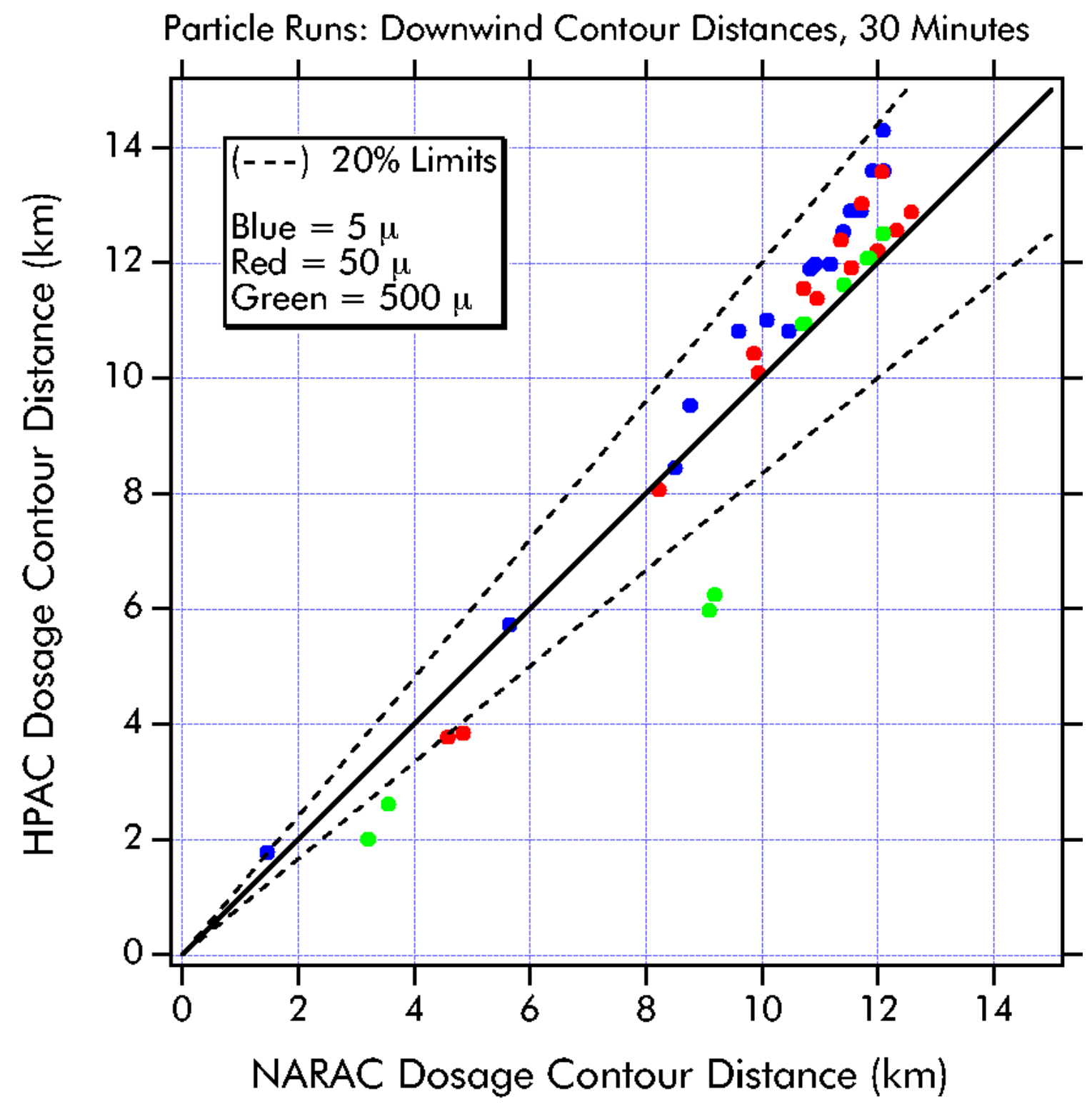

Figure 3-25. Scatter Plot Comparison of Downwind Contour Distances at 30 Minutes for Particle Runs MvM 10 through 14, 16, and 17: Colors Indicate Particle Size and Dashed Lines are $\mathbf{2 0} \%$ Overprediction Limits 


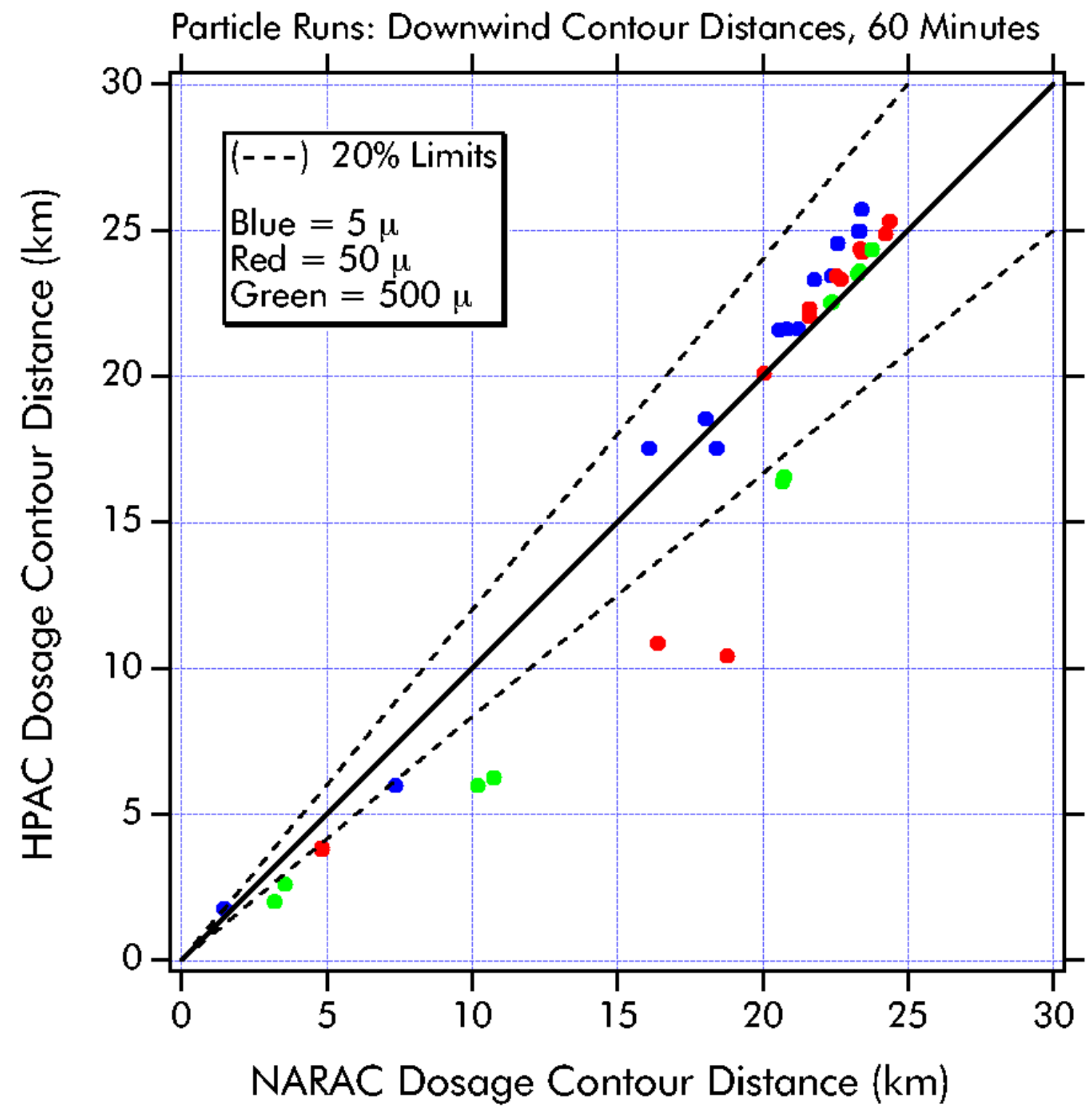

Figure 3-26. Scatter Plot Comparison of Downwind Contour Distances at 60 Minutes for Particle Runs MvM 10 through 14, 16, and 17: Colors Indicate Particle Size and Dashed Lines are $20 \%$ Overprediction Limits 


\section{Influence of Release Height on Comparisons}

Release height plays a major role on model agreement for particle releases, with a trend for better agreement with lower release heights. Figures 3-27, 3-28, and 3-29 show dosage contours at 60 minutes for the three $5 \mu$ runs, with increasing release heights: run $10($ release height $=2 \mathrm{~m})$, run $11($ release height $=250 \mathrm{~m})$ and run $12($ release height $=$ $400 \mathrm{~m})$. The release duration for these 3 runs is 15 minutes.

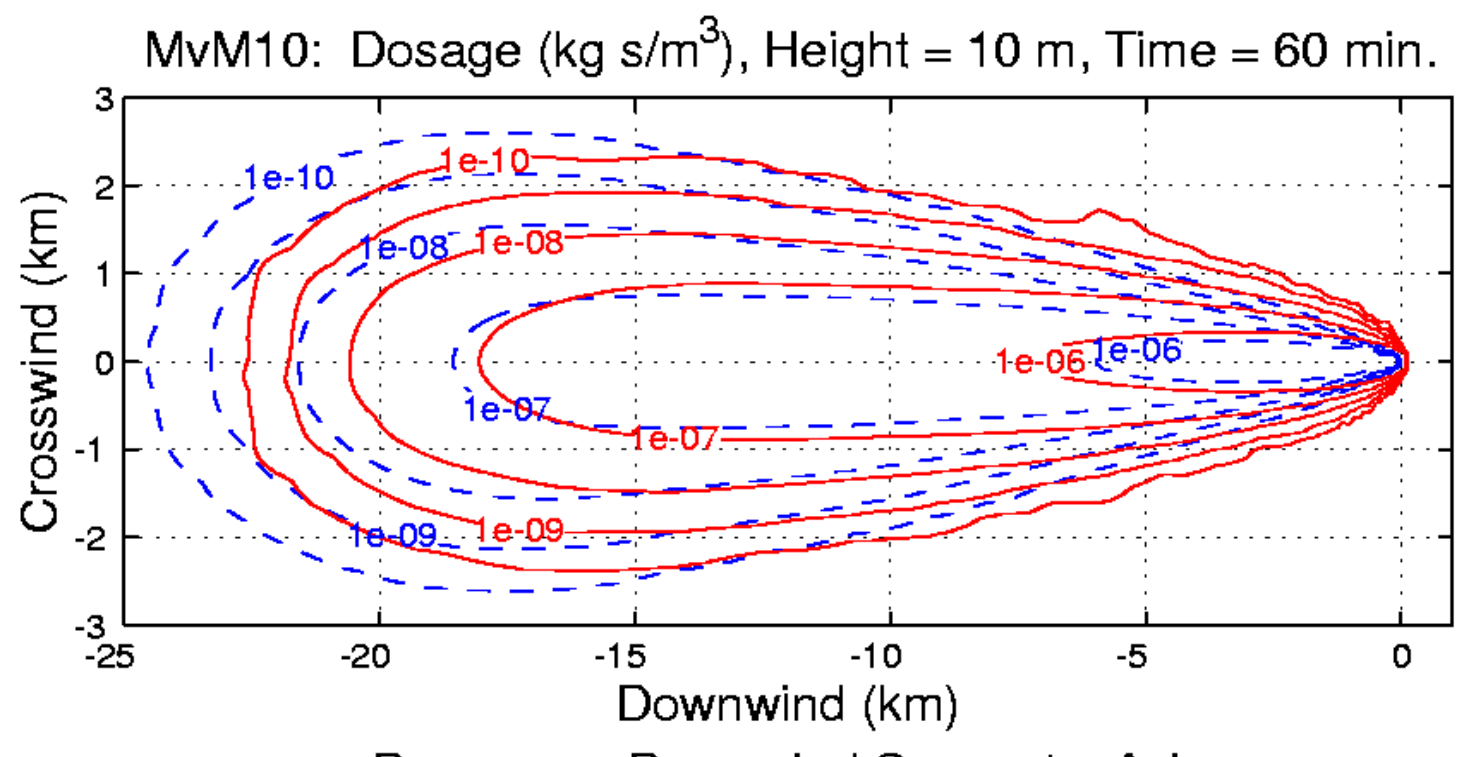

Dosage on Downwind Symmetry Axis

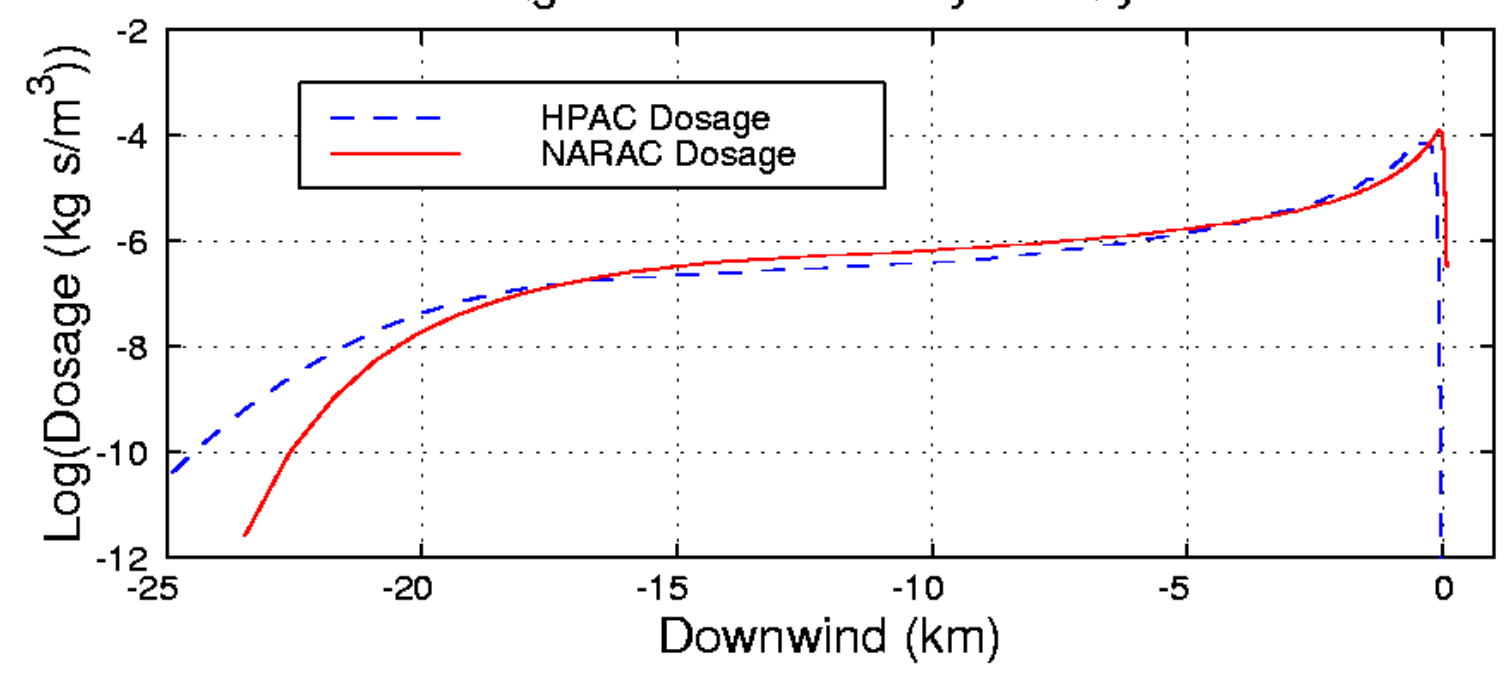

Figure 3-27. MvM 10 at 60 Minutes with Upper: NARAC (Red -) and HPAC (Blue - -) Dosage Contours; Lower: Log Dosages on Downwind Symmetry Axis. Particle Diameter is $5 \mu$, Release Height is $\mathbf{2} \mathbf{~ m}$, and Release Duration is $\mathbf{1 5} \mathrm{min}$. 


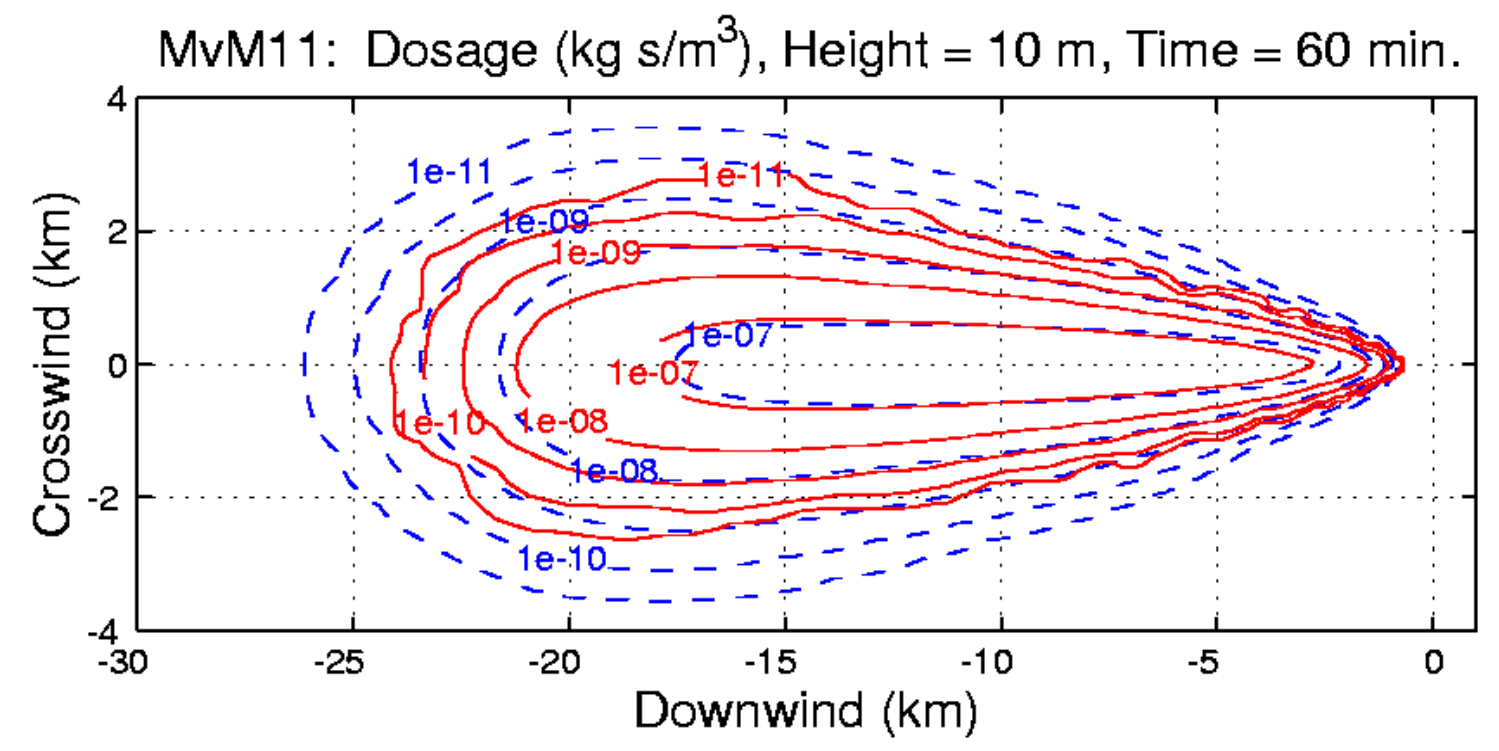

Dosage on Downwind Symmetry Axis

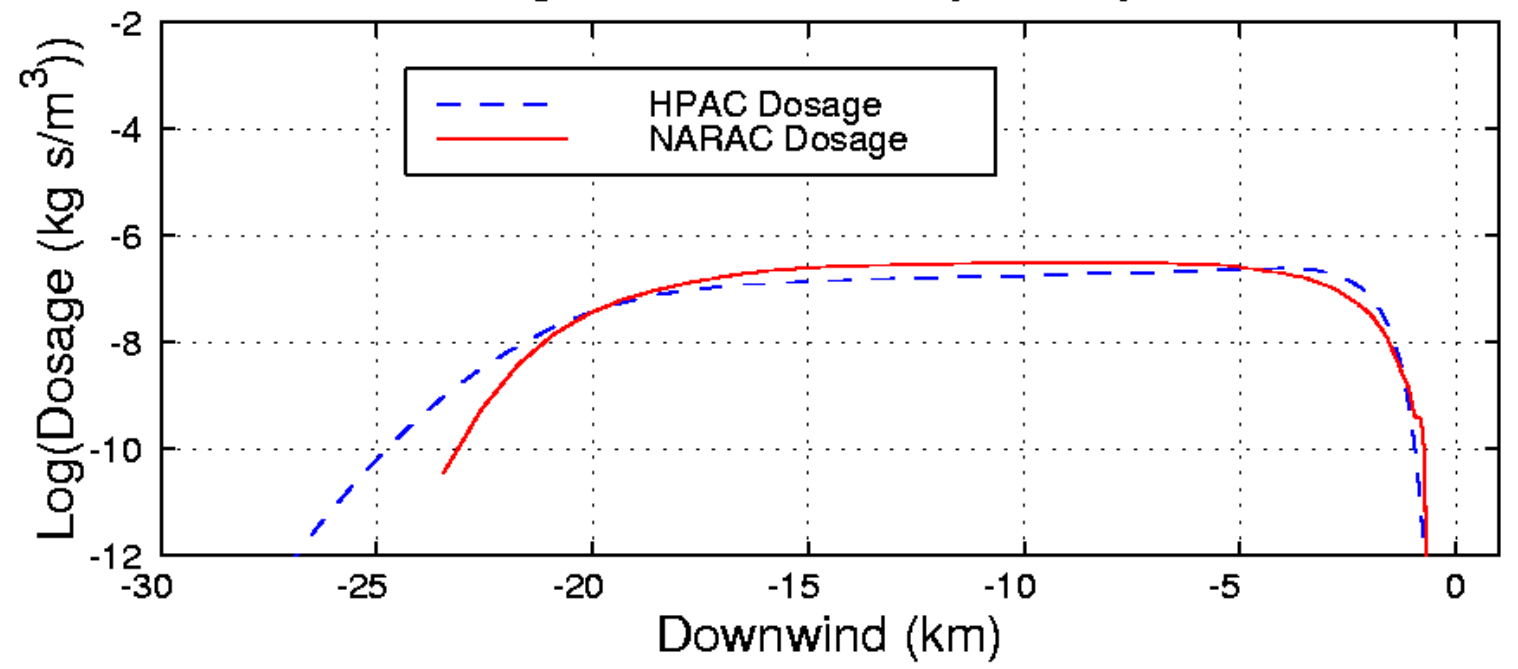

Figure 3-28. MvM 11 at 60 Minutes with Upper: NARAC (Red -) and HPAC (Blue - -) Dosage Contours; Lower: Log Dosages on Downwind Symmetry Axis. Particle Diameter is $5 \mu$, Release Height is $\mathbf{2 5 0} \mathrm{m}$, and Release Duration is $15 \mathrm{~min}$. 

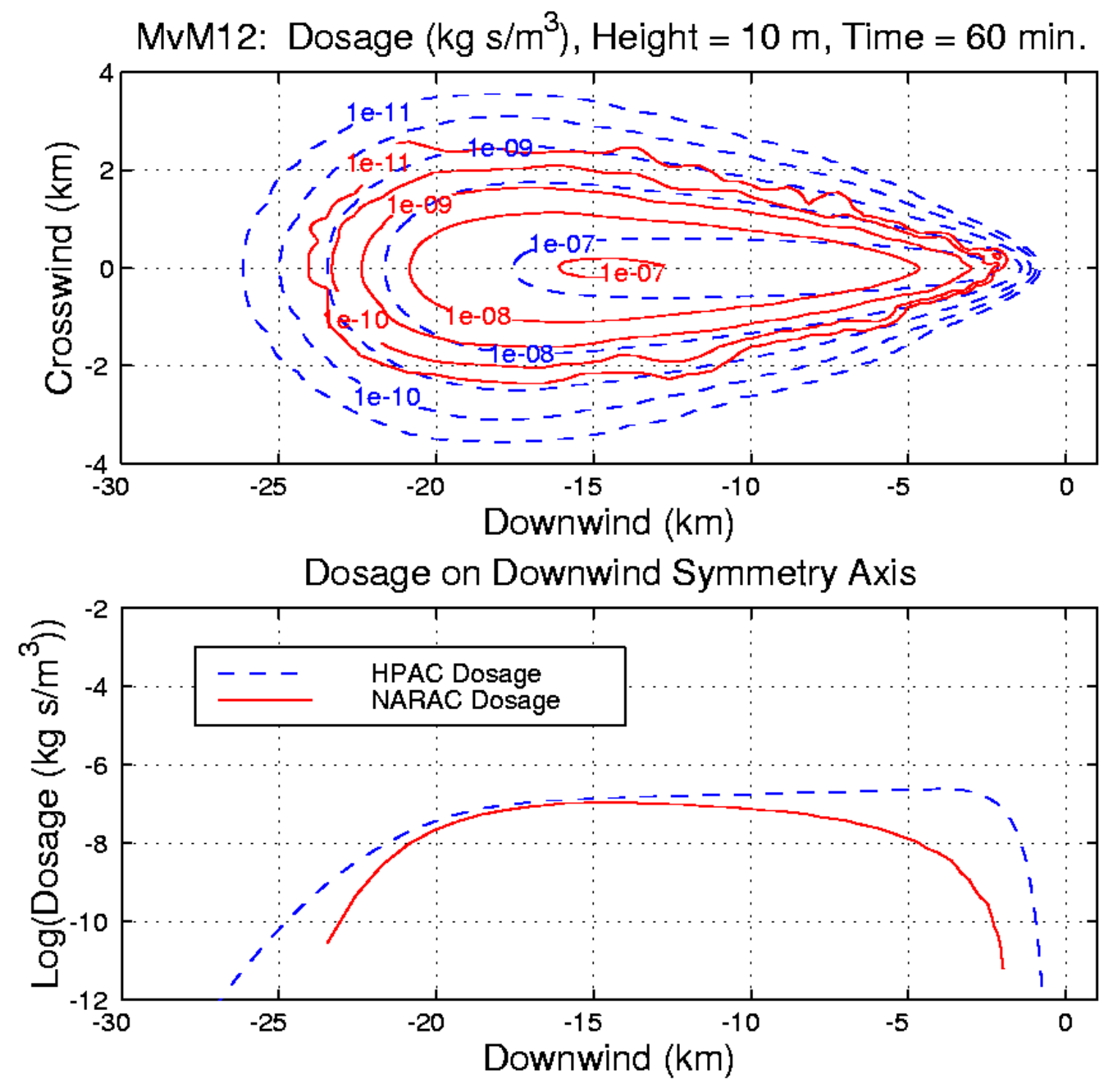

Figure 3-29. MvM 12 at 60 Minutes with Upper: NARAC (Red -) and HPAC (Blue - -) Dosage Contours; Lower: Log Dosages on Downwind Symmetry Axis. Particle Diameter is $5 \mu$, Release Height is $\mathbf{4 0 0} \mathrm{m}$, and Release Duration is $15 \mathrm{~min}$.

As the release height increases, the HPAC dosage contours tend to envelop the corresponding NARAC contours. This is shown by the examination of the area-based 
MOE for the three runs, as shown in Figure 3-30. The MOE values clearly separate by height, with the blue circles (2-meter release) showing the closest agreement, followed by the red circles (250-meter release), and finally the green circles (400-meter release). The trend for increasing HPAC overprediction (below the diagonal) with increasing release height is evident from the figure. NARAC tends to overpredict HPAC for the 2-meter release height, which suggests that there is an intermediate release height where the two models have maximal agreement.

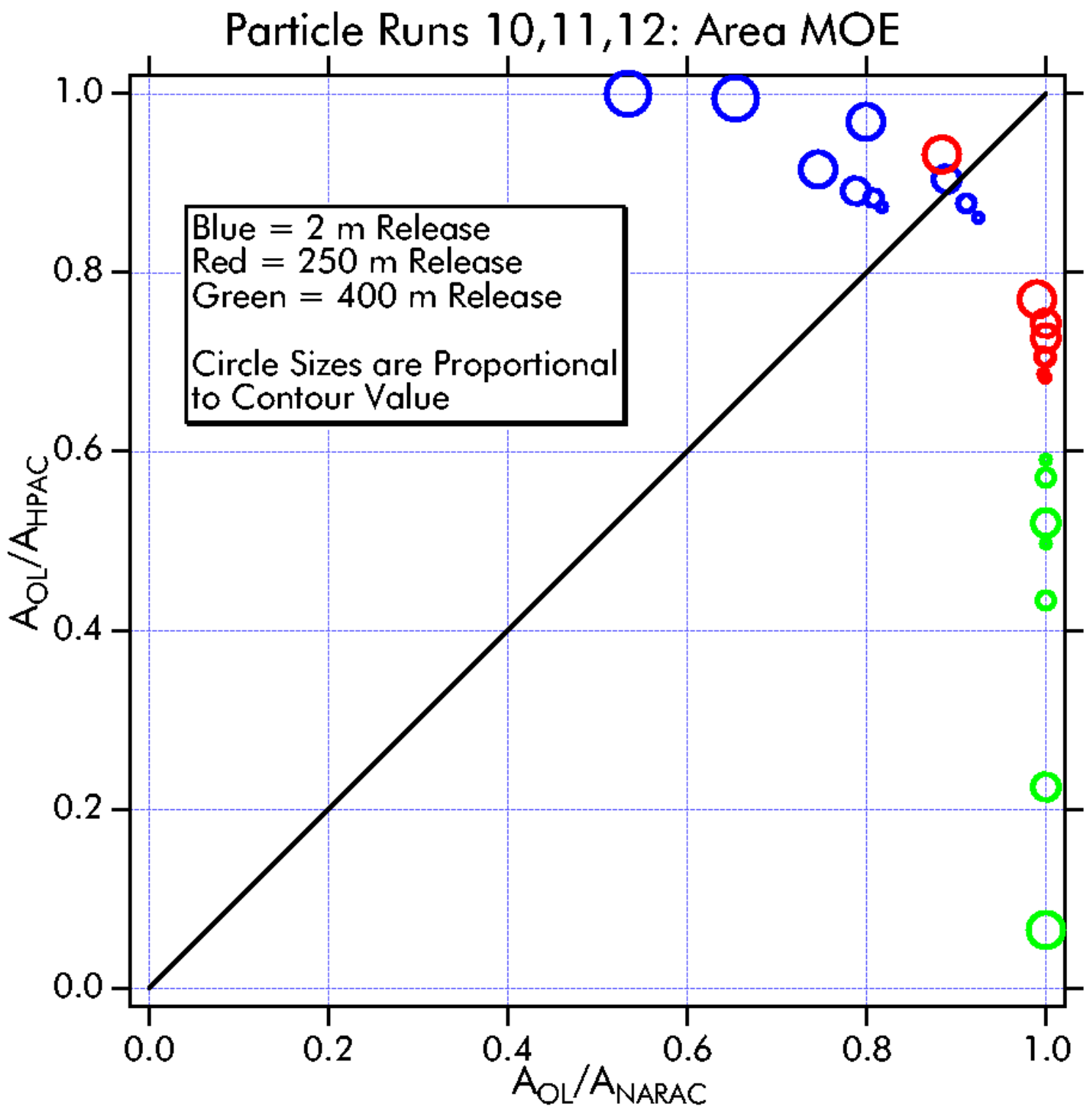

Figure 3-30. Area-Based MOE for Particle Runs 10, 11, and 12 at 30 and 60 Minutes. Colors Indicate Release Height and Circle Size is Proportional to Dosage Contour Level. 


\section{High Altitude Release: Run 15}

The $50 \mu$ particle release at a height of 750 meters, MvM 15, shows considerable model disagreement. This was the only release that was studied where the release height was greater than the boundary layer height $(500 \mathrm{~m})$. The run was chosen to have a 4-hour duration, in order to yield significant dosages at the 10-meter sampler height. Table 3-2 shows a comparison of the maximum dosages for the two models at various times after the release, computed over the entire horizontal grid at the sampler height of 10 meters.

Table 3-2. Maximum Dosages for MvM 15 at a Sampling Height of 10 Meters

\begin{tabular}{|c|c|c|}
\hline Time (min) & $\begin{array}{c}\text { Max HPAC Dosage } \\
\left(\mathbf{k g - s} / \mathbf{m}^{\mathbf{3}} \mathbf{)}\right.\end{array}$ & $\begin{array}{c}\text { Max NARAC Dosage } \\
\left(\mathbf{k g - s} / \mathbf{m}^{\mathbf{3}} \mathbf{)}\right.\end{array}$ \\
\hline 30 & 0 & 0 \\
\hline 60 & $1.2 \times 10^{-14}$ & 0 \\
\hline 120 & $4.6 \times 10^{-9}$ & $1.2 \times 10^{-8}$ \\
\hline 180 & $3.5 \times 10^{-8}$ & $7.2 \times 10^{-8}$ \\
\hline 240 & $3.5 \times 10^{-8}$ & $8.4 \times 10^{-8}$ \\
\hline
\end{tabular}

At 30 minutes, neither model has a non-zero dosage at the 10-meter sampler height. At 60 minutes, the HPAC plume has descended to the sampling height, while the NARAC particles have not. At later times, the maximum NARAC dosage overtakes the maximum HPAC dosage and continues to increase, while the HPAC dosage levels off. ${ }^{11}$

Figures 3-31 and 3-32 show dosage contour plots ${ }^{12}$ for MvM 15 at 120 and 240 minutes, respectively (other figures for MvM 15 can be found in Appendix D). At 120 minutes, all of the HPAC contours envelop the corresponding NARAC contours. At 240 minutes, the higher-level contours compare more favorably; however, the low level NARAC contours are still enveloped by the HPAC contours. This trend is captured in the area MOE plot for MvM 15, shown in Figure 3-33. In the figure, symbol color denotes the time after the release (blue $=120$, red $=180$, and green $=240$ minutes) and symbol size is proportional to contour level. Fewer contours were used at later times, due to the truncation of low-level contours at the horizontal domain boundary. It is clear

11 Recall, the dosage values shown in Table 3-2 reflect a $1 \mathrm{~kg}$ release. We expect that increasing the release mass would lead to proportionately increased dosages.

12 Note that some low level contours are truncated at the boundary of the horizontal domain. This is an artifact of the chosen domain size and does not alter the conclusions drawn in this section. 
from the figure that, at 120 minutes (blue), all of the HPAC contours surround the NARAC contours. At 180 minutes (red) and 240 minutes (green), the higher level NARAC and HPAC contours begin to intersect and the MOE values move away from the $x=1$ axis.
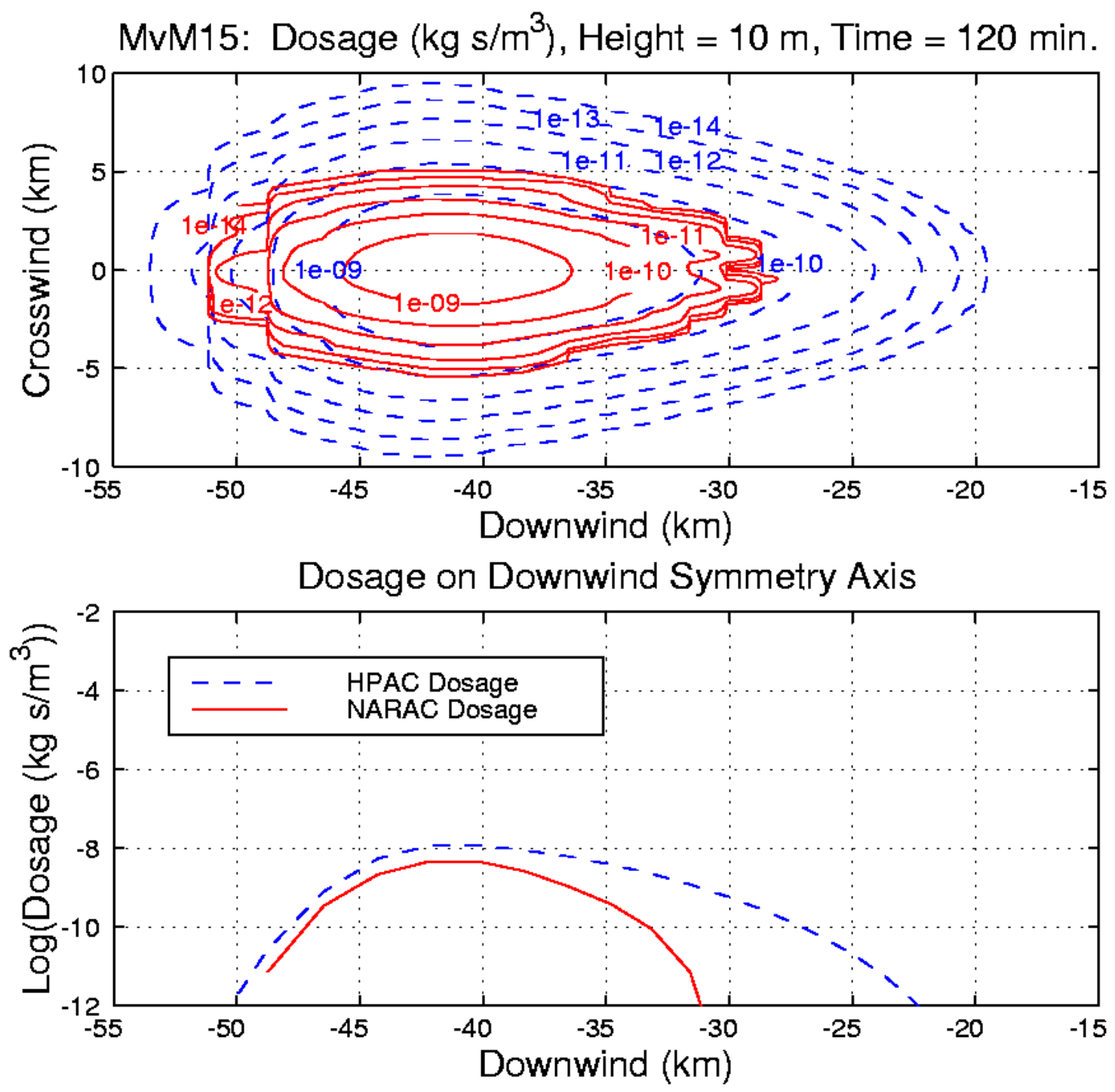

Figure 3-31. MvM 15 at 120 Minutes with Upper: Dosage Contours for HPAC (Blue - -) and NARAC (Red -); Lower: Dosage on Downwind Symmetry Axis 


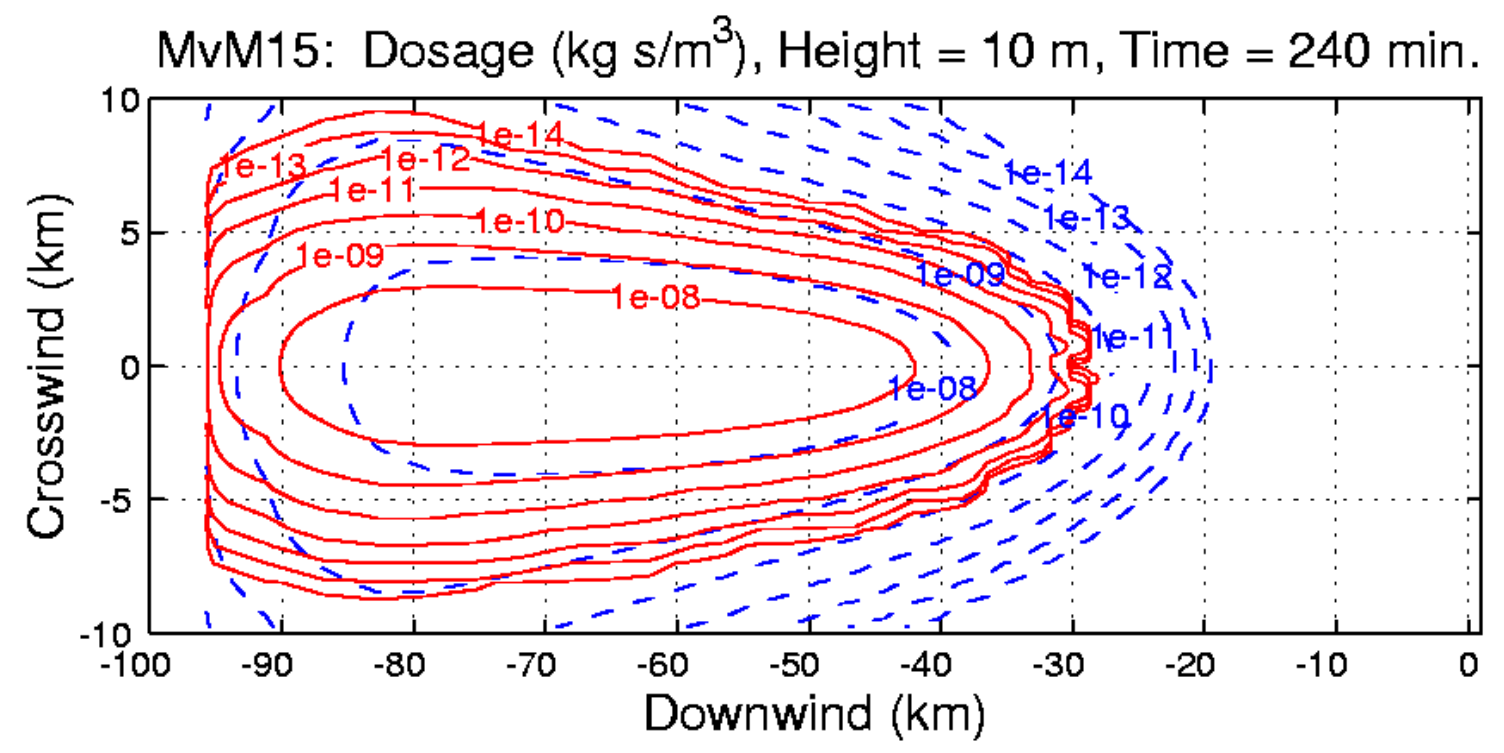

Dosage on Downwind Symmetry Axis

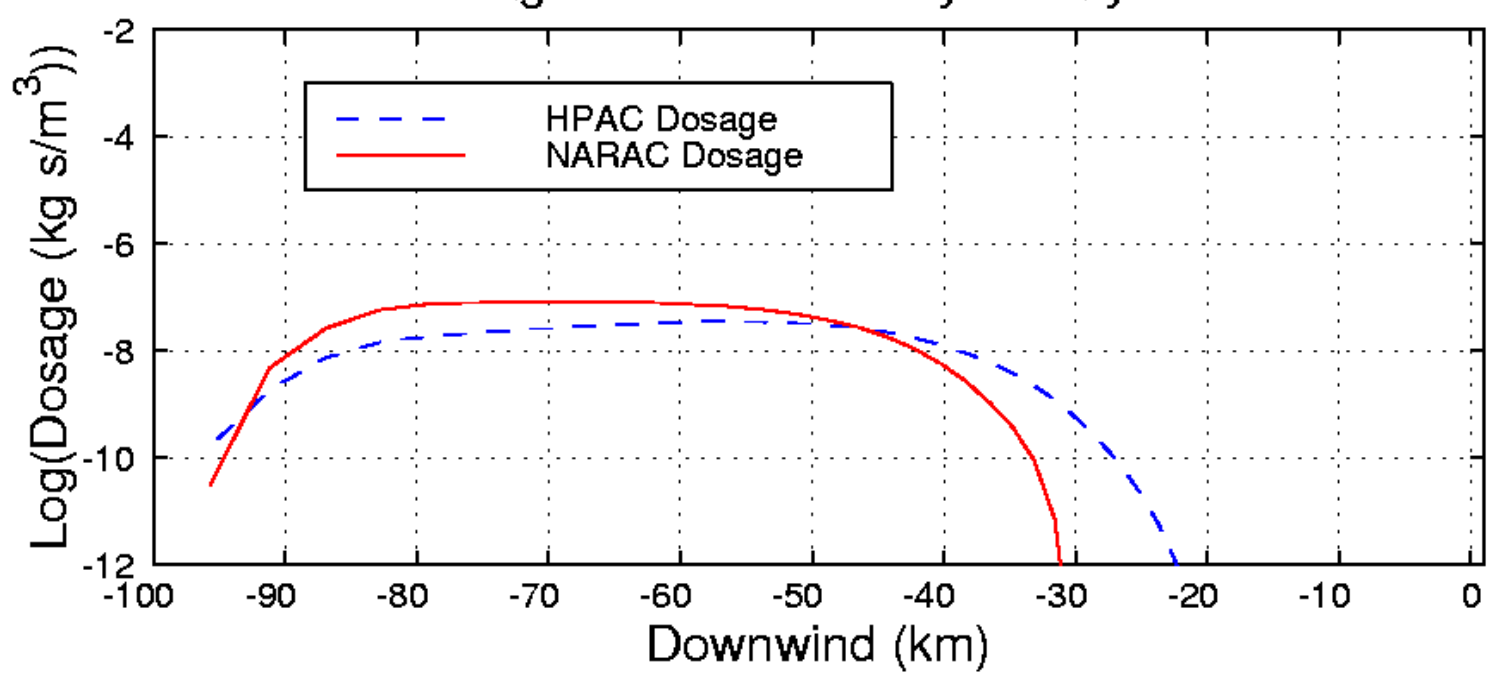

Figure 3-32. MvM 15 at 240 Minutes with Upper: Dosage Contours for HPAC (Blue - -) and NARAC (Red -); Lower: Dosage on Downwind Symmetry Axis 


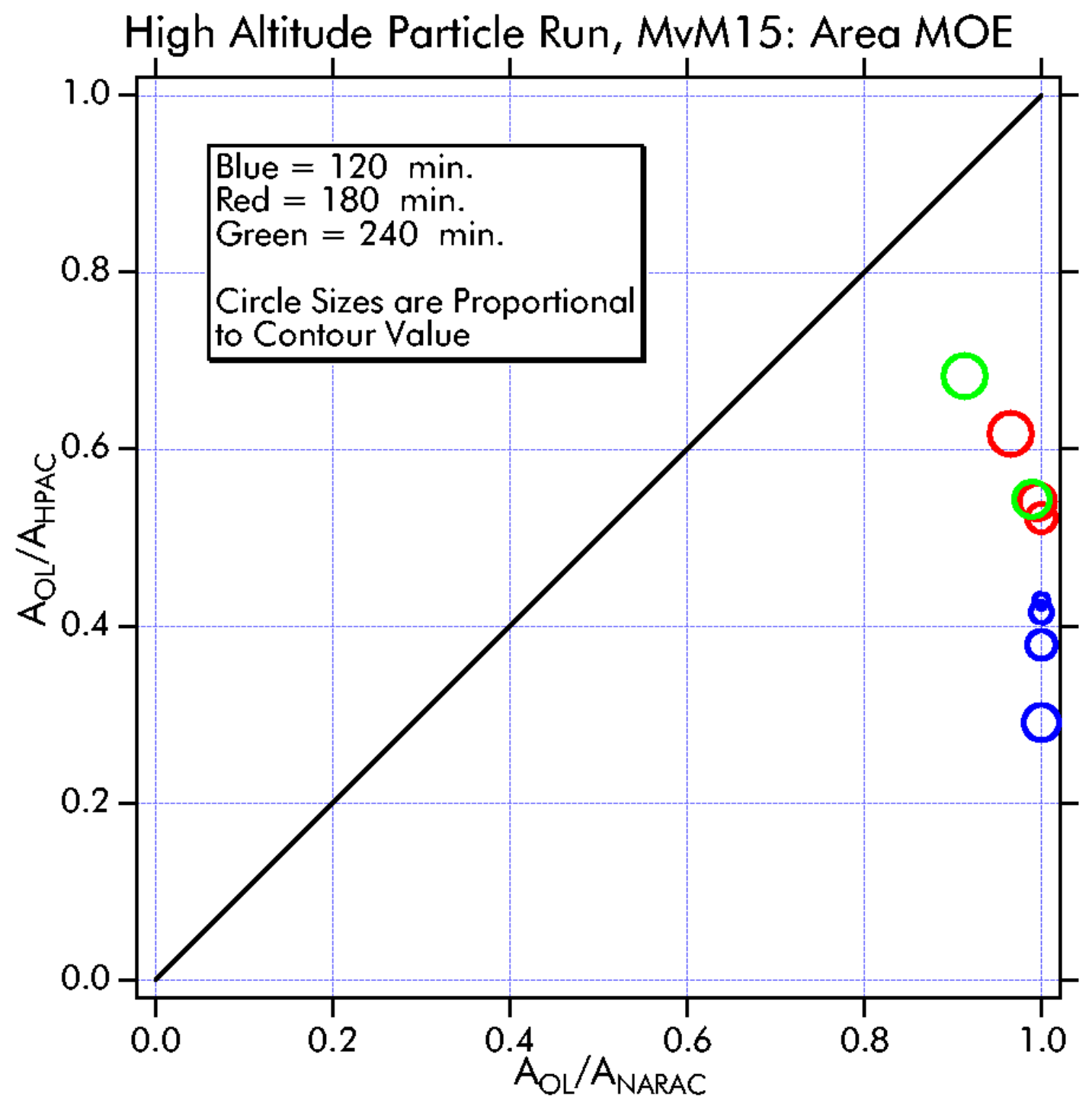

Figure 3-33. Area-Based MOE for Particle MvM 15: Colors Indicate Time After Release and Circle Size is Proportional to Dosage Contour Level. Agreement is Better for Later Times and Higher Dosages.

The trends observed for MvM 15 are similar to those observed in the other higher altitude releases near the boundary layer: MvM 2 with release height $50 \mathrm{~m}$ and MvM 3 with release height $80 \mathrm{~m}$, each with boundary layer height $100 \mathrm{~m}$ (recall Section A of this chapter). The cause of these differences is associated with the different vertical diffusivity parameterizations used by HPAC and NARAC.

Figure 3-34 compares NARAC and HPAC instantaneous concentrations for MvM 3 at 10-minute intervals after the release $(t=10,20,30,40,50$ and 60 minutes $)$. The 
material in Figure 3-34 is moving from right to left. At each time there is a single HPAC contour (blue) and a single NARAC contour (red), and the concentration value for all contours is $10^{-9} \mathrm{~kg} / \mathrm{m}^{3}$. For times through 40 minutes, the horizontal positions and horizontal widths of the HPAC and NARAC concentration plumes agree well, however the vertical diffusion is much more pronounced in the HPAC plume. After 40 minutes the HPAC plume descends quickly (at 60 minutes the HPAC plume is on the ground near $x=-27 \mathrm{~km}$, and is barely visible), while the NARAC plume remains aloft.

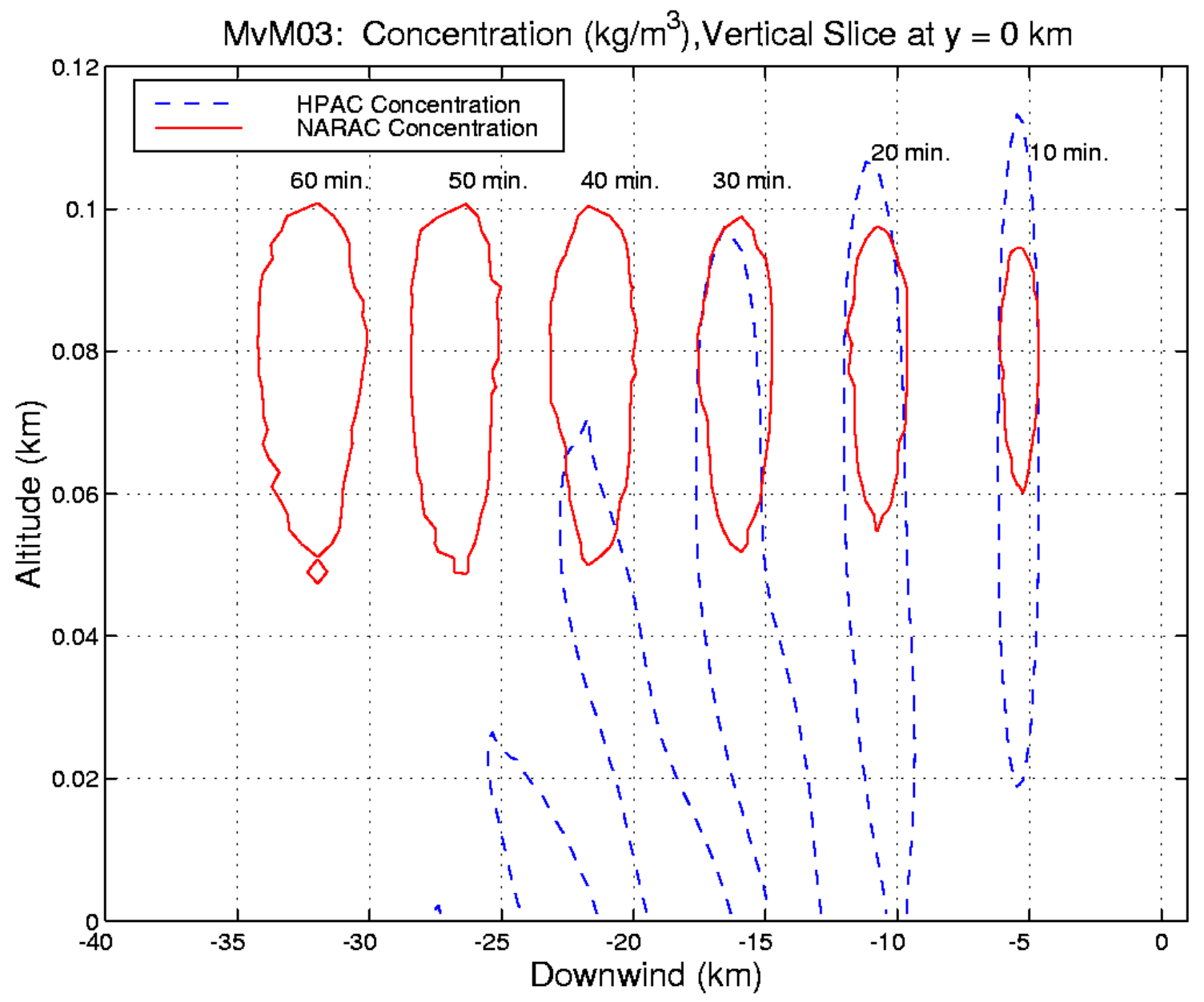

Figure 3-34. NARAC and HPAC Instantaneous Concentrations $\left(1.0 \times 10^{-9} \mathrm{~kg} / \mathrm{m}^{3}\right)$ for MvM 3 at $t=10,20,30,40,50$, and 60 Minutes. The Material is Moving from Right to Left. The HPAC Contours Show Much Greater Vertical Diffusion and Descend at a Greater Rate.

The marked difference in the vertical dynamics for the two models points to a difference in the modeling of the vertical diffusivity. NARAC uses a significantly lower 
free atmosphere diffusivity than HPAC [Ref. 3-3]. HPAC blends the free atmosphere and boundary layer diffusivities over roughly the top half of the boundary layer, while NARAC blends over a relative shallow layer at the boundary layer. Thus, a plausible hypothesis for the differences observed is that the $80 \mathrm{~m}$ release height (in the $100 \mathrm{~m}$ deep stable boundary layer) is associated with the vertical diffusivity blending layer (between the boundary layer and free atmosphere).

It is difficult to characterize the turbulence in the stable boundary layer, especially above the surface and unfortunately there is no good data on elevated diffusion under stable conditions. There are well-known limitations to the similarity-theory turbulence scaling relationships that are used. Above the surface layer in the moderately stable $\left(\mathrm{z}_{\mathrm{i}} / \mathrm{L}>1\right)$ boundary layer, the local fluxes of heat and momentum, and not surface fluxes, can be the most important turbulence scaling parameters. However, local fluxes are often not available, and scaling relationships for the stable boundary layer based on surface fluxes are used. For very stable conditions $\left(\mathrm{z}_{\mathrm{i}} / \mathrm{L}>6\right)$, turbulence may be intermittent in portions of the boundary layer, and no satisfactory theory has yet been developed. 'Upside down' boundary layers, with higher turbulence aloft due to elevated wind maxima, are observed in very stable conditions, but not in less stable conditions.

Comparison with the HPAC results also shows that, for releases occurring at a significant fraction of the boundary layer depth, the NARAC plumes show less horizontal (i.e., crosswind) diffusion than the HPAC results. This is most likely the result of different diffusivity parameterizations within the upper half of the boundary layer. (Note that this is in contrast to the results observed in the short-range, low-altitude release HPAC/NARAC Prairie Grass simulations, where the NARAC plumes are consistently wider than the HPAC plumes [Ref. 3-1].)

\section{EXCURSIONS}

In this final section of Chapter 3, we discuss the sensitivity of the model comparisons to input parameters that control spatial and temporal resolution. In the initial stages of this study, we arrived at the "baseline" parameters, outlined in Chapter 2, through a series of test comparisons, using a variety of parameter settings. This section serves to document some of the more important effects that were found in the course of these initial explorations. It also serves to underscore the need to understand and account for the intrinsic computational framework of the models that are being compared in a model-to-model study. 
Three main effects were observed, two concerning HPAC spatial resolution and one concerning HPAC temporal resolution. ${ }^{13}$

\section{HPAC Vertical Resolution}

Significant changes in HPAC downwind plume transport were observed when the HPAC vertical resolution was changed. This effect was most prominent in the lowaltitude stable gas release, MvM 1. Figures 3-35 and 3-36 show the dosage contour comparisons with two values of the HPAC vertical resolution: a "coarse" value of 40 meters (the default HPAC value for the specified grid top height) and a "fine" value of 10 meters (the adopted "baseline" setting). The coarse resolution HPAC plume (blue), shown in Figure 3-35, is seen to propagate much farther downwind than the fine resolution HPAC plume, shown in Figure 3-36. For example, an examination of the HPAC dosage contour at $10^{-9} \mathrm{~kg}-\mathrm{s} / \mathrm{m}^{3}$ shows that in the coarse resolution case, this contour extends approximately $37 \mathrm{~km}$ downwind, versus $29 \mathrm{~km}$ in the fine resolution case.

The effect is caused by the relative under-sampling of the vertical wind profile for the coarse resolution case, resulting in an artificially high transport speed at heights near the release height of 2 meters.

Figure 3-37 shows the vertical wind profile for MvM 1 and a horizontal line at 40 meters (the first sampling height for coarse sampling). Since the release occurs at 2 meters, where the wind speed is approximately $3 \mathrm{~m} / \mathrm{s}$, and since the release is stable, implying a minimum of vertical mixing, it is reasonable to expect an effective transport speed near $3 \mathrm{~m} / \mathrm{s}$. It is clear from Figure 3-37 that sampling the vertical wind profile at a vertical resolution of 40 meters could artificially inflate the transport speed well beyond 3 $\mathrm{m} / \mathrm{s}$, compared to sampling at 10-meter resolution. Although this effect was most dramatic in MvM 1, it was agreed to adopt the fine vertical resolution value of 10 meters as the baseline for all MvM runs (with the exception of MvM 15, which was run with 20meter vertical resolution). This is a clear example of the need to move away from a default parameter setting in order to ensure a fair comparison of different model predictions.

13 Related considerations apply to setting up NARAC meteorological and concentration grids but are not discussed here. (See Chapter 2 for additional discussion.) 
As noted above, the vertical resolution effect was most prominent for MvM 1. Recalling the vertical wind profiles of Figure 2-3, we can understand the origin of this relative prominence. First, the vertical wind speed profile for MvM 1 through 3 had the greatest speeds above the height of 10 meters, with a much more rapid increase in speed as a function of height than the profiles used for MvM 4 through 17. Therefore, the vertical profile associated with MvM 1 through 3 would be expected to be the most sensitive (i.e., artificially inflated) to the use of the lower (40-meter) vertical resolution.
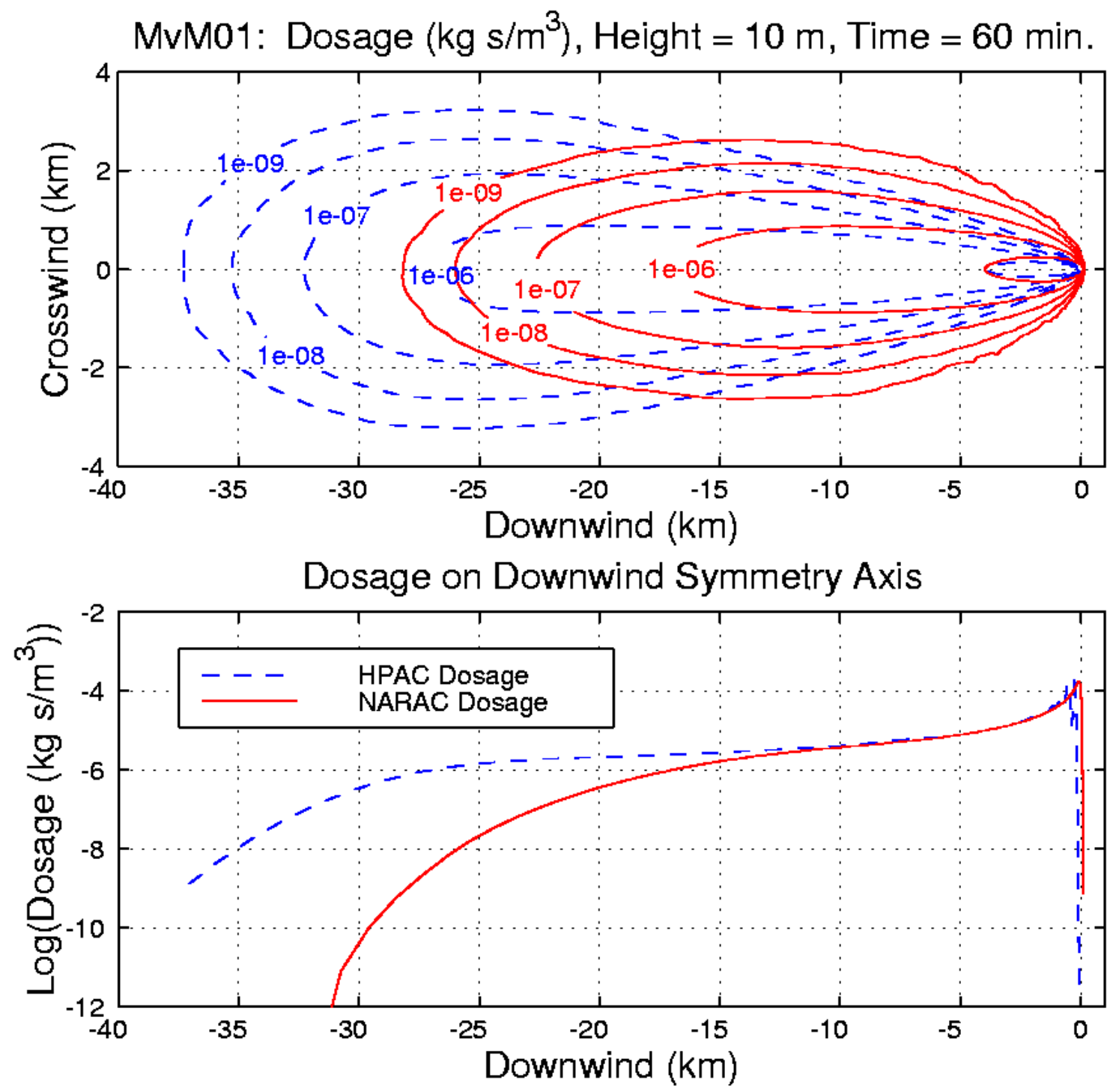

Figure 3-35. MvM 1 at 60 Minutes with Upper: Dosage Contours for HPAC (Blue - -) and NARAC (Red -); Lower: Dosage on Downwind Symmetry Axis. HPAC Run Done at Coarse Vertical Resolution Value of $\mathbf{4 0}$ Meters (Default HPAC Value). Note Extended HPAC Plume in Downwind Direction. 


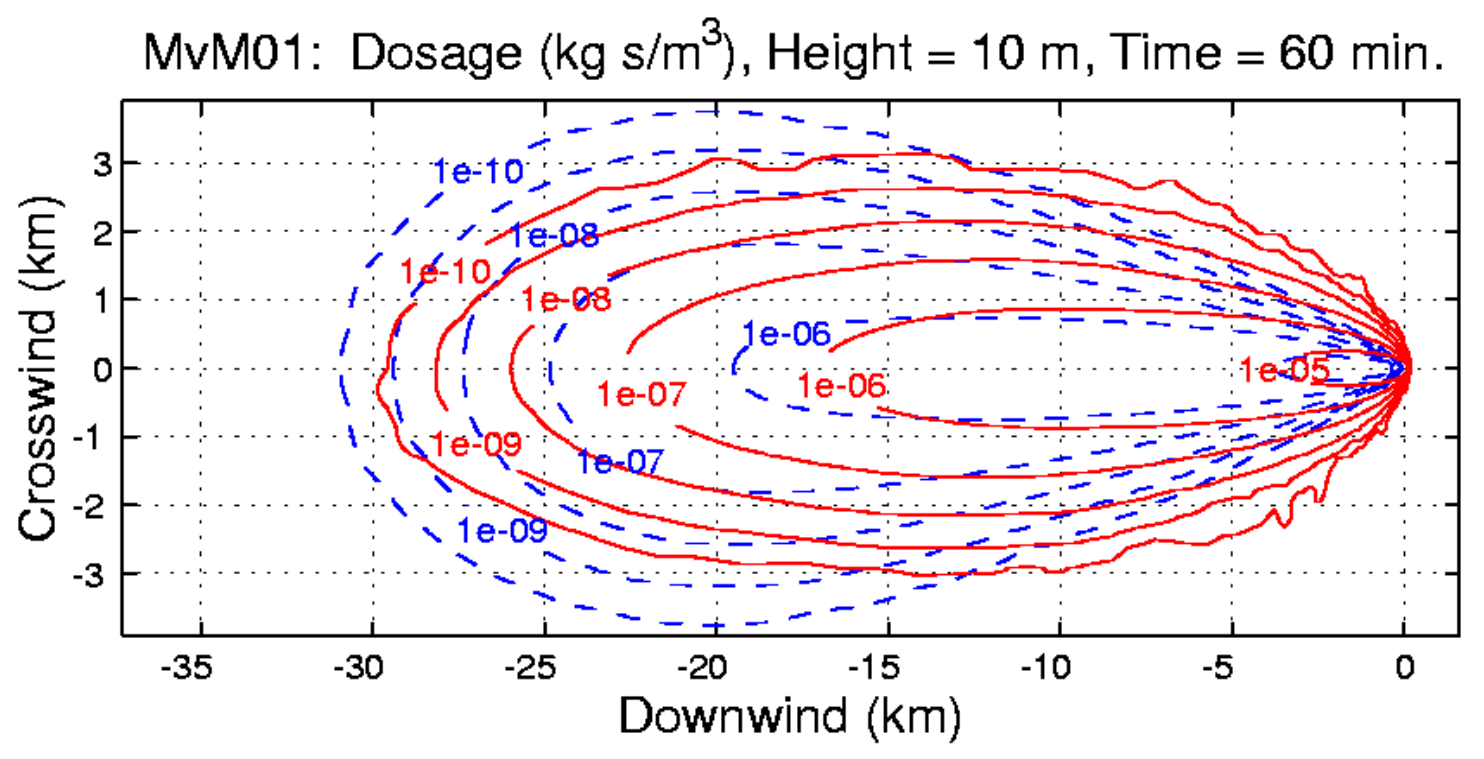

Dosage on Downwind Symmetry Axis

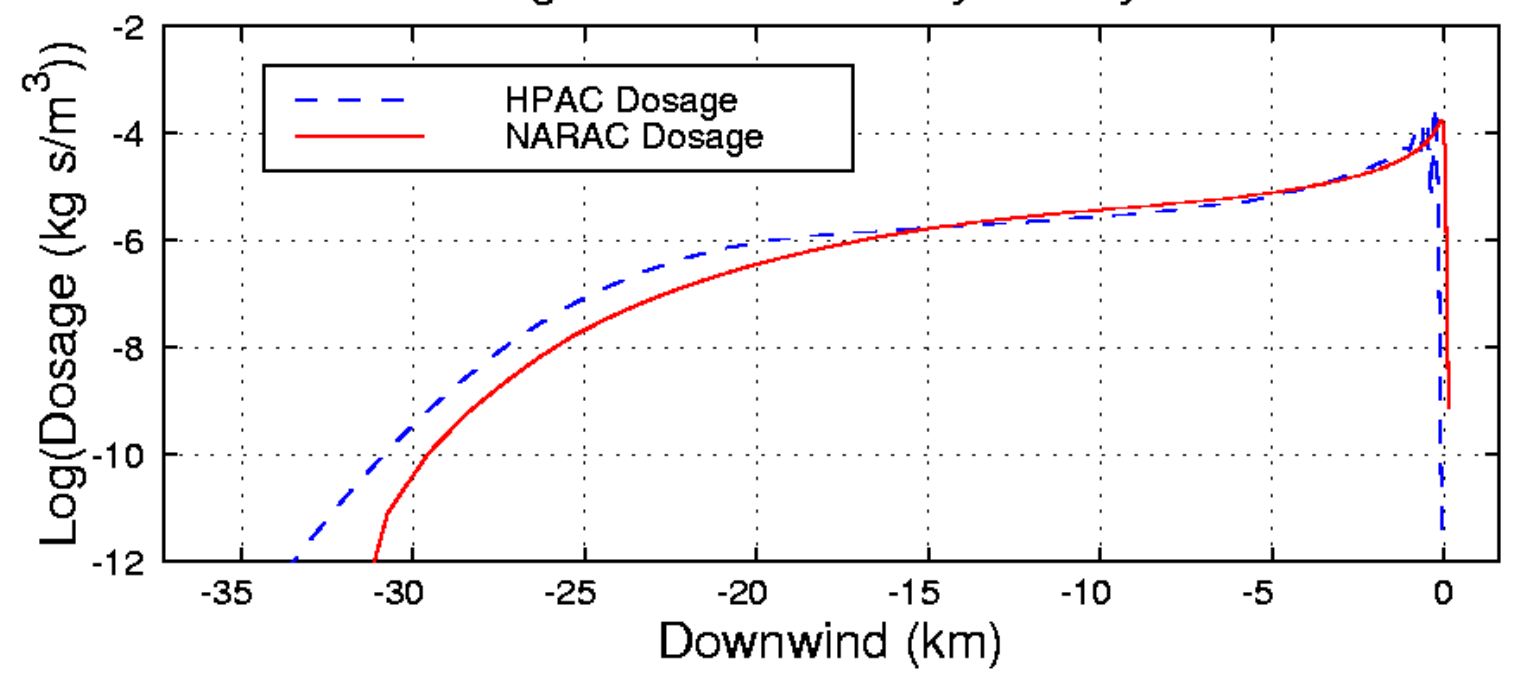

Figure 3-36. MvM 1 at 60 Minutes with Upper: Dosage Contours for HPAC (Blue - -) and NARAC (Red -); Lower: Dosage on Downwind Symmetry Axis. HPAC Run Done at Fine Vertical Resolution Value of 10 Meters (Adopted Baseline HPAC Value). Effective Transport Speed of HPAC Plume is Lower With Finer Vertical Sampling. 


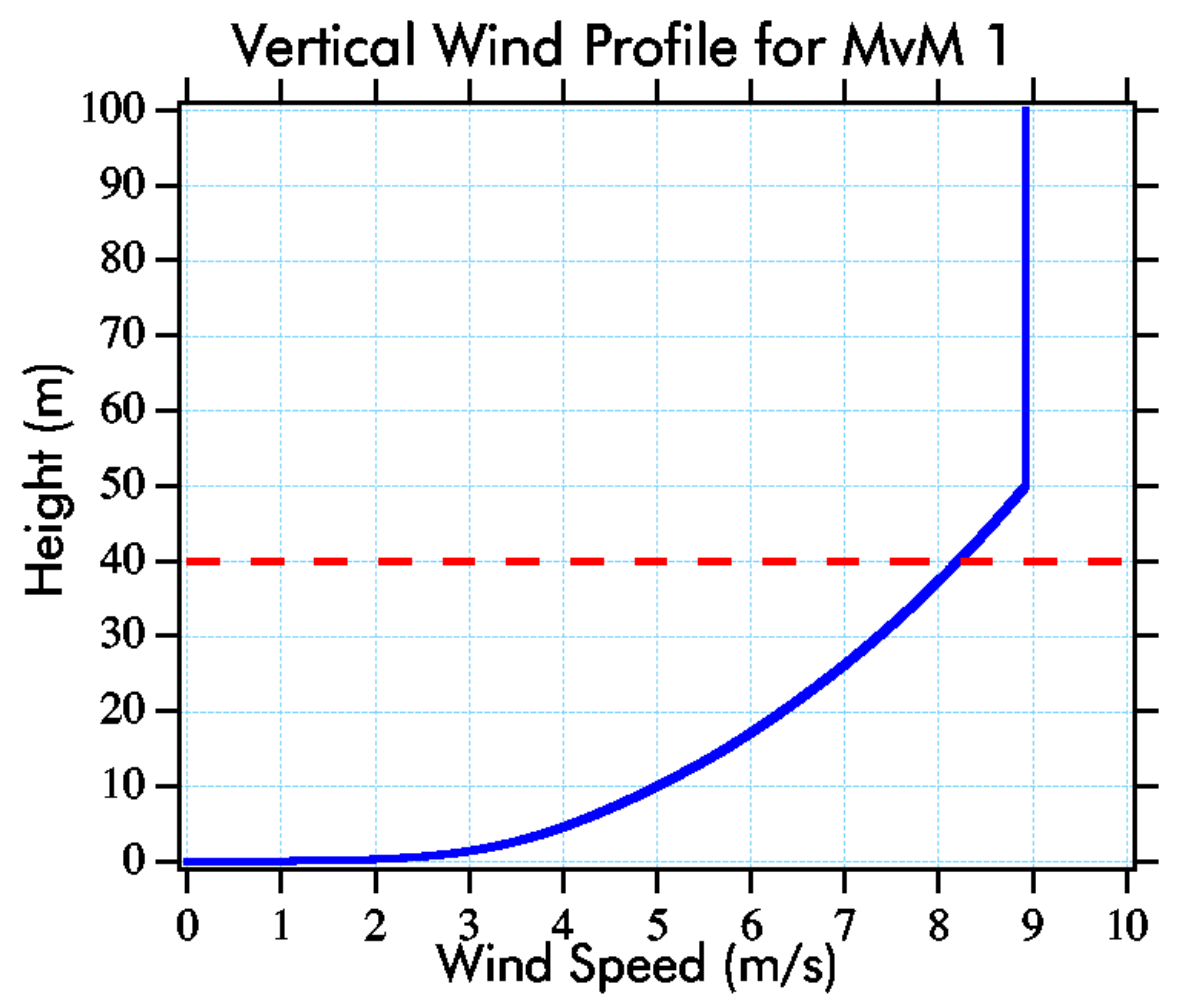

Figure 3-37. Vertical Wind Profile for MvM 1 (Blue -) and 40-Meter Sampling Height (Red - -). Coarse Vertical Sampling Artificially Inflates the Effective Transport Speed.

Also, recall that MvM 1, 2, and 3 had release heights of 2, 50, and 80 meters, respectively. Above 50 meters, all three vertical profiles that were considered were flat, that is, there was no change in wind speed with increasing altitude. Thus, only MvM 1's release occurred at a height where the associated wind speed was based on the first resolved 40-meter value (the significantly inflated value). For the conditions examined, the combination of low altitude release and steep vertical wind gradient led to a situation where substantially different predictions resulted from varying the vertical resolution.

\section{HPAC Horizontal Resolution}

A second resolution-induced effect was observed in HPAC dosage output, when the horizontal resolution (set in the HPAC Domain Editor) was changed from the default value of approximately $1 \mathrm{~km}$ to the finer value of $0.4 \mathrm{~km}$. Figure $3-38$ shows a screen capture of the HPAC surface dosage contours for MvM 1 at 60 minutes. The color-filled contours were computed at the finer $0.4-\mathrm{km}$ horizontal resolution value, while the solid black contours span the same contour levels and were computed at the default horizontal 
resolution value of $1 \mathrm{~km}$. Both sets of contours were computed with a 40-meter vertical resolution (the HPAC default value, discussed above).

Two differences between the contour sets are apparent. First, the downwind plume extent is reduced for the fine resolution contours, at least for the smaller dosages (e.g., $10^{-7}$ and $10^{-8}$ ). Next, there is the undesirable introduction of high-frequency spatial modulation in the fine resolution contours that distort the plume shape, particularly at larger dosages (see, for example, the boundary between the yellow and green regions).

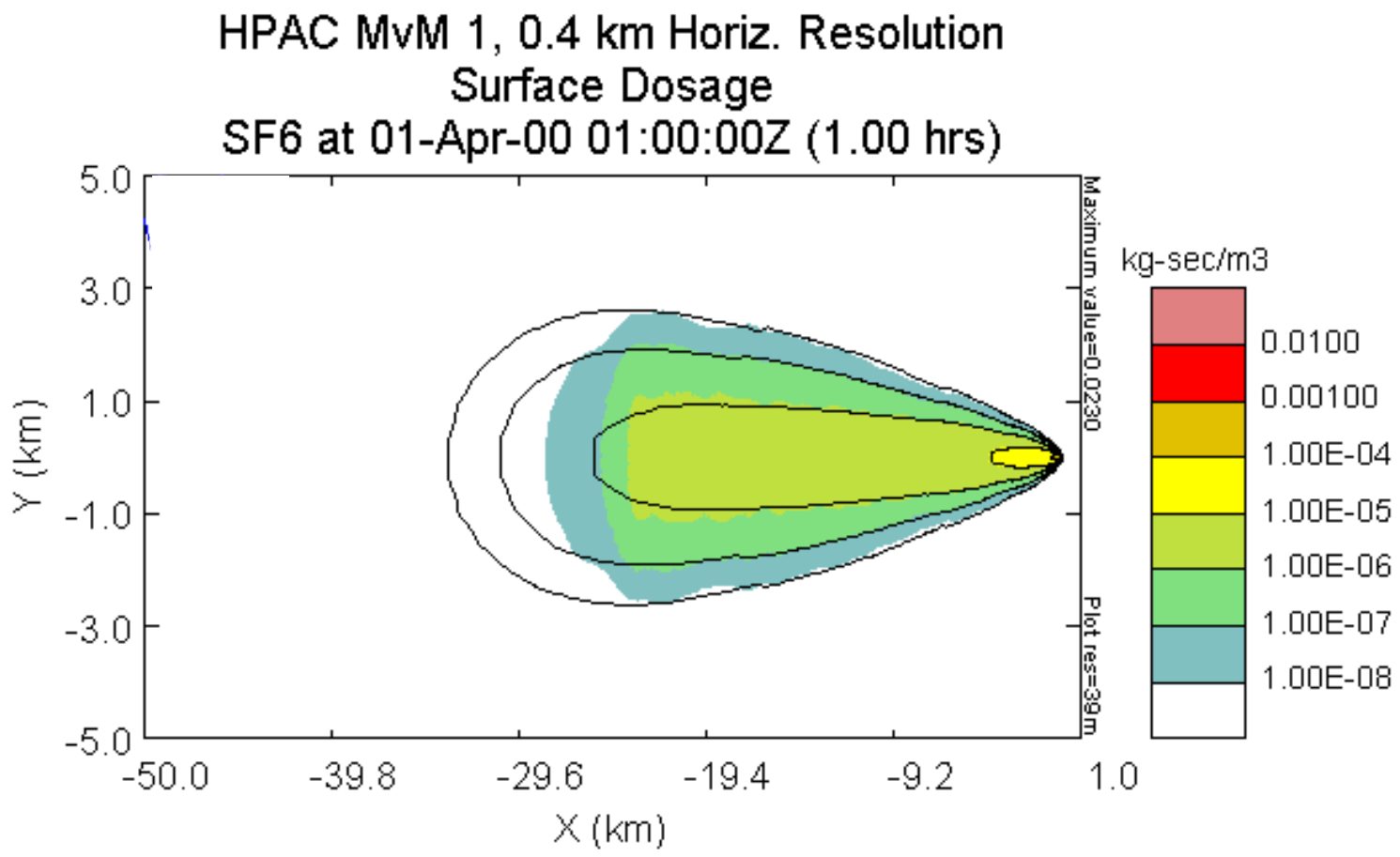

Figure 3-38. HPAC Surface Dosage Contours for MvM 1 at 60 Minutes. Color-Filled Contours Are For $\mathbf{0 . 4} \mathrm{km}$ Horizontal Resolution and Solid Black Contours (at Same Contour Levels) Are For 1 km Horizontal Resolution. Note High-Frequency Distortions Introduced in Color Contours, Believed to Be an Artifact of "Puff-Splitting" Routines in SCIPUFF.

The observed high-frequency spatial modulation is believed to be due to computational artifacts introduced by "puff-splitting" routines in SCIPUFF that control the creation of new Gaussian concentration puffs when plumes cross resolution cells. At the advice of the developer of SCIPUFF [Ref. 3-4], it was agreed to adopt the default HPAC horizontal resolution value of $1 \mathrm{~km}$ as the baseline value in all model-to-model comparisons. This choice, combined with the 10-meter vertical resolution choice, 
produced HPAC contours that had acceptable transport speeds and acceptable (sensible) smoothness properties.

It is interesting to note the asymmetry in the HPAC results with respect to changes in horizontal and vertical resolution. In the horizontal direction, coarsening the resolution improves the results by eliminating artificial high frequency modulation. In the vertical direction, making the resolution finer improves the comparative results with respect to transport speed. These effects were not anticipated and they underscore the complexities involved in making a fair model-to-model comparison.

\section{HPAC Time-Step Resolution}

The final parameter excursion investigated involves the HPAC maximum output time-step. This parameter is set within the Time Editor in the Project Editor, and, for all runs, the baseline value was chosen to be the default HPAC value of 60 seconds. The maximum time-step controls the time interval at which concentration values are listed in the HPAC sampler (.smp) file. The sampler file concentration data are then integrated, using Equation 2-2, to produce HPAC output dosages.

It was noted in Section A.1 that, for some releases, there are significant spatial oscillations $^{14}$ in the HPAC dosage near the release (see symmetry axis plots in Figures 3-3 and 3-4 and the blue trace in Figure 3-39 below). These oscillations eventually decay with downwind distance ( $\sim 1$ to $3 \mathrm{~km}$ downwind). A survey of the downwind symmetry axis plots for all runs (see Appendices C and D) shows that the oscillations are present only for the 2-meter, instantaneous releases (MvM runs 1, 4, 7, 13, 16, and 17). Oscillations are present in both gas and particle runs, and at 30 and 60 minutes after the release.

The magnitude of these oscillations is related to the output time-step. Figure 3-39 shows the symmetry axis dosage for MvM 4 at 30 minutes, computed with two timesteps: 60 seconds (the baseline value, in blue) and 30 seconds (in red). Decreasing the time-step by a factor of two diminishes the magnitude of the oscillations by as much as a factor of 100 .

14 By viewing "raw" dosage values, it has been verified that the oscillations are not artifacts of the interpolation scheme used to compute dosages on the symmetry axis nor of the contouring routine used to generate dosage contours. 
The SCIPUFF developer believes the dosage oscillations may be due to the following [Ref. 3-5]. At early times and large output time steps an instantaneous release plume can pass completely over an output sampler in one time step, with the result that the sampler records little or no concentration signal at that time step (this is especially true for the small release geometries considered in this study). Sampling the plume more frequently increases the chance that a sampler that previously recorded little or no concentration will now record a higher concentration. At later times (larger downwind distances), the plume has had time to grow dispersively and the undersampling effect is diminished. Future model-to-model studies that involve comparisons of short-range HPAC dosages would likely benefit from further reductions in the time-step.

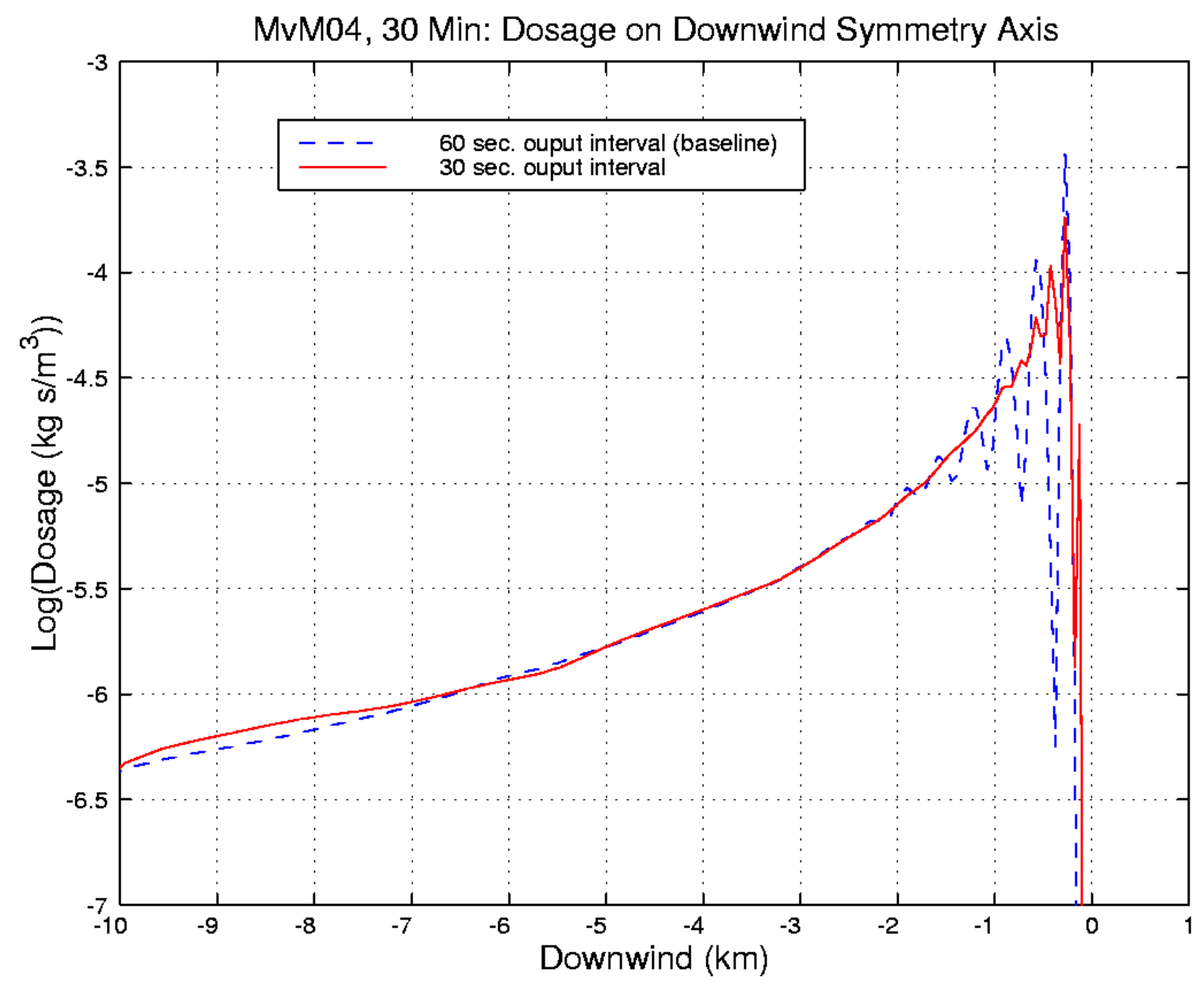

Figure 3-39. HPAC Dosage Along Downwind Symmetry Axis for MvM 4 at 30 Minutes. Blue Trace Is for 60 Second Time-Step (Baseline Value) and Red Trace Is for $\mathbf{3 0}$ Second Time-Step. The Magnitude of the Dosage Oscillations Decreases Substantially by Decreasing the Time-Step. 


\section{REFERENCES}

3-1. Warner S., Platt, N., Heagy, J. F., Bradley, S., Bieberbach, G., Sugiyama, G., Nasstrom, J. S., Foster, K. T, and Larson, D., User-Oriented Measures of Effectiveness for the Evaluation of Transport and Dispersion Models, IDA Paper P-3554, 8 January 2001.

3-2. ibid, pp. 3-31 and pp. I-18, Figure I-18, "800 meter arc, 95\%" chart.

3-3. Sykes, R. I., Re: HPAC/NARAC Comparisons, e-mail to LLNL, December 2000.

3-4. Sykes, R. I., private communication, July 2000.

3-5. Sykes, R. I., Re: Spatial Oscillations in HPAC Output, e-mail to IDA, October 2000. 
APPENDIX A

ACRONYMS 



\section{APPENDIX A ACRONYMS}

2D

ADAPT

$A_{\text {HPAC }}$

$\mathrm{A}_{\mathrm{OL}}$

$\mathrm{A}_{\mathrm{OP}}$

A NARAC

ARAC

ARAP

$A_{U P}$

CB

CBIAC

$\operatorname{deg} \mathrm{C}$

DOD

DOE

DTRA

FOM

GMU

HPAC

$\mathrm{hr}$

IDA

$\mathrm{kg}$

$\mathrm{km}$

L

LLNL

LODI

$\mu$
Two-dimensional

Atmospheric Data Assimilation and Parameterization Techniques dosage region/area of an HPAC prediction region where model predictions agree region where model 1 overpredicts model 2 dosage region/area of a NARAC prediction Atmospheric Release Advisory Center (same as NARAC) Aeronautical Research Associates of Princeton region where model 1 underpredicts model 2

Chemical and Biological

Chemical and Biological Defense Information Analysis Center

degrees Celsius

Department of Defense

Department of Energy

Defense Threat Reduction Agency

Figure Of Merit

George Mason University

Hazard Prediction and Assessment Capability

hour

Institute for Defense Analyses

kilogram

kilometer

Monin-Obukhov length

Lawrence Livermore National Laboratory

Lagrangian Operational Dispersion Integrator

microns 


\begin{tabular}{|c|c|}
\hline $\mathrm{m}$ & meters \\
\hline $\mathrm{mg}$ & milligram \\
\hline $\min$ & minutes \\
\hline MMD & Mass Median Diameter \\
\hline MOE & Measure of Effectiveness \\
\hline $\mathrm{m} / \mathrm{s}$ & meters per second \\
\hline MvM & Model-Versus-Model \\
\hline NARAC & National Atmospheric Release Advisory Center (same as ARAC) \\
\hline NOAA & National Oceanic and Atmospheric Administration \\
\hline$\psi_{m}$ & Stability Correction. \\
\hline S & seconds \\
\hline SCIPUFF & Second-Order Closure Integrated Puff \\
\hline sec & seconds \\
\hline $\mathrm{SF}_{6}$ or SF6 & Sulfur Hexafluoride \\
\hline $\mathrm{t}$ & time \\
\hline $\mathrm{T} \& \mathrm{D}$ & Transport and Dispersion \\
\hline$u$ & wind speed $(\mathrm{m} / \mathrm{s})$ \\
\hline $\mathrm{V} \& \mathrm{~V}$ & Verification and Validation \\
\hline VV\&A & Verification, Validation, and Accreditation \\
\hline WMD & Weapons of Mass Destruction \\
\hline $\mathrm{z}$ & height (m) \\
\hline $\mathrm{z}_{0}$ & surface roughness factor $(\mathrm{m})$ \\
\hline $\mathrm{z}_{\mathrm{I}}$ or $\mathrm{zi}$ & boundary layer height (m) \\
\hline $\mathrm{Z}_{\mathrm{r}}$ & release height $(\mathrm{m})$ \\
\hline $\mathrm{Z}_{\mathrm{S}}$ & surface layer height (m) \\
\hline
\end{tabular}


APPENDIX B

INITIAL CONDITIONS FOR HPAC AND NARAC PREDICTIONS 



\section{APPENDIX B INITIAL CONDITIONS FOR HPAC AND NARAC PREDICTIONS}

This Appendix lists the input parameters and settings that were used for HPAC and NARAC for all seventeen model-to-model comparisons. For each of the seventeen runs, HPAC parameters are tabulated first, followed by NARAC "namelists" and other auxiliary NARAC input files. NARAC grid generation files are given at the end of this Appendix.

The information provided in this appendix should allow for the reproduction of any and all of the model runs that were used for this study. Furthermore, starting with the input conditions described in this appendix, future analyses could easily extend these examinations by simply adjusting specific parameters. 


\section{HPAC MvM1}

\begin{tabular}{|c|c|c|}
\hline mvm1 & HPAC 3.2 paramet er & HPAC 3.2 value \\
\hline HPAC SCREIN & agent & SF6 \\
\hline \multirow[t]{12}{*}{ New Project Set up } & project file name & mvm1.prj \\
\hline & coordinat es & cart esian \\
\hline & local origin $\mathrm{x}$ & $0 \mathrm{~km}$ \\
\hline & local origin $y$ & $0 \mathrm{~km}$ \\
\hline & local origin latitude & $45 \operatorname{deg} N$ \\
\hline & local origin longitude & 0 deg \\
\hline & reference times & UTC \\
\hline & local time of $00: 00 \mathrm{Z}$ & 0 \\
\hline & mode & standard \\
\hline & dynamics & dense gas \\
\hline & static puffs & enabled \\
\hline & hazard area & of $f$ \\
\hline New Project Editor & edit mode & advanced \\
\hline \multirow[t]{8}{*}{ Mat erial Editor } & type & gas \\
\hline & name & SF6 \\
\hline & mat erial file & Sf6.mtl \\
\hline & units & $\mathrm{kg}$ \\
\hline & bin boundaries & NA \\
\hline & ou tput flags & surf. dosage, surf. depos. \\
\hline & dayt ime decay rate & 0 \\
\hline & night time decay rate & 0 \\
\hline \multirow[t]{3}{*}{ Gas Parameter Editor } & density ratio ( rho/ rho air) & 5.02917 \\
\hline & deposition velocity & 0 \\
\hline & minimum concent ration & 0 \\
\hline \multirow[t]{15}{*}{ Release Edit or } & time & 0 \\
\hline & $\mathbf{x}$ & 0 \\
\hline & $y$ & 0 \\
\hline & height of release & $2 \mathrm{~m}$ \\
\hline & source uncert aint $y$ & no \\
\hline & specification & simple \\
\hline & randomize location & no \\
\hline & release duration & ins tant aneous \\
\hline & release rate & NA \\
\hline & agent mass & $1 \mathrm{~kg}$ \\
\hline & $\mathrm{x}$ size & $1 \mathrm{~m}$ \\
\hline & y size & $1 \mathrm{~m}$ \\
\hline & z size & $1 \mathrm{~m}$ \\
\hline & moment um & 0 \\
\hline & buoyancy & 0 \\
\hline \multirow[t]{6}{*}{ Time Edit or } & start day & $4 / 1 / 00$ \\
\hline & start time & 0 \\
\hline & st op day & $4 / 1 / 00$ \\
\hline & stop time & 100 \\
\hline & maximum time st ep & $60 \mathrm{sec}$ \\
\hline & out put interval & $15 \mathrm{~min}$ \\
\hline \multirow[t]{7}{*}{ Domain Edit or } & $\mathrm{xmin}$ domain & $-50 \mathrm{~km}$ \\
\hline & $x \max$ domain & $1 \mathrm{~km}$ \\
\hline & ymin domain & $-5 \mathrm{~km}$ \\
\hline & ymax domain & $5 \mathrm{~km}$ \\
\hline & horizontal resolu tion & default \\
\hline & vertical domain max height & $500 \mathrm{~m}$ \\
\hline & vertical domain resolution & $10 \mathrm{~m}$ \\
\hline Weat her Edit or & weat her da ta type & surface obs. only \\
\hline & boundary layer type & observations \\
\hline & large scale variability & none \\
\hline & large scale variability length scale & NA \\
\hline & large scale variability variance & NA \\
\hline & surface roughness & $0.008 \mathrm{~m}$ \\
\hline & precipitation & none \\
\hline & obs. time bin size & $1 \mathrm{hr}$ \\
\hline Met eorology Option Editor & save met eorology fields & no \\
\hline & t errain/ land cover file & no \\
\hline Surface Observa tions File & $\begin{array}{c}\text { file name } \\
\end{array}$ & mmvS.sfc \\
\hline & $\begin{array}{r}\text { eleva tion } \\
\end{array}$ & $10 \mathrm{~m}$ \\
\hline & zi (boundary layer height) & $100 \mathrm{~m}$ \\
\hline & $\mathrm{z}$ (altit ude for wind measurement) & $10 \mathrm{~m}$ \\
\hline & wind direction ( from) & $90 \mathrm{deg}$ (eas $\mathrm{t}$ ) \\
\hline & $\begin{array}{c}\text { wind speed } \\
\end{array}$ & $5 \mathrm{~m} / \mathrm{s}$ \\
\hline & MOL (Monin-Obukhov Length) & $25 \mathrm{~m}$ \\
\hline Options Edit or & puff split grid level & 2 \\
\hline & surface resolution & default \\
\hline & puff grid resolution & 0 \\
\hline & boundary layer pts & 11 \\
\hline & stable at $\mathrm{m}$. t urbulence & $1 \mathrm{e}-2 \mathrm{~m}^{\wedge} 2 / \mathrm{s}^{\wedge} 2$ \\
\hline & st able atm. scale & $10 \mathrm{~m}$ \\
\hline & stable dissipation & $4 \mathrm{e}-4 \mathrm{~m}^{\wedge} 2 / \mathrm{s}^{\wedge} 3$ \\
\hline & calm cond. turbulence & $0.25 \mathrm{~m}^{\wedge} 2 / \mathrm{s}^{\wedge} 2$ \\
\hline & calm cond. scale & $1000 \mathrm{~m}$ \\
\hline & surface dosage height & 0 \\
\hline & minimum puff mass & $1 e-20$ \\
\hline & conditional averaging time & $1 \mathrm{hr}$ \\
\hline & lumped boundary layer & no \\
\hline
\end{tabular}




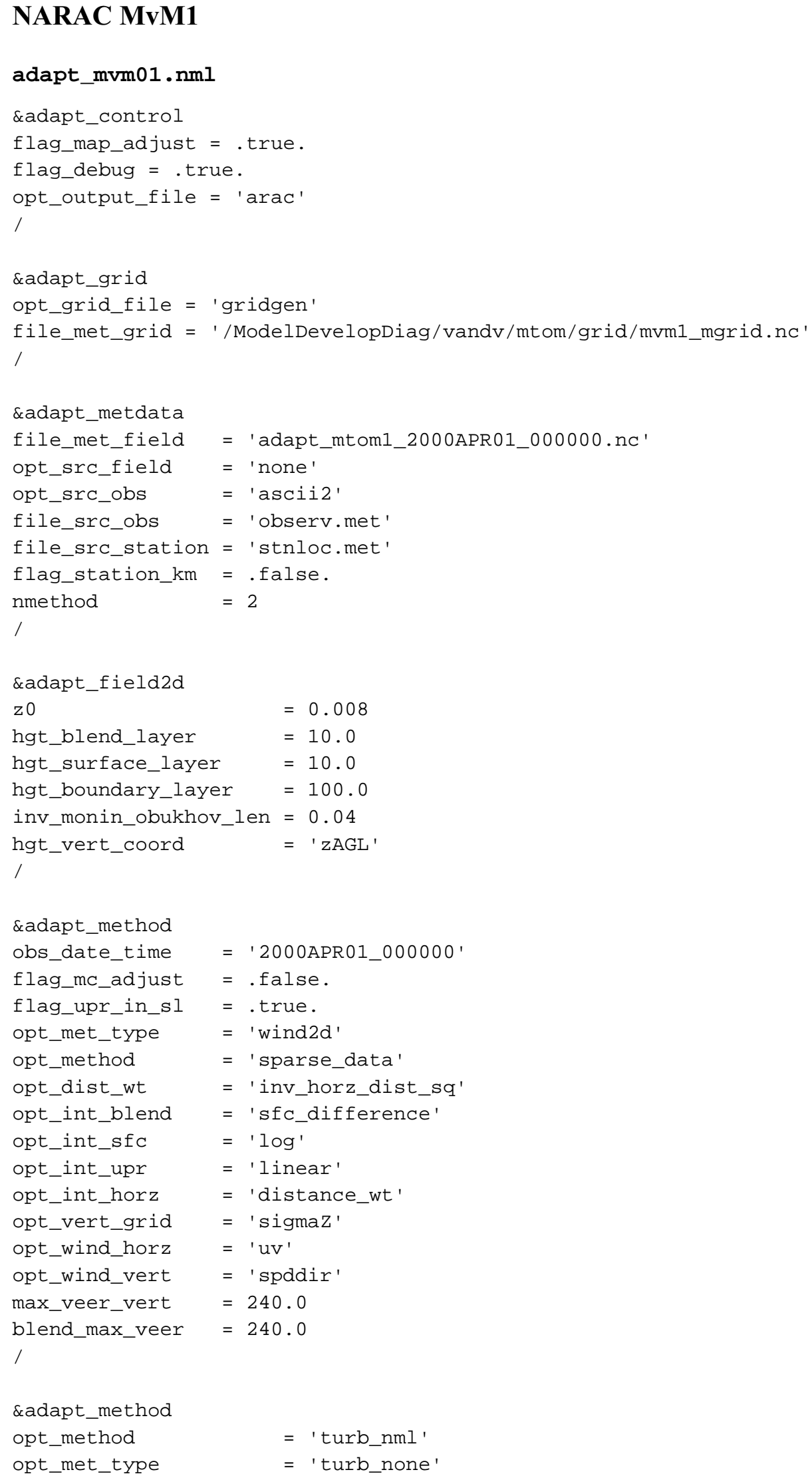




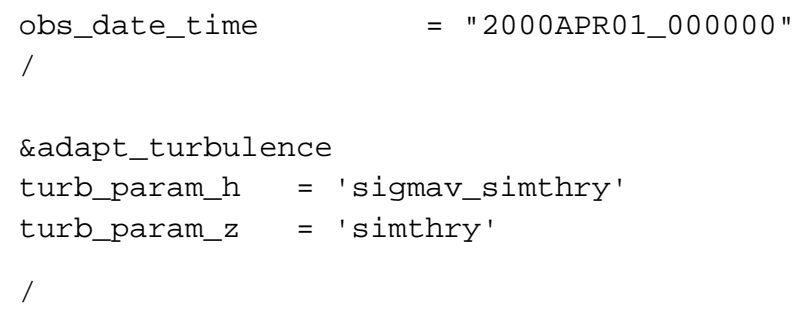

NARAC MvM1

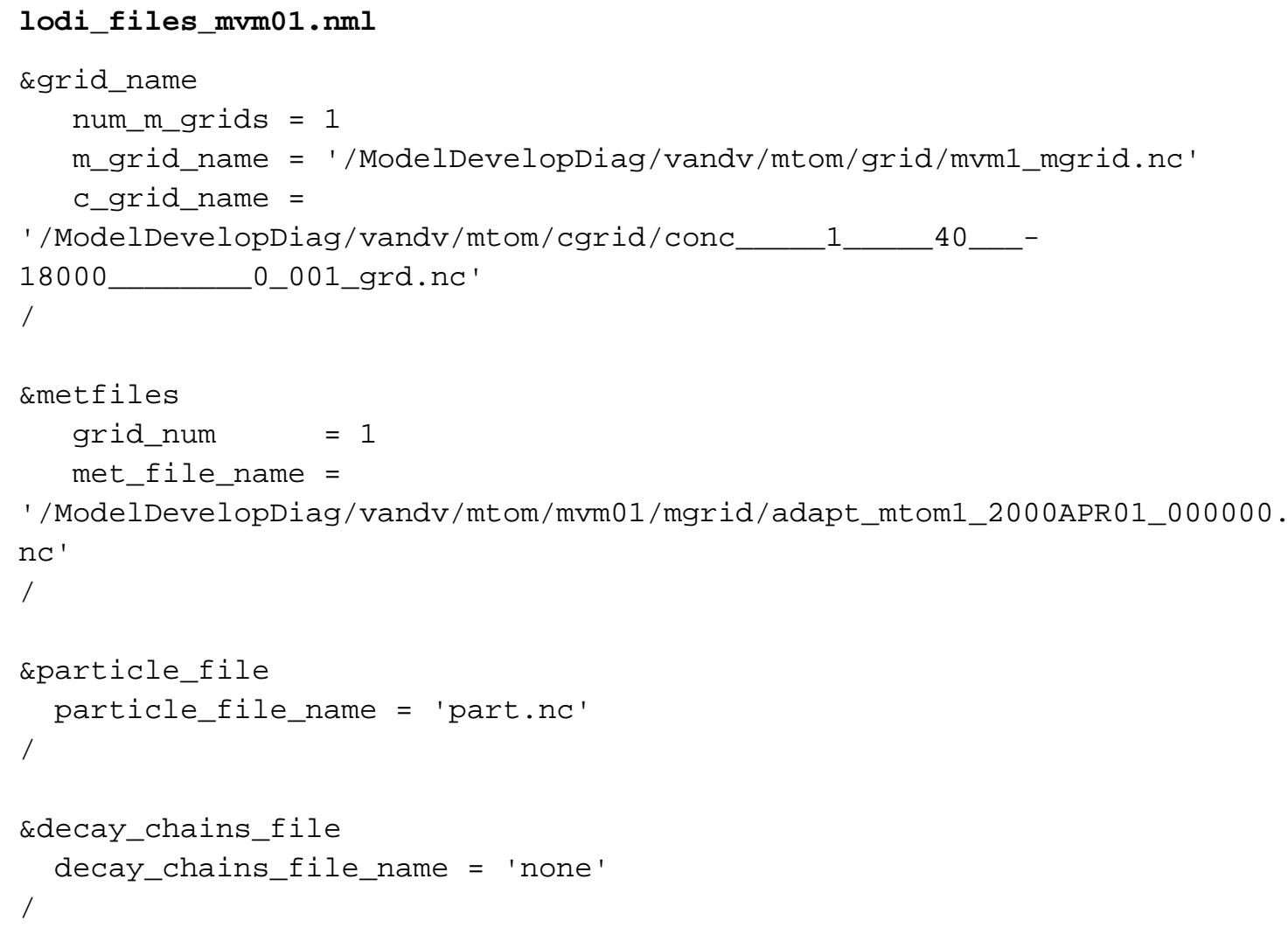

NARAC MvM1

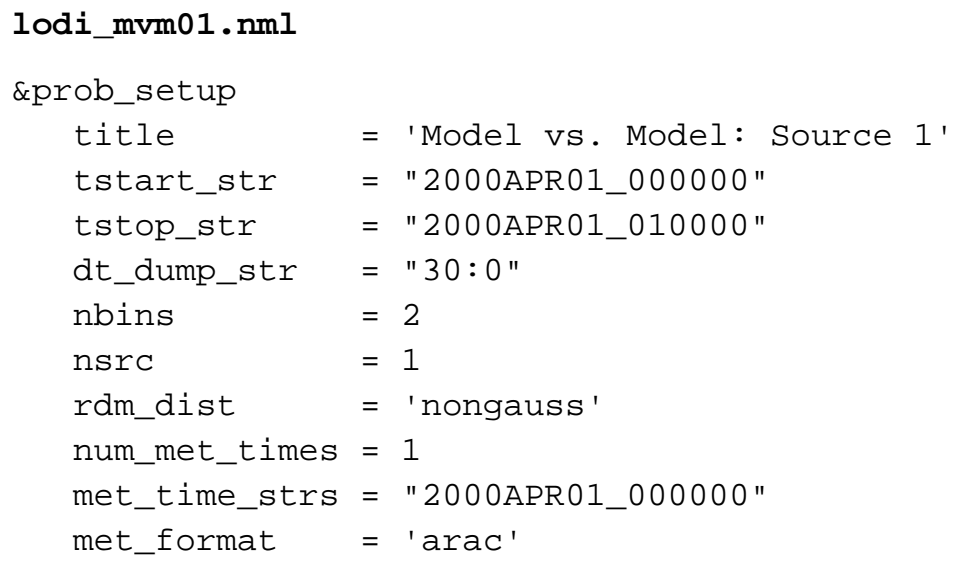




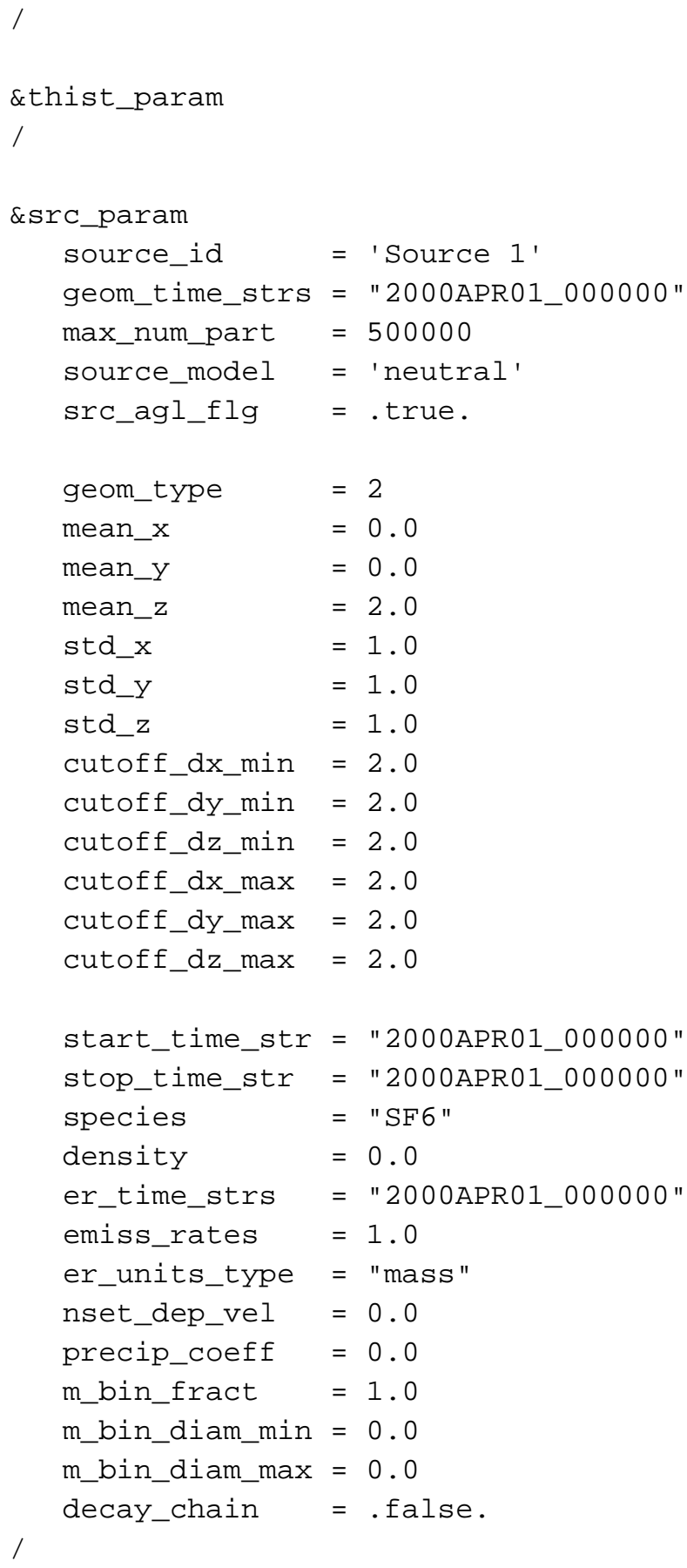

\section{NARAC MvM1}

lodi_mvm01.nml (continued)

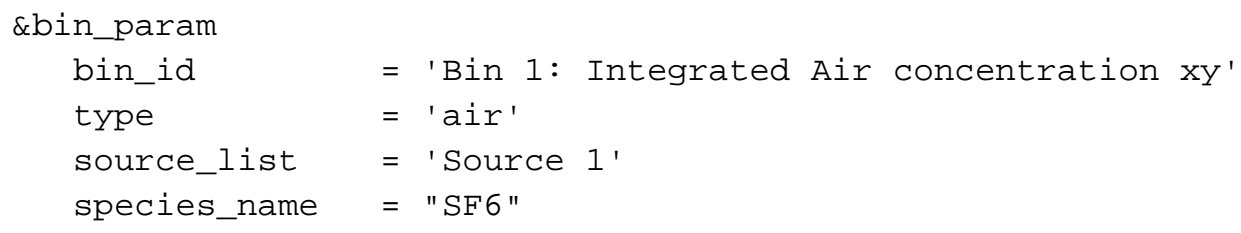




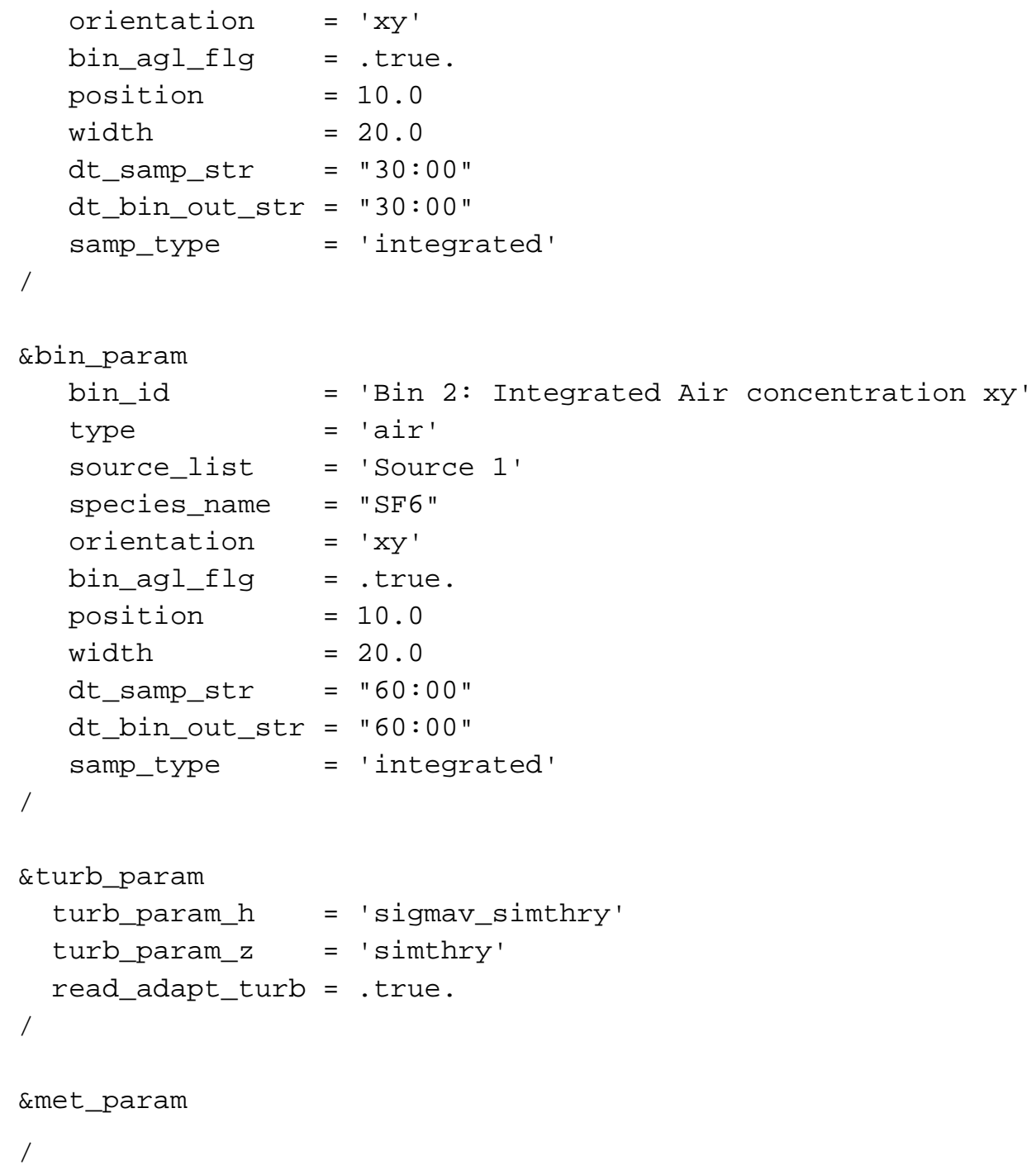

NARAC MvM1

stnloc_mvm01.met

SFC

$\begin{array}{lllll}\text { 'MtoM1' } & 0.0 & 0.0 & 10.0\end{array}$

UPR

'MtoM1' $0.0 \quad 0.0$

\section{NARAC MvM1}

observ_mvm01.met

$\begin{array}{lccc}\text { 'MtOM1' } & 0.008 & 90 & 0.0008 \\ \text { METDATASET } & \text { '2000APR01_000000' } \\ \text { UPR } & \\ \text { 'MtoM1' } & 0.5 & 90 & 2.3467\end{array}$




\begin{tabular}{|c|c|c|c|}
\hline 'MtoM1 ' & 1 & 90 & 2.7835 \\
\hline 'MtoM1 ' & 1.5 & 90 & 3.0606 \\
\hline 'Mtom1 ' & 2 & 90 & 3.2724 \\
\hline 'MtoM1 ' & 2.5 & 90 & 3.4484 \\
\hline 'MtoM1 ' & 3 & 90 & 3.6017 \\
\hline 'MtoM1 ' & 3.5 & 90 & 3.7394 \\
\hline 'MtoM1 ' & 4 & 90 & 3.8657 \\
\hline 'Mtom1' & 4.5 & 90 & 3.9832 \\
\hline 'MtoM1 ' & 5 & 90 & 4.0938 \\
\hline 'Mtom1 ' & 5.5 & 90 & 4.1988 \\
\hline 'MtoM1 ' & 6 & 90 & 4.2993 \\
\hline 'MtoM1 ' & 6.5 & 90 & 4.3959 \\
\hline 'MtoM1 ' & 7 & 90 & 4.4891 \\
\hline 'Mtom1 ' & 7.5 & 90 & 4.5796 \\
\hline 'Mtom1 ' & 8 & 90 & 4.6675 \\
\hline 'MtoM1 ' & 8.5 & 90 & 4.7533 \\
\hline 'Mtom1 ' & 9 & 90 & 4.8372 \\
\hline 'MtoM1 ' & 9.5 & 90 & 4.9194 \\
\hline 'MtoM1 ' & 10 & 90 & 5 \\
\hline 'MtoM1 ' & 10.5 & 90 & 5.0792 \\
\hline ' Mtom1' & 11 & 90 & 5.1572 \\
\hline 'Mtom1' & 11.5 & 90 & 5.234 \\
\hline 'MtoM1 ' & 12 & 90 & 5.3098 \\
\hline 'MtoM1 ' & 12.5 & 90 & 5.3846 \\
\hline 'MtoM1 ' & 13 & 90 & 5.4577 \\
\hline 'MtoM1' & 13.5 & 90 & 5.5288 \\
\hline 'MtoM1 ' & 14 & 90 & 5.598 \\
\hline 'MtoM1 ' & 14.5 & 90 & 5.6656 \\
\hline 'Mtom1 ' & 15 & 90 & 5.7318 \\
\hline 'Mtom1 ' & 15.5 & 90 & 5.7967 \\
\hline 'Mtom1 ' & 16 & 90 & 5.8605 \\
\hline 'MtoM1 ' & 16.5 & 90 & 5.9234 \\
\hline 'MtoM1' & 17 & 90 & 5.9852 \\
\hline 'MtoM1' & 17.5 & 90 & 6.0462 \\
\hline 'MtoM1' & 18 & 90 & 6.1063 \\
\hline 'Mtom1' & 18.5 & 90 & 6.1657 \\
\hline 'MtoM1' & 19 & 90 & 6.2243 \\
\hline 'MtoM1' & 19.5 & 90 & 6.2822 \\
\hline 'MtoM1' & 20 & 90 & 6.3394 \\
\hline ' Mtom1' & 20.5 & 90 & 6.396 \\
\hline 'Mtom1' & 21 & 90 & 6.4519 \\
\hline 'Mtom1' & 21.5 & 90 & 6.5071 \\
\hline 'Mtom1' & 22 & 90 & 6.5618 \\
\hline 'MtoM1 ' & 22.5 & 90 & 6.6159 \\
\hline 'Mtom1 ' & 23 & 90 & 6.6694 \\
\hline 'Mtom1 ' & 23.5 & 90 & 6.7223 \\
\hline 'Mt oM1 ' & 24 & 90 & 6.7747 \\
\hline 'MtoM1 ' & 24.5 & 90 & 6.8266 \\
\hline 'Mtom1 ' & 25 & 90 & 6.8779 \\
\hline
\end{tabular}




\begin{tabular}{|c|c|c|c|}
\hline 'MtoM1 ' & 25.5 & 90 & 6.9287 \\
\hline 'MtoM1 ' & 26 & 90 & 6.979 \\
\hline 'MtoM1 ' & 26.5 & 90 & 7.0287 \\
\hline 'MtoM1 ' & 27 & 90 & 7.078 \\
\hline 'MtoM1 ' & 27.5 & 90 & 7.1268 \\
\hline 'MtoM1 ' & 28 & 90 & 7.1751 \\
\hline 'MtoM1 ' & 28.5 & 90 & 7.223 \\
\hline 'MtoM1 ' & 29 & 90 & 7.2704 \\
\hline 'MtoM1 ' & 29.5 & 90 & 7.3173 \\
\hline 'MtoM1 ' & 30 & 90 & 7.3638 \\
\hline 'MtoM1 ' & 30.5 & 90 & 7.4098 \\
\hline 'MtoM1 ' & 31 & 90 & 7.4554 \\
\hline 'MtoM1 ' & 31.5 & 90 & 7.5006 \\
\hline 'Mtom1 ' & 32 & 90 & 7.5454 \\
\hline 'MtoM1' & 32.5 & 90 & 7.5898 \\
\hline 'MtoM1' & 33 & 90 & 7.6337 \\
\hline 'MtoM1' & 33.5 & 90 & 7.6773 \\
\hline 'MtoM1' & 34 & 90 & 7.7204 \\
\hline 'MtoM1 ' & 34.5 & 90 & 7.7632 \\
\hline 'MtoM1 ' & 35 & 90 & 7.8056 \\
\hline 'MtoM1 ' & 35.5 & 90 & 7.8476 \\
\hline 'MtoM1 ' & 36 & 90 & 7.8893 \\
\hline 'MtoM1 ' & 36.5 & 90 & 7.9306 \\
\hline 'MtoM1 ' & 37 & 90 & 7.9715 \\
\hline 'MtoM1 ' & 37.5 & 90 & 8.0121 \\
\hline 'MtoM1 ' & 38 & 90 & 8.0523 \\
\hline 'MtoM1 ' & 38.5 & 90 & 8.0922 \\
\hline 'MtoM1 ' & 39 & 90 & 8.1317 \\
\hline 'MtoM1 ' & 39.5 & 90 & 8.171 \\
\hline 'MtoM1' & 40 & 90 & 8.2099 \\
\hline 'MtoM1' & 40.5 & 90 & 8.2484 \\
\hline 'MtoM1 ' & 41 & 90 & 8.2867 \\
\hline 'MtoM1 ' & 41.5 & 90 & 8.3246 \\
\hline 'MtoM1 ' & 42 & 90 & 8.3623 \\
\hline 'MtoM1 ' & 42.5 & 90 & 8.3996 \\
\hline 'MtoM1' & 43 & 90 & 8.4366 \\
\hline 'MtoM1' & 43.5 & 90 & 8.4734 \\
\hline ' MtoM1 ' & 44 & 90 & 8.5098 \\
\hline ' MtoM1 ' & 44.5 & 90 & 8.546 \\
\hline ' MtoM1 ' & 45 & 90 & 8.5819 \\
\hline ' MtoM1 ' & 45.5 & 90 & 8.6175 \\
\hline 'MtoM1 ' & 46 & 90 & 8.6528 \\
\hline 'MtoM1' & 46.5 & 90 & 8.6879 \\
\hline 'MtoM1 ' & 47 & 90 & 8.7227 \\
\hline 'MtoM1 ' & 47.5 & 90 & 8.7572 \\
\hline 'MtoM1 ' & 48 & 90 & 8.7915 \\
\hline
\end{tabular}




$\begin{array}{llll}\text { 'MtoM1' } & 48.5 & 90 & 8.8255 \\ \text { 'MtoM1' } & 49 & 90 & 8.8593 \\ \text { 'MtoM1' } & 49.5 & 90 & 8.8928 \\ \text { 'MtoM1' } & 50 & 90 & 8.9261\end{array}$




\section{HPAC MvM2}

\begin{tabular}{|c|c|c|}
\hline mvm2 & HPAC 3.2 parame ter & HPAC 3.2 value \\
\hline HPAC SCREEN & agent & SF6 \\
\hline \multirow[t]{12}{*}{ New Project Setup } & project file name & mvm2.prj \\
\hline & coordina tes & cartesian \\
\hline & local origin $\mathrm{x}$ & $0 \mathrm{~km}$ \\
\hline & local origin $y$ & $0 \mathrm{~km}$ \\
\hline & local origin lat i tude & $45 \operatorname{deg} N$ \\
\hline & local origin longi tude & $0 \mathrm{deg}$ \\
\hline & reference times & UTC \\
\hline & local time of $00: 00 z$ & 0 \\
\hline & mode & st andard \\
\hline & dynamics & dense gas \\
\hline & static puffs & enabled \\
\hline & hazard area & off \\
\hline New Project Editor & edit mode & advanœed \\
\hline \multirow{8}{*}{ Material Editor } & type & gas \\
\hline & name & SF6 \\
\hline & material file & Sf $6 . \mathrm{mt}$ \\
\hline & units & $\mathrm{kg}$ \\
\hline & bin boundaries & NA \\
\hline & output flags & surf. dosage, surf. depos \\
\hline & daytime decay rate & $\begin{array}{r}0 \\
\end{array}$ \\
\hline & nighttime decay ra te & 0 \\
\hline \multirow[t]{3}{*}{ Gas Parame ter Editor } & density ratio (rho/ rho_air) & 5.02917 \\
\hline & deposition velocity & 0 \\
\hline & minimum concen tra tion & 0 \\
\hline \multirow[t]{15}{*}{ Release Editor } & time & 0 \\
\hline & $\mathbf{x}$ & 0 \\
\hline & $y$ & 0 \\
\hline & height of release & $50 \mathrm{~m}$ \\
\hline & source uncert ainty & no \\
\hline & specification & simple \\
\hline & randomize location & no \\
\hline & release dura tion & instantaneous \\
\hline & release ra te & NA \\
\hline & agent mass & $1 \mathrm{~kg}$ \\
\hline & $x$ size & $1 \mathrm{~m}$ \\
\hline & y size & $1 \mathrm{~m}$ \\
\hline & z size & $1 \mathrm{~m}$ \\
\hline & momentum & 0 \\
\hline & buoyancy & 0 \\
\hline \multirow[t]{6}{*}{ Time Editor } & start day & $4 / 1 / 00$ \\
\hline & start time & 0 \\
\hline & s top day & $4 / 1 / 00$ \\
\hline & stop time & 100 \\
\hline & maximum time step & $60 \mathrm{sec}$ \\
\hline & out put interval & $15 \mathrm{~min}$ \\
\hline \multirow[t]{7}{*}{ Domain Editor } & xmin domain & $-50 \mathrm{~km}$ \\
\hline & $x \max$ domain & $1 \mathrm{~km}$ \\
\hline & ymin domain & $-5 \mathrm{~km}$ \\
\hline & ymax domain & $5 \mathrm{~km}$ \\
\hline & horizontal resolution & default \\
\hline & vertical domain max height & $500 \mathrm{~m}$ \\
\hline & vertical domain resolution & $10 \mathrm{~m}$ \\
\hline Wea ther Editor & weather dat a type & surface obs. only \\
\hline & boundary layer t ype & observations \\
\hline & large scale variability & none \\
\hline & large scale variability length scale & NA \\
\hline & large scale variability variance & NA \\
\hline & $\begin{array}{c}\text { surf ace roughness } \\
\end{array}$ & $0.008 \mathrm{~m}$ \\
\hline & precipita tion & none \\
\hline & obs. time bin size & $1 \mathrm{hr}$ \\
\hline Meteorology Option Edi tor & save me te orology fields & no \\
\hline & terrain/land cover file & no \\
\hline Surface Observations File & file name & mmvS.sc \\
\hline & $\begin{array}{c}\text { elevation } \\
\end{array}$ & $10 \mathrm{~m}$ \\
\hline & zi (boundary layer height) & $100 \mathrm{~m}$ \\
\hline & $z$ (al ti tude for wind measur ement) & $10 \mathrm{~m}$ \\
\hline & wind dire ction ( from) & 90 deg (east) \\
\hline & $\begin{array}{c}\text { wind speed } \\
\end{array}$ & $5 \mathrm{~m} / \mathrm{s}$ \\
\hline & MOL (Monin-Obukhov Leng th) & $25 \mathrm{~m}$ \\
\hline Op tions Editor & puff split grid level & 2 \\
\hline & surface resolution & default \\
\hline & puf f grid resolution & 0 \\
\hline & boundary layer pts & 11 \\
\hline & stable atm. turbulence & $1 \mathrm{e}-2 \mathrm{~m}^{\wedge} 2 / \mathrm{s}^{\wedge} 2$ \\
\hline & stable a tm. scale & $10 \mathrm{~m}$ \\
\hline & stable dissipa tion & $4 \mathrm{e}-4 \mathrm{~m}^{\wedge} 2 / \mathrm{s}^{\wedge} 3$ \\
\hline & calm cond. turbulence & $0.25 \mathrm{~m}^{\wedge} 2 / \mathrm{s}^{\wedge} 2$ \\
\hline & calm cond. scale & $1000 \mathrm{~m}$ \\
\hline & surface dosage height & 0 \\
\hline & minimum puf $\mathrm{f}$ mass & $1 \mathrm{e}-20$ \\
\hline & conditional averaging time & $1 \mathrm{hr}$ \\
\hline & lumped boundary layer & no \\
\hline
\end{tabular}




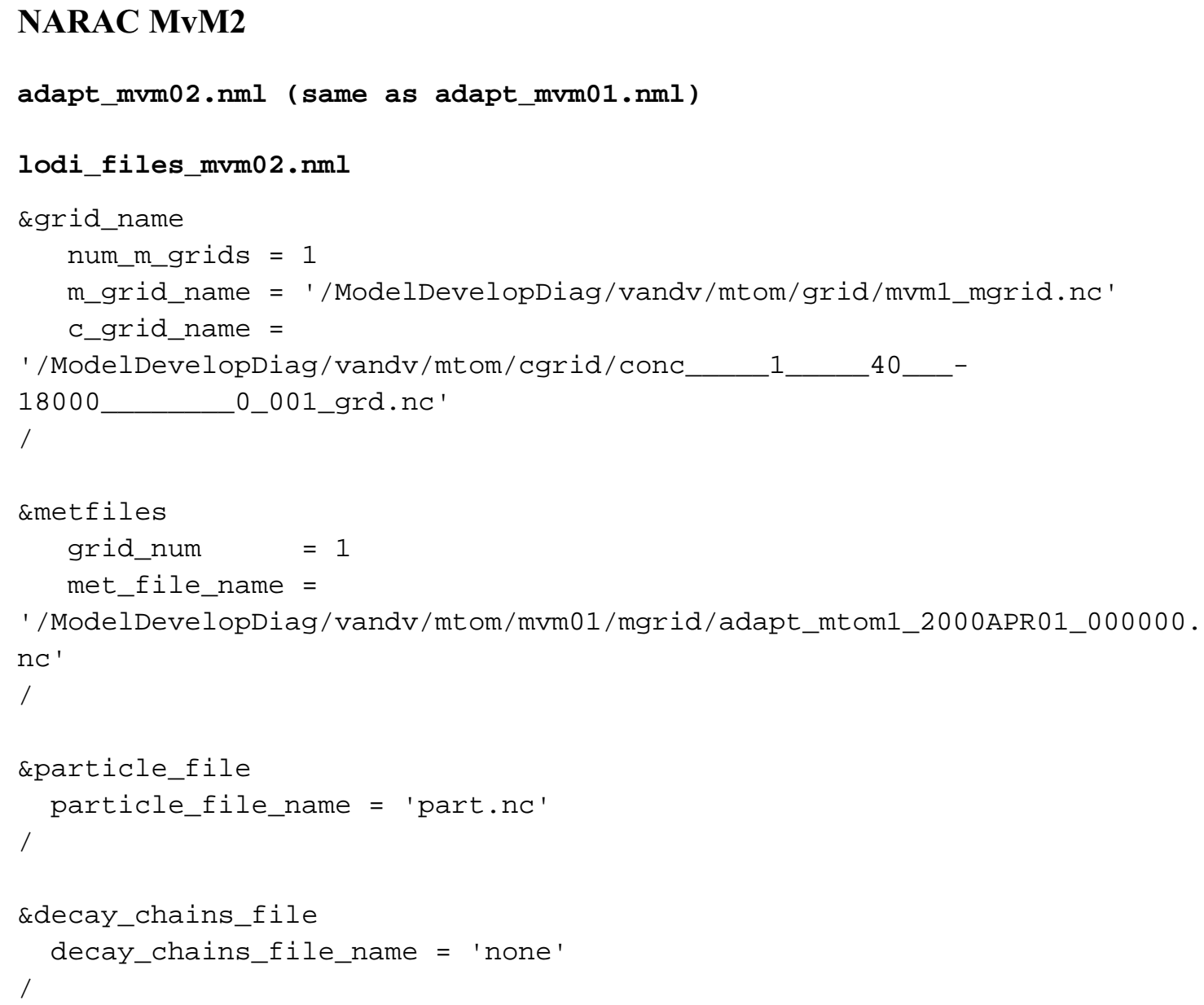

\section{NARAC MvM2}

lodi_mvm02.nml

\&prob_setup 


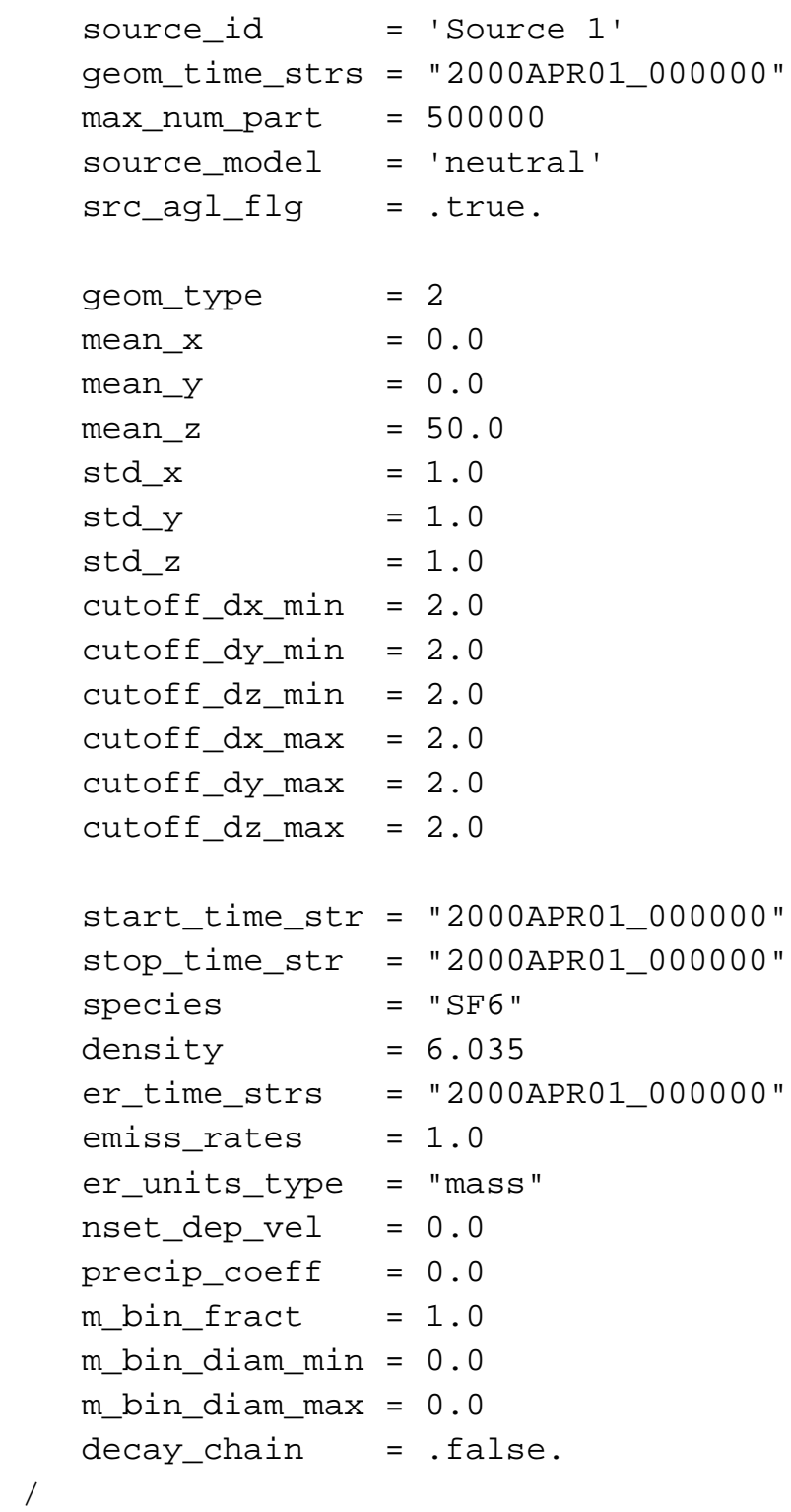

\section{NARAC MvM2}

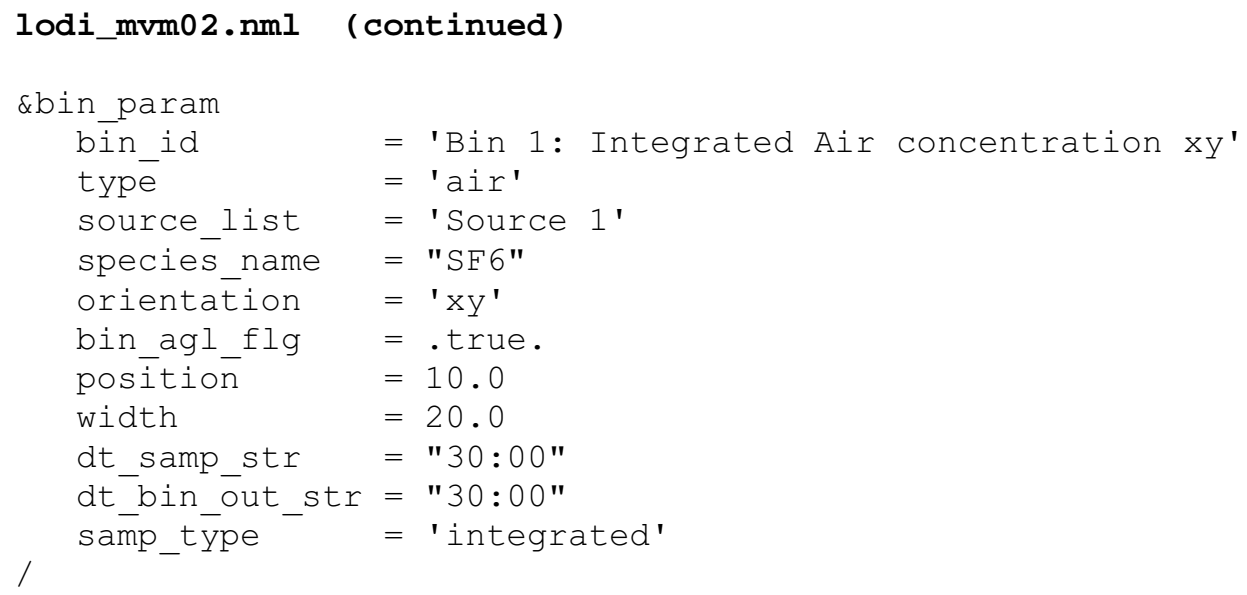




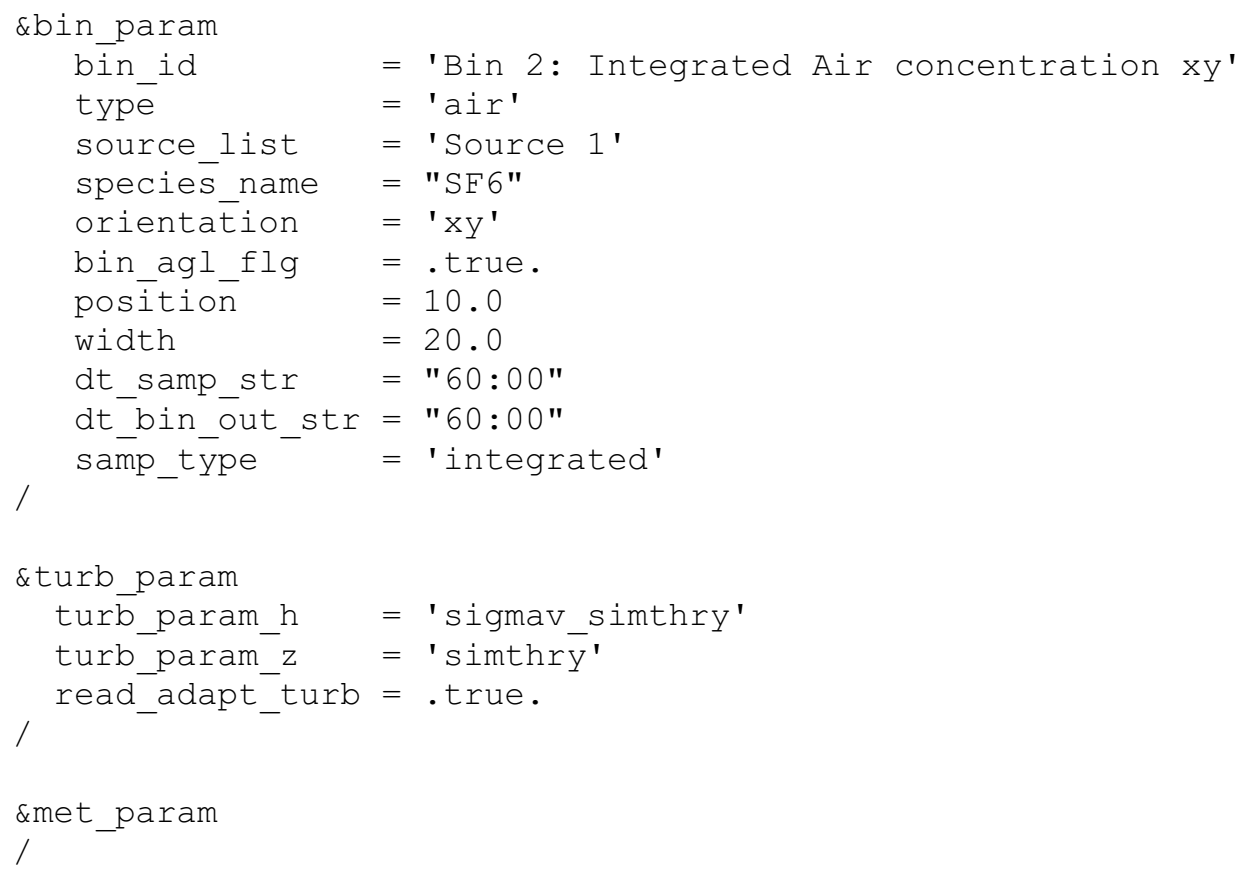

\section{NARAC MvM2}

stnloc_mvm02.met (same as stnloc_mvm01.met)

observ_mvm02.met (same as observ_mvm01.met) 


\section{HPAC MvM3}

\begin{tabular}{|c|c|c|}
\hline mvm3 & HPAC 3.2 parame ter & HPAC 3.2 value \\
\hline HPAC SCREEN & agent & SF6 \\
\hline \multirow[t]{12}{*}{ New Project Setup } & project file name & mvm3.prj \\
\hline & coordina tes & cartesian \\
\hline & local origin $\mathrm{x}$ & $0 \mathrm{~km}$ \\
\hline & local origin $y$ & $0 \mathrm{~km}$ \\
\hline & local origin lat i tude & $45 \operatorname{deg} N$ \\
\hline & local origin longi tude & $0 \mathrm{deg}$ \\
\hline & reference times & UTC \\
\hline & local time of $00: 00 z$ & 0 \\
\hline & mode & st andard \\
\hline & dynamics & dense gas \\
\hline & static puffs & enabled \\
\hline & hazard area & off \\
\hline New Project Editor & edit mode & advanœed \\
\hline \multirow{8}{*}{ Material Editor } & type & gas \\
\hline & name & SF6 \\
\hline & material file & Sf $6 . \mathrm{mt}$ \\
\hline & units & $\mathrm{kg}$ \\
\hline & bin boundaries & NA \\
\hline & output flags & surf. dosage, surf. depos \\
\hline & daytime decay rate & $\begin{array}{r}0 \\
\end{array}$ \\
\hline & nighttime decay ra te & 0 \\
\hline \multirow[t]{3}{*}{ Gas Parame ter Editor } & density ratio (rho/ rho_air) & 5.02917 \\
\hline & deposition velocity & 0 \\
\hline & minimum concen tra tion & 0 \\
\hline \multirow[t]{15}{*}{ Release Editor } & time & 0 \\
\hline & $\mathbf{x}$ & 0 \\
\hline & $y$ & 0 \\
\hline & height of release & $80 \mathrm{~m}$ \\
\hline & source uncert ainty & no \\
\hline & specification & simple \\
\hline & randomize location & no \\
\hline & release dura tion & instantaneous \\
\hline & release ra te & NA \\
\hline & agent mass & $1 \mathrm{~kg}$ \\
\hline & $x$ size & $1 \mathrm{~m}$ \\
\hline & y size & $1 \mathrm{~m}$ \\
\hline & z size & $1 \mathrm{~m}$ \\
\hline & momentum & 0 \\
\hline & buoyancy & 0 \\
\hline \multirow[t]{6}{*}{ Time Editor } & start day & $4 / 1 / 00$ \\
\hline & start time & 0 \\
\hline & s top day & $4 / 1 / 00$ \\
\hline & stop time & 100 \\
\hline & maximum time step & $60 \mathrm{sec}$ \\
\hline & out put interval & $15 \mathrm{~min}$ \\
\hline \multirow[t]{7}{*}{ Domain Editor } & xmin domain & $-50 \mathrm{~km}$ \\
\hline & $x \max$ domain & $1 \mathrm{~km}$ \\
\hline & ymin domain & $-5 \mathrm{~km}$ \\
\hline & ymax domain & $5 \mathrm{~km}$ \\
\hline & horizontal resolution & default \\
\hline & vertical domain max height & $500 \mathrm{~m}$ \\
\hline & vertical domain resolution & $10 \mathrm{~m}$ \\
\hline Wea ther Editor & weather dat a type & surface obs. only \\
\hline & boundary layer t ype & observations \\
\hline & large scale variability & none \\
\hline & large scale variability length scale & NA \\
\hline & large scale variability variance & NA \\
\hline & $\begin{array}{c}\text { surf ace roughness } \\
\end{array}$ & $0.008 \mathrm{~m}$ \\
\hline & precipita tion & none \\
\hline & obs. time bin size & $1 \mathrm{hr}$ \\
\hline Meteorology Option Edi tor & save me te orology fields & no \\
\hline & terrain/land cover file & no \\
\hline Surface Observations File & file name & mvmS.sc \\
\hline & $\begin{array}{c}\text { elevation } \\
\end{array}$ & $10 \mathrm{~m}$ \\
\hline & zi (boundary layer height) & $100 \mathrm{~m}$ \\
\hline & $z$ (al ti tude for wind measur ement) & $10 \mathrm{~m}$ \\
\hline & wind dire ction ( from) & 90 deg (east) \\
\hline & $\begin{array}{c}\text { wind speed } \\
\end{array}$ & $5 \mathrm{~m} / \mathrm{s}$ \\
\hline & MOL (Monin-Obukhov Leng th) & $25 \mathrm{~m}$ \\
\hline Op tions Editor & puff split grid level & 2 \\
\hline & surface resolution & default \\
\hline & puf f grid resolution & 0 \\
\hline & boundary layer pts & 11 \\
\hline & stable atm. turbulence & $1 \mathrm{e}-2 \mathrm{~m}^{\wedge} 2 / \mathrm{s}^{\wedge} 2$ \\
\hline & stable a tm. scale & $10 \mathrm{~m}$ \\
\hline & stable dissipa tion & $4 \mathrm{e}-4 \mathrm{~m}^{\wedge} 2 / \mathrm{s}^{\wedge} 3$ \\
\hline & calm cond. turbulence & $0.25 \mathrm{~m}^{\wedge} 2 / \mathrm{s}^{\wedge} 2$ \\
\hline & calm cond. scale & $1000 \mathrm{~m}$ \\
\hline & surface dosage height & 0 \\
\hline & minimum puf $\mathrm{f}$ mass & $1 \mathrm{e}-20$ \\
\hline & conditional averaging time & $1 \mathrm{hr}$ \\
\hline & lumped boundary layer & no \\
\hline
\end{tabular}




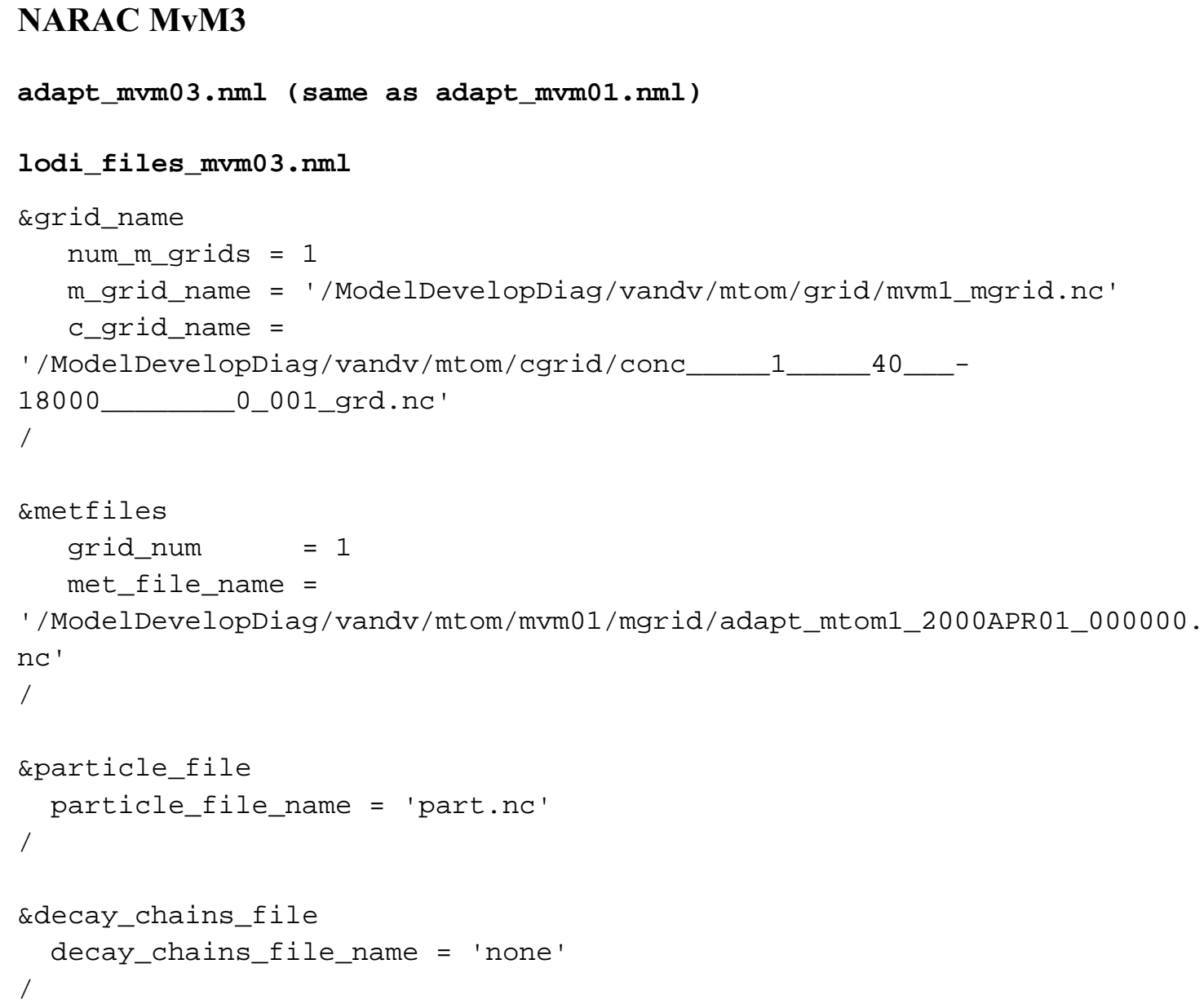




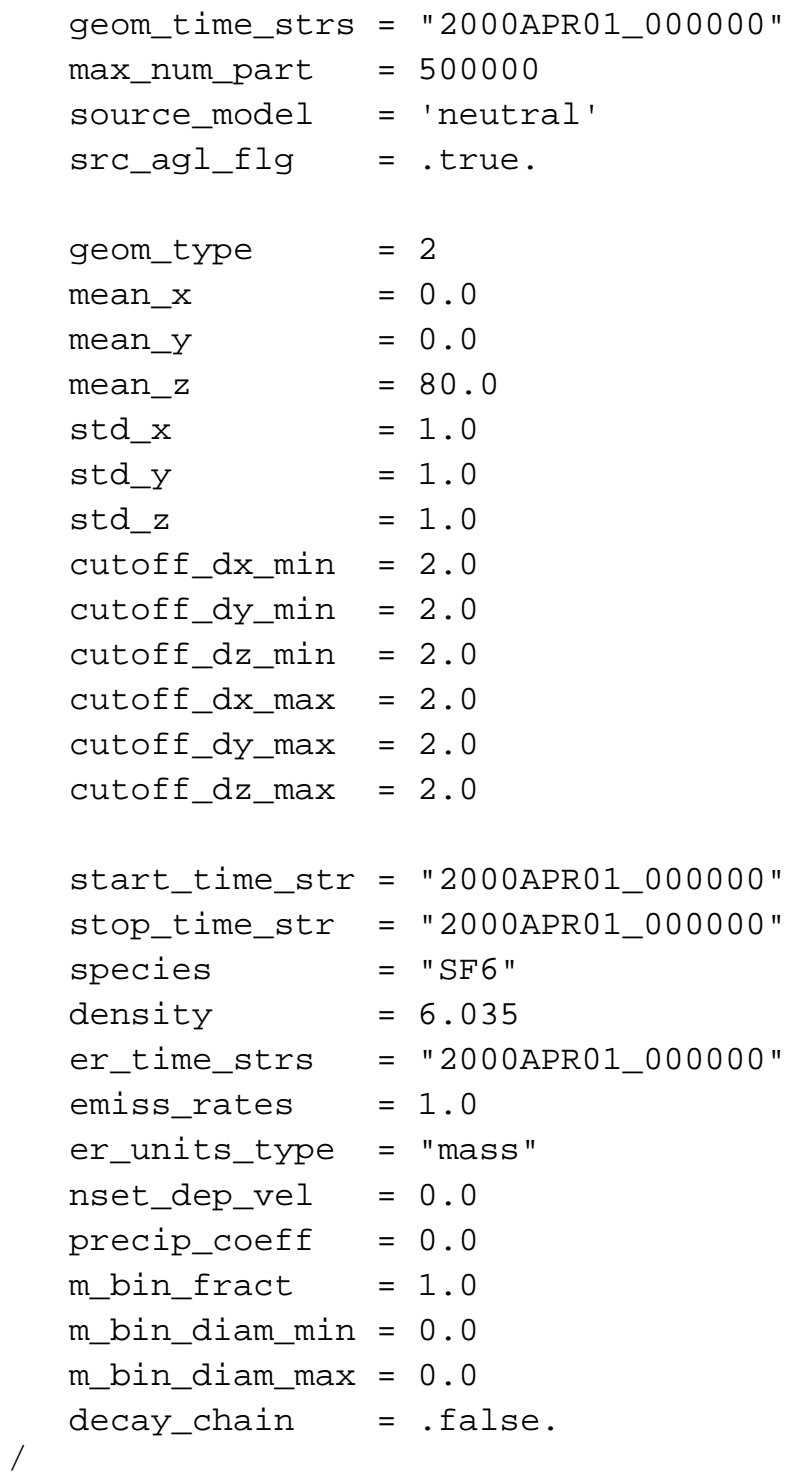

\section{NARAC MvM3}

\section{lodi_mvm03.nml (continued)}

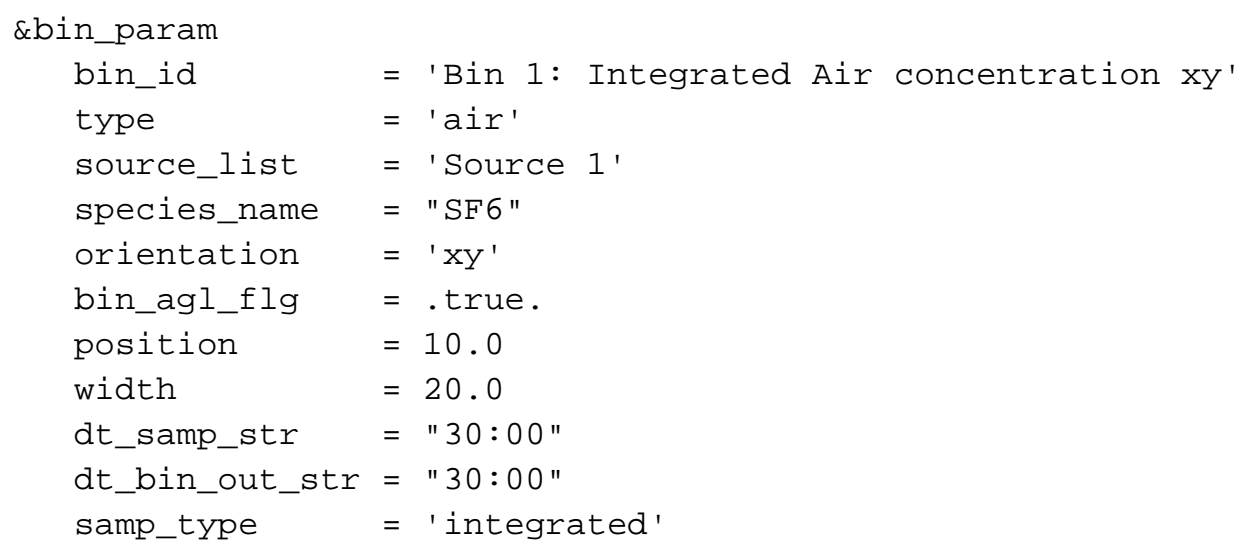




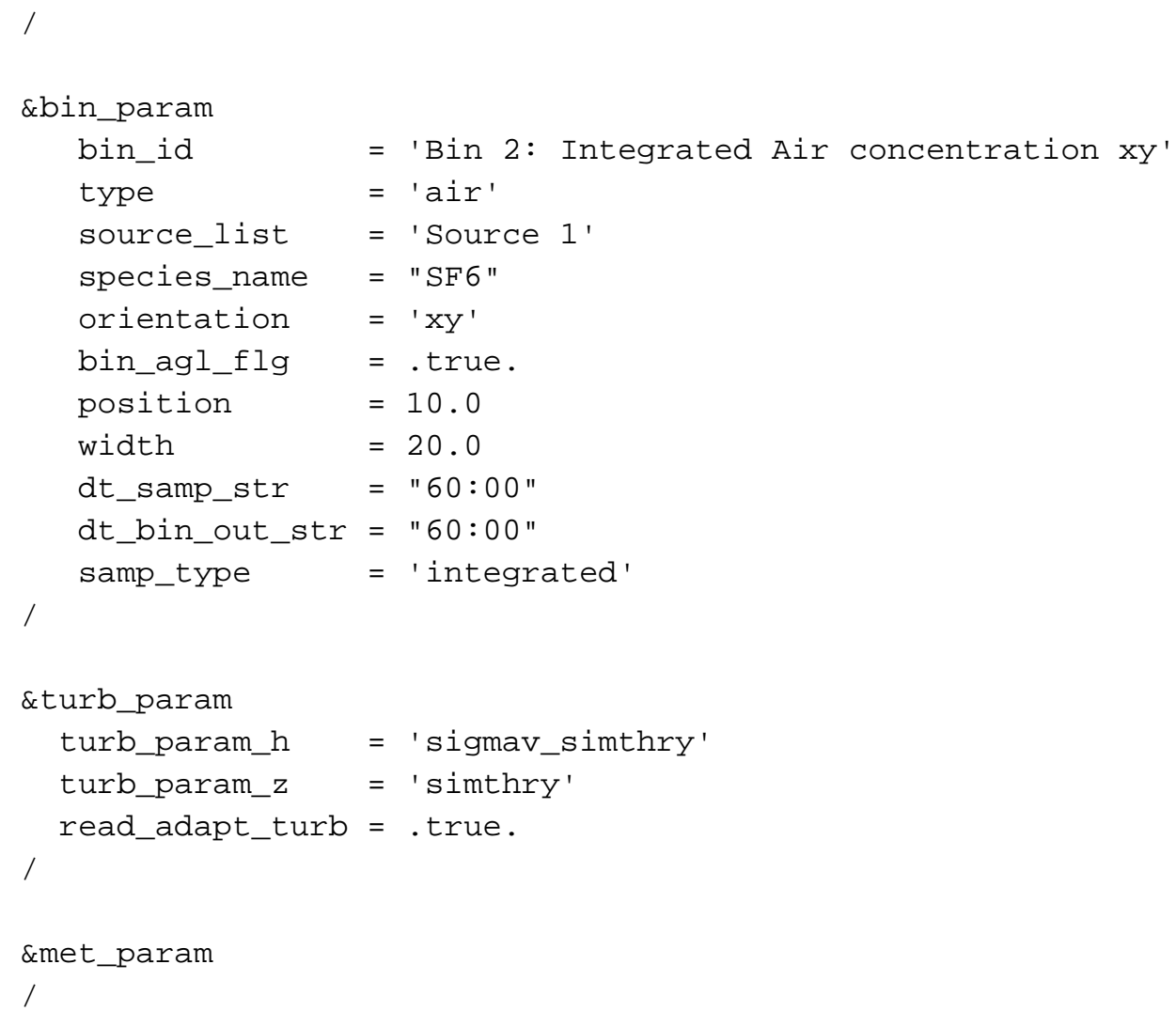

\section{NARAC MvM3}

stnloc_mvm03.met (same as stnloc_mvm01.met)

observ_mvm03.met (same as observ_mvm01.met) 


\section{HPAC MvM4}

\begin{tabular}{|c|c|c|}
\hline mvm4 & HPAC 3.2 parame ter & HPAC 3.2 value \\
\hline HPAC SCREEN & agent & $\mathrm{SF6}$ \\
\hline \multirow[t]{12}{*}{ New Project Setup } & project file name & mvm4.prj \\
\hline & coordina tes & cartesian \\
\hline & local origin $\mathrm{x}$ & $0 \mathrm{~km}$ \\
\hline & local origin $y$ & $0 \mathrm{~km}$ \\
\hline & local origin lat itude & $45 \operatorname{deg} N$ \\
\hline & local origin longi tude & $0 \mathrm{deg}$ \\
\hline & reference times & UTC \\
\hline & local time of $00: 00 z$ & 0 \\
\hline & mode & st andard \\
\hline & dynamics & dense gas \\
\hline & static puffs & enabled \\
\hline & hazard area & off \\
\hline New Project Editor & edit mode & advanœd \\
\hline \multirow{8}{*}{ Material Edi tor } & type & gas \\
\hline & name & SF6 \\
\hline & ma terial file & Sf $6 . \mathrm{mt}$ \\
\hline & units & $\mathrm{kg}$ \\
\hline & bin boundaries & NA \\
\hline & ou tput flags & surf. dosage, surf. depos \\
\hline & daytime decay rate & $\begin{array}{c}0 \\
\end{array}$ \\
\hline & nighttime decay rate & 0 \\
\hline \multirow[t]{3}{*}{ Gas Parame ter Editor } & density ratio (rho/ rho_air) & 5.02917 \\
\hline & deposition velocity & 0 \\
\hline & minimum concen tra tion & 0 \\
\hline \multirow[t]{15}{*}{ Release Editor } & time & 0 \\
\hline & $\mathbf{x}$ & 0 \\
\hline & $y$ & 0 \\
\hline & height of release & $2 \mathrm{~m}$ \\
\hline & source uncert ainty & no \\
\hline & specifica tion & simple \\
\hline & randomize location & no \\
\hline & release dura tion & inst antaneous \\
\hline & release ra te & NA \\
\hline & agent mass & $1 \mathrm{~kg}$ \\
\hline & $\mathrm{x}$ size & $1 \mathrm{~m}$ \\
\hline & y size & $1 \mathrm{~m}$ \\
\hline & $z$ size & $1 \mathrm{~m}$ \\
\hline & momentum & 0 \\
\hline & buoyancy & 0 \\
\hline \multirow[t]{6}{*}{ Time Editor } & start day & $4 / 1 / 00$ \\
\hline & start time & 0 \\
\hline & s top day & $4 / 1 / 00$ \\
\hline & Stop time & 100 \\
\hline & maximum time step & $60 \mathrm{sec}$ \\
\hline & out put interval & $15 \mathrm{~min}$ \\
\hline \multirow[t]{7}{*}{ Domain Editor } & xmin domain & $-50 \mathrm{~km}$ \\
\hline & xmax domain & $1 \mathrm{~km}$ \\
\hline & ymin domain & $-5 \mathrm{~km}$ \\
\hline & ymax domain & $5 \mathrm{~km}$ \\
\hline & horizon tal resolution & default \\
\hline & vertical domain max height & $500 \mathrm{~m}$ \\
\hline & vertical domain resolution & $10 \mathrm{~m}$ \\
\hline Wea ther Editor & weather dat a type & surface obs. only \\
\hline & boundary layer t ype & observations \\
\hline & $\begin{array}{l}\text { large scale variability } \\
\end{array}$ & none \\
\hline & large scale variability length scale & NA \\
\hline & large scale variability variance & NA \\
\hline & surface roughness & $0.008 \mathrm{~m}$ \\
\hline & precipita tion & none \\
\hline & obs. time bin size & $1 \mathrm{hr}$ \\
\hline Meteorology Option Edi tor & save me te orology fields & no \\
\hline & terrain/land cover file & no \\
\hline Surface Observations File & $\begin{array}{r}\text { file name } \\
\end{array}$ & mvmN.sfc \\
\hline & $\begin{array}{c}\text { elevation } \\
\end{array}$ & $10 \mathrm{~m}$ \\
\hline & zi (boundary layer height) & $500 \mathrm{~m}$ \\
\hline & $z$ (al titude for wind measurement) & $10 \mathrm{~m}$ \\
\hline & wind direction ( from) & 90 deg (east) \\
\hline & $\begin{array}{c}\text { wind speed } \\
\end{array}$ & $5 \mathrm{~m} / \mathrm{s}$ \\
\hline & MOL (Monin-Obukhov Leng th) & $-500 \mathrm{~m}$ \\
\hline Op tions Editor & puff split grid level & 2 \\
\hline & surface resolution & default \\
\hline & puf $f$ grid resolution & 0 \\
\hline & boundary layer pts & 11 \\
\hline & stable atm. turbulence & $1 e-2 m^{\wedge} 2 / s^{\wedge} 2$ \\
\hline & s table a tm. scale & $10 \mathrm{~m}$ \\
\hline & stable dissipa tion & $4 e-4 m^{\wedge} 2 / s^{\wedge} 3$ \\
\hline & calm cond. turbulence & $0.25 \mathrm{~m}^{\wedge} 2 / \mathrm{s}^{\wedge} 2$ \\
\hline & calm cond. scale & $1000 \mathrm{~m}$ \\
\hline & surface dosage height & 0 \\
\hline & minimum puf $f$ mass & $1 \mathrm{e}-20$ \\
\hline & conditional averaging time & $1 \mathrm{hr}$ \\
\hline & lumped boundary layer & no \\
\hline
\end{tabular}




\section{NARAC MvM4}

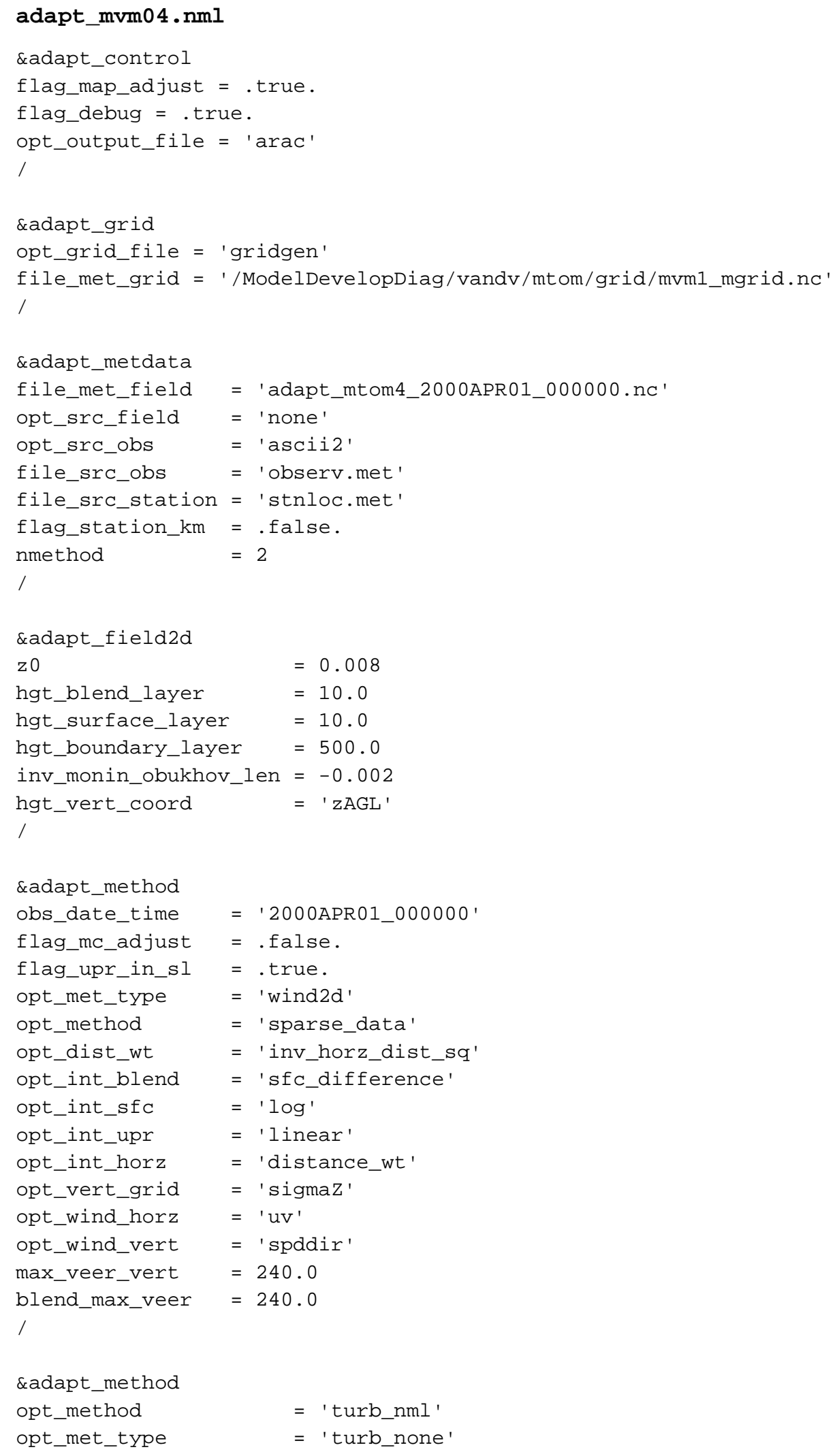




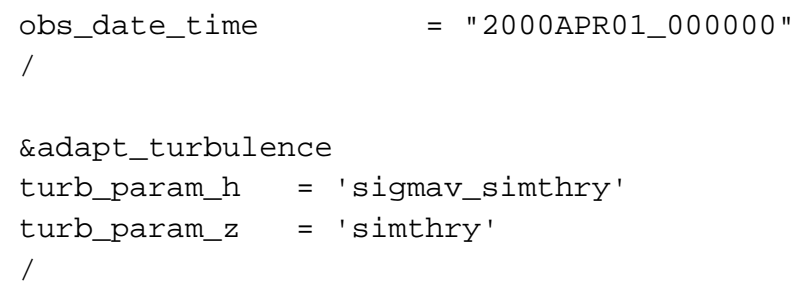

\section{NARAC MvM4}

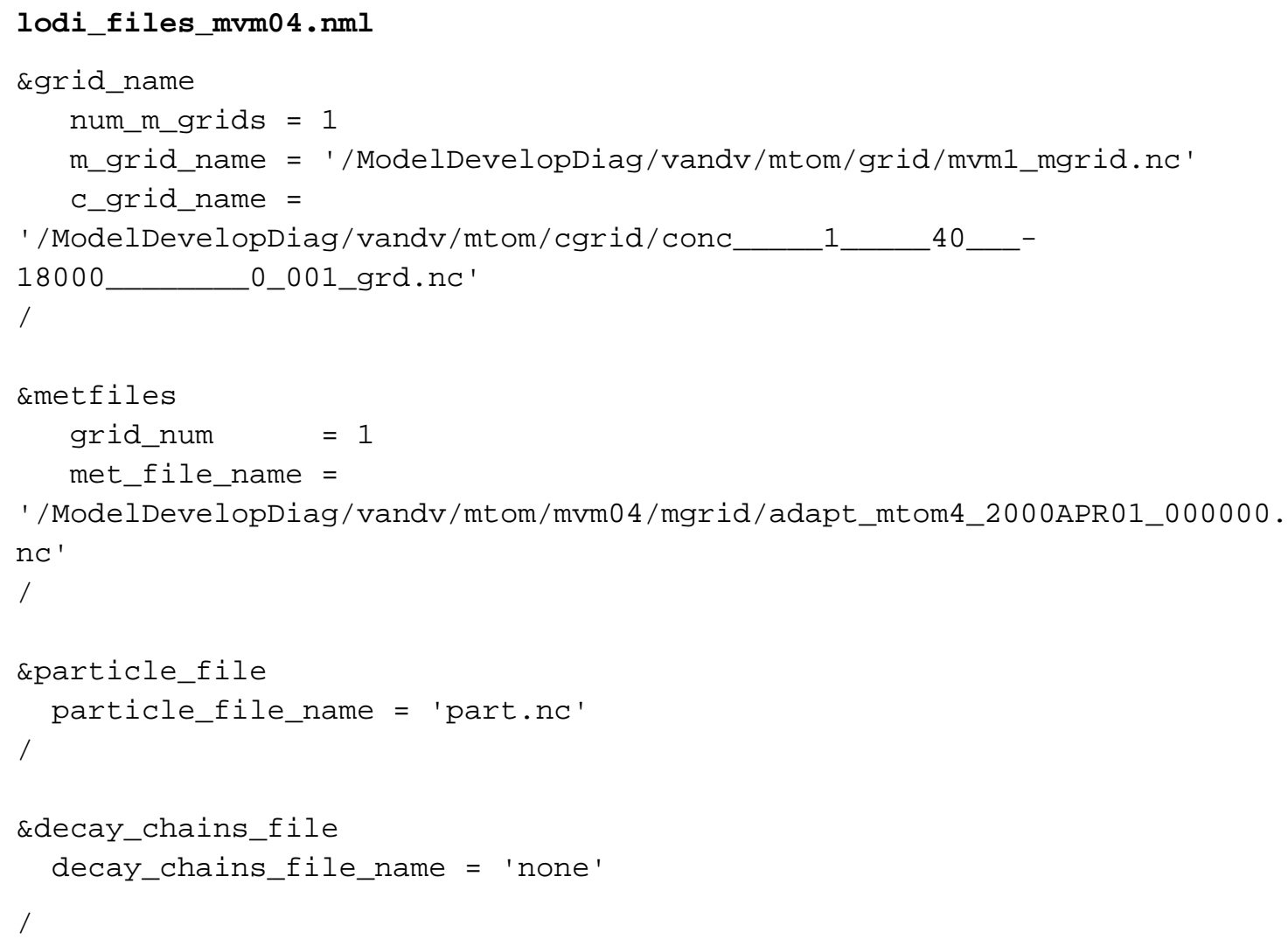

\section{NARAC MvM4}

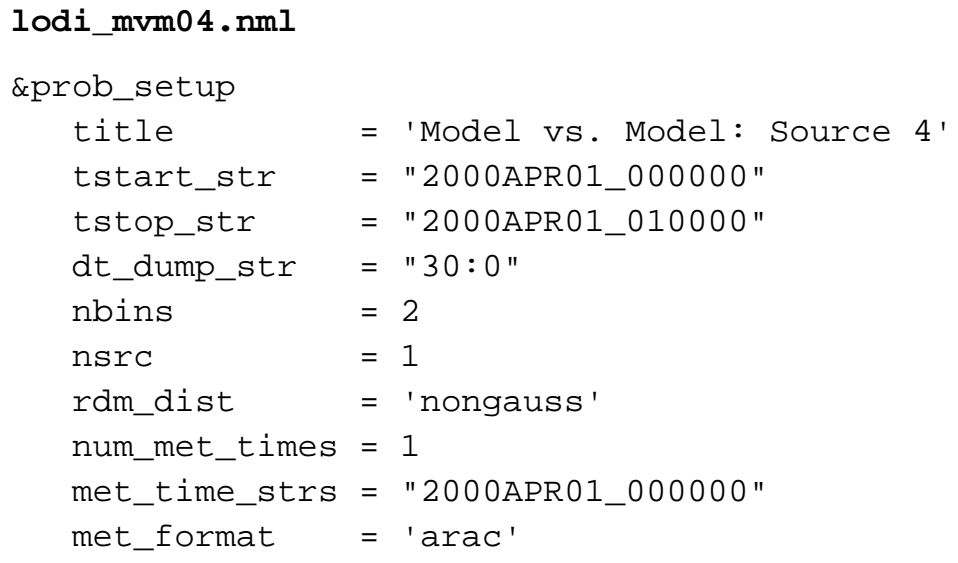




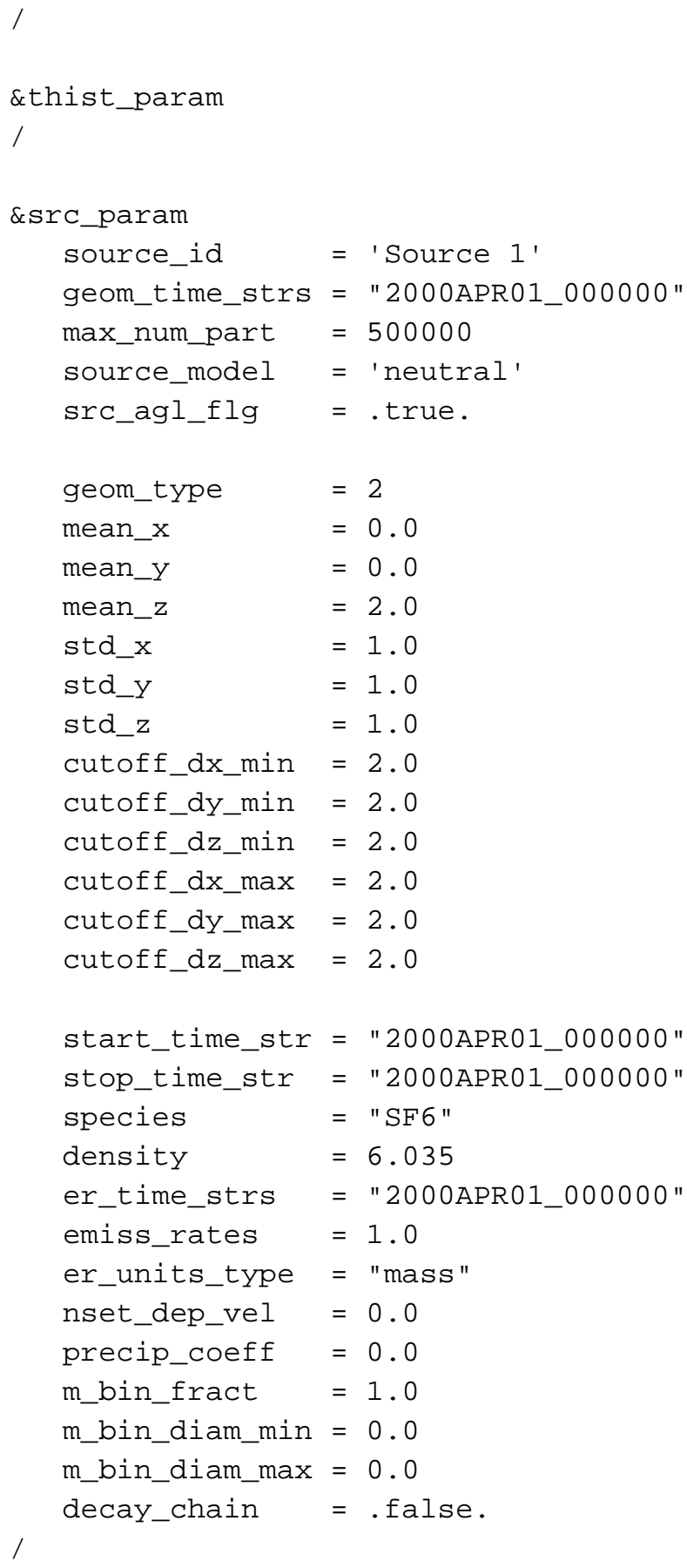

\section{NARAC MvM4}

lodi_mvm04.nml (continued)

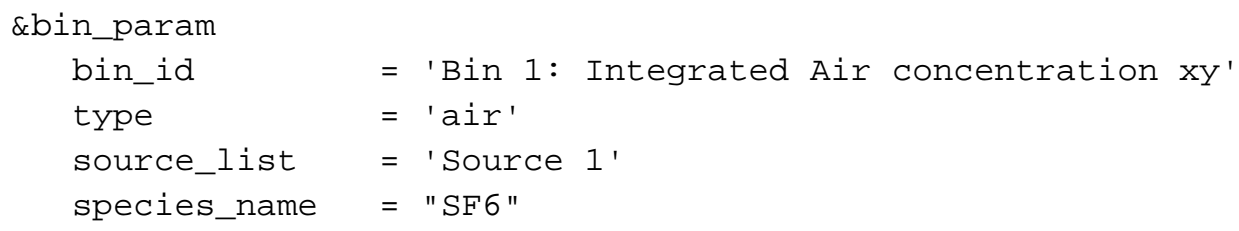




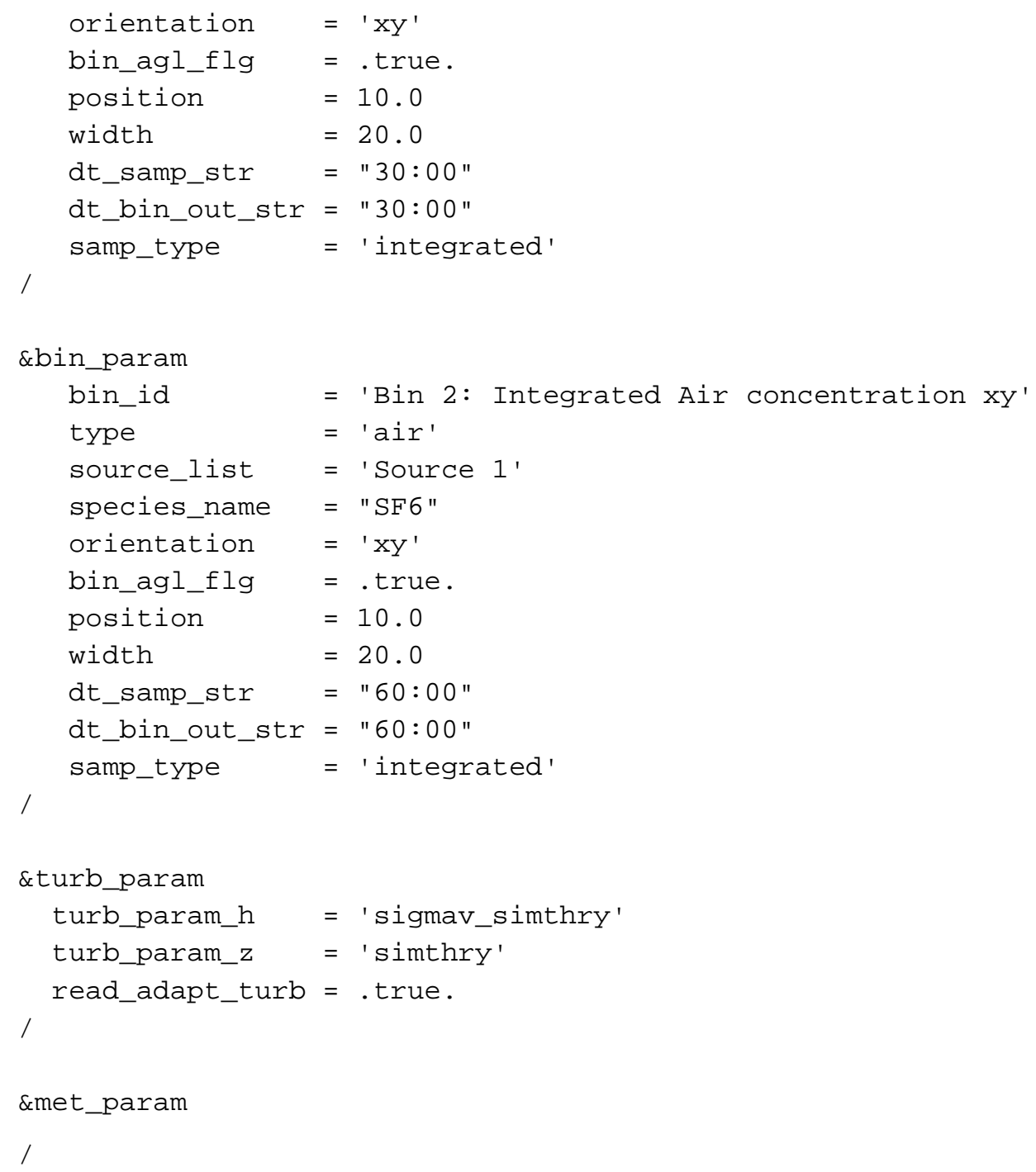

\section{NARAC MvM4}

stnloc_mvm04.met

SFC

'MtoM1' $0.0 \quad 0.0 \quad 10.0$

UPR

'MtoM1' $0.0 \quad 0.0$

\section{NARAC MvM4}

observ_mvm04.met

$\begin{array}{llcl}\text { METDATASET } & \text { '2000APR01_000000' } \\ \text { UPR } & & & \\ \text { 'MtoM1' } & 0.5 & 90 & 2.9251 \\ \text { 'MtoM1' } & 1 & 90 & 3.4132\end{array}$




\begin{tabular}{|c|c|c|c|}
\hline 'MtoM1 ' & 1.5 & 90 & 3.6977 \\
\hline 'MtoM1 ' & 2 & 90 & 3.8988 \\
\hline 'MtoM1 ' & 2.5 & 90 & 4.0543 \\
\hline 'MtoM1 ' & 3 & 90 & 4.1808 \\
\hline 'MtoM1' & 3.5 & 90 & 4.2875 \\
\hline 'MtoM1' & 4 & 90 & 4.3795 \\
\hline 'MtoM1 ' & 4.5 & 90 & 4.4605 \\
\hline 'MtoM1 ' & 5 & 90 & 4.5326 \\
\hline 'Mtom1 ' & 5.5 & 90 & 4.5977 \\
\hline 'MtoM1' & 6 & 90 & 4.6569 \\
\hline 'MtoM1' & 6.5 & 90 & 4.7112 \\
\hline 'MtoM1' & 7 & 90 & 4.7613 \\
\hline 'MtoM1' & 7.5 & 90 & 4.8078 \\
\hline 'MtoM1 ' & 8 & 90 & 4.8511 \\
\hline 'MtoM1 ' & 8.5 & 90 & 4.8918 \\
\hline 'MtoM1 ' & 9 & 90 & 4.9299 \\
\hline 'MtoM1 ' & 9.5 & 90 & 4.9659 \\
\hline 'MtoM1' & 10 & 90 & 5 \\
\hline 'MtoM1' & 10.5 & 90 & 5.0323 \\
\hline 'MtoM1' & 11 & 90 & 5.063 \\
\hline 'MtoM1 ' & 11.5 & 90 & 5.0923 \\
\hline 'MtoM1 ' & 12 & 90 & 5.1202 \\
\hline 'MtoM1 ' & 12.5 & 90 & 5.147 \\
\hline 'MtoM1 ' & 13 & 90 & 5.1726 \\
\hline 'MtoM1 ' & 13.5 & 90 & 5.1971 \\
\hline 'MtoM1' & 14 & 90 & 5.2208 \\
\hline 'MtoM1 ' & 14.5 & 90 & 5.2435 \\
\hline 'MtoM1 ' & 15 & 90 & 5.2654 \\
\hline 'MtoM1 ' & 15.5 & 90 & 5.2865 \\
\hline 'MtoM1 ' & 16 & 90 & 5.3069 \\
\hline 'MtoM1' & 16.5 & 90 & 5.3267 \\
\hline 'MtoM1' & 17 & 90 & 5.3457 \\
\hline 'MtoM1' & 17.5 & 90 & 5.3642 \\
\hline 'MtoM1 ' & 18 & 90 & 5.3822 \\
\hline 'MtoM1 ' & 18.5 & 90 & 5.3996 \\
\hline 'MtoM1 ' & 19 & 90 & 5.4164 \\
\hline 'MtoM1 ' & 19.5 & 90 & 5.4329 \\
\hline 'MtoM1' & 20 & 90 & 5.4488 \\
\hline 'MtoM1' & 20.5 & 90 & 5.4643 \\
\hline 'MtoM1 ' & 21 & 90 & 5.4795 \\
\hline 'MtoM1 ' & 21.5 & 90 & 5.4942 \\
\hline ' MtoM1 ' & 22 & 90 & 5.5085 \\
\hline 'MtoM1' & 22.5 & 90 & 5.5225 \\
\hline 'MtoM1' & 23 & 90 & 5.5362 \\
\hline 'MtoM1 ' & 23.5 & 90 & 5.5495 \\
\hline 'MtoM1' & 24 & 90 & 5.5626 \\
\hline 'MtoM1 ' & 24.5 & 90 & 5.5753 \\
\hline 'MtoM1 ' & 25 & 90 & 5.5878 \\
\hline 'MtoM1 ' & 25.5 & 90 & 5.5999 \\
\hline
\end{tabular}




\section{NARAC MvM4}

observ_mvm04.met (continued)

\begin{tabular}{|c|c|c|c|}
\hline 'MtoM1 ' & 26 & 90 & 5.6118 \\
\hline 'MtoM1 ' & 26.5 & 90 & 5.6235 \\
\hline 'MtoM1 ' & 27 & 90 & 5.6349 \\
\hline 'MtoM1 ' & 27.5 & 90 & 5.6461 \\
\hline 'MtoM1 ' & 28 & 90 & 5.6571 \\
\hline 'MtoM1 ' & 28.5 & 90 & 5.6678 \\
\hline 'MtoM1 ' & 29 & 90 & 5.6784 \\
\hline 'MtoM1 ' & 29.5 & 90 & 5.6887 \\
\hline 'MtoM1 ' & 30 & 90 & 5.6989 \\
\hline 'MtoM1 ' & 30.5 & 90 & 5.7088 \\
\hline 'MtoM1 ' & 31 & 90 & 5.7186 \\
\hline 'MtoM1 ' & 31.5 & 90 & 5.7282 \\
\hline 'MtoM1 ' & 32 & 90 & 5.7376 \\
\hline 'MtoM1 ' & 32.5 & 90 & 5.7469 \\
\hline 'MtoM1 ' & 33 & 90 & 5.756 \\
\hline 'MtoM1 ' & 33.5 & 90 & 5.765 \\
\hline 'MtoM1 ' & 34 & 90 & 5.7738 \\
\hline 'MtoM1 ' & 34.5 & 90 & 5.7824 \\
\hline 'MtoM1 ' & 35 & 90 & 5.791 \\
\hline 'MtoM1 ' & 35.5 & 90 & 5.7993 \\
\hline 'MtoM1 ' & 36 & 90 & 5.8076 \\
\hline 'MtoM1 ' & 36.5 & 90 & 5.8157 \\
\hline 'MtoM1 ' & 37 & 90 & 5.8237 \\
\hline 'MtoM1 ' & 37.5 & 90 & 5.8316 \\
\hline 'MtoM1 ' & 38 & 90 & 5.8394 \\
\hline 'MtoM1 ' & 38.5 & 90 & 5.847 \\
\hline 'Mtom1' & 39 & 90 & 5.8545 \\
\hline 'MtoM1 ' & 39.5 & 90 & 5.862 \\
\hline 'MtoM1 ' & 40 & 90 & 5.8693 \\
\hline 'MtoM1 ' & 40.5 & 90 & 5.8765 \\
\hline 'MtoM1 ' & 41 & 90 & 5.8836 \\
\hline 'MtoM1 ' & 41.5 & 90 & 5.8906 \\
\hline 'MtoM1 ' & 42 & 90 & 5.8975 \\
\hline 'MtoM1 ' & 42.5 & 90 & 5.9044 \\
\hline 'MtoM1 ' & 43 & 90 & 5.9111 \\
\hline 'MtoM1 ' & 43.5 & 90 & 5.9178 \\
\hline 'MtoM1' & 44 & 90 & 5.9243 \\
\hline 'MtoM1' & 44.5 & 90 & 5.9308 \\
\hline 'MtoM1 ' & 45 & 90 & 5.9372 \\
\hline 'MtoM1 ' & 45.5 & 90 & 5.9435 \\
\hline 'MtoM1 ' & 46 & 90 & 5.9497 \\
\hline 'MtoM1' & 46.5 & 90 & 5.9559 \\
\hline 'MtoM1 ' & 47 & 90 & 5.962 \\
\hline 'MtoM1 ' & 47.5 & 90 & 5.968 \\
\hline 'MtoM1 ' & 48 & 90 & 5.9739 \\
\hline 'MtoM1 ' & 48.5 & 90 & 5.9798 \\
\hline
\end{tabular}


'MtoM1' $49 \quad 90 \quad 5.9856$

'MtoM1' $\quad 49.5 \quad 90 \quad 5.9913$

'MtoM1' $50 \quad 90 \quad 5.997$ 


\section{HPAC MvM5}

\begin{tabular}{|c|c|c|}
\hline mvm5 & HPAC 3.2 parame ter & HPAC 3.2 value \\
\hline HPAC SCREEN & agent & SF6 \\
\hline \multirow[t]{12}{*}{ New Project Setup } & project file name & mvm1_1.prj \\
\hline & coordina tes & cartesian \\
\hline & local origin $\mathrm{x}$ & $0 \mathrm{~km}$ \\
\hline & local origin $y$ & $0 \mathrm{~km}$ \\
\hline & local origin lat i tude & $45 \operatorname{deg} N$ \\
\hline & local origin longi tude & $0 \mathrm{deg}$ \\
\hline & reference times & UTC \\
\hline & local time of $00: 00 z$ & 0 \\
\hline & mode & st andard \\
\hline & dynamics & dense gas \\
\hline & static puffs & enabled \\
\hline & hazard area & off \\
\hline New Project Editor & edit mode & advanœed \\
\hline \multirow{8}{*}{ Material Editor } & type & gas \\
\hline & name & SF6 \\
\hline & material file & Sf $6 . \mathrm{mt}$ \\
\hline & units & $\mathrm{kg}$ \\
\hline & bin boundaries & NA \\
\hline & output flags & surf. dosage, surf. depos \\
\hline & daytime decay rate & $\begin{array}{r}0 \\
\end{array}$ \\
\hline & nighttime decay ra te & 0 \\
\hline \multirow[t]{3}{*}{ Gas Parame ter Editor } & density ratio (rho/ rho_air) & 5.02917 \\
\hline & deposition velocity & 0 \\
\hline & minimum concen tra tion & 0 \\
\hline \multirow[t]{15}{*}{ Release Editor } & time & 0 \\
\hline & $\mathbf{x}$ & 0 \\
\hline & $y$ & 0 \\
\hline & height of release & $250 \mathrm{~m}$ \\
\hline & source uncert ainty & no \\
\hline & specification & simple \\
\hline & randomize location & no \\
\hline & release dura tion & instantaneous \\
\hline & release ra te & NA \\
\hline & agent mass & $1 \mathrm{~kg}$ \\
\hline & $x$ size & $1 \mathrm{~m}$ \\
\hline & y size & $1 \mathrm{~m}$ \\
\hline & z size & $1 \mathrm{~m}$ \\
\hline & momentum & 0 \\
\hline & buoyancy & 0 \\
\hline \multirow[t]{6}{*}{ Time Editor } & start day & $4 / 1 / 00$ \\
\hline & start time & 0 \\
\hline & s top day & $4 / 1 / 00$ \\
\hline & stop time & 100 \\
\hline & maximum time step & $60 \mathrm{sec}$ \\
\hline & out put interval & $15 \mathrm{~min}$ \\
\hline \multirow[t]{7}{*}{ Domain Editor } & xmin domain & $-50 \mathrm{~km}$ \\
\hline & $x \max$ domain & $1 \mathrm{~km}$ \\
\hline & ymin domain & $-5 \mathrm{~km}$ \\
\hline & ymax domain & $5 \mathrm{~km}$ \\
\hline & horizontal resolution & default \\
\hline & vertical domain max height & $500 \mathrm{~m}$ \\
\hline & vertical domain resolution & $10 \mathrm{~m}$ \\
\hline Wea ther Editor & weather dat a type & surface obs. only \\
\hline & boundary layer t ype & observations \\
\hline & large scale variability & none \\
\hline & large scale variability length scale & NA \\
\hline & large scale variability variance & NA \\
\hline & $\begin{array}{c}\text { surf ace roughness } \\
\end{array}$ & $0.008 \mathrm{~m}$ \\
\hline & precipita tion & none \\
\hline & obs. time bin size & $1 \mathrm{hr}$ \\
\hline Meteorology Option Edi tor & save me te orology fields & no \\
\hline & terrain/land cover file & no \\
\hline Surface Obsenations File & file name & mvmN.sfc \\
\hline & $\begin{array}{c}\text { elevation } \\
\end{array}$ & $10 \mathrm{~m}$ \\
\hline & zi (boundary layer height) & $500 \mathrm{~m}$ \\
\hline & $z$ (al ti tude for wind measur ement) & $10 \mathrm{~m}$ \\
\hline & wind dire ction ( from) & $90 \mathrm{deg}$ (east) \\
\hline & $\begin{array}{c}\text { wind speed } \\
\end{array}$ & $5 \mathrm{~m} / \mathrm{s}$ \\
\hline & MOL (Monin-Obukhov Leng th) & $-500 \mathrm{~m}$ \\
\hline Op tions Editor & puff split grid level & 2 \\
\hline & surface resolution & default \\
\hline & puf f grid resolution & 0 \\
\hline & boundary layer pts & 11 \\
\hline & stable atm. turbulence & $1 \mathrm{e}-2 \mathrm{~m}^{\wedge} 2 / \mathrm{s}^{\wedge} 2$ \\
\hline & stable a tm. scale & $10 \mathrm{~m}$ \\
\hline & stable dissipa tion & $4 \mathrm{e}-4 \mathrm{~m}^{\wedge} 2 / \mathrm{s}^{\wedge} 3$ \\
\hline & calm cond. turbulence & $0.25 \mathrm{~m}^{\wedge} 2 / \mathrm{s}^{\wedge} 2$ \\
\hline & calm cond. scale & $1000 \mathrm{~m}$ \\
\hline & surface dosage height & 0 \\
\hline & minimum puf $\mathrm{f}$ mass & $1 \mathrm{e}-20$ \\
\hline & conditional averaging time & $1 \mathrm{hr}$ \\
\hline & lumped boundary layer & no \\
\hline
\end{tabular}




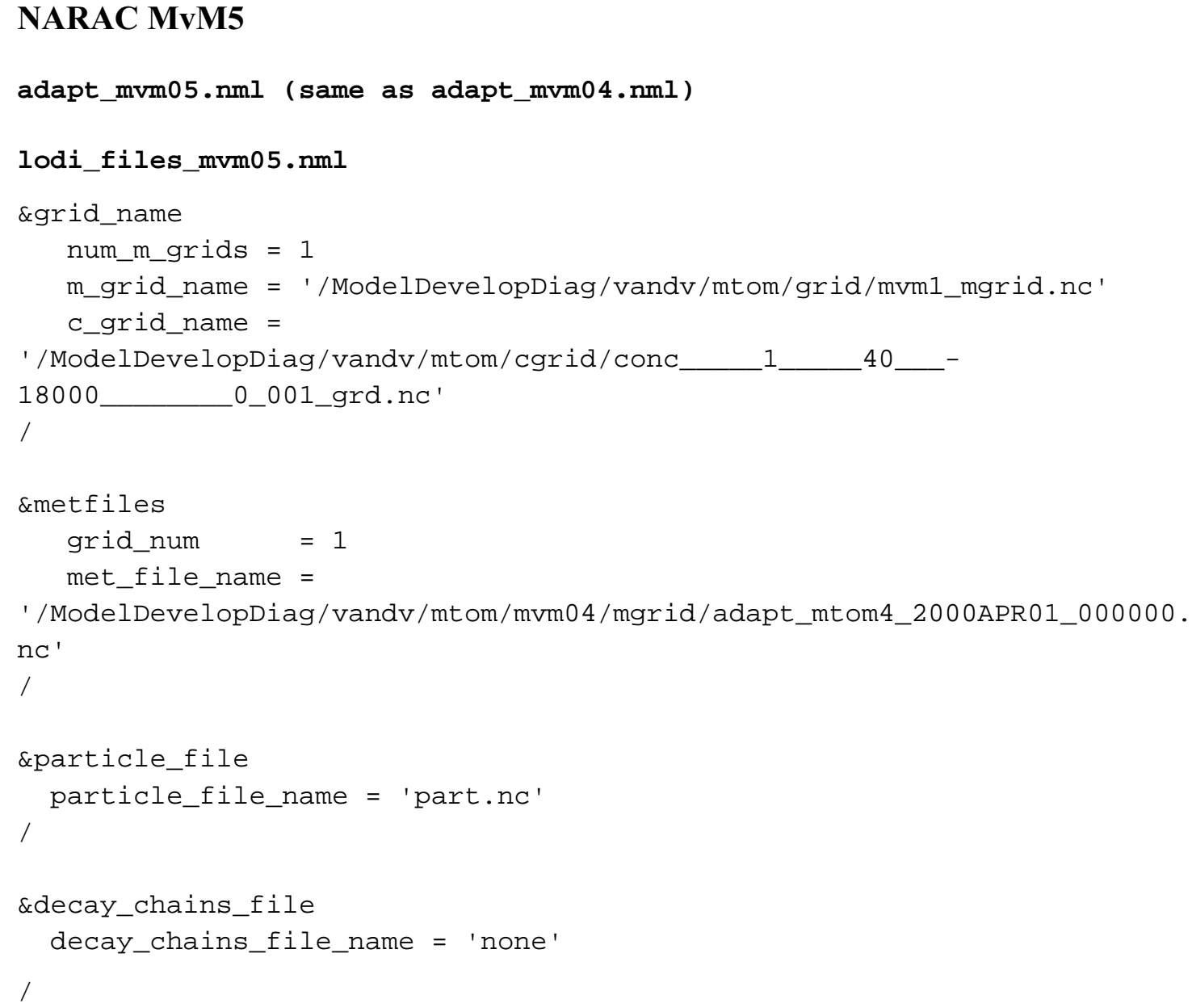

\section{NARAC MvM5}

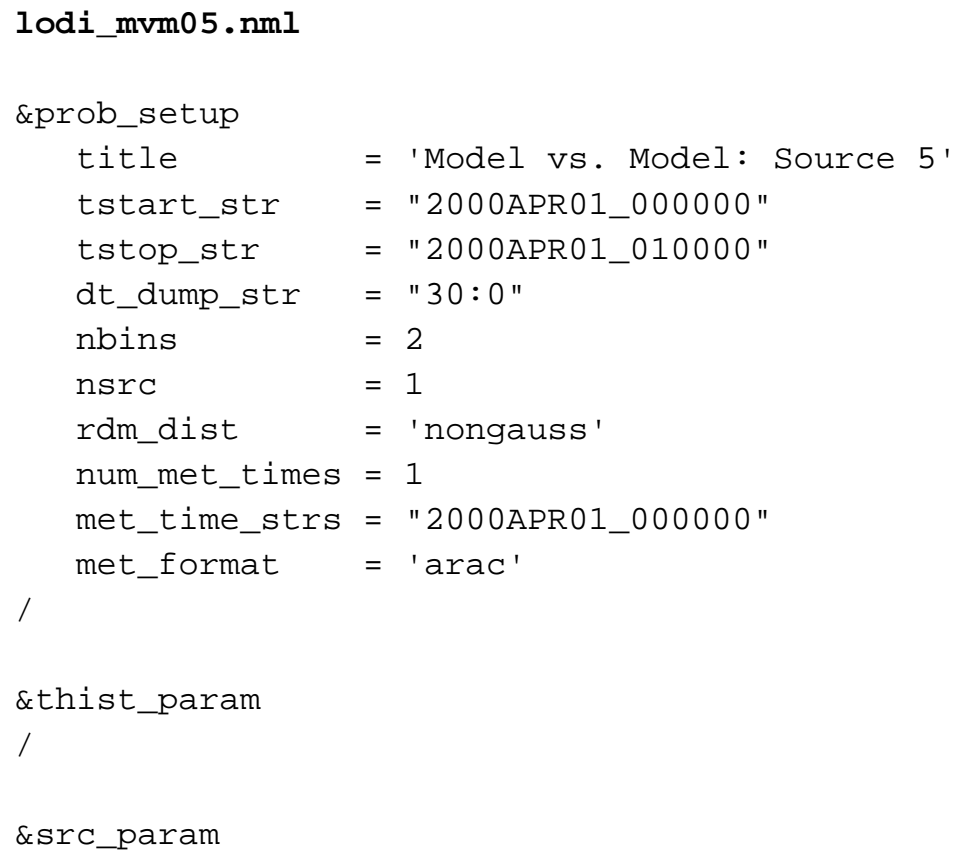




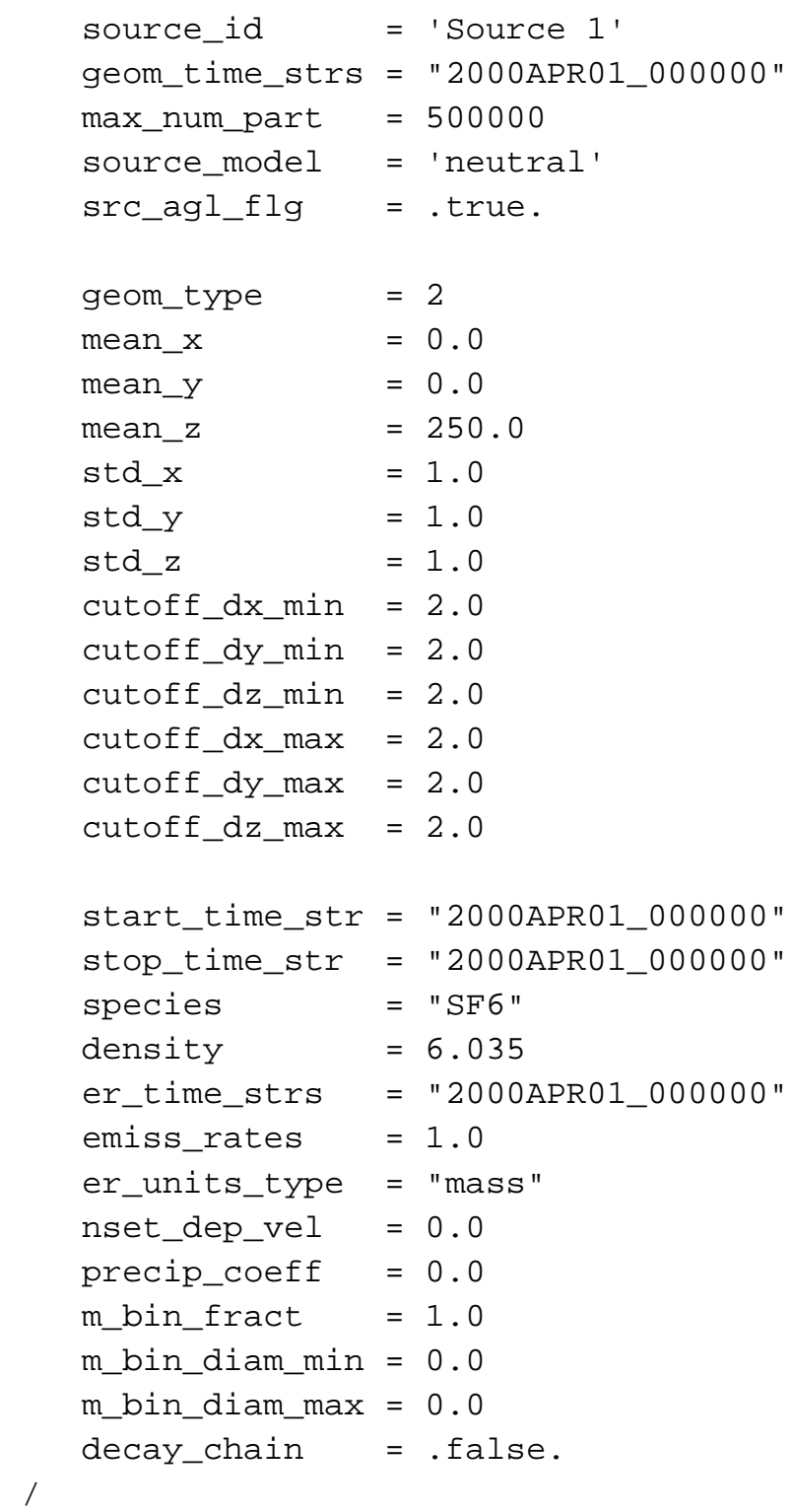

\section{NARAC MvM5}

lodi_mvm05.nml (continued)

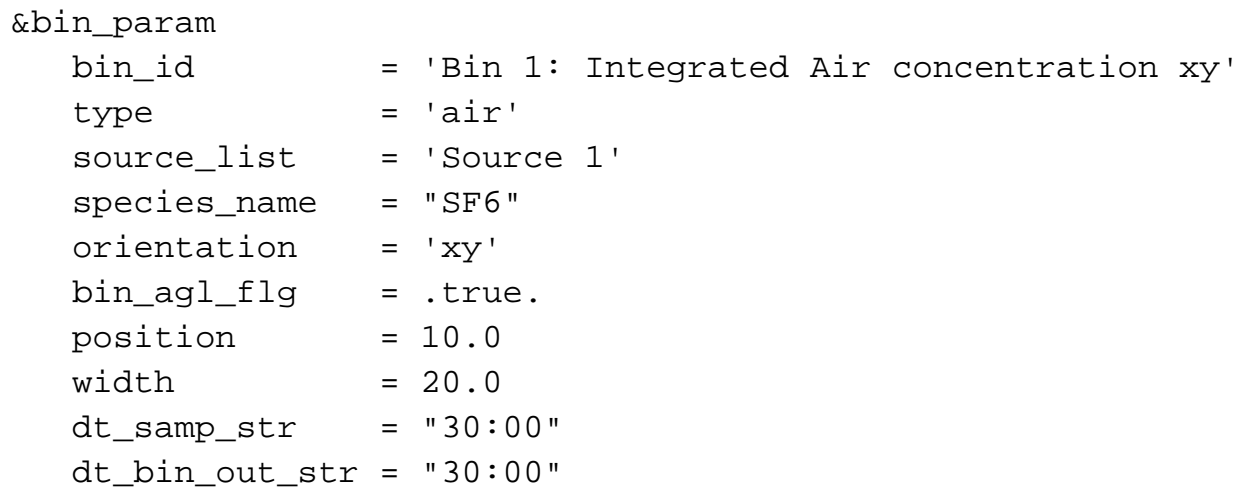




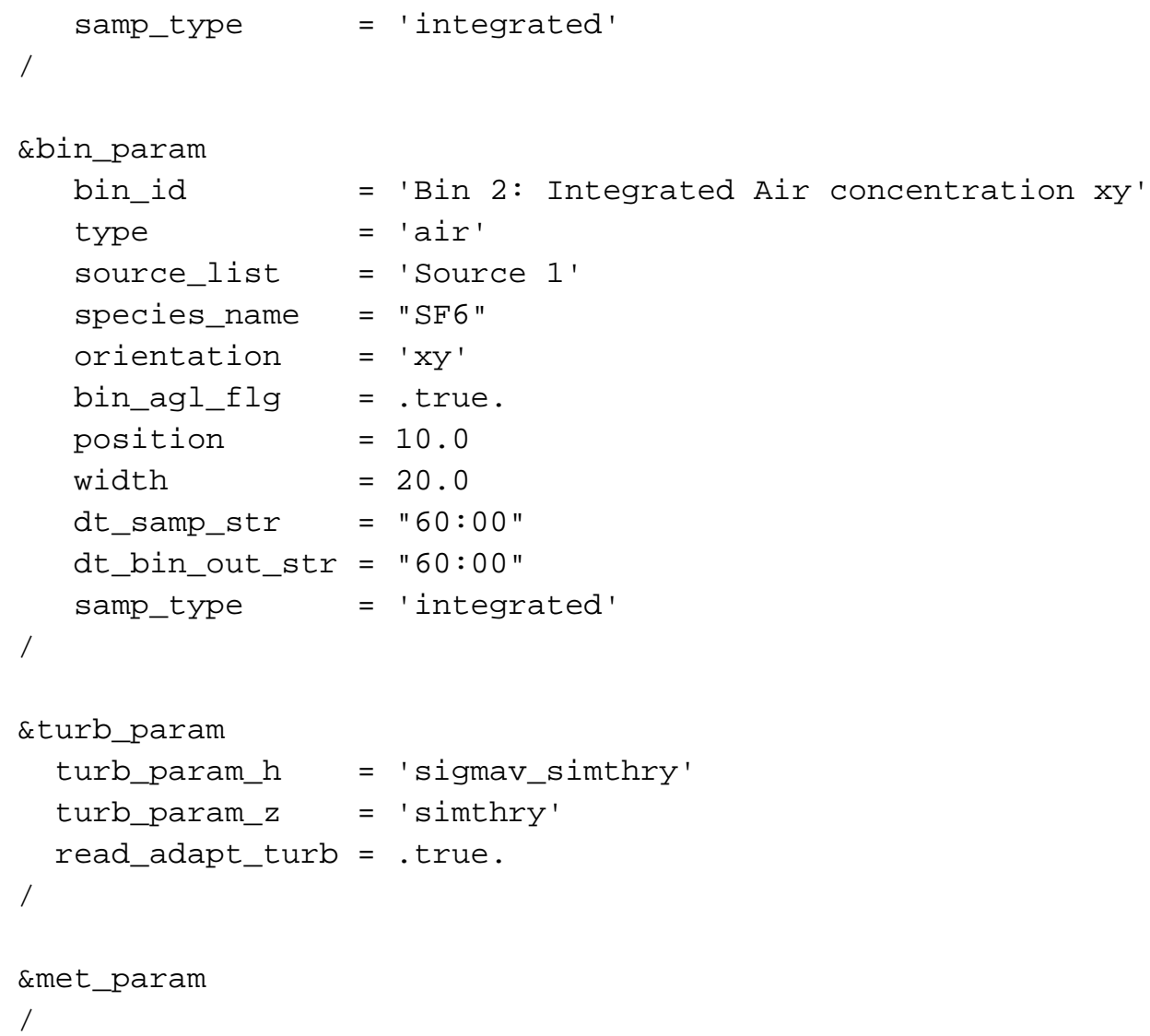

\section{NARAC MvM5}

stnloc_mvm05.met (same as stnloc_mvm04.met)

observ_mvm05.met (same as observ_mvm04.met) 


\section{HPAC MvM6}

\begin{tabular}{|c|c|c|}
\hline mvm6 & HPAC 3.2 parame ter & HPAC 3.2 value \\
\hline HPAC SCREEN & agent & $\mathrm{SF6}$ \\
\hline \multirow{12}{*}{ New Project Setup } & project file name & mvm6.prj \\
\hline & coordina tes & cartesian \\
\hline & local origin $\mathrm{x}$ & $0 \mathrm{~km}$ \\
\hline & local origin $y$ & $0 \mathrm{~km}$ \\
\hline & local origin lat itude & $45 \operatorname{deg} N$ \\
\hline & local origin longi tude & 0 deg \\
\hline & reference times & UTC \\
\hline & local time of $00: 00 z$ & 0 \\
\hline & mode & st andard \\
\hline & dynamics & dense gas \\
\hline & static puffs & enabled \\
\hline & hazard area & off \\
\hline New Project Editor & edit mode & advanœd \\
\hline \multirow{8}{*}{ Material Edi tor } & type & gas \\
\hline & name & SF6 \\
\hline & ma terial file & Sf $6 . \mathrm{mt}$ \\
\hline & uni ts & $\mathrm{kg}$ \\
\hline & bin boundaries & NA \\
\hline & ou tput flags & surf. dosage, surf. depos \\
\hline & daytime decay rate & $\begin{array}{c}0 \\
\end{array}$ \\
\hline & nigh ttime decay rate & 0 \\
\hline \multirow[t]{3}{*}{ Gas Parame ter Editor } & density ratio (rho/ rho_air) & 5.02917 \\
\hline & deposition velocity & 0 \\
\hline & minimum concen tra tion & 0 \\
\hline \multirow[t]{15}{*}{ Release Editor } & time & 0 \\
\hline & $\mathbf{x}$ & 0 \\
\hline & $\mathrm{y}$ & 0 \\
\hline & height of release & $400 \mathrm{~m}$ \\
\hline & source uncert ainty & no \\
\hline & specifica tion & simple \\
\hline & randomize location & no \\
\hline & release dura tion & inst antaneous \\
\hline & release ra te & NA \\
\hline & agent mass & $1 \mathrm{~kg}$ \\
\hline & $\mathrm{x}$ size & $1 \mathrm{~m}$ \\
\hline & y size & $1 \mathrm{~m}$ \\
\hline & z size & $1 \mathrm{~m}$ \\
\hline & momentum & 0 \\
\hline & buoyancy & 0 \\
\hline \multirow[t]{6}{*}{ Time Editor } & start day & $4 / 1 / 00$ \\
\hline & start time & 0 \\
\hline & s top day & $4 / 1 / 00$ \\
\hline & stop time & 100 \\
\hline & maximum time step & $60 \mathrm{sec}$ \\
\hline & out put interval & $15 \mathrm{~min}$ \\
\hline \multirow[t]{7}{*}{ Domain Editor } & xmin domain & $-50 \mathrm{~km}$ \\
\hline & xmax domain & $1 \mathrm{~km}$ \\
\hline & ymin domain & $-5 \mathrm{~km}$ \\
\hline & ymax domain & $5 \mathrm{~km}$ \\
\hline & horizon tal resolution & default \\
\hline & vertical domain max height & $500 \mathrm{~m}$ \\
\hline & vertical domain resolution & $10 \mathrm{~m}$ \\
\hline Wea ther Editor & weather dat a type & surface obs. only \\
\hline & boundary layer t ype & observations \\
\hline & large scale variability & none \\
\hline & large scale variability length scale & NA \\
\hline & large scale variability variance & NA \\
\hline & surface roughness & $0.008 \mathrm{~m}$ \\
\hline & precipita tion & none \\
\hline & obs. time bin size & $1 \mathrm{hr}$ \\
\hline Meteorology Option Edi tor & save me te orology fields & no \\
\hline & terrain/land cover file & no \\
\hline Surface Observations File & $\begin{array}{r}\text { file name } \\
\end{array}$ & mvmN.sfc \\
\hline & $\begin{array}{c}\text { elevation } \\
\end{array}$ & $10 \mathrm{~m}$ \\
\hline & zi (boundary layer height) & $500 \mathrm{~m}$ \\
\hline & $z$ (al titude for wind measurement) & $10 \mathrm{~m}$ \\
\hline & wind direction ( from) & 90 deg (east) \\
\hline & $\begin{array}{c}\text { wind speed } \\
\end{array}$ & $5 \mathrm{~m} / \mathrm{s}$ \\
\hline & MOL (Monin-Obukhov Leng th) & $-500 \mathrm{~m}$ \\
\hline Op tions Editor & puff split grid level & 2 \\
\hline & surface resolution & default \\
\hline & puf $f$ grid resolution & 0 \\
\hline & boundary layer pts & 11 \\
\hline & stable atm. turbulence & $1 e-2 m^{\wedge} 2 / s^{\wedge} 2$ \\
\hline & s table a tm. scale & $10 \mathrm{~m}$ \\
\hline & stable dissipa tion & $4 e-4 m^{\wedge} 2 / s^{\wedge} 3$ \\
\hline & calm cond. turbulence & $0.25 \mathrm{~m}^{\wedge} 2 / \mathrm{s}^{\wedge} 2$ \\
\hline & calm cond. scale & $1000 \mathrm{~m}$ \\
\hline & surface dosage height & 0 \\
\hline & minimum puf $f$ mass & $1 \mathrm{e}-20$ \\
\hline & conditional averaging time & $1 \mathrm{hr}$ \\
\hline & lumped boundary layer & no \\
\hline
\end{tabular}




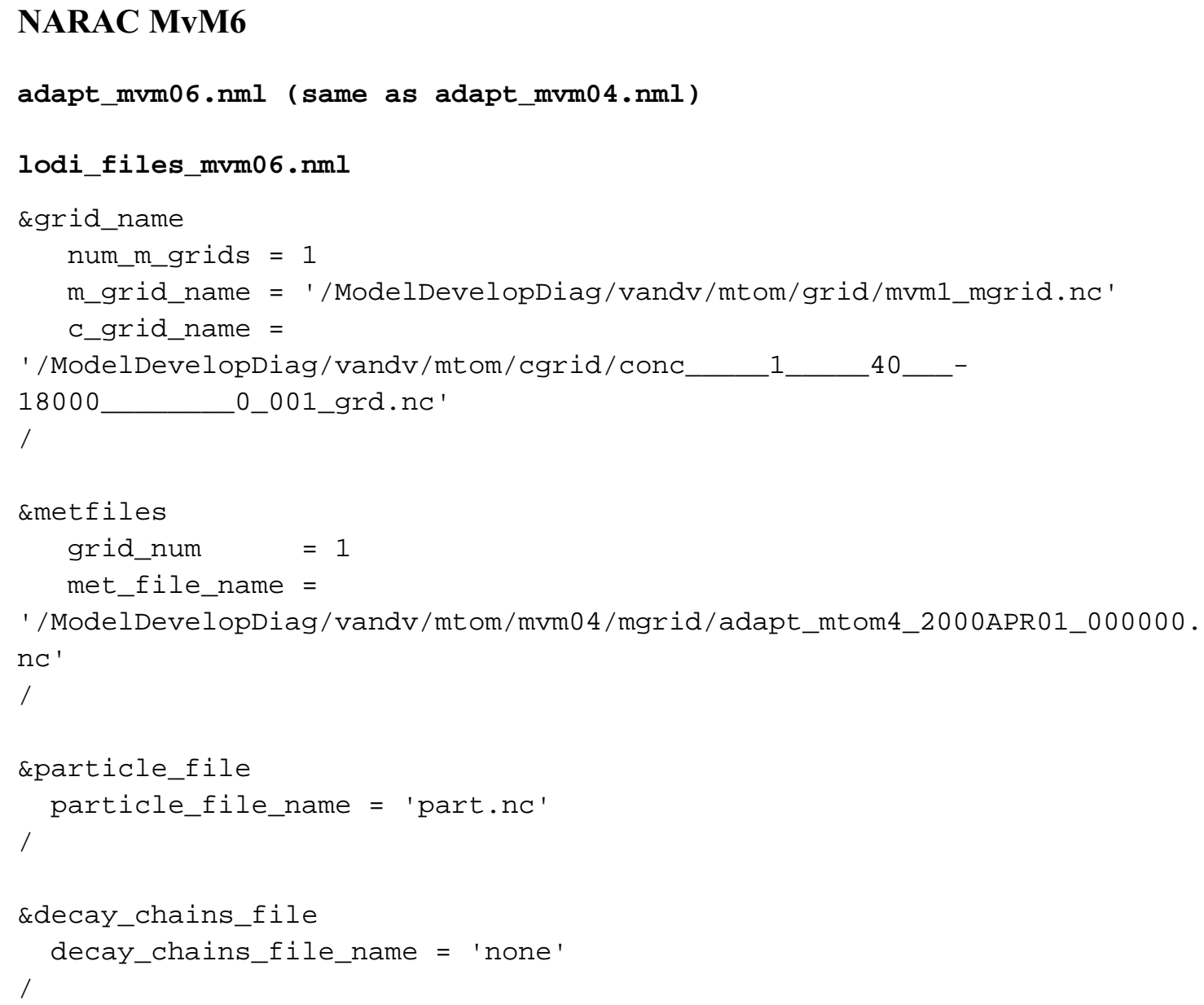

\section{NARAC MvM6}

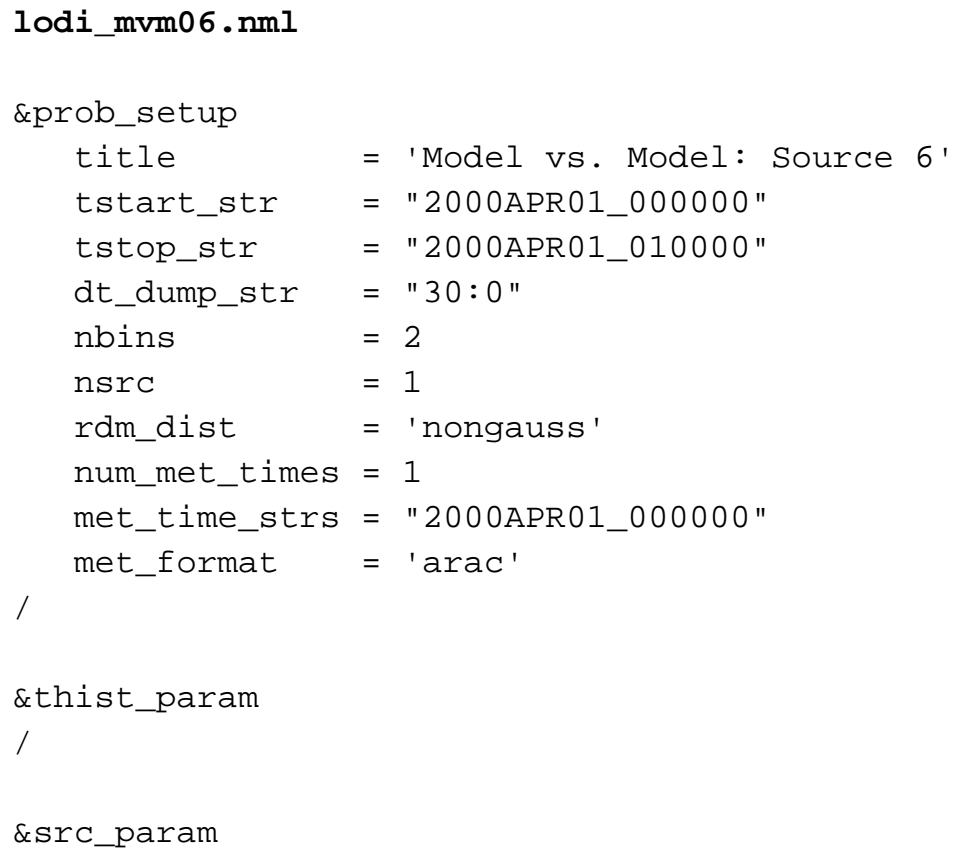




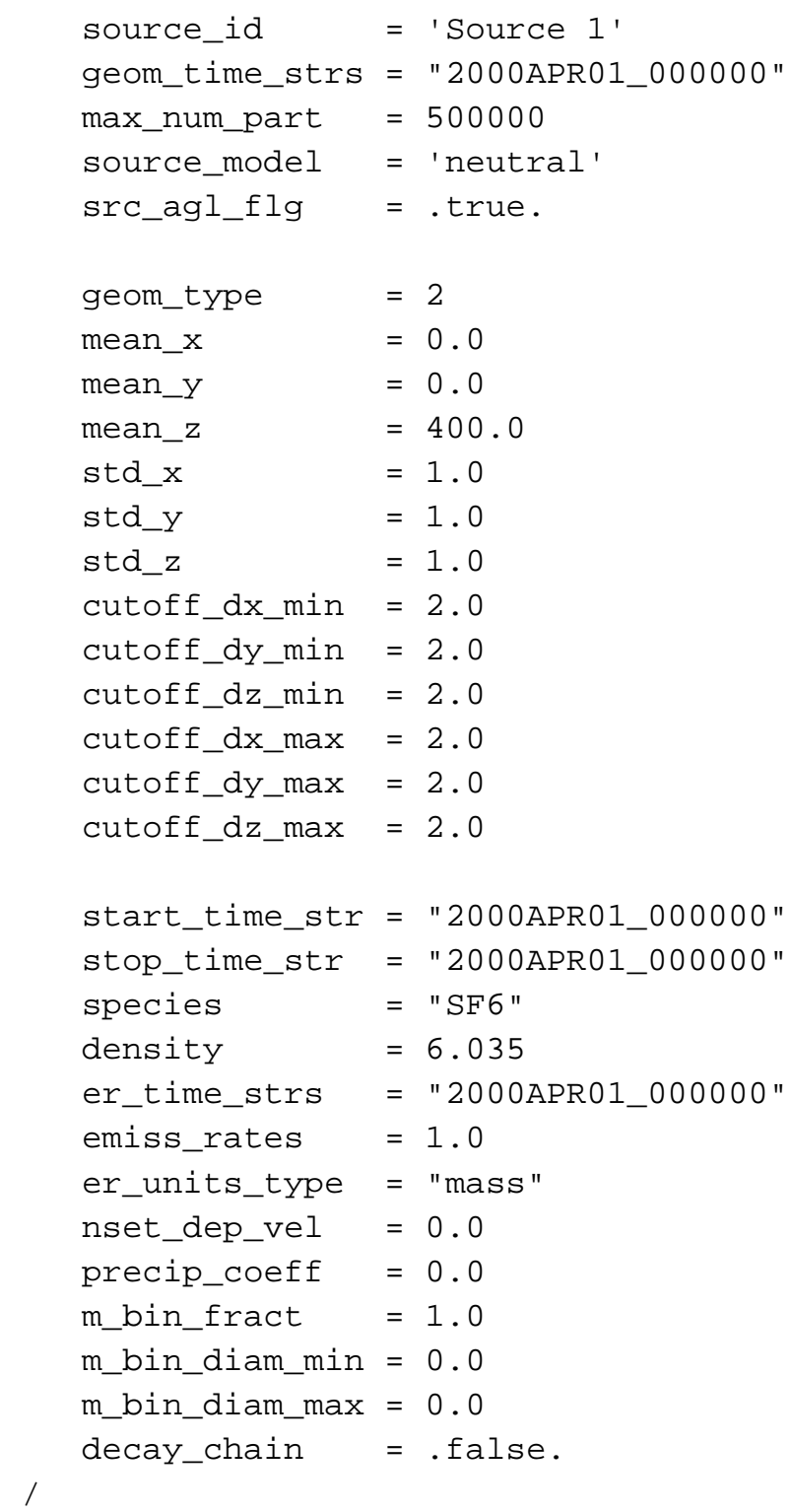

\section{NARAC MvM6}

lodi_mvm06.nml (continued)

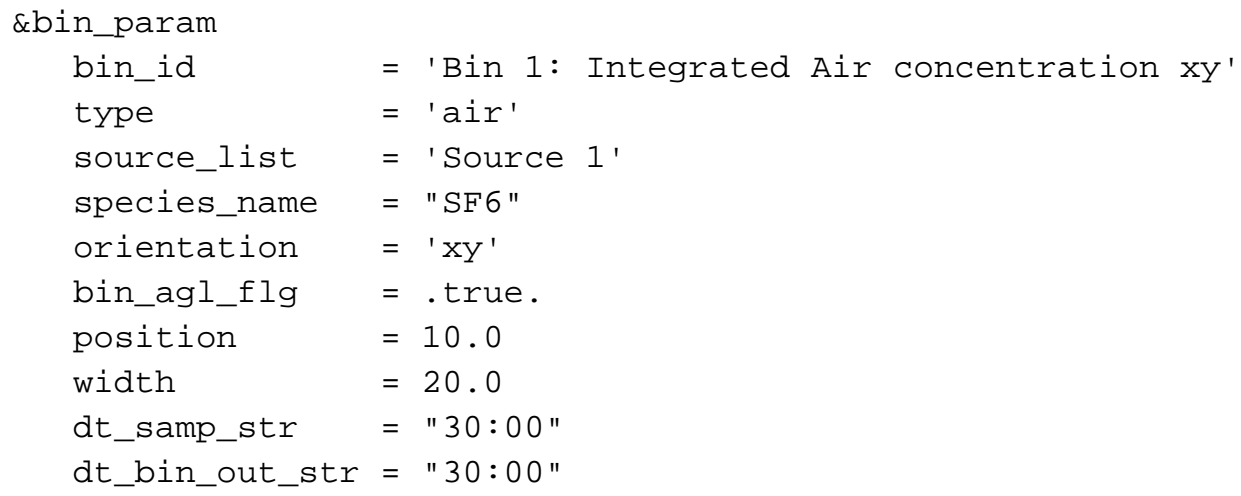




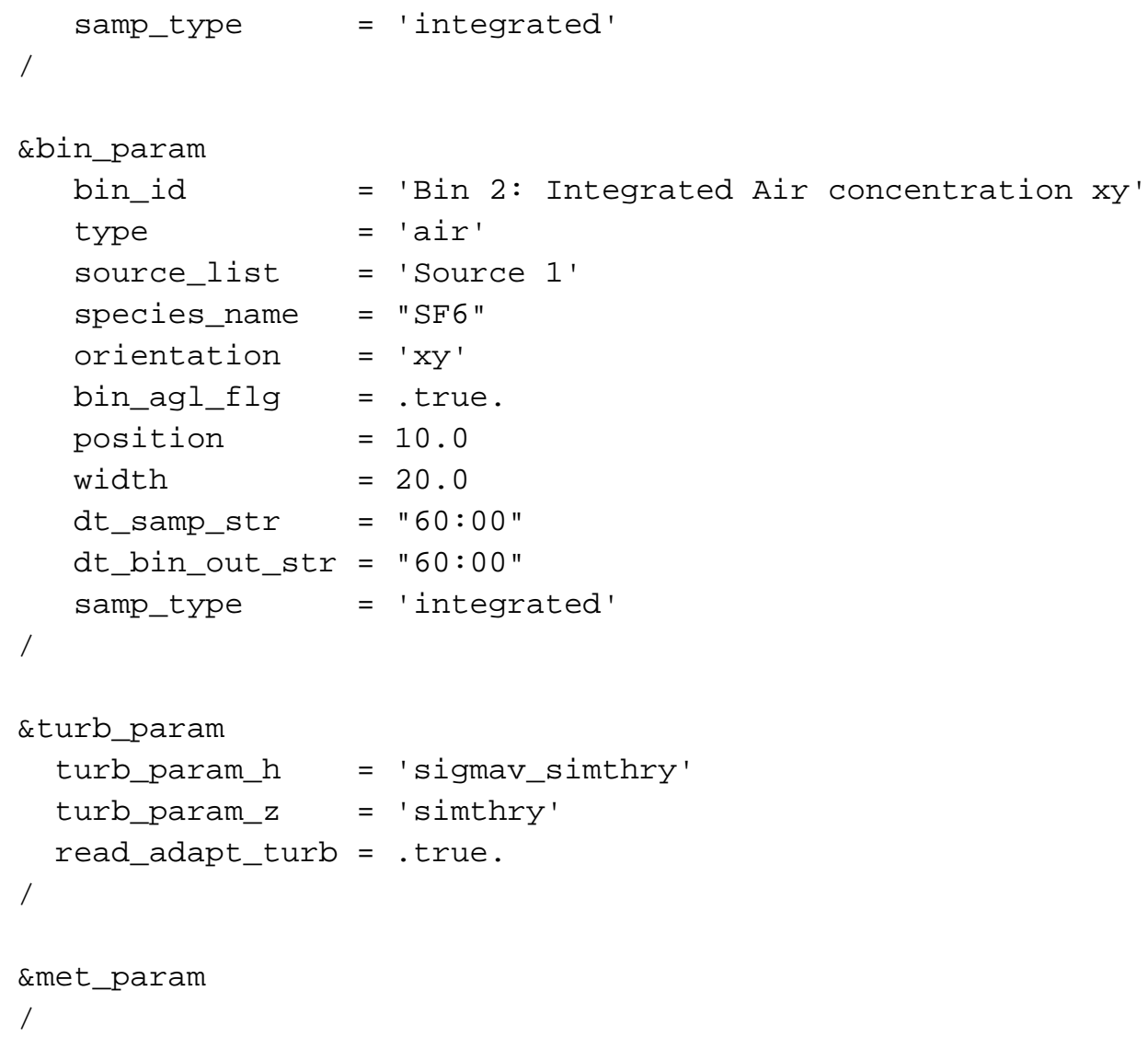

NARAC MvM6

stnloc_mvm06.met (same as stnloc_mvm04.met)

observ_mvm06.met (same as observ_mvm04.met) 


\section{HPAC MvM7}

\begin{tabular}{|c|c|c|}
\hline mvm7 & HPAC 3.2 parame ter & HPAC 3.2 value \\
\hline HPAC SCREEN & agent & SF6 \\
\hline \multirow[t]{12}{*}{ New Project Setup } & project file name & mvm7.prj \\
\hline & coordina tes & cartesian \\
\hline & local origin $\mathrm{x}$ & $0 \mathrm{~km}$ \\
\hline & local origin $y$ & $0 \mathrm{~km}$ \\
\hline & local origin lat i tude & $45 \operatorname{deg} N$ \\
\hline & local origin longi tude & $0 \mathrm{deg}$ \\
\hline & reference times & UTC \\
\hline & local time of $00: 00 z$ & 0 \\
\hline & mode & st andard \\
\hline & dynamics & dense gas \\
\hline & static puffs & enabled \\
\hline & hazard area & off \\
\hline New Project Editor & edit mode & advanœed \\
\hline \multirow{8}{*}{ Material Editor } & type & gas \\
\hline & name & SF6 \\
\hline & material file & Sf $6 . \mathrm{mt}$ \\
\hline & units & $\mathrm{kg}$ \\
\hline & bin boundaries & NA \\
\hline & output flags & surf. dosage, surf. depos \\
\hline & daytime decay rate & $\begin{array}{r}0 \\
\end{array}$ \\
\hline & nighttime decay ra te & 0 \\
\hline \multirow[t]{3}{*}{ Gas Parame ter Editor } & density ratio (rho/ rho_air) & 5.02917 \\
\hline & deposition velocity & 0 \\
\hline & minimum concen tra tion & 0 \\
\hline \multirow[t]{15}{*}{ Release Editor } & time & 0 \\
\hline & $\mathbf{x}$ & 0 \\
\hline & $y$ & 0 \\
\hline & height of release & $2 \mathrm{~m}$ \\
\hline & source uncert ainty & no \\
\hline & specification & simple \\
\hline & randomize location & no \\
\hline & release dura tion & instantaneous \\
\hline & release ra te & NA \\
\hline & agent mass & $1 \mathrm{~kg}$ \\
\hline & $x$ size & $1 \mathrm{~m}$ \\
\hline & y size & $1 \mathrm{~m}$ \\
\hline & z size & $1 \mathrm{~m}$ \\
\hline & momentum & 0 \\
\hline & buoyancy & 0 \\
\hline \multirow[t]{6}{*}{ Time Editor } & start day & $4 / 1 / 00$ \\
\hline & start time & 0 \\
\hline & s top day & $4 / 1 / 00$ \\
\hline & stop time & 100 \\
\hline & maximum time step & $60 \mathrm{sec}$ \\
\hline & out put interval & $15 \mathrm{~min}$ \\
\hline \multirow[t]{7}{*}{ Domain Editor } & xmin domain & $-50 \mathrm{~km}$ \\
\hline & $x \max$ domain & $1 \mathrm{~km}$ \\
\hline & ymin domain & $-5 \mathrm{~km}$ \\
\hline & ymax domain & $5 \mathrm{~km}$ \\
\hline & horizontal resolution & default \\
\hline & vertical domain max height & $500 \mathrm{~m}$ \\
\hline & vertical domain resolution & $10 \mathrm{~m}$ \\
\hline Wea ther Editor & weather dat a type & surface obs. only \\
\hline & boundary layer t ype & observations \\
\hline & large scale variability & none \\
\hline & large scale variability length scale & NA \\
\hline & large scale variability variance & NA \\
\hline & $\begin{array}{c}\text { surf ace roughness } \\
\end{array}$ & $0.008 \mathrm{~m}$ \\
\hline & precipita tion & none \\
\hline & obs. time bin size & $1 \mathrm{hr}$ \\
\hline Meteorology Option Edi tor & save me te orology fields & no \\
\hline & terrain/land cover file & no \\
\hline Surface Observations File & file name & mvmU.sfc \\
\hline & $\begin{array}{c}\text { elevation } \\
\end{array}$ & $10 \mathrm{~m}$ \\
\hline & zi (boundary layer height) & $500 \mathrm{~m}$ \\
\hline & $z$ (al ti tude for wind measur ement) & $10 \mathrm{~m}$ \\
\hline & wind dire ction ( from) & $90 \mathrm{deg}$ (east) \\
\hline & $\begin{array}{c}\text { wind speed } \\
\end{array}$ & $5 \mathrm{~m} / \mathrm{s}$ \\
\hline & MOL (Monin-Obukhov Leng th) & $-50 \mathrm{~m}$ \\
\hline Op tions Editor & puff split grid level & 2 \\
\hline & surface resolution & default \\
\hline & puf f grid resolution & 0 \\
\hline & boundary layer pts & 11 \\
\hline & stable atm. turbulence & $1 \mathrm{e}-2 \mathrm{~m}^{\wedge} 2 / \mathrm{s}^{\wedge} 2$ \\
\hline & stable a tm. scale & $10 \mathrm{~m}$ \\
\hline & stable dissipa tion & $4 \mathrm{e}-4 \mathrm{~m}^{\wedge} 2 / \mathrm{s}^{\wedge} 3$ \\
\hline & calm cond. turbulence & $0.25 \mathrm{~m}^{\wedge} 2 / \mathrm{s}^{\wedge} 2$ \\
\hline & calm cond. scale & $1000 \mathrm{~m}$ \\
\hline & surface dosage height & 0 \\
\hline & minimum puf $\mathrm{f}$ mass & $1 \mathrm{e}-20$ \\
\hline & conditional averaging time & $1 \mathrm{hr}$ \\
\hline & lumped boundary layer & no \\
\hline
\end{tabular}




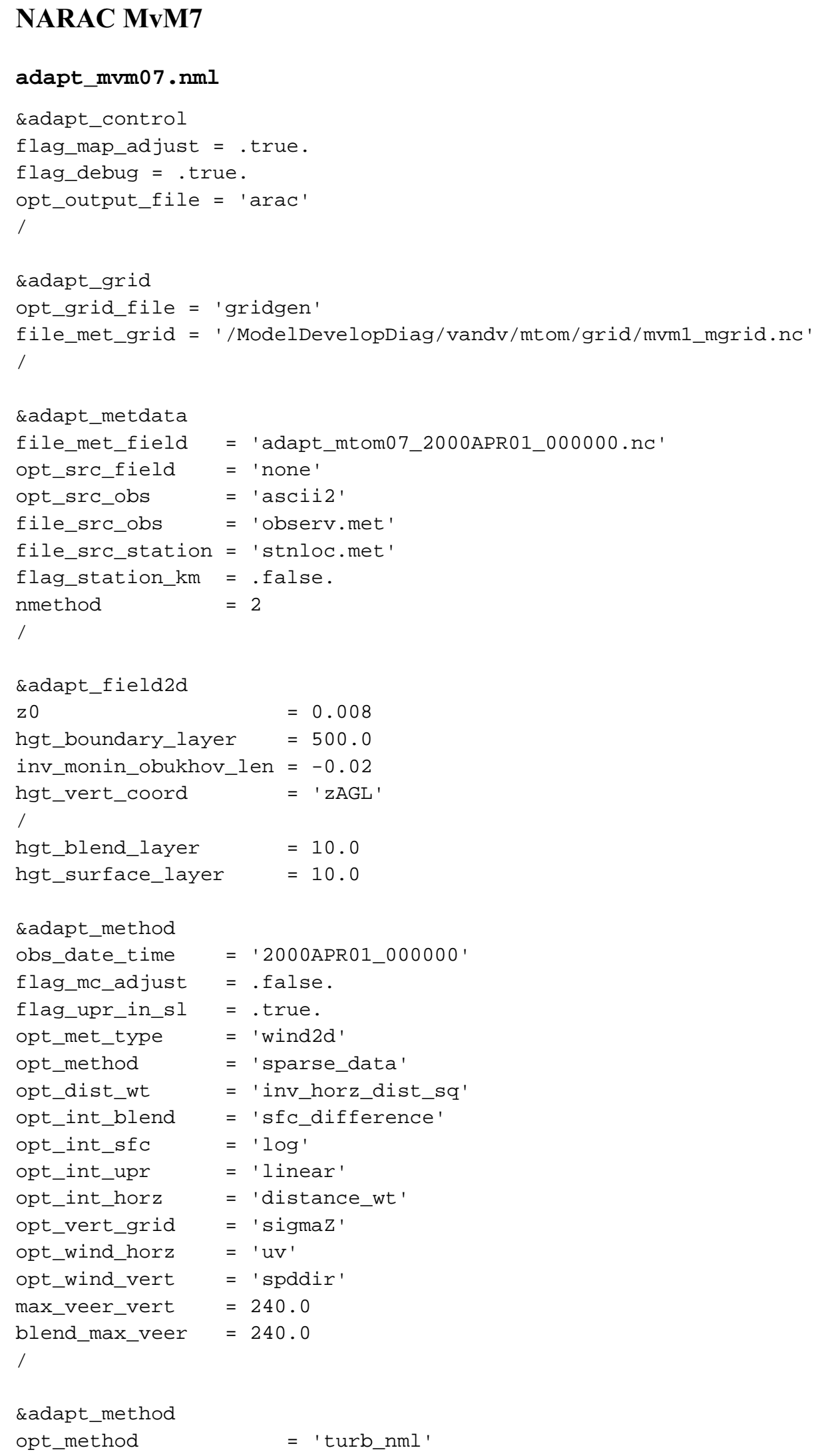




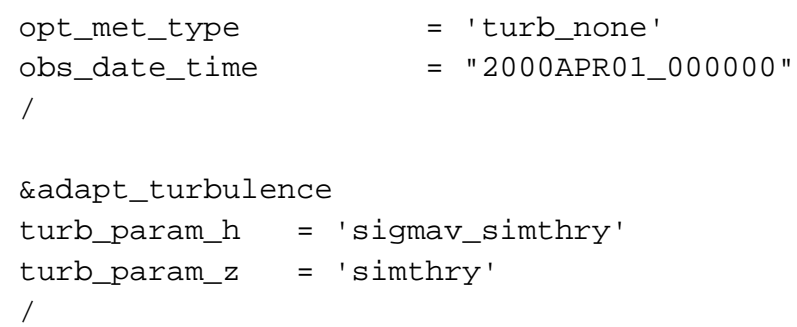

\section{NARAC MvM7}

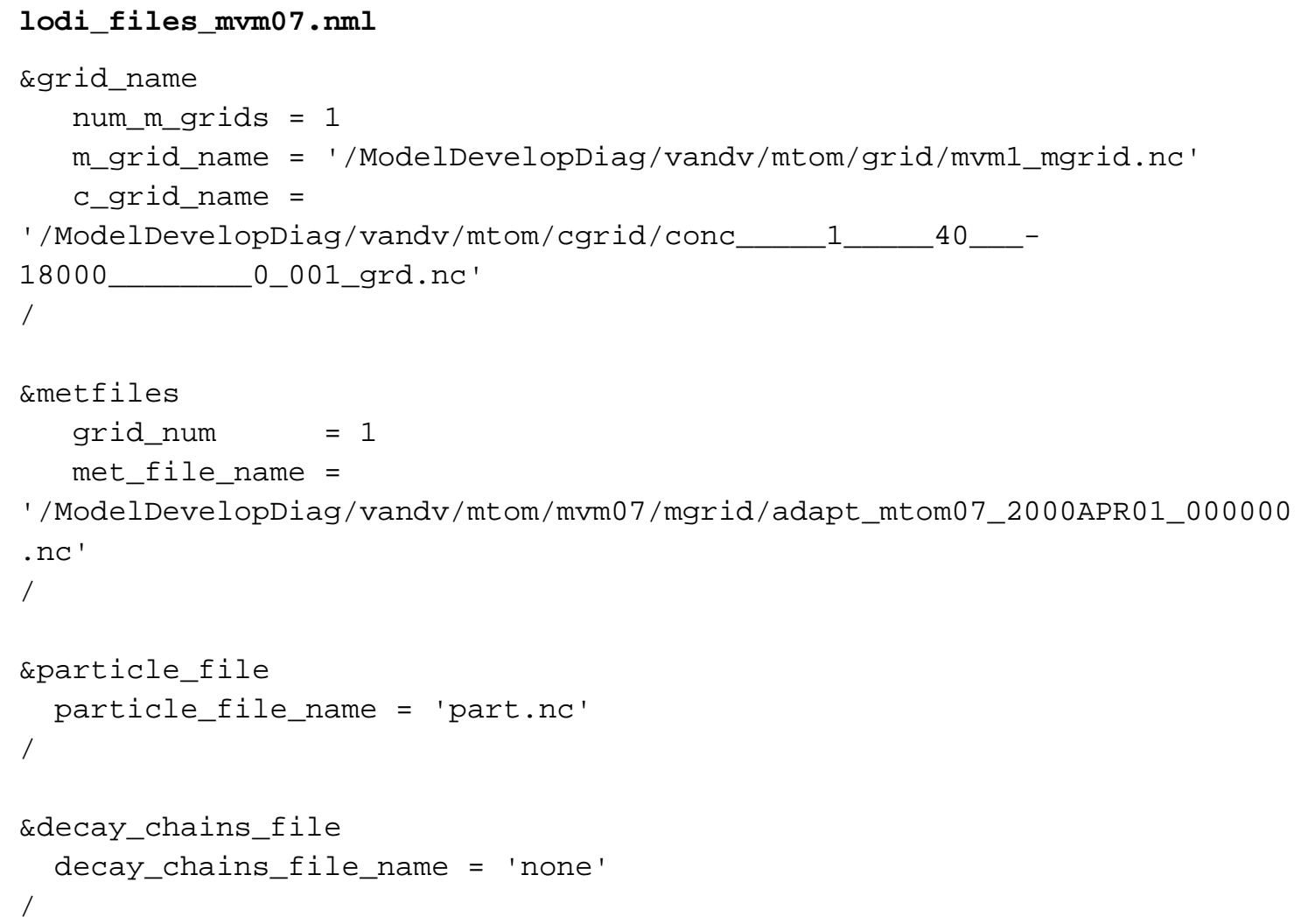

NARAC MvM7

lodi_mvm07.nml

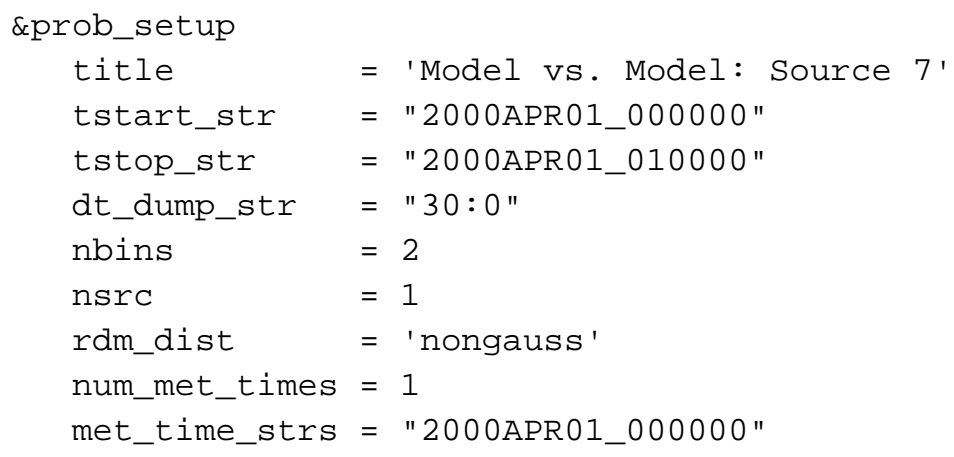




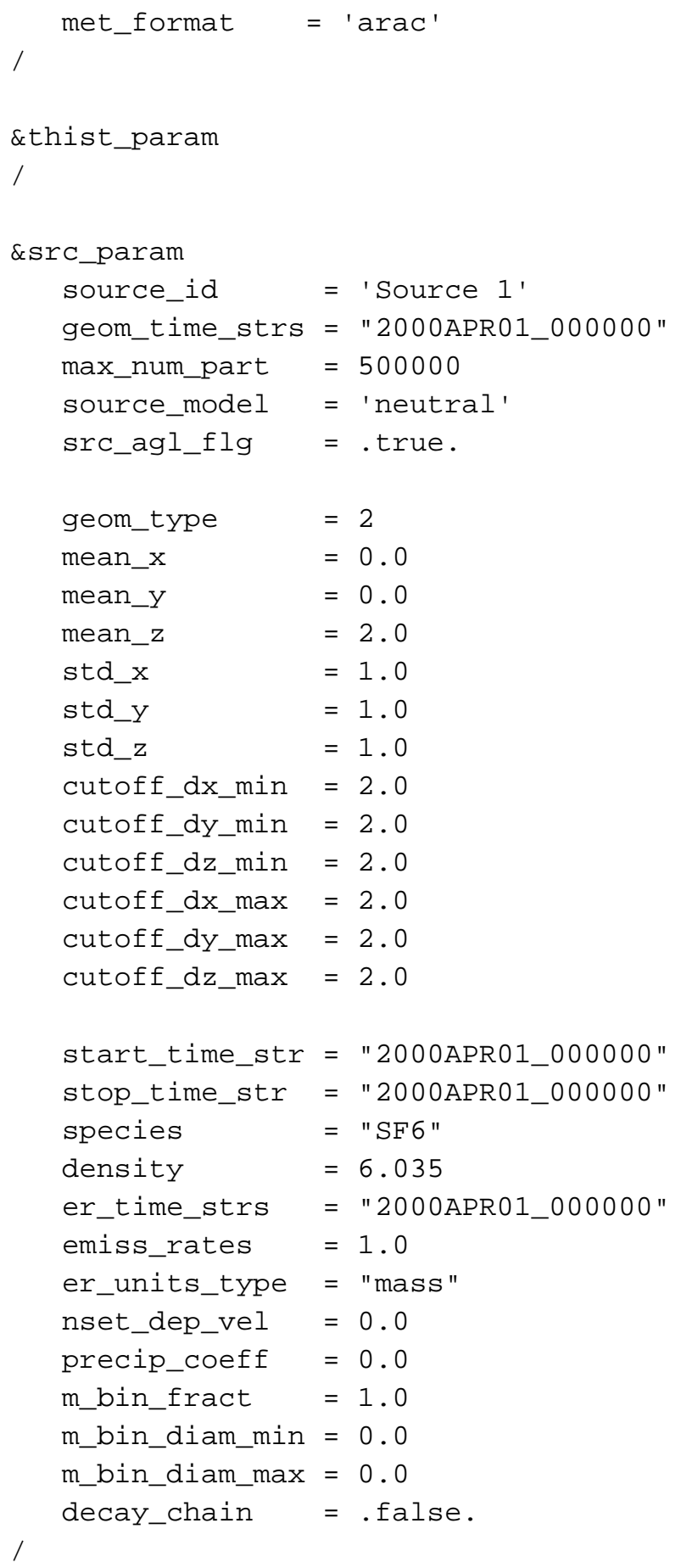

\section{NARAC MvM7}

lodi_mvm07.nml (continued)

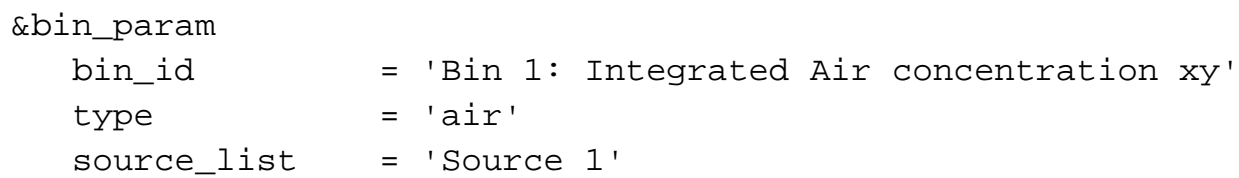




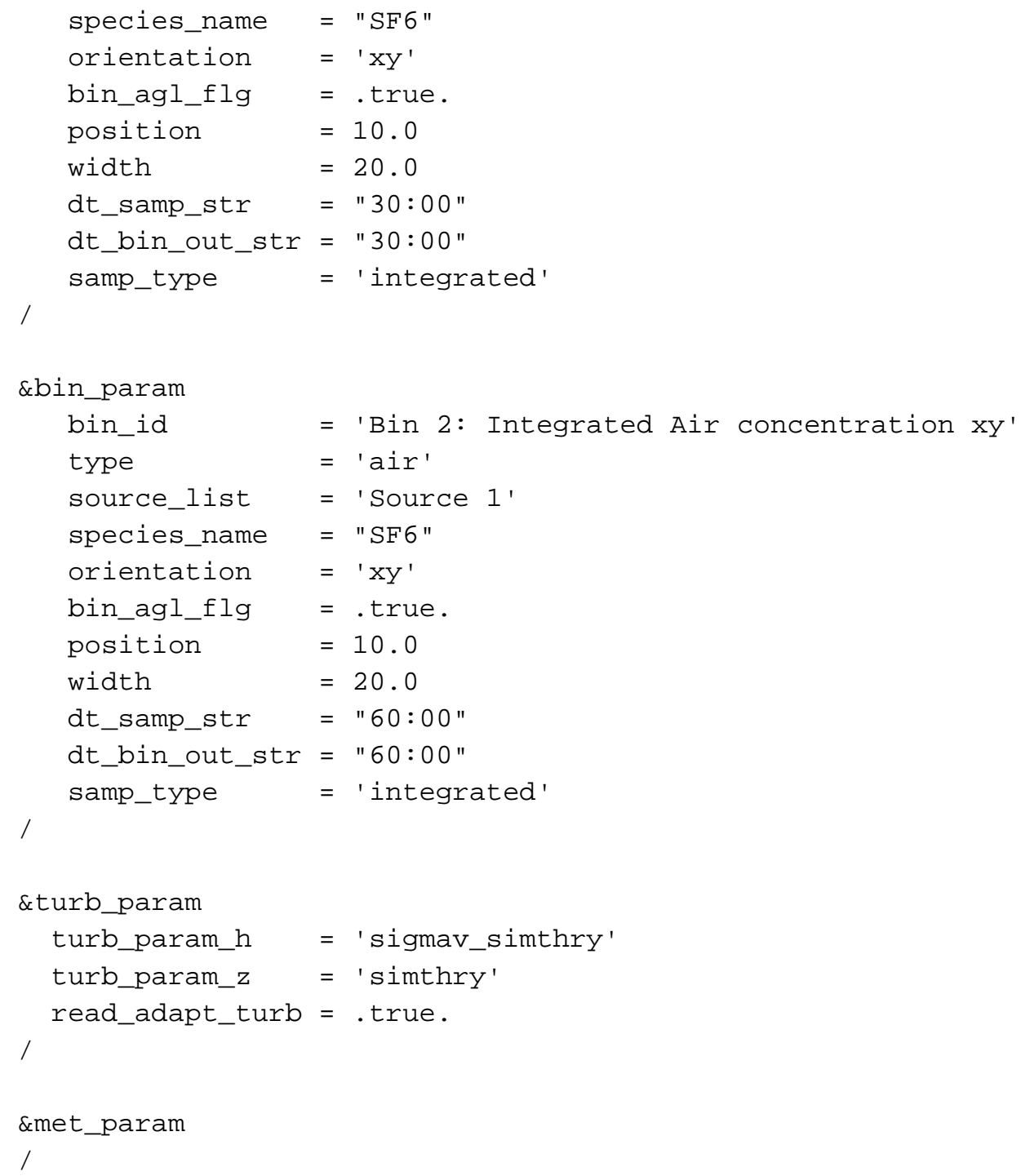

NARAC MvM7

stnloc_mvm07.met

SFC

'Mtom1' $0.0 \quad 0.0 \quad 10.0$

UPR

$\begin{array}{lll}\text { 'MtoM1' } 0.0 \quad 0.0 & 0.00\end{array}$

\section{NARAC MvM7}

observ_mvm07.met

$\begin{array}{llll}\text { METDATASET } & \text { '2000APR01_000000' } \\ \text { UPR } & & & \\ \text { 'MtoM1' } & 0.5 & 90 & 3.0643 \\ \text { 'MtoM1' } & 1 & 90 & 3.5578\end{array}$




\begin{tabular}{|c|c|c|c|}
\hline 'MtoM1 ' & 1.5 & 90 & 3.838 \\
\hline 'MtoM1 ' & 2 & 90 & 4.0316 \\
\hline 'MtoM1 ' & 2.5 & 90 & 4.1783 \\
\hline 'MtoM1 ' & 3 & 90 & 4.2956 \\
\hline 'MtoM1' & 3.5 & 90 & 4.3929 \\
\hline 'MtoM1' & 4 & 90 & 4.4756 \\
\hline 'MtoM1 ' & 4.5 & 90 & 4.5473 \\
\hline 'MtoM1 ' & 5 & 90 & 4.6104 \\
\hline 'MtoM1 ' & 5.5 & 90 & 4.6666 \\
\hline 'MtoM1 ' & 6 & 90 & 4.7173 \\
\hline 'MtoM1 ' & 6.5 & 90 & 4.7632 \\
\hline 'MtoM1 ' & 7 & 90 & 4.8052 \\
\hline 'MtoM1 ' & 7.5 & 90 & 4.8439 \\
\hline 'MtoM1 ' & 8 & 90 & 4.8796 \\
\hline 'MtoM1 ' & 8.5 & 90 & 4.9128 \\
\hline 'MtoM1 ' & 9 & 90 & 4.9438 \\
\hline 'MtoM1 ' & 9.5 & 90 & 4.9728 \\
\hline 'MtoM1 ' & 10 & 90 & 5 \\
\hline 'MtoM1 ' & 10.5 & 90 & 5.0257 \\
\hline 'MtoM1 ' & 11 & 90 & 5.0499 \\
\hline 'MtoM1 ' & 11.5 & 90 & 5.0729 \\
\hline 'MtoM1 ' & 12 & 90 & 5.0947 \\
\hline 'MtoM1 ' & 12.5 & 90 & 5.1155 \\
\hline 'MtoM1 ' & 13 & 90 & 5.1353 \\
\hline 'MtoM1 ' & 13.5 & 90 & 5.1541 \\
\hline 'MtoM1' & 14 & 90 & 5.1722 \\
\hline 'Mtom1 ' & 14.5 & 90 & 5.1895 \\
\hline 'MtoM1' & 15 & 90 & 5.2061 \\
\hline 'MtoM1' & 15.5 & 90 & 5.2221 \\
\hline 'MtoM1 ' & 16 & 90 & 5.2374 \\
\hline 'MtoM1' & 16.5 & 90 & 5.2522 \\
\hline 'MtoM1 ' & 17 & 90 & 5.2664 \\
\hline 'MtoM1' & 17.5 & 90 & 5.2802 \\
\hline 'MtoM1' & 18 & 90 & 5.2935 \\
\hline 'MtoM1' & 18.5 & 90 & 5.3063 \\
\hline 'MtoM1' & 19 & 90 & 5.3187 \\
\hline 'MtoM1 ' & 19.5 & 90 & 5.3308 \\
\hline 'MtoM1 ' & 20 & 90 & 5.3424 \\
\hline 'MtoM1 ' & 20.5 & 90 & 5.3538 \\
\hline 'MtoM1 ' & 21 & 90 & 5.3647 \\
\hline 'MtoM1' & 21.5 & 90 & 5.3754 \\
\hline 'MtoM1' & 22 & 90 & 5.3858 \\
\hline 'MtoM1' & 22.5 & 90 & 5.3959 \\
\hline ' Mtom1 ' & 23 & 90 & 5.4057 \\
\hline 'MtoM1 ' & 23.5 & 90 & 5.4153 \\
\hline
\end{tabular}

NARAC MvM7

observ_mvm07.met (continued) 


\begin{tabular}{|c|c|c|c|}
\hline 'MtoM1 ' & 24 & 90 & 5.4246 \\
\hline 'MtoM1 ' & 24.5 & 90 & 5.4337 \\
\hline 'MtoM1 ' & 25 & 90 & 5.4425 \\
\hline 'MtoM1 ' & 25.5 & 90 & 5.4512 \\
\hline 'MtoM1' & 26 & 90 & 5.4596 \\
\hline 'MtoM1' & 26.5 & 90 & 5.4679 \\
\hline 'MtoM1 ' & 27 & 90 & 5.476 \\
\hline 'MtoM1 ' & 27.5 & 90 & 5.4838 \\
\hline 'MtoM1 ' & 28 & 90 & 5.4915 \\
\hline 'MtoM1 ' & 28.5 & 90 & 5.4991 \\
\hline 'MtoM1 ' & 29 & 90 & 5.5065 \\
\hline 'MtoM1' & 29.5 & 90 & 5.5137 \\
\hline 'MtoM1' & 30 & 90 & 5.5208 \\
\hline 'MtoM1 ' & 30.5 & 90 & 5.5277 \\
\hline 'MtoM1 ' & 31 & 90 & 5.5345 \\
\hline 'MtoM1 ' & 31.5 & 90 & 5.5412 \\
\hline 'MtoM1 ' & 32 & 90 & 5.5477 \\
\hline 'MtoM1' & 32.5 & 90 & 5.5541 \\
\hline 'MtoM1' & 33 & 90 & 5.5604 \\
\hline 'MtoM1' & 33.5 & 90 & 5.5666 \\
\hline 'MtoM1 ' & 34 & 90 & 5.5726 \\
\hline 'MtoM1 ' & 34.5 & 90 & 5.5786 \\
\hline 'MtoM1 ' & 35 & 90 & 5.5845 \\
\hline 'MtoM1 ' & 35.5 & 90 & 5.5902 \\
\hline 'MtoM1 ' & 36 & 90 & 5.5959 \\
\hline 'MtoM1 ' & 36.5 & 90 & 5.6014 \\
\hline 'MtoM1 ' & 37 & 90 & 5.6069 \\
\hline 'MtoM1 ' & 37.5 & 90 & 5.6122 \\
\hline 'MtoM1 ' & 38 & 90 & 5.6175 \\
\hline 'MtoM1 ' & 38.5 & 90 & 5.6227 \\
\hline 'MtoM1' & 39 & 90 & 5.6278 \\
\hline 'MtoM1' & 39.5 & 90 & 5.6329 \\
\hline 'MtoM1' & 40 & 90 & 5.6378 \\
\hline 'MtoM1 ' & 40.5 & 90 & 5.6427 \\
\hline 'MtoM1 ' & 41 & 90 & 5.6475 \\
\hline 'MtoM1 ' & 41.5 & 90 & 5.6523 \\
\hline 'MtoM1 ' & 42 & 90 & 5.6569 \\
\hline 'MtoM1' & 42.5 & 90 & 5.6615 \\
\hline 'MtoM1' & 43 & 90 & 5.6661 \\
\hline 'MtoM1 ' & 43.5 & 90 & 5.6705 \\
\hline 'MtoM1 ' & 44 & 90 & 5.6749 \\
\hline 'MtoM1 ' & 44.5 & 90 & 5.6793 \\
\hline 'MtoM1' & 45 & 90 & 5.6836 \\
\hline 'MtoM1' & 45.5 & 90 & 5.6878 \\
\hline 'MtoM1' & 46 & 90 & 5.692 \\
\hline 'MtoM1' & 46.5 & 90 & 5.6961 \\
\hline 'MtoM1 ' & 47 & 90 & 5.7002 \\
\hline 'MtoM1 ' & 47.5 & 90 & 5.7042 \\
\hline 'MtoM1 ' & 48 & 90 & 5.7081 \\
\hline
\end{tabular}




$\begin{array}{llll}\text { 'MtoM1' } & 48.5 & 90 & 5.712 \\ \text { 'MtoM1' } & 49 & 90 & 5.7159 \\ \text { 'MtoM1' } & 49.5 & 90 & 5.7197 \\ \text { 'MtoM1' } & 50 & 90 & 5.7234\end{array}$


HPAC MvM8

\begin{tabular}{|c|c|c|}
\hline HPAC SCREEN & agent & SF6 \\
\hline \multirow[t]{12}{*}{ New Project Setup } & project file name & mvm8.prj \\
\hline & coordina tes & cartesian \\
\hline & local origin $\mathrm{x}$ & $0 \mathrm{~km}$ \\
\hline & local origin y & $0 \mathrm{~km}$ \\
\hline & local origin lat i tude & $45 \operatorname{deg} N$ \\
\hline & local origin longi tude & $0 \mathrm{deg}$ \\
\hline & reference times & UTC \\
\hline & local time of $00: 00 z$ & 0 \\
\hline & mode & st andard \\
\hline & dynamics & dense gas \\
\hline & static puffs & enabled \\
\hline & hazard area & off \\
\hline New Project Editor & edit mode & advanœed \\
\hline \multirow{8}{*}{ Material Edi tor } & type & gas \\
\hline & name & SF6 \\
\hline & ma terial file & Sf $6 . \mathrm{mt}$ \\
\hline & units & $\mathrm{kg}$ \\
\hline & bin boundaries & NA \\
\hline & output flags & surf. dosage, surf. depos \\
\hline & daytime decay rate & 0 \\
\hline & nigh tt ime decay rate & 0 \\
\hline \multirow[t]{3}{*}{ Gas Parame ter Editor } & density ratio (rho/ rho air) & 5.02917 \\
\hline & deposition velocity & 0 \\
\hline & minimum concen tra tion & 0 \\
\hline \multirow[t]{15}{*}{ Release Editor } & time & 0 \\
\hline & $\mathbf{x}$ & 0 \\
\hline & $y$ & 0 \\
\hline & height of release & $250 \mathrm{~m}$ \\
\hline & source uncert ainty & no \\
\hline & specifica tion & simple \\
\hline & randomize loc ation & no \\
\hline & release dura tion & inst antaneous \\
\hline & release ra te & NA \\
\hline & agent mass & $1 \mathrm{~kg}$ \\
\hline & $x$ size & $1 \mathrm{~m}$ \\
\hline & y size & $1 \mathrm{~m}$ \\
\hline & z size & $1 \mathrm{~m}$ \\
\hline & momentum & 0 \\
\hline & buoyancy & 0 \\
\hline \multirow[t]{6}{*}{ Time Editor } & start day & $4 / 1 / 00$ \\
\hline & start time & 0 \\
\hline & s top day & $4 / 1 / 00$ \\
\hline & s top time & 100 \\
\hline & maximum time step & $60 \mathrm{sec}$ \\
\hline & out put interval & $15 \mathrm{~min}$ \\
\hline \multirow[t]{7}{*}{ Domain Editor } & xmin domain & $-50 \mathrm{~km}$ \\
\hline & xmax domain & $1 \mathrm{~km}$ \\
\hline & ymin domain & $-5 \mathrm{~km}$ \\
\hline & ymax domain & $5 \mathrm{~km}$ \\
\hline & horizon tal resolution & default \\
\hline & vertical domain max height & $500 \mathrm{~m}$ \\
\hline & vertical domain resolution & $10 \mathrm{~m}$ \\
\hline Wea ther Editor & weather dat a type & surface obs. only \\
\hline & boundary layer t ype & observations \\
\hline & $\begin{array}{c}\text { large scale variability } \\
\end{array}$ & none \\
\hline & large scale variability length scale & NA \\
\hline & large scale variability variance & NA \\
\hline & $\begin{array}{c}\text { surf ace roughness } \\
\end{array}$ & $0.008 \mathrm{~m}$ \\
\hline & precipita tion & none \\
\hline & obs. time bin size & $1 \mathrm{hr}$ \\
\hline Meteorology Option Edi tor & save me teorology fields & no \\
\hline & terrain/land cover file & no \\
\hline Surface Obsenations File & $\begin{array}{r}\text { file name } \\
\end{array}$ & mvmU.sfc \\
\hline & $\begin{array}{c}\text { elevation } \\
\end{array}$ & $10 \mathrm{~m}$ \\
\hline & zi (boundary layer height) & $500 \mathrm{~m}$ \\
\hline & $z$ (al ti tude for wind measurement) & $10 \mathrm{~m}$ \\
\hline & wind direction (from) & $90 \mathrm{deg}$ (east) \\
\hline & $\begin{array}{c}\text { wind speed } \\
\end{array}$ & $5 \mathrm{~m} / \mathrm{s}$ \\
\hline & MOL (Monin-Obukhov Leng th) & $-50 \mathrm{~m}$ \\
\hline Op tions Editor & puff split grid level & 2 \\
\hline & surface resolution & default \\
\hline & puf $f$ grid resolution & 0 \\
\hline & boundary layer pts & 11 \\
\hline & stable atm. turbulence & $1 \mathrm{e}-2 \mathrm{~m}^{\wedge} 2 / \mathrm{s}^{\wedge} 2$ \\
\hline & stable a tm. scale & $10 \mathrm{~m}$ \\
\hline & stable dissipa tion & $4 \mathrm{e}-4 \mathrm{~m}^{\wedge} 2 / \mathrm{s}^{\wedge} 3$ \\
\hline & calm cond. turbulence & $0.25 \mathrm{~m}^{\wedge} 2 / \mathrm{s}^{\wedge} 2$ \\
\hline & calm cond. scale & $1000 \mathrm{~m}$ \\
\hline & surface dosage height & 0 \\
\hline & minimum puf $f$ mass & $1 \mathrm{e}-20$ \\
\hline & conditional averaging time & $1 \mathrm{hr}$ \\
\hline & lumped boundary layer & no \\
\hline
\end{tabular}




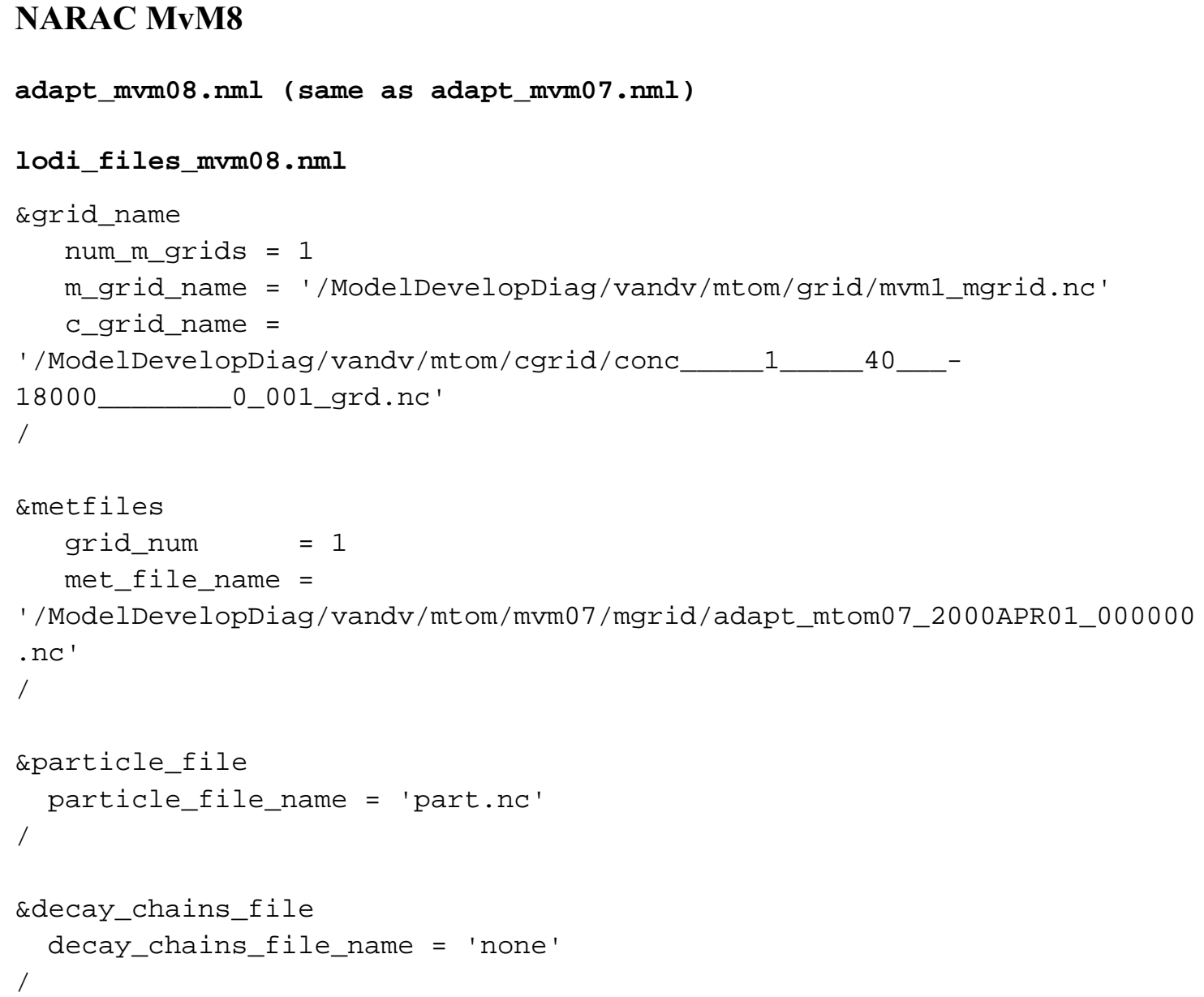




$$
\begin{aligned}
& \text { geom_time_strs }=\text { "2000APR01_000000" } \\
& \text { max_num_part }=500000 \\
& \text { source_model = 'neutral' } \\
& \text { src_agl_flg = .true. }
\end{aligned}
$$

\section{NARAC MvM8}

\section{lodi_mvm08.nml (continued)}

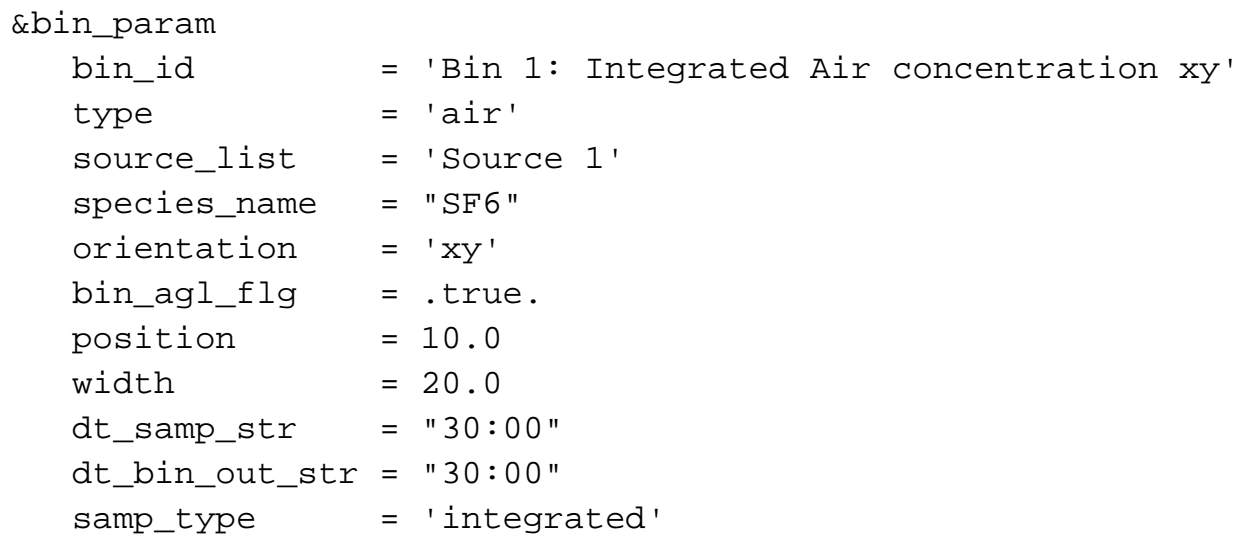




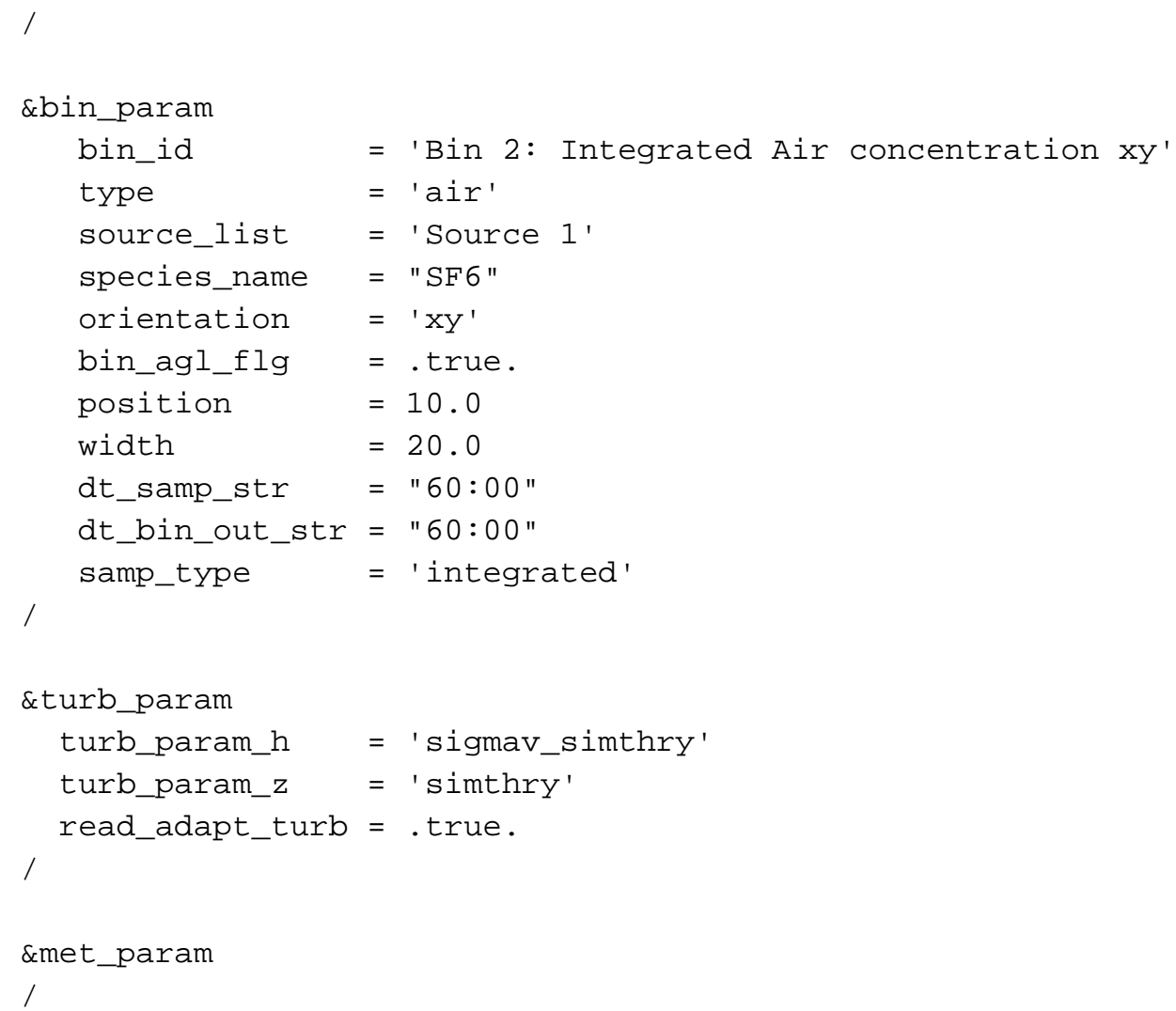

\section{NARAC MvM8}

stnloc_mvm08.met (same as stnloc_mvm07.met)

observ_mvm08.met (same as observ_mvm07.met) 


\section{HPAC MvM9}

\begin{tabular}{|c|c|c|}
\hline mvm9 & HPAC 3.2 parame ter & HPAC 3.2 value \\
\hline HPAC SCREEN & agent & SF6 \\
\hline \multirow[t]{12}{*}{ New Project Setup } & project file name & mvm9.prj \\
\hline & coordina tes & cartesian \\
\hline & local origin $\mathrm{x}$ & $0 \mathrm{~km}$ \\
\hline & local origin $y$ & $0 \mathrm{~km}$ \\
\hline & local origin lat i tude & $45 \operatorname{deg} N$ \\
\hline & local origin longi tude & $0 \mathrm{deg}$ \\
\hline & reference times & UTC \\
\hline & local time of $00: 00 z$ & 0 \\
\hline & mode & st andard \\
\hline & dynamics & dense gas \\
\hline & static puffs & enabled \\
\hline & hazard area & off \\
\hline New Project Editor & edit mode & advanœed \\
\hline \multirow{8}{*}{ Material Editor } & type & gas \\
\hline & name & SF6 \\
\hline & material file & Sf $6 . \mathrm{mt}$ \\
\hline & units & $\mathrm{kg}$ \\
\hline & bin boundaries & NA \\
\hline & output flags & surf. dosage, surf. depos \\
\hline & daytime decay rate & $\begin{array}{r}0 \\
\end{array}$ \\
\hline & nighttime decay ra te & 0 \\
\hline \multirow[t]{3}{*}{ Gas Parame ter Editor } & density ratio (rho/ rho_air) & 5.02917 \\
\hline & deposition velocity & 0 \\
\hline & minimum concen tra tion & 0 \\
\hline \multirow[t]{15}{*}{ Release Editor } & time & 0 \\
\hline & $\mathbf{x}$ & 0 \\
\hline & $y$ & 0 \\
\hline & height of release & $400 \mathrm{~m}$ \\
\hline & source uncert ainty & no \\
\hline & specification & simple \\
\hline & randomize location & no \\
\hline & release dura tion & instantaneous \\
\hline & release ra te & NA \\
\hline & agent mass & $1 \mathrm{~kg}$ \\
\hline & $x$ size & $1 \mathrm{~m}$ \\
\hline & y size & $1 \mathrm{~m}$ \\
\hline & z size & $1 \mathrm{~m}$ \\
\hline & momentum & 0 \\
\hline & buoyancy & 0 \\
\hline \multirow[t]{6}{*}{ Time Editor } & start day & $4 / 1 / 00$ \\
\hline & start time & 0 \\
\hline & s top day & $4 / 1 / 00$ \\
\hline & stop time & 100 \\
\hline & maximum time step & $60 \mathrm{sec}$ \\
\hline & out put interval & $15 \mathrm{~min}$ \\
\hline \multirow[t]{7}{*}{ Domain Editor } & xmin domain & $-50 \mathrm{~km}$ \\
\hline & $x \max$ domain & $1 \mathrm{~km}$ \\
\hline & ymin domain & $-5 \mathrm{~km}$ \\
\hline & ymax domain & $5 \mathrm{~km}$ \\
\hline & horizontal resolution & default \\
\hline & vertical domain max height & $500 \mathrm{~m}$ \\
\hline & vertical domain resolution & $10 \mathrm{~m}$ \\
\hline Wea ther Editor & weather dat a type & surface obs. only \\
\hline & boundary layer t ype & observations \\
\hline & large scale variability & none \\
\hline & large scale variability length scale & NA \\
\hline & large scale variability variance & NA \\
\hline & $\begin{array}{c}\text { surf ace roughness } \\
\end{array}$ & $0.008 \mathrm{~m}$ \\
\hline & precipita tion & none \\
\hline & obs. time bin size & $1 \mathrm{hr}$ \\
\hline Meteorology Option Edi tor & save me te orology fields & no \\
\hline & terrain/land cover file & no \\
\hline Surface Observations File & file name & mvmU.sfc \\
\hline & $\begin{array}{c}\text { elevation } \\
\end{array}$ & $10 \mathrm{~m}$ \\
\hline & zi (boundary layer height) & $500 \mathrm{~m}$ \\
\hline & $z$ (al ti tude for wind measur ement) & $10 \mathrm{~m}$ \\
\hline & wind dire ction ( from) & $90 \mathrm{deg}$ (east) \\
\hline & $\begin{array}{c}\text { wind speed } \\
\end{array}$ & $5 \mathrm{~m} / \mathrm{s}$ \\
\hline & MOL (Monin-Obukhov Leng th) & $-50 \mathrm{~m}$ \\
\hline Op tions Editor & puff split grid level & 2 \\
\hline & surface resolution & default \\
\hline & puf f grid resolution & 0 \\
\hline & boundary layer pts & 11 \\
\hline & stable atm. turbulence & $1 \mathrm{e}-2 \mathrm{~m}^{\wedge} 2 / \mathrm{s}^{\wedge} 2$ \\
\hline & stable a tm. scale & $10 \mathrm{~m}$ \\
\hline & stable dissipa tion & $4 \mathrm{e}-4 \mathrm{~m}^{\wedge} 2 / \mathrm{s}^{\wedge} 3$ \\
\hline & calm cond. turbulence & $0.25 \mathrm{~m}^{\wedge} 2 / \mathrm{s}^{\wedge} 2$ \\
\hline & calm cond. scale & $1000 \mathrm{~m}$ \\
\hline & surface dosage height & 0 \\
\hline & minimum puf $\mathrm{f}$ mass & $1 \mathrm{e}-20$ \\
\hline & conditional averaging time & $1 \mathrm{hr}$ \\
\hline & lumped boundary layer & no \\
\hline
\end{tabular}




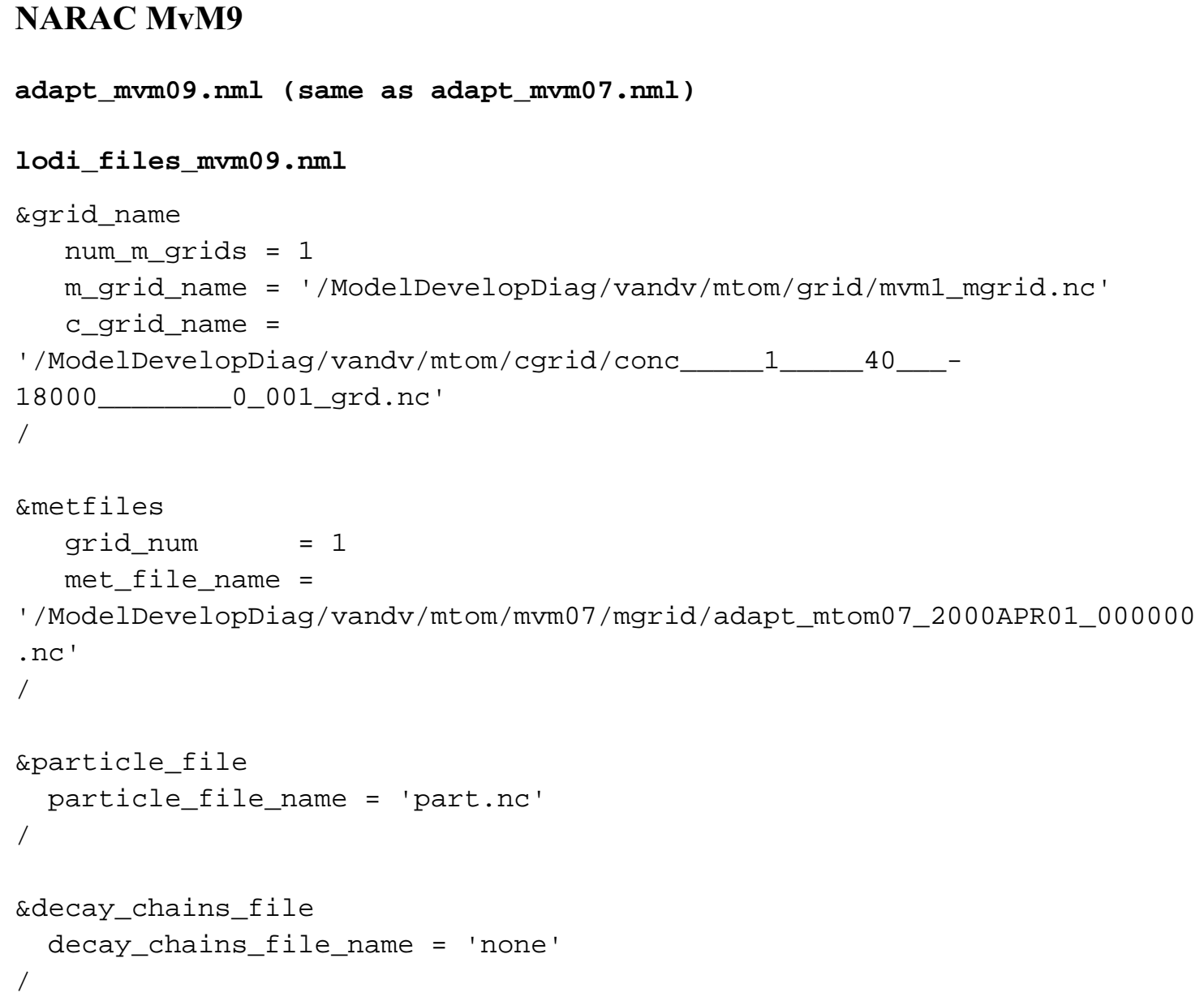

NARAC MvM9

lodi_mvm09.nml 


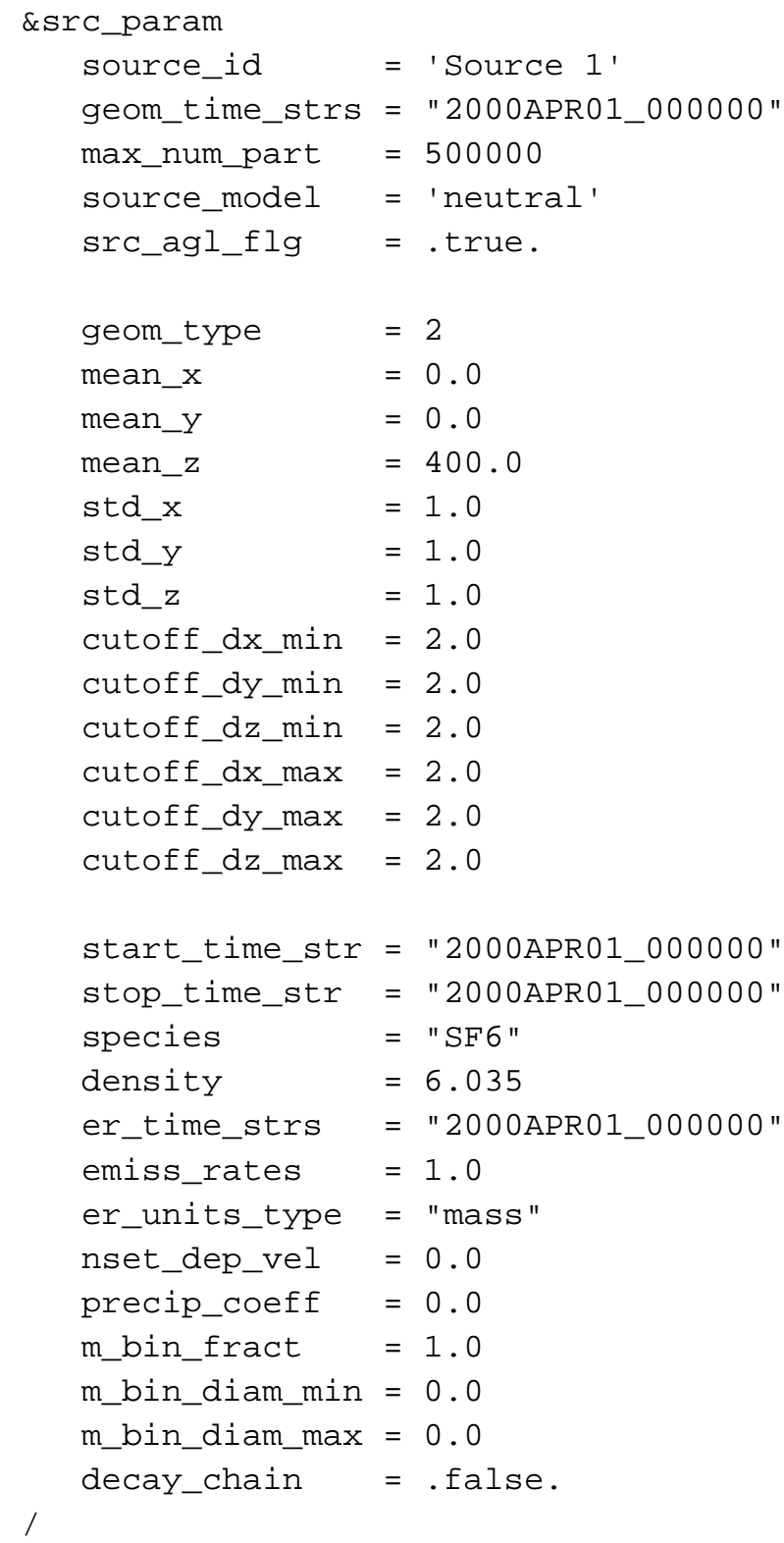

\section{NARAC MvM9}

lodi_mvm09.nml (continued)

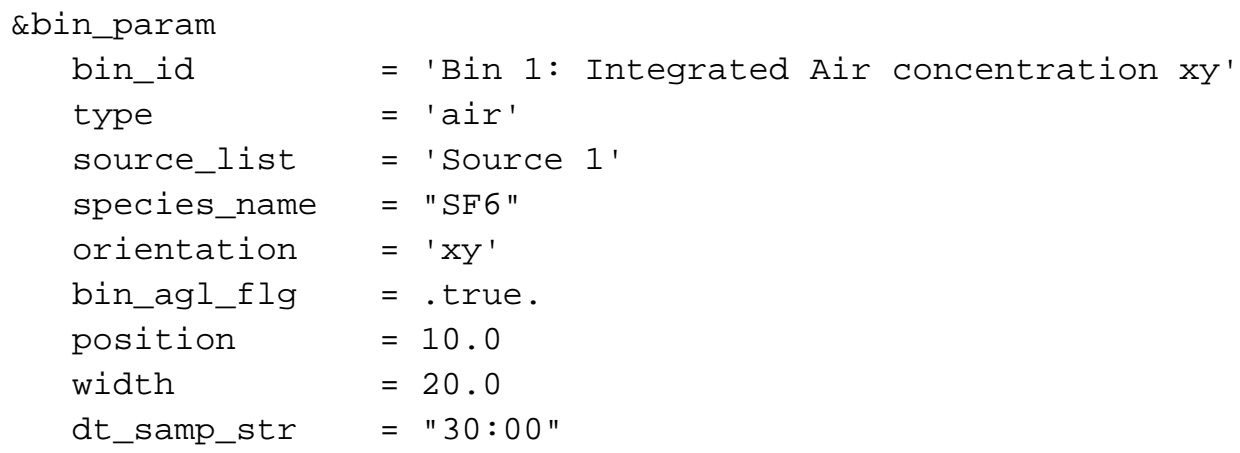




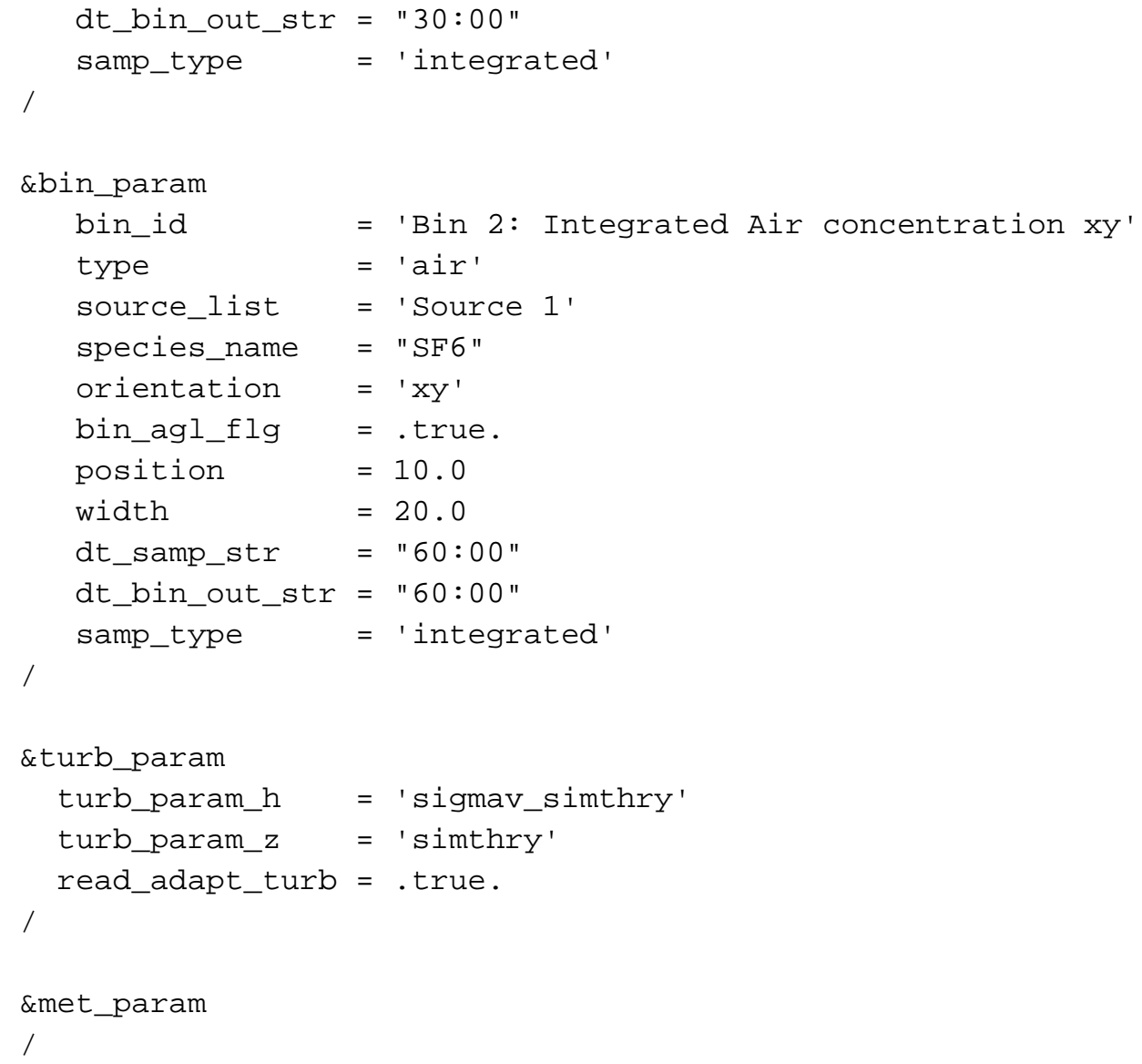

NARAC MvM9

stnloc_mvm09.met (same as stnloc_mvm07.met)

observ_mvm09.met (same as observ_mvm07.met) 


\section{HPAC MvM10}

\begin{tabular}{|c|c|c|}
\hline mvm10 & HPAC 3.2 parame ter & HPAC 3.2 value \\
\hline HPAC SCREEN & agent & 5 micron par ticles \\
\hline \multirow[t]{12}{*}{ New Project Setup } & project file name & $m v m 10 . p j$ \\
\hline & coordina tes & cartesian \\
\hline & local origin $\mathrm{x}$ & $0 \mathrm{~km}$ \\
\hline & local origin $y$ & $0 \mathrm{~km}$ \\
\hline & local origin lat i tude & $45 \operatorname{deg} N$ \\
\hline & local origin longi tude & $0 \mathrm{deg}$ \\
\hline & reference times & UTC \\
\hline & local time of $00: 00 z$ & 0 \\
\hline & mode & st andard \\
\hline & dynamics & dense gas \\
\hline & static puffs & enabled \\
\hline & hazard area & off \\
\hline New Project Editor & edit mode & advanœed \\
\hline \multirow{8}{*}{ Material Editor } & type & particle \\
\hline & name & STUFF5 \\
\hline & mat erial file name & Stuff5. $\mathrm{mtI}$ \\
\hline & units & $\mathrm{kg}$ \\
\hline & bin boundaries & $4.89 \quad \mu, 5.12$ \\
\hline & output flags & surf. dosage, surf. depos \\
\hline & daytime decay rate & $\begin{array}{r}0 \\
\end{array}$ \\
\hline & nighttime decay rate & 0 \\
\hline \multirow[t]{3}{*}{ Particle Parame ter Editor } & density & $500 \mathrm{~kg} / \mathrm{m}^{\wedge} 3$ \\
\hline & deposition velocity & NA \\
\hline & minimum concen tra tion & 0 \\
\hline \multirow[t]{15}{*}{ Release Editor } & time & 0 \\
\hline & $\mathbf{x}$ & 0 \\
\hline & $y$ & 0 \\
\hline & height of release & $2 \mathrm{~m}$ \\
\hline & source uncert ainty & no \\
\hline & specification & simple \\
\hline & randomize location & NA \\
\hline & release dura tion & $15 \mathrm{~min}$ \\
\hline & release ra te & $0.067 \mathrm{~kg} / \mathrm{min}$ \\
\hline & agent mass & $1 \mathrm{~kg}$ \\
\hline & $x$ size & NA \\
\hline & y size & $1 \mathrm{~m}$ \\
\hline & z size & $1 \mathrm{~m}$ \\
\hline & momentum & 0 \\
\hline & buoyancy & 0 \\
\hline \multirow[t]{6}{*}{ Time Editor } & start day & $4 / 1 / 00$ \\
\hline & start time & 0 \\
\hline & stop day & $4 / 1 / 00$ \\
\hline & stop time & 100 \\
\hline & maximum time step & $60 \mathrm{sec}$ \\
\hline & out put interval & $15 \mathrm{~min}$ \\
\hline \multirow[t]{7}{*}{ Domain Editor } & xmin domain & $-50 \mathrm{~km}$ \\
\hline & $x \max$ domain & $1 \mathrm{~km}$ \\
\hline & ymin domain & $-5 \mathrm{~km}$ \\
\hline & ymax domain & $5 \mathrm{~km}$ \\
\hline & horizontal resolution & default \\
\hline & vertical domain max height & $500 \mathrm{~m}$ \\
\hline & vertical domain resolution & $10 \mathrm{~m}$ \\
\hline Wea ther Editor & weather dat a type & surface obs. only \\
\hline & boundary layer t ype & observations \\
\hline & $\begin{array}{c}\text { large scale variability } \\
\end{array}$ & none \\
\hline & large scale variability length scale & NA \\
\hline & large scale variability variance & NA \\
\hline & $\begin{array}{c}\text { surf ace roughness } \\
\end{array}$ & $0.008 \mathrm{~m}$ \\
\hline & precipita tion & none \\
\hline & obs. time bin size & $1 \mathrm{hr}$ \\
\hline Meteorology Option Editor & save me te orology fields & no \\
\hline & terrain/land cover file & no \\
\hline Surface Obsenations File & $\begin{array}{r}\text { file name } \\
\end{array}$ & $\mathrm{mvmN.sfc}$ \\
\hline & $\begin{array}{c}\text { elevation } \\
\end{array}$ & $10 \mathrm{~m}$ \\
\hline & zi (boundary layer height) & $500 \mathrm{~m}$ \\
\hline & $z$ (al ti tude for wind measur ement) & $10 \mathrm{~m}$ \\
\hline & wind direction ( from) & $90 \mathrm{deg}$ (east) \\
\hline & $\begin{array}{c}\text { wind speed } \\
\end{array}$ & $5 \mathrm{~m} / \mathrm{s}$ \\
\hline & MOL (Monin-Obukhov Leng th) & $-500 \mathrm{~m}$ \\
\hline Options Editor & $\begin{array}{l}\text { puff split grid level } \\
\end{array}$ & 2 \\
\hline & surface resolution & default \\
\hline & puf f grid resolution & 0 \\
\hline & boundary layer pts & 11 \\
\hline & stable atm. turbulence & $1 \mathrm{e}-2 \mathrm{~m}^{\wedge} 2 / \mathrm{s}^{\wedge} 2$ \\
\hline & stable a tm. scale & $10 \mathrm{~m}$ \\
\hline & stable dissipa tion & $4 \mathrm{e}-4 \mathrm{~m}^{\wedge} 2 / \mathrm{s}^{\wedge} 3$ \\
\hline & calm cond. turbulence & $0.25 \mathrm{~m}^{\wedge} 2 / \mathrm{s}^{\wedge} 2$ \\
\hline & calm cond. scale & $1000 \mathrm{~m}$ \\
\hline & surface dosage height & 0 \\
\hline & minimum puf $\mathrm{f}$ mass & $1 \mathrm{e}-20$ \\
\hline & conditional averaging time & $1 \mathrm{hr}$ \\
\hline & lumped boundary layer & no \\
\hline
\end{tabular}




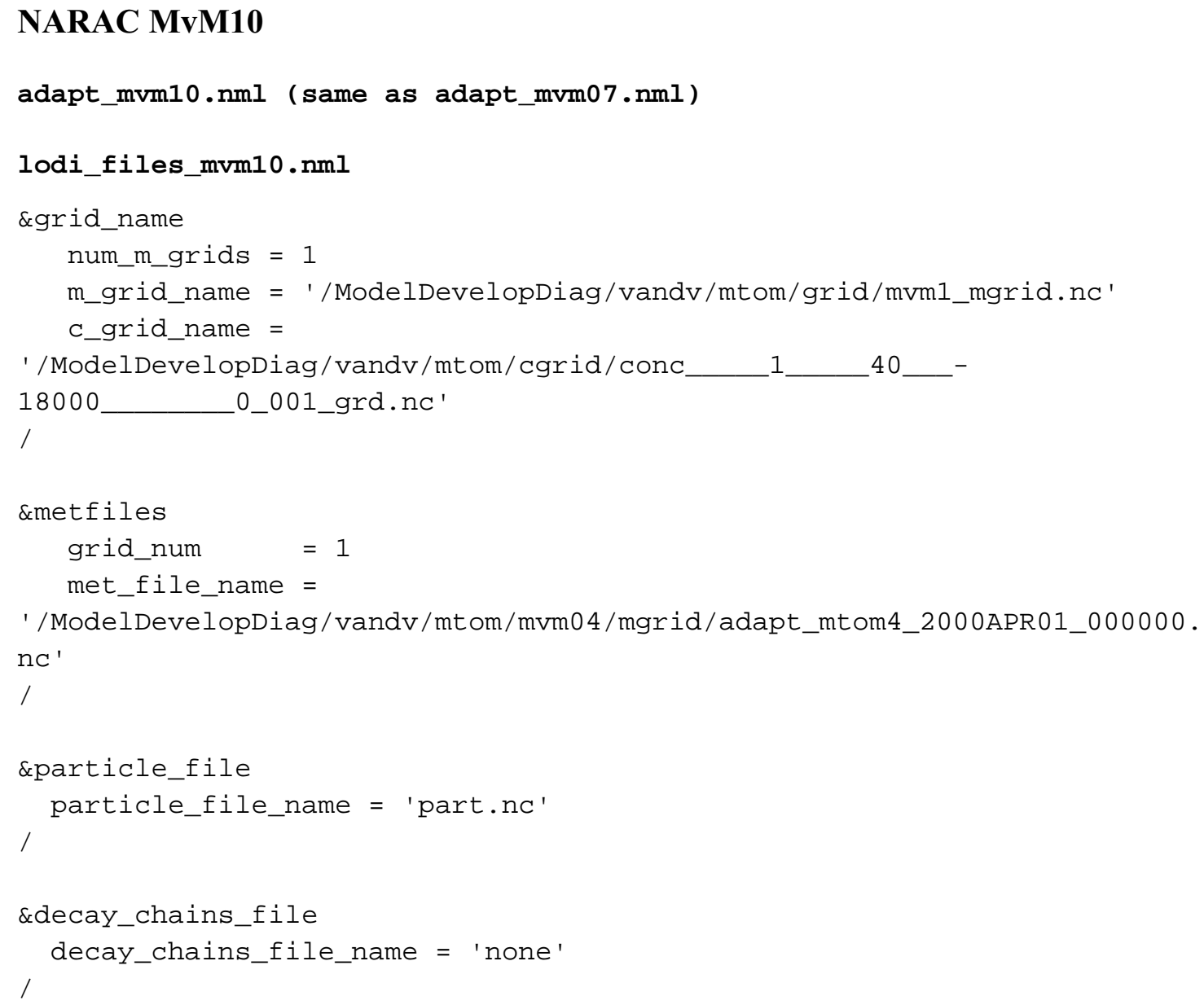

\section{NARAC MvM10}

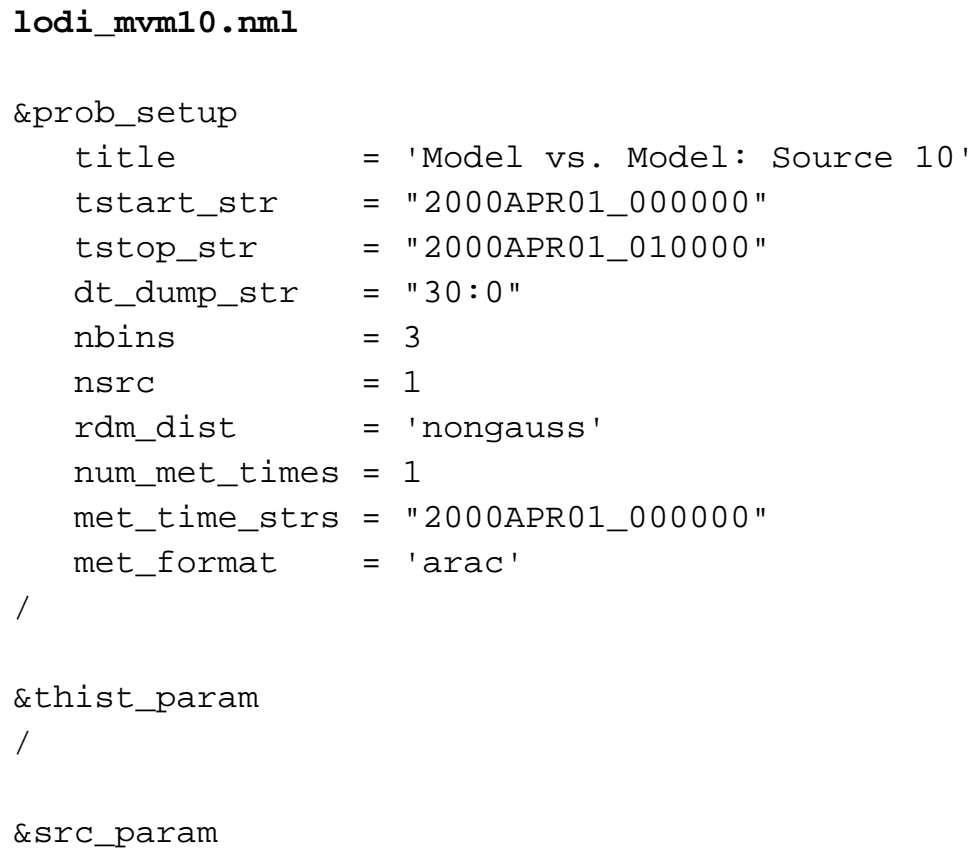




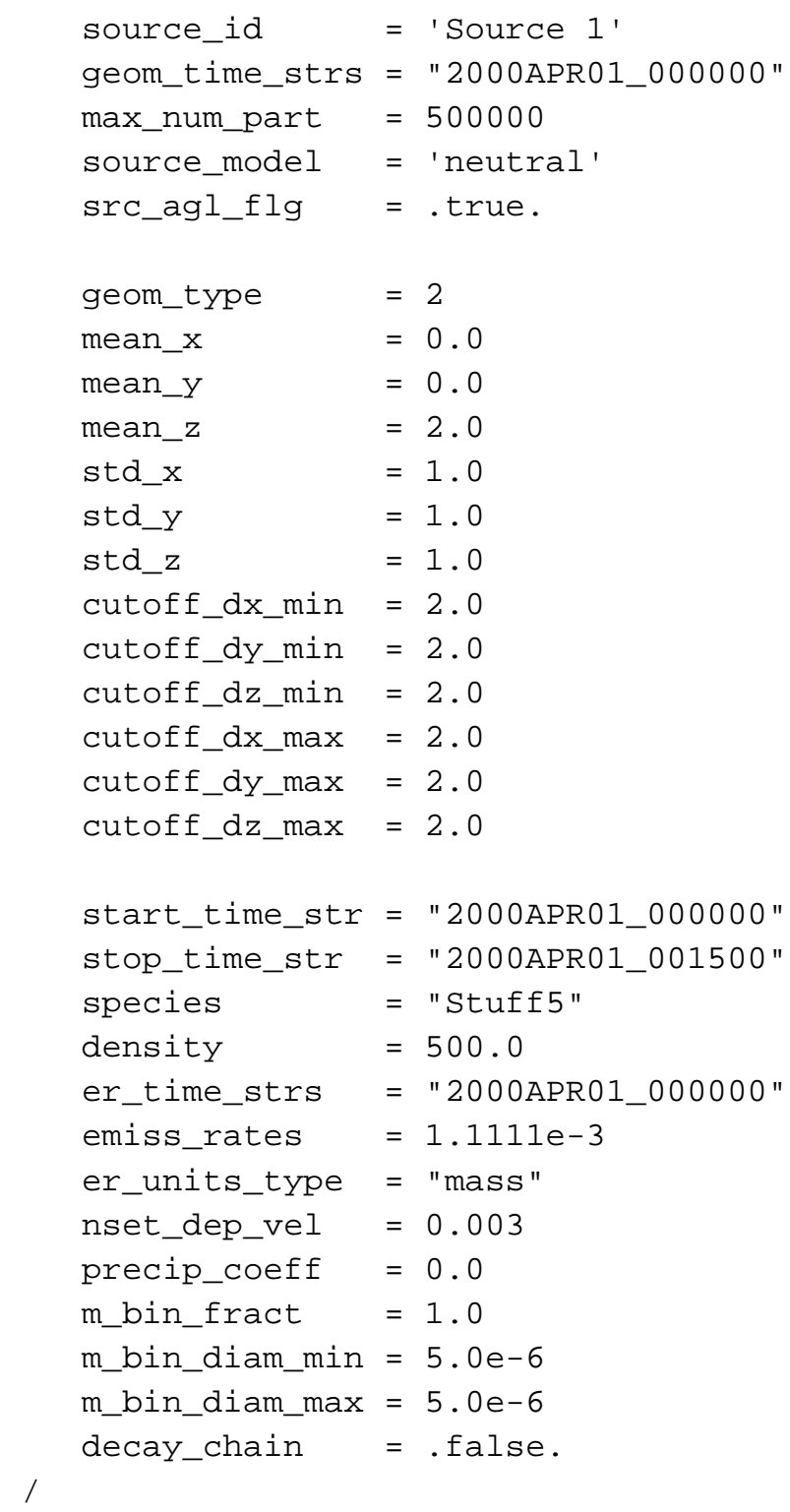

\section{NARAC MvM10}

lodi_mvm10.nml (continued)

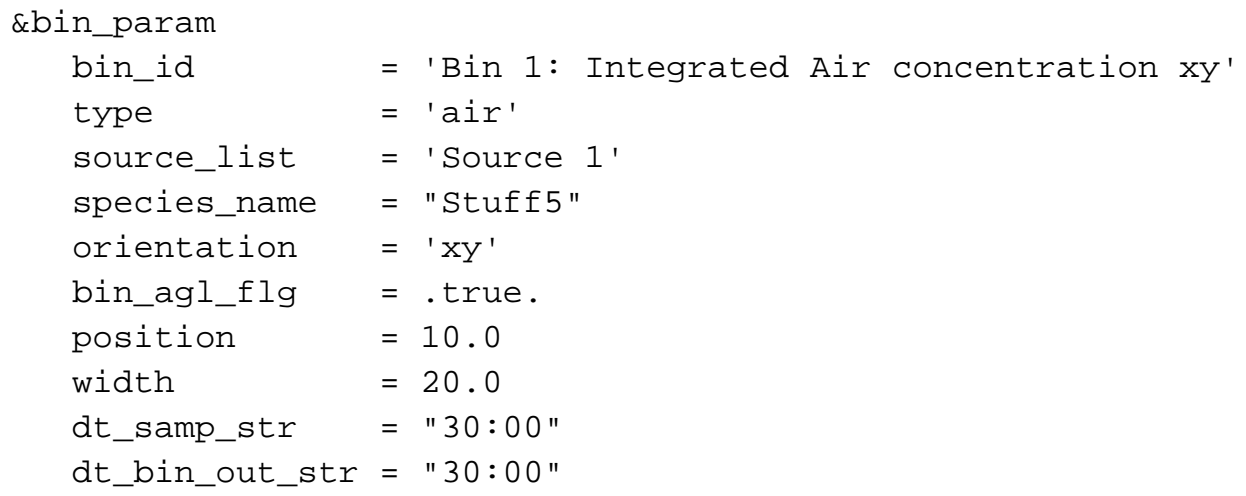




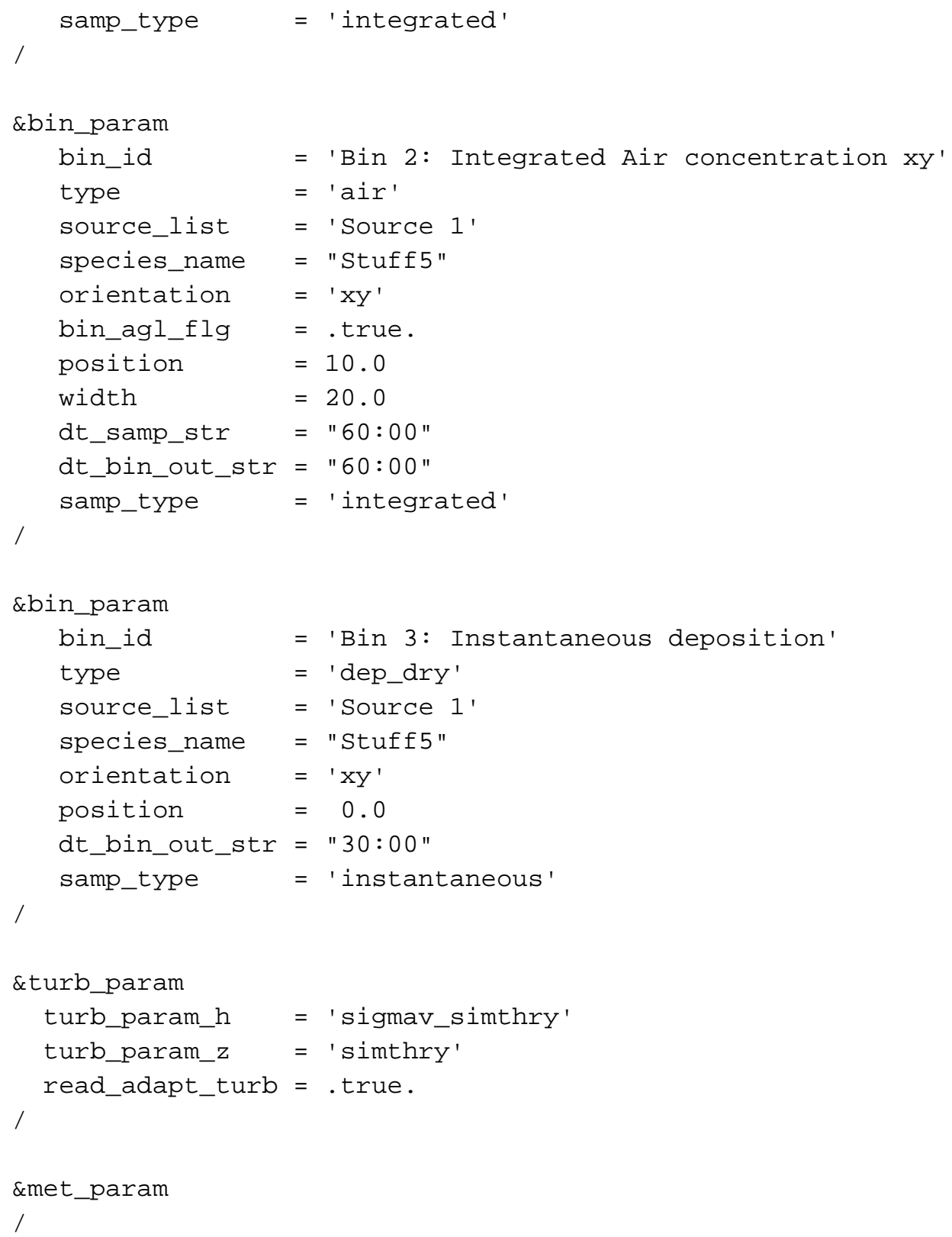

NARAC MvM10

stnloc_mvm10.met (same as stnloc_mvm07.met)

observ_mvm10.met (same as observ_mvm07.met) 


\section{HPAC MvM11}

\begin{tabular}{|c|c|c|}
\hline mvm11 & HPAC 3.2 parame ter & HPAC 3.2 value \\
\hline HPAC SCREEN & agent & 5 micron par ticles \\
\hline \multirow[t]{12}{*}{ New Project Setup } & project file name & $m v m 11 . p j$ \\
\hline & coordina tes & cartesian \\
\hline & local origin $\mathrm{x}$ & $0 \mathrm{~km}$ \\
\hline & local origin $y$ & $0 \mathrm{~km}$ \\
\hline & local origin lat i tude & $45 \operatorname{deg} N$ \\
\hline & local origin longi tude & $0 \mathrm{deg}$ \\
\hline & reference times & UTC \\
\hline & local time of $00: 00 z$ & 0 \\
\hline & mode & st andard \\
\hline & dynamics & dense gas \\
\hline & static puffs & enabled \\
\hline & hazard area & off \\
\hline New Project Editor & edit mode & advanœed \\
\hline \multirow{8}{*}{ Material Editor } & type & particle \\
\hline & name & STUFF5 \\
\hline & mat erial file name & Stuff5. $\mathrm{mtI}$ \\
\hline & units & $\mathrm{kg}$ \\
\hline & bin boundaries & $4.89 \quad \mu, 5.12$ \\
\hline & output flags & surf. dosage, surf. depos \\
\hline & daytime decay rate & $\begin{array}{r}0 \\
\end{array}$ \\
\hline & nighttime decay rate & 0 \\
\hline \multirow[t]{3}{*}{ Particle Parame ter Editor } & density & $500 \mathrm{~kg} / \mathrm{m}^{\wedge} 3$ \\
\hline & deposition velocity & NA \\
\hline & minimum concen tra tion & 0 \\
\hline \multirow[t]{15}{*}{ Release Editor } & time & 0 \\
\hline & $\mathbf{x}$ & 0 \\
\hline & $y$ & 0 \\
\hline & height of release & $250 \mathrm{~m}$ \\
\hline & source uncert ainty & no \\
\hline & specification & simple \\
\hline & randomize location & NA \\
\hline & release dura tion & $15 \mathrm{~min}$ \\
\hline & release ra te & $0.067 \mathrm{~kg} / \mathrm{min}$ \\
\hline & agent mass & $1 \mathrm{~kg}$ \\
\hline & $x$ size & NA \\
\hline & y size & $1 \mathrm{~m}$ \\
\hline & z size & $1 \mathrm{~m}$ \\
\hline & momentum & 0 \\
\hline & buoyancy & 0 \\
\hline \multirow[t]{6}{*}{ Time Editor } & start day & $4 / 1 / 00$ \\
\hline & start time & 0 \\
\hline & stop day & $4 / 1 / 00$ \\
\hline & stop time & 100 \\
\hline & maximum time step & $60 \mathrm{sec}$ \\
\hline & out put interval & $15 \mathrm{~min}$ \\
\hline \multirow[t]{7}{*}{ Domain Editor } & xmin domain & $-50 \mathrm{~km}$ \\
\hline & $x \max$ domain & $1 \mathrm{~km}$ \\
\hline & ymin domain & $-5 \mathrm{~km}$ \\
\hline & ymax domain & $5 \mathrm{~km}$ \\
\hline & horizontal resolution & default \\
\hline & vertical domain max height & $500 \mathrm{~m}$ \\
\hline & vertical domain resolution & $10 \mathrm{~m}$ \\
\hline Wea ther Editor & weather dat a type & surface obs. only \\
\hline & boundary layer t ype & observations \\
\hline & $\begin{array}{c}\text { large scale variability } \\
\end{array}$ & none \\
\hline & large scale variability length scale & NA \\
\hline & large scale variability variance & NA \\
\hline & $\begin{array}{c}\text { surf ace roughness } \\
\end{array}$ & $0.008 \mathrm{~m}$ \\
\hline & precipita tion & none \\
\hline & obs. time bin size & $1 \mathrm{hr}$ \\
\hline Meteorology Option Editor & save me te orology fields & no \\
\hline & terrain/land cover file & no \\
\hline Surface Obsenations File & $\begin{array}{r}\text { file name } \\
\end{array}$ & $\mathrm{mvmN.sfc}$ \\
\hline & $\begin{array}{c}\text { elevation } \\
\end{array}$ & $10 \mathrm{~m}$ \\
\hline & zi (boundary layer height) & $500 \mathrm{~m}$ \\
\hline & $z$ (al ti tude for wind measur ement) & $10 \mathrm{~m}$ \\
\hline & wind direction ( from) & $90 \mathrm{deg}$ (east) \\
\hline & $\begin{array}{c}\text { wind speed } \\
\end{array}$ & $5 \mathrm{~m} / \mathrm{s}$ \\
\hline & MOL (Monin-Obukhov Leng th) & $-500 \mathrm{~m}$ \\
\hline Options Editor & $\begin{array}{l}\text { puff split grid level } \\
\end{array}$ & 2 \\
\hline & surface resolution & default \\
\hline & puf f grid resolution & 0 \\
\hline & boundary layer pts & 11 \\
\hline & stable atm. turbulence & $1 \mathrm{e}-2 \mathrm{~m}^{\wedge} 2 / \mathrm{s}^{\wedge} 2$ \\
\hline & stable a tm. scale & $10 \mathrm{~m}$ \\
\hline & stable dissipa tion & $4 \mathrm{e}-4 \mathrm{~m}^{\wedge} 2 / \mathrm{s}^{\wedge} 3$ \\
\hline & calm cond. turbulence & $0.25 \mathrm{~m}^{\wedge} 2 / \mathrm{s}^{\wedge} 2$ \\
\hline & calm cond. scale & $1000 \mathrm{~m}$ \\
\hline & surface dosage height & 0 \\
\hline & minimum puf $\mathrm{f}$ mass & $1 \mathrm{e}-20$ \\
\hline & conditional averaging time & $1 \mathrm{hr}$ \\
\hline & lumped boundary layer & no \\
\hline
\end{tabular}




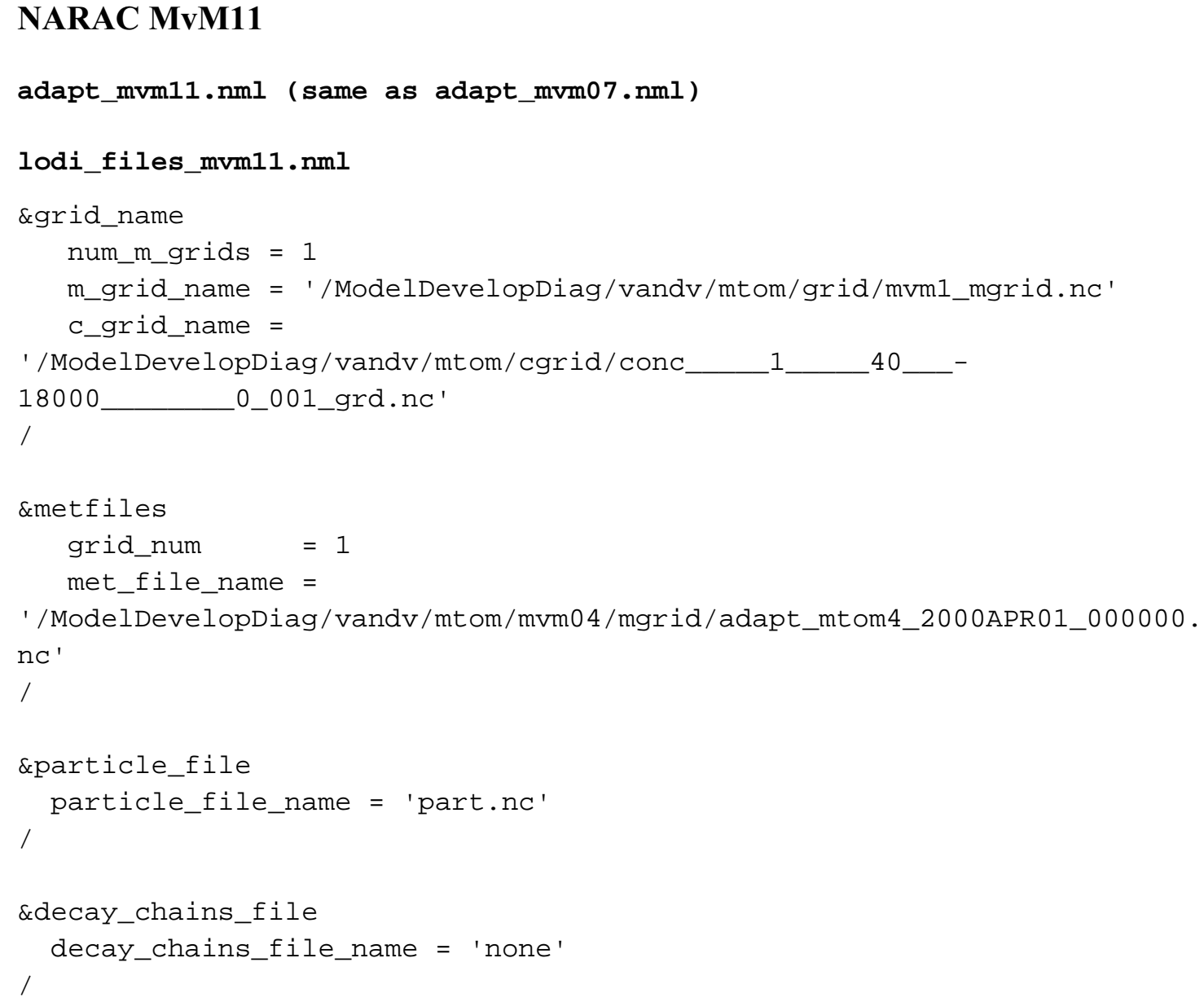

\section{NARAC MvM11}

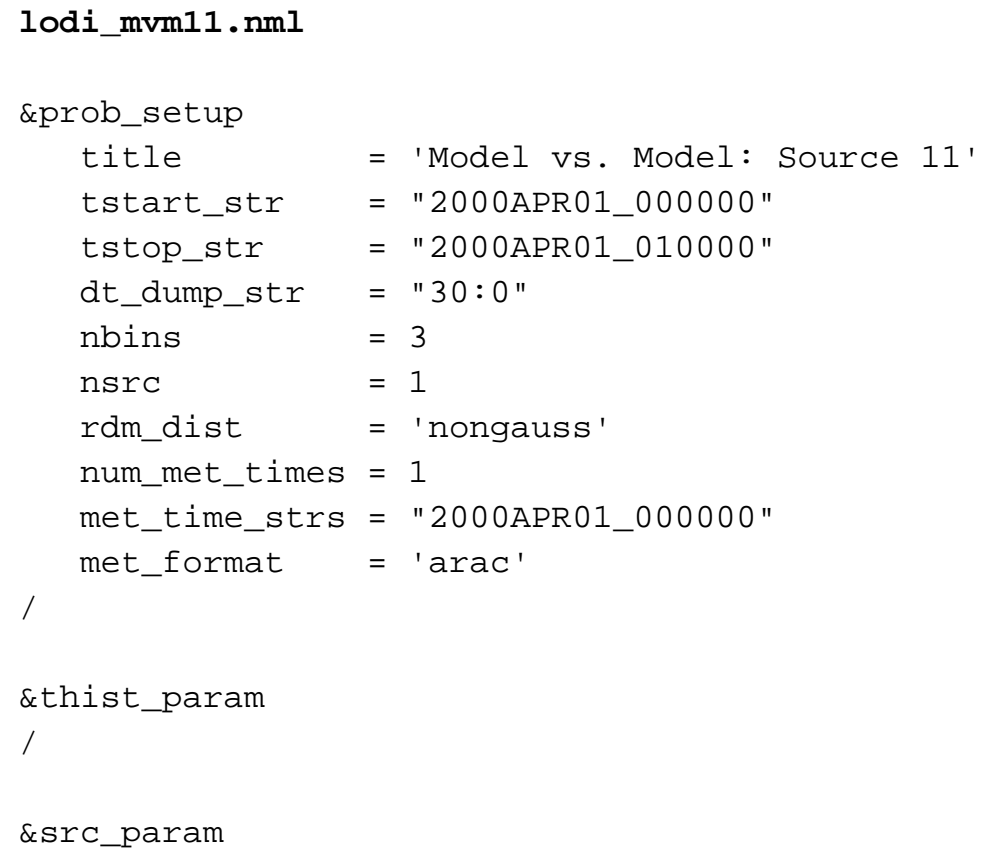




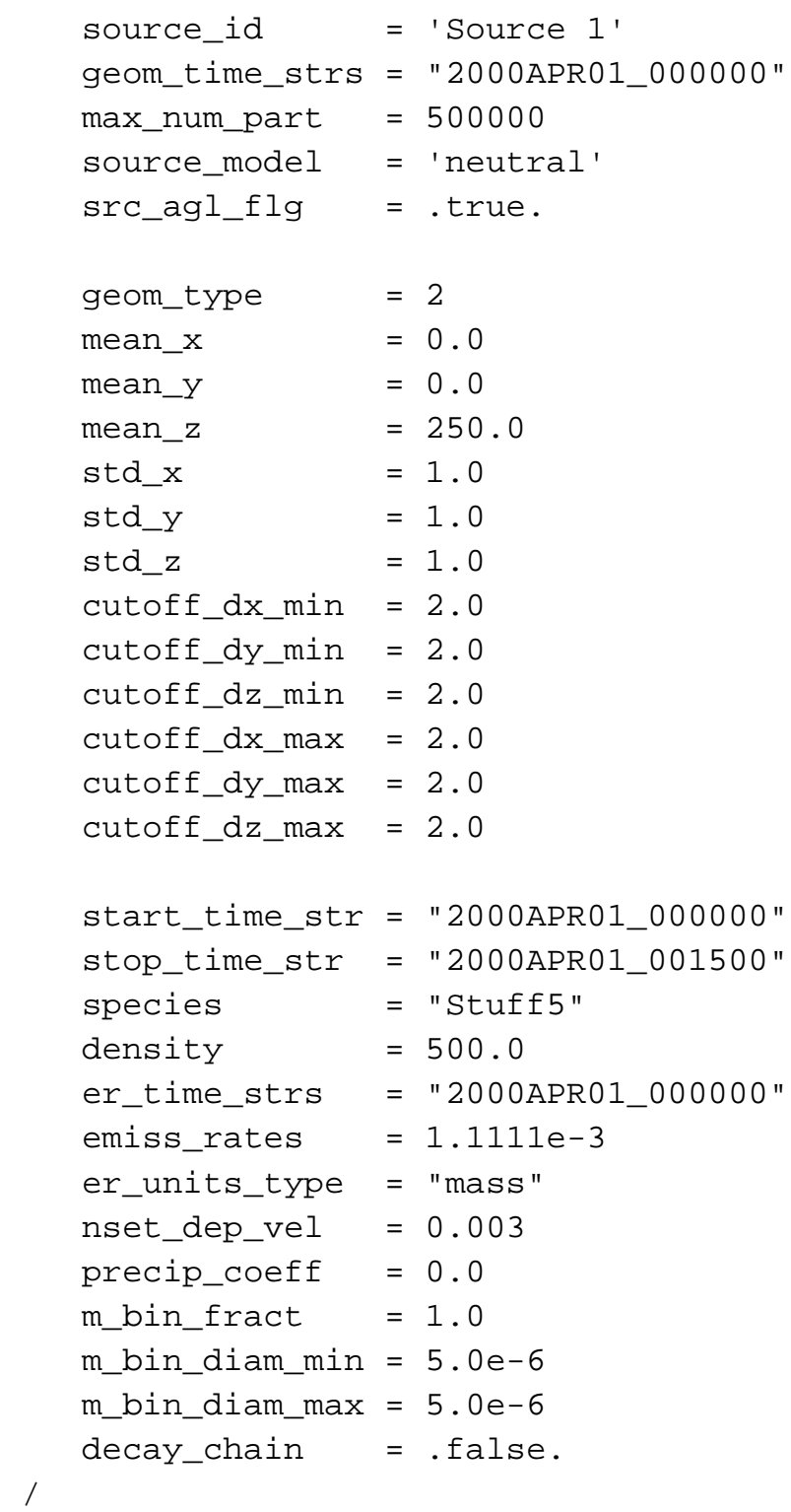

\section{NARAC MvM11}

lodi_mvm11.nml (continued)

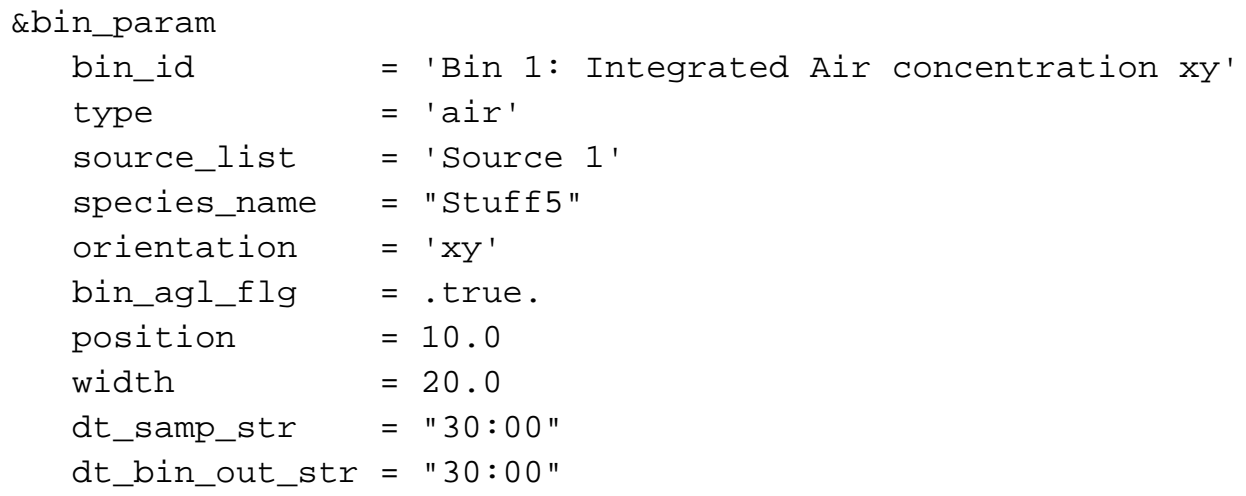




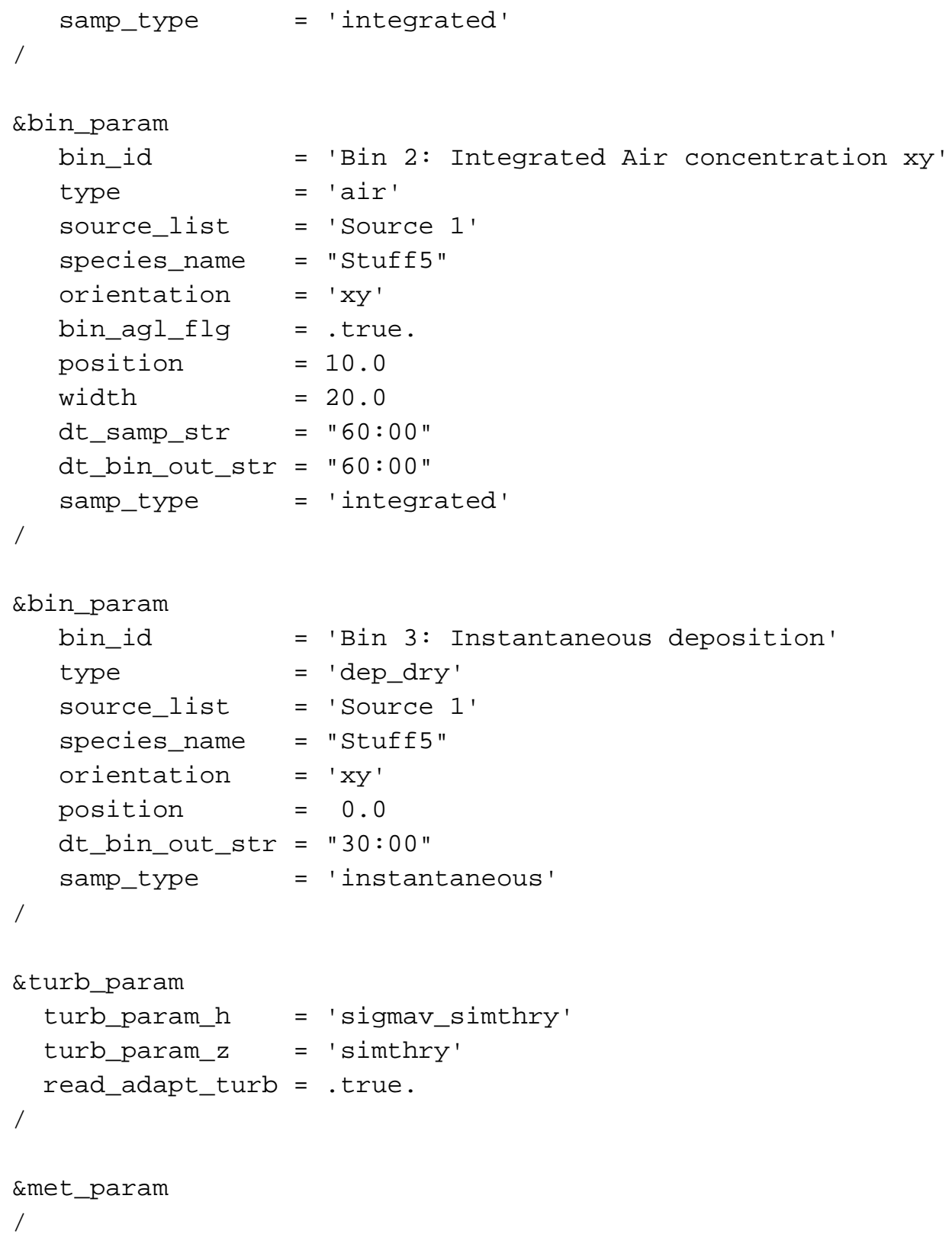

\section{NARAC MvM11}

stnloc_mvm11.met (same as stnloc_mvm07.met)

observ_mvm11.met (same as observ_mvm07.met) 


\section{HPAC MvM12}

\begin{tabular}{|c|c|c|}
\hline mvm12 & HPAC 3.2 parame ter & HPAC 3.2 value \\
\hline HPAC SCREEN & agent & 5 micron par ticles \\
\hline \multirow[t]{12}{*}{ New Project Setup } & project file name & $\mathrm{mvm} 12 . p j$ \\
\hline & coordina tes & cartesian \\
\hline & local origin $x$ & $0 \mathrm{~km}$ \\
\hline & local origin $y$ & $0 \mathrm{~km}$ \\
\hline & local origin lat i tude & $45 \operatorname{deg} N$ \\
\hline & local origin longi tude & $0 \mathrm{deg}$ \\
\hline & reference times & UTC \\
\hline & local time of $00: 00 z$ & 0 \\
\hline & mode & st andard \\
\hline & dynamics & dense gas \\
\hline & static puffs & enabled \\
\hline & hazard area & off \\
\hline New Project Editor & edit mode & advanœed \\
\hline \multirow{8}{*}{ Material Editor } & type & particle \\
\hline & name & STUFF5 \\
\hline & mat erial file name & Stuff5. $\mathrm{mtI}$ \\
\hline & units & $\mathrm{kg}$ \\
\hline & bin boundaries & $\begin{array}{ll}4.89 & \mu, 5.12 \\
\end{array}$ \\
\hline & output flags & surf. dosage, surf. depos \\
\hline & daytime decay rate & $\begin{array}{r}0 \\
\end{array}$ \\
\hline & nighttime decay rate & 0 \\
\hline \multirow[t]{3}{*}{ Particle Parame ter Editor } & density & $500 \mathrm{~kg} / \mathrm{m}^{\wedge} 3$ \\
\hline & deposition velocity & NA \\
\hline & minimum concen tra tion & 0 \\
\hline \multirow[t]{15}{*}{ Release Editor } & time & 0 \\
\hline & $\mathbf{x}$ & 0 \\
\hline & $y$ & 0 \\
\hline & height of release & $400 \mathrm{~m}$ \\
\hline & source uncert ainty & no \\
\hline & specification & simple \\
\hline & randomize location & NA \\
\hline & release dura tion & $15 \mathrm{~min}$ \\
\hline & release ra te & $0.067 \mathrm{~kg} / \mathrm{min}$ \\
\hline & agent mass & $1 \mathrm{~kg}$ \\
\hline & $x$ size & NA \\
\hline & y size & $1 \mathrm{~m}$ \\
\hline & z size & $1 \mathrm{~m}$ \\
\hline & momentum & 0 \\
\hline & buoyancy & 0 \\
\hline \multirow[t]{6}{*}{ Time Editor } & start day & $4 / 1 / 00$ \\
\hline & start time & 0 \\
\hline & stop day & $4 / 1 / 00$ \\
\hline & stop time & 100 \\
\hline & maximum time step & $60 \mathrm{sec}$ \\
\hline & out put interval & $15 \mathrm{~min}$ \\
\hline \multirow[t]{7}{*}{ Domain Editor } & xmin domain & $-50 \mathrm{~km}$ \\
\hline & $x \max$ domain & $1 \mathrm{~km}$ \\
\hline & ymin domain & $-5 \mathrm{~km}$ \\
\hline & ymax domain & $5 \mathrm{~km}$ \\
\hline & horizontal resolution & default \\
\hline & vertical domain max height & $500 \mathrm{~m}$ \\
\hline & vert ical domain resolution & $10 \mathrm{~m}$ \\
\hline Wea ther Editor & weather dat a type & surface obs. only \\
\hline & boundary layer t ype & observations \\
\hline & $\begin{array}{c}\text { large scale variability } \\
\end{array}$ & none \\
\hline & large scale variability length scale & NA \\
\hline & large scale variability variance & NA \\
\hline & $\begin{array}{c}\text { surf ace roughness } \\
\end{array}$ & $0.008 \mathrm{~m}$ \\
\hline & precipita tion & none \\
\hline & obs. time bin size & $1 \mathrm{hr}$ \\
\hline Meteorology Option Editor & save me te orology fields & no \\
\hline & terrain/land cover file & no \\
\hline Surface Obsenations File & $\begin{array}{r}\text { file name } \\
\end{array}$ & $\mathrm{mvmN.sfc}$ \\
\hline & $\begin{array}{c}\text { elevation } \\
\end{array}$ & $10 \mathrm{~m}$ \\
\hline & zi (boundary layer height) & $500 \mathrm{~m}$ \\
\hline & $z$ (al ti tude for wind measur ement) & $10 \mathrm{~m}$ \\
\hline & wind direction ( from) & $90 \mathrm{deg}$ (east) \\
\hline & $\begin{array}{c}\text { wind speed } \\
\end{array}$ & $5 \mathrm{~m} / \mathrm{s}$ \\
\hline & MOL (Monin-Obukhov Leng th) & $-500 \mathrm{~m}$ \\
\hline Options Editor & $\begin{array}{l}\text { puff split grid level } \\
\end{array}$ & 2 \\
\hline & surface resolution & default \\
\hline & puf f grid resolution & 0 \\
\hline & boundary layer pts & 11 \\
\hline & stable atm. turbulence & $1 \mathrm{e}-2 \mathrm{~m}^{\wedge} 2 / \mathrm{s}^{\wedge} 2$ \\
\hline & stable a tm. scale & $10 \mathrm{~m}$ \\
\hline & stable dissipa tion & $4 \mathrm{e}-4 \mathrm{~m}^{\wedge} 2 / \mathrm{s}^{\wedge} 3$ \\
\hline & calm cond. turbulence & $0.25 \mathrm{~m}^{\wedge} 2 / \mathrm{s}^{\wedge} 2$ \\
\hline & calm cond. scale & $1000 \mathrm{~m}$ \\
\hline & surface dosage height & 0 \\
\hline & minimum puf $\mathrm{f}$ mass & $1 \mathrm{e}-20$ \\
\hline & conditional averaging time & $1 \mathrm{hr}$ \\
\hline & lumped boundary layer & no \\
\hline
\end{tabular}




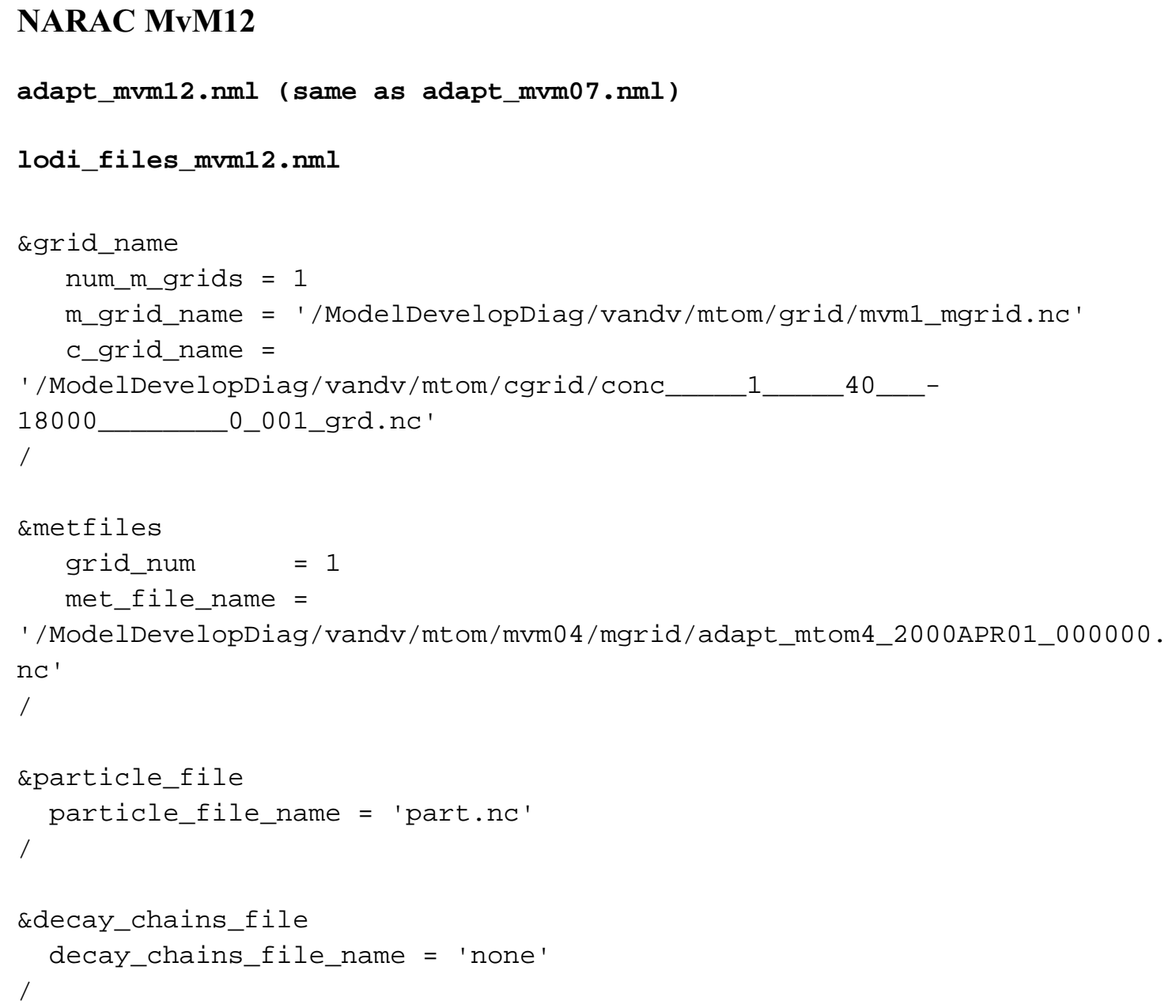

\section{NARAC MvM12}

lodi_mvm12.nml

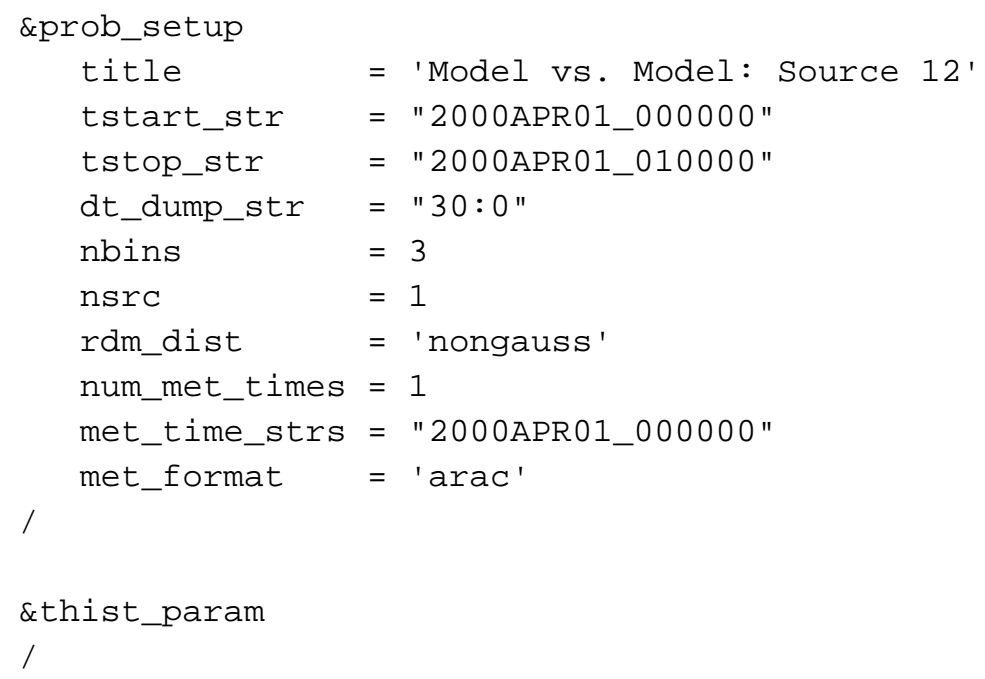




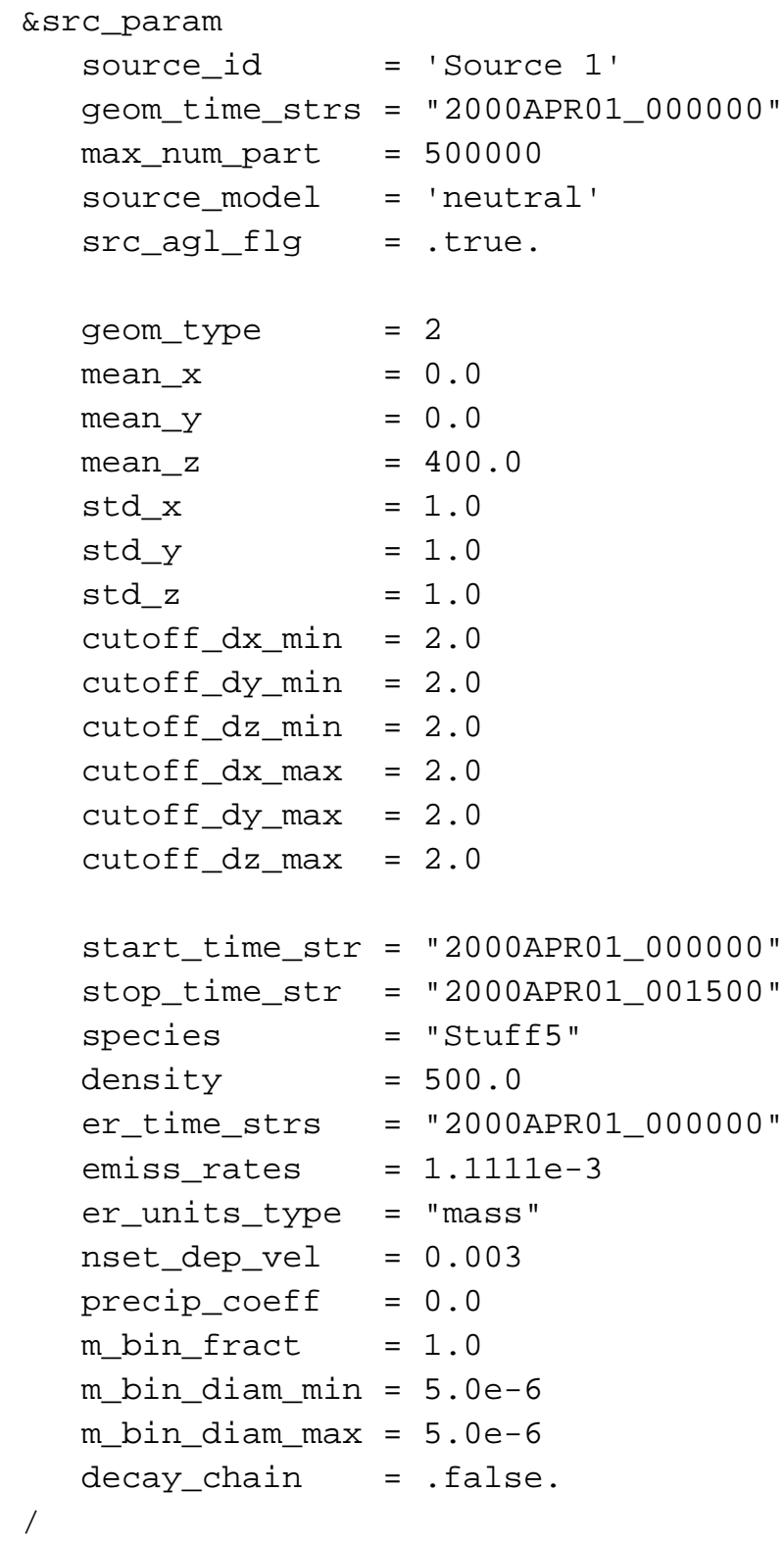

\section{NARAC MvM12}

\section{lodi_mvm12.nml (continued)}

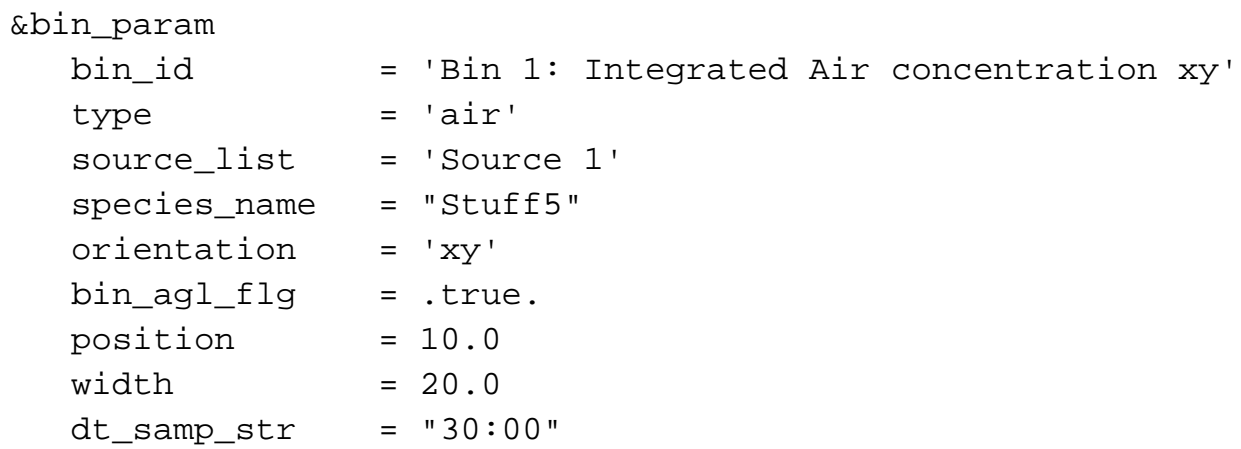




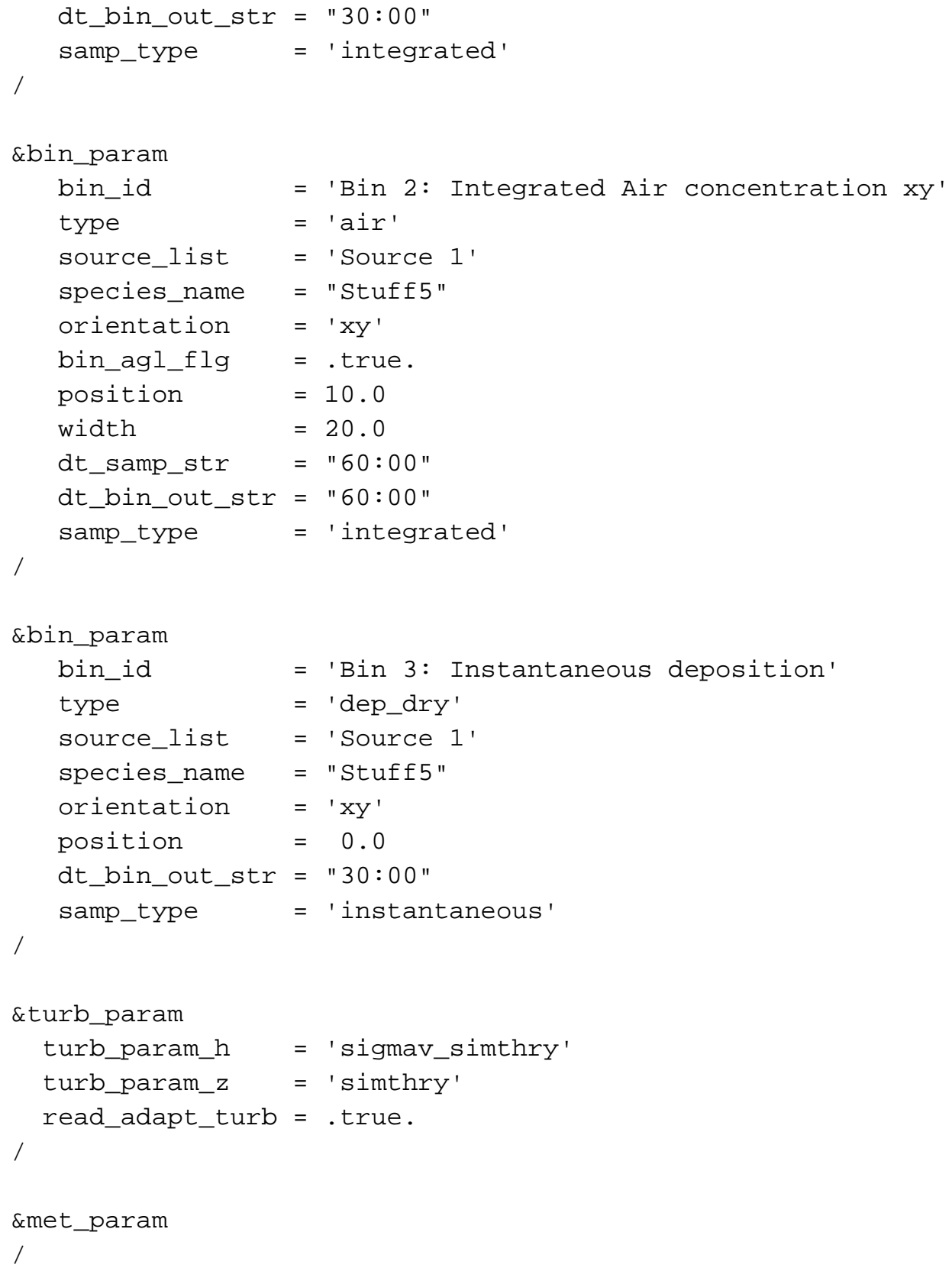

NARAC MvM12

stnloc_mvm12.met (same as stnloc_mvm07.met)

observ_mvm12.met (same as observ_mvm07.met) 


\section{HPAC MvM13}

\begin{tabular}{|c|c|c|}
\hline mvm13 & HPAC 3.2 parame ter & HPAC 3.2 value \\
\hline HPAC SCREEN & agent & 50 micron part icles \\
\hline \multirow[t]{12}{*}{ New Project Setup } & project file name & mvm13.pj \\
\hline & coordina tes & cartesian \\
\hline & local origin $\mathrm{x}$ & $0 \mathrm{~km}$ \\
\hline & local origin $y$ & $0 \mathrm{~km}$ \\
\hline & local origin lat i tude & $45 \operatorname{deg} N$ \\
\hline & local origin longi tude & $0 \mathrm{deg}$ \\
\hline & reference times & UTC \\
\hline & local time of $00: 00 z$ & 0 \\
\hline & mode & st andard \\
\hline & dynamics & dense gas \\
\hline & static puffs & enabled \\
\hline & hazard area & off \\
\hline New Project Editor & edit mode & advanœed \\
\hline \multirow{8}{*}{ Material Editor } & type & particle \\
\hline & name & STUFF50 \\
\hline & mat erial file name & Stuff5 0.mt \\
\hline & units & $\mathrm{kg}$ \\
\hline & bin boundaries & $\begin{array}{ll}48.9 & \mu, 51.1 \\
\end{array}$ \\
\hline & output flags & surf. dosage, surf. depos \\
\hline & daytime decay rate & $\begin{array}{r}0 \\
\end{array}$ \\
\hline & nighttime decay rate & 0 \\
\hline \multirow[t]{3}{*}{ Particle Parame ter Editor } & density & $500 \mathrm{~kg} / \mathrm{m}^{\wedge} 3$ \\
\hline & deposition velocity & NA \\
\hline & minimum concen tra tion & 0 \\
\hline \multirow[t]{15}{*}{ Release Editor } & time & 0 \\
\hline & $\mathbf{x}$ & 0 \\
\hline & $y$ & 0 \\
\hline & height of release & $2 \mathrm{~m}$ \\
\hline & source uncert ainty & no \\
\hline & specification & simple \\
\hline & randomize location & no \\
\hline & release dura tion & inst antaneous \\
\hline & release ra te & NA \\
\hline & agent mass & $1 \mathrm{~kg}$ \\
\hline & $x$ size & $1 \mathrm{~m}$ \\
\hline & y size & $1 \mathrm{~m}$ \\
\hline & z size & $1 \mathrm{~m}$ \\
\hline & momentum & 0 \\
\hline & buoyancy & 0 \\
\hline \multirow[t]{6}{*}{ Time Editor } & start day & $4 / 1 / 00$ \\
\hline & start time & 0 \\
\hline & s top day & $4 / 1 / 00$ \\
\hline & stop time & 100 \\
\hline & maximum time step & $60 \mathrm{sec}$ \\
\hline & out put interval & $15 \mathrm{~min}$ \\
\hline \multirow[t]{7}{*}{ Domain Editor } & xmin domain & $-50 \mathrm{~km}$ \\
\hline & $x \max$ domain & $1 \mathrm{~km}$ \\
\hline & ymin domain & $-5 \mathrm{~km}$ \\
\hline & ymax domain & $5 \mathrm{~km}$ \\
\hline & horizontal resolution & default \\
\hline & vertical domain max height & $500 \mathrm{~m}$ \\
\hline & vert ical domain resolution & $10 \mathrm{~m}$ \\
\hline Wea ther Editor & weather dat a type & surface obs. only \\
\hline & boundary layer t ype & observations \\
\hline & $\begin{array}{l}\text { large scale variability } \\
\end{array}$ & none \\
\hline & large scale variability length scale & NA \\
\hline & large scale variability variance & NA \\
\hline & $\begin{array}{c}\text { surf ace roughness } \\
\end{array}$ & $0.008 \mathrm{~m}$ \\
\hline & precipita tion & none \\
\hline & obs. time bin size & $1 \mathrm{hr}$ \\
\hline Meteorology Option Editor & save me te orology fields & no \\
\hline & terrain/land cover file & no \\
\hline Surface Obsenations File & $\begin{array}{r}\text { file name } \\
\end{array}$ & $\mathrm{mvmN.sfc}$ \\
\hline & $\begin{array}{c}\text { elevation } \\
\end{array}$ & $10 \mathrm{~m}$ \\
\hline & zi (boundary layer height) & $500 \mathrm{~m}$ \\
\hline & $z$ (al ti tude for wind measur ement) & $10 \mathrm{~m}$ \\
\hline & wind direction ( from) & $90 \mathrm{deg}$ (east) \\
\hline & $\begin{array}{c}\text { wind speed } \\
\end{array}$ & $5 \mathrm{~m} / \mathrm{s}$ \\
\hline & MOL (Monin-Obukhov Leng th) & $-500 \mathrm{~m}$ \\
\hline Options Editor & $\begin{array}{l}\text { puff split grid level } \\
\end{array}$ & 2 \\
\hline & surface resolution & default \\
\hline & puf f grid resolution & 0 \\
\hline & boundary layer pts & 11 \\
\hline & stable atm. turbulence & $1 \mathrm{e}-2 \mathrm{~m}^{\wedge} 2 / \mathrm{s}^{\wedge} 2$ \\
\hline & stable a tm. scale & $10 \mathrm{~m}$ \\
\hline & stable dissipa tion & $4 \mathrm{e}-4 \mathrm{~m}^{\wedge} 2 / \mathrm{s}^{\wedge} 3$ \\
\hline & calm cond. turbulence & $0.25 \mathrm{~m}^{\wedge} 2 / \mathrm{s}^{\wedge} 2$ \\
\hline & calm cond. scale & $1000 \mathrm{~m}$ \\
\hline & surface dosage height & 0 \\
\hline & minimum puf $\mathrm{f}$ mass & $1 \mathrm{e}-20$ \\
\hline & conditional averaging time & $1 \mathrm{hr}$ \\
\hline & lumped boundary layer & no \\
\hline
\end{tabular}




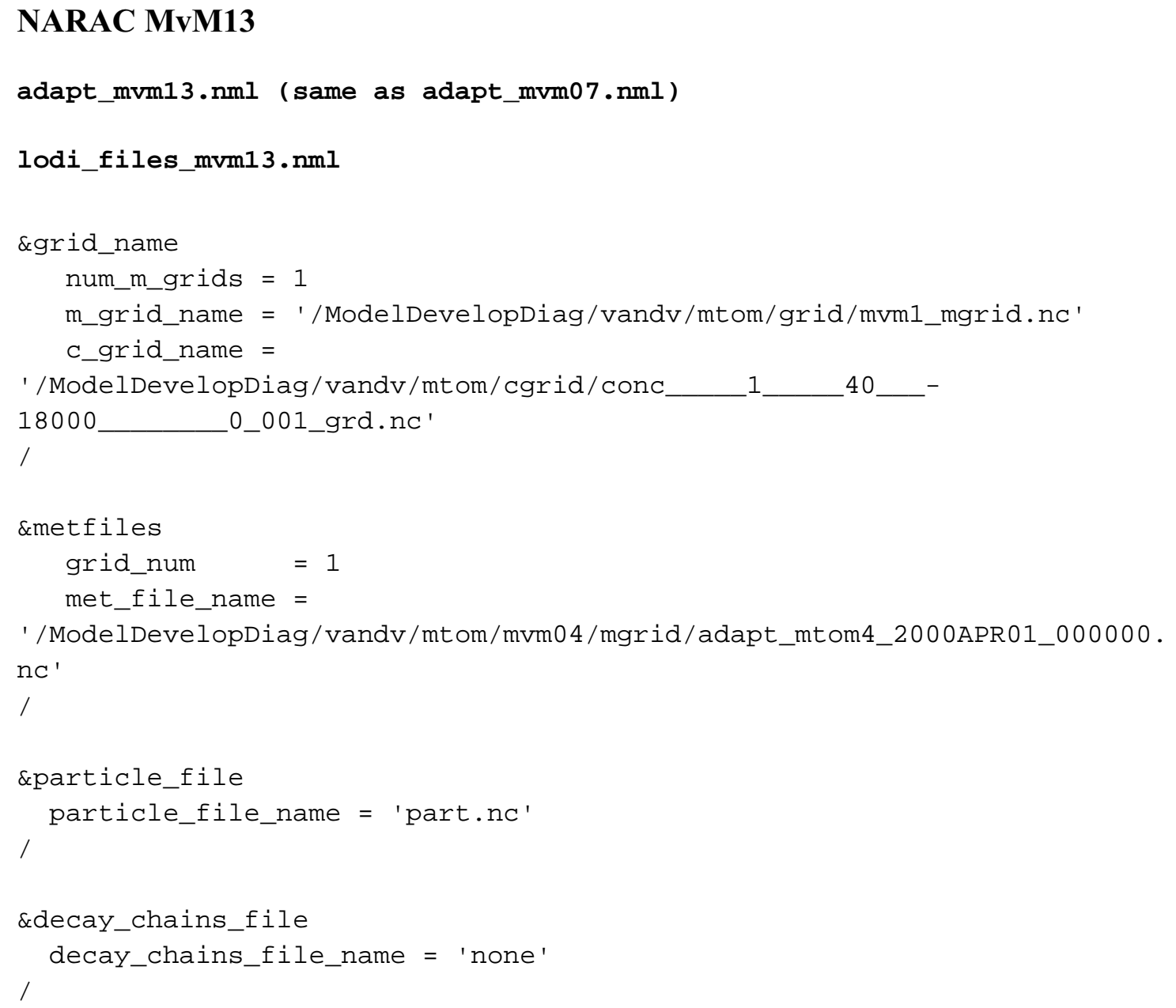

\section{NARAC MvM13}

lodi_mvm13.nml

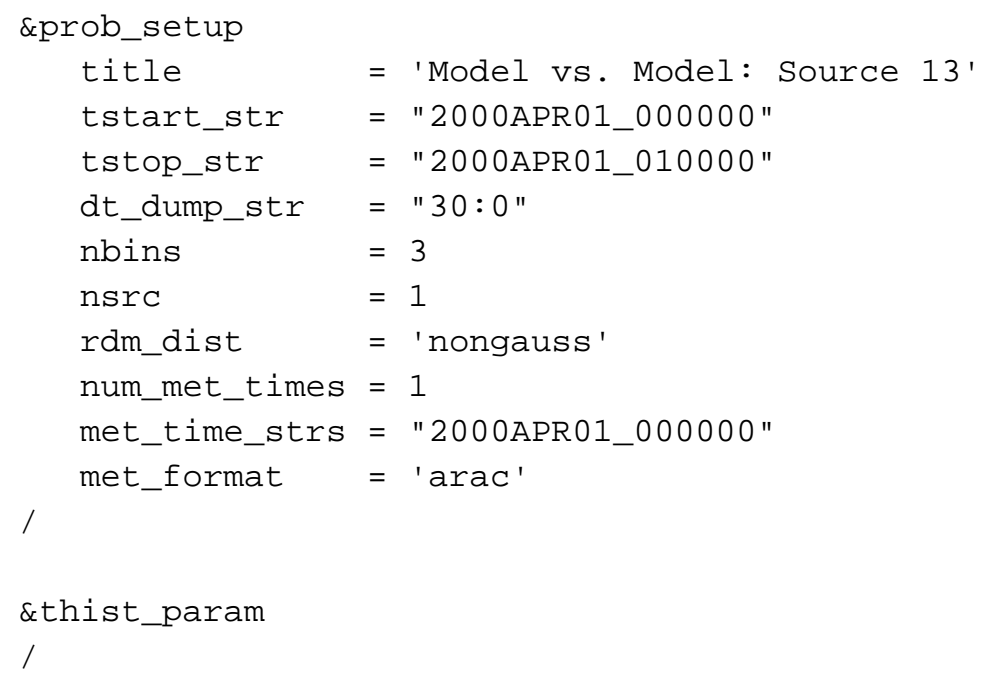




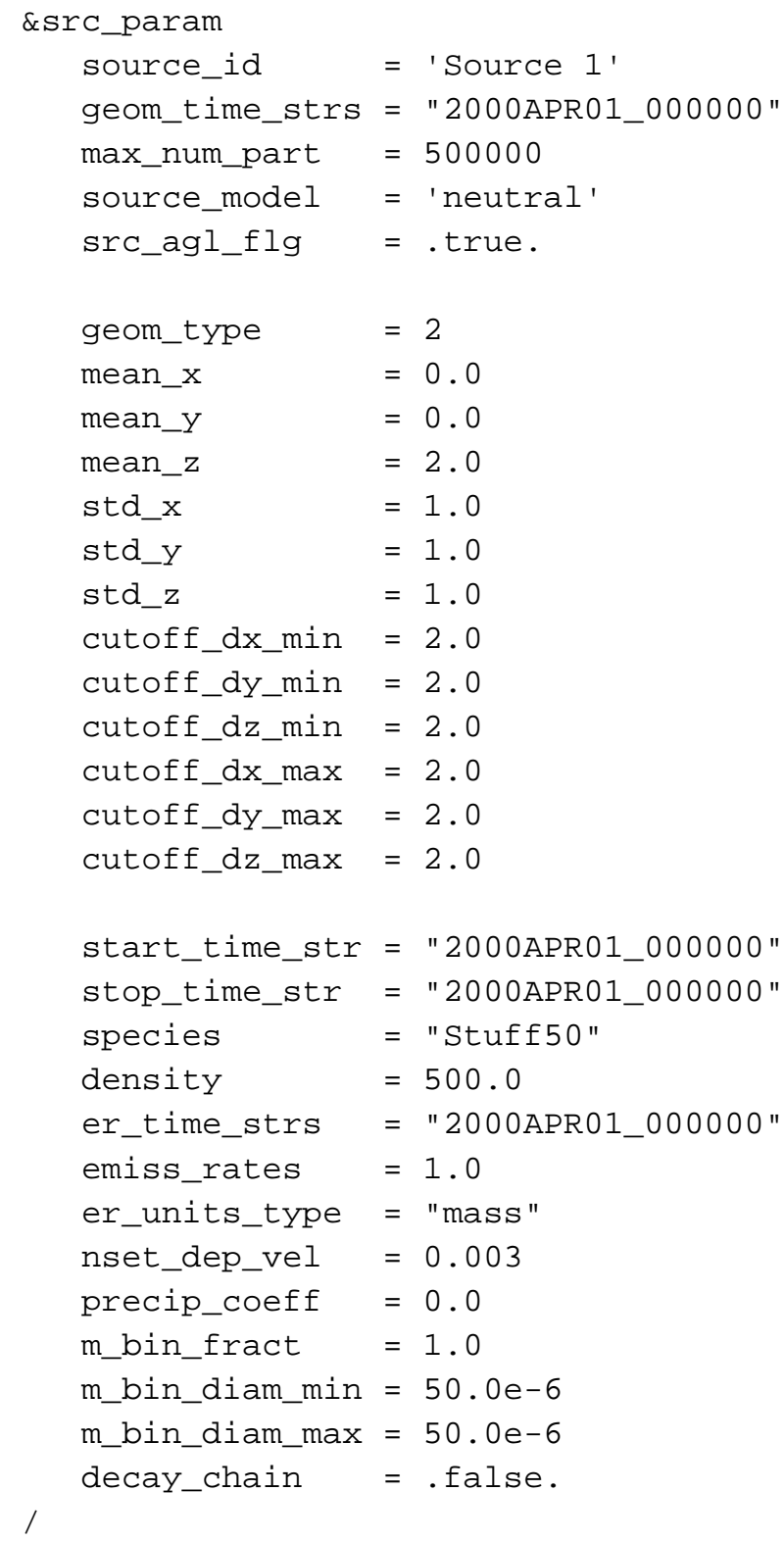

\section{NARAC MvM13}

lodi_mvm13.nml (continued)

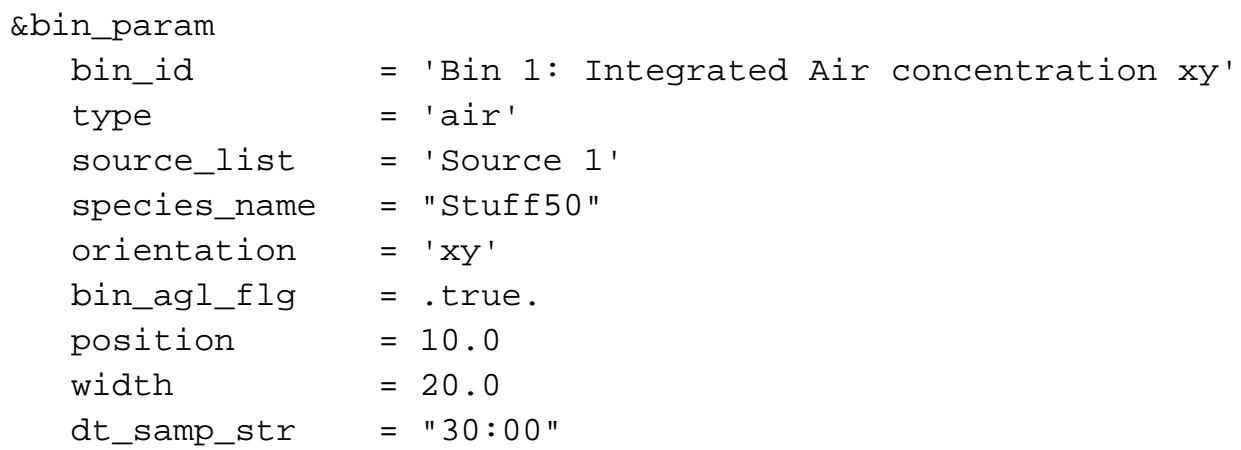




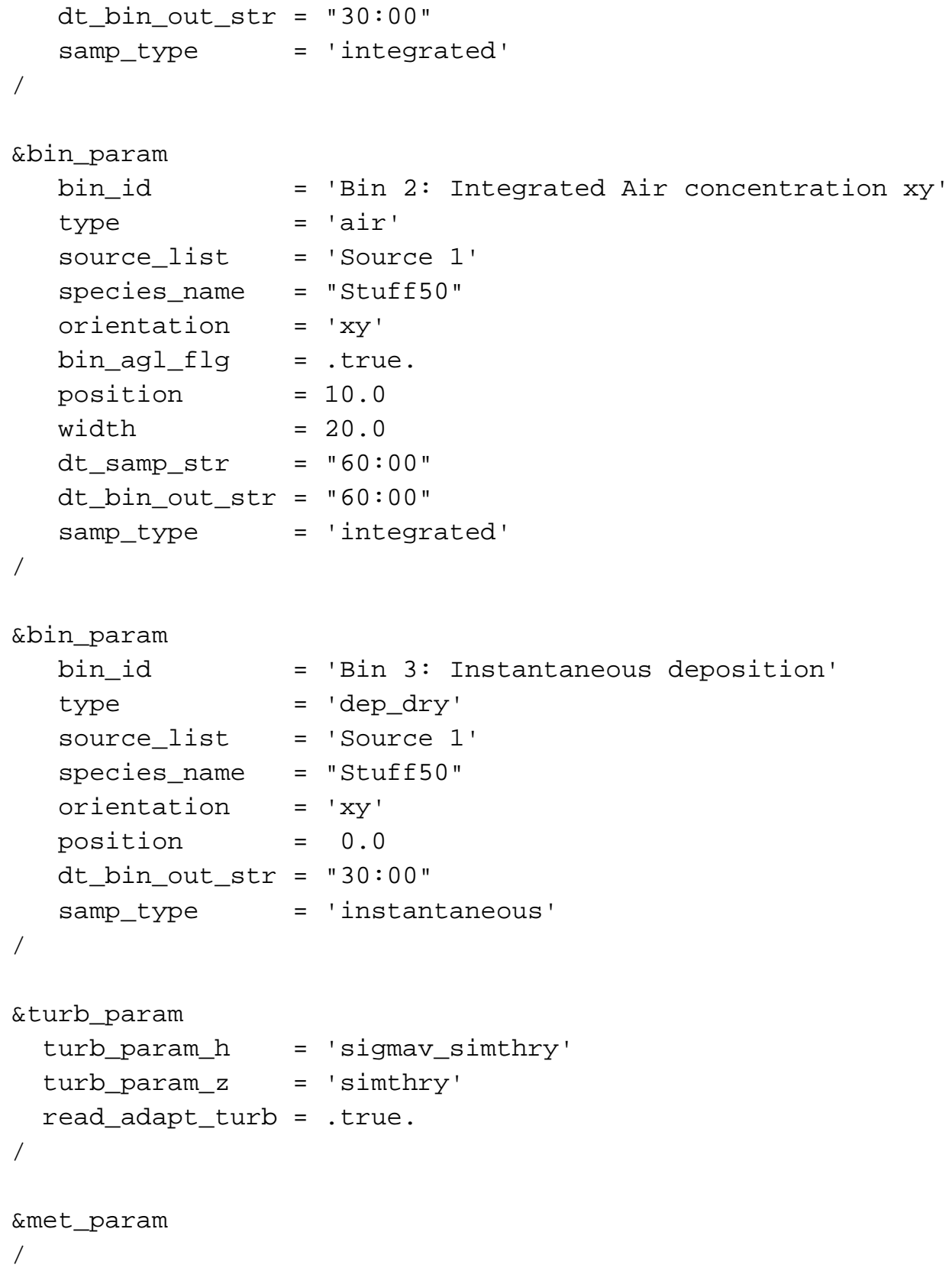

NARAC MvM13

stnloc_mvm13.met (same as stnloc_mvm07.met)

observ_mvm13.met (same as observ_mvm07.met) 
HPAC MvM14

\begin{tabular}{|c|c|c|}
\hline mvm 14 & HPAC 3.2 parame ter & HPAC 3.2 value \\
\hline HPAC SCREEN & agent & 50 micron particles \\
\hline \multirow{12}{*}{ New Project Setup } & project file name & mvm14.prj \\
\hline & coordina tes & car tesian \\
\hline & local origin $x$ & $0 \mathrm{~km}$ \\
\hline & local origin $y$ & $0 \mathrm{~km}$ \\
\hline & local origin latitude & $45 \operatorname{deg} N$ \\
\hline & local origin longitude & $0 \mathrm{deg}$ \\
\hline & reference times & UTC \\
\hline & local time of $00: 00 \mathrm{Z}$ & 0 \\
\hline & mode & standard \\
\hline & dynamics & dense gas \\
\hline & static puffs & enabled \\
\hline & hazard area & of $f$ \\
\hline New Project Editor & edit mode & advanced \\
\hline \multirow[t]{8}{*}{ Mat erial Editor } & type & part icle \\
\hline & name & STUFF50 \\
\hline & material file name & Stuff $50 . \mathrm{mtl}$ \\
\hline & units & $\mathrm{kg}$ \\
\hline & bin boundaries & $\begin{array}{rr}48.9 & \mu, 51.1 \\
\end{array}$ \\
\hline & out put flags & surf. dosage, surf. depos. \\
\hline & daytime decay rate & $\begin{array}{c}0 \\
\end{array}$ \\
\hline & nigh ttime decay rate & 0 \\
\hline \multirow[t]{3}{*}{ Particle Parameter Editor } & density & $500 \mathrm{~kg} / \mathrm{m}^{\wedge} 3$ \\
\hline & deposition velocity & NA \\
\hline & minimum concent ration & 0 \\
\hline \multirow[t]{15}{*}{ Release Editor } & time & 0 \\
\hline & $\mathbf{x}$ & 0 \\
\hline & $y$ & 0 \\
\hline & height of release & $2 \mathrm{~m}$ \\
\hline & source uncertainty & no \\
\hline & specification & simple \\
\hline & randomize loca tion & NA \\
\hline & release duration & $15 \mathrm{~min}$ \\
\hline & release rate & $0.067 \mathrm{~kg} / \mathrm{min}$ \\
\hline & agent mass & $1 \mathrm{~kg}$ \\
\hline & $\mathrm{x}$ size & NA \\
\hline & $y$ size & $1 \mathrm{~m}$ \\
\hline & $z$ size & $1 \mathrm{~m}$ \\
\hline & momen tum & 0 \\
\hline & buoyancy & 0 \\
\hline \multirow[t]{6}{*}{ Time Edit or } & start day & $4 / 1 / 00$ \\
\hline & start time & 0 \\
\hline & stop day & $4 / 1 / 00$ \\
\hline & st op time & 100 \\
\hline & maximum time step & $60 \mathrm{sec}$ \\
\hline & ou tput interval & $15 \mathrm{~min}$ \\
\hline \multirow[t]{7}{*}{ Domain Editor } & xmin domain & $-50 \mathrm{~km}$ \\
\hline & xmax domain & $1 \mathrm{~km}$ \\
\hline & $y \min$ domain & $-5 \mathrm{~km}$ \\
\hline & ymax domain & $5 \mathrm{~km}$ \\
\hline & horizont al resolution & default \\
\hline & vertical domain max height & $500 \mathrm{~m}$ \\
\hline & vertical domain resolution & $10 \mathrm{~m}$ \\
\hline Weat her Editor & weat her dat a type & surface obs. only \\
\hline & boundary layer type & observations \\
\hline & $\begin{array}{l}\text { large scale variability } \\
\end{array}$ & none \\
\hline & large scale variability length scale & NA \\
\hline & large scale variability variance & NA \\
\hline & $\begin{array}{c}\text { surface roughness } \\
\end{array}$ & $0.008 \mathrm{~m}$ \\
\hline & precipitation & none \\
\hline & obs. time bin size & $1 \mathrm{hr}$ \\
\hline Met eorology Option Editor & save mete orology fields & no \\
\hline & te rrain/l and cover file & no \\
\hline Surface Observations File & $\begin{array}{c}\text { file name } \\
\end{array}$ & mvmN.sfc \\
\hline & $\begin{array}{c}\text { elevation } \\
\end{array}$ & $10 \mathrm{~m}$ \\
\hline & zi (boundary layer heigh $\mathrm{t}$ ) & $500 \mathrm{~m}$ \\
\hline & $z$ (altitude for wind measurement) & $10 \mathrm{~m}$ \\
\hline & \begin{tabular}{|c|} 
wind direction ( from) \\
\end{tabular} & 90 deg (eas $t)$ \\
\hline & $\begin{array}{c}\text { wind speed } \\
\end{array}$ & $5 \mathrm{~m} / \mathrm{s}$ \\
\hline & MOL (Monin-Obukhov Lengt h) & $-500 \mathrm{~m}$ \\
\hline Options Editor & puff split grid level & 2 \\
\hline & surface resolution & default \\
\hline & puf $f$ grid resolution & 0 \\
\hline & boundary layer pts & 11 \\
\hline & stable at $\mathrm{m}$. t urbulence & $1 \mathrm{e}-2 \mathrm{~m}^{\wedge} 2 / \mathrm{s}^{\wedge} 2$ \\
\hline & stable at m. scale & $10 \mathrm{~m}$ \\
\hline & stable dissipation & $4 e-4 m^{\wedge} 2 / s^{\wedge} 3$ \\
\hline & calm cond. t urbulence & $0.25 \mathrm{~m}^{\wedge} 2 / \mathrm{s}^{\wedge} 2$ \\
\hline & calm cond. scale & $1000 \mathrm{~m}$ \\
\hline & surface dosage height & 0 \\
\hline & minimum puff mass & $1 \mathrm{e}-20$ \\
\hline & conditional averaging time & $1 \mathrm{hr}$ \\
\hline & lumped boundary layer & no \\
\hline
\end{tabular}




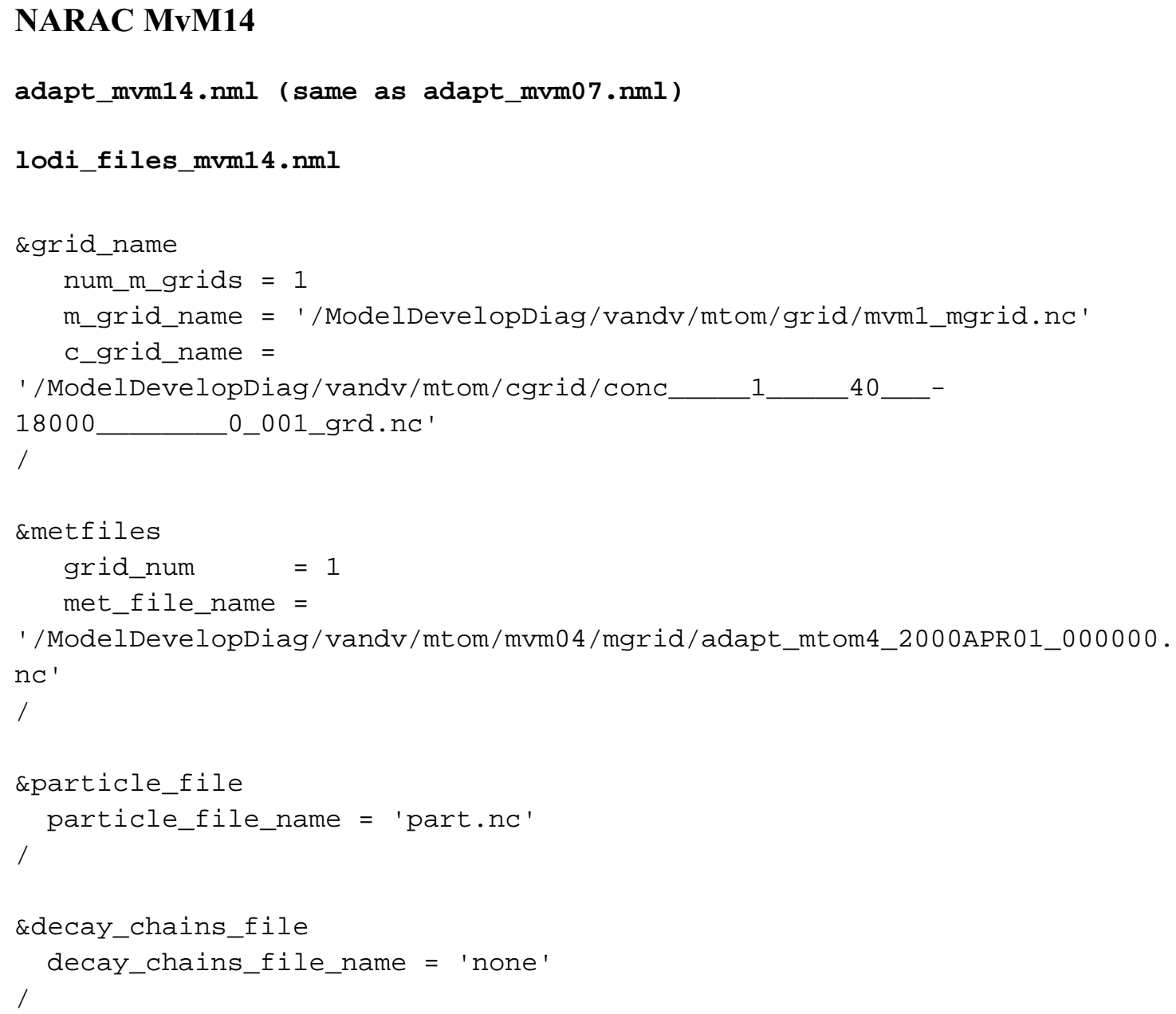

\section{NARAC MvM14}

lodi_mvm14. $\mathrm{nml}$

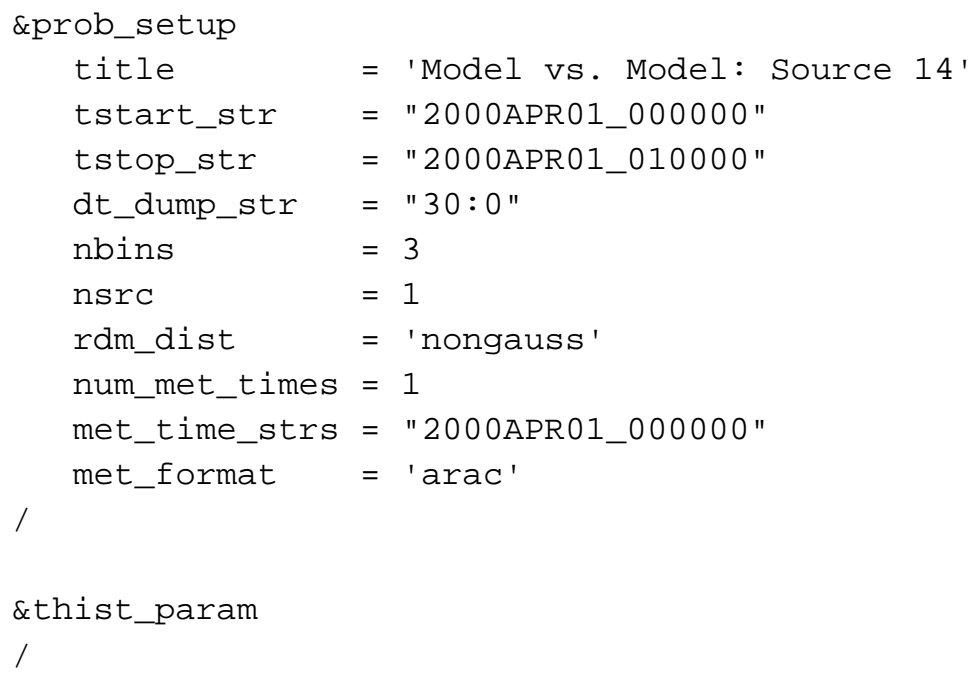




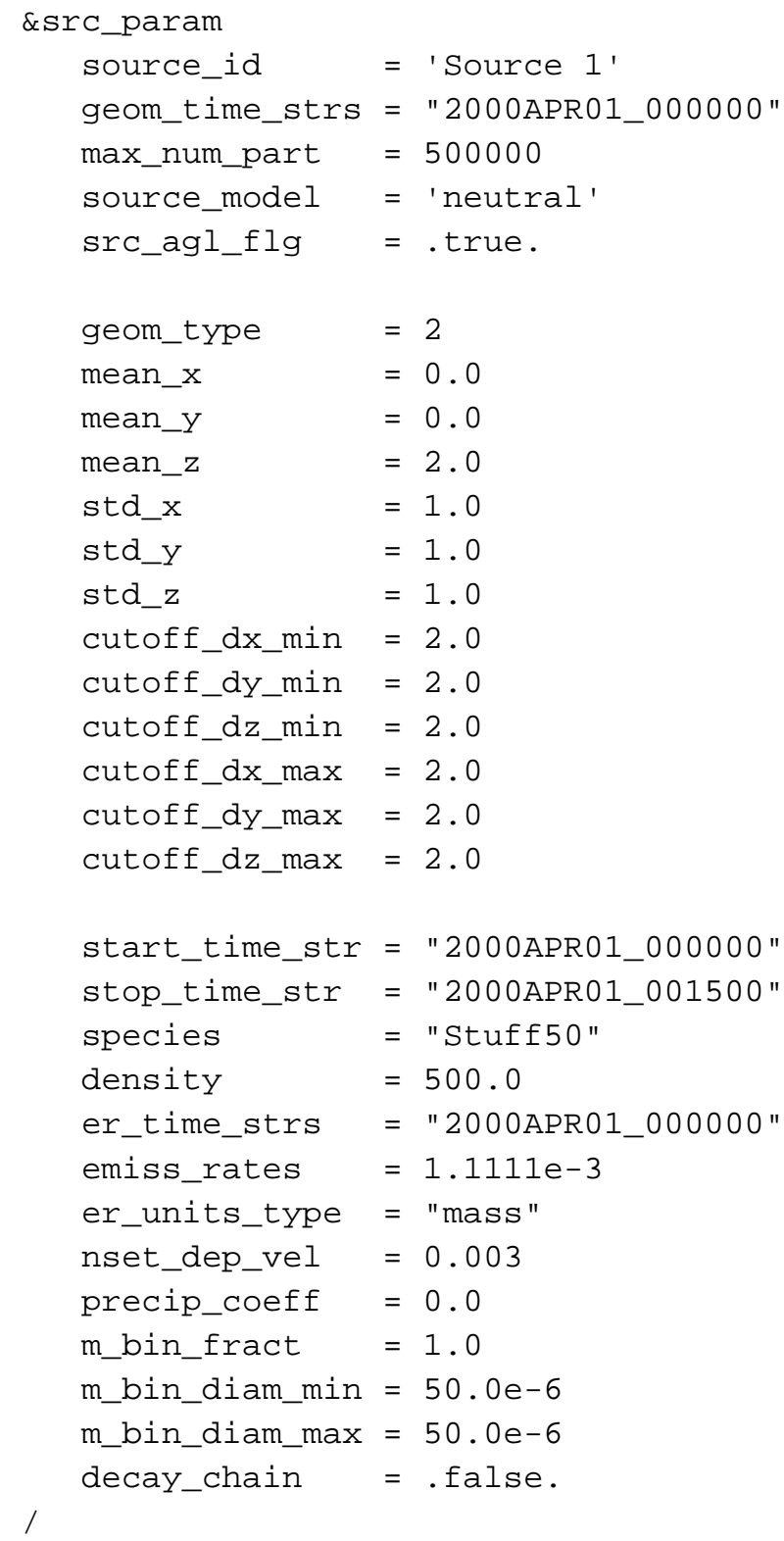

\section{NARAC MvM14}

\section{lodi_mvm14.nml (continued)}

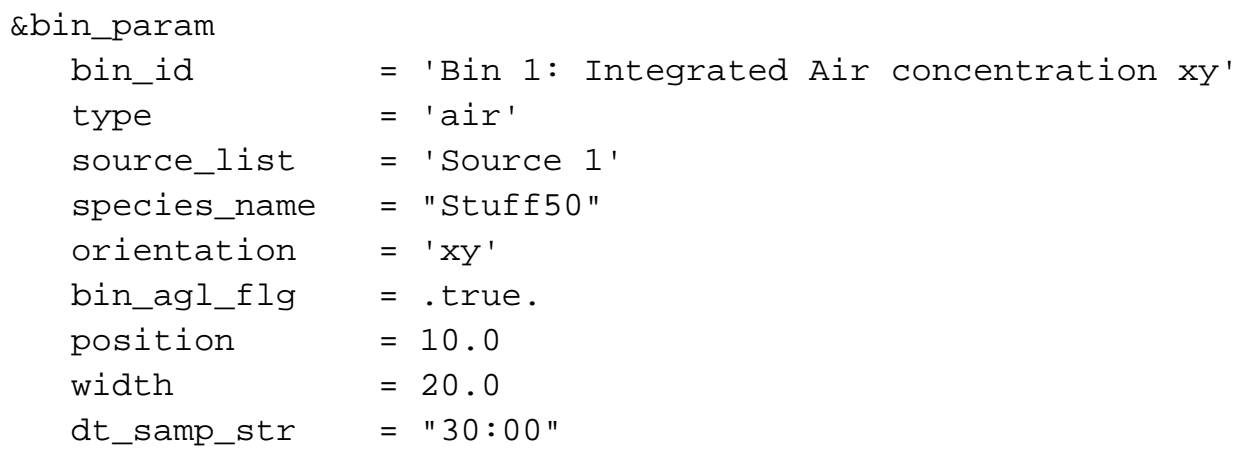




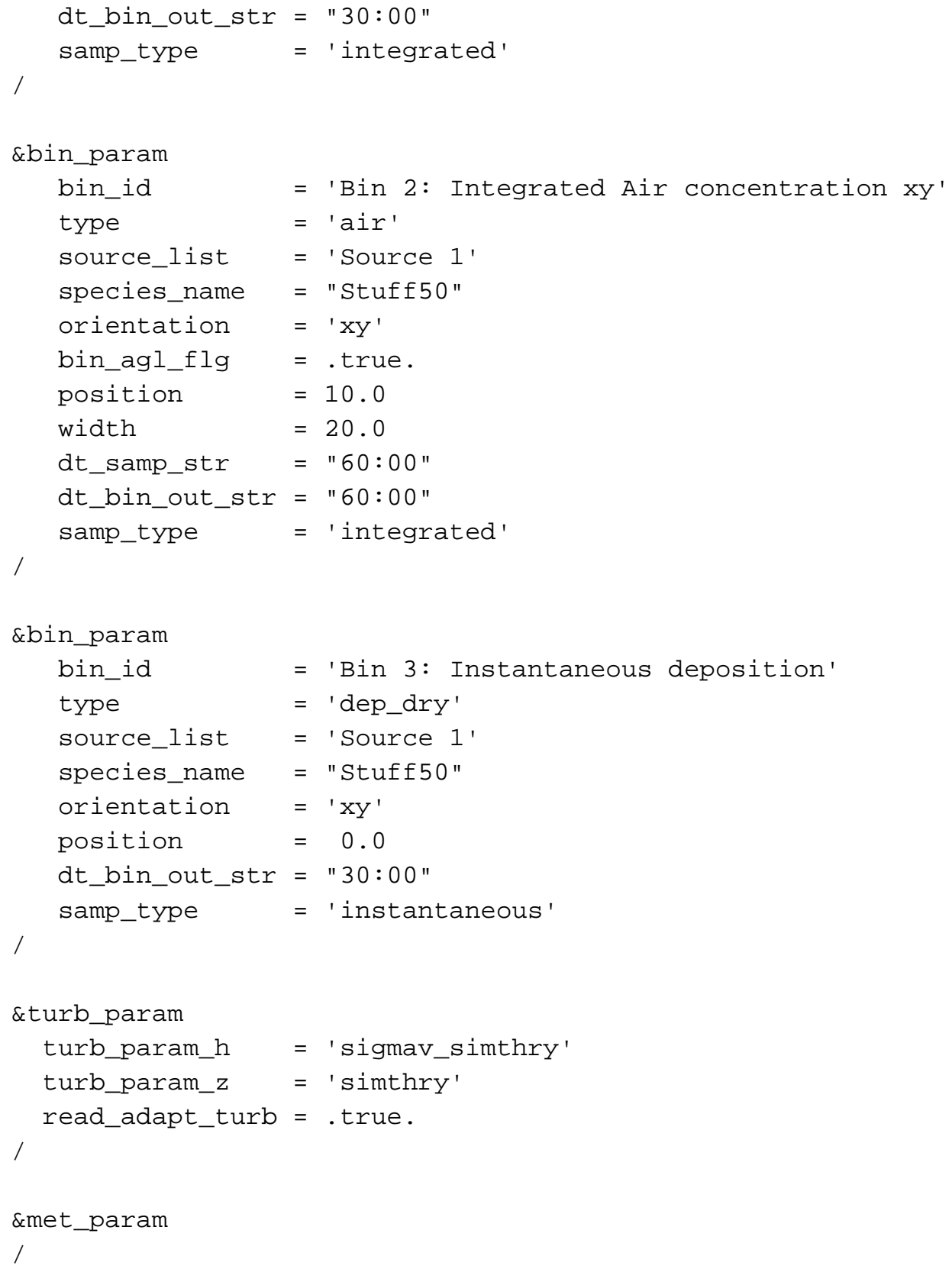

NARAC MvM14

stnloc_mvm14.met (same as stnloc_mvm07.met)

observ_mvm14.met (same as observ_mvm07.met) 


\section{HPAC MvM15}

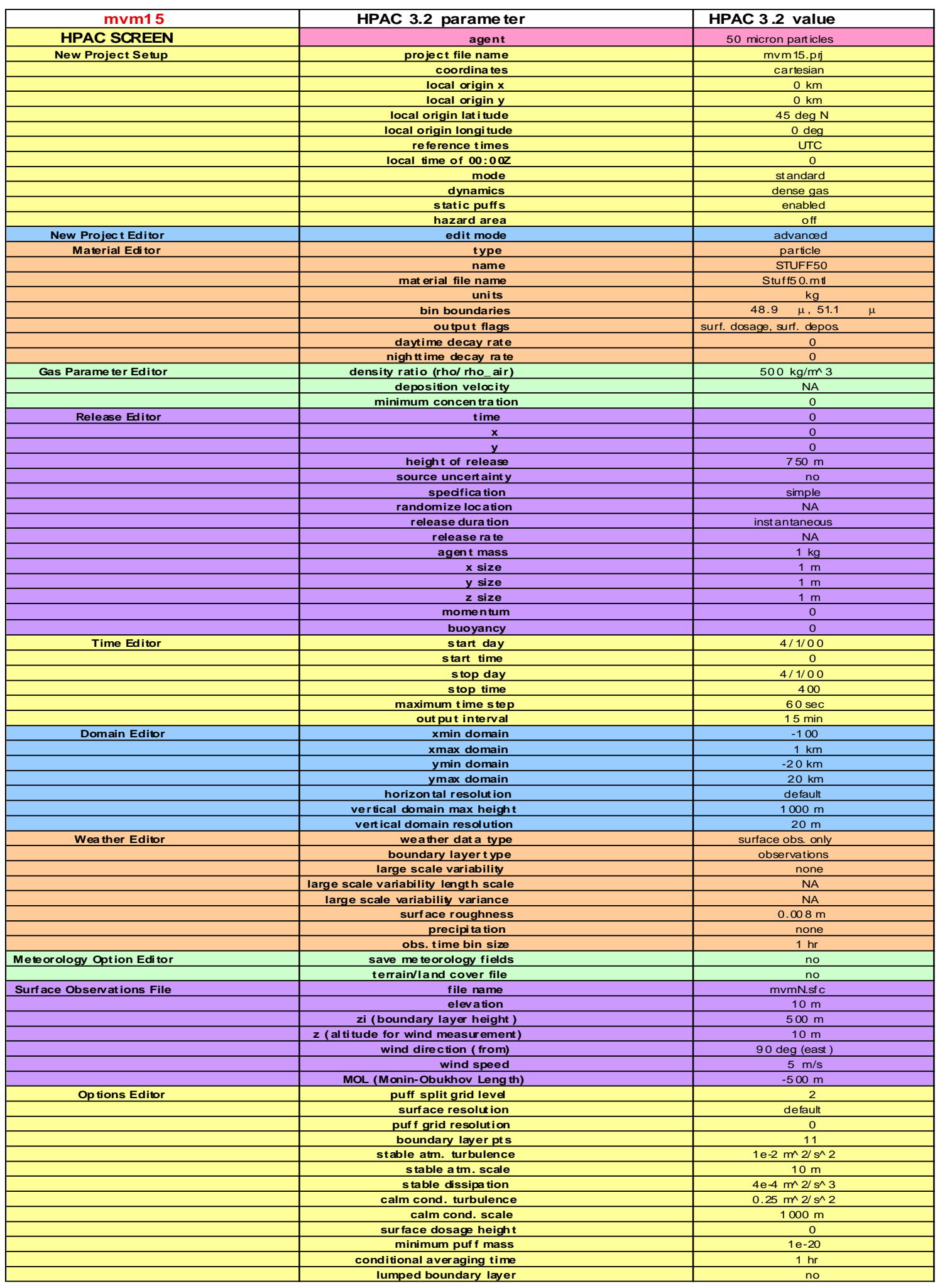




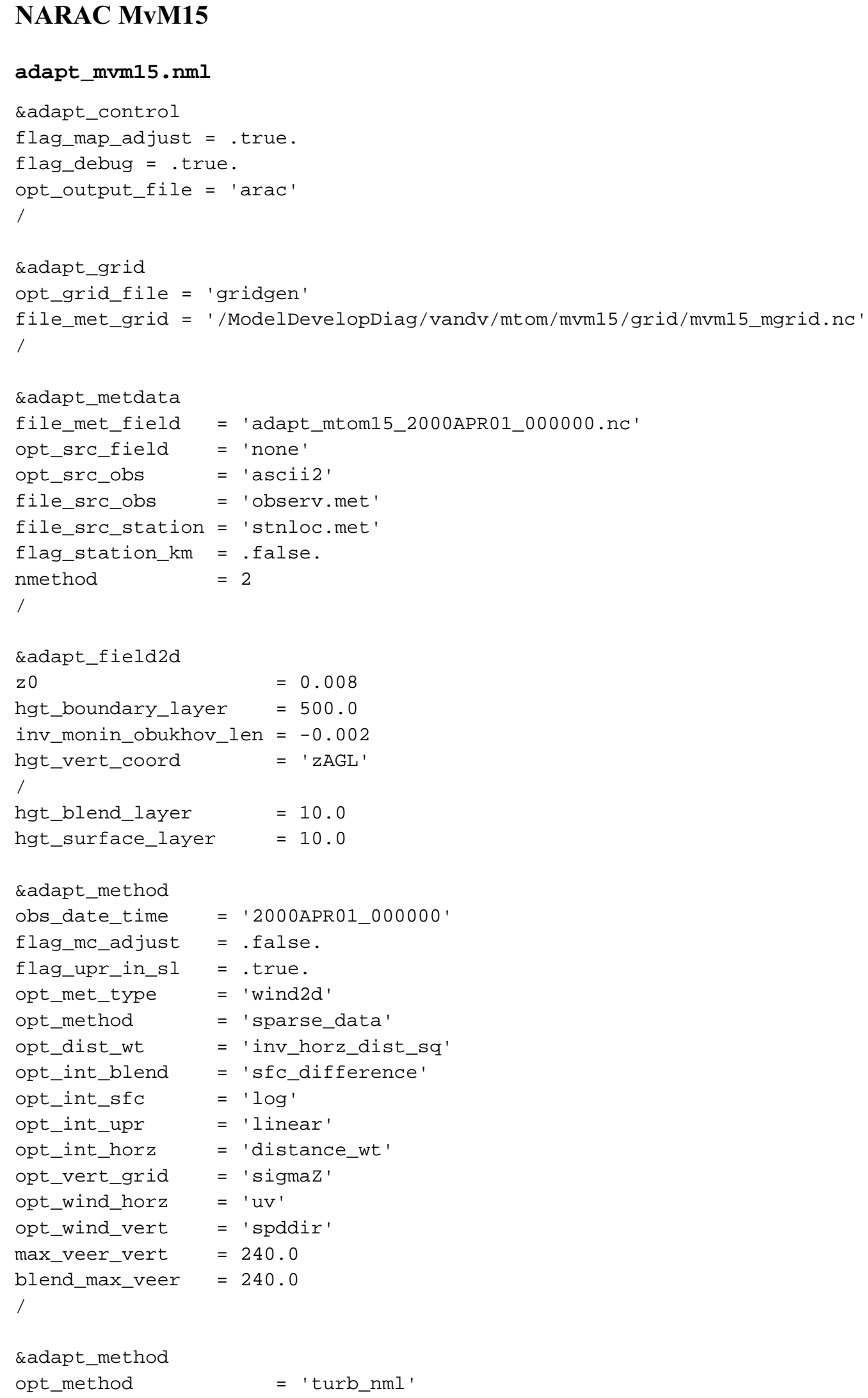




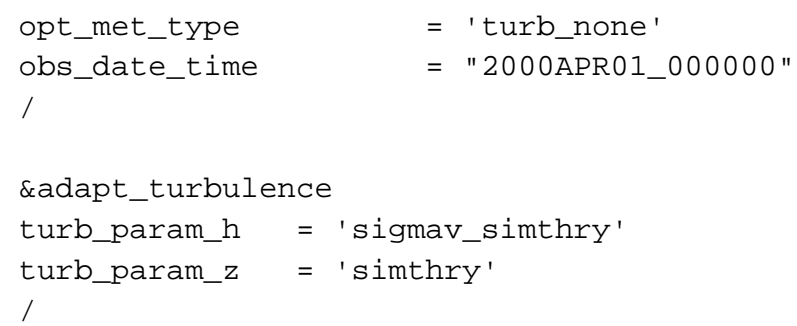

\section{NARAC MvM15}

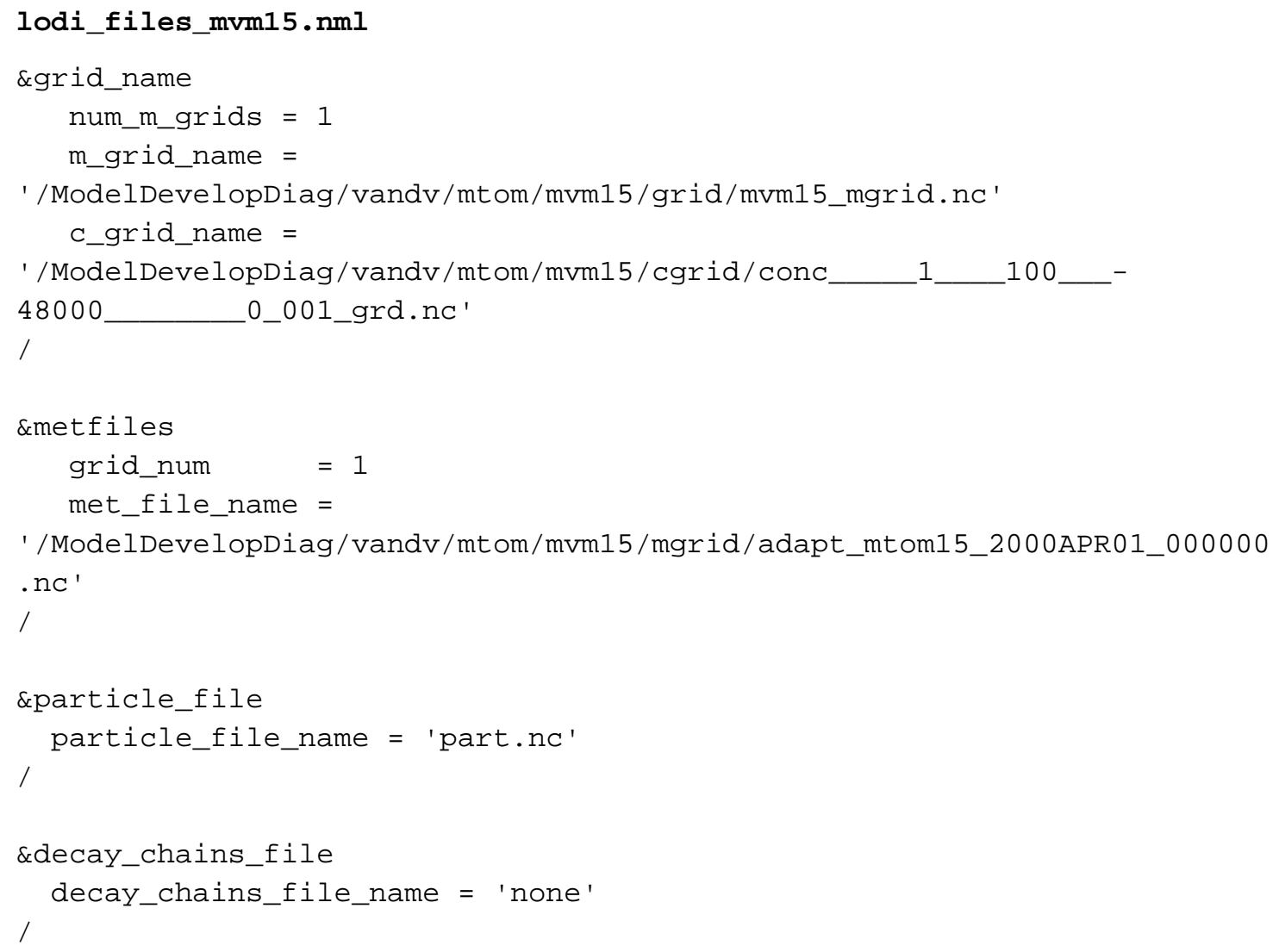

\section{NARAC MvM15}

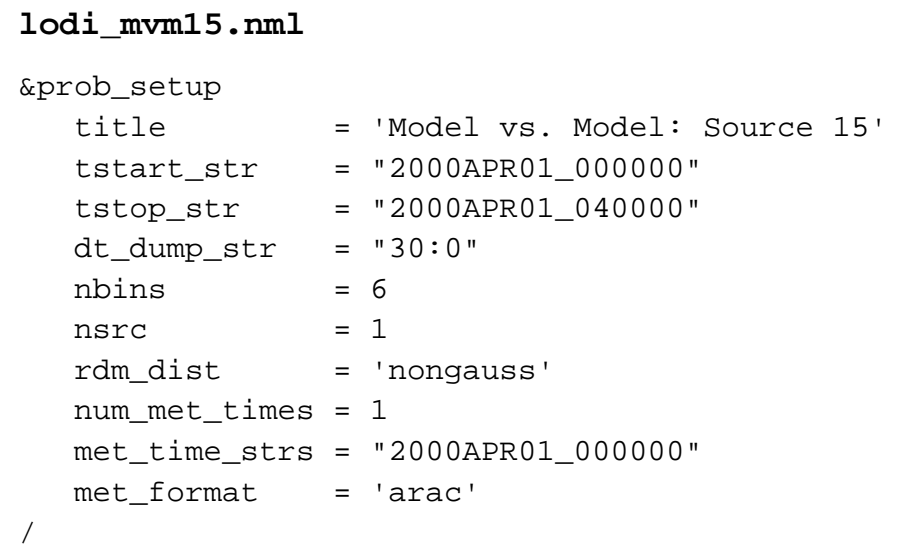




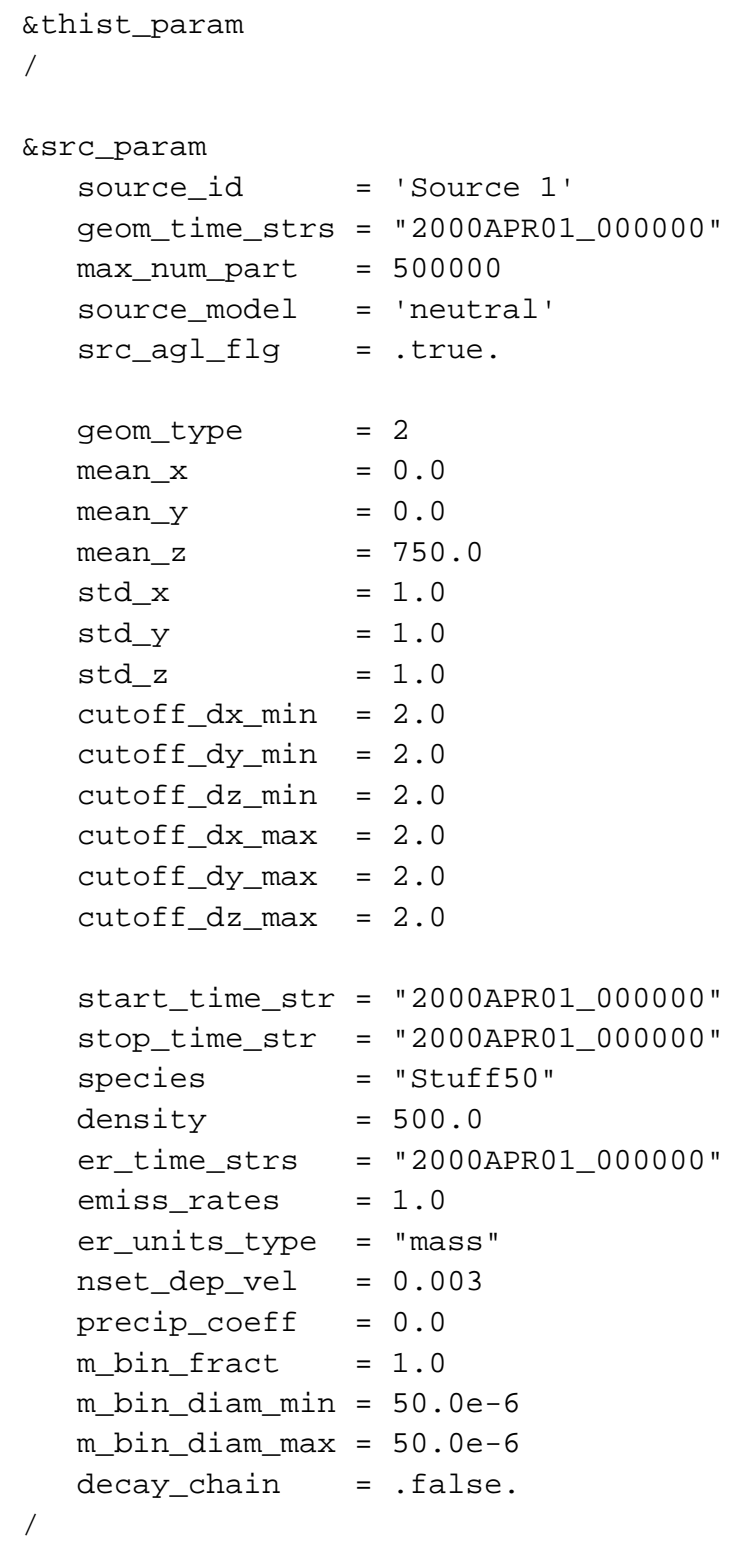

\section{NARAC MvM15}

\section{lodi_mvm15.nml (continued)}

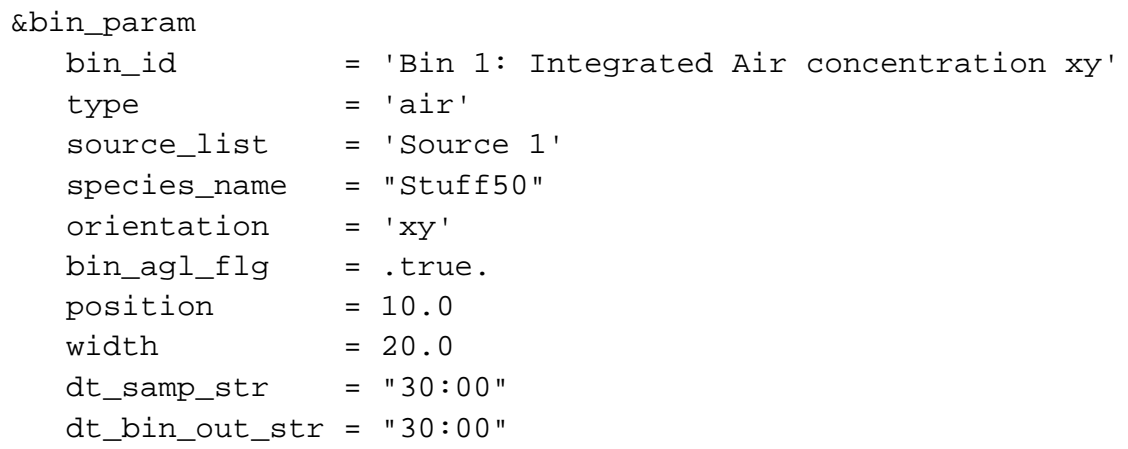




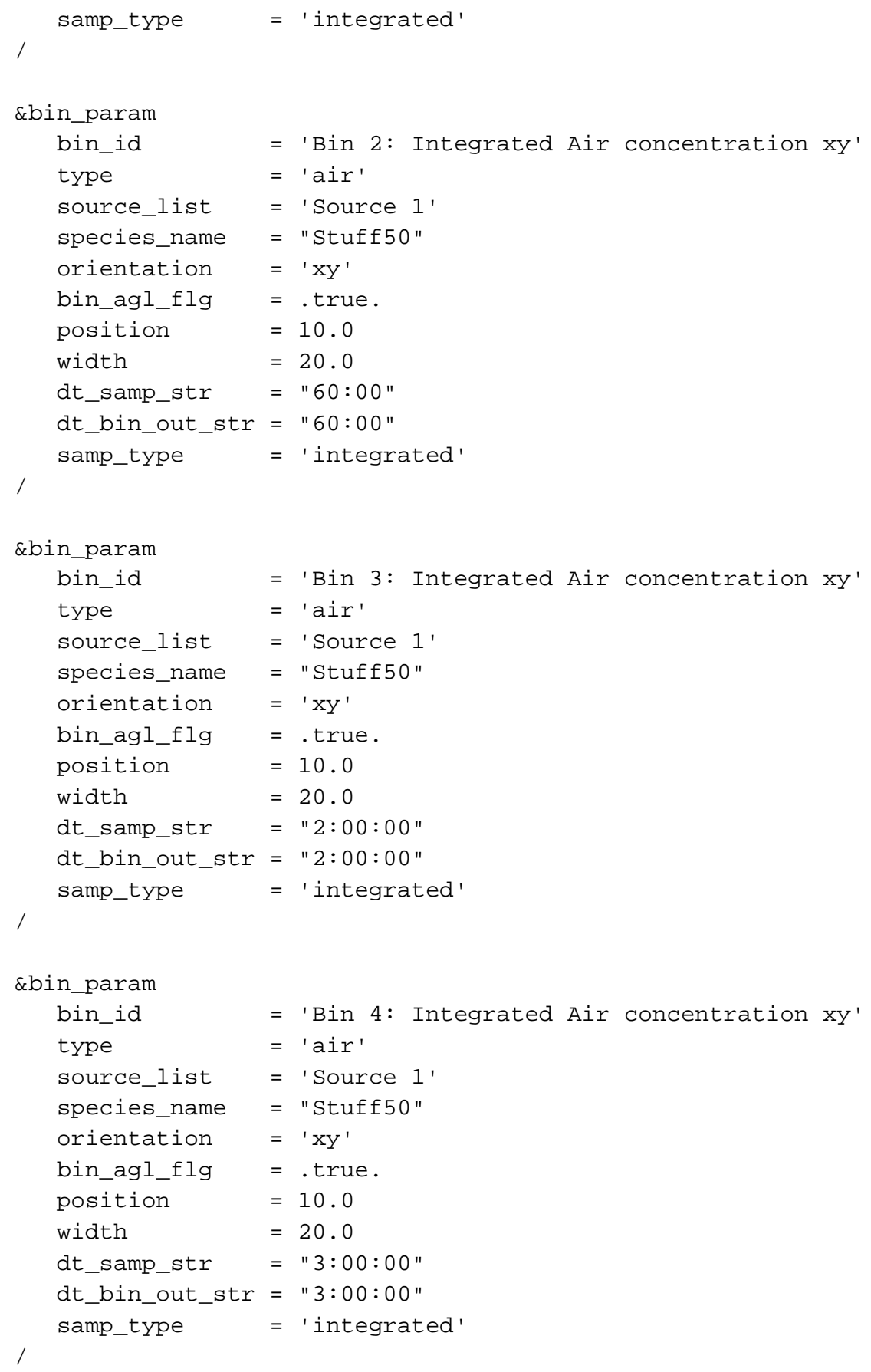

\section{NARAC MvM15}

\section{lodi_mvm15.nml (continued)}

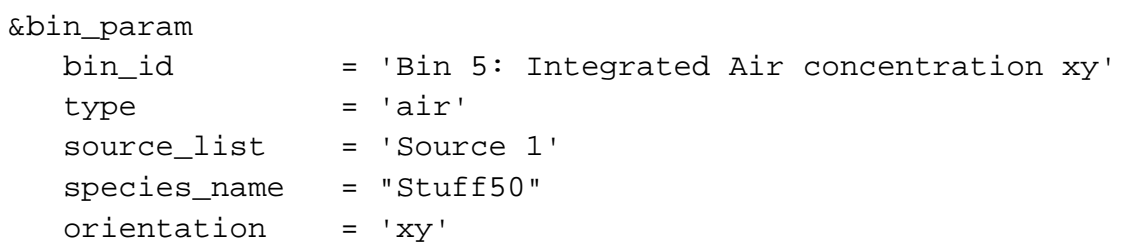




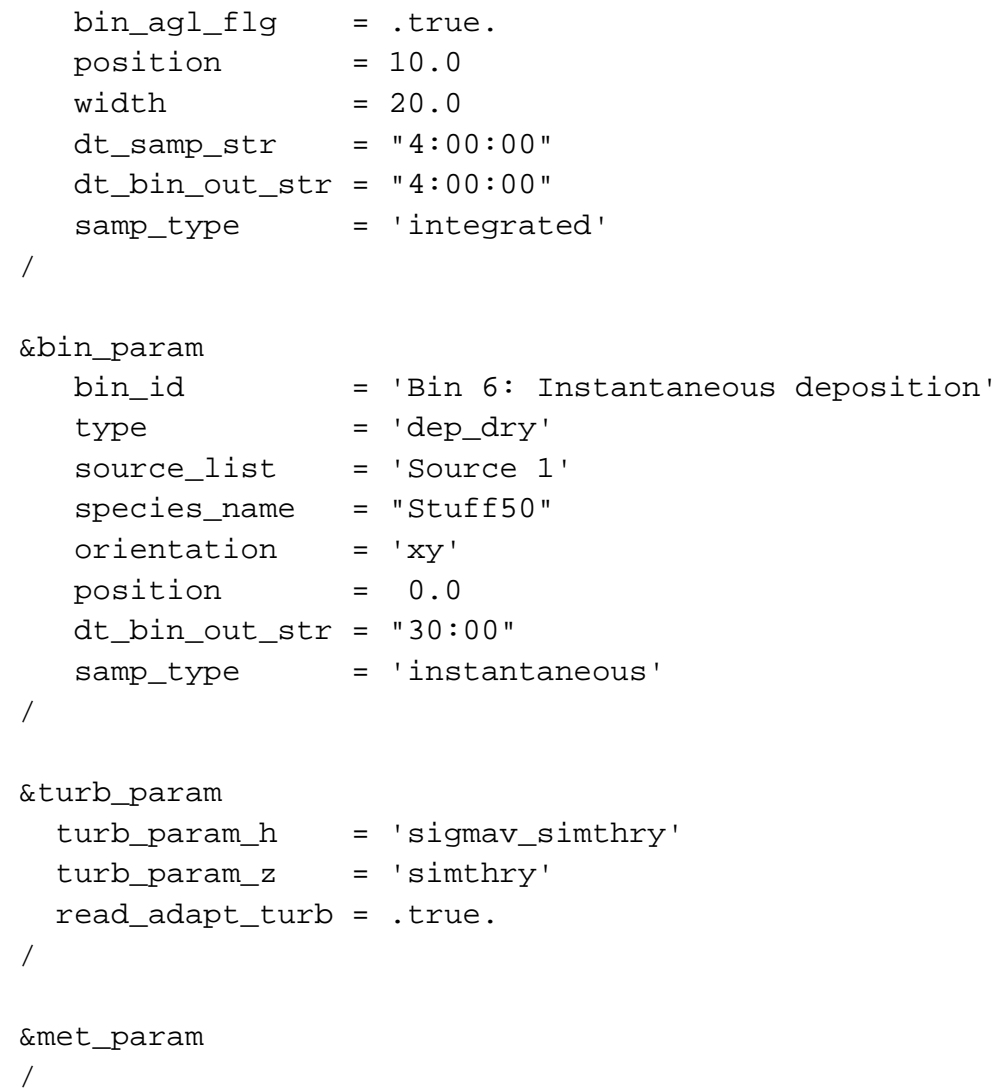

NARAC MvM15

stnloc_mvm15.met

SFC

$\begin{array}{lllll}\text { 'MtoM1' } & 0.0 & 0.0 & 10.0\end{array}$

UPR

'MtoM1' $0.0 \quad 0.0$

\section{NARAC MvM15}

observ_mvm15.met

METDATASET '2000APR01_000000'

UPR

$\begin{array}{llll}\text { 'MtoM1' } & 0.5 & 90 & 2.9251 \\ \text { 'MtoM1' } & 1 & 90 & 3.4132 \\ \text { 'MtoM1' } & 1.5 & 90 & 3.6977 \\ \text { 'MtoM1' } & 2 & 90 & 3.8988 \\ \text { 'MtoM1' } & 2.5 & 90 & 4.0543 \\ \text { 'MtoM1' } & 3 & 90 & 4.1808 \\ \text { 'MtoM1' } & 3.5 & 90 & 4.2875 \\ \text { 'MtoM1' } & 4 & 90 & 4.3795 \\ \text { 'MtoM1' } & 4.5 & 90 & 4.4605 \\ \text { 'MtoM1' } & 5 & 90 & 4.5326\end{array}$




\begin{tabular}{|c|c|c|c|}
\hline 'Mtom1 ' & 5.5 & 90 & 4.5977 \\
\hline 'MtoM1' & 6 & 90 & 4.6569 \\
\hline 'Mtom1' & 6.5 & 90 & 4.7112 \\
\hline 'MtoM1 ' & 7 & 90 & 4.7613 \\
\hline 'Mtom1 ' & 7.5 & 90 & 4.8078 \\
\hline 'Mtom1 ' & 8 & 90 & 4.8511 \\
\hline 'MtoM1 ' & 8.5 & 90 & 4.8918 \\
\hline 'MtoM1 ' & 9 & 90 & 4.9299 \\
\hline 'Mtom1 ' & 9.5 & 90 & 4.9659 \\
\hline 'Mtom1 ' & 10 & 90 & 5 \\
\hline 'MtoM1 ' & 10.5 & 90 & 5.0323 \\
\hline 'MtoM1 ' & 11 & 90 & 5.063 \\
\hline 'MtoM1 ' & 11.5 & 90 & 5.0923 \\
\hline 'Mtom1' & 12 & 90 & 5.1202 \\
\hline 'Mtom1' & 12.5 & 90 & 5.147 \\
\hline 'Mtom1' & 13 & 90 & 5.1726 \\
\hline 'Mtom1' & 13.5 & 90 & 5.1971 \\
\hline 'Mtom1 ' & 14 & 90 & 5.2208 \\
\hline 'Mtom1 ' & 14.5 & 90 & 5.2435 \\
\hline 'Mtom1 ' & 15 & 90 & 5.2654 \\
\hline ' Mtom1' & 15.5 & 90 & 5.2865 \\
\hline ' Mtom1' & 16 & 90 & 5.3069 \\
\hline 'MtoM1 ' & 16.5 & 90 & 5.3267 \\
\hline 'MtoM1 ' & 17 & 90 & 5.3457 \\
\hline 'MtoM1 ' & 17.5 & 90 & 5.3642 \\
\hline 'MtoM1 ' & 18 & 90 & 5.3822 \\
\hline 'Mtom1' & 18.5 & 90 & 5.3996 \\
\hline 'Mtom1' & 19 & 90 & 5.4164 \\
\hline 'Mtom1' & 19.5 & 90 & 5.4329 \\
\hline 'Mtom1' & 20 & 90 & 5.4488 \\
\hline 'MtoM1 ' & 20.5 & 90 & 5.4643 \\
\hline 'MtoM1' & 21 & 90 & 5.4795 \\
\hline 'Mtom1' & 21.5 & 90 & 5.4942 \\
\hline ' Mtom1' & 22 & 90 & 5.5085 \\
\hline ' Mtom1' & 22.5 & 90 & 5.5225 \\
\hline ' Mtom1' & 23 & 90 & 5.5362 \\
\hline 'Mtom1 ' & 23.5 & 90 & 5.5495 \\
\hline 'Mtom1 ' & 24 & 90 & 5.5626 \\
\hline 'Mtom1 ' & 24.5 & 90 & 5.5753 \\
\hline 'MtoM1 ' & 25 & 90 & 5.5878 \\
\hline ' Mt om1' & 25.5 & 90 & 5.5999 \\
\hline
\end{tabular}

\section{NARAC MvM15}

observ_mvm015.met (continued)

$\begin{array}{llll}\text { 'MtoM1' } & 26 & 90 & 5.6118 \\ \text { 'MtoM1' } & 26.5 & 90 & 5.6235 \\ \text { 'MtoM1' } & 27 & 90 & 5.6349 \\ \text { 'MtoM1' } & 27.5 & 90 & 5.6461\end{array}$




\begin{tabular}{|c|c|c|c|}
\hline 'MtoM1 ' & 28 & 90 & 5.6571 \\
\hline 'MtoM1 ' & 28.5 & 90 & 5.6678 \\
\hline 'MtoM1 ' & 29 & 90 & 5.6784 \\
\hline 'MtoM1 ' & 29.5 & 90 & 5.6887 \\
\hline 'MtoM1 ' & 30 & 90 & 5.6989 \\
\hline 'MtoM1 ' & 30.5 & 90 & 5.7088 \\
\hline 'MtoM1 ' & 31 & 90 & 5.7186 \\
\hline 'MtoM1 ' & 31.5 & 90 & 5.7282 \\
\hline 'MtoM1 ' & 32 & 90 & 5.7376 \\
\hline 'Mtom1 ' & 32.5 & 90 & 5.7469 \\
\hline 'Mtom1 ' & 33 & 90 & 5.756 \\
\hline 'MtoM1 ' & 33.5 & 90 & 5.765 \\
\hline 'MtoM1 ' & 34 & 90 & 5.7738 \\
\hline 'Mtom1 ' & 34.5 & 90 & 5.7824 \\
\hline 'Mtom1 ' & 35 & 90 & 5.791 \\
\hline 'MtoM1 ' & 35.5 & 90 & 5.7993 \\
\hline 'Mtom1 ' & 36 & 90 & 5.8076 \\
\hline 'MtoM1 ' & 36.5 & 90 & 5.8157 \\
\hline 'MtoM1 ' & 37 & 90 & 5.8237 \\
\hline 'MtoM1 ' & 37.5 & 90 & 5.8316 \\
\hline ' Mtom1' & 38 & 90 & 5.8394 \\
\hline 'Mtom1' & 38.5 & 90 & 5.847 \\
\hline 'MtoM1 ' & 39 & 90 & 5.8545 \\
\hline 'Mtom1' & 39.5 & 90 & 5.862 \\
\hline 'Mtom1 ' & 40 & 90 & 5.8693 \\
\hline 'Mtom1 ' & 40.5 & 90 & 5.8765 \\
\hline 'MtoM1 ' & 41 & 90 & 5.8836 \\
\hline 'MtoM1 ' & 41.5 & 90 & 5.8906 \\
\hline 'MtoM1 ' & 42 & 90 & 5.8975 \\
\hline 'MtoM1 ' & 42.5 & 90 & 5.9044 \\
\hline 'MtoM1 ' & 43 & 90 & 5.9111 \\
\hline 'MtoM1 ' & 43.5 & 90 & 5.9178 \\
\hline 'MtoM1 ' & 44 & 90 & 5.9243 \\
\hline 'Mtom1' & 44.5 & 90 & 5.9308 \\
\hline 'Mtom1' & 45 & 90 & 5.9372 \\
\hline 'Mtom1' & 45.5 & 90 & 5.9435 \\
\hline 'Mtom1' & 46 & 90 & 5.9497 \\
\hline 'Mtom1 ' & 46.5 & 90 & 5.9559 \\
\hline 'Mtom1 ' & 47 & 90 & 5.962 \\
\hline 'Mtom1 ' & 47.5 & 90 & 5.968 \\
\hline ' Mtom1' & 48 & 90 & 5.9739 \\
\hline ' Mtom1' & 48.5 & 90 & 5.9798 \\
\hline ' Mtom1' & 49 & 90 & 5.9856 \\
\hline ' Mtom1' & 49.5 & 90 & 5.9913 \\
\hline 'MtoM1 ' & 50 & 90 & 5.997 \\
\hline
\end{tabular}


HPAC MvM16

\begin{tabular}{|c|c|c|}
\hline mvm16 & HPAC 3.2 parame ter & HPAC 3.2 value \\
\hline HPAC SCREEN & agent & 500 micron particles \\
\hline \multirow[t]{12}{*}{ New Project Setup } & project file name & $m v m 16 . p j$ \\
\hline & coordina tes & cartesian \\
\hline & local origin $\mathrm{x}$ & $0 \mathrm{~km}$ \\
\hline & local origin $y$ & $0 \mathrm{~km}$ \\
\hline & local origin lat i tude & $45 \operatorname{deg} N$ \\
\hline & local origin longi tude & $0 \mathrm{deg}$ \\
\hline & reference times & UTC \\
\hline & local time of $00: 00 z$ & 0 \\
\hline & mode & st andard \\
\hline & dynamics & dense gas \\
\hline & static puffs & enabled \\
\hline & hazard area & off \\
\hline New Project Editor & edit mode & advanœed \\
\hline \multirow{8}{*}{ Material Editor } & type & particle \\
\hline & name & STUFF500 \\
\hline & mat erial file name & Stuff $500 . \mathrm{mtl}$ \\
\hline & units & $\mathrm{kg}$ \\
\hline & bin boundaries & see comment \\
\hline & output flags & surf. dosage, surf. depos. \\
\hline & daytime decay rate & $\begin{array}{r}0 \\
\end{array}$ \\
\hline & nighttime decay ra te & 0 \\
\hline \multirow[t]{3}{*}{ Gas Parame ter Editor } & density ratio (rho/ rho_air) & $500 \mathrm{~kg} / \mathrm{m}^{\wedge} 3$ \\
\hline & deposition velocity & NA \\
\hline & minimum concen tra tion & 0 \\
\hline \multirow[t]{15}{*}{ Release Editor } & time & 0 \\
\hline & $\mathbf{x}$ & 0 \\
\hline & $y$ & 0 \\
\hline & height of release & $2 \mathrm{~m}$ \\
\hline & source uncert ainty & no \\
\hline & specification & simple \\
\hline & randomize location & NA \\
\hline & release dura tion & inst antaneous \\
\hline & release ra te & NA \\
\hline & agent mass & $1 \mathrm{~kg}$ \\
\hline & $x$ size & $1 \mathrm{~m}$ \\
\hline & y size & $1 \mathrm{~m}$ \\
\hline & $z$ size & $1 \mathrm{~m}$ \\
\hline & MMD & $500 \quad \mu$ \\
\hline & sigma & 2 \\
\hline \multirow[t]{6}{*}{ Time Editor } & start day & $4 / 1 / 00$ \\
\hline & start time & 0 \\
\hline & stop day & $4 / 1 / 00$ \\
\hline & stop time & 100 \\
\hline & maximum time step & $60 \mathrm{sec}$ \\
\hline & out put interval & $5 \mathrm{~min}$ \\
\hline \multirow[t]{7}{*}{ Domain Editor } & xmin domain & $-3 \mathrm{~km}$ \\
\hline & $x \max$ domain & $0.5 \mathrm{~km}$ \\
\hline & ymin domain & $-0.1 \mathrm{~km}$ \\
\hline & ymax domain & $0.1 \mathrm{~km}$ \\
\hline & horizontal resolution & default \\
\hline & vertical domain max height & $500 \mathrm{~m}$ \\
\hline & vertical domain resolution & $10 \mathrm{~m}$ \\
\hline Wea ther Editor & weather dat a type & surface obs. only \\
\hline & boundary layer type & observations \\
\hline & large scale variability & none \\
\hline & large scale variability length scale & NA \\
\hline & large scale variability variance & NA \\
\hline & $\begin{array}{c}\text { surf ace roughness } \\
\end{array}$ & $0.008 \mathrm{~m}$ \\
\hline & precipita tion & none \\
\hline & obs. time bin size & $1 \mathrm{hr}$ \\
\hline Meteorology Option Editor & save me te orology fields & no \\
\hline & terrain/land cover file & no \\
\hline Surface Obsenations File & file name & $\mathrm{mvmN.sfc}$ \\
\hline & $\begin{array}{c}\text { elevation } \\
\end{array}$ & $10 \mathrm{~m}$ \\
\hline & zi (boundary layer height) & $500 \mathrm{~m}$ \\
\hline & $z$ (al ti tude for wind measur ement) & $10 \mathrm{~m}$ \\
\hline & wind dire ction ( from) & $90 \mathrm{deg}$ (east) \\
\hline & $\begin{array}{c}\text { wind speed } \\
\end{array}$ & $5 \mathrm{~m} / \mathrm{s}$ \\
\hline & MOL (Monin-Obukhov Leng th) & $-500 \mathrm{~m}$ \\
\hline Op tions Editor & puff split grid level & 2 \\
\hline & surface resolution & default \\
\hline & puf $\mathrm{f}$ grid resolution & 0 \\
\hline & boundary layer pts & 11 \\
\hline & stable atm. turbulence & $1 \mathrm{e}-2 \mathrm{~m}^{\wedge} 2 / \mathrm{s}^{\wedge} 2$ \\
\hline & stable a tm. scale & $10 \mathrm{~m}$ \\
\hline & stable dissipa tion & $4 \mathrm{e}-4 \mathrm{~m}^{\wedge} 2 / \mathrm{s}^{\wedge} 3$ \\
\hline & calm cond. turbulence & $0.25 \mathrm{~m}^{\wedge} 2 / \mathrm{s}^{\wedge} 2$ \\
\hline & calm cond. scale & $1000 \mathrm{~m}$ \\
\hline & surface dosage height & 0 \\
\hline & minimum puf $\mathrm{f}$ mass & $1 \mathrm{e}-20$ \\
\hline & conditional averaging time & $1 \mathrm{hr}$ \\
\hline & lumped boundary layer & no \\
\hline
\end{tabular}




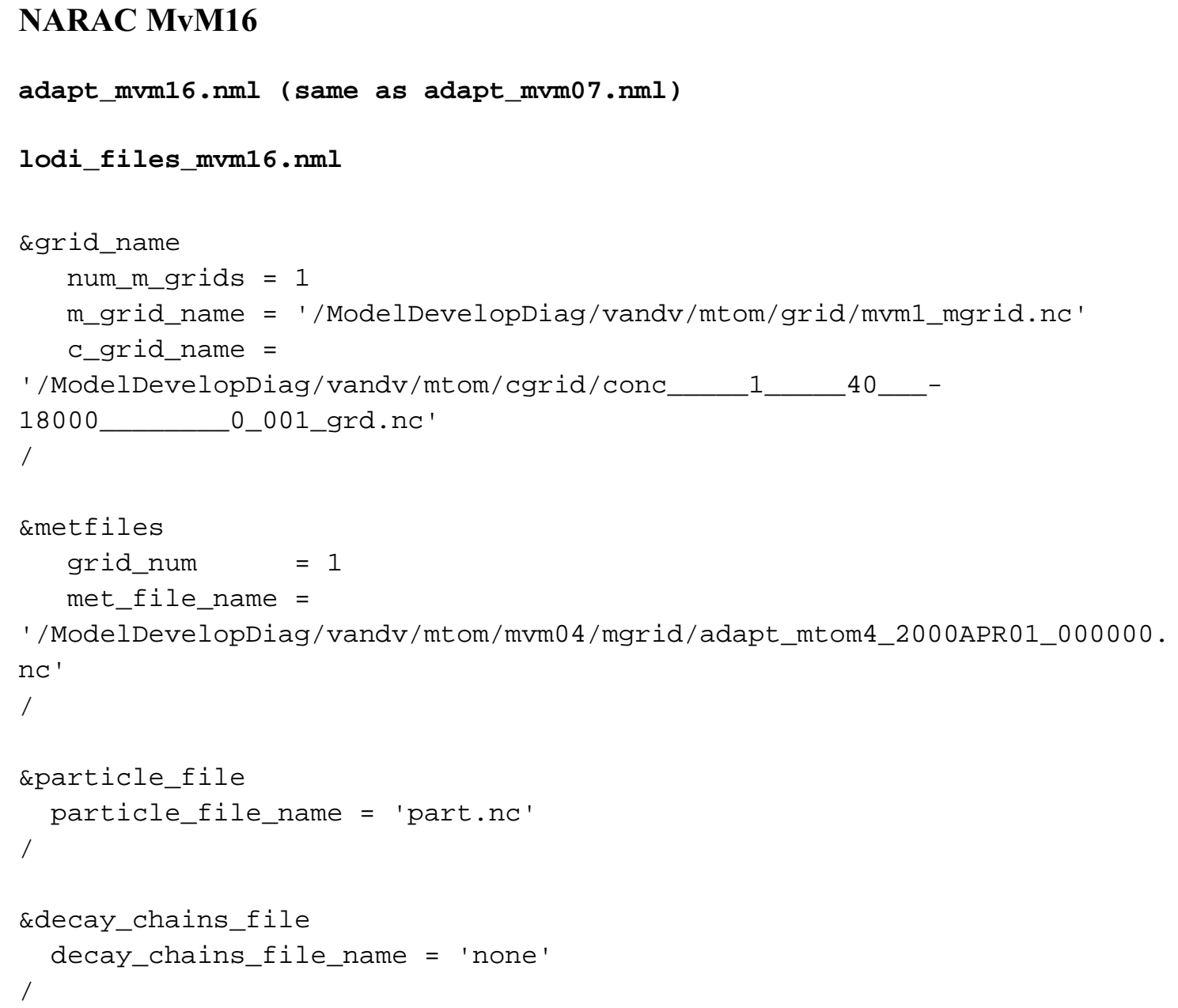

\section{NARAC MvM16}

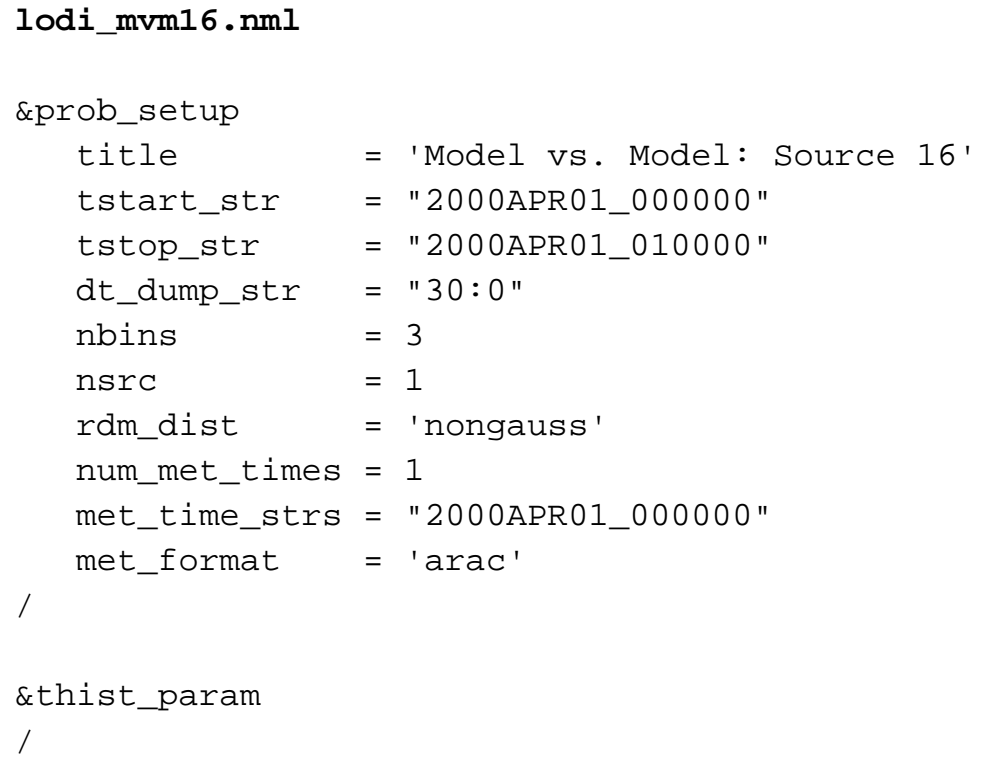




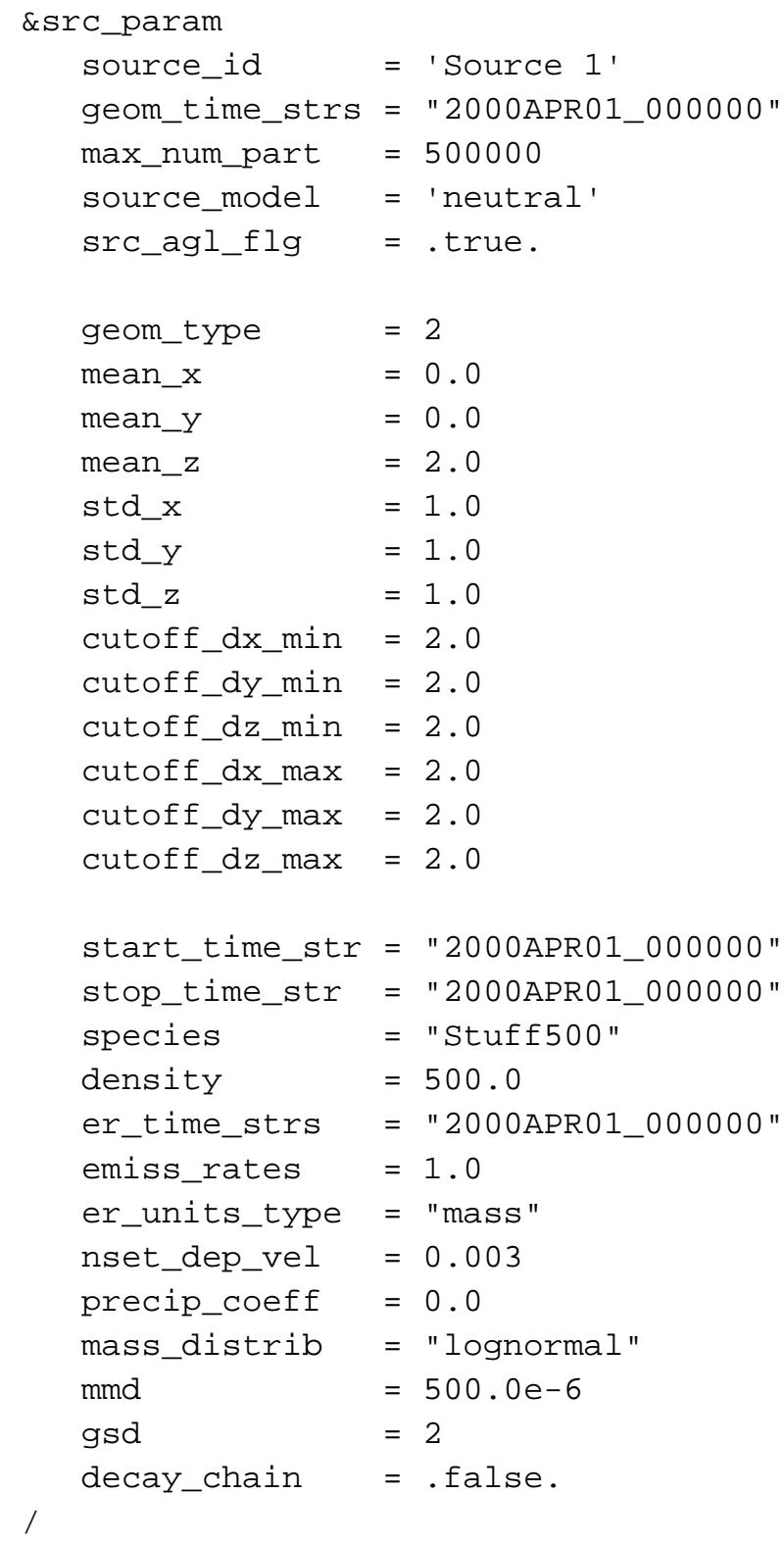

\section{NARAC MvM16}

lodi_mvm16.nml (continued)

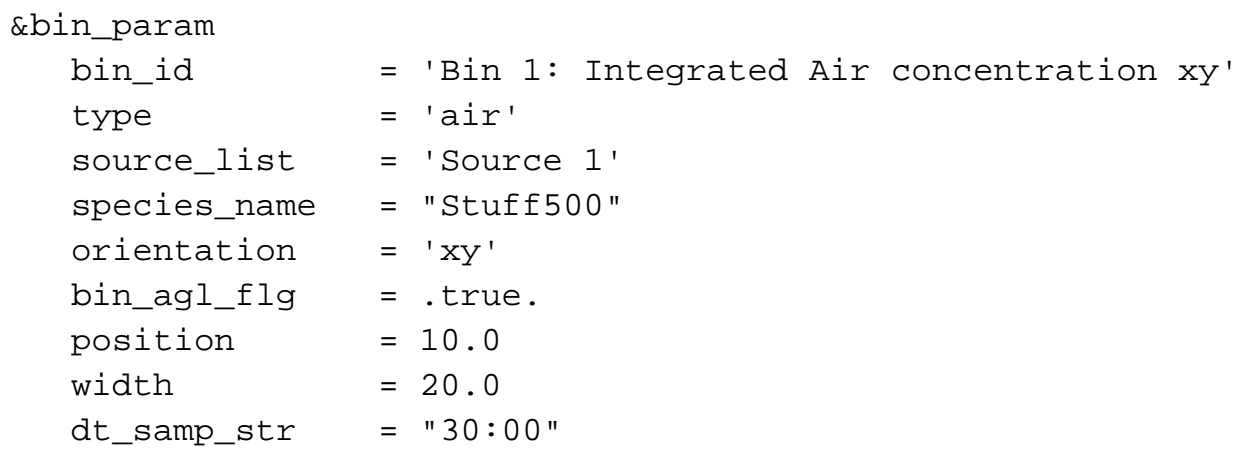




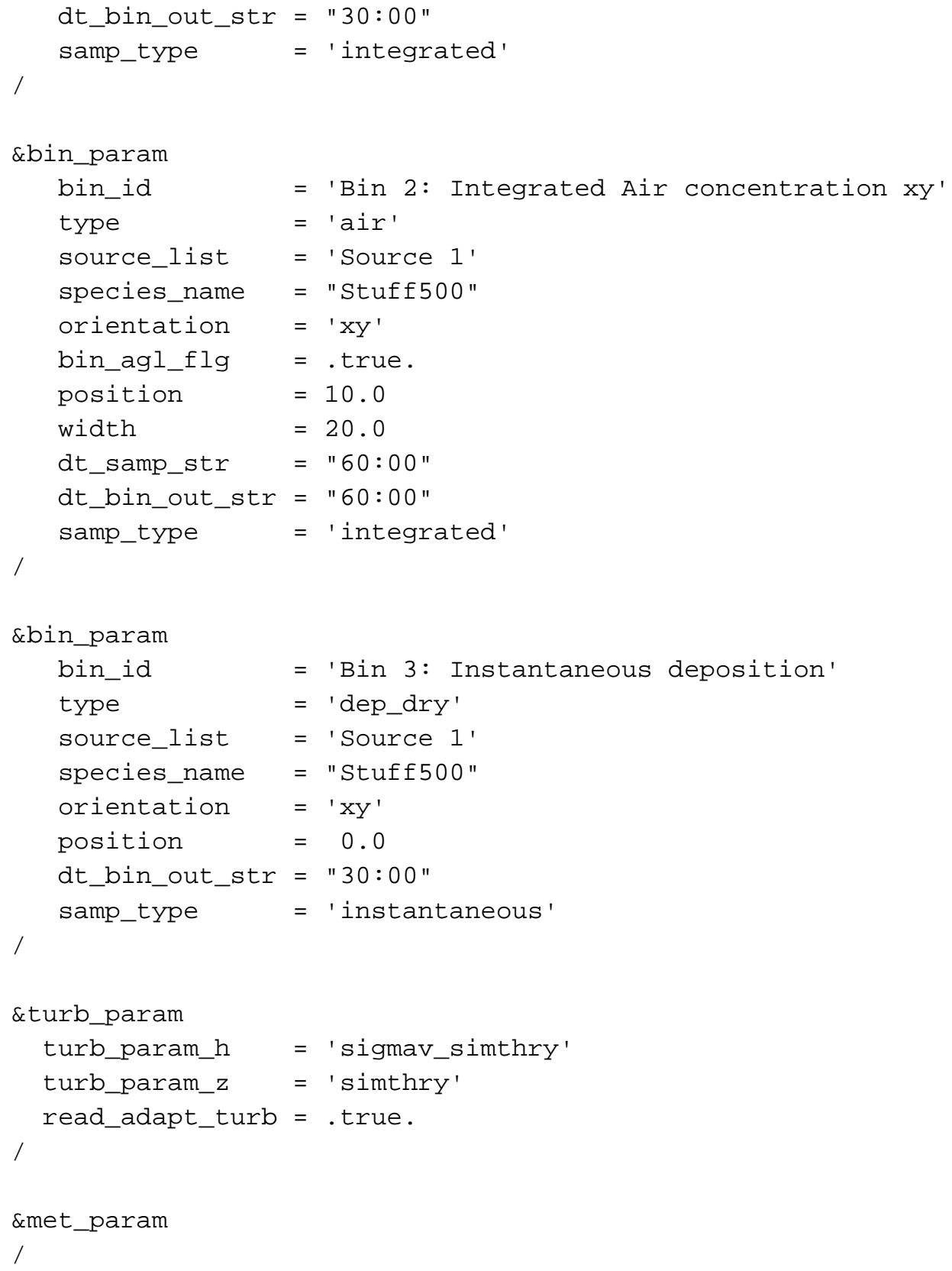

NARAC MvM16

stnloc_mvm16.met (same as stnloc_mvm07.met)

observ_mvm16.met (same as observ_mvm07.met) 


\section{HPAC MvM17}

\begin{tabular}{|c|c|c|}
\hline mvm17 & HPAC 3.2 parame ter & HPAC 3.2 value \\
\hline HPAC SCREEN & agent & 500 micron particles \\
\hline \multirow[t]{12}{*}{ New Project Setup } & project file name & mvm17.pj \\
\hline & coordina tes & cartesian \\
\hline & local origin $\mathrm{x}$ & $0 \mathrm{~km}$ \\
\hline & local origin $y$ & $0 \mathrm{~km}$ \\
\hline & local origin lat i tude & $45 \operatorname{deg} N$ \\
\hline & local origin longi tude & $0 \mathrm{deg}$ \\
\hline & reference times & UTC \\
\hline & local time of $00: 00 z$ & 0 \\
\hline & mode & st andard \\
\hline & dynamics & dense gas \\
\hline & static puffs & enabled \\
\hline & hazard area & off \\
\hline New Project Editor & edit mode & advanœed \\
\hline \multirow{8}{*}{ Material Editor } & type & particle \\
\hline & name & STUFF500 \\
\hline & mat erial file name & Stuff $500 . \mathrm{mtl}$ \\
\hline & units & $\mathrm{kg}$ \\
\hline & bin boundaries & see comment \\
\hline & output flags & surf. dosage, surf. depos. \\
\hline & daytime decay rate & $\begin{array}{r}0 \\
\end{array}$ \\
\hline & nigh ttime decay rate & 0 \\
\hline \multirow[t]{3}{*}{ Gas Parame ter Editor } & density ratio (rho/ rho_air) & $500 \mathrm{~kg} / \mathrm{m}^{\wedge} 3$ \\
\hline & deposition velocity & NA \\
\hline & minimum concen tra tion & 0 \\
\hline \multirow[t]{15}{*}{ Release Editor } & time & 0 \\
\hline & $\mathbf{x}$ & 0 \\
\hline & $y$ & $-0.25 \mathrm{~km}$ \\
\hline & height of release & $2 \mathrm{~m}$ \\
\hline & source uncert ainty & no \\
\hline & specification & simple \\
\hline & randomize location & NA \\
\hline & release dura tion & $1 \mathrm{sec}$ \\
\hline & release ra te & $1 \mathrm{~kg} / \mathrm{s}$ \\
\hline & agent mass & $1 \mathrm{~kg}$ \\
\hline & $\mathrm{x}$ size, $\mathrm{x}$ velocity & $\mathrm{NA}, 0$ \\
\hline & $y$ size, $y$ velocity & $1 \mathrm{~m}, 500 \mathrm{~m} / \mathrm{s}$ \\
\hline & $z$ size, $z$ velocity & $1 \mathrm{~m}, 0$ \\
\hline & MMD & $500 \quad \mu$ \\
\hline & sigma & 2 \\
\hline \multirow[t]{6}{*}{ Time Editor } & start day & $4 / 1 / 00$ \\
\hline & start time & 0 \\
\hline & stop day & $4 / 1 / 00$ \\
\hline & stop time & 100 \\
\hline & maximum time step & $60 \mathrm{sec}$ \\
\hline & out put interval & $15 \mathrm{~min}$ \\
\hline \multirow[t]{7}{*}{ Domain Editor } & xmin domain & $-50 \mathrm{~km}$ \\
\hline & $x \max$ domain & $1 \mathrm{~km}$ \\
\hline & ymin domain & $-5 \mathrm{~km}$ \\
\hline & ymax domain & $5 \mathrm{~km}$ \\
\hline & horizon tal resolution & default \\
\hline & vertical domain max height & $500 \mathrm{~m}$ \\
\hline & vertical domain resolution & $10 \mathrm{~m}$ \\
\hline Wea ther Editor & weather dat a type & surface obs. only \\
\hline & boundary layer type & observations \\
\hline & large scale variability & none \\
\hline & large scale variability length scale & NA \\
\hline & large scale variability variance & NA \\
\hline & $\begin{array}{c}\text { surf ace roughness } \\
\end{array}$ & $0.008 \mathrm{~m}$ \\
\hline & precipita tion & none \\
\hline & obs. time bin size & $1 \mathrm{hr}$ \\
\hline Meteorology Option Editor & save me te orology fields & no \\
\hline & terrain/land cover file & no \\
\hline Surface Obsenations File & file name & $\mathrm{mvmN.sfc}$ \\
\hline & $\begin{array}{c}\text { elevation } \\
\end{array}$ & $10 \mathrm{~m}$ \\
\hline & zi (boundary layer height) & $500 \mathrm{~m}$ \\
\hline & $z$ (al ti tude for wind measur ement) & $10 \mathrm{~m}$ \\
\hline & wind dire ction ( from) & $90 \mathrm{deg}$ (east) \\
\hline & $\begin{array}{c}\text { wind speed } \\
\end{array}$ & $5 \mathrm{~m} / \mathrm{s}$ \\
\hline & MOL (Monin-Obukhov Leng th) & $-500 \mathrm{~m}$ \\
\hline Options Editor & $\begin{array}{l}\text { puff split grid level } \\
\end{array}$ & 2 \\
\hline & surface resolution & default \\
\hline & puf f grid resolution & 0 \\
\hline & boundary layer pts & 11 \\
\hline & stable atm. turbulence & $1 \mathrm{e}-2 \mathrm{~m}^{\wedge} 2 / \mathrm{s}^{\wedge} 2$ \\
\hline & stable a tm. scale & $10 \mathrm{~m}$ \\
\hline & s table dissipa tion & $4 \mathrm{e}-4 \mathrm{~m}^{\wedge} 2 / \mathrm{s}^{\wedge} 3$ \\
\hline & calm cond. turbulence & $0.25 \mathrm{~m}^{\wedge} 2 / \mathrm{s}^{\wedge} 2$ \\
\hline & calm cond. scale & $1000 \mathrm{~m}$ \\
\hline & surface dosage height & 0 \\
\hline & minimum puf $\mathrm{f}$ mass & $1 \mathrm{e}-20$ \\
\hline & conditional averaging time & $1 \mathrm{hr}$ \\
\hline & lumped boundary layer & no \\
\hline
\end{tabular}




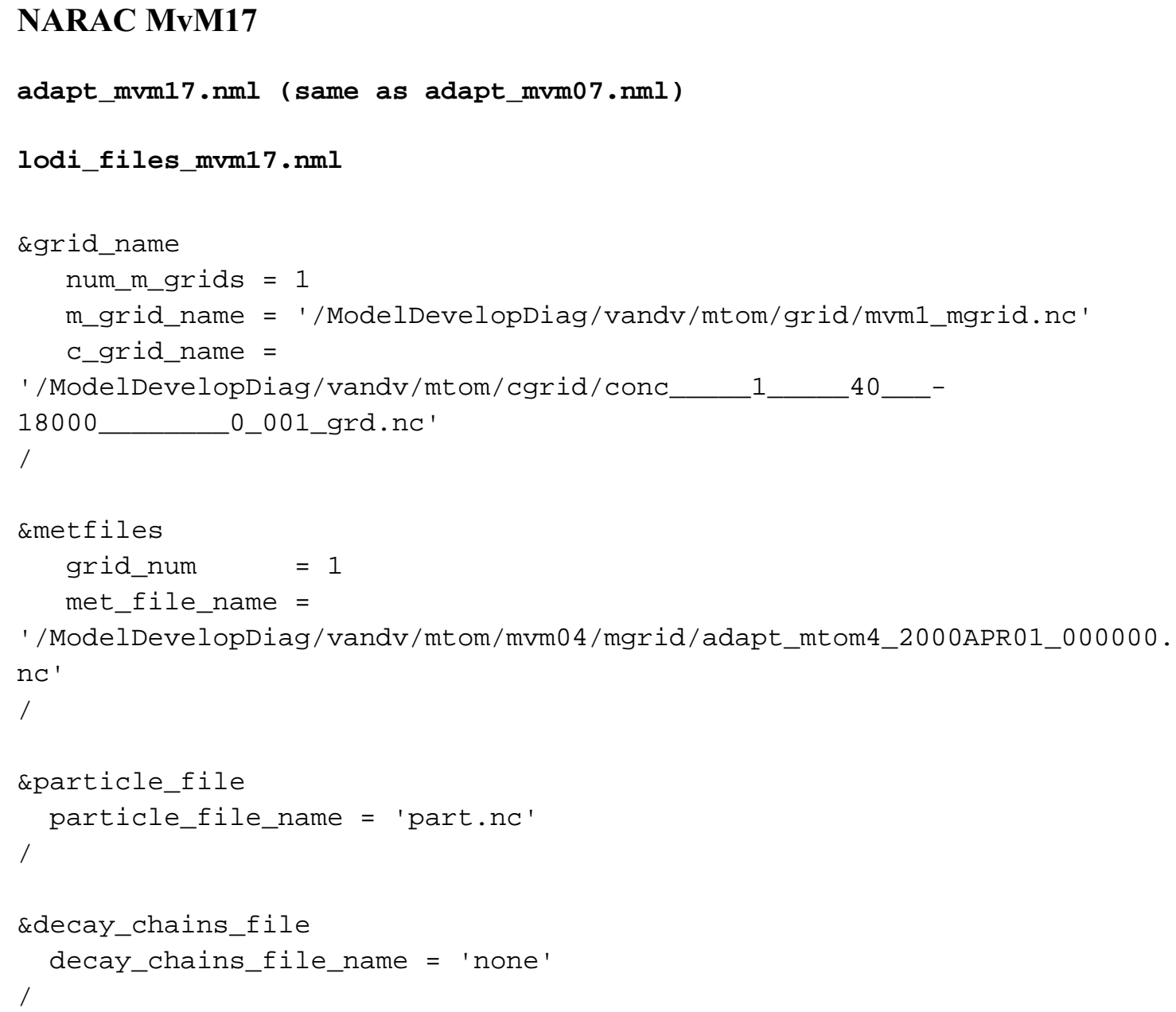

\section{NARAC MvM17}

lodi_mvm17. $\mathrm{nml}$

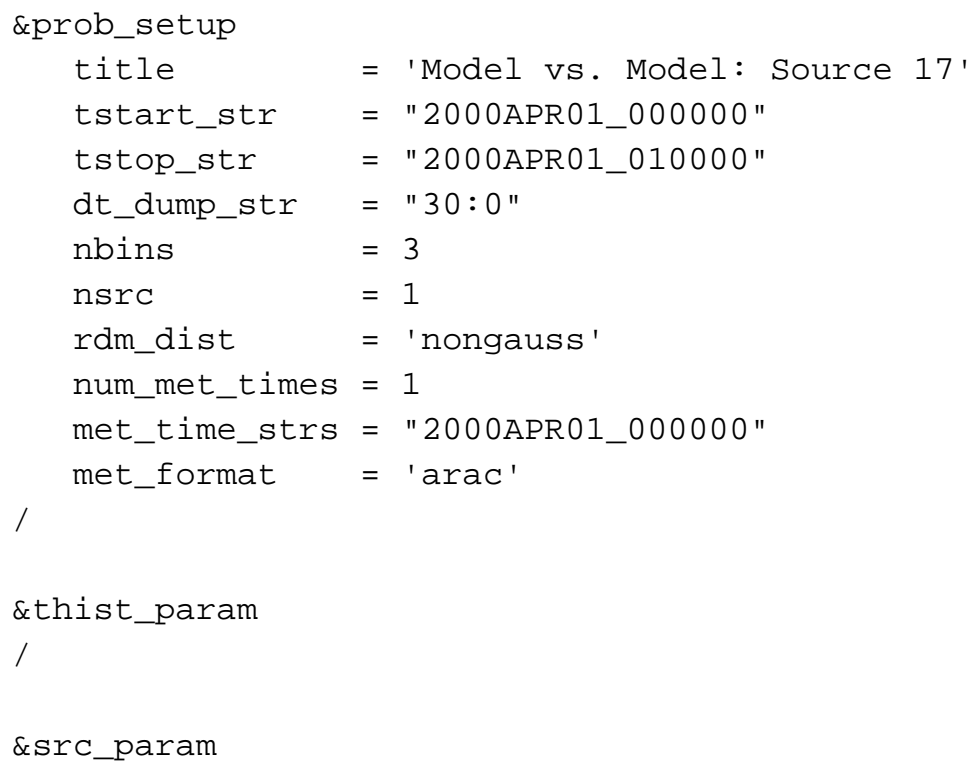




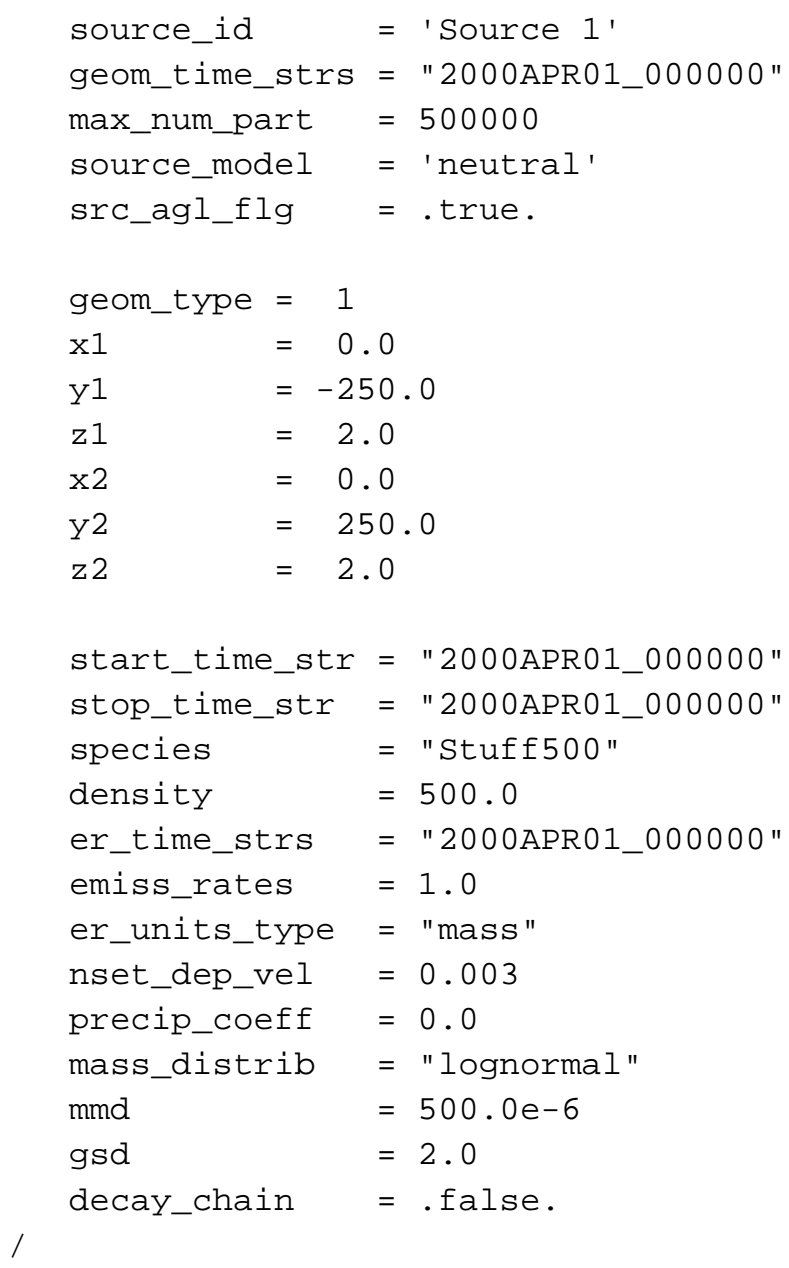

\section{NARAC MvM17}

\section{lodi_mvm17.nml (continued)}

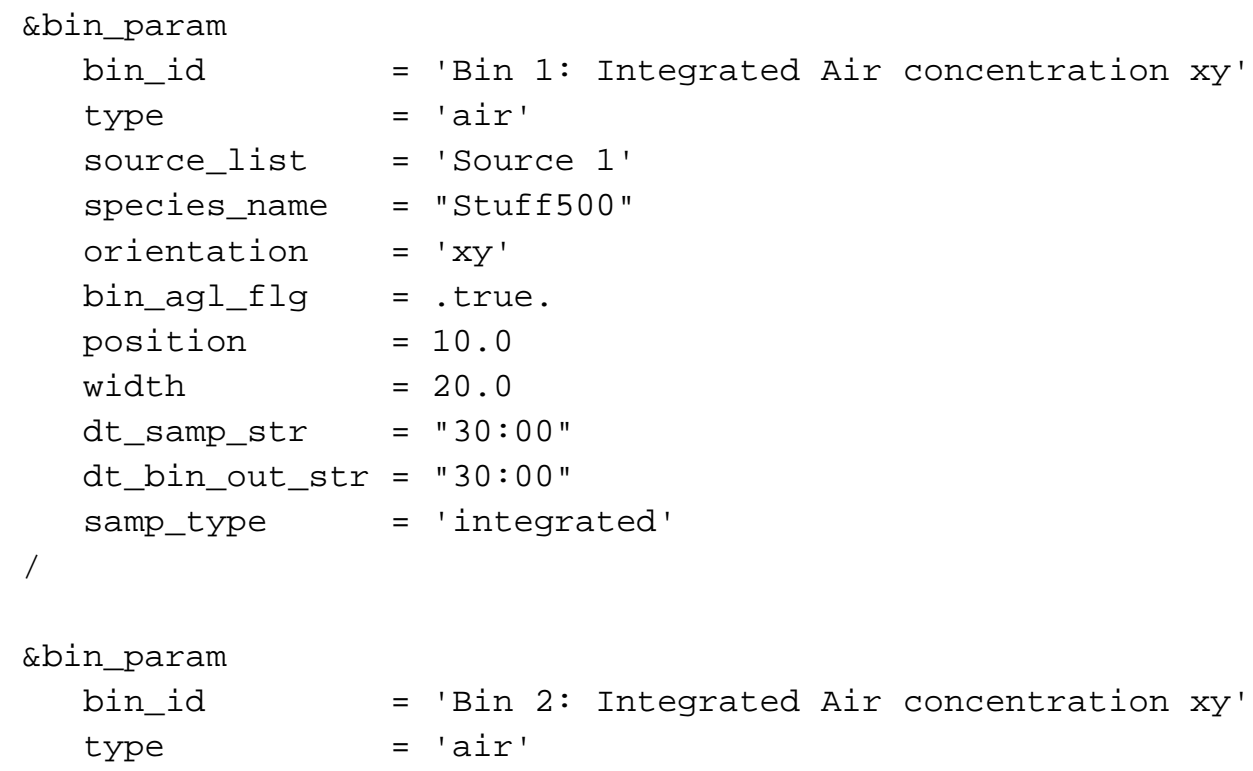




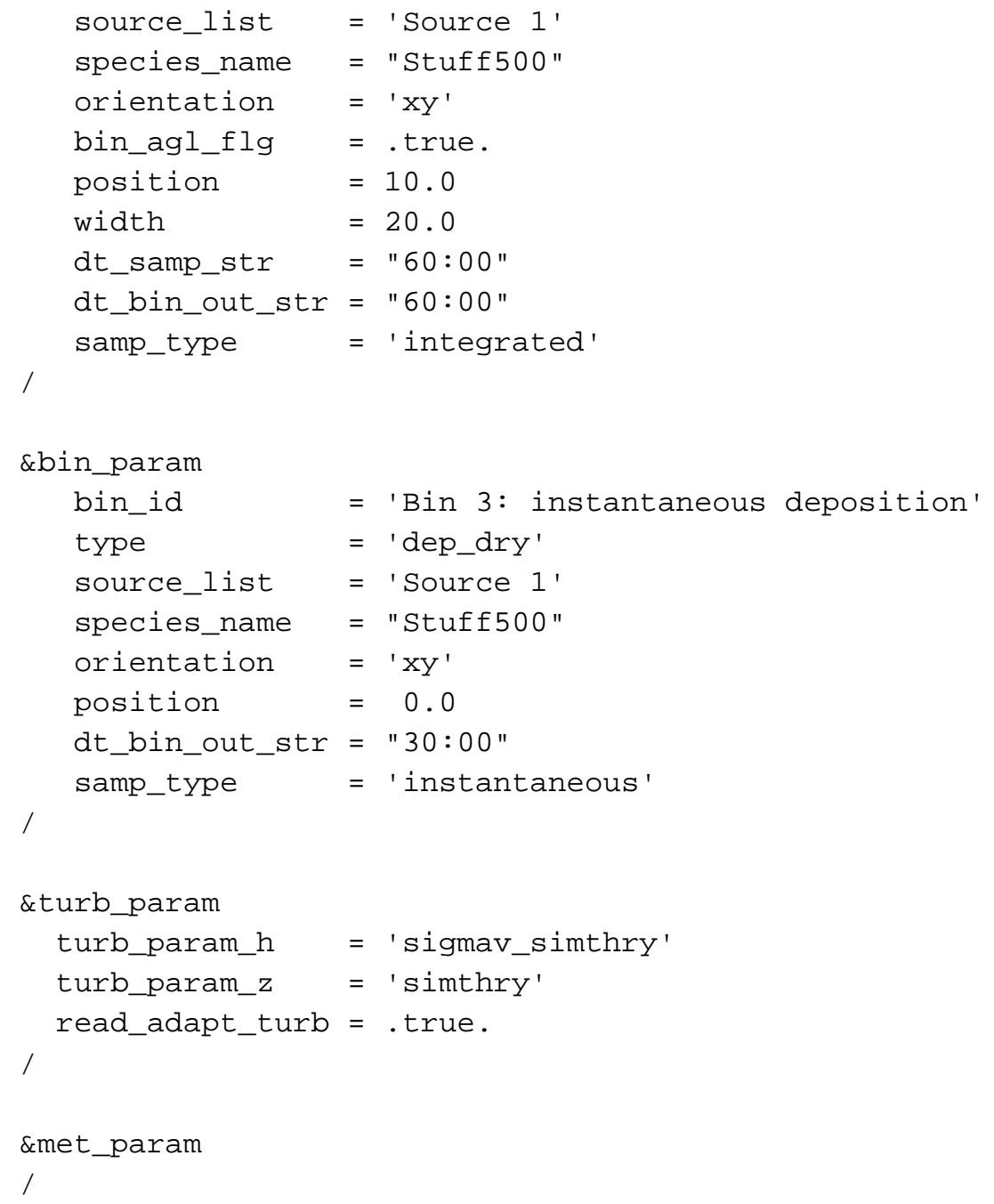

\section{NARAC Gridgen Files, MvM 1-14, 16, 17}

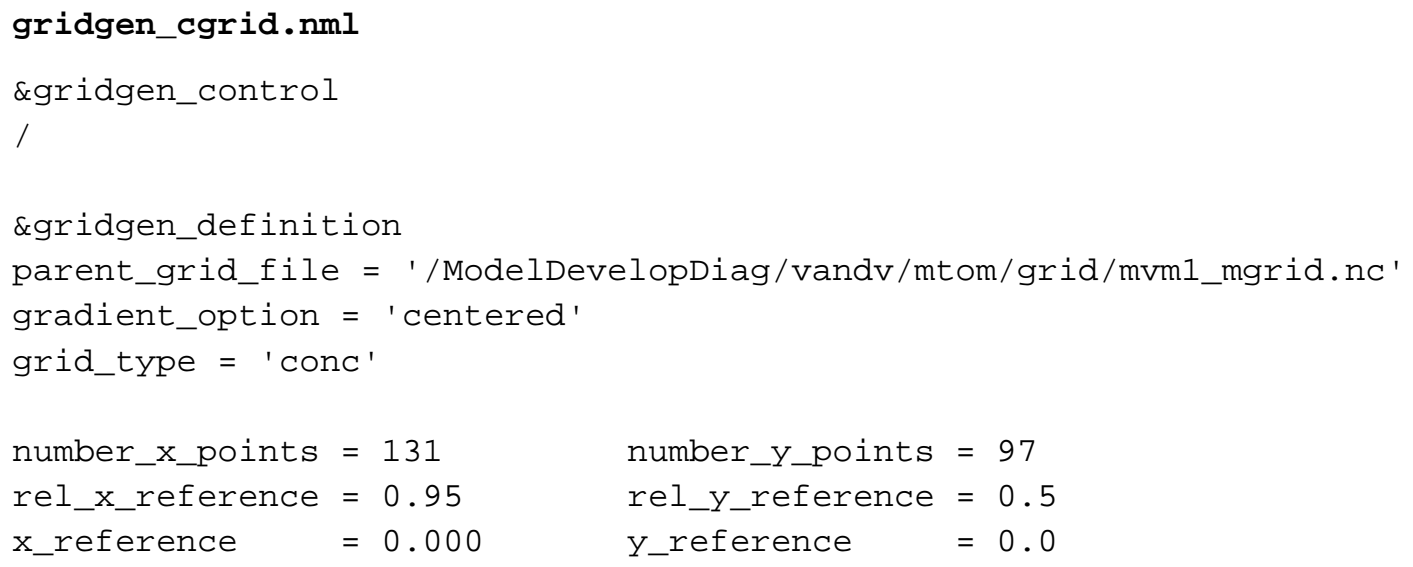




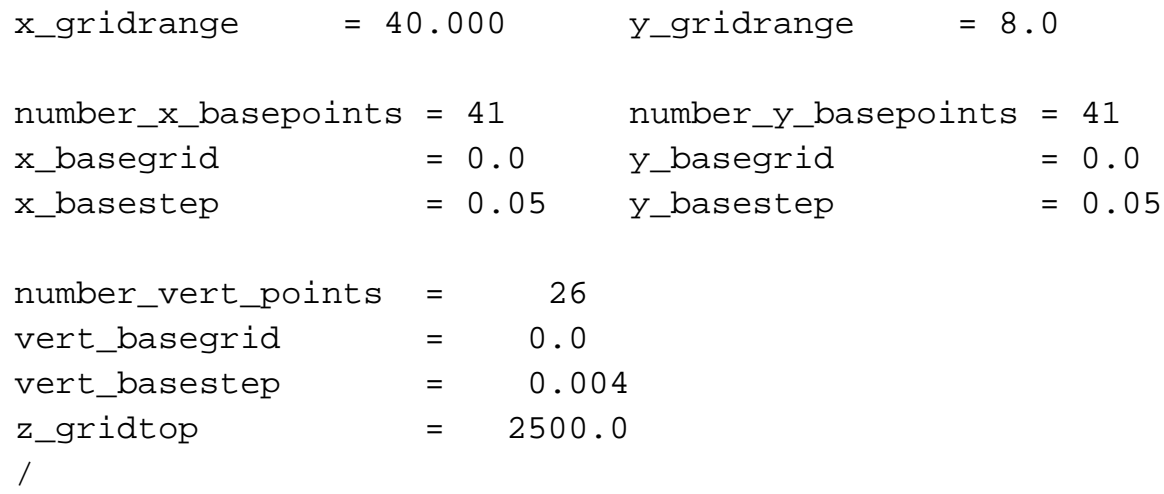

NARAC Gridgen Files, MvM15

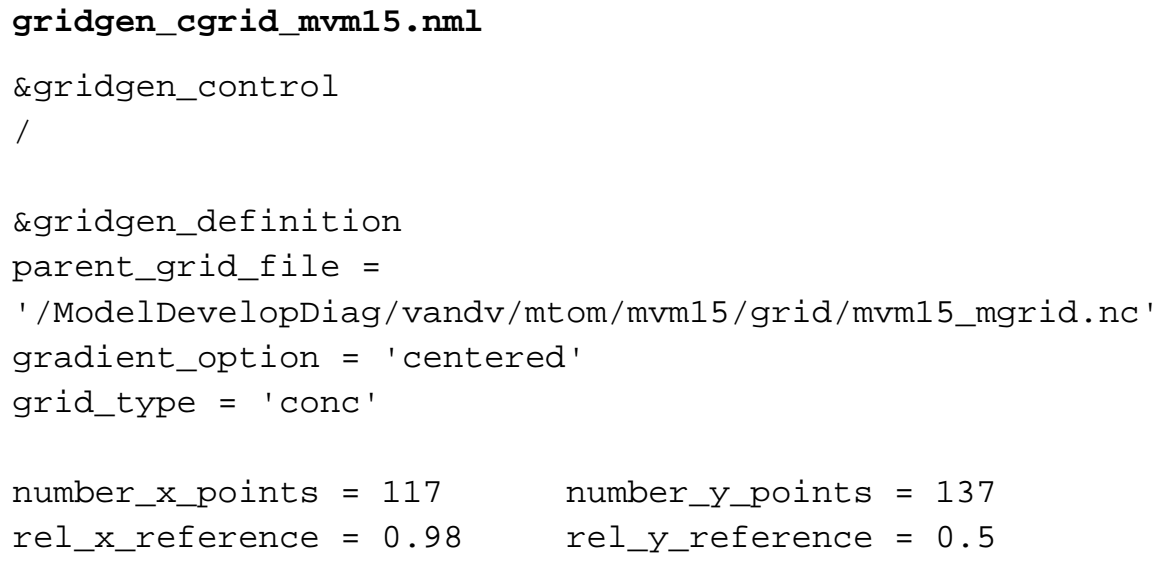




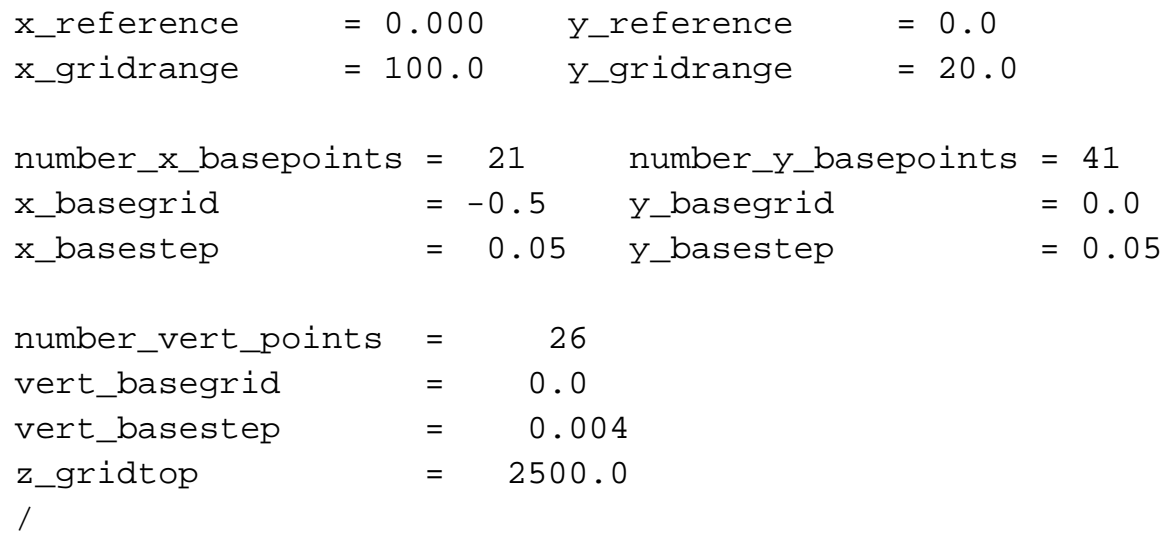



APPENDIX C

\section{GAS RELEASE COMPARISON PLOTS}





\section{APPENDIX C GAS RELEASE COMPARISON PLOTS}

This appendix contains dosage contours, crosswind dosage profiles, and dosage histograms for all of the gas releases. The 54 figures of this appendix are grouped by run number and time (30 and 60 minutes after the release).
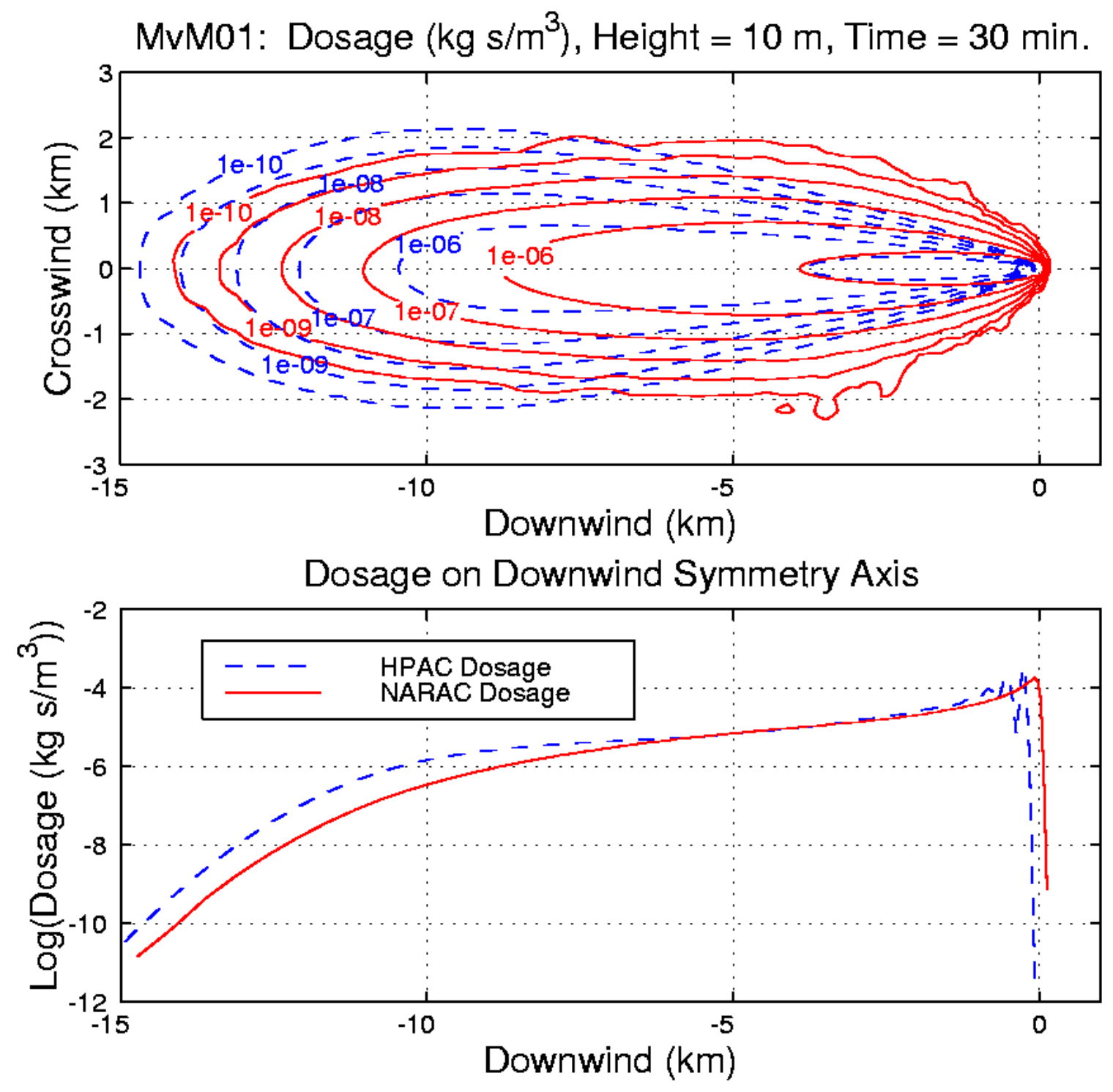

Figure C-1. MvM 1 at 30 Minutes with Upper: Dosage Contours for HPAC (BLUE - -) and NARAC (RED -); Lower: Dosage on Downwind Symmetry Axis 


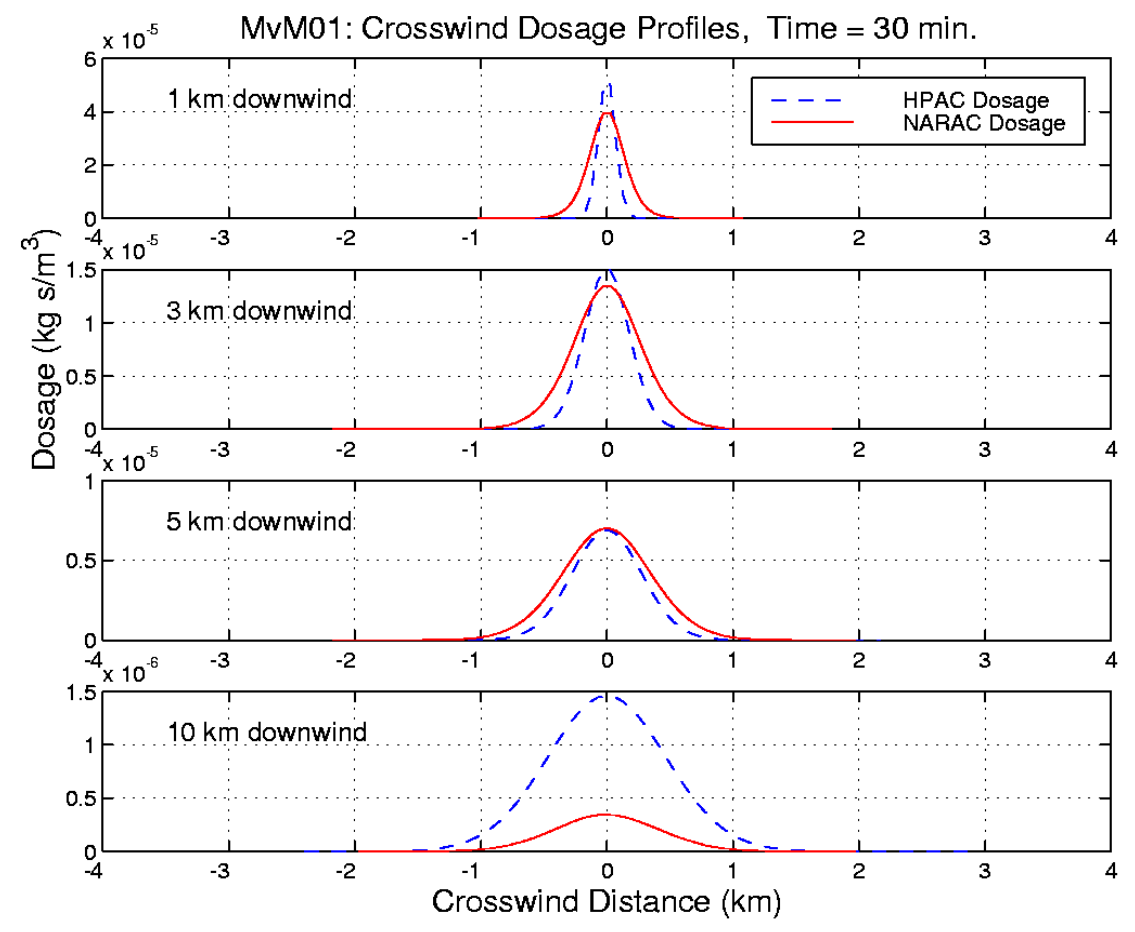

Figure C-2. MvM 1 at 30 Minutes: HPAC (BLUE - -) and NARAC (RED -) Crosswind Dosage Plumes for Various Downwind Distances

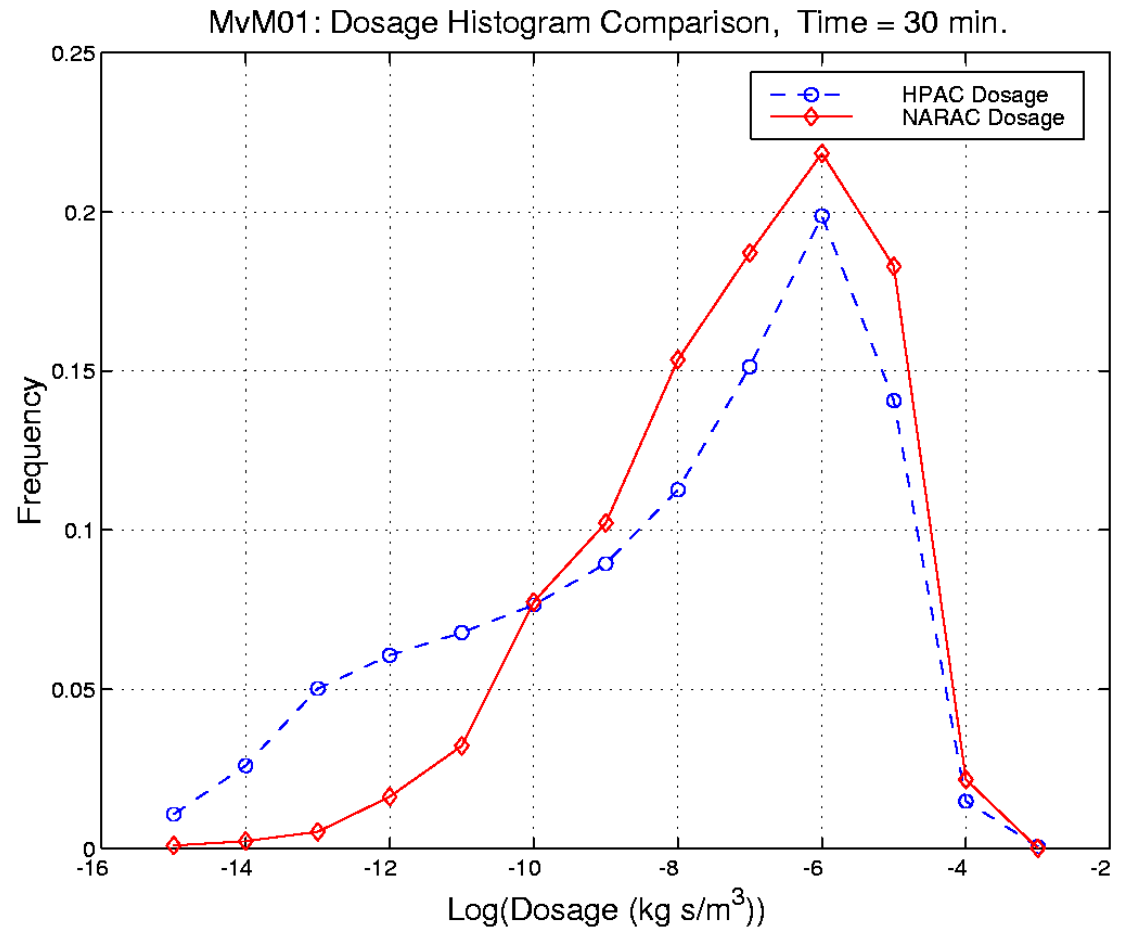

Figure C-3. MvM 1 at 30 Minutes: Dosage Histograms for HPAC (BLUE - -) and NARAC (RED -) 

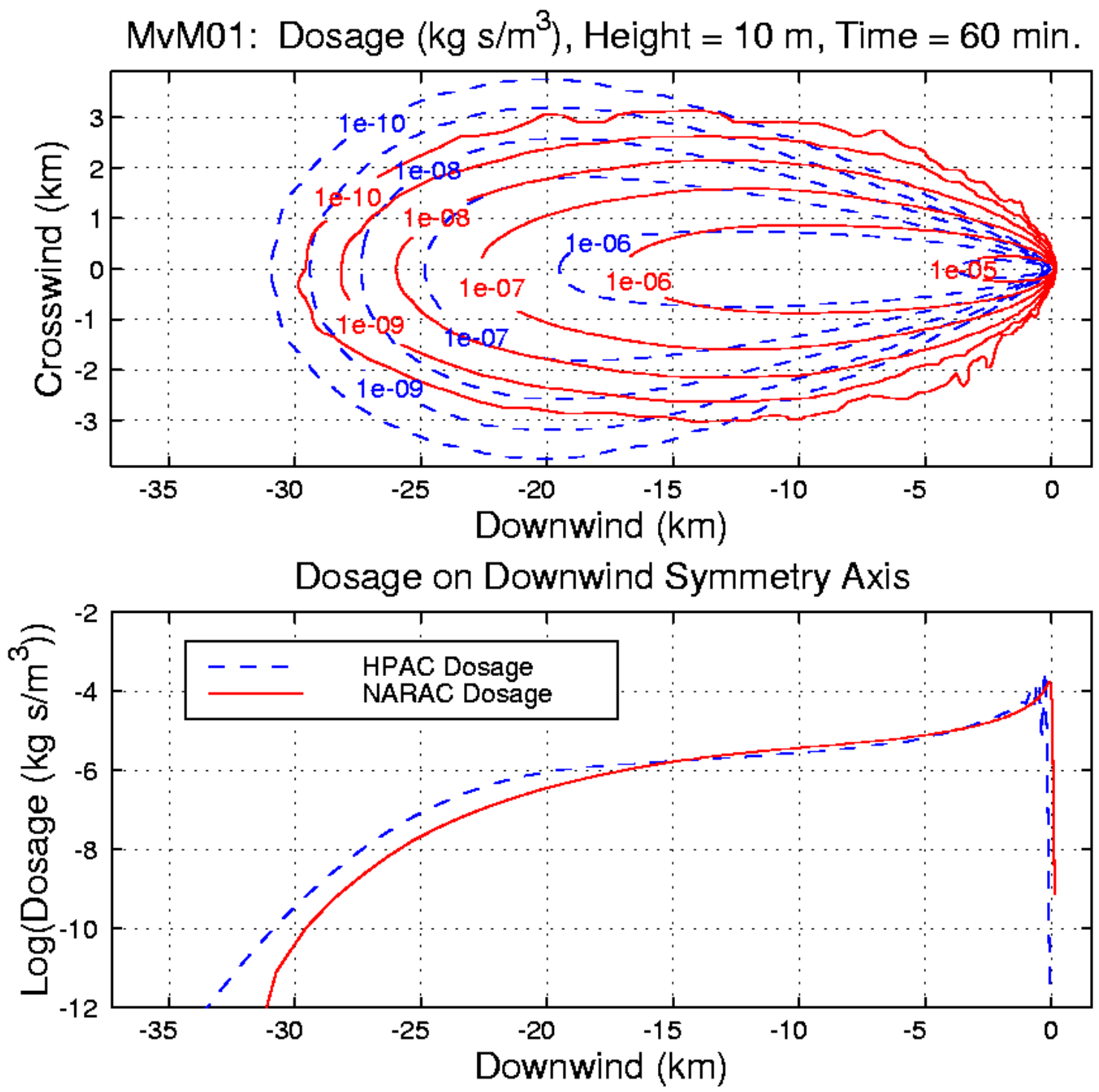

Figure C-4. MvM 1 at 60 Minutes with Upper: Dosage Contours for HPAC (BLUE - -) and NARAC (RED -); Lower: Dosage on Downwind Symmetry Axis 

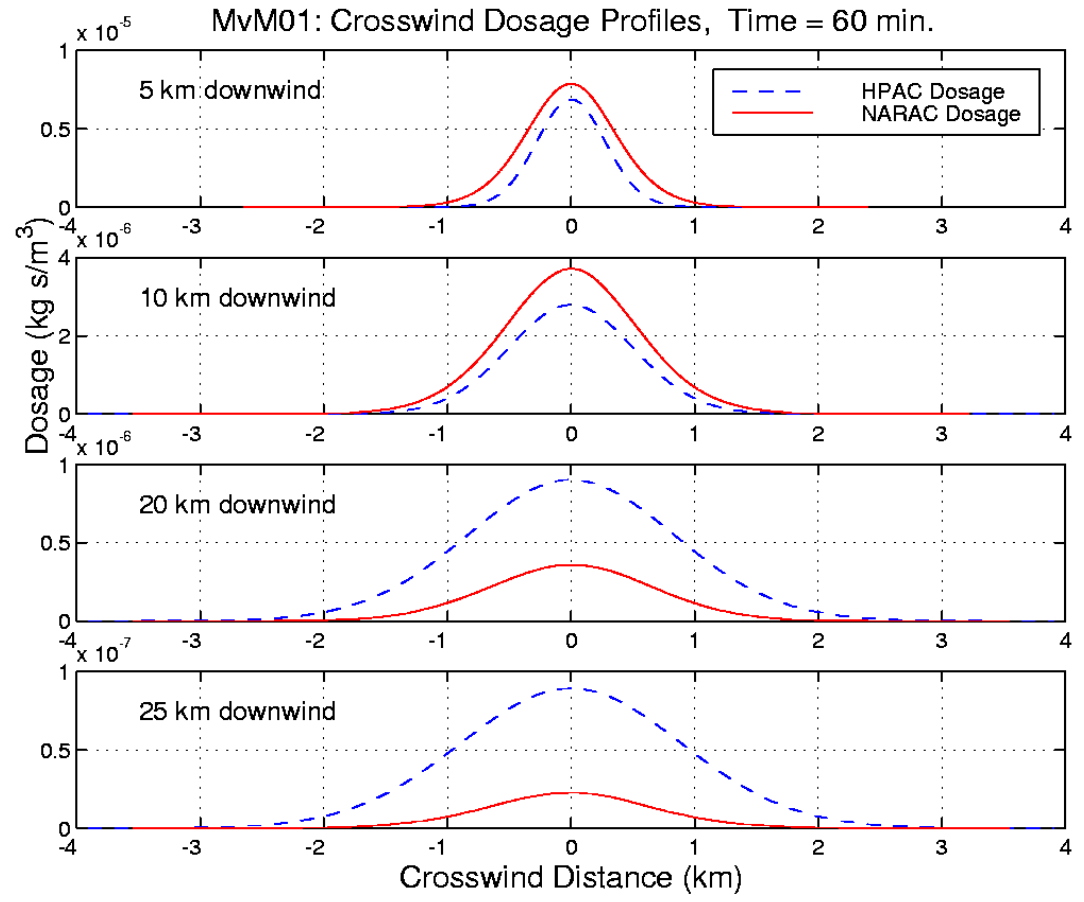

Figure C-5. MvM 1 at 60 Minutes: HPAC (BLUE - -) and NARAC (RED -) Crosswind Dosage Plumes for Various Downwind Distances

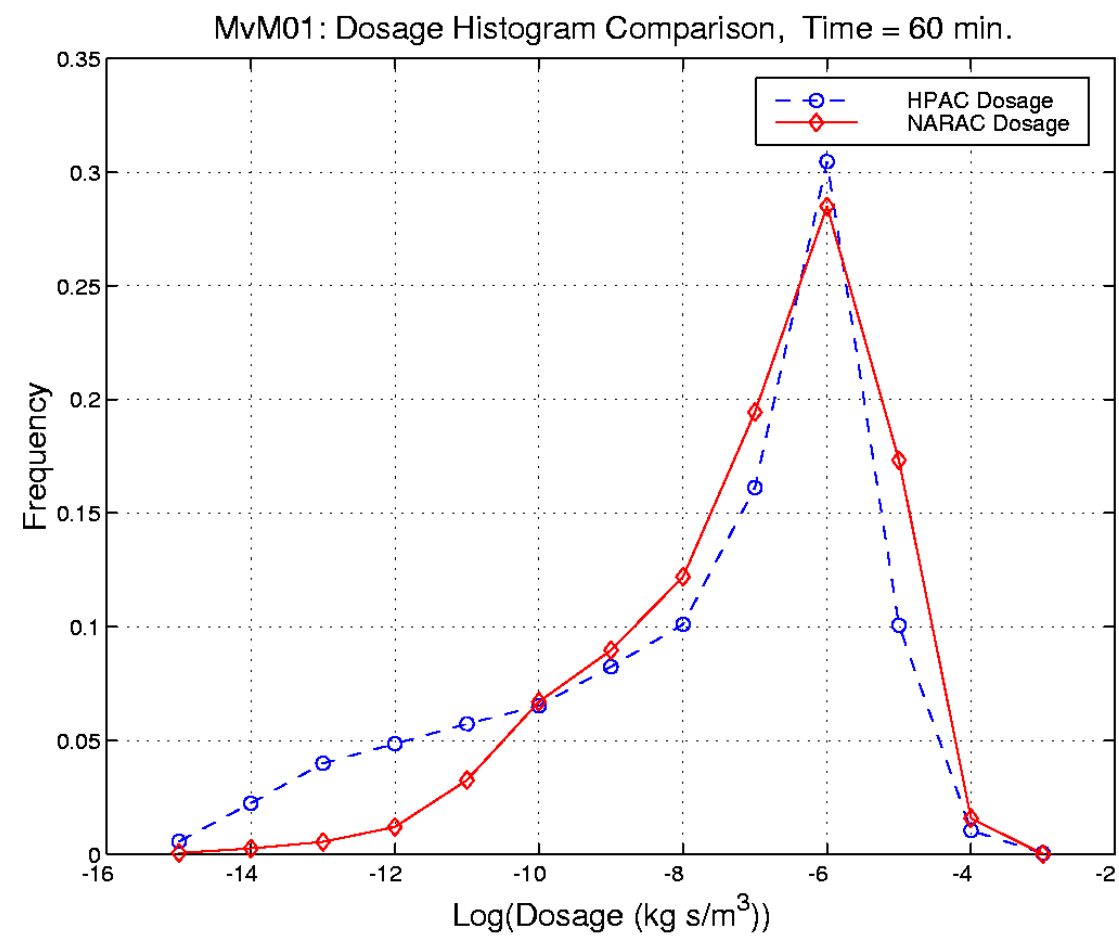

Figure C-6. MvM 1 at 60 Minutes: Dosage Histograms for HPAC (BLUE - -) and NARAC (RED -) 


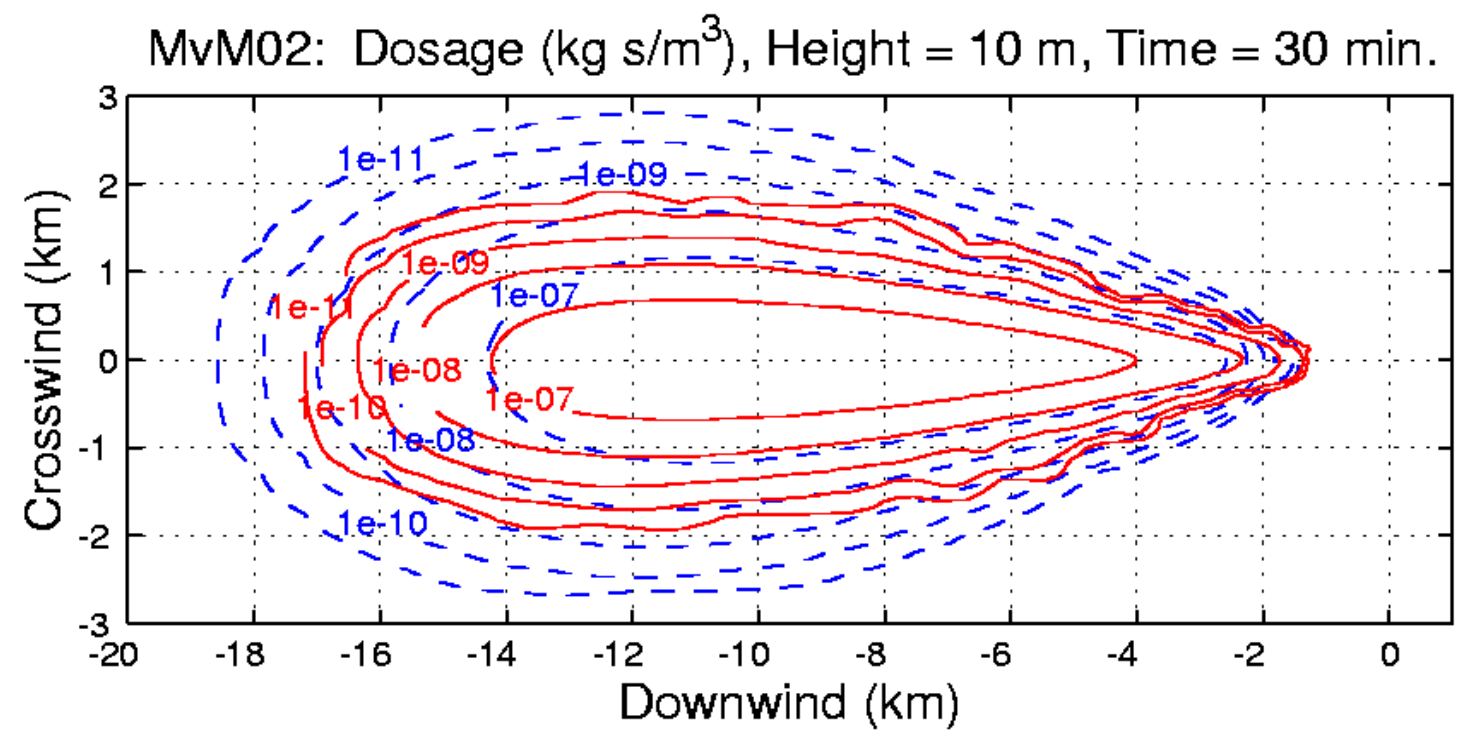

Dosage on Downwind Symmetry Axis

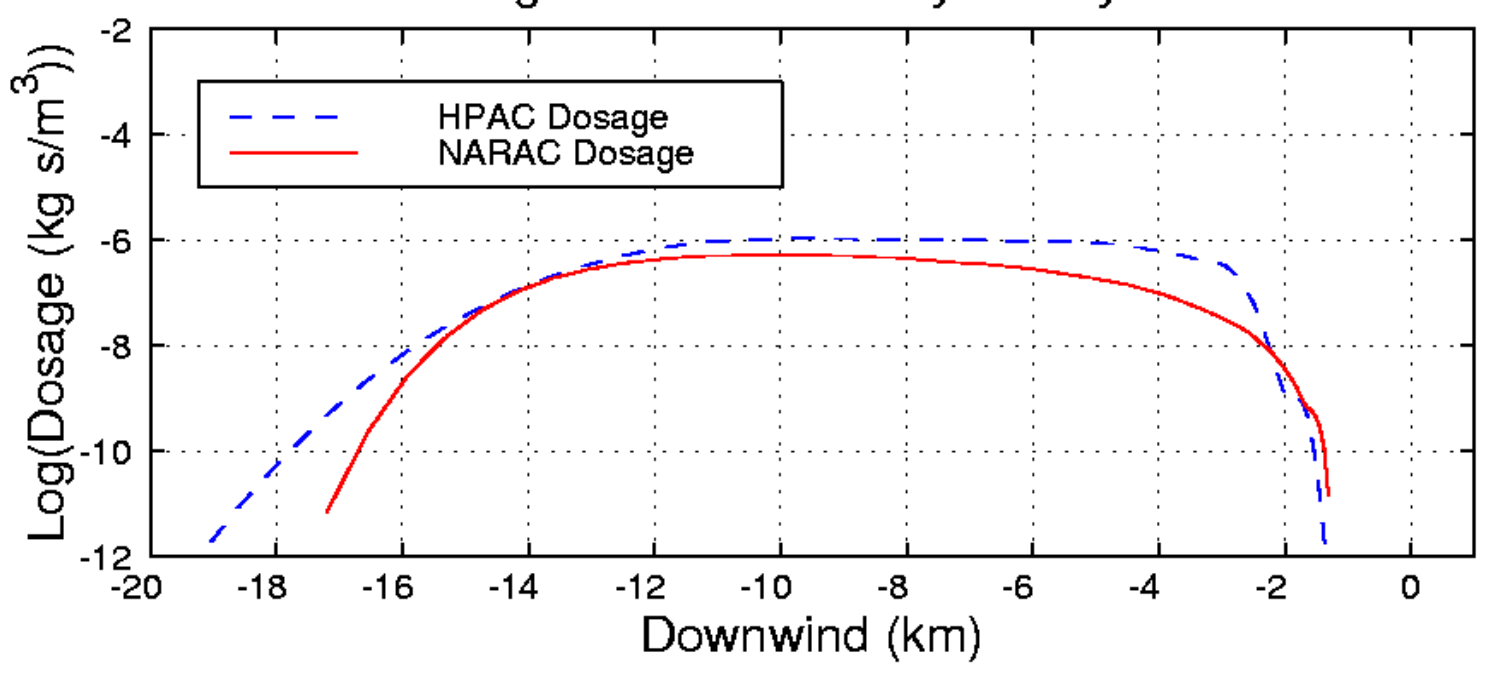

Figure C-7. MvM 2 at 30 Minutes with Upper: Dosage Contours for HPAC (BLUE - -) and NARAC (RED -); Lower: Dosage on Downwind Symmetry Axis 

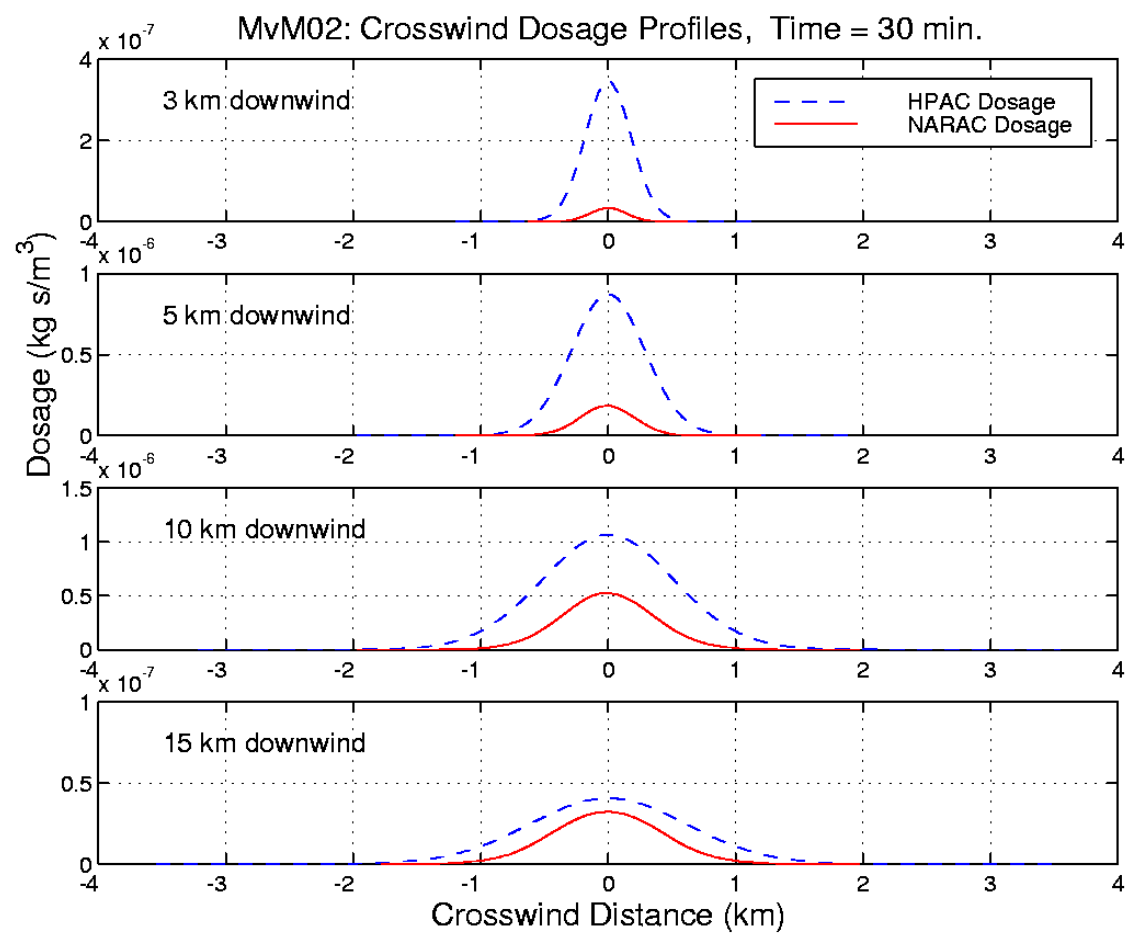

Figure C-8. MvM 2 at 30 Minutes: HPAC (BLUE - -) and NARAC (RED -) Crosswind Dosage Plumes for Various Downwind Distances

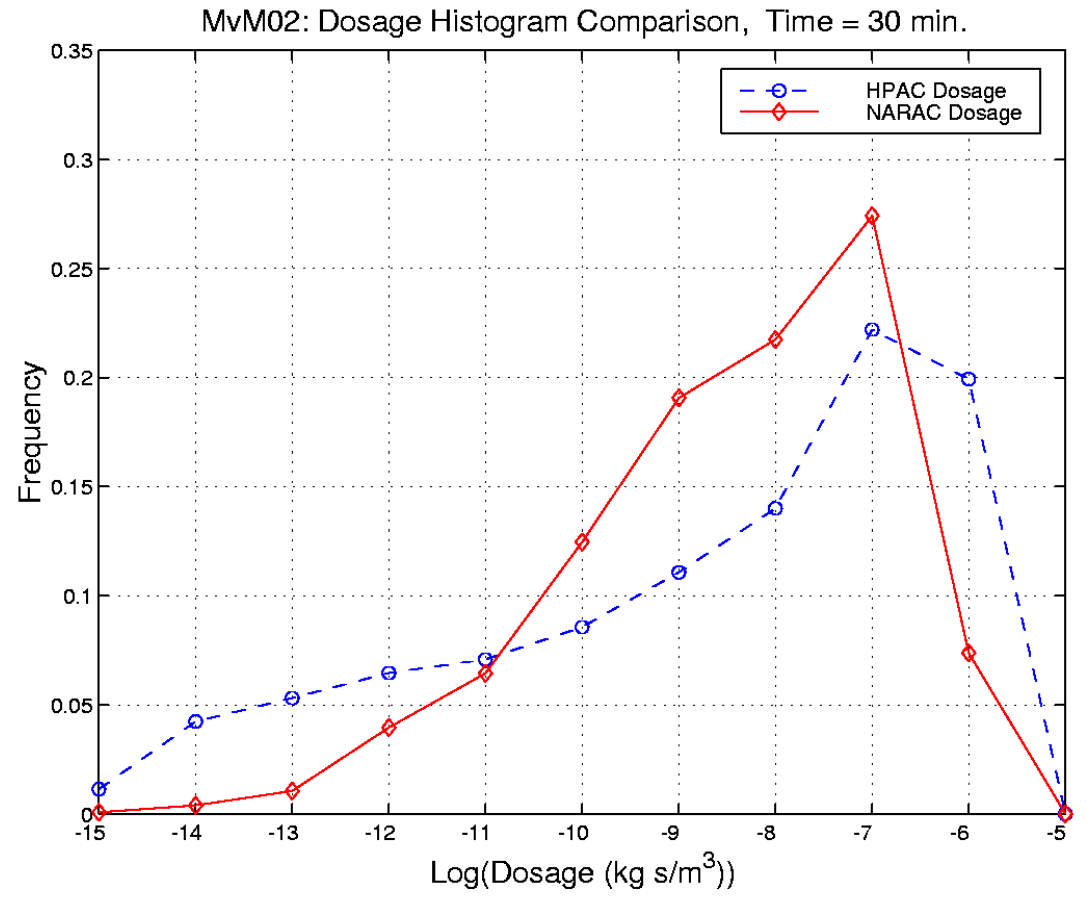

Figure C-9. MvM 2 at 30 Minutes: Dosage Histograms for HPAC (BLUE - -) and NARAC (RED -) 

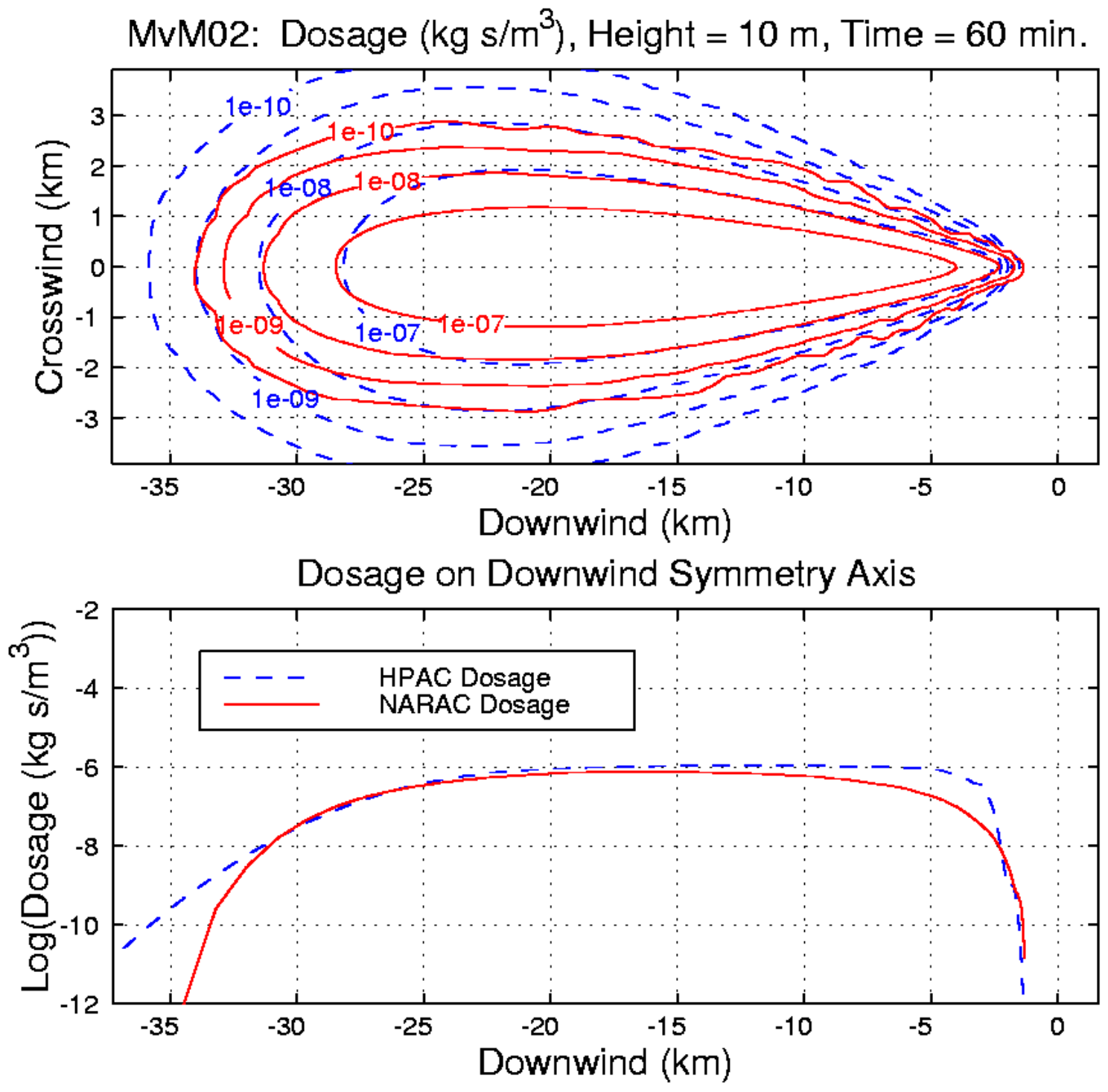

Figure C-10. MvM 2 at 60 Minutes with Upper: Dosage Contours for HPAC (BLUE - -) and NARAC (RED -); Lower: Dosage on Downwind Symmetry Axis 

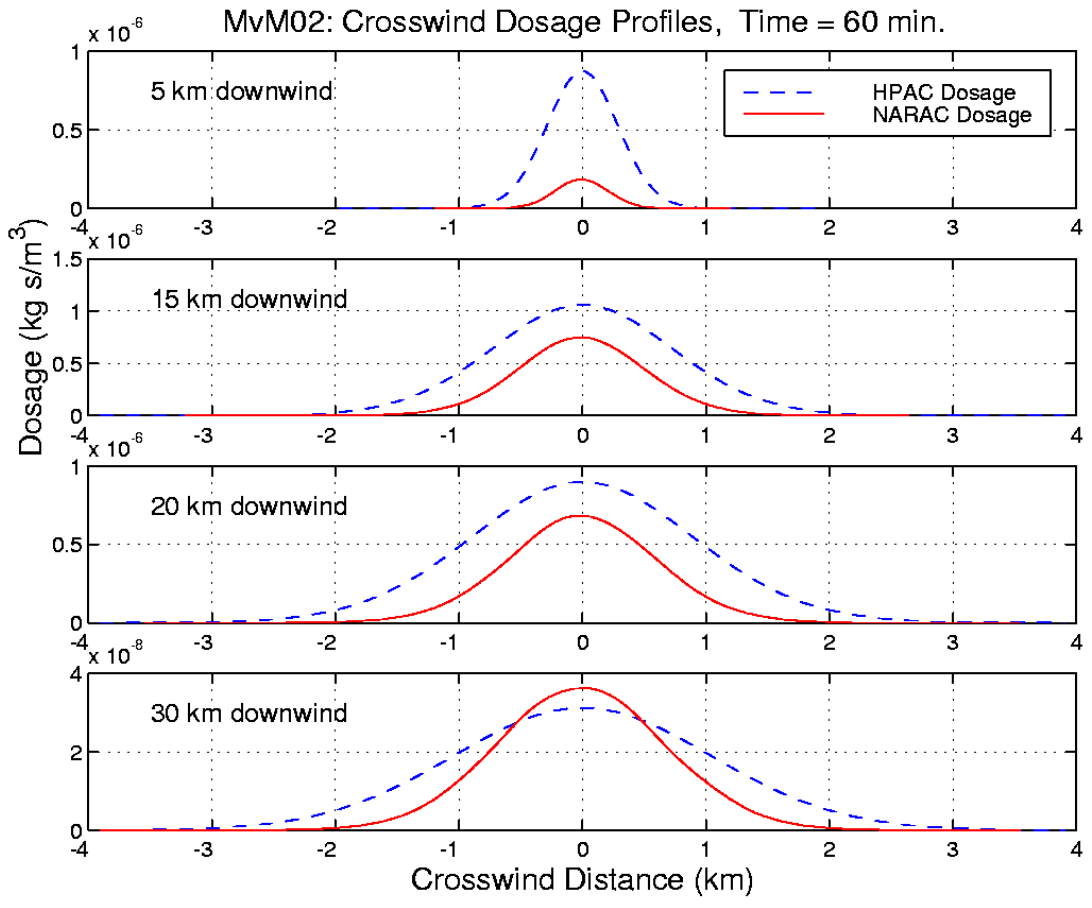

Figure C-11. MvM 2 at 60 Minutes: HPAC (BLUE - -) and NARAC (RED -) Crosswind Dosage Plumes for Various Downwind Distances

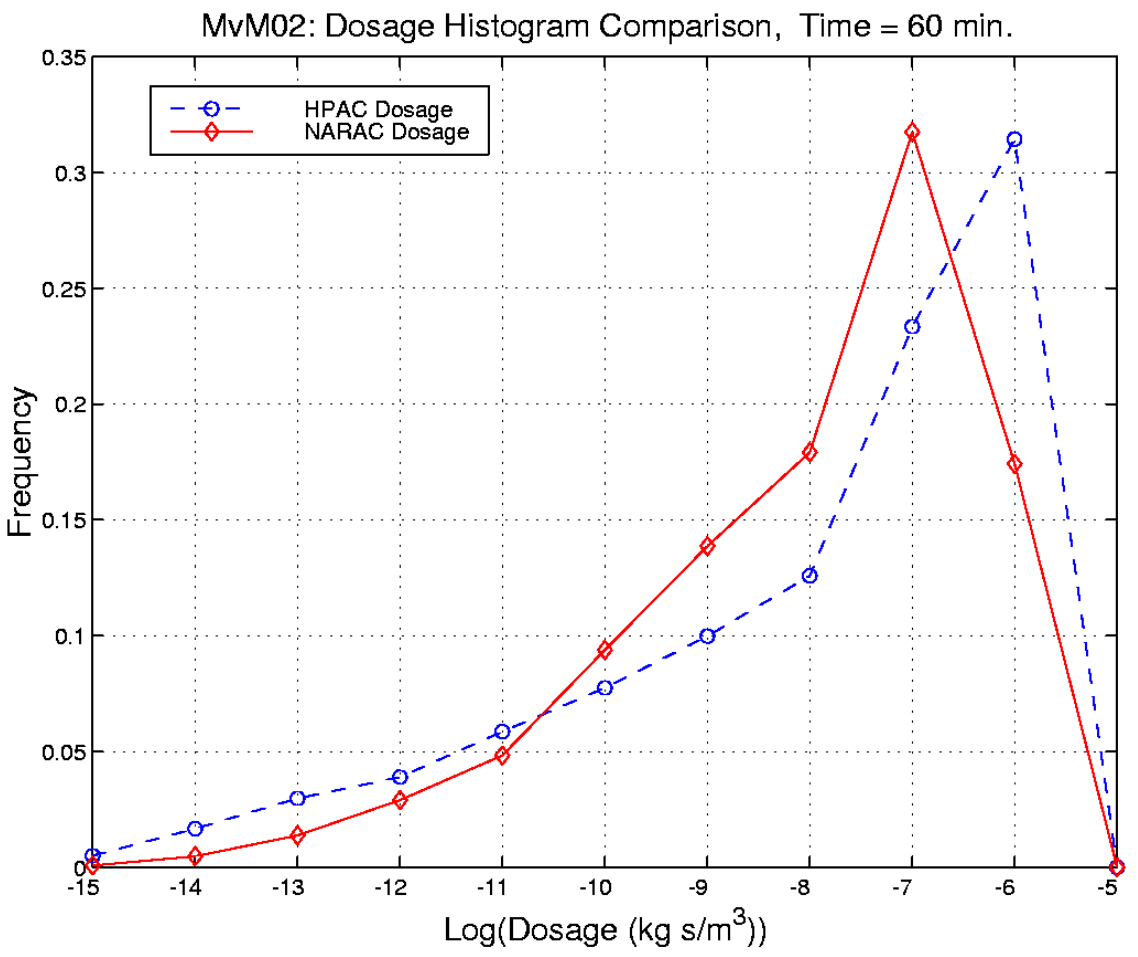

Figure C-12. MvM 2 at 60 Minutes: Dosage Histograms for HPAC (BLUE - -) and NARAC (RED -) 


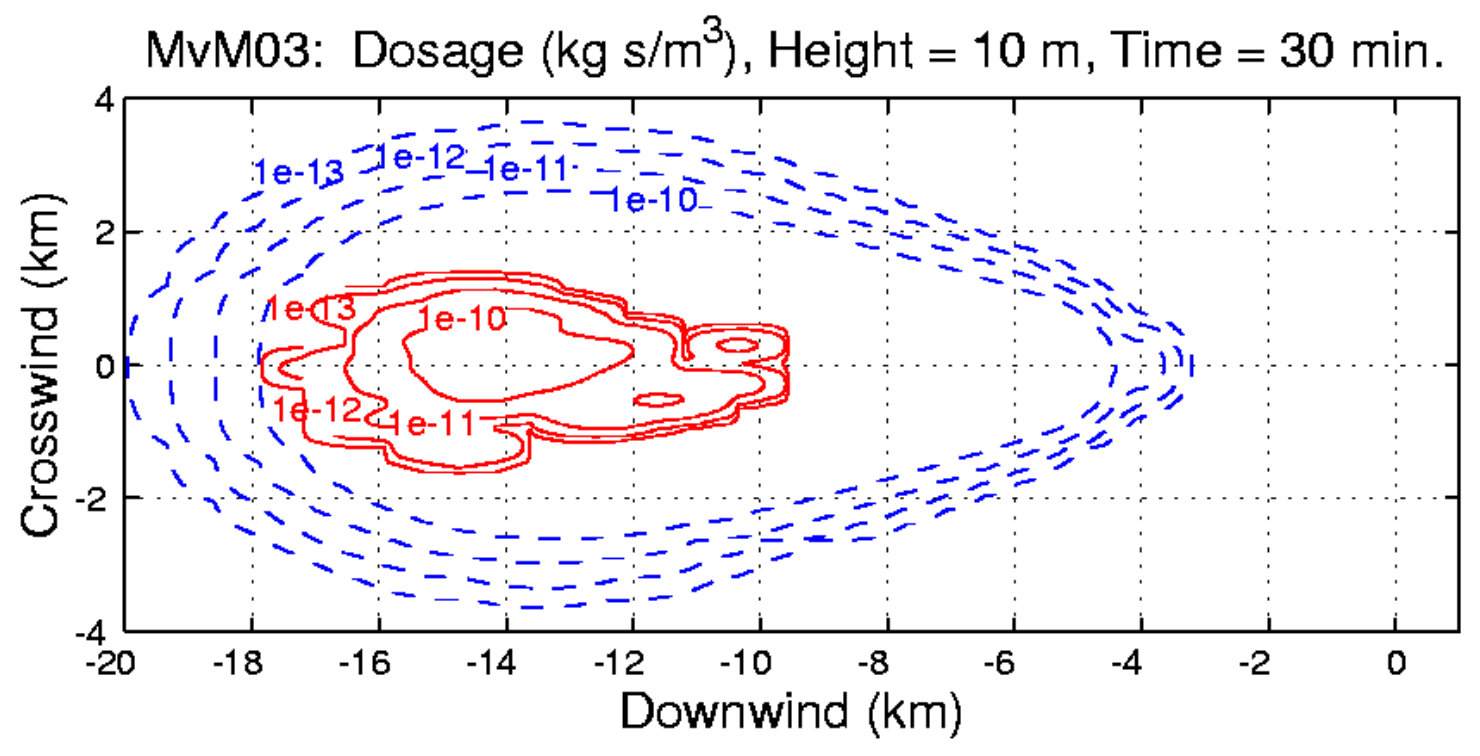

Dosage on Downwind Symmetry Axis

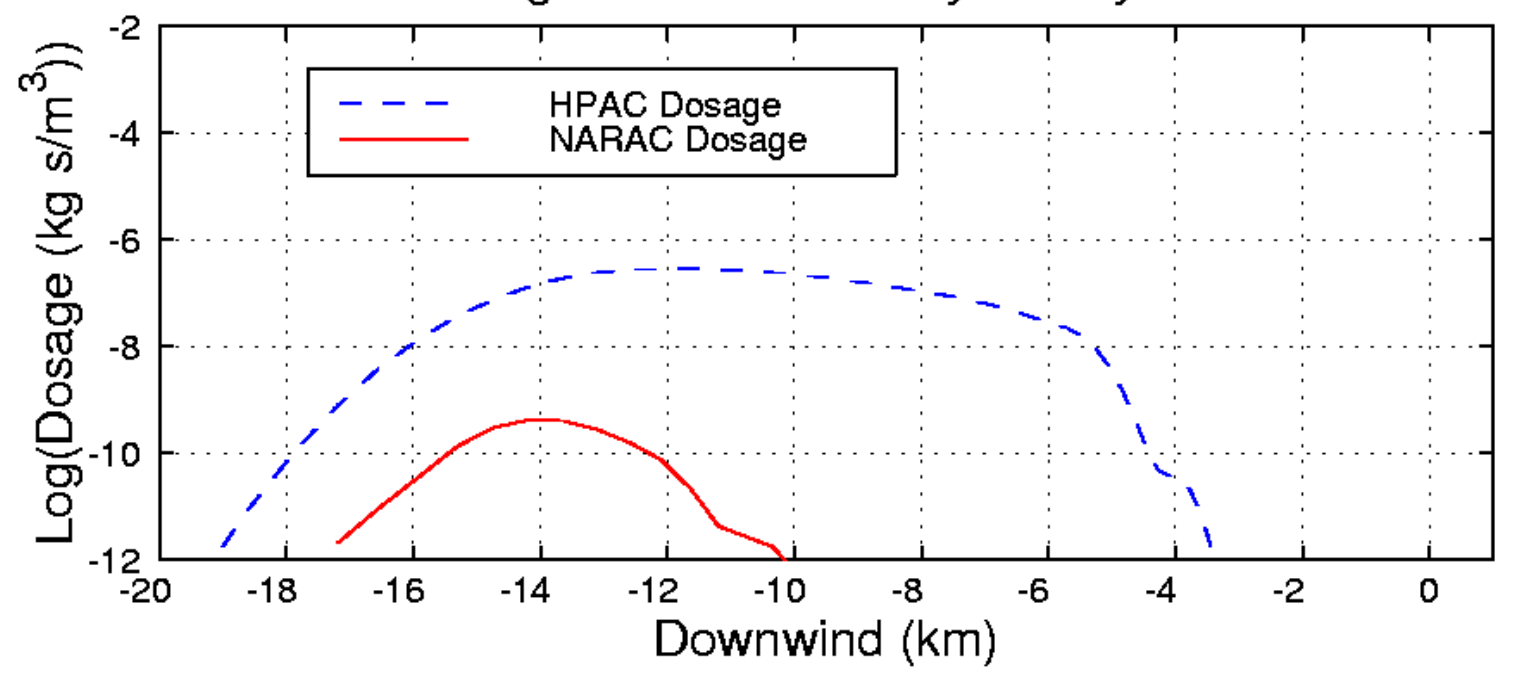

Figure C-13. MvM 3 at 30 Minutes with Upper: Dosage Contours for HPAC (BLUE - -) and NARAC (RED -); Lower: Dosage on Downwind Symmetry Axis 
MvM03: Crosswind Dosage Profiles, Time $=30 \mathrm{~min}$.
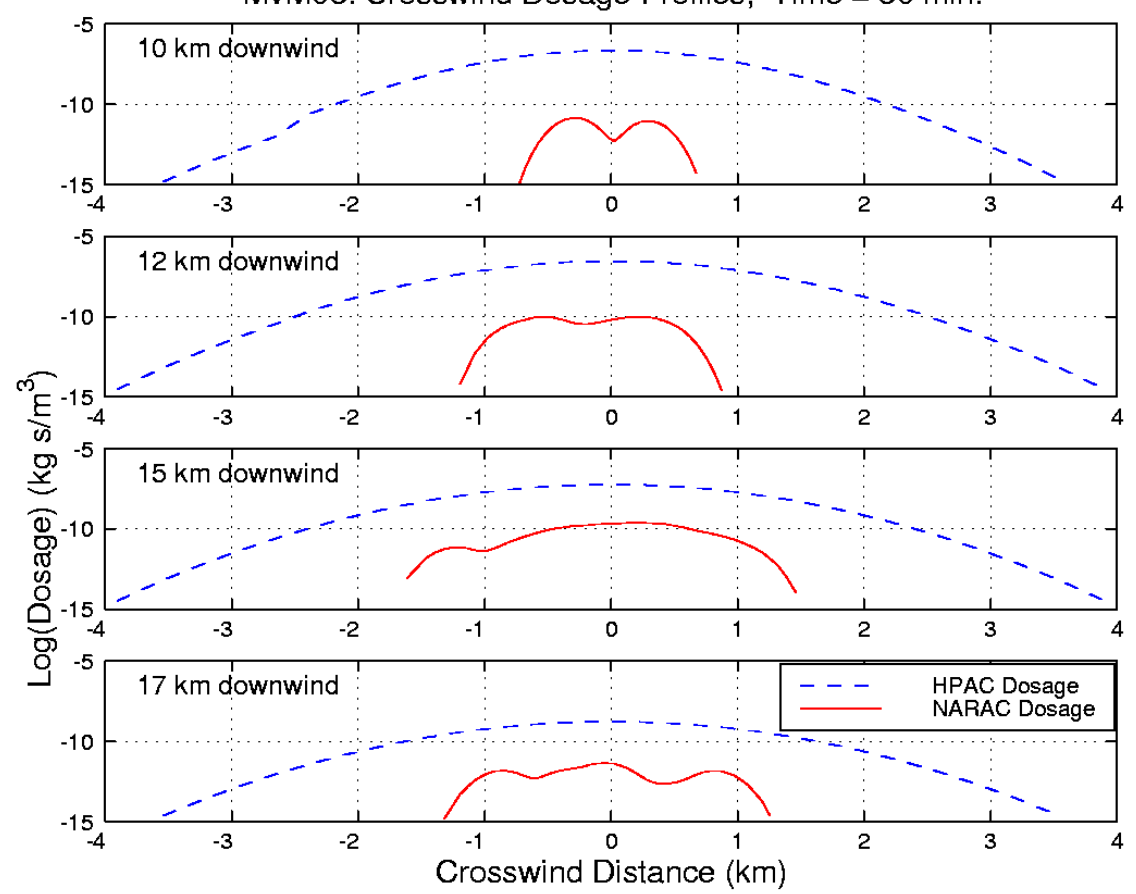

Figure C-14. MvM 3 at 30 Minutes: HPAC (BLUE - -) and NARAC (RED -) Crosswind Dosage Plumes for Various Downwind Distances

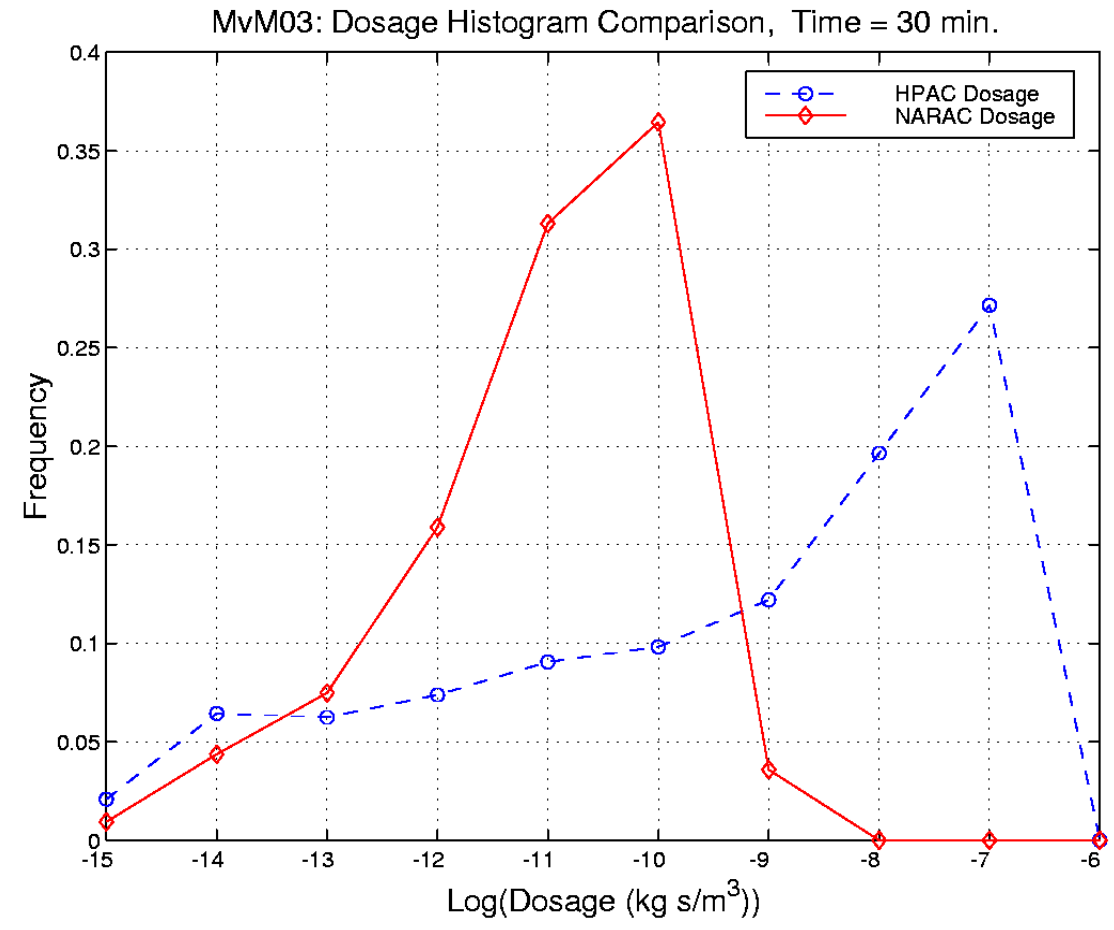

Figure C-15. MvM 3 at 30 Minutes: Dosage Histograms for HPAC (BLUE - -) and NARAC (RED -) 
MvM03: Dosage $\left(\mathrm{kg} \mathrm{s} / \mathrm{m}^{3}\right)$, Height $=10 \mathrm{~m}$, Time $=60 \mathrm{~min}$.

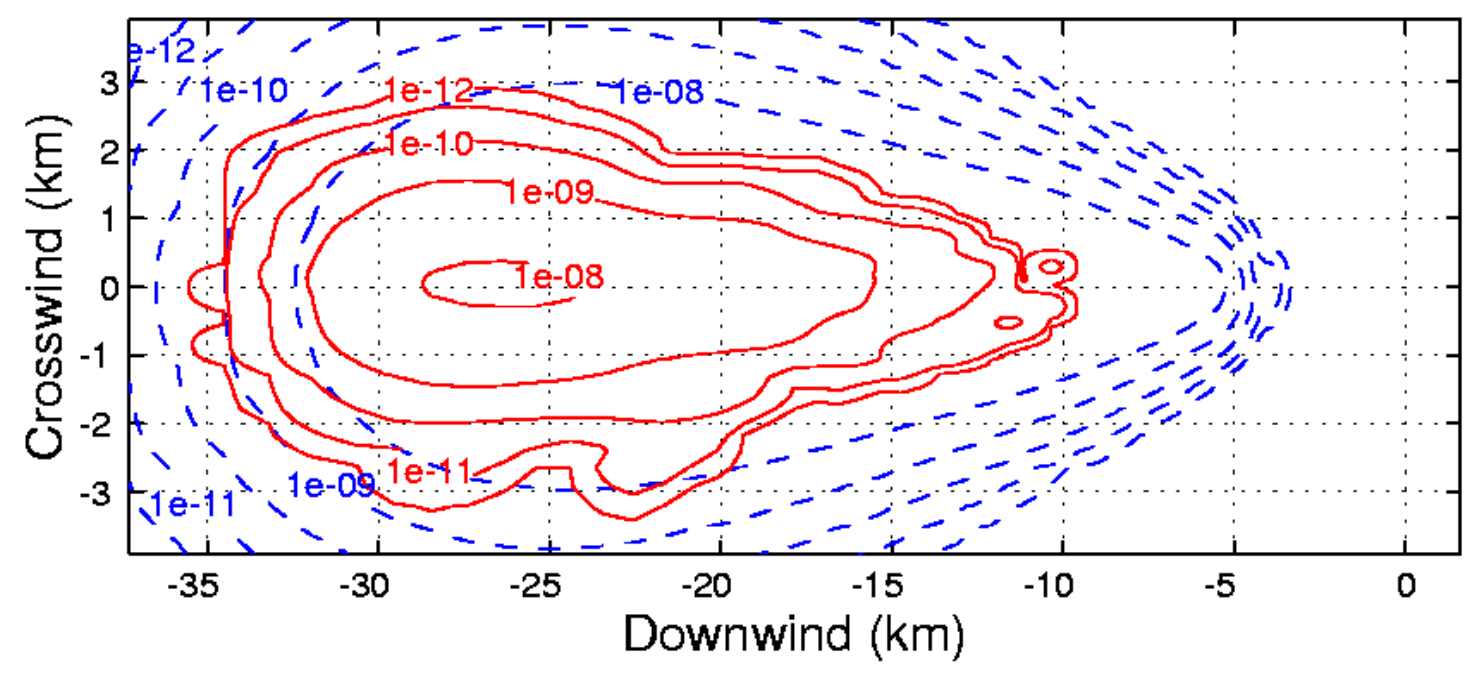

Dosage on Downwind Symmetry Axis

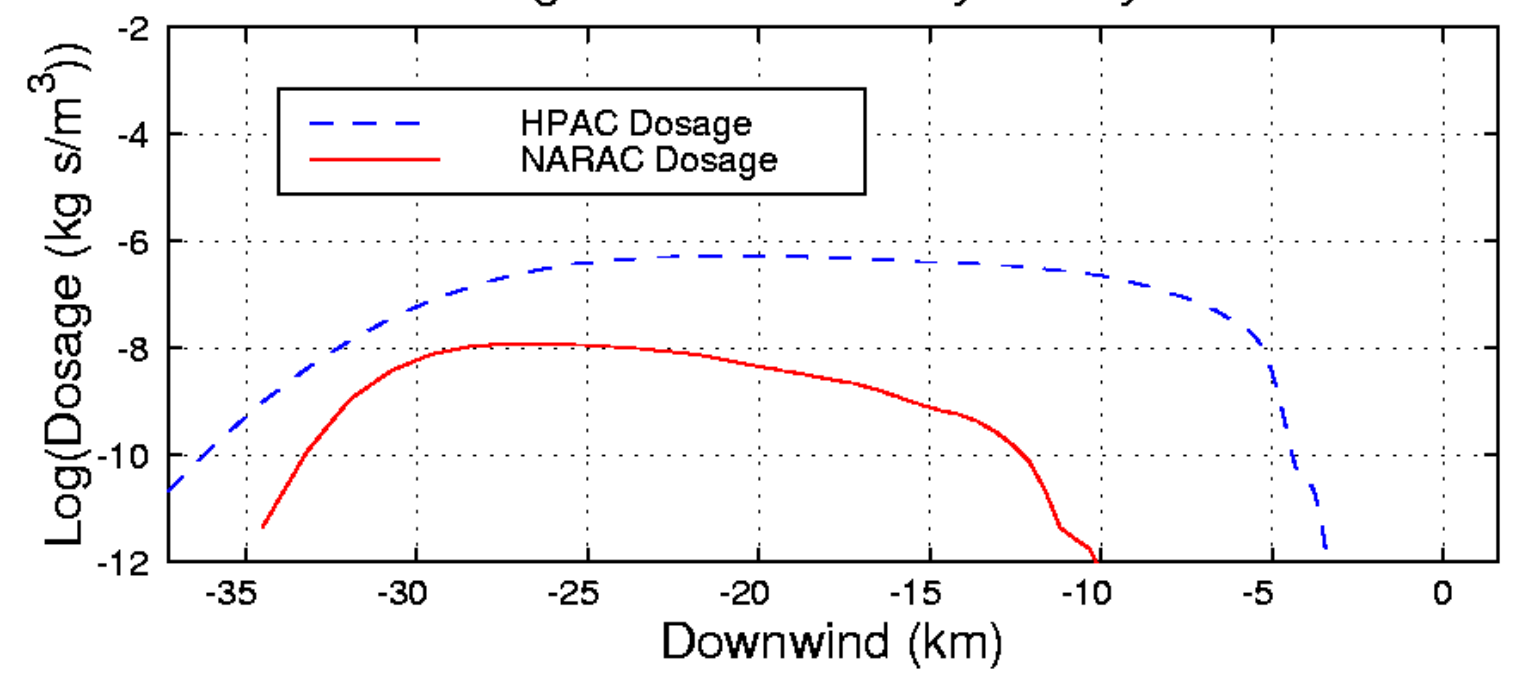

Figure C-16. MvM 3 at 60 Minutes with Upper: Dosage Contours for HPAC (BLUE - -) and NARAC (RED -); Lower: Dosage on Downwind Symmetry Axis 
MvM03: Crosswind Dosage Profiles, Time $=60 \mathrm{~min}$.
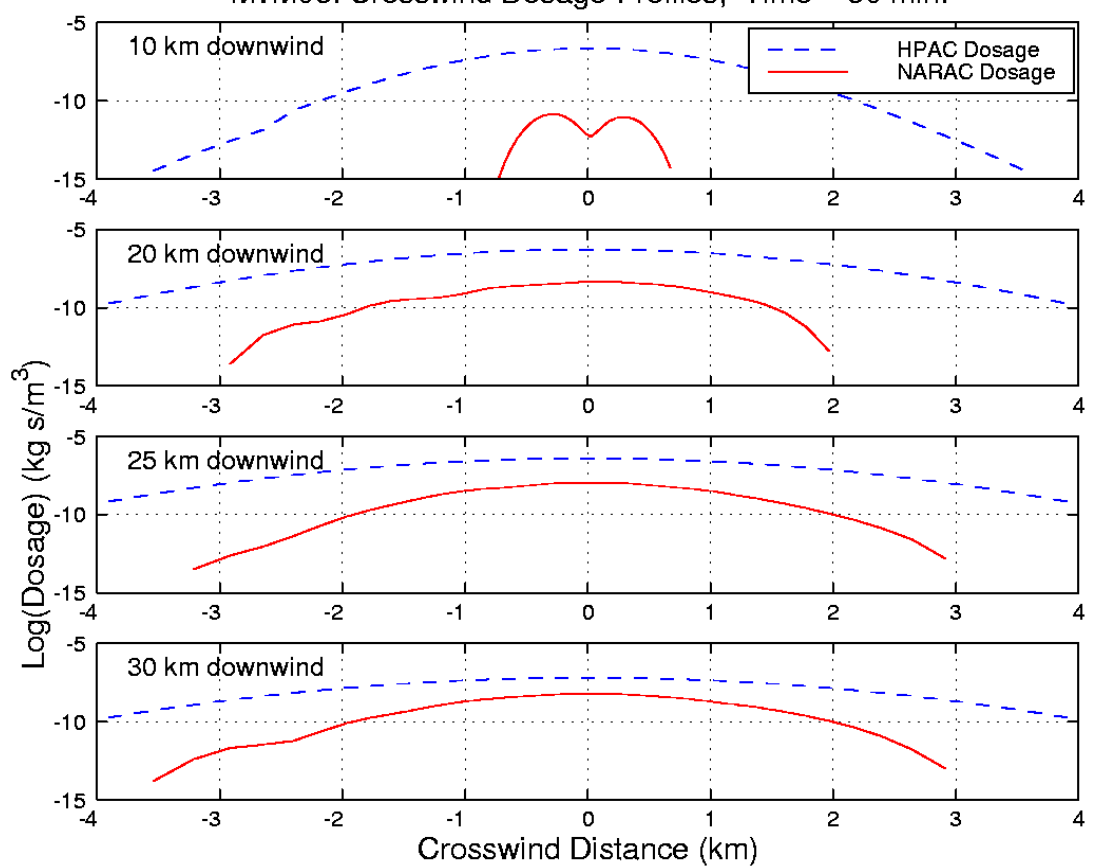

Figure C-17. MvM 3 at 60 Minutes: HPAC (BLUE - -) and NARAC (RED -) Crosswind Dosage Plumes for Various Downwind Distances

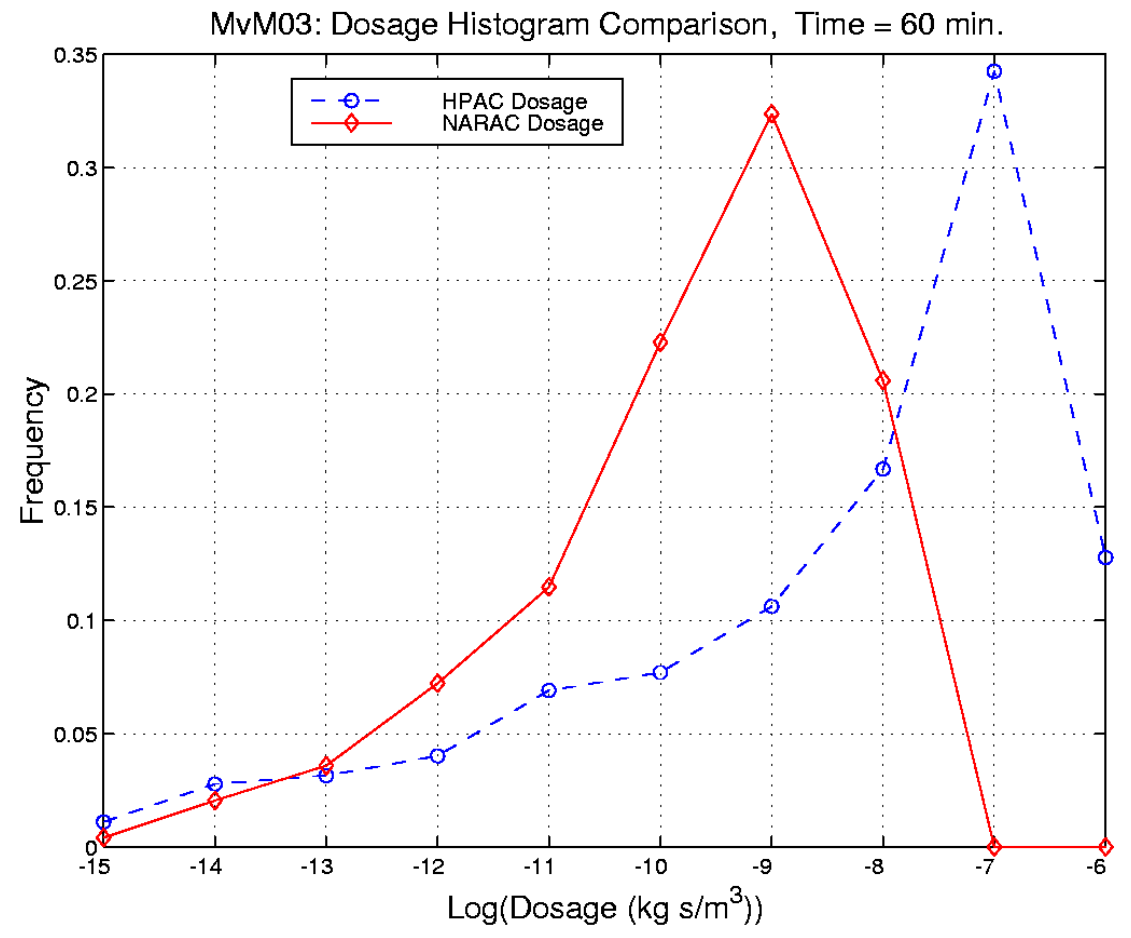

Figure C-18. MvM 3 at 60 Minutes: Dosage Histograms for HPAC (BLUE - -) and NARAC (RED -) 

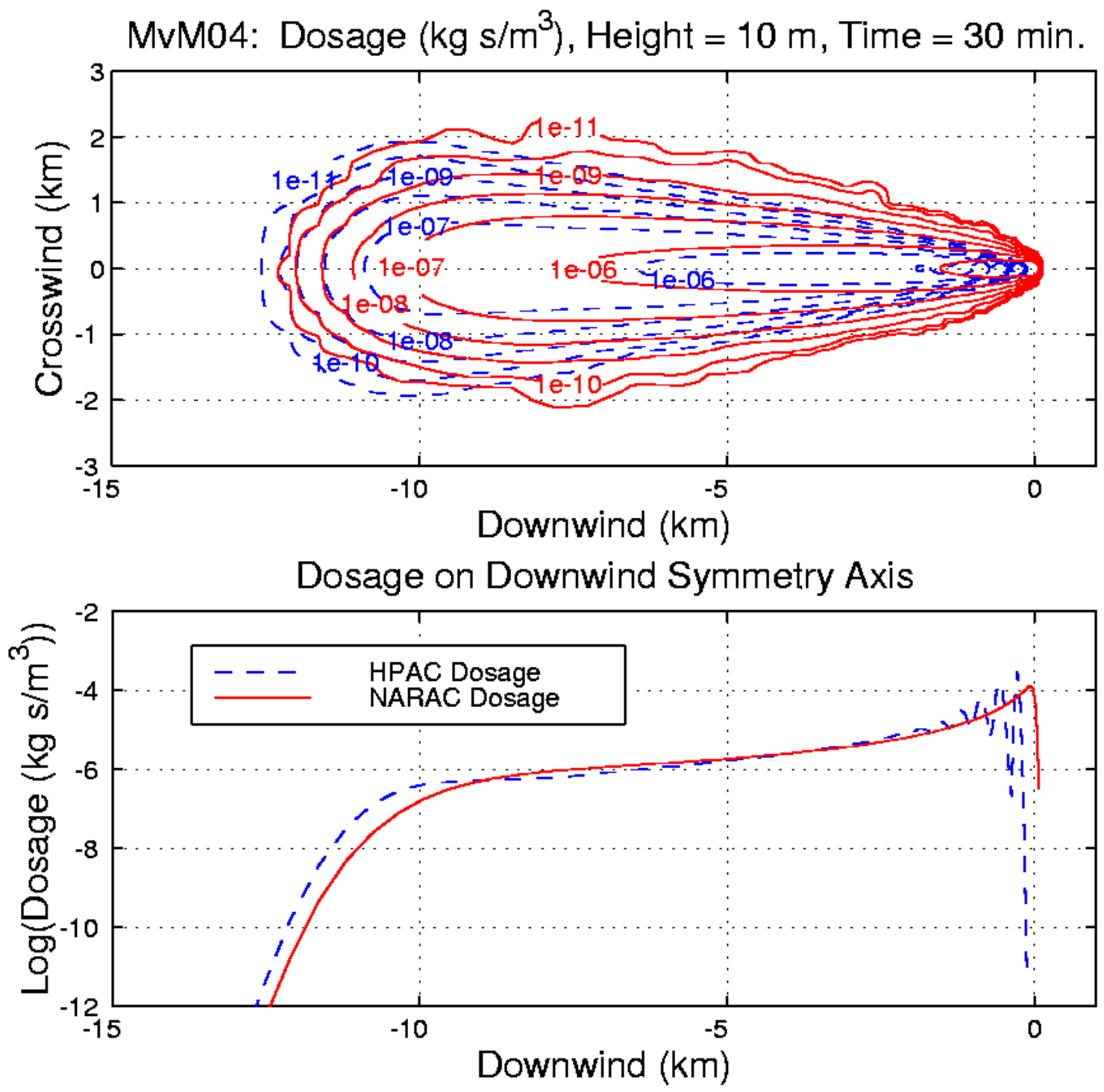

Figure C-19. MvM 4 at 30 Minutes with Upper: Dosage Contours for HPAC (BLUE - -) and NARAC (RED -); Lower: Dosage on Downwind Symmetry Axis 


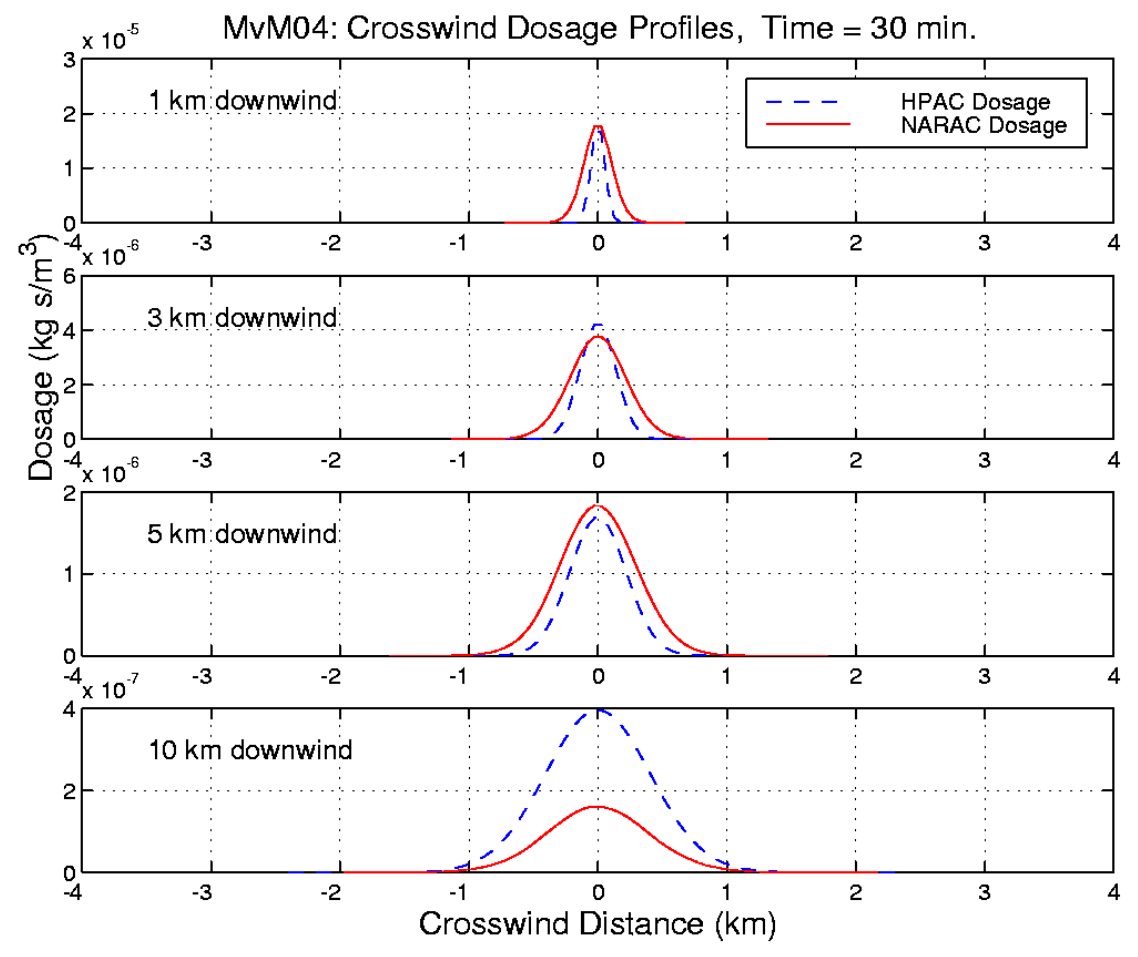

Figure C-20. MvM 4 at 30 Minutes: HPAC (BLUE - -) and NARAC (RED -) Crosswind Dosage Plumes for Various Downwind Distances

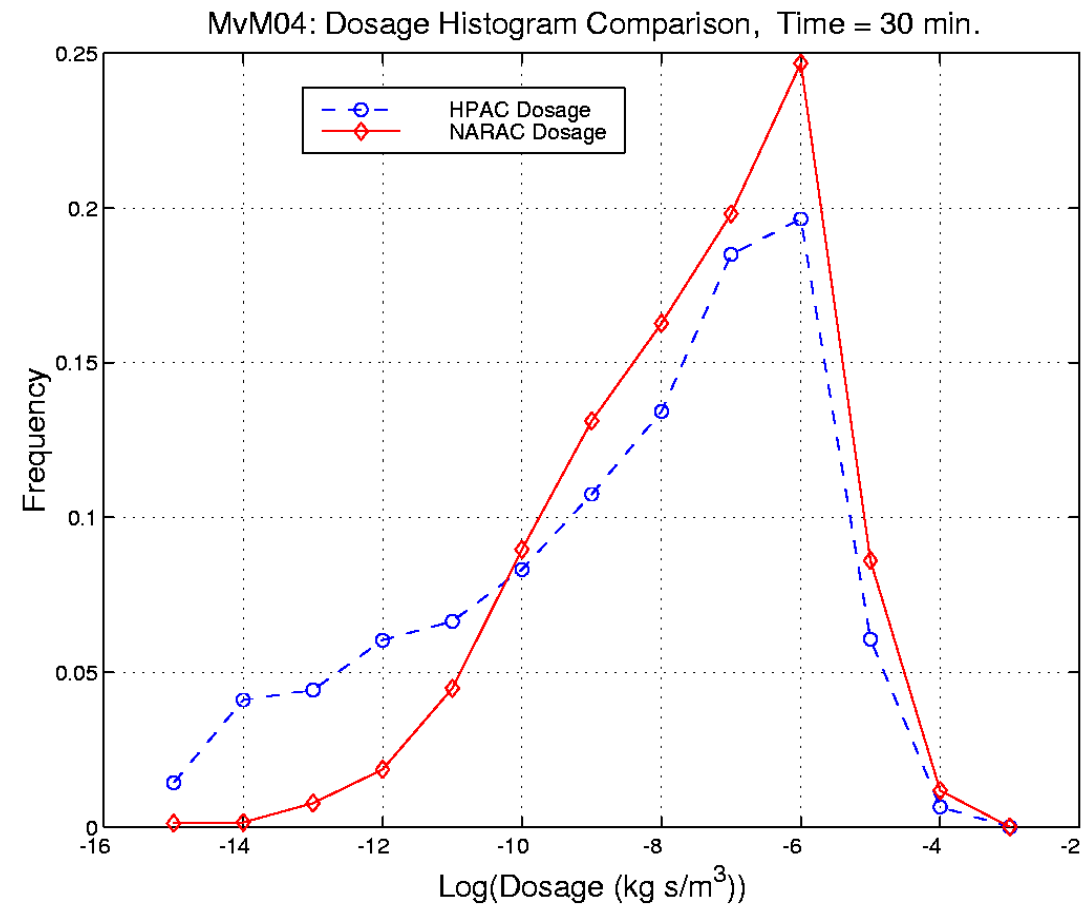

Figure C-21. MvM 4 at 30 Minutes: Dosage Histograms for HPAC (BLUE - -) and NARAC (RED -) 


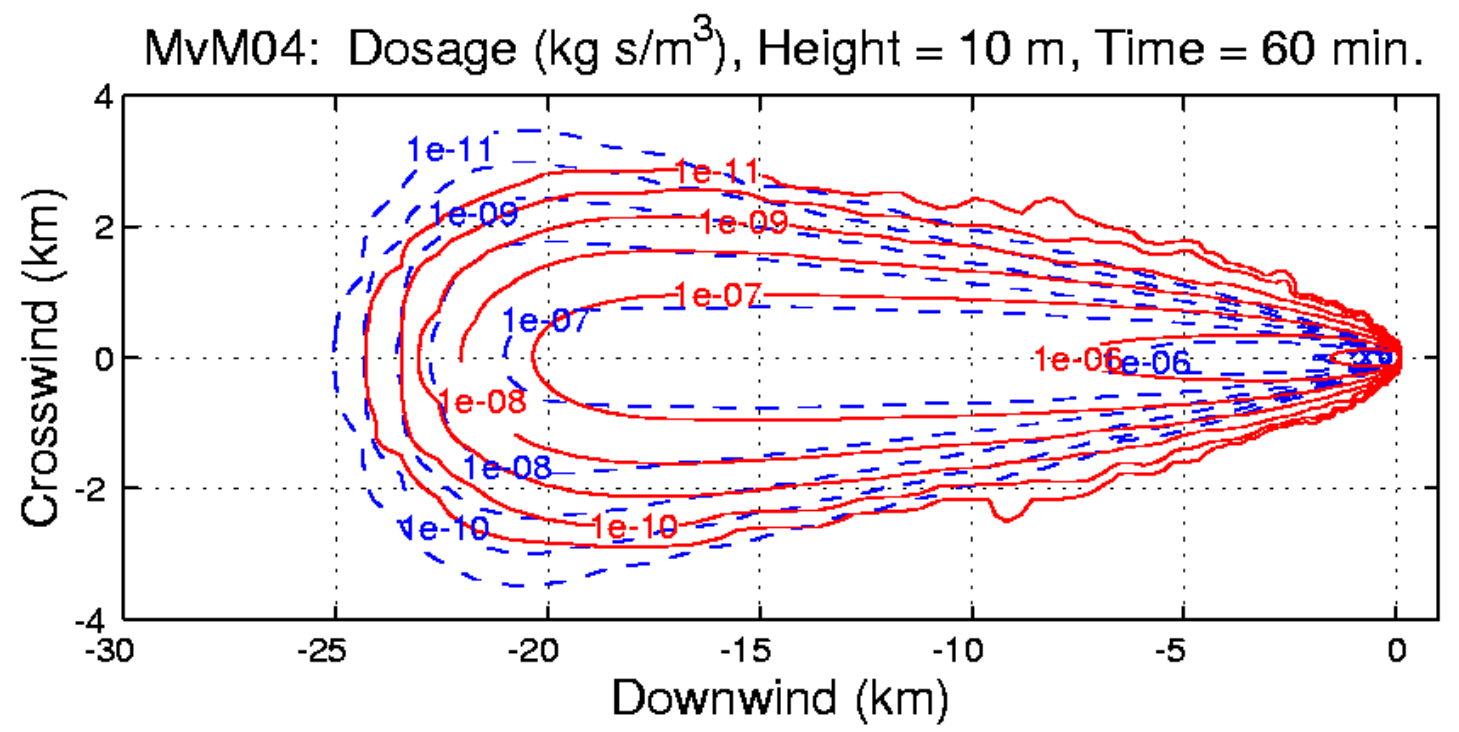

Dosage on Downwind Symmetry Axis

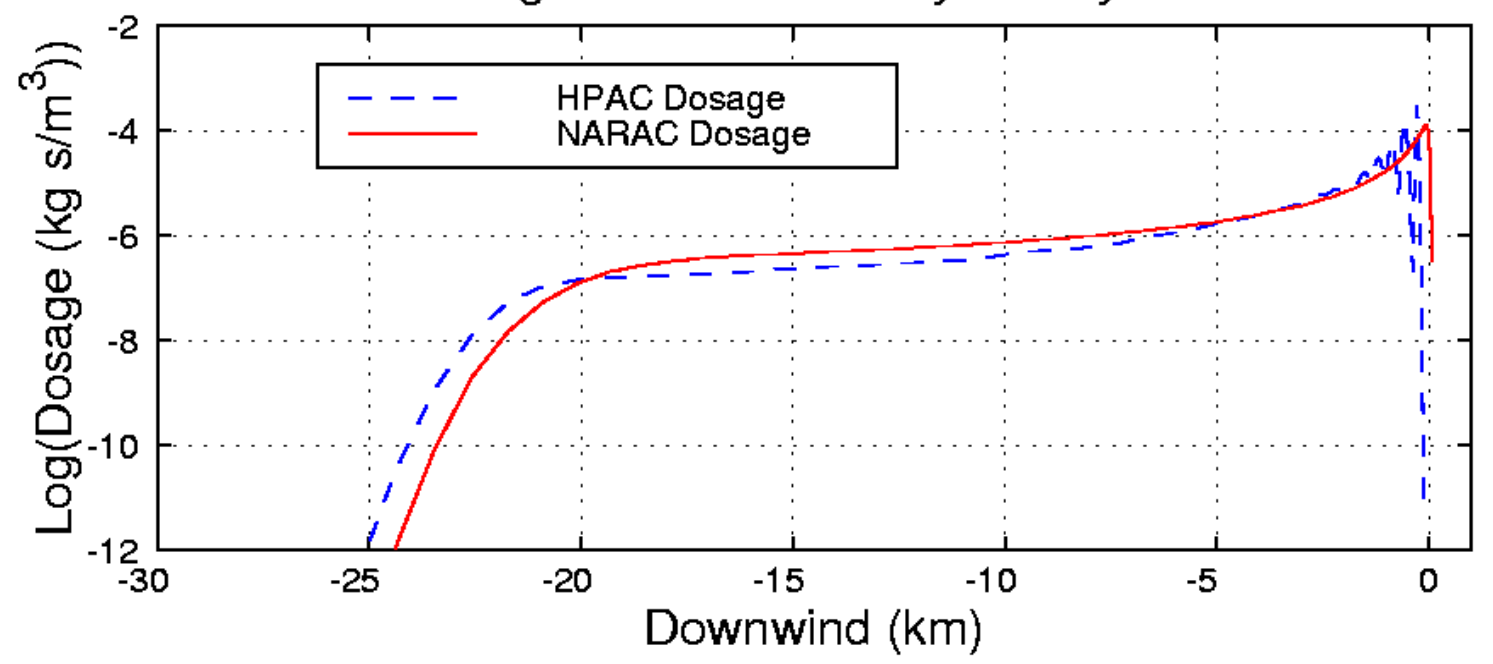

Figure C-22. MvM 4 at 60 Minutes with Upper: Dosage Contours for HPAC (BLUE - -) and NARAC (RED -); Lower: Dosage on Downwind Symmetry Axis 

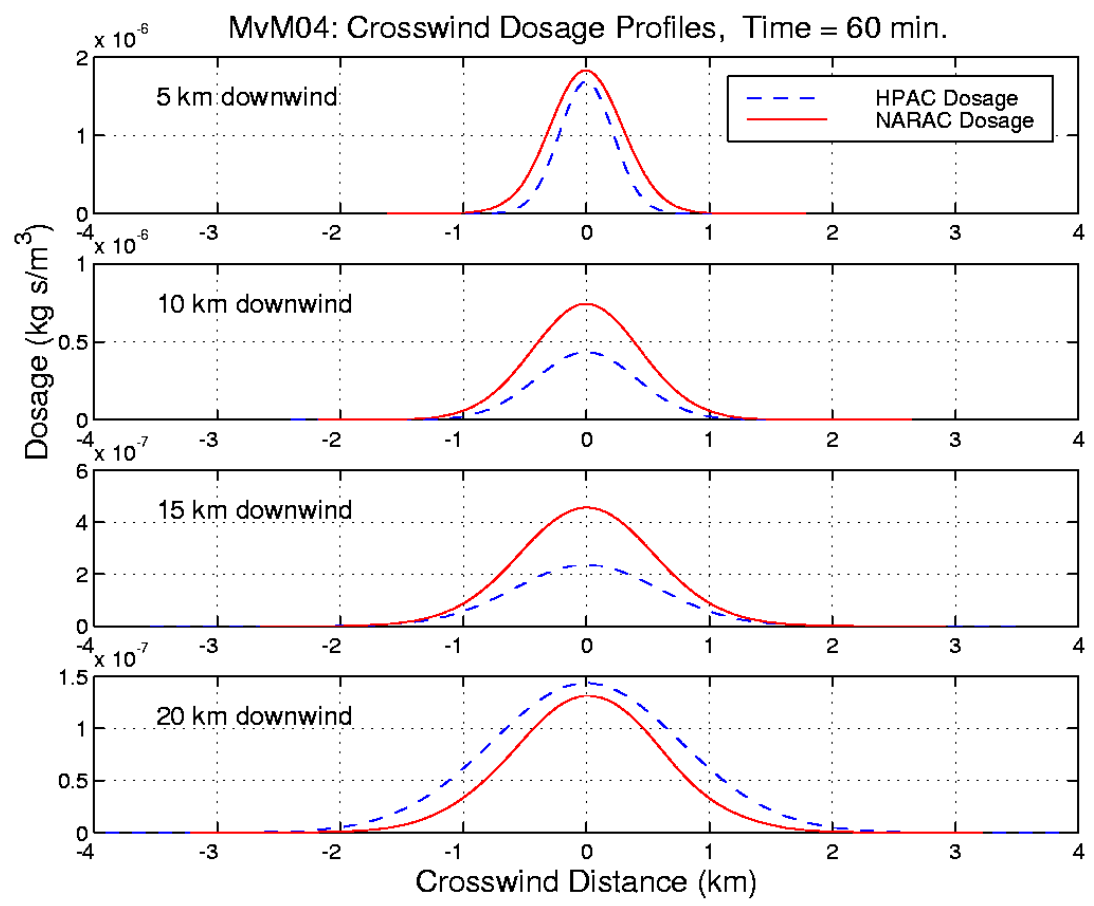

Figure C-23. MvM 4 at 60 Minutes: HPAC (BLUE - -) and NARAC (RED -) Crosswind Dosage Plumes for Various Downwind Distances

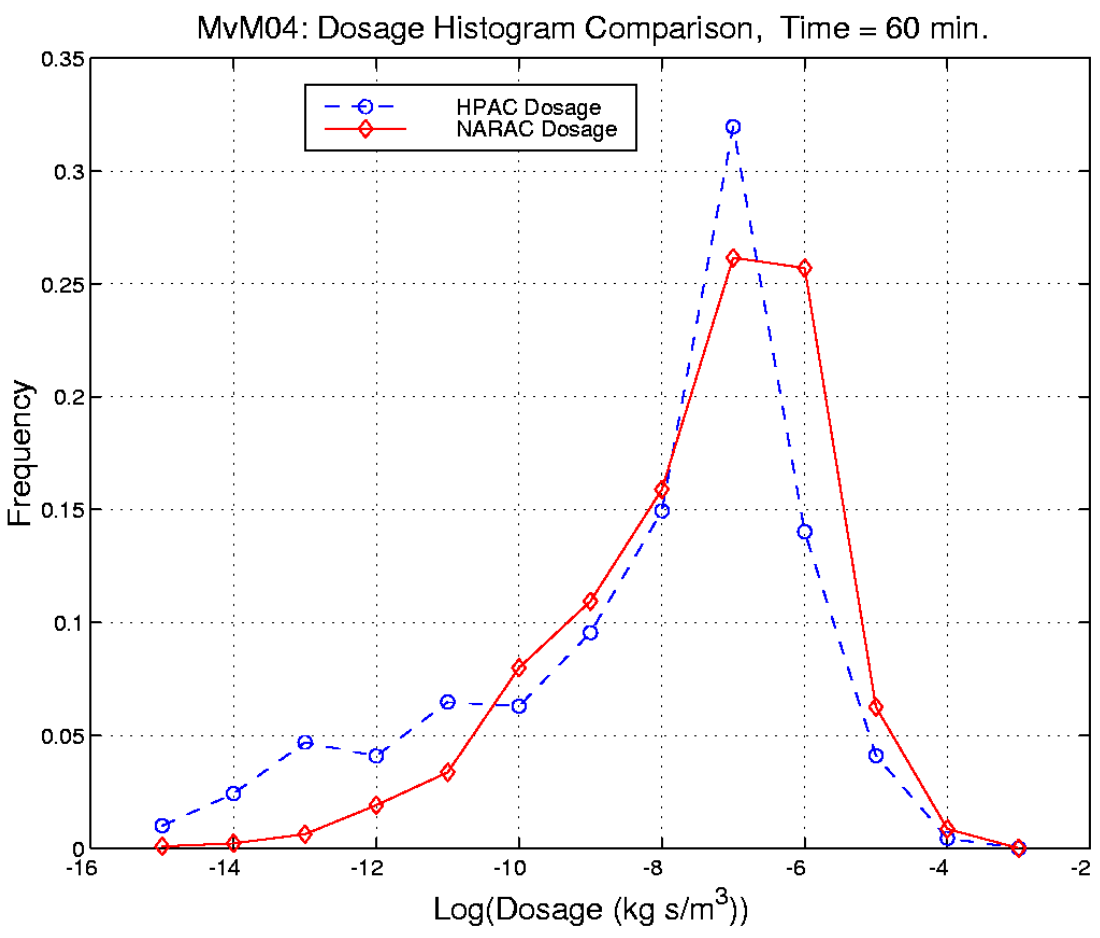

Figure C-24. MvM 4 at 60 Minutes: Dosage Histograms for HPAC (BLUE - -) and NARAC (RED -) 

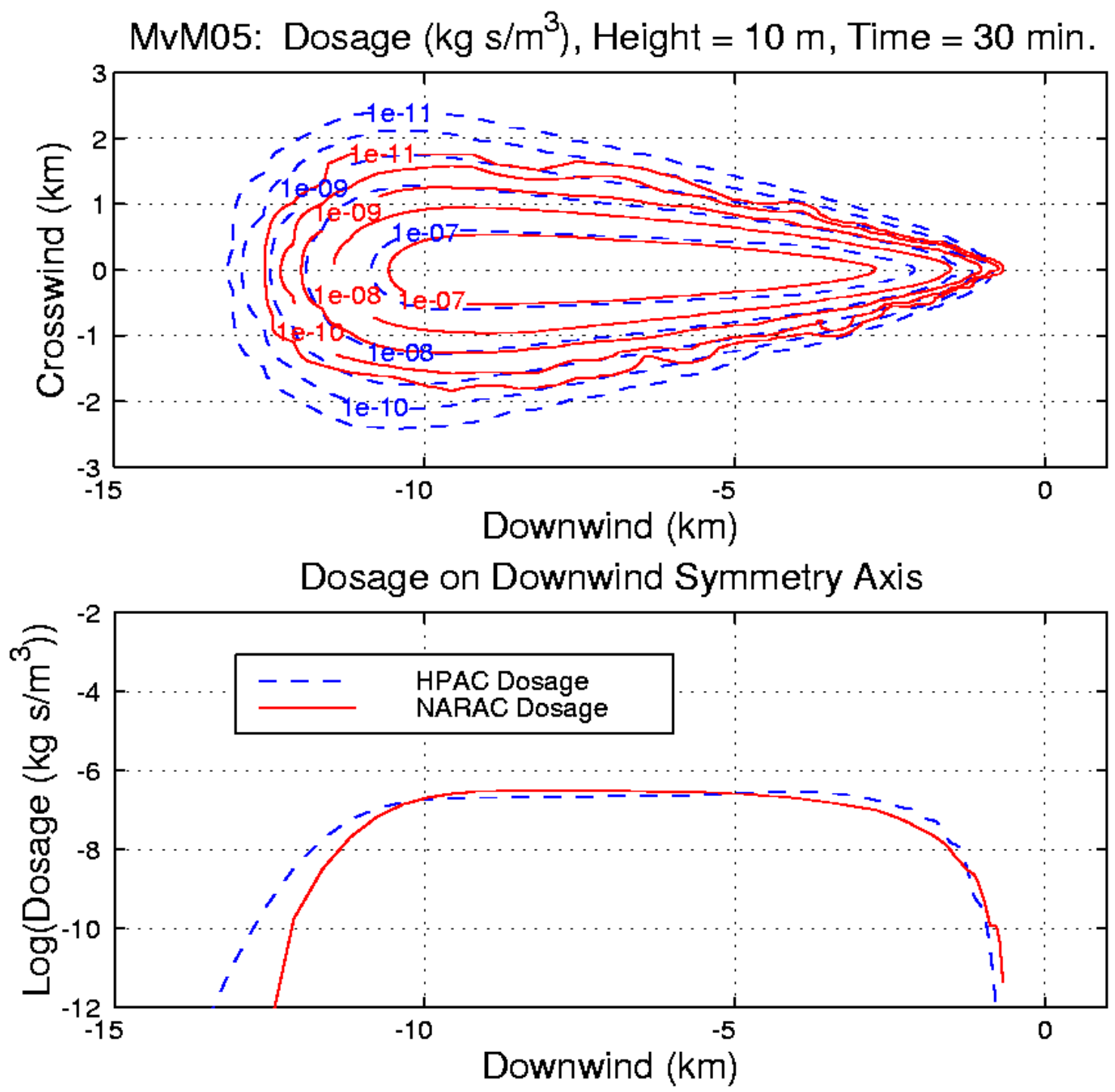

Figure C-25. MvM 5 at 30 Minutes with Upper: Dosage Contours for HPAC (BLUE - -) and NARAC (RED -); Lower: Dosage on Downwind Symmetry Axis 

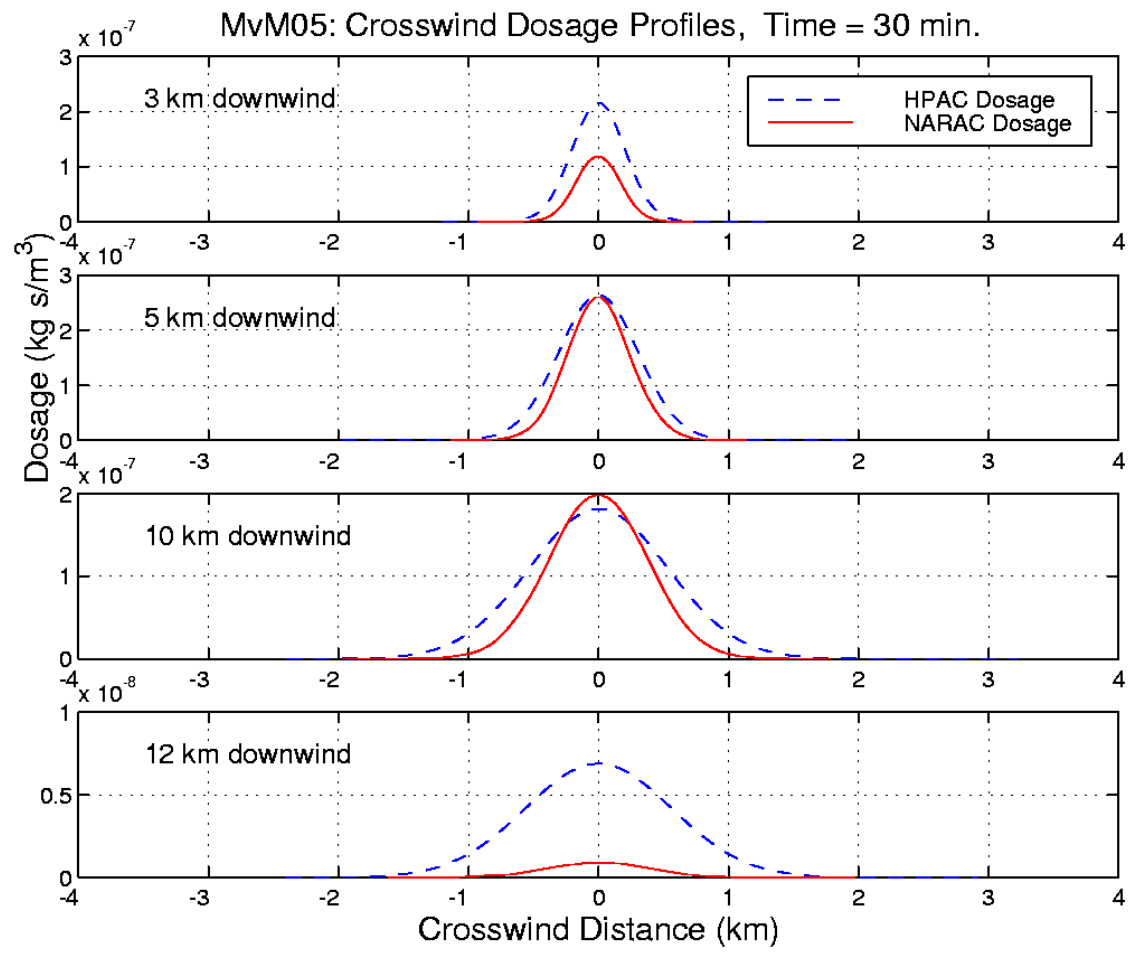

Figure C-26. MvM 5 at 30 Minutes: HPAC (BLUE - -) and NARAC (RED -) Crosswind Dosage Plumes for Various Downwind Distances

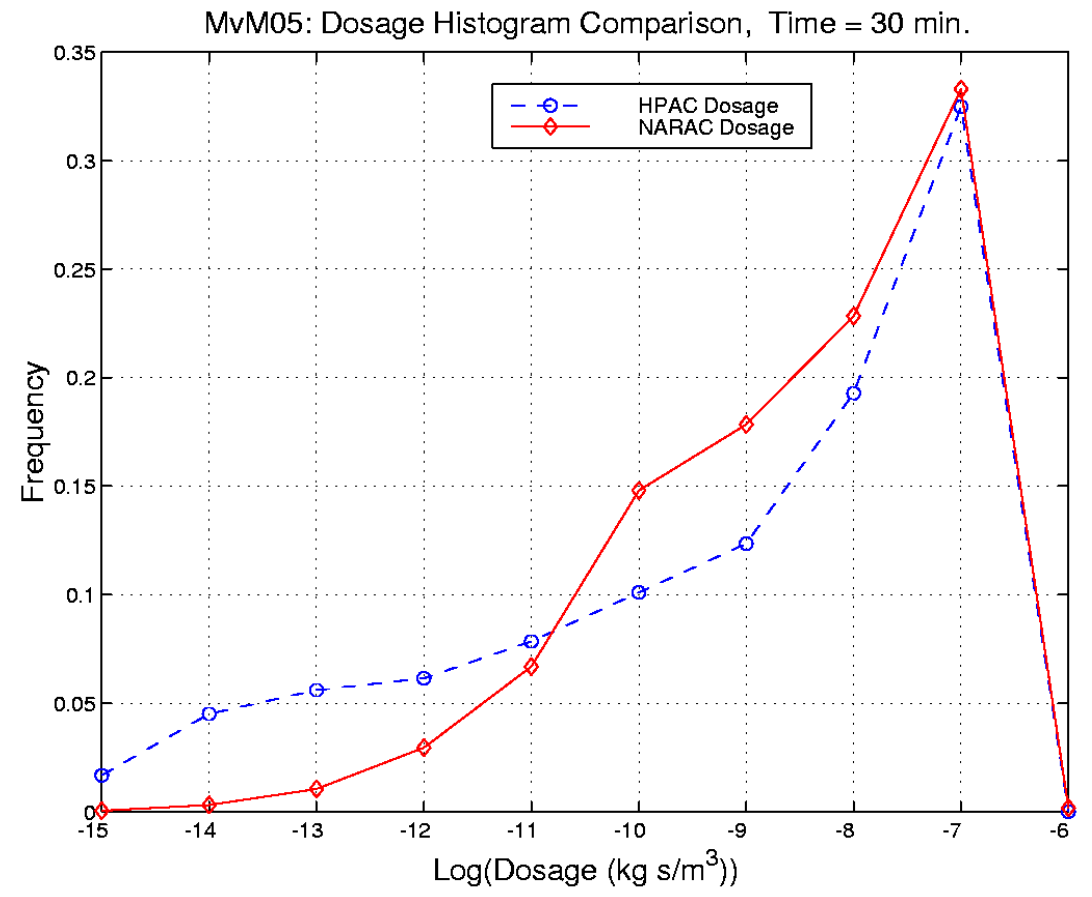

Figure C-27. MvM 5 at 30 Minutes: Dosage Histograms for HPAC (BLUE - -) and NARAC (RED -) 


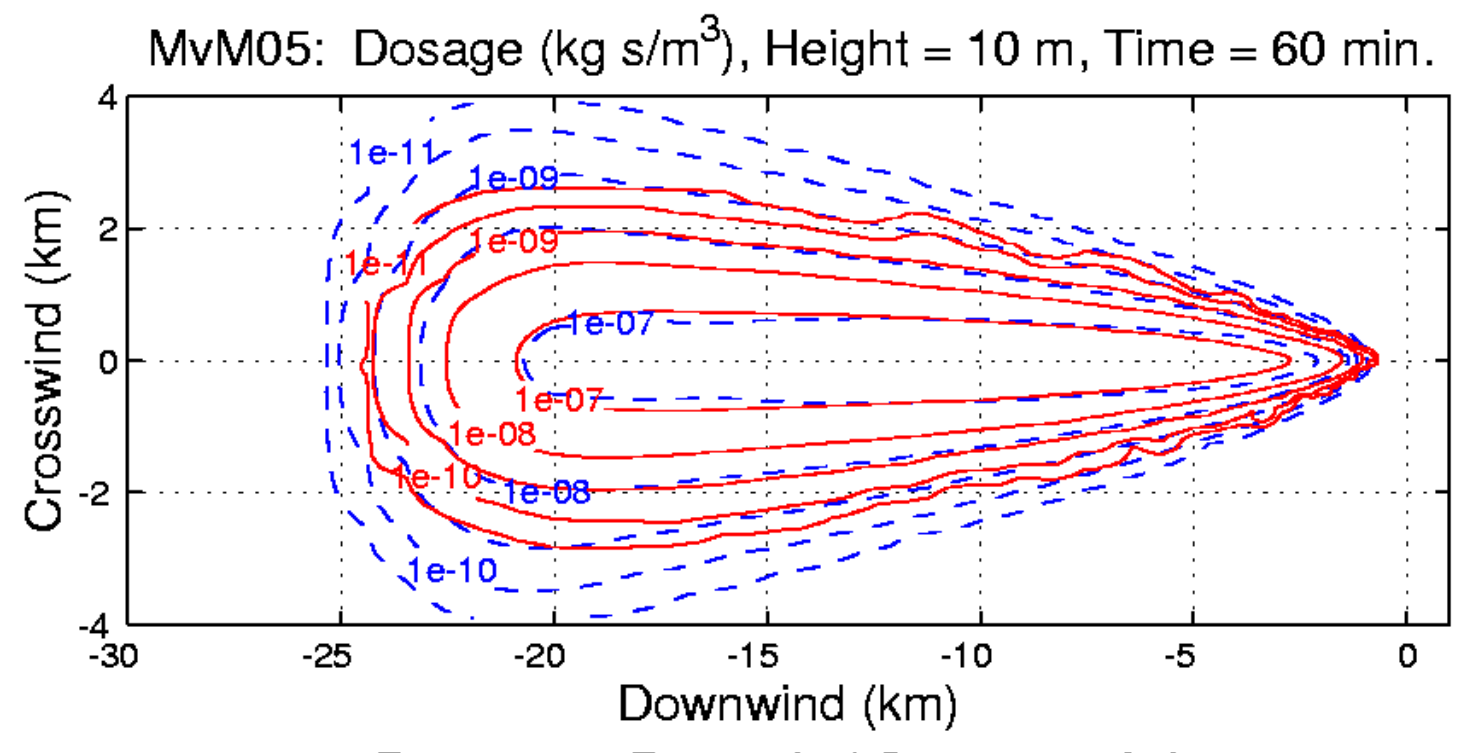

Dosage on Downwind Symmetry Axis

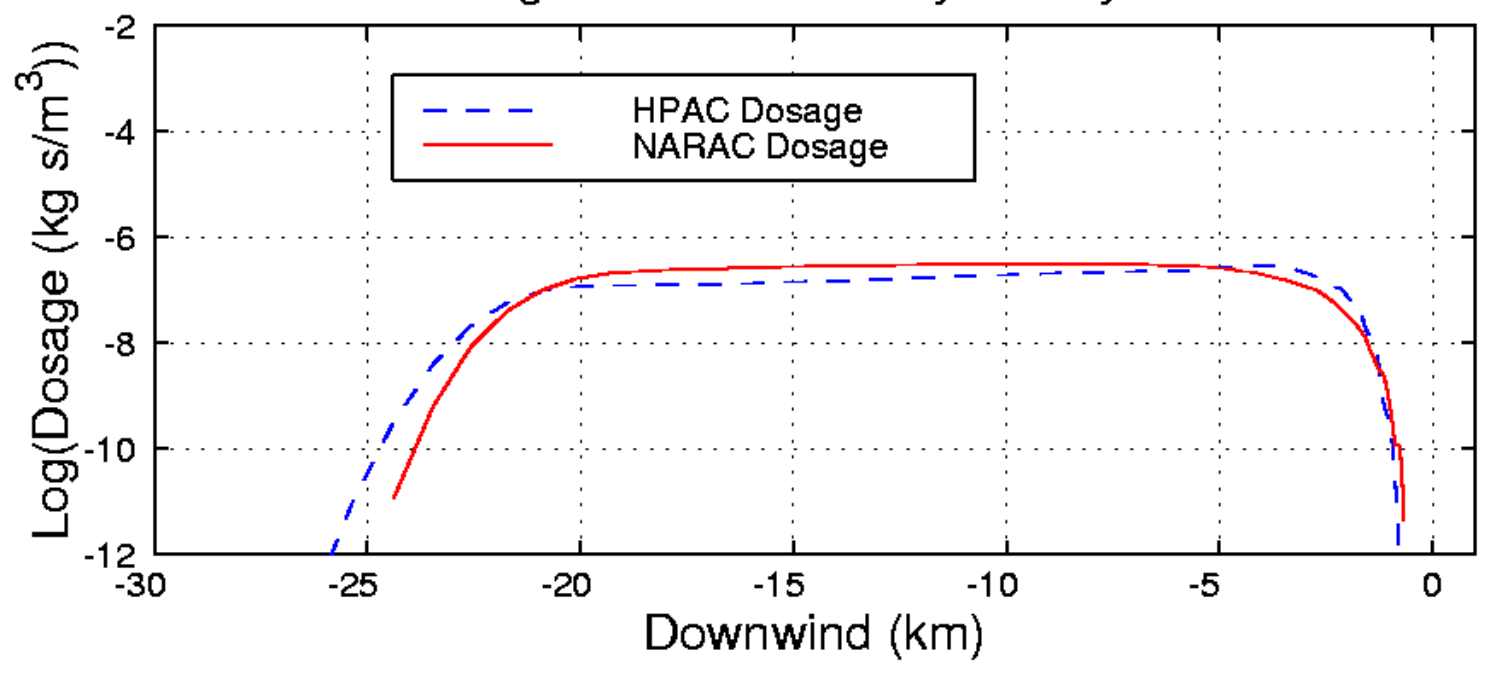

Figure C-28. MvM 5 at 60 Minutes with Upper: Dosage Contours for HPAC (BLUE - -) and NARAC (RED -); Lower: Dosage on Downwind Symmetry Axis 

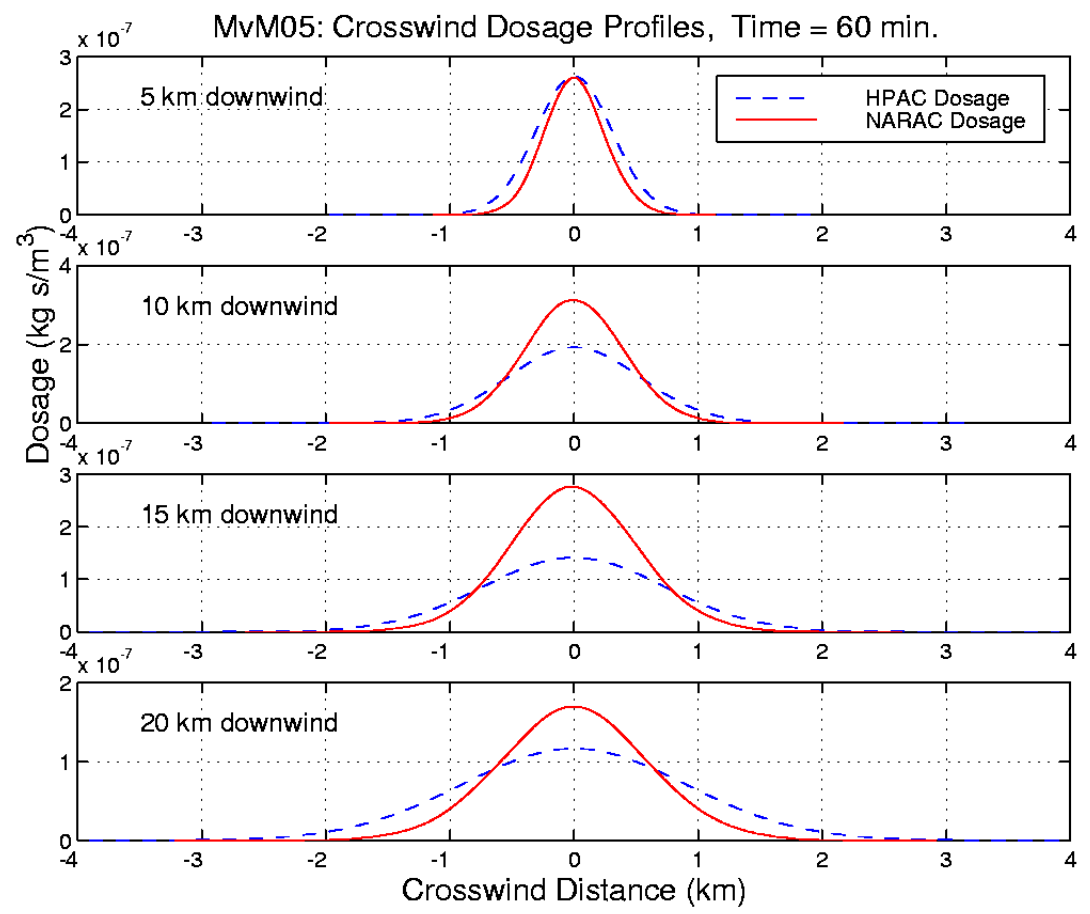

Figure C-29. MvM 5 at 60 Minutes: HPAC (BLUE - -) and NARAC (RED -) Crosswind Dosage Plumes for Various Downwind Distances

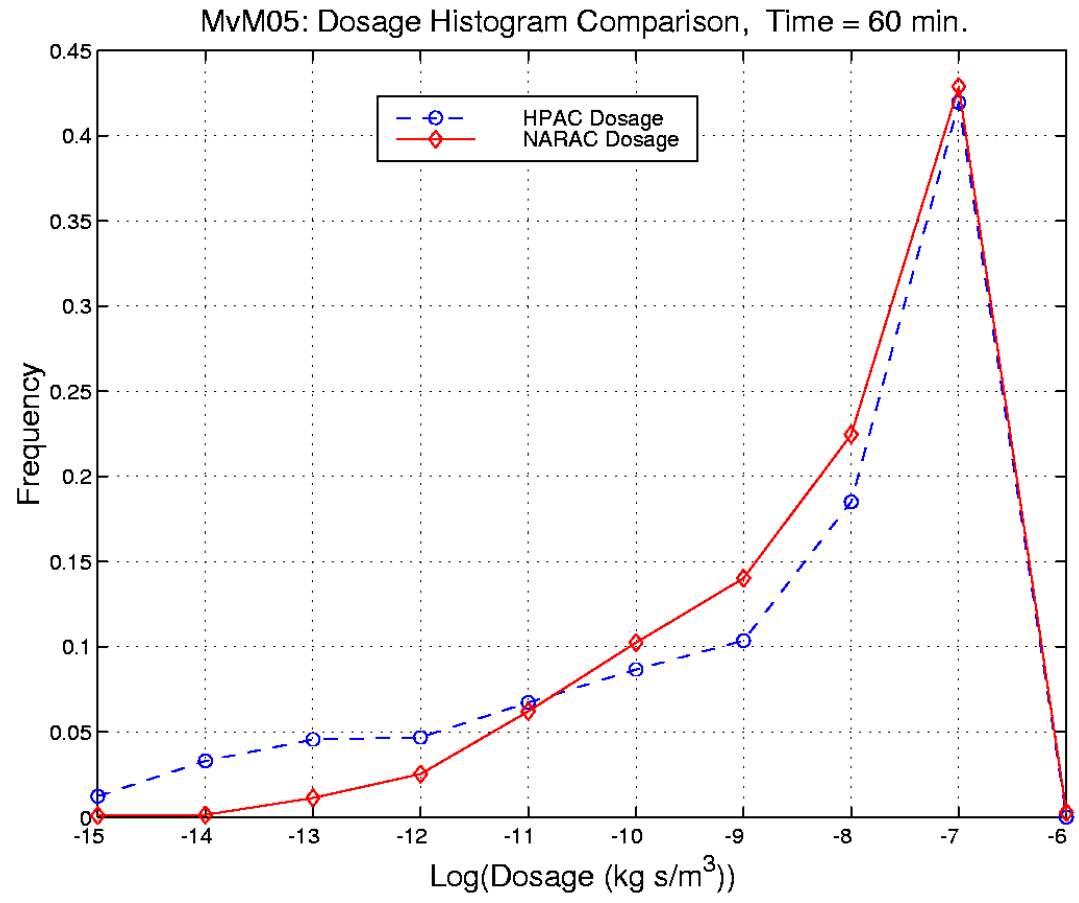

Figure C-30. MvM 5 at 60 Minutes: Dosage Histograms for HPAC (BLUE - -) and NARAC (RED -) 

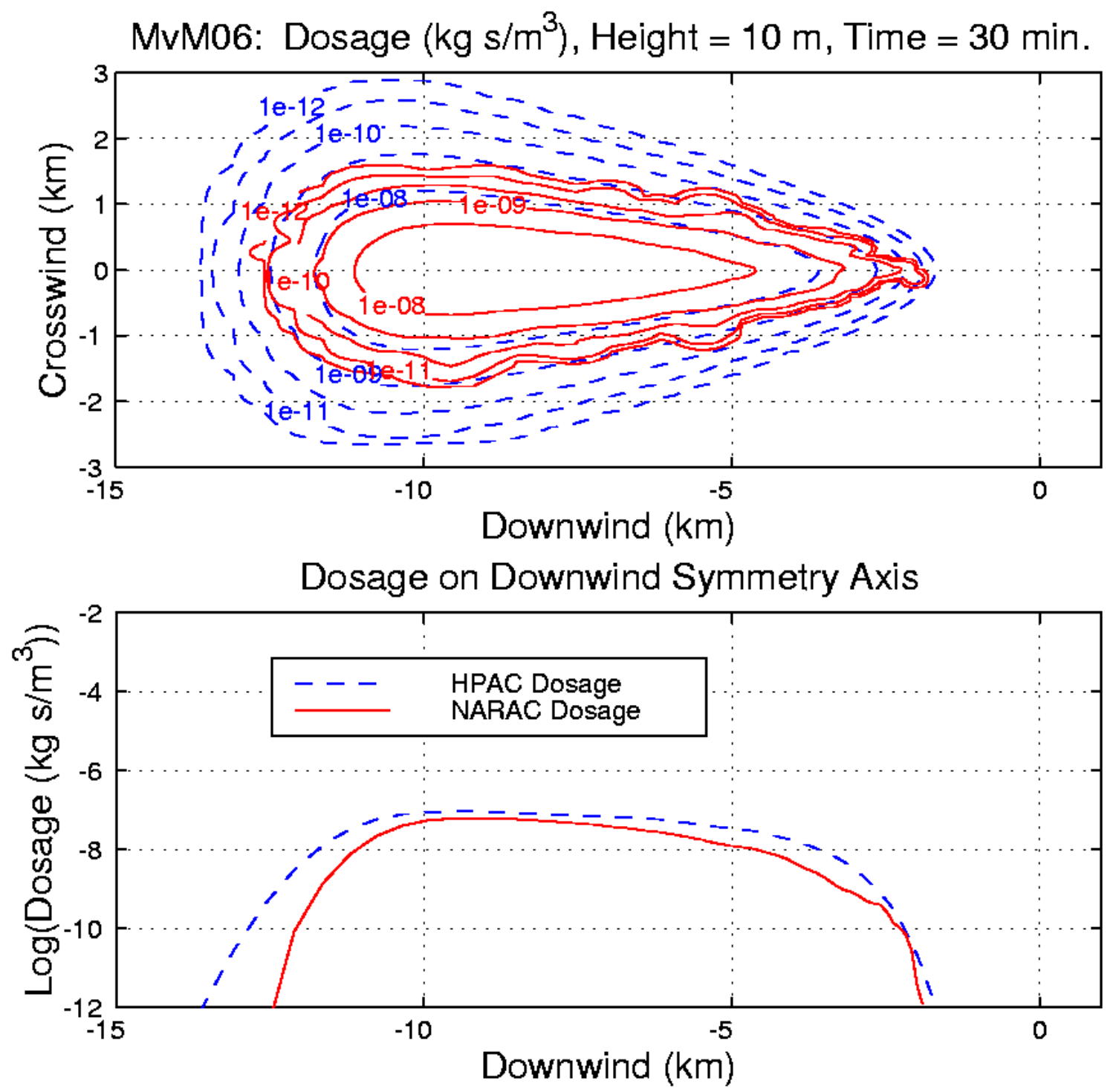

Figure C-31. MvM 6 at 30 Minutes with Upper: Dosage Contours for HPAC (BLUE - -) and NARAC (RED -); Lower: Dosage on Downwind Symmetry Axis 

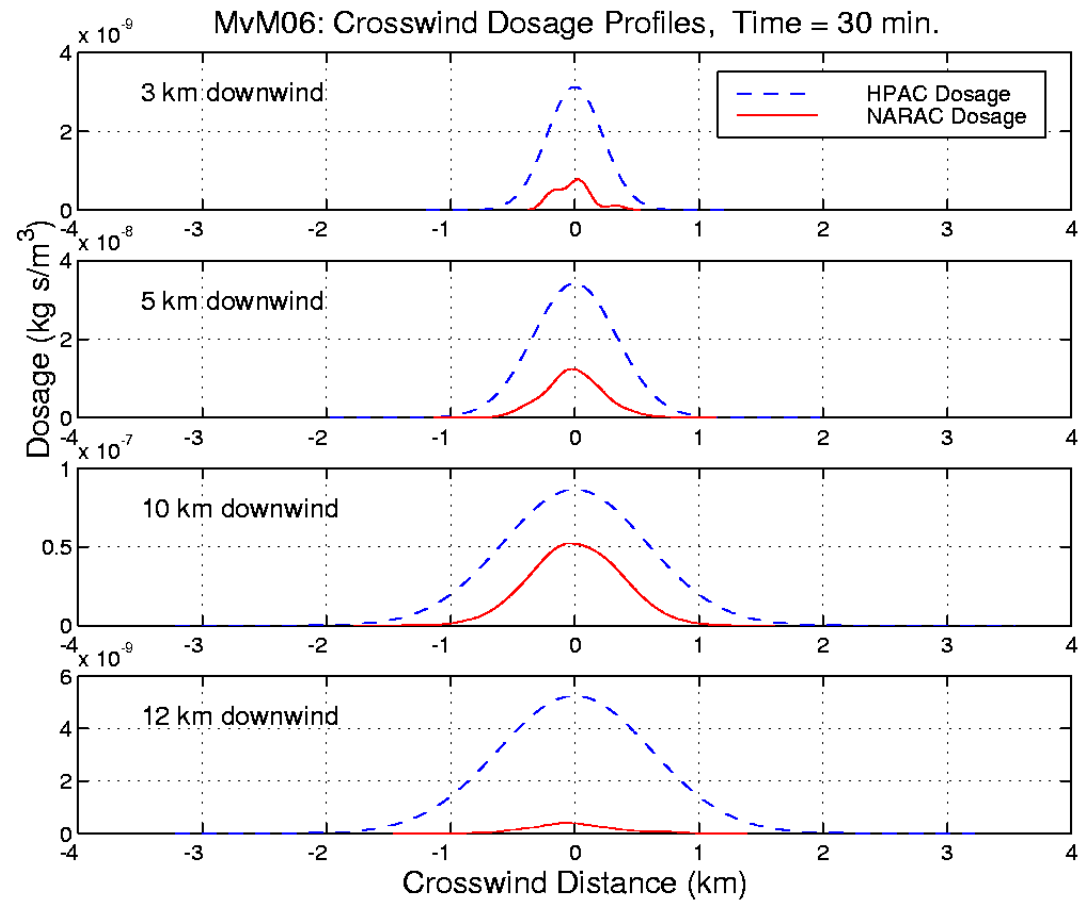

Figure C-32. MvM 6 at 30 Minutes: HPAC (BLUE - -) and NARAC (RED -) Crosswind Dosage Plumes for Various Downwind Distances

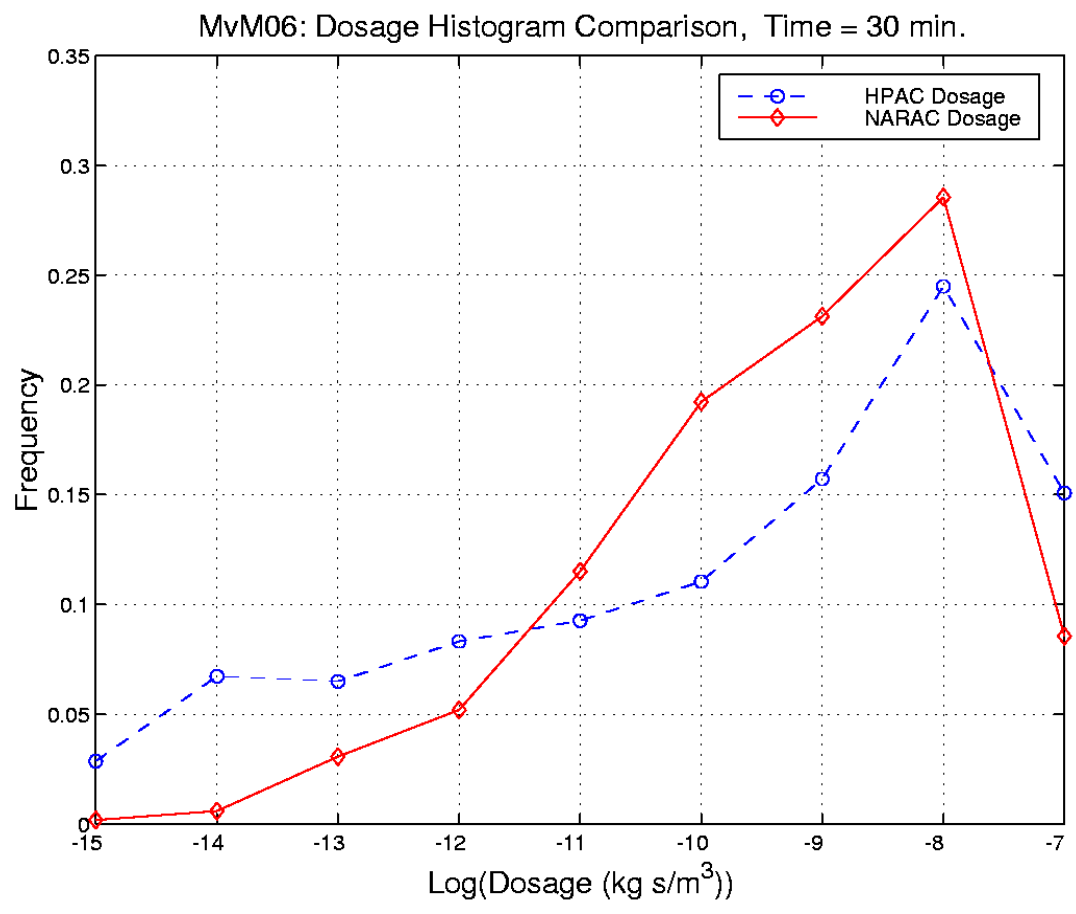

Figure C-33. MvM 6 at 30 Minutes: Dosage Histograms for HPAC (BLUE - -) and NARAC (RED -) 

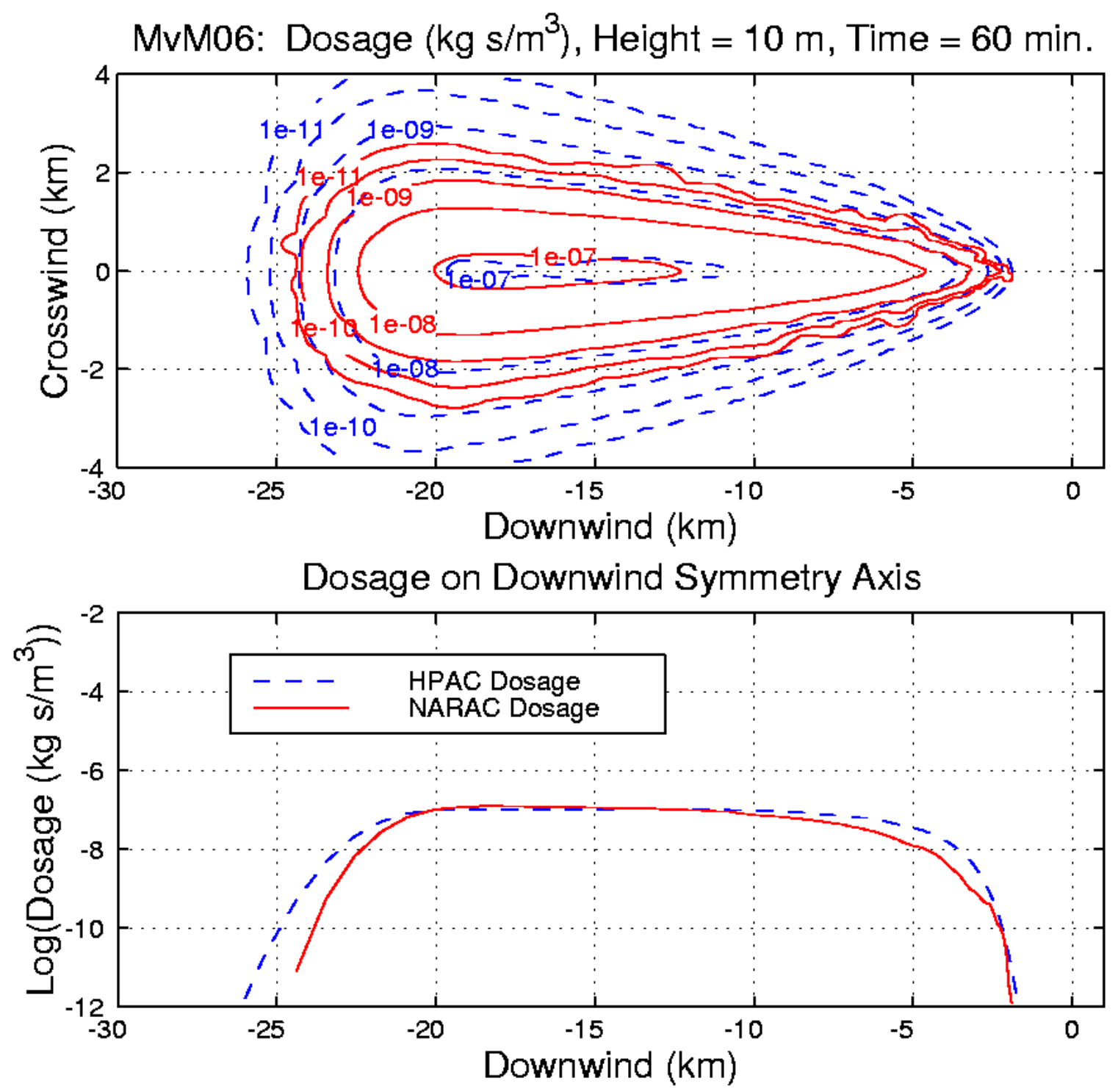

Figure C-34. MvM 6 at 60 Minutes with Upper: Dosage Contours for HPAC (BLUE - -) and NARAC (RED -); Lower: Dosage on Downwind Symmetry Axis 

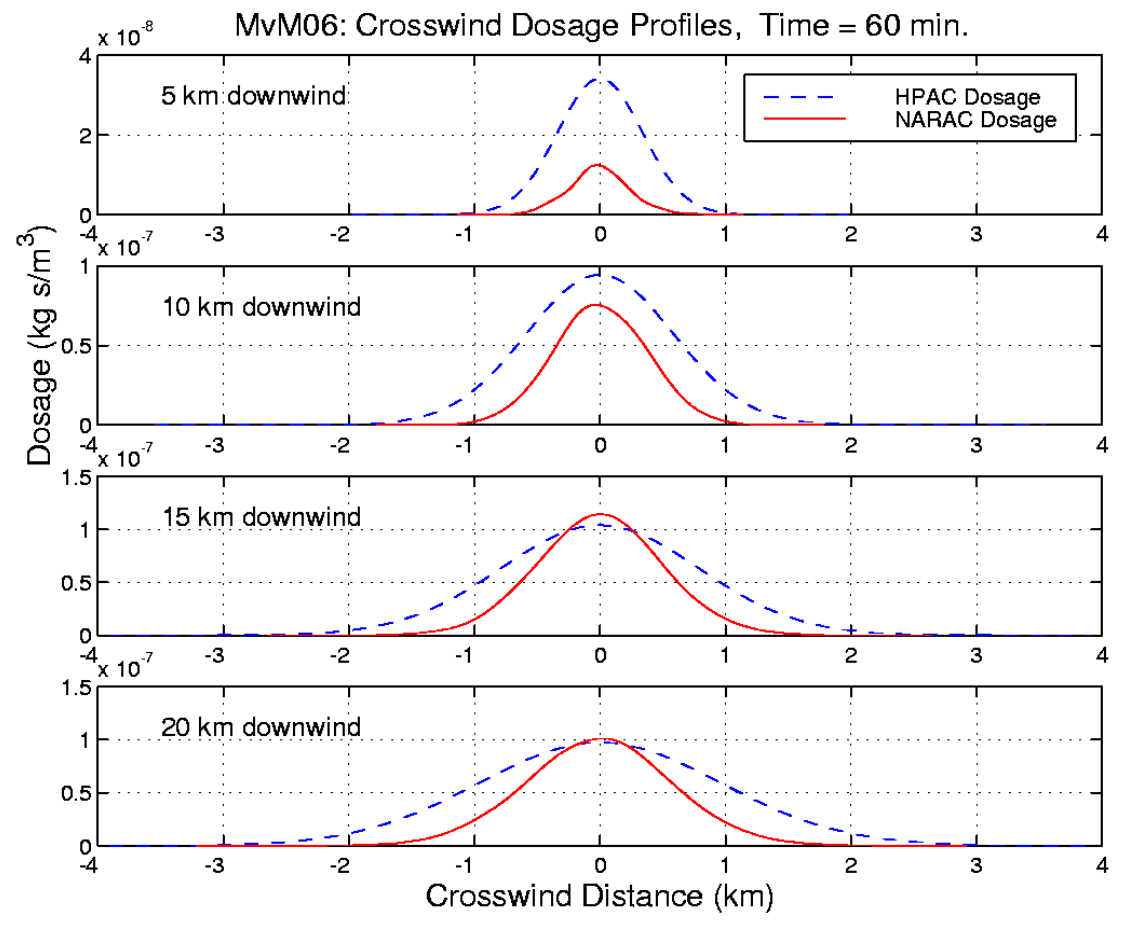

Figure C-35. MvM 6 at 60 Minutes: HPAC (BLUE - -) and NARAC (RED -) Crosswind Dosage Plumes for Various Downwind Distances

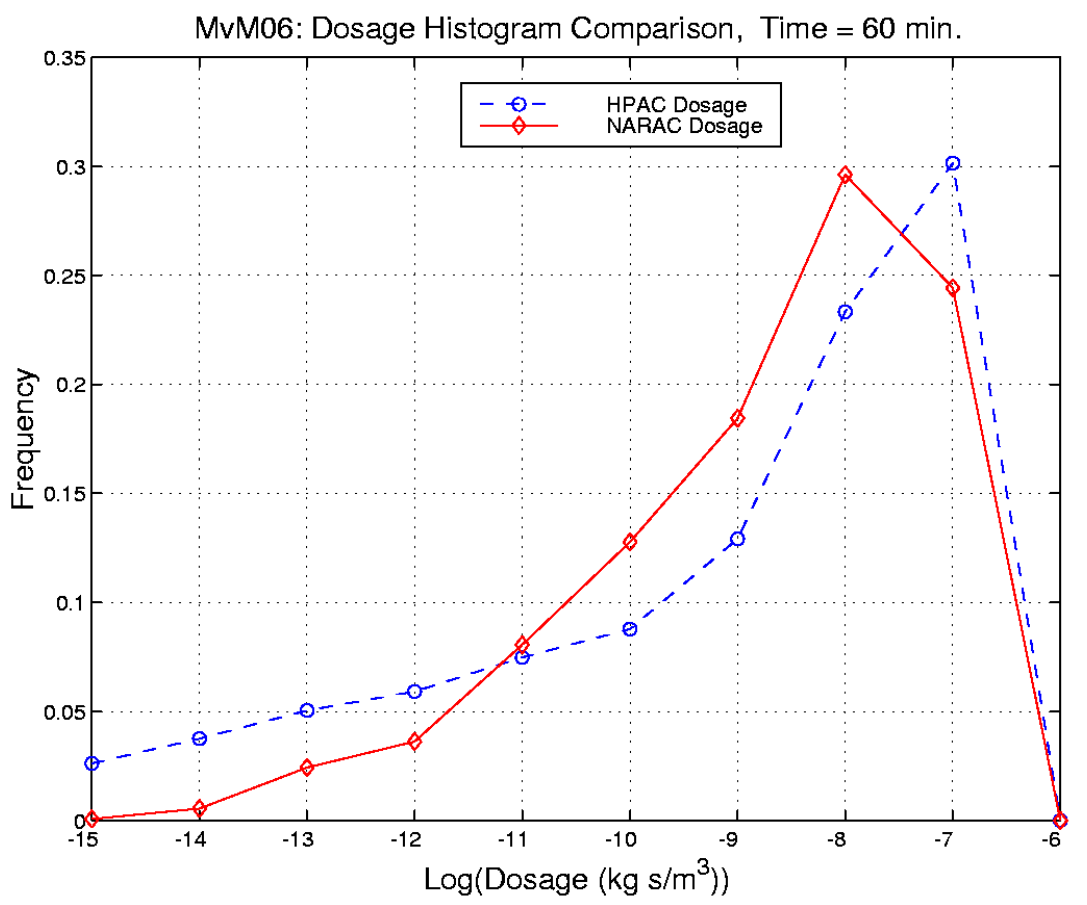

Figure C-36. MvM 6 at 60 Minutes: Dosage Histograms for HPAC (BLUE - -) and NARAC (RED -) 

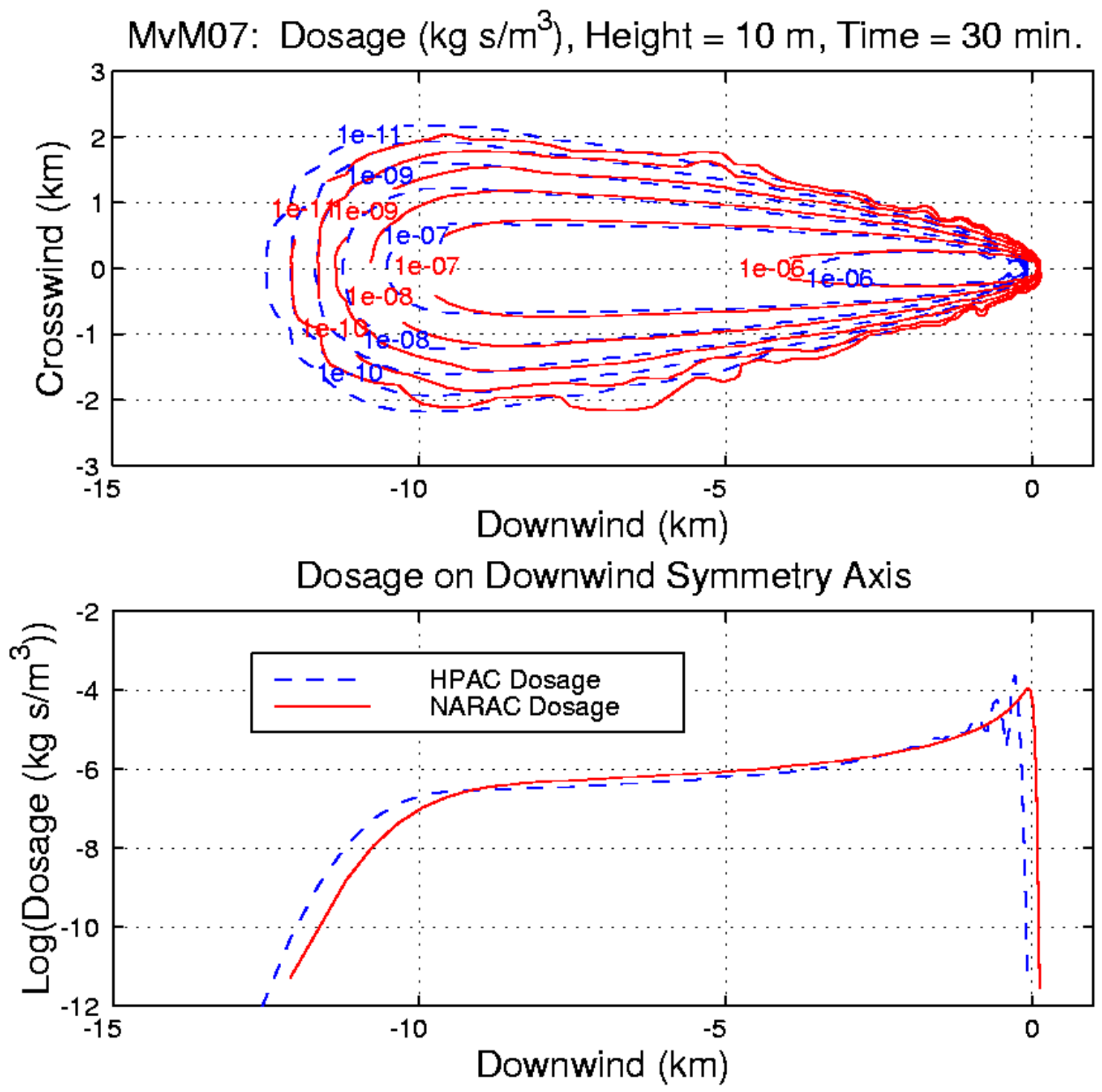

Figure C-37. MvM 7 at 30 Minutes with Upper: Dosage Contours for HPAC (BLUE - -) and NARAC (RED -); Lower: Dosage on Downwind Symmetry Axis 

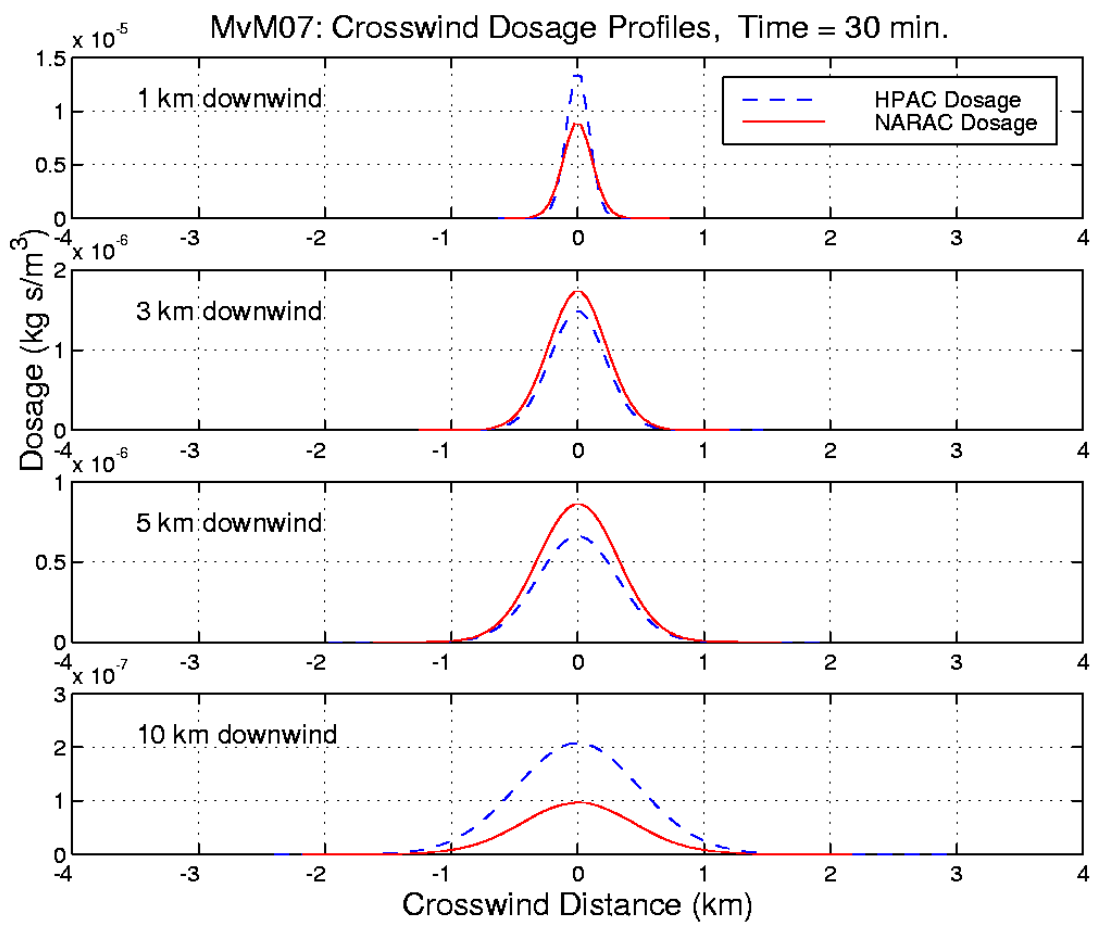

Figure C-38. MvM 7 at 30 Minutes: HPAC (BLUE - -) and NARAC (RED -) Crosswind Dosage Plumes for Various Downwind Distances

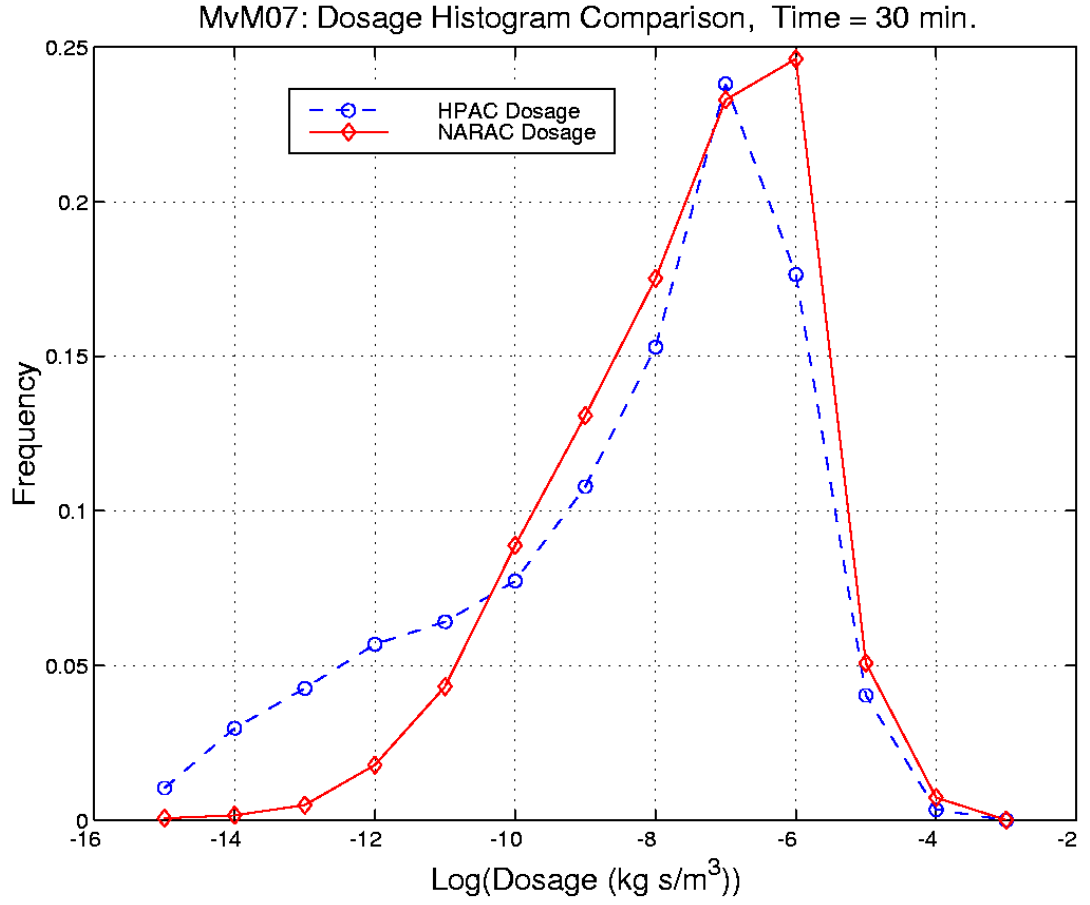

Figure C-39. MvM 7 at 30 Minutes: Dosage Histograms for HPAC (BLUE - -) and NARAC (RED -) 


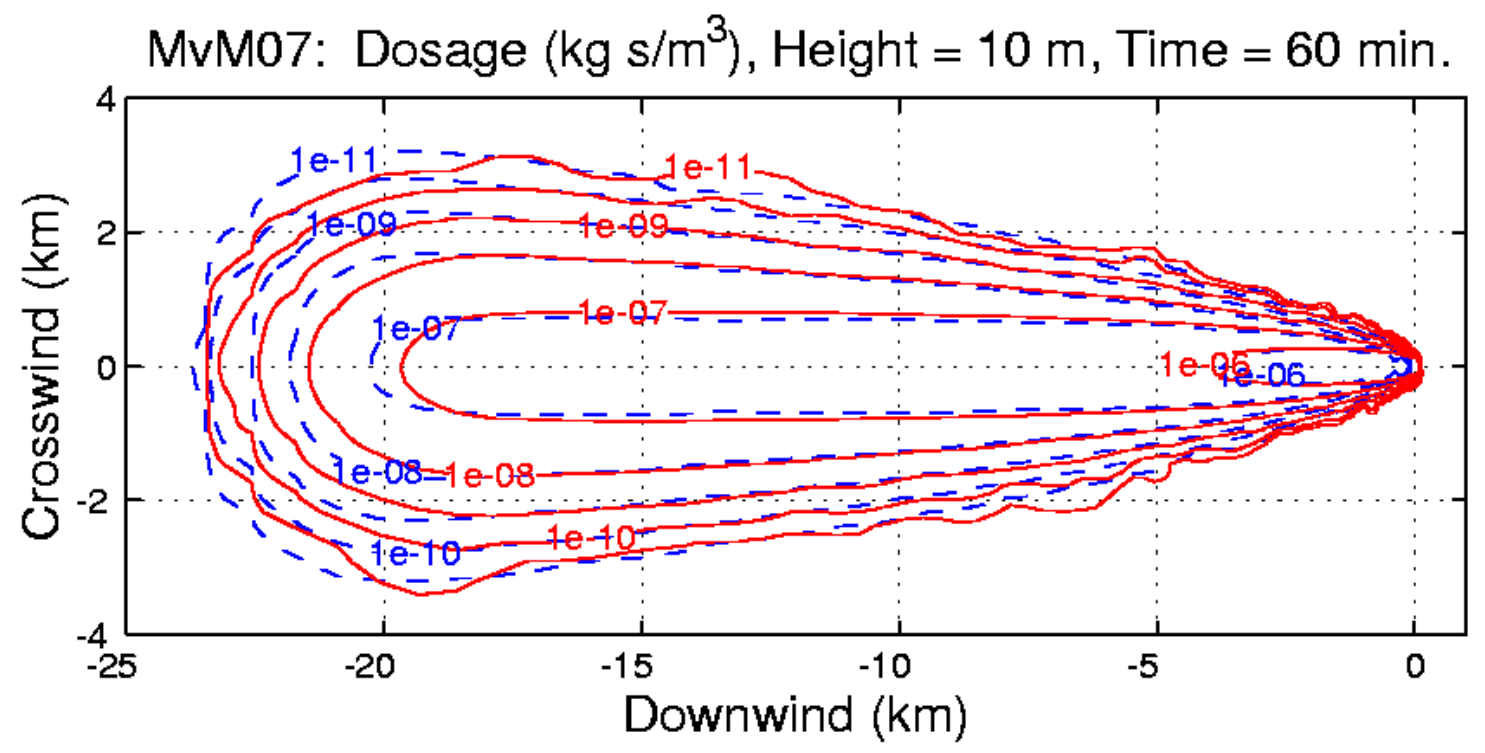

Dosage on Downwind Symmetry Axis

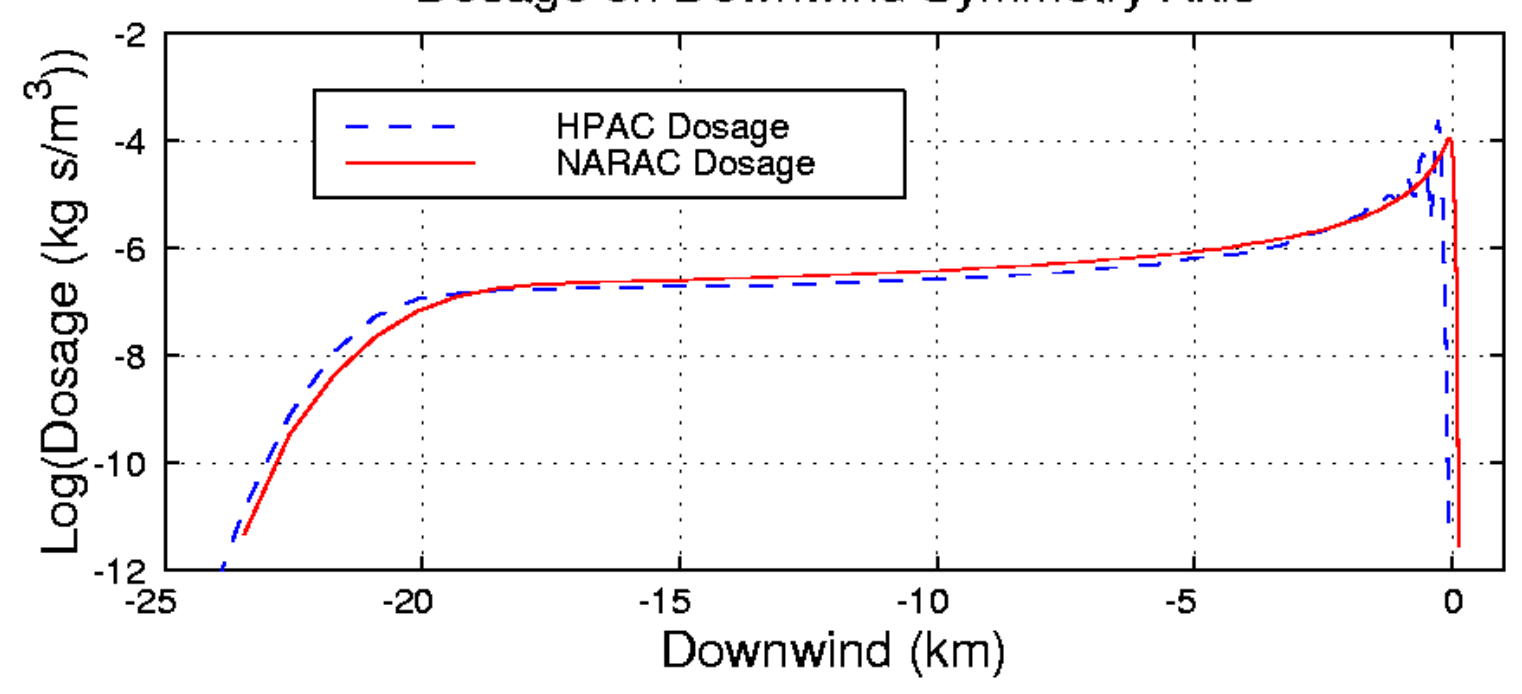

Figure C-40. MvM 7 at 60 Minutes with Upper: Dosage Contours for HPAC (BLUE - -) and NARAC (RED -); Lower: Dosage on Downwind Symmetry Axis 

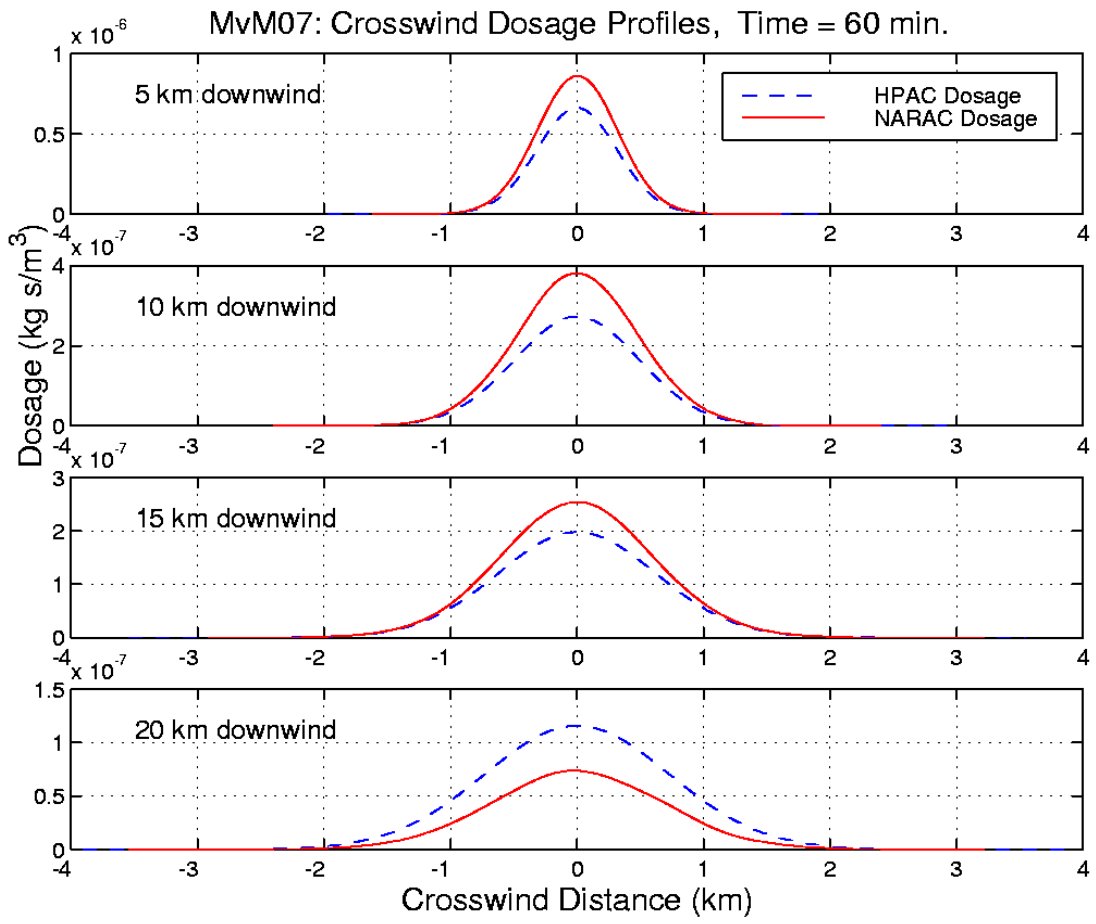

Figure C-41. MvM 7 at 60 Minutes: HPAC (BLUE - -) and NARAC (RED -) Crosswind Dosage Plumes for Various Downwind Distances

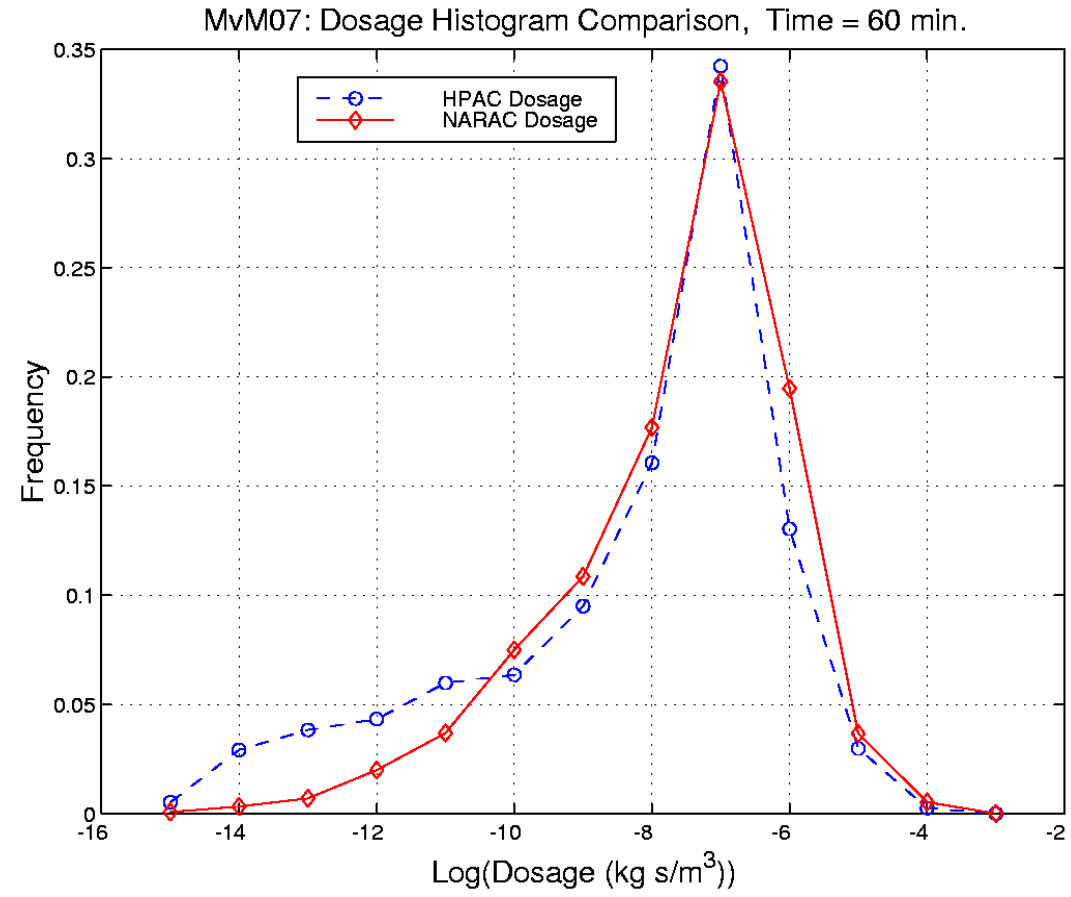

Figure C-42. MvM 7 at 60 Minutes: Dosage Histograms for HPAC (BLUE - -) and NARAC (RED -) 


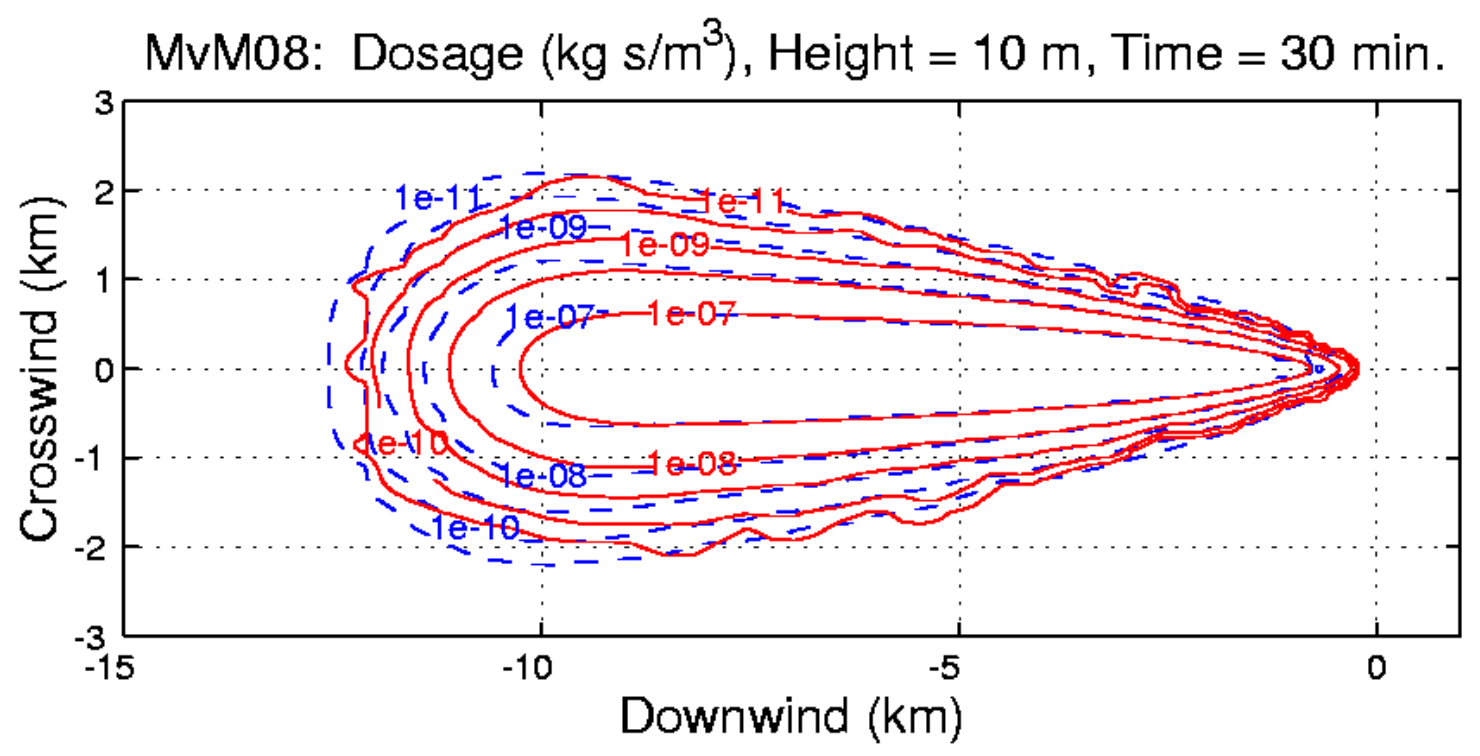

Dosage on Downwind Symmetry Axis

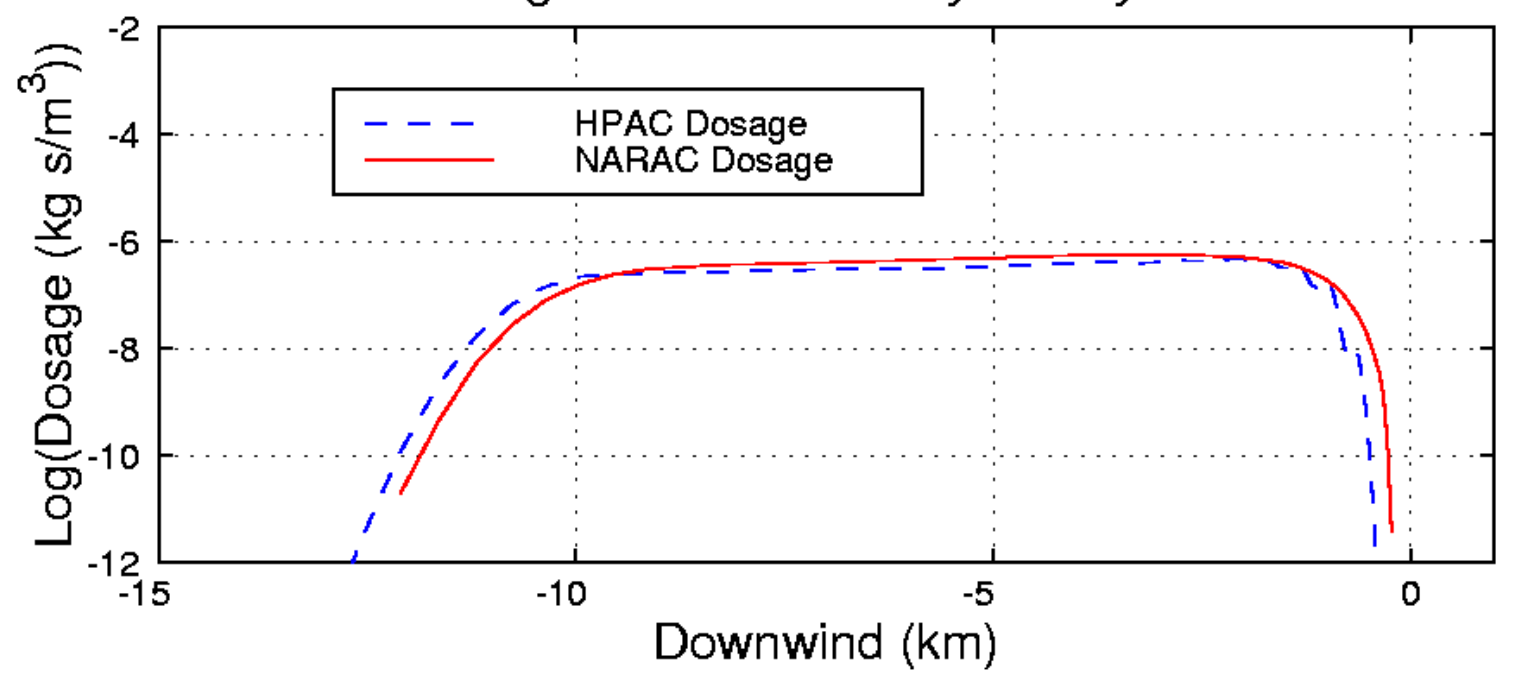

Figure C-43. MvM 8 at 30 Minutes with Upper: Dosage Contours for HPAC (BLUE - -) and NARAC (RED -); Lower: Dosage on Downwind Symmetry Axis 

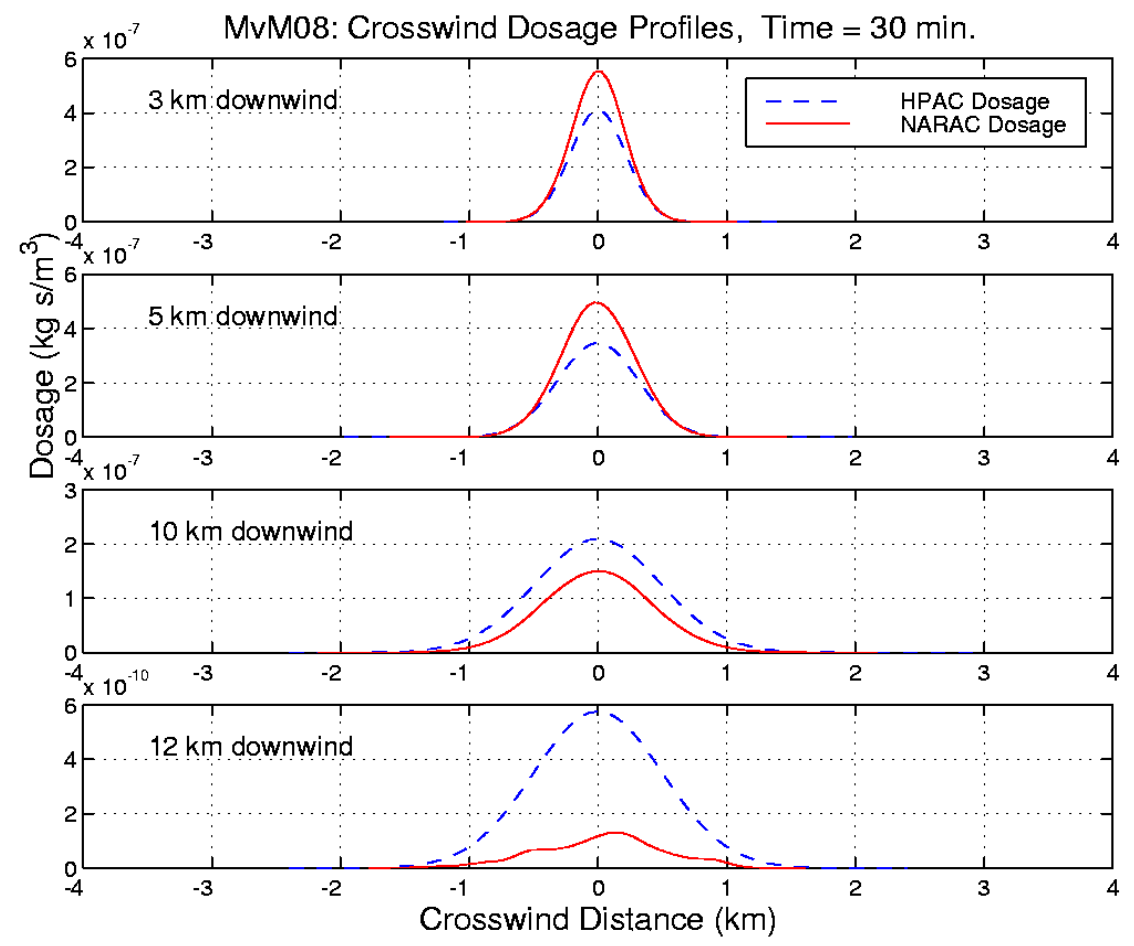

Figure C-44. MvM 8 at 30 Minutes: HPAC (BLUE - -) and NARAC (RED -) Crosswind Dosage Plumes for Various Downwind Distances

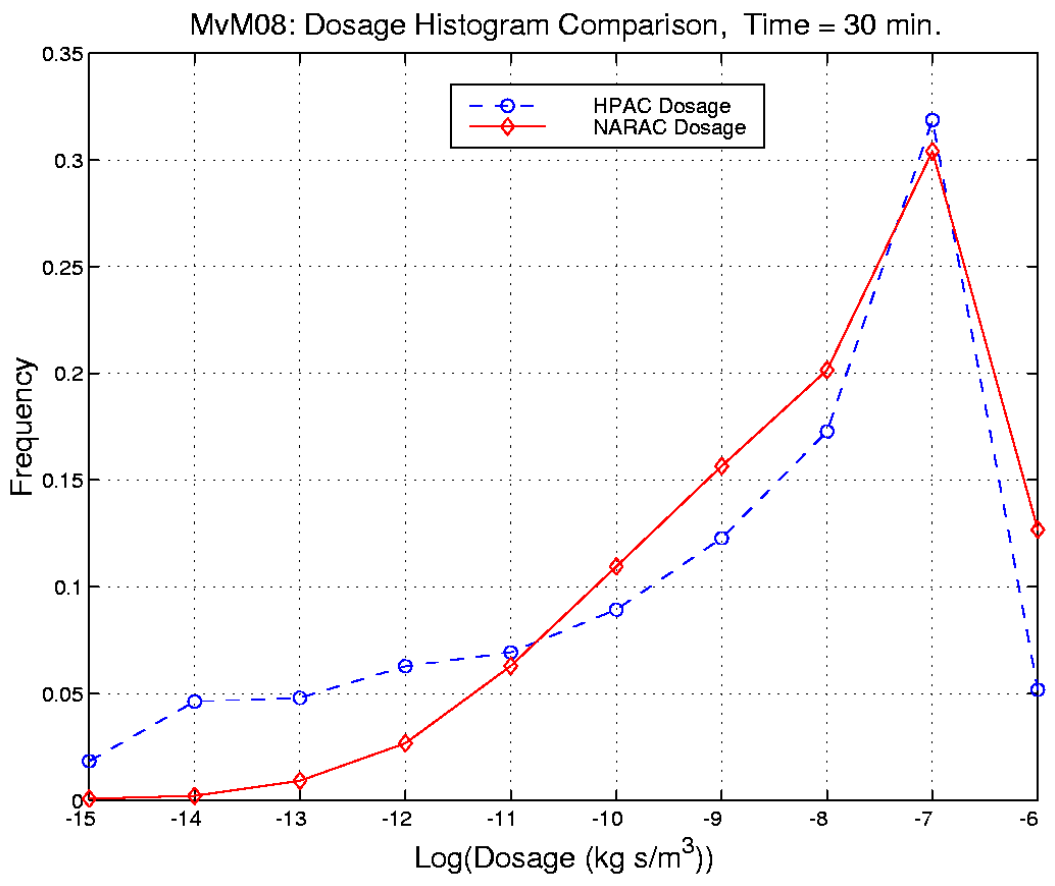

Figure C-45. MvM 8 at 30 Minutes: Dosage Histograms for HPAC (BLUE - -) and NARAC (RED -) 

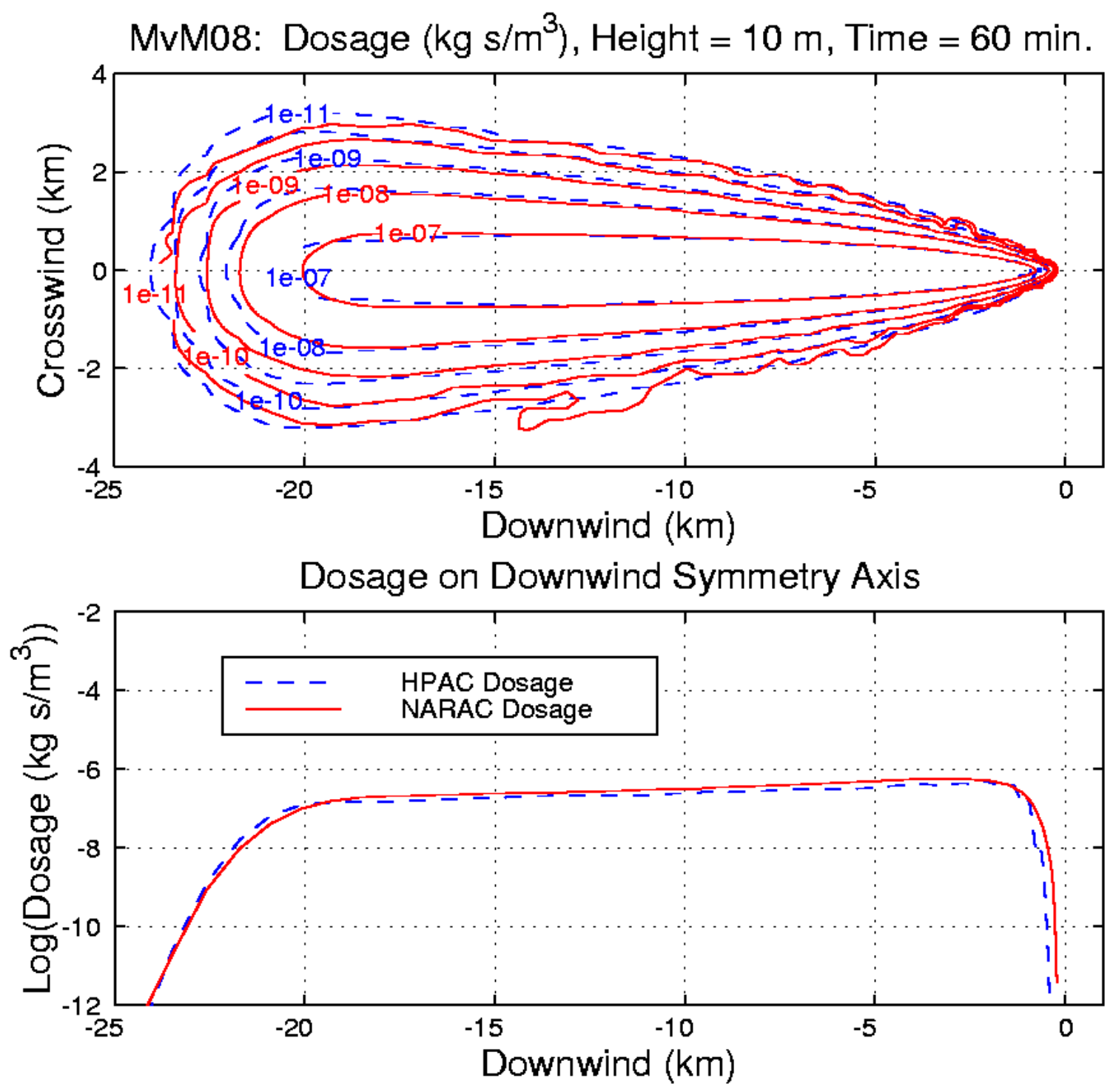

Figure C-46. MvM 8 at 60 Minutes with Upper: Dosage Contours for HPAC (BLUE - -) and NARAC (RED -); Lower: Dosage on Downwind Symmetry Axis 

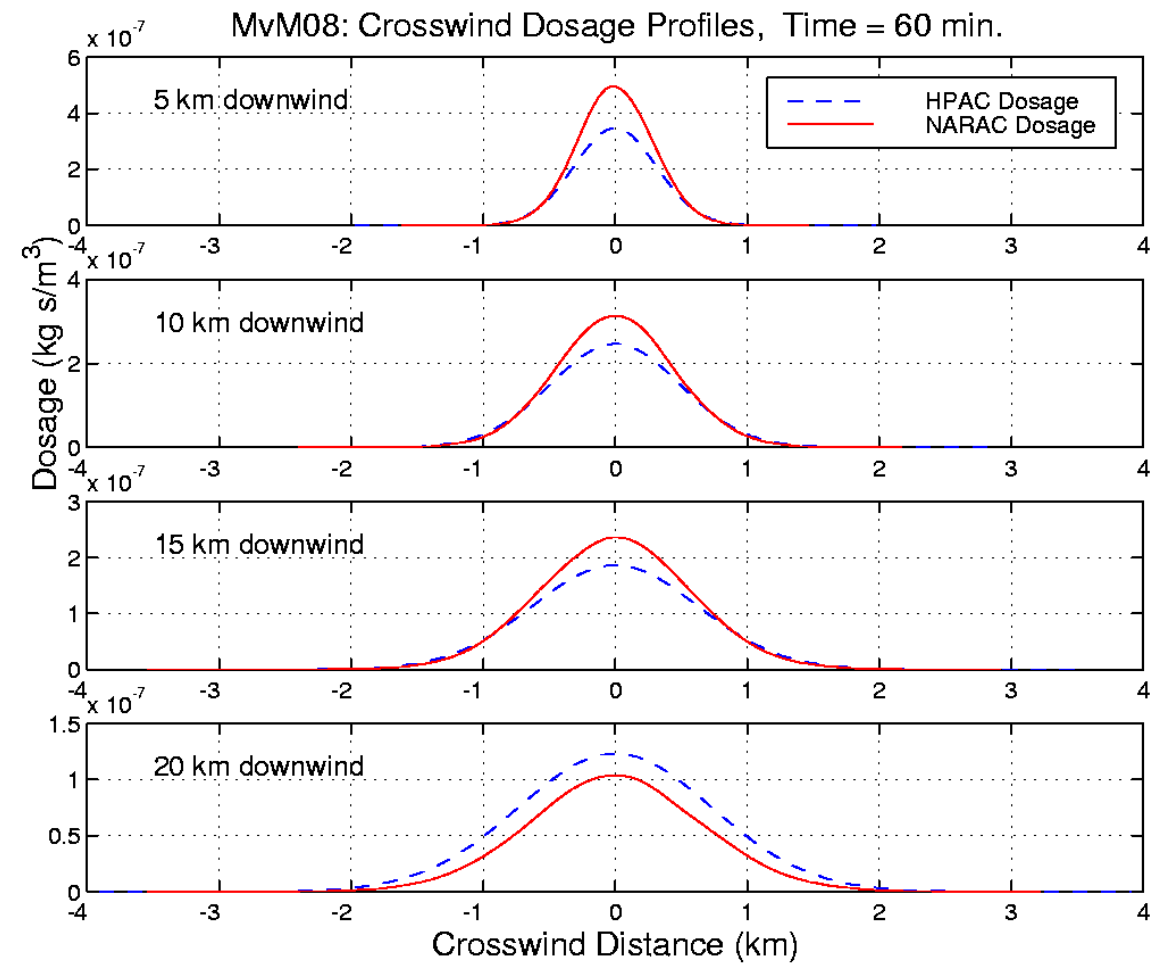

Figure C-47. MvM 8 at 60 Minutes: HPAC (BLUE - -) and NARAC (RED -) Crosswind Dosage Plumes for Various Downwind Distances

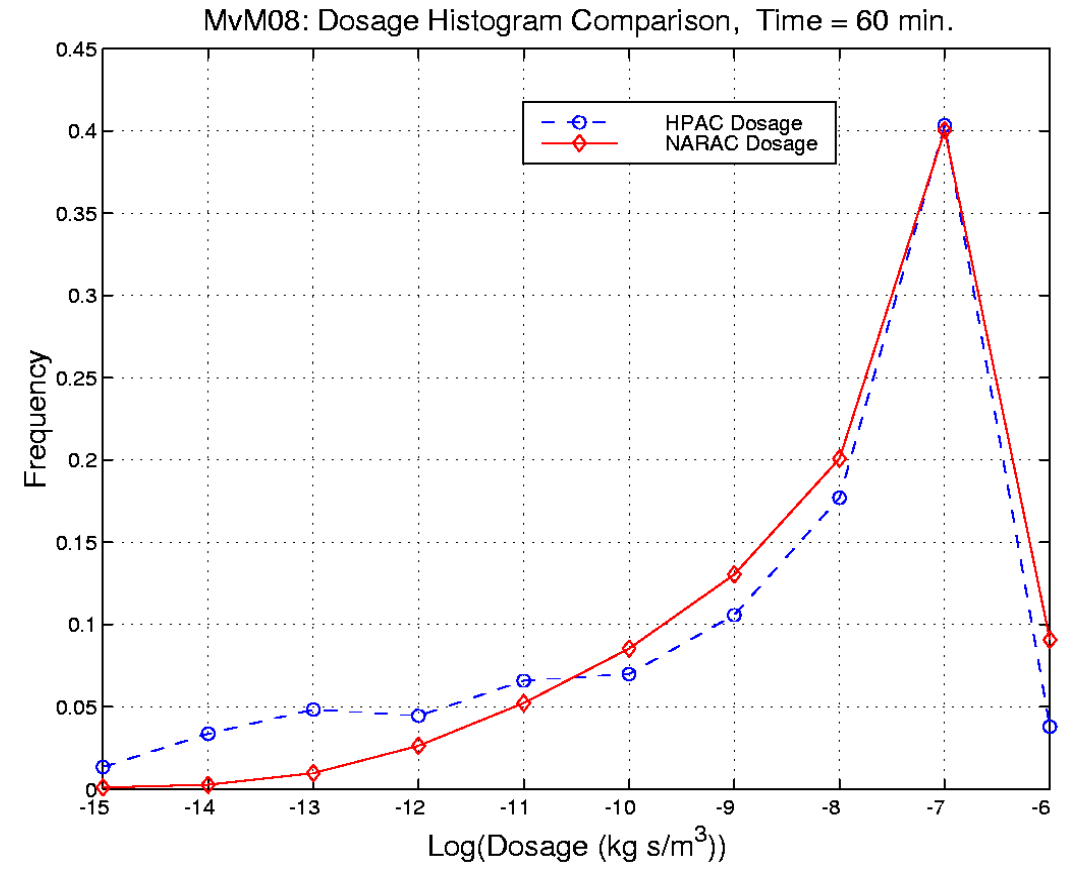

Figure C-48. MvM 8 at 60 Minutes: Dosage Histograms for HPAC (BLUE - -) and NARAC (RED -) 

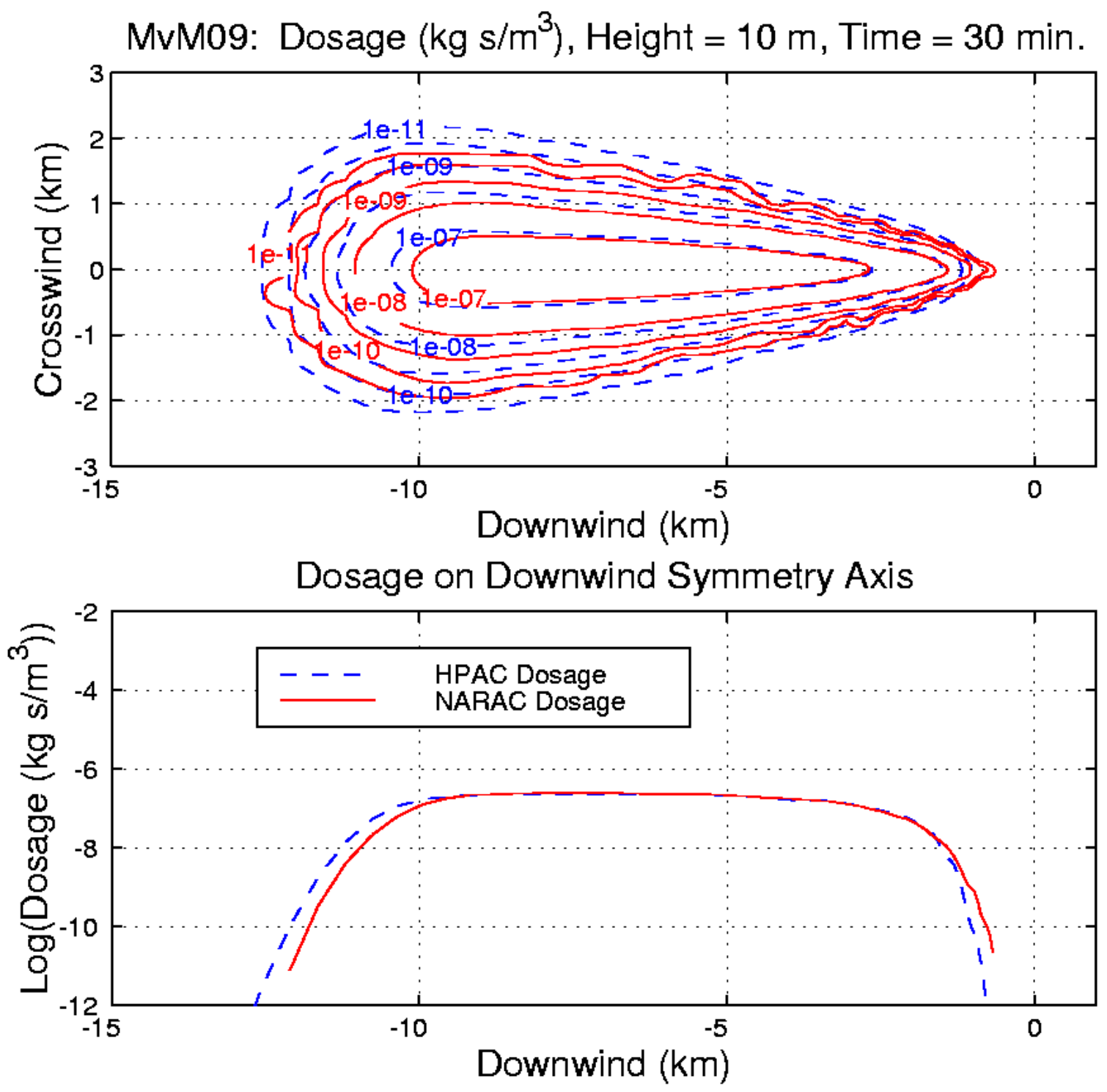

Figure C-49. MvM 9 at 30 Minutes with Upper: Dosage Contours for HPAC (BLUE - -) and NARAC (RED -); Lower: Dosage on Downwind Symmetry Axis 

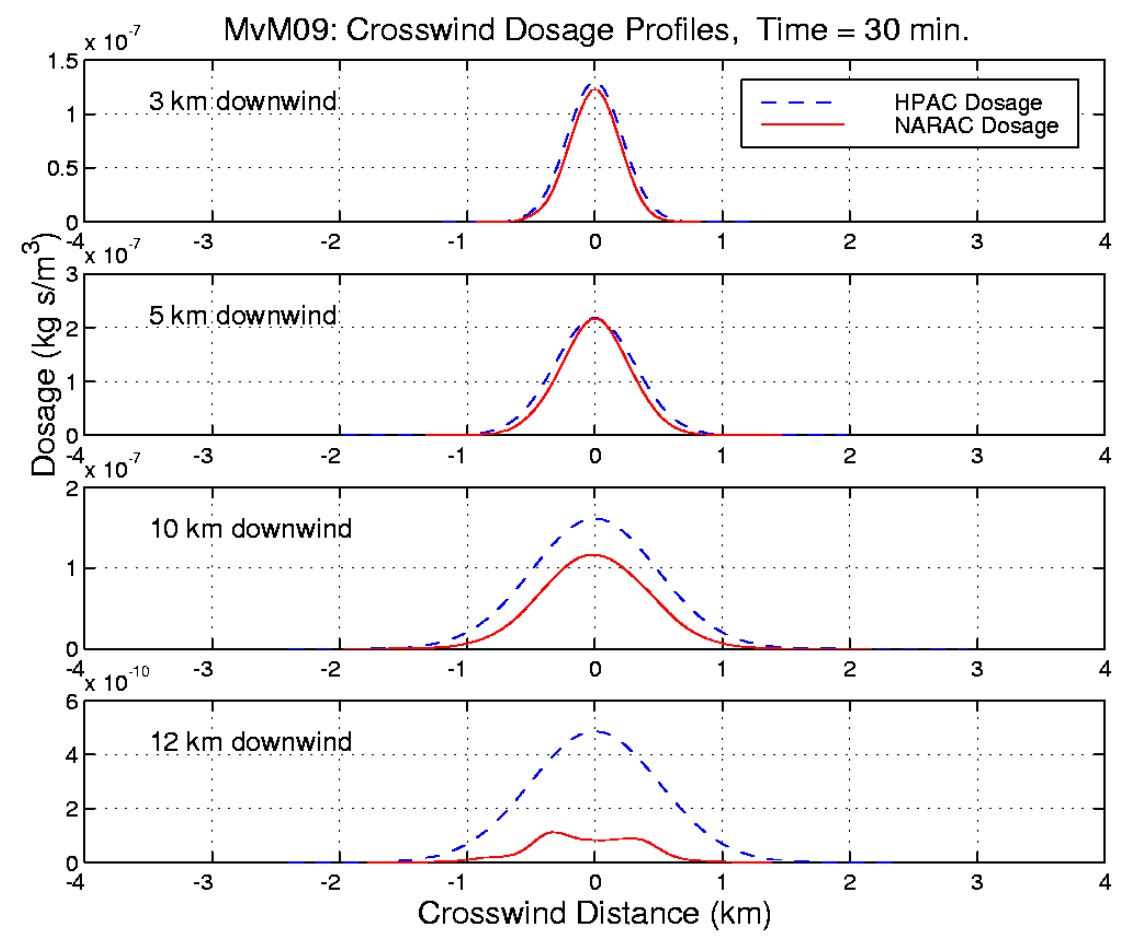

Figure C-50. MvM 9 at 30 Minutes: HPAC (BLUE - -) and NARAC (RED -) Crosswind Dosage Plumes for Various Downwind Distances

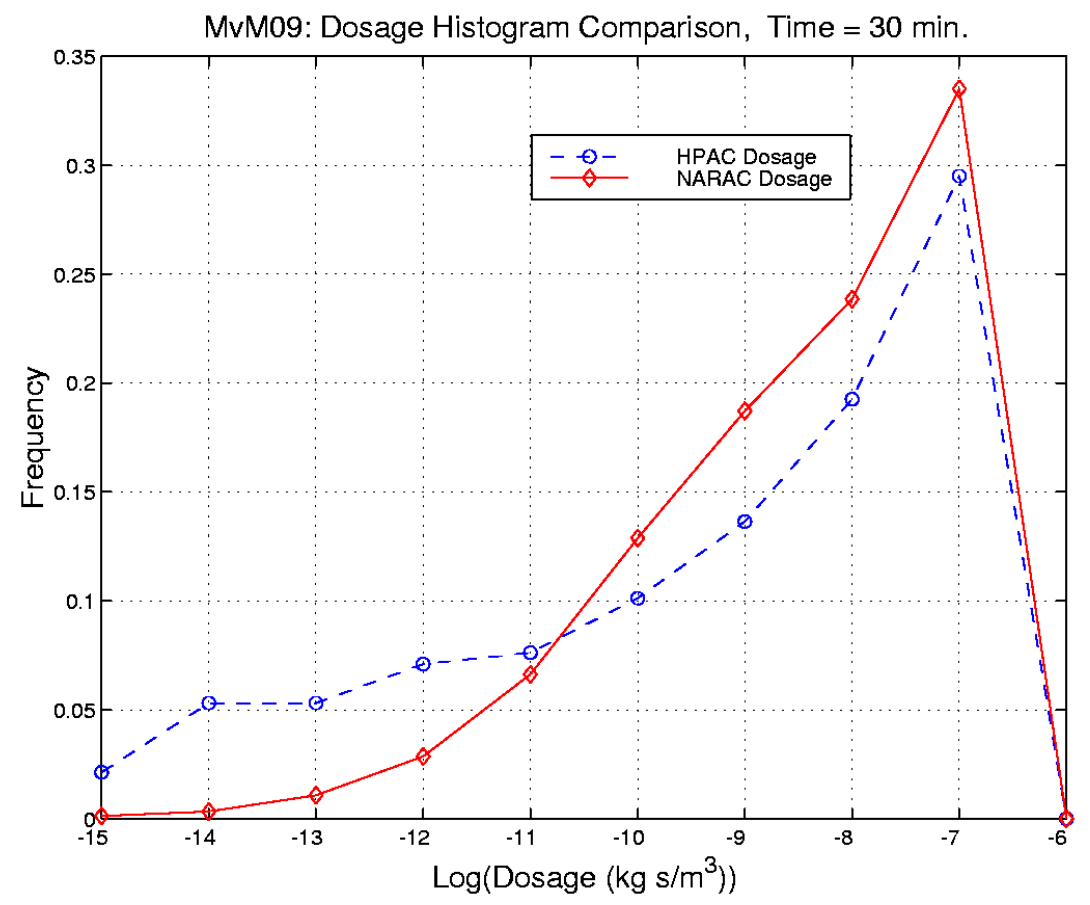

Figure C-51. MvM 9 at 30 Minutes: Dosage Histograms for HPAC (BLUE - -) and NARAC (RED -) 

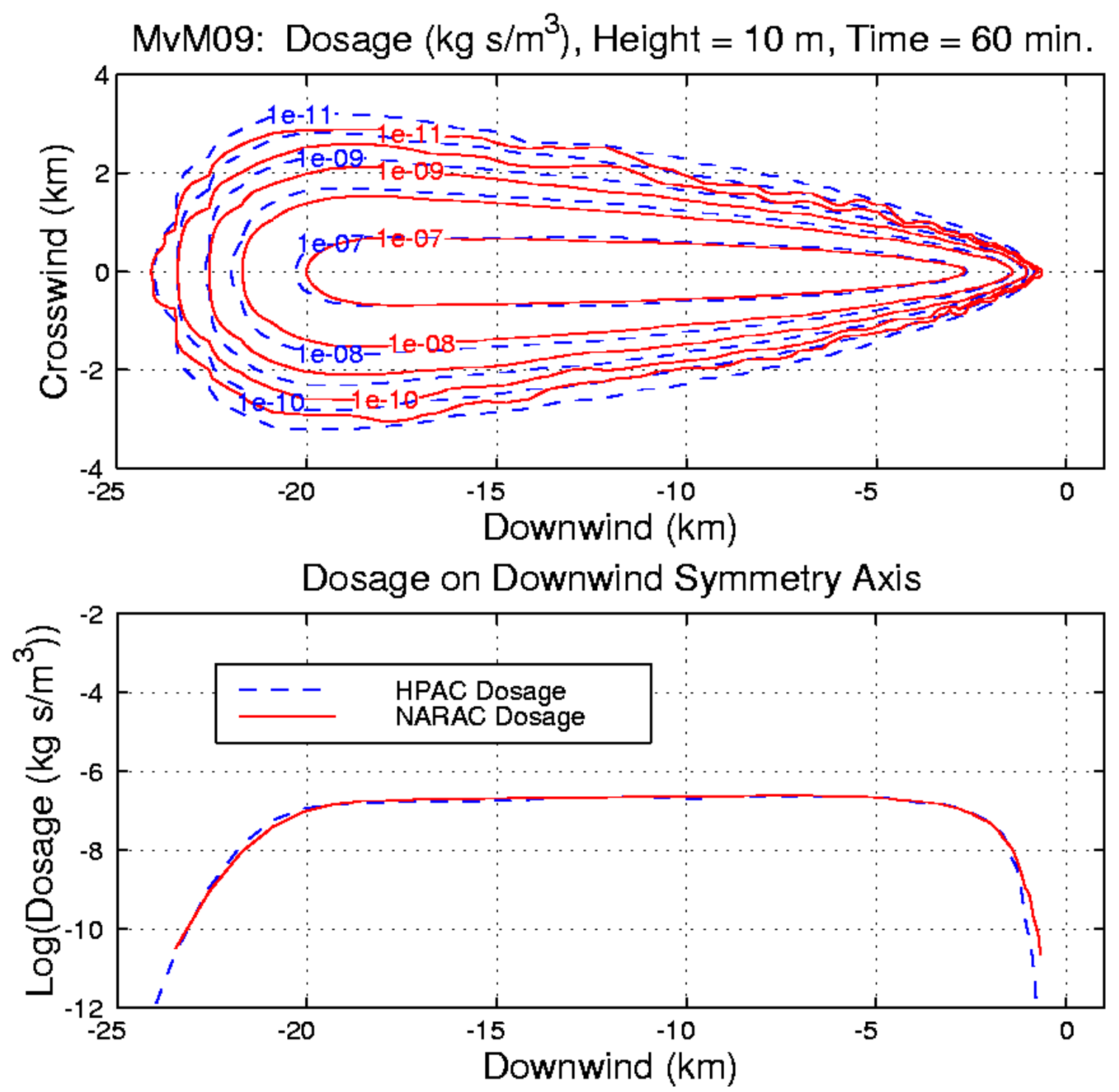

Figure C-52. MvM 9 at 60 Minutes with Upper: Dosage Contours for HPAC (BLUE - -) and NARAC (RED -); Lower: Dosage on Downwind Symmetry Axis 

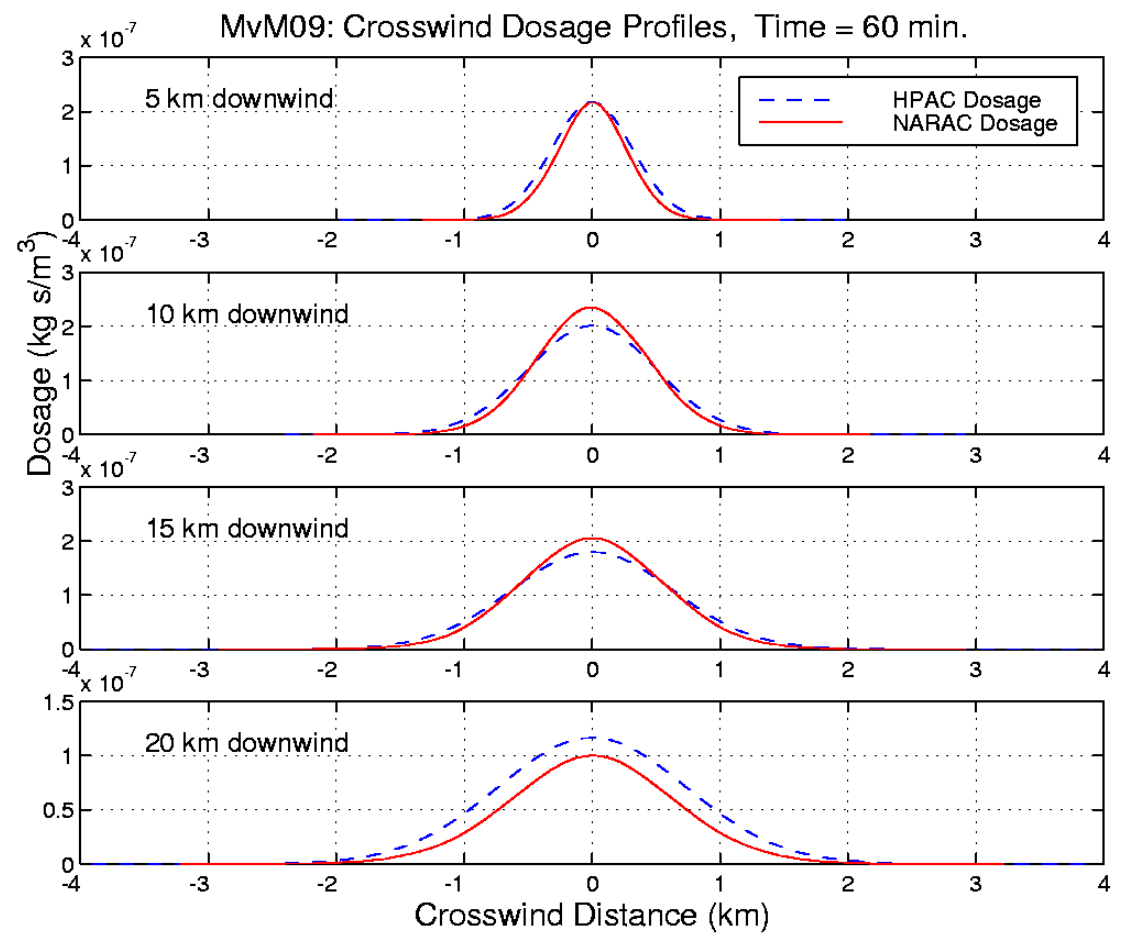

Figure C-53. MvM 9 at 60 Minutes: HPAC (BLUE - -) and NARAC (RED -) Crosswind Dosage Plumes for Various Downwind Distances

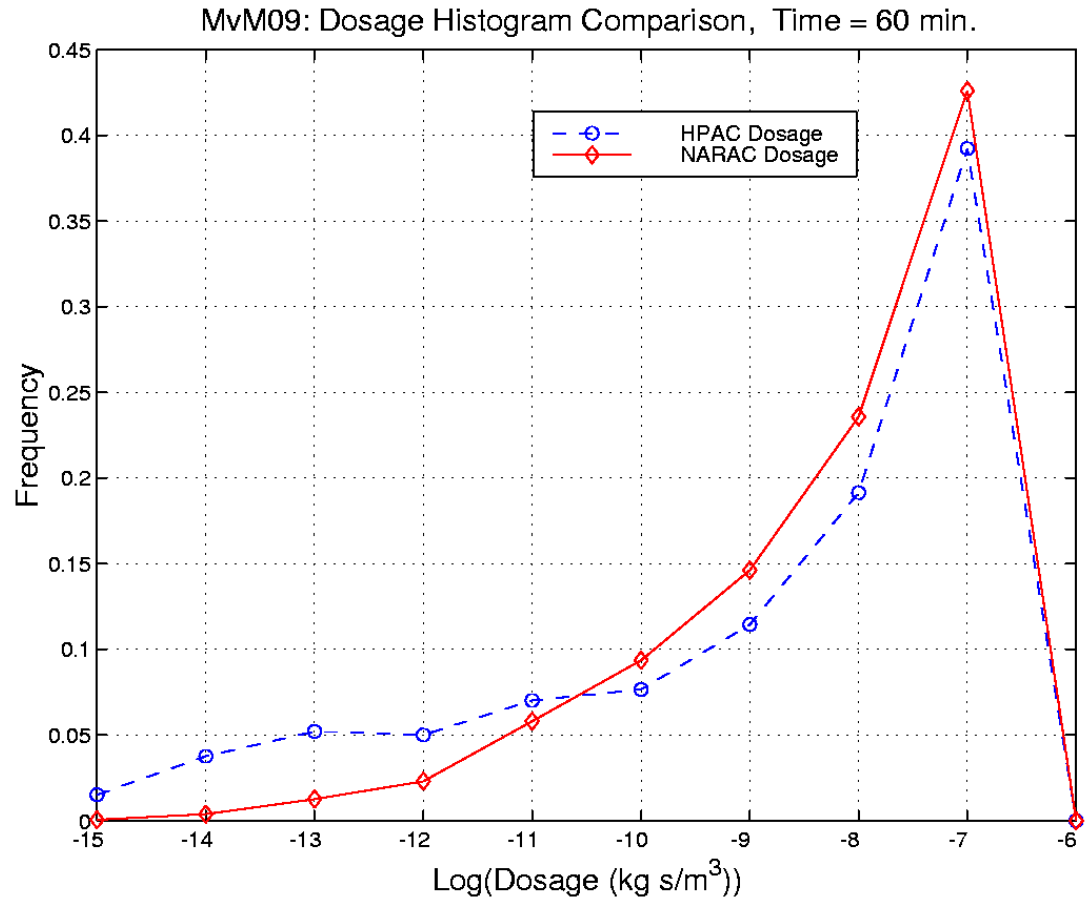

Figure C-54. MvM 9 at 60 Minutes: Dosage Histograms for HPAC (BLUE - -) and NARAC (RED -) 
APPENDIX D

PARTICLE RELEASE COMPARISON PLOTS 



\section{APPENDIX D \\ PARTICLE RELEASE COMPARISON PLOTS}

This appendix contains dosage contours, crosswind dosage profiles, and dosage histograms for all of the particle releases. The 51 figures shown in this appendix are grouped by run number and time: 30 and 60 minutes after the release (120, 180, and 240 minutes after the release for the high altitude release, MvM 15).
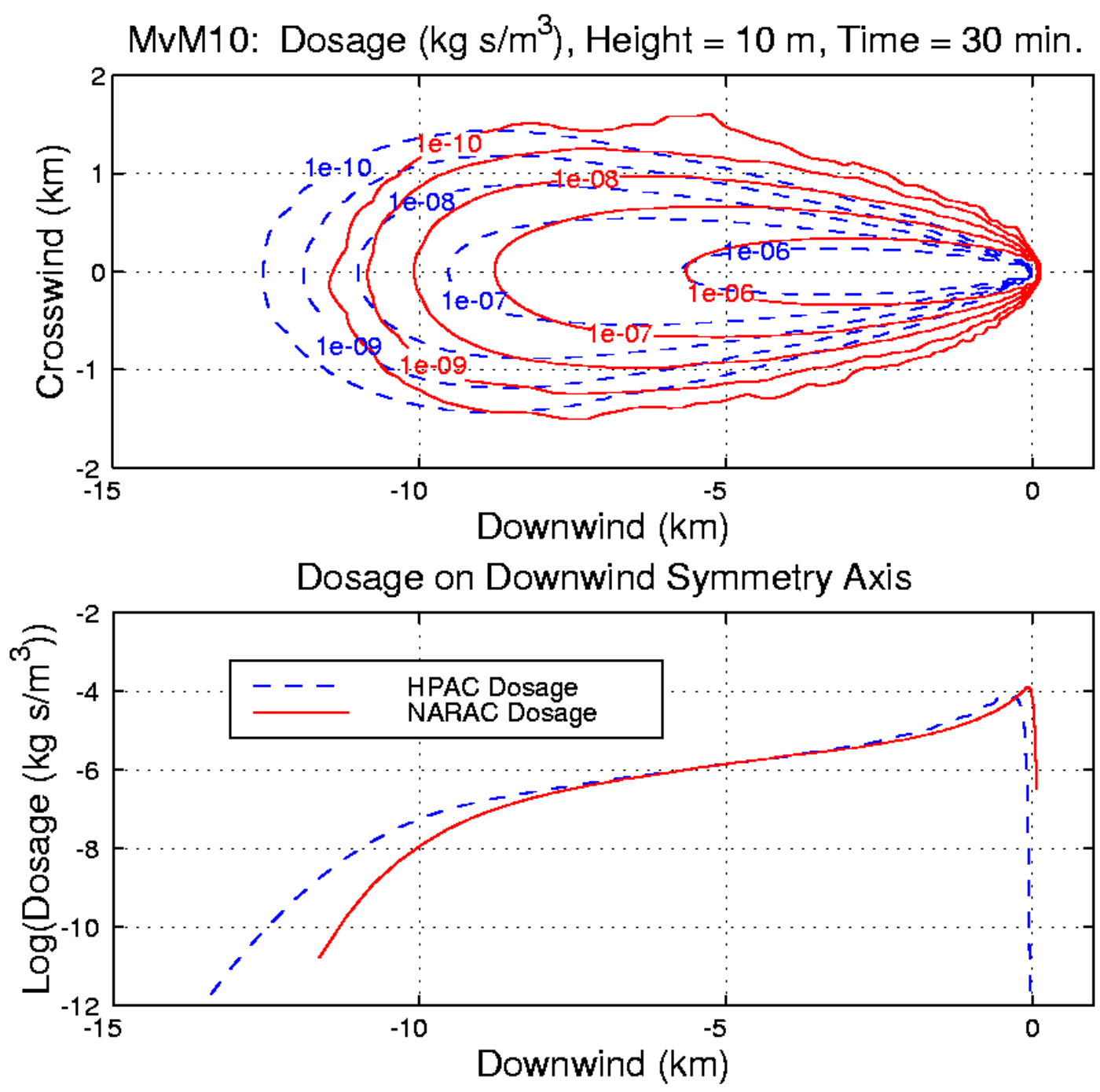

Figure D-1. MvM 10 at 30 Minutes with Upper: Dosage Contours for HPAC (BLUE - -) and NARAC (RED -); Lower: Dosage on Downwind Symmetry Axis 


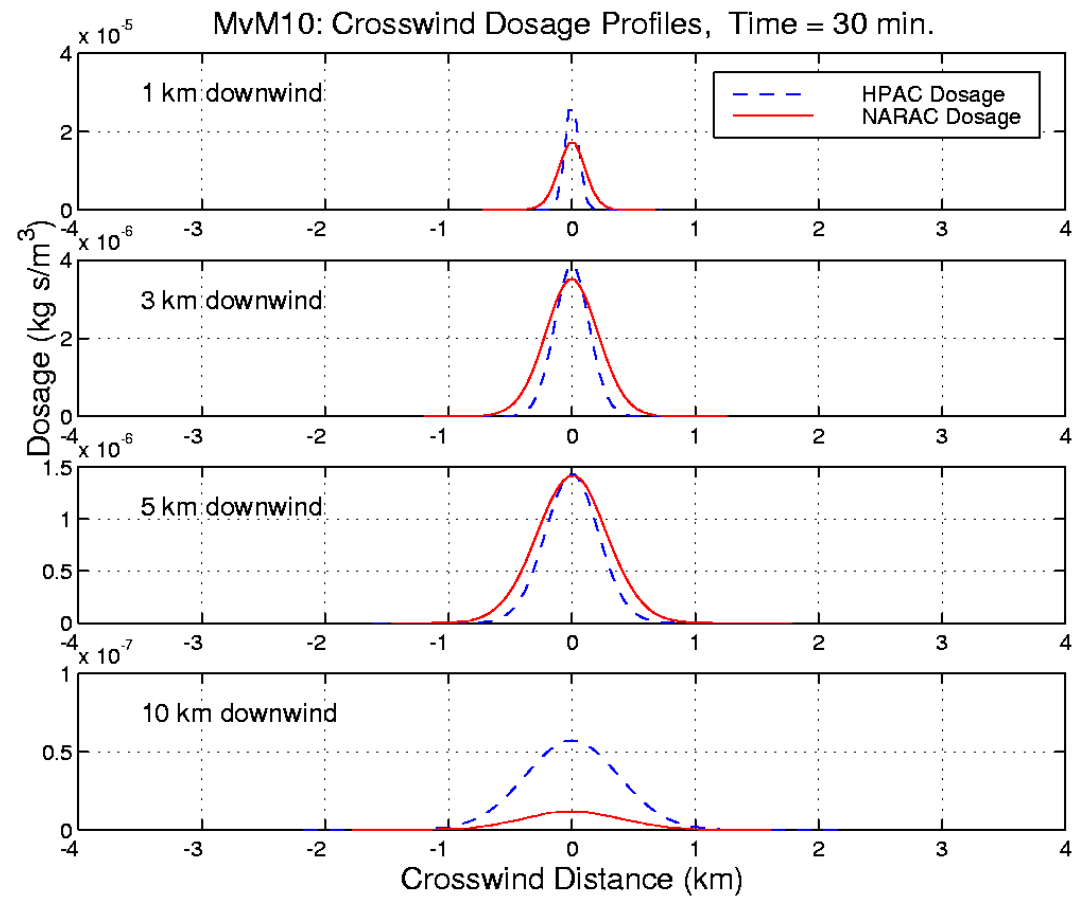

Figure D-2. MvM 10 at 30 Minutes: HPAC (BLUE - -) and NARAC (RED -) Crosswind Dosage Plumes for Various Downwind Distances

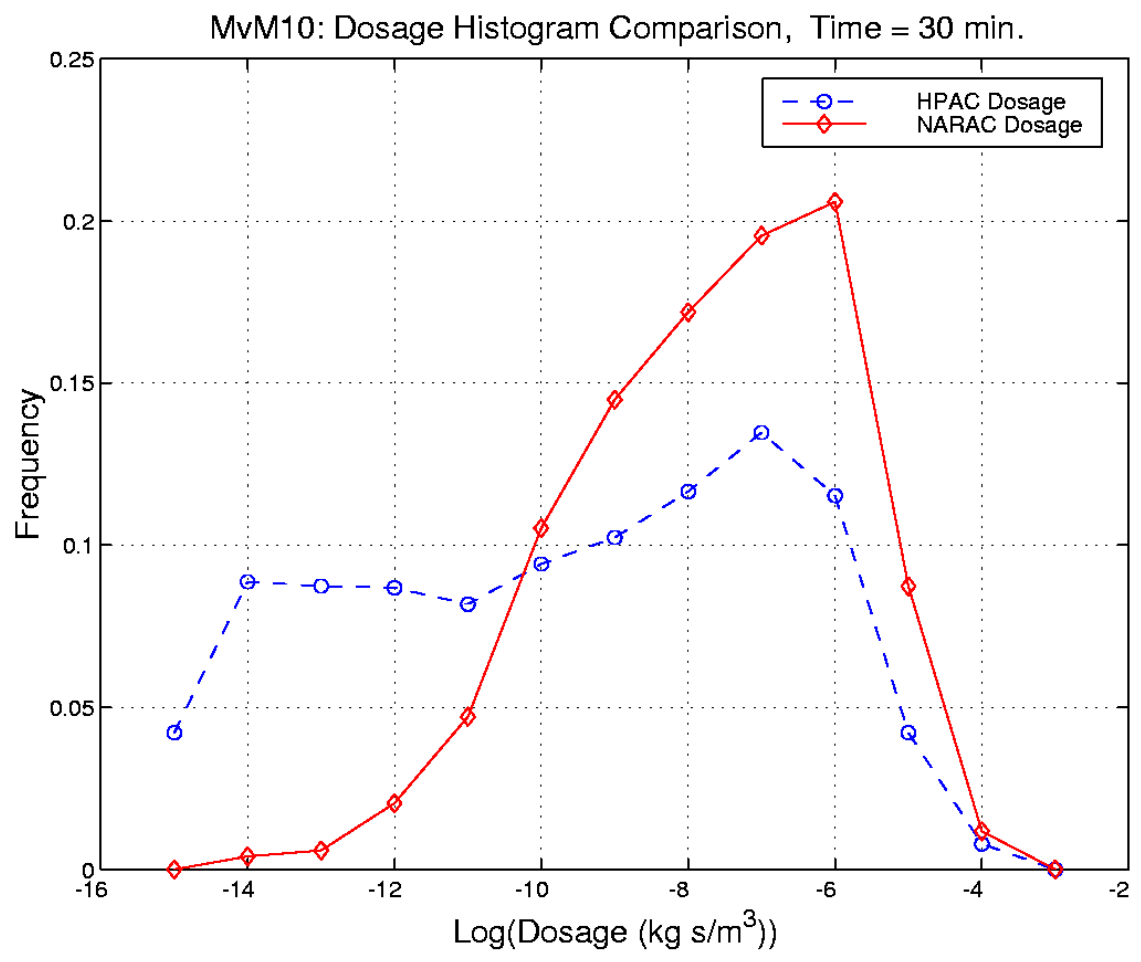

Figure D-3. MvM 10 at 30 Minutes: Dosage Histograms for HPAC (BLUE - -) and NARAC (RED -) 


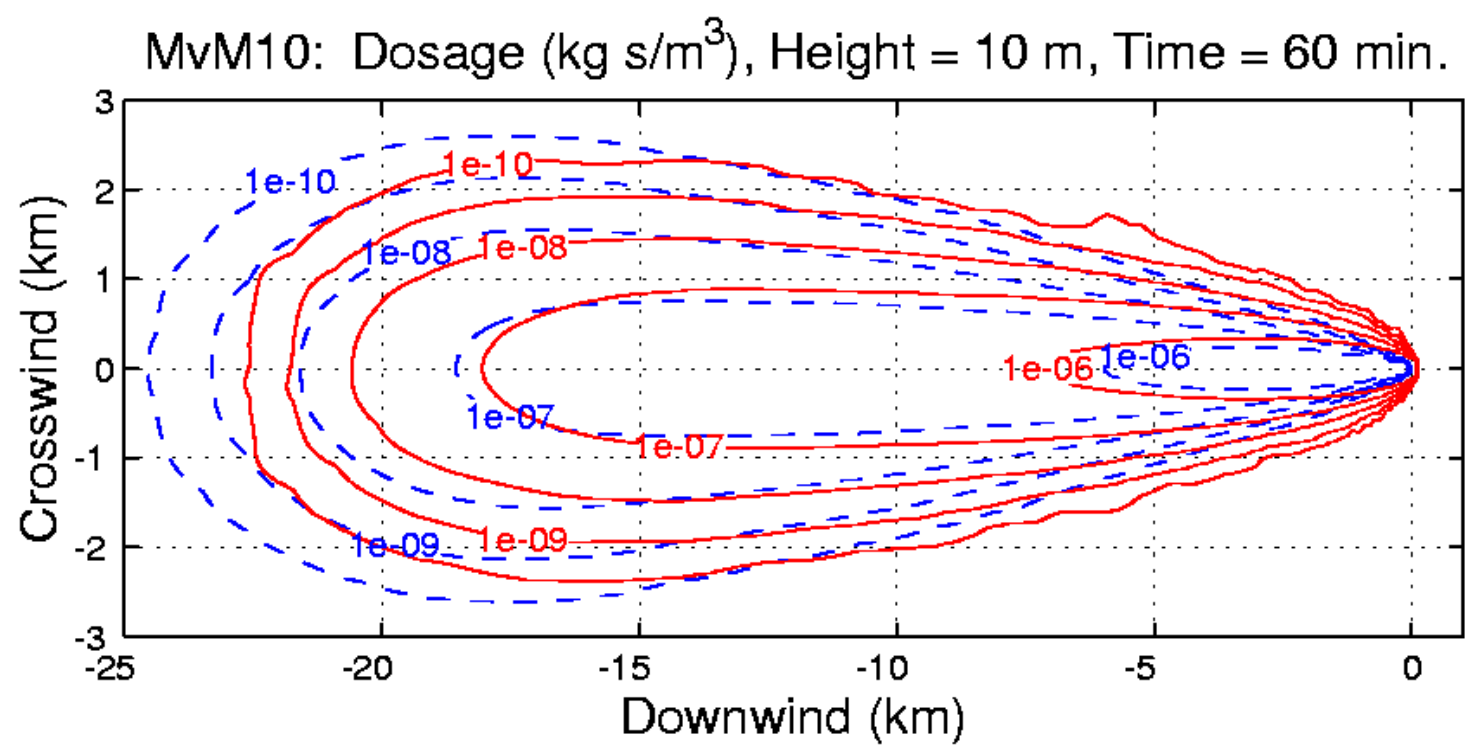

Dosage on Downwind Symmetry Axis

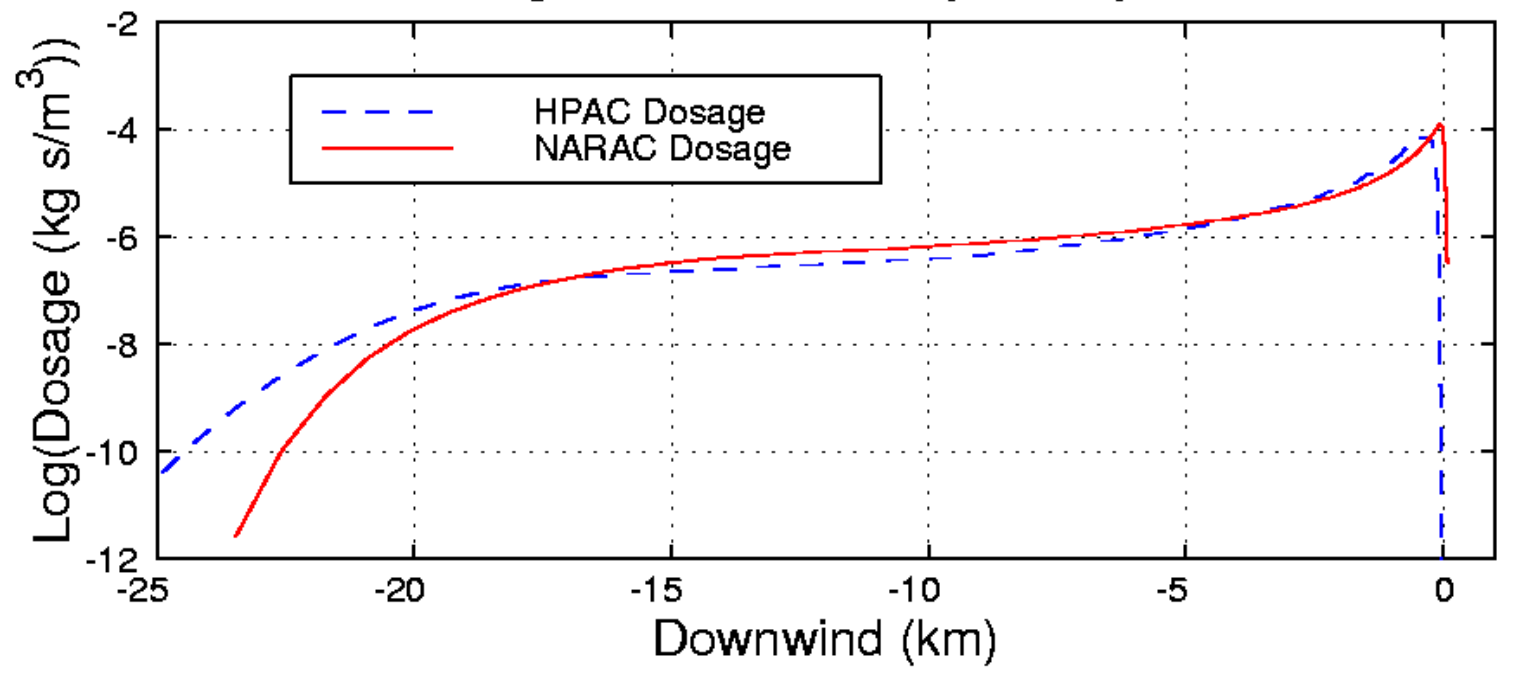

Figure D-4. MvM 10 at 60 Minutes with Upper: Dosage Contours for HPAC (BLUE - -) and NARAC (RED -); Lower: Dosage on Downwind Symmetry Axis 

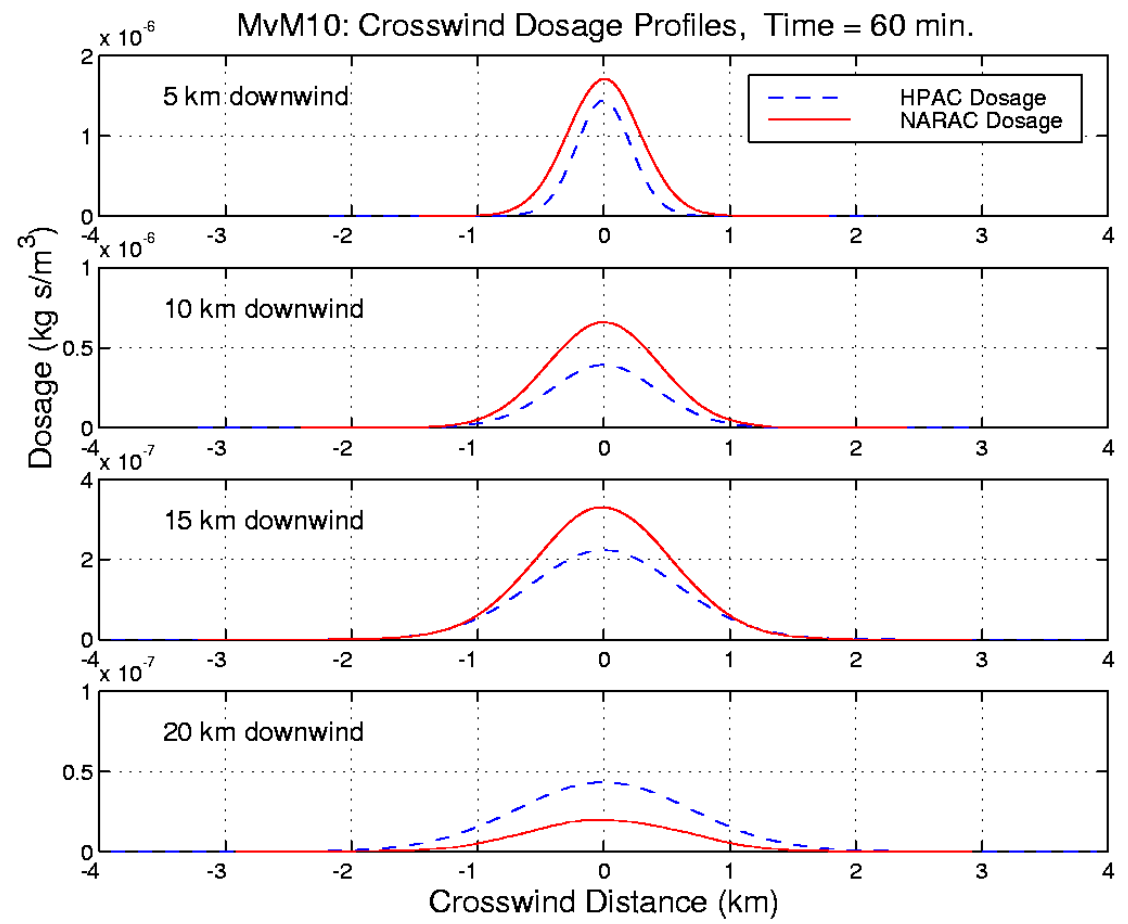

Figure D-5. MvM 10 at 60 Minutes: HPAC (BLUE - -) and NARAC (RED -) Crosswind Dosage Plumes for Various Downwind Distances

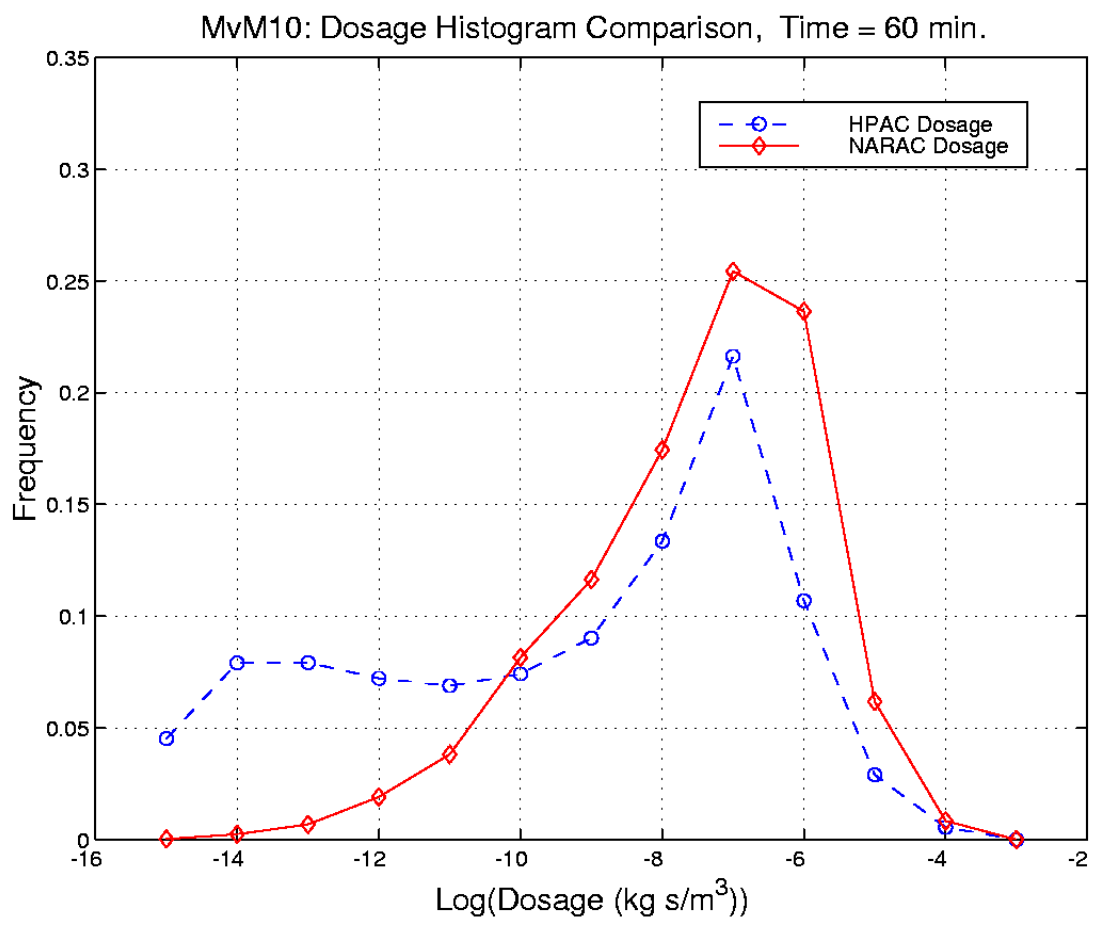

Figure D-6. MvM 10 at 60 Minutes: Dosage Histograms for HPAC (BLUE - -) and NARAC (RED -) 

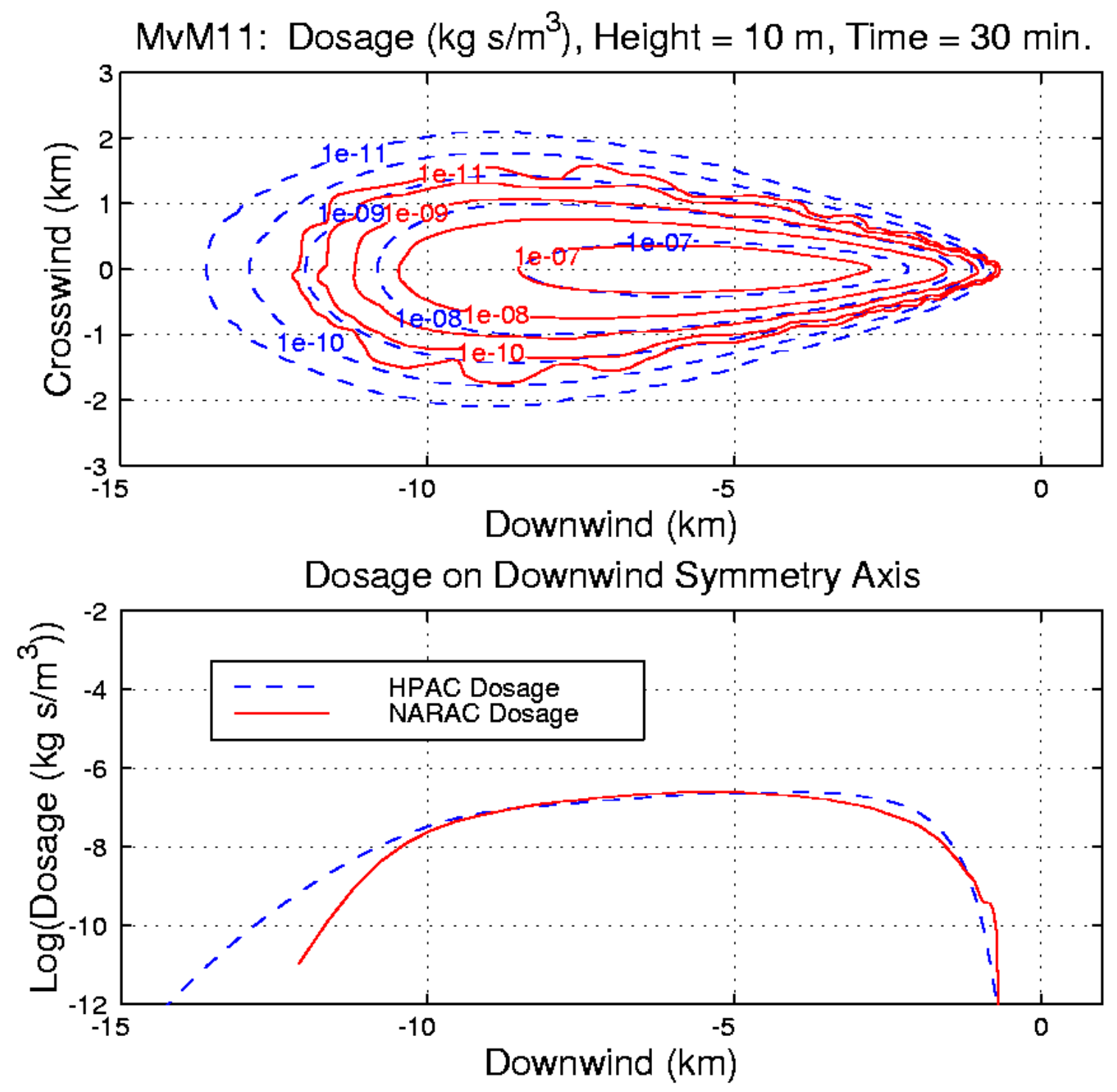

Figure D-7. MvM 11 at 30 Minutes with Upper: Dosage Contours for HPAC (BLUE - -) and NARAC (RED -); Lower: Dosage on Downwind Symmetry Axis 

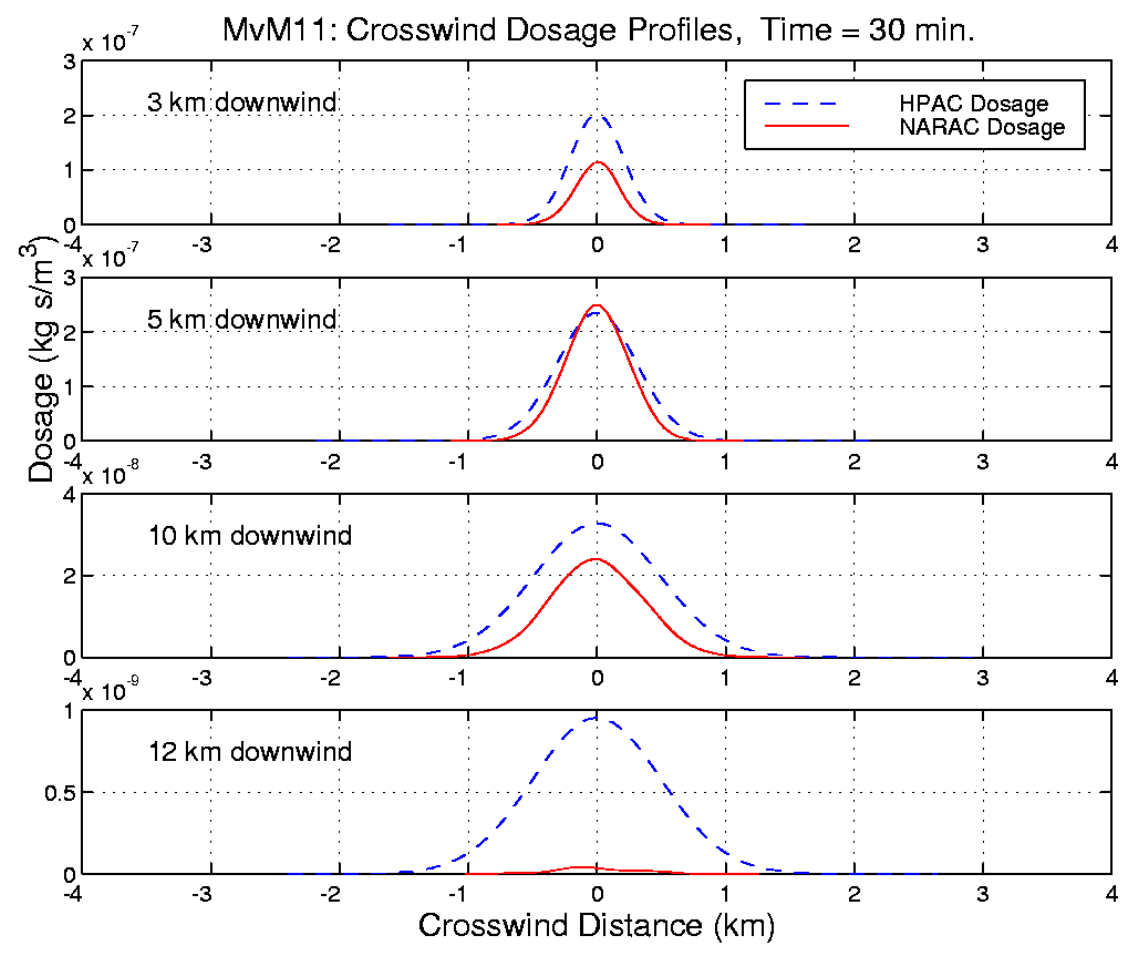

Figure D-8. MvM 11 at 30 Minutes: HPAC (BLUE - -) and NARAC (RED -) Crosswind Dosage Plumes for Various Downwind Distances

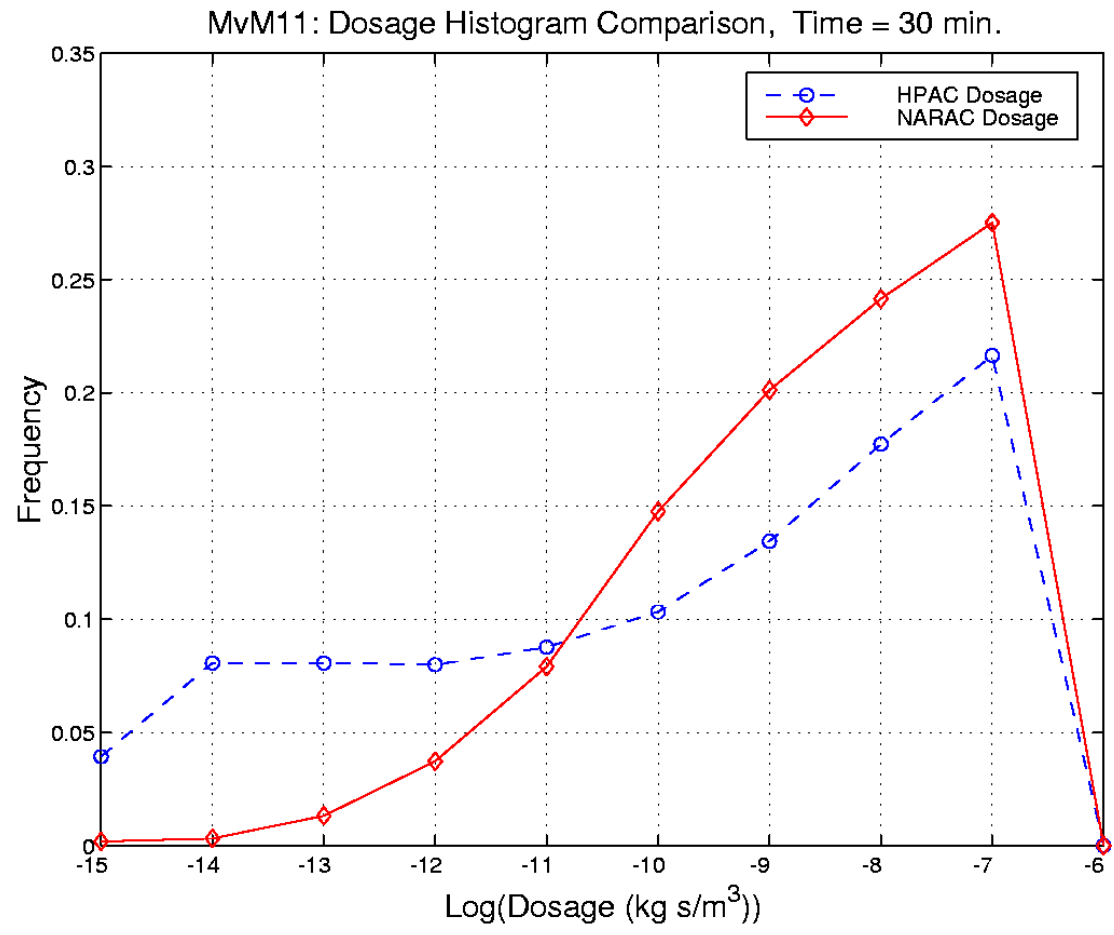

Figure D-9. MvM 11 at 30 Minutes: Dosage Histograms for HPAC (BLUE - -) and NARAC (RED -) 


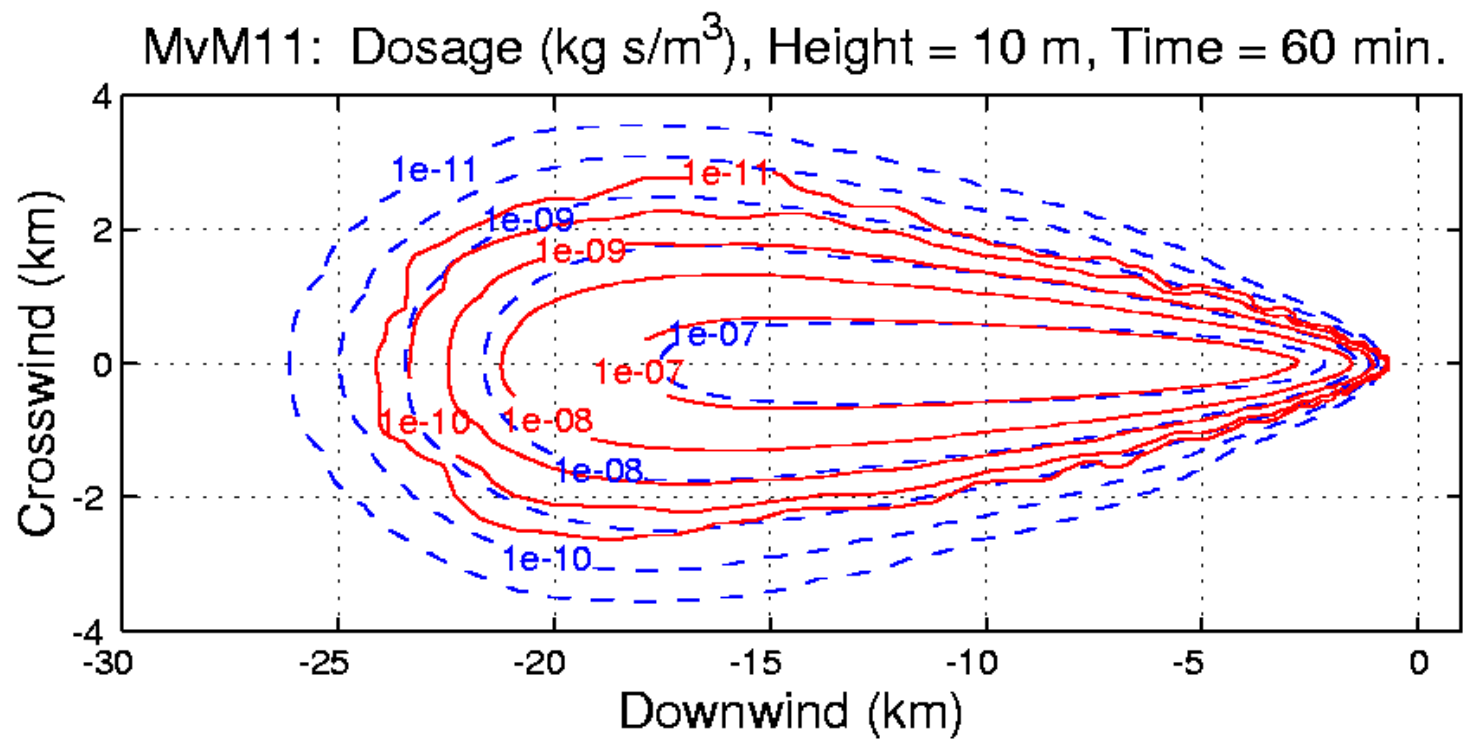

Dosage on Downwind Symmetry Axis

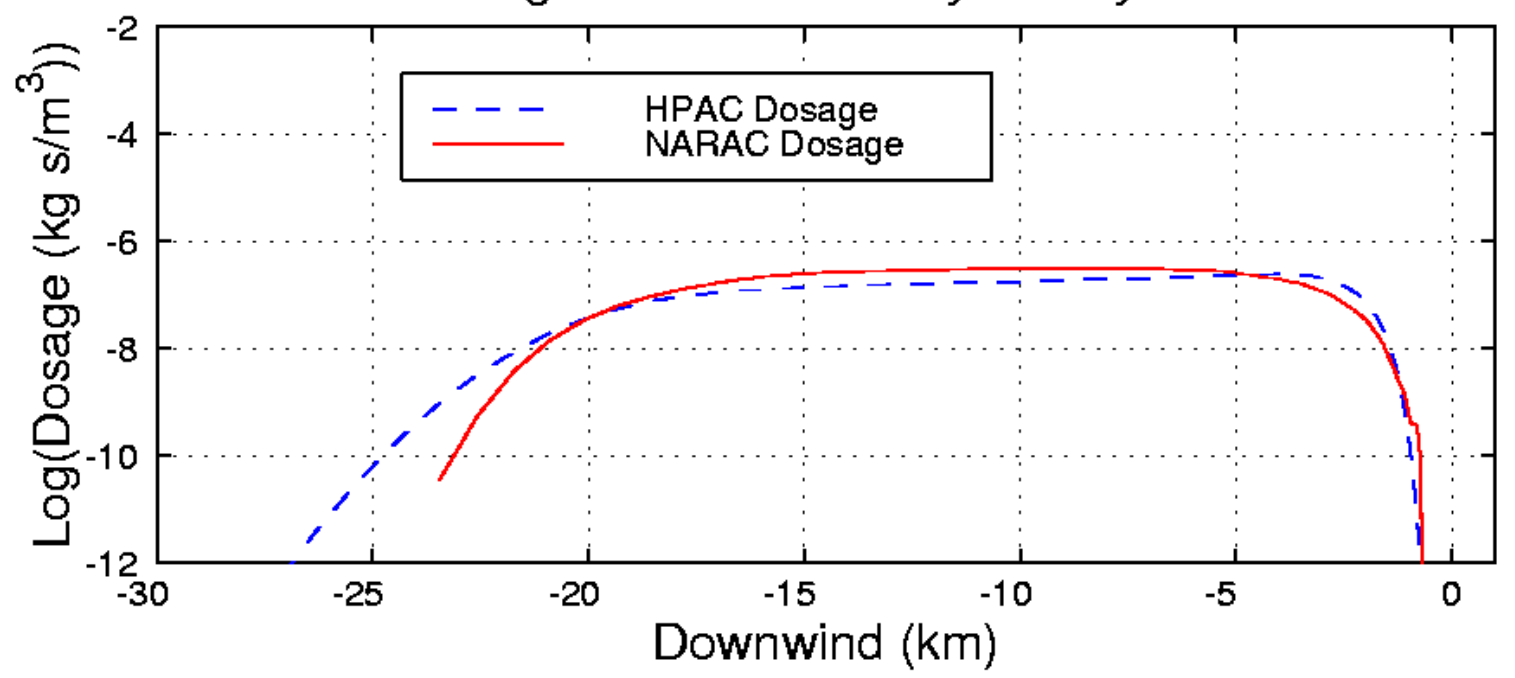

Figure D-10. MvM 11 at 60 Minutes with Upper: Dosage Contours for HPAC (BLUE - -) and NARAC (RED -); Lower: Dosage on Downwind Symmetry Axis 

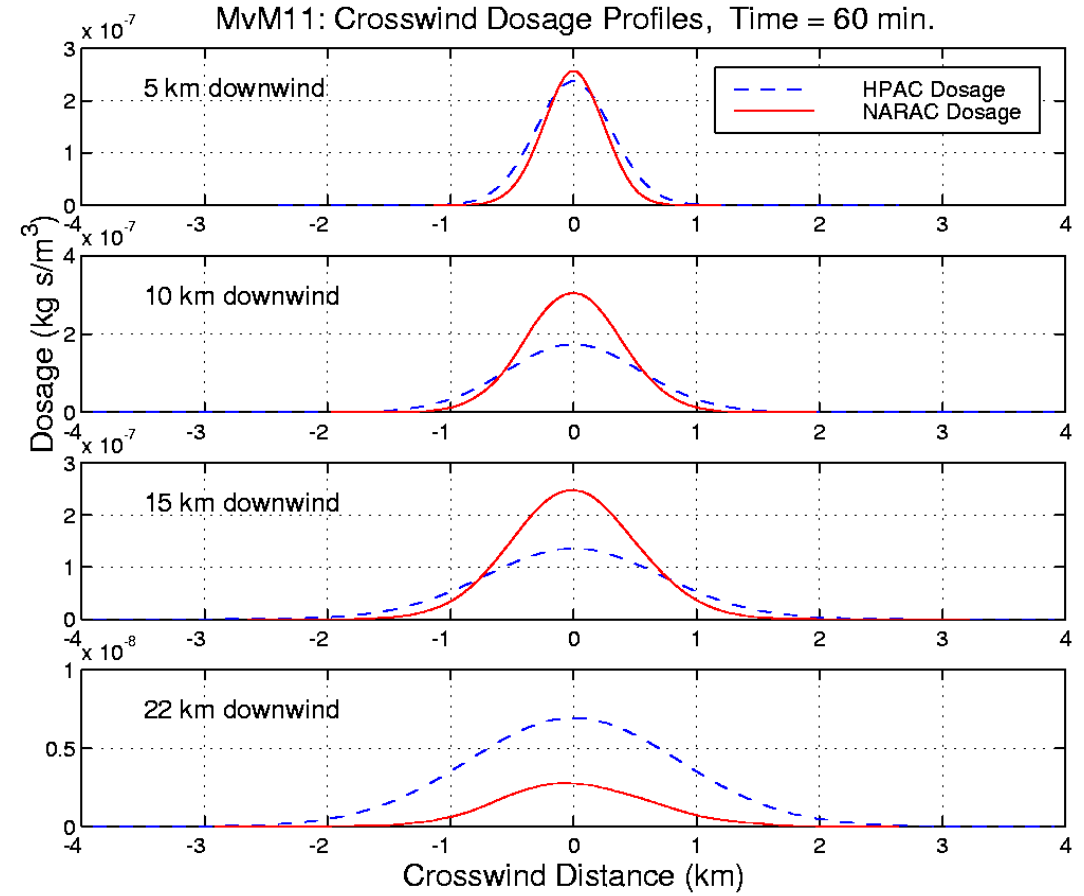

Figure D-11. MvM 11 at 60 Minutes: HPAC (BLUE - -) and NARAC (RED -) Crosswind Dosage Plumes for Various Downwind Distances

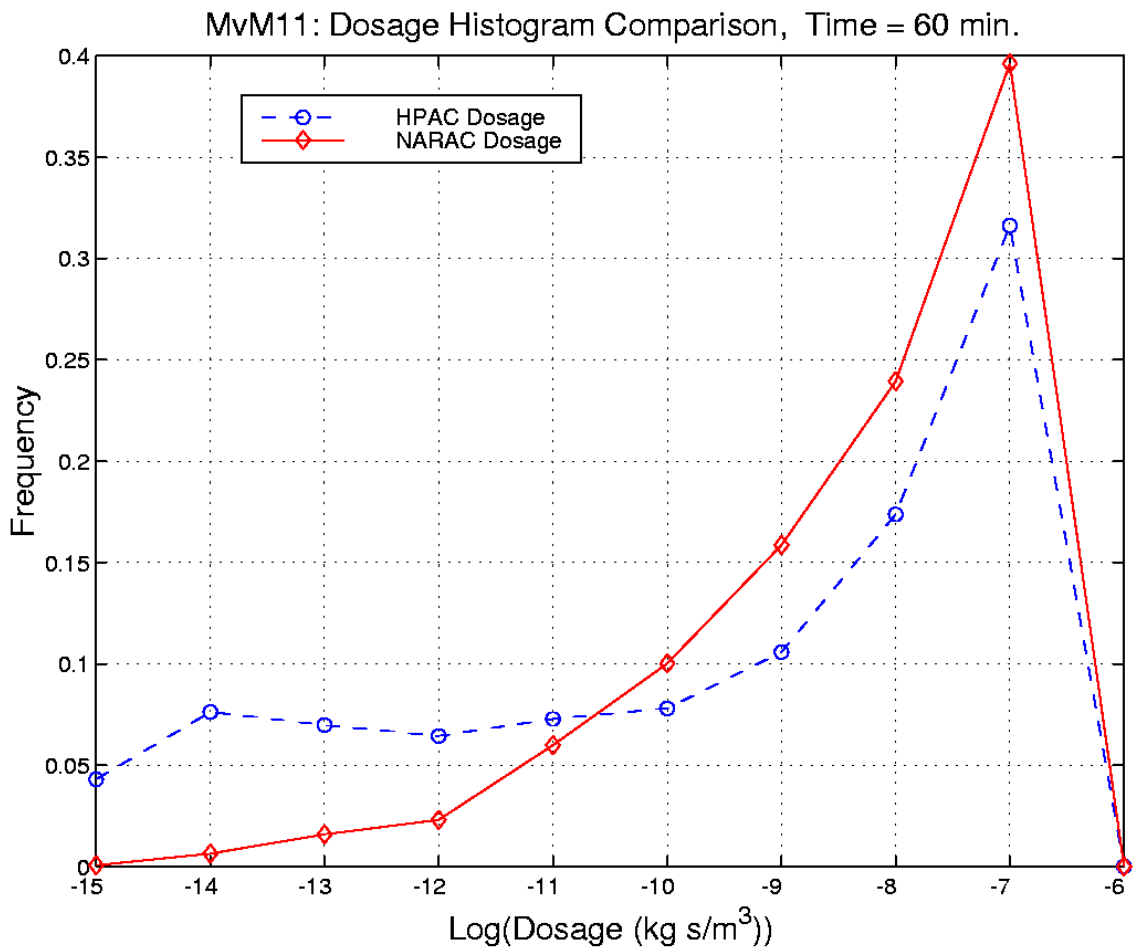

Figure D-12. MvM 11 at 60 Minutes: Dosage Histograms for HPAC (BLUE - -) and NARAC (RED -) 

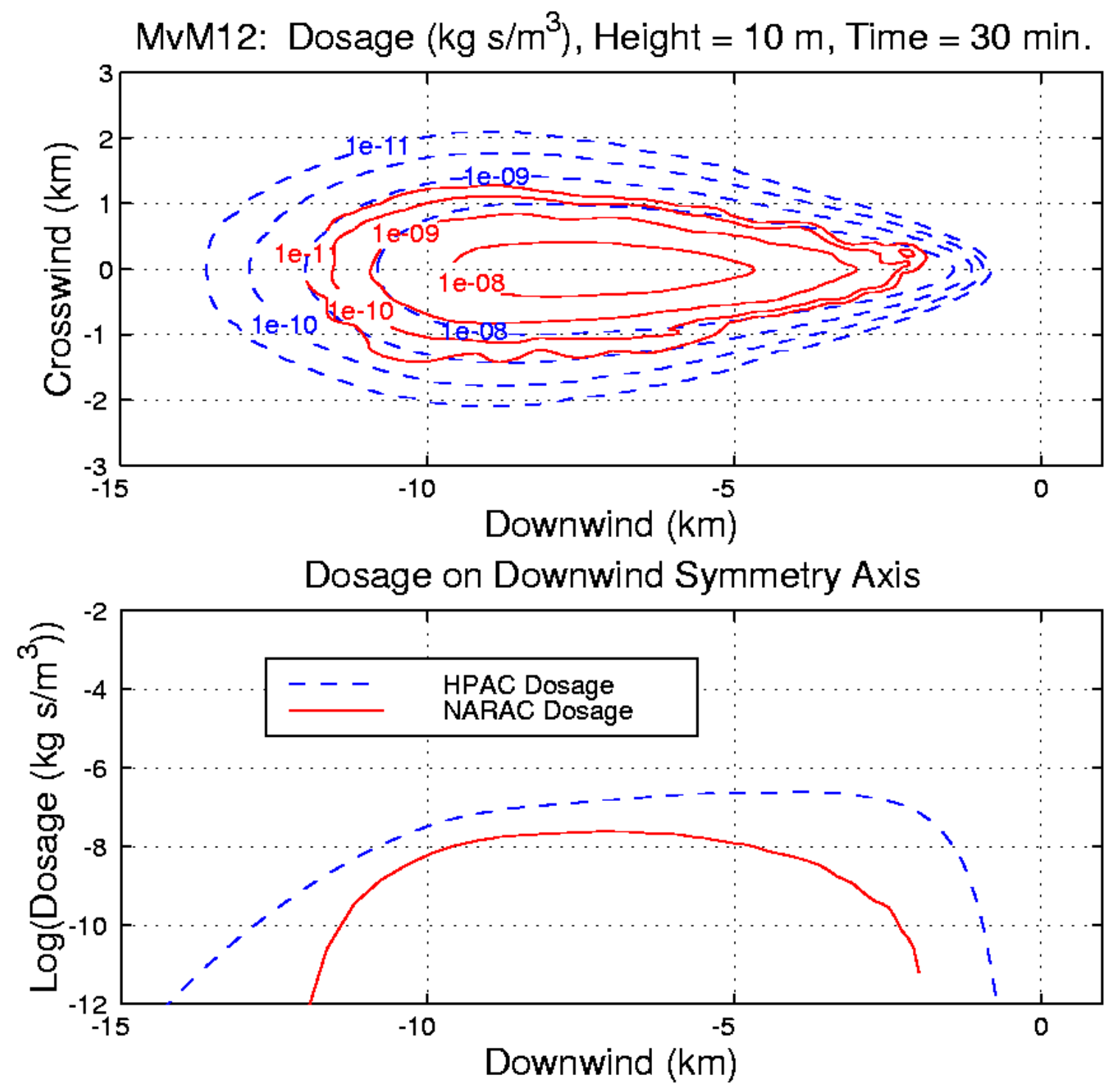

Figure D-13. MvM 12 at 30 Minutes with Upper: Dosage Contours for HPAC (BLUE - -) and NARAC (RED -); Lower: Dosage on Downwind Symmetry Axis 
MvM03: Crosswind Dosage Profiles, Time $=30 \mathrm{~min}$.
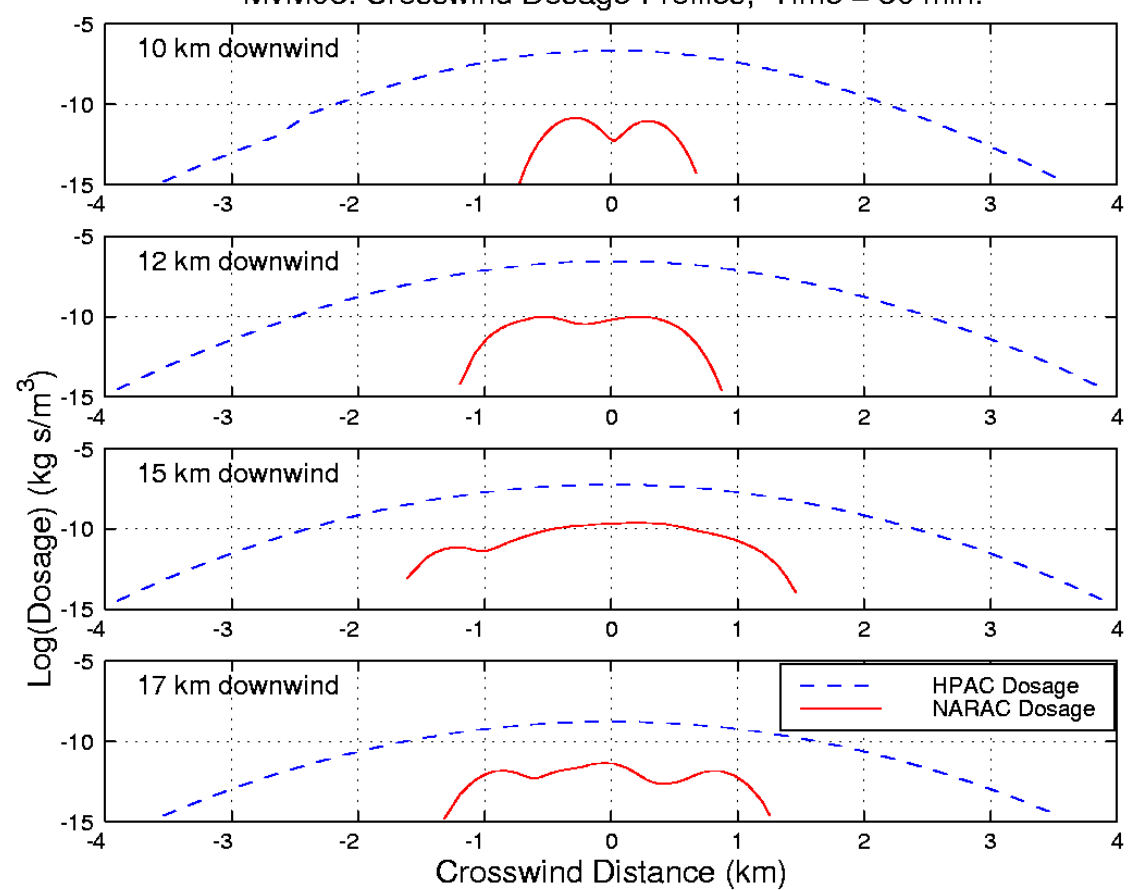

Figure D-14. MvM 12 at 30 Minutes: HPAC (BLUE - -) and NARAC (RED -) Crosswind Dosage Plumes for Various Downwind Distances

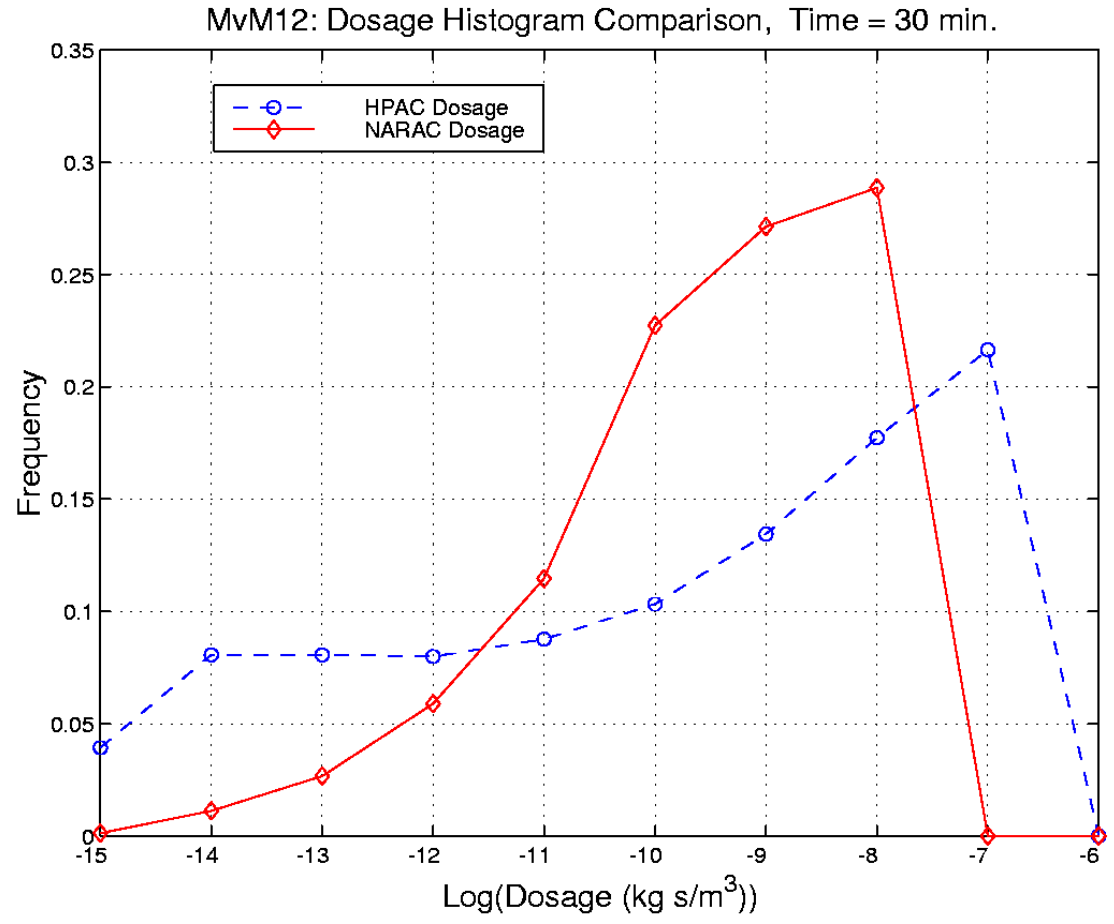

Figure C-15. MvM 3 at 30 Minutes: Dosage Histograms for HPAC (BLUE - -) and NARAC (RED -) 

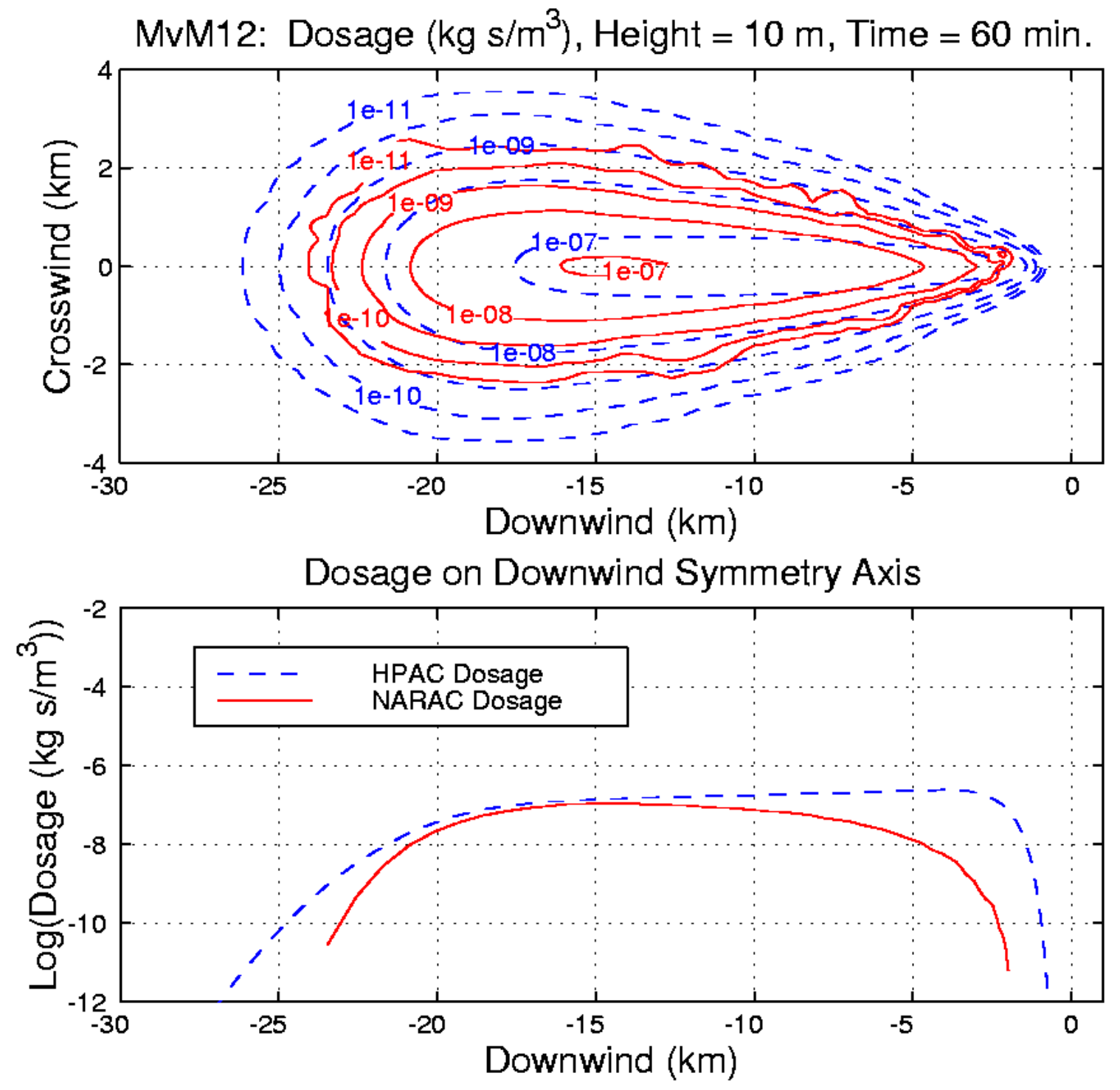

Figure D-16. MvM 12 at 60 Minutes with Upper: Dosage Contours for HPAC (BLUE - -) and NARAC (RED -); Lower: Dosage on Downwind Symmetry Axis 

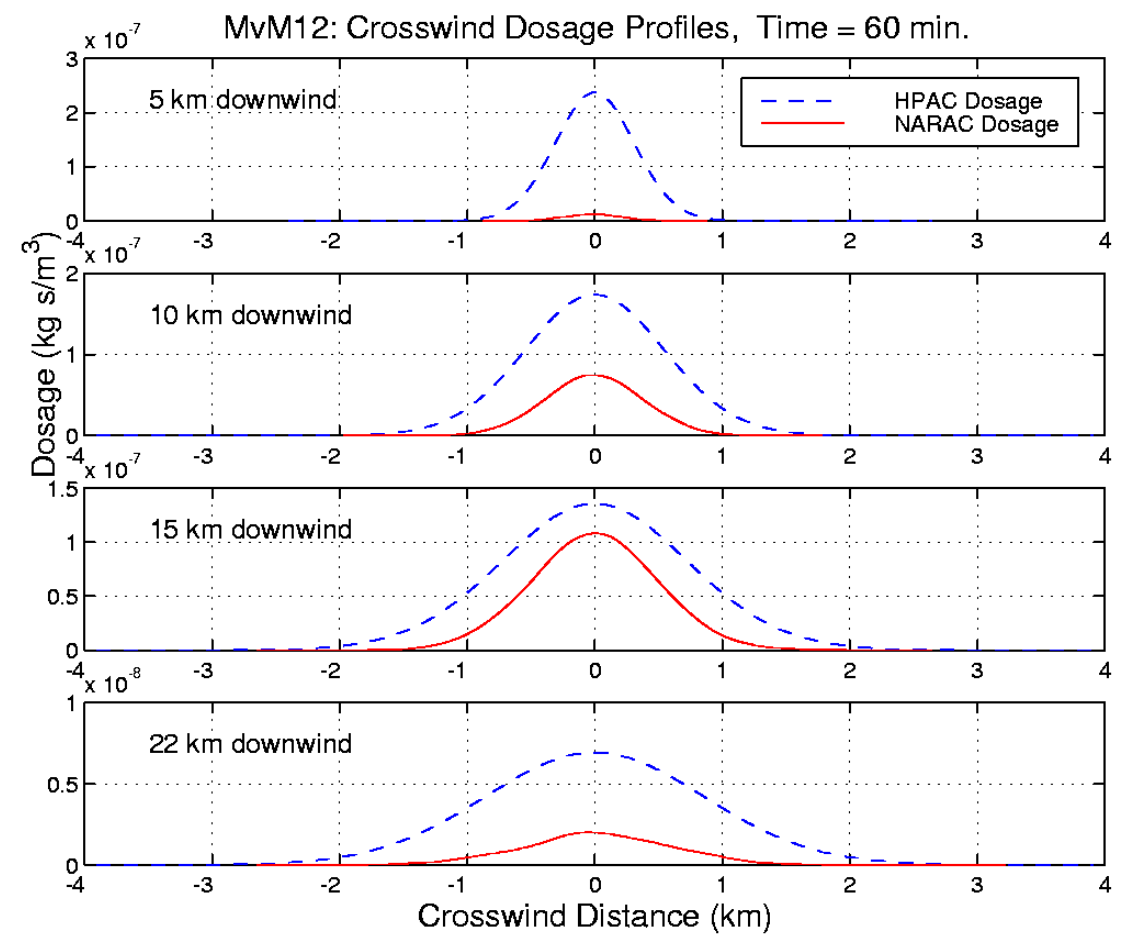

Figure D-17. MvM 12 at 60 Minutes: HPAC (BLUE - -) and NARAC (RED -) Crosswind Dosage Plumes for Various Downwind Distances

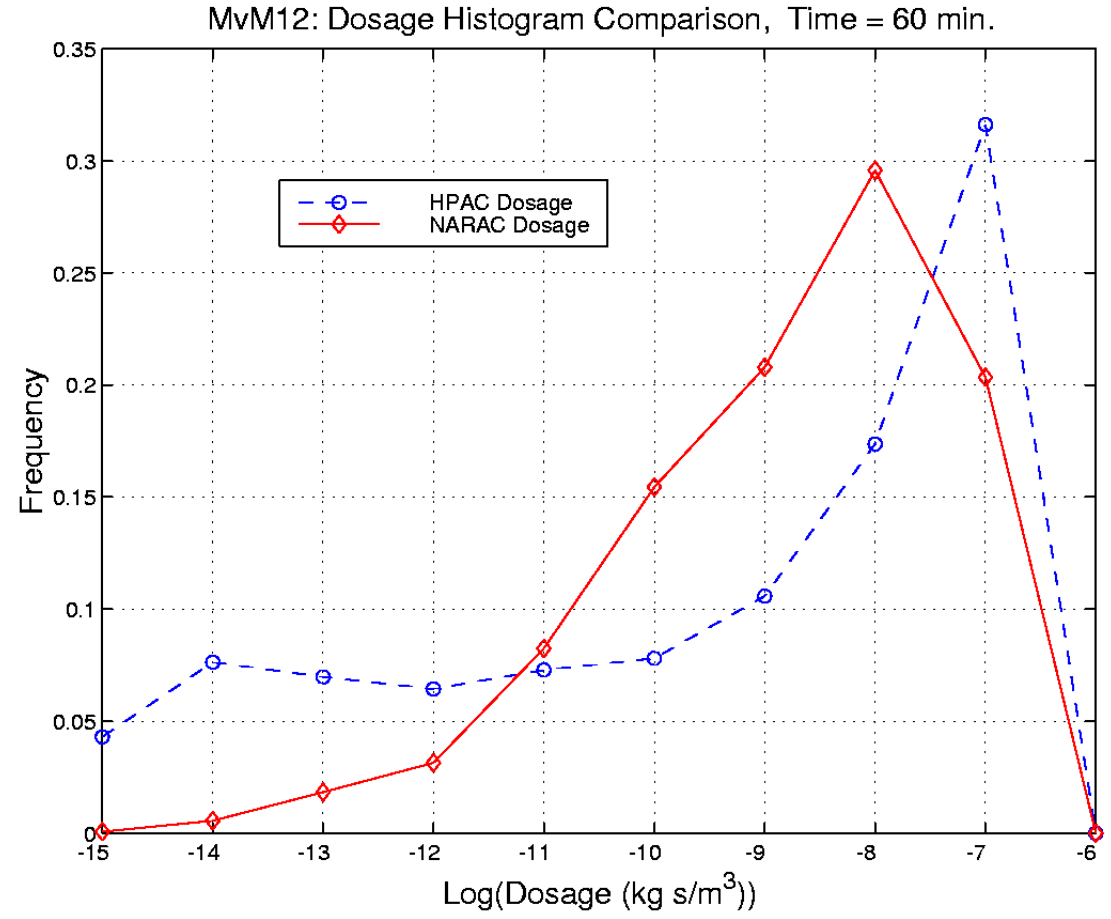

Figure D-18. MvM 12 at 60 Minutes: Dosage Histograms for HPAC (BLUE - -) and NARAC (RED -) 

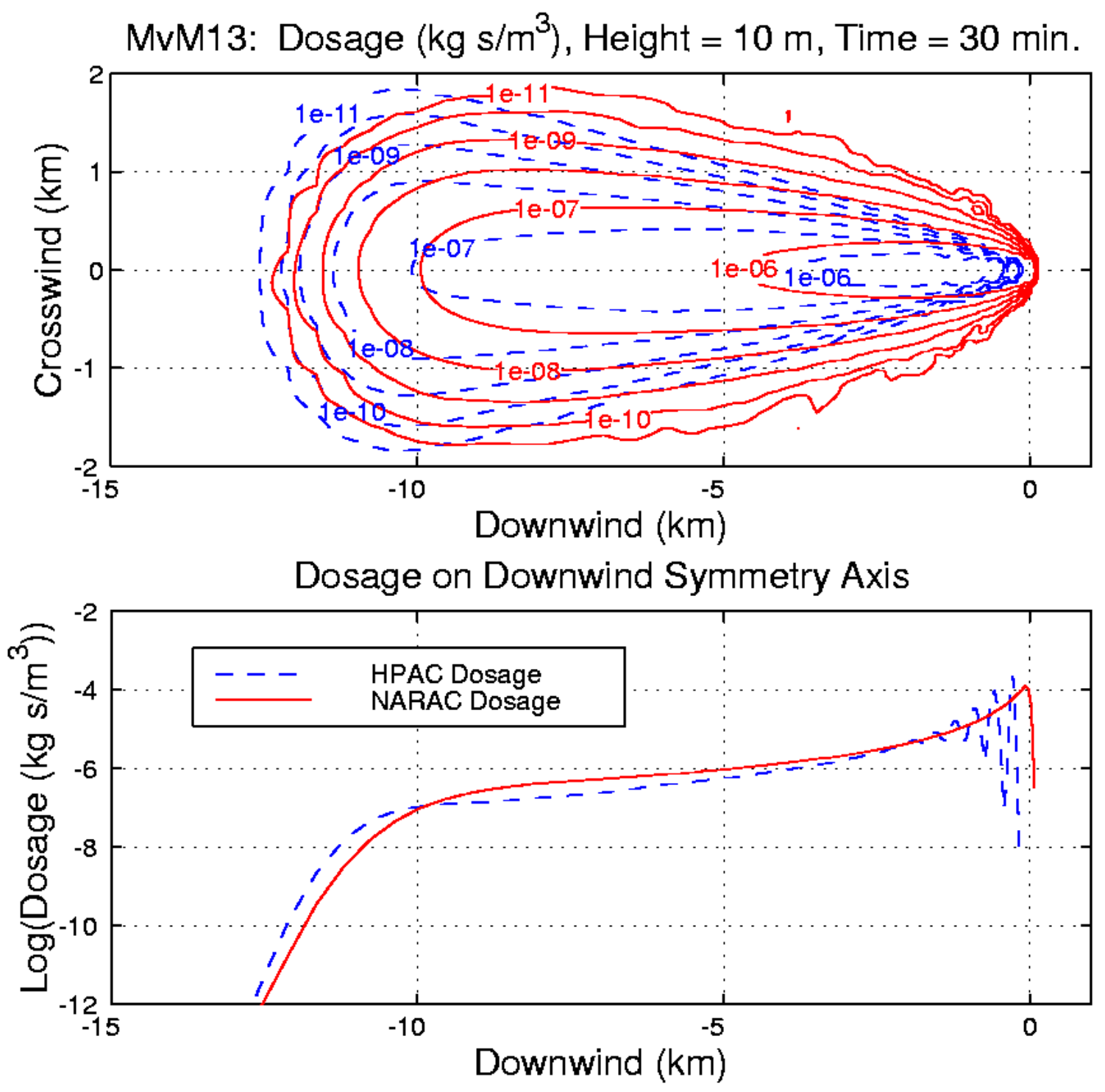

Figure D-19. MvM 13 at 30 Minutes with Upper: Dosage Contours for HPAC (BLUE - -) and NARAC (RED -); Lower: Dosage on Downwind Symmetry Axis 

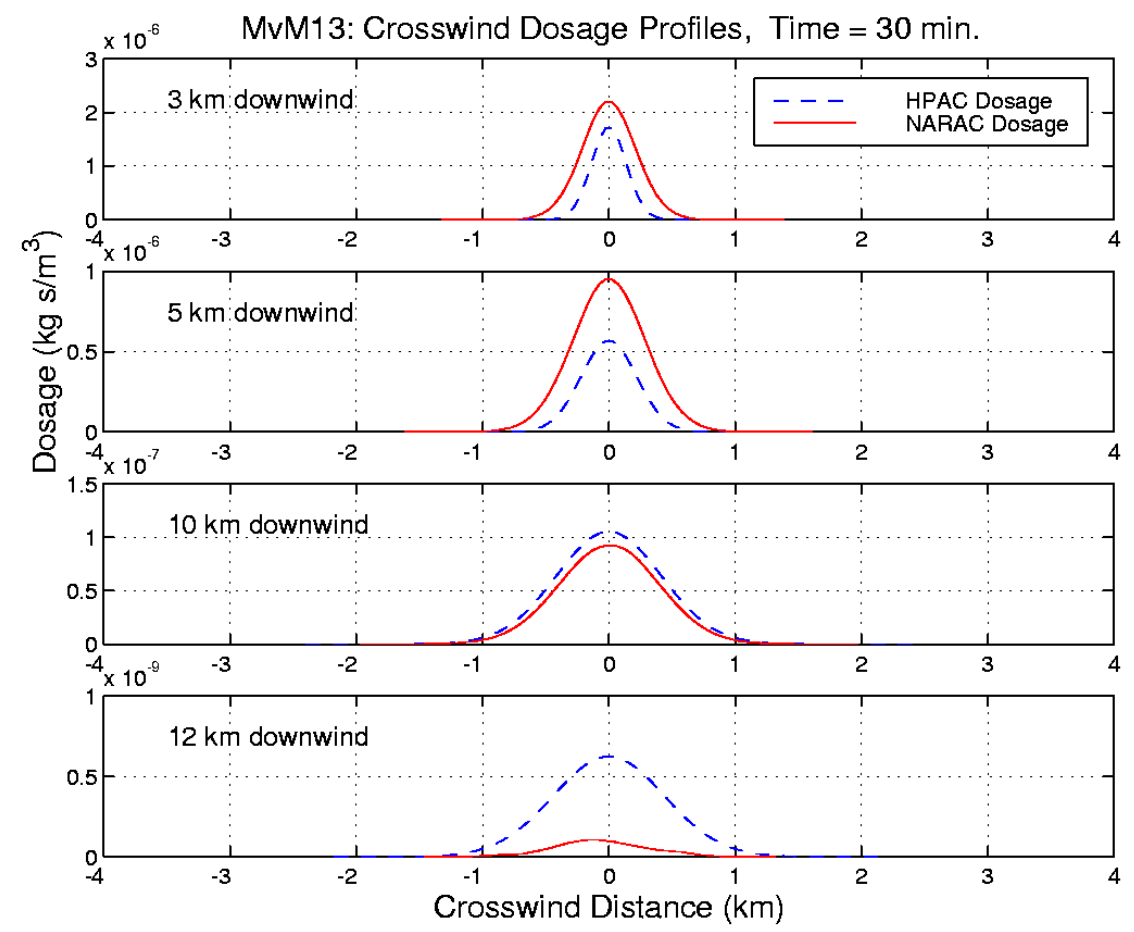

Figure D-20. MvM 13 at 30 Minutes: HPAC (BLUE - -) and NARAC (RED -) Crosswind Dosage Plumes for Various Downwind Distances

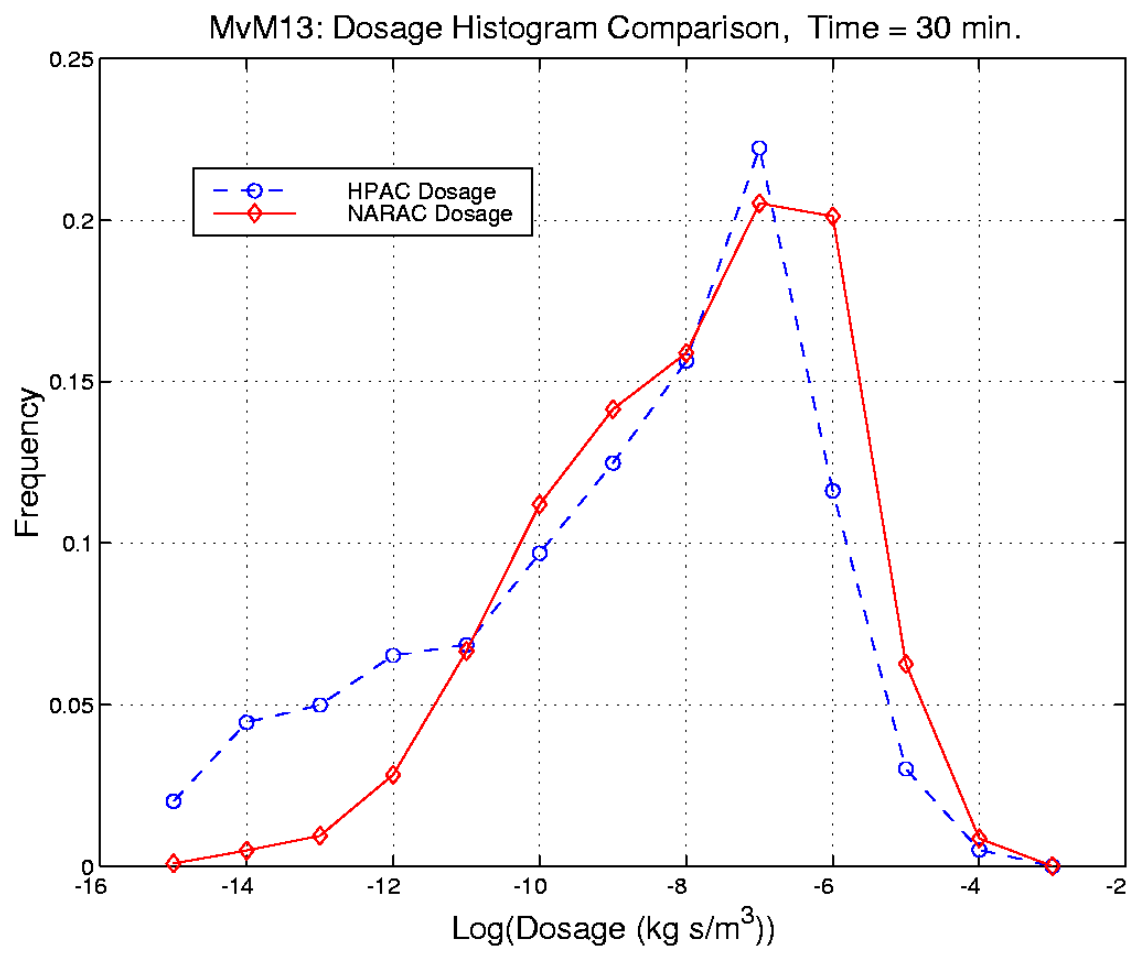

Figure D-21. MvM 13 at 30 Minutes: Dosage Histograms for HPAC (BLUE - -) and NARAC (RED -) 


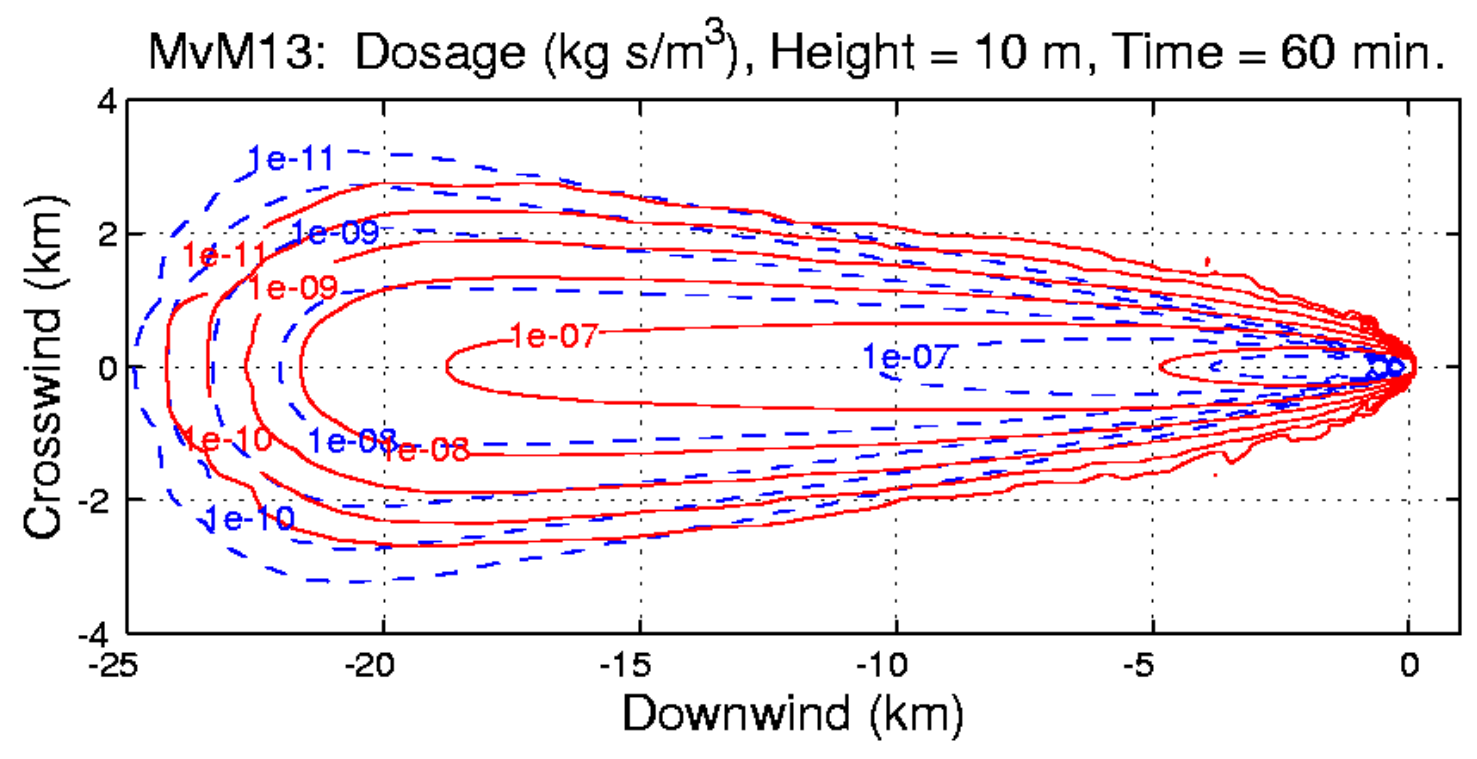

Dosage on Downwind Symmetry Axis

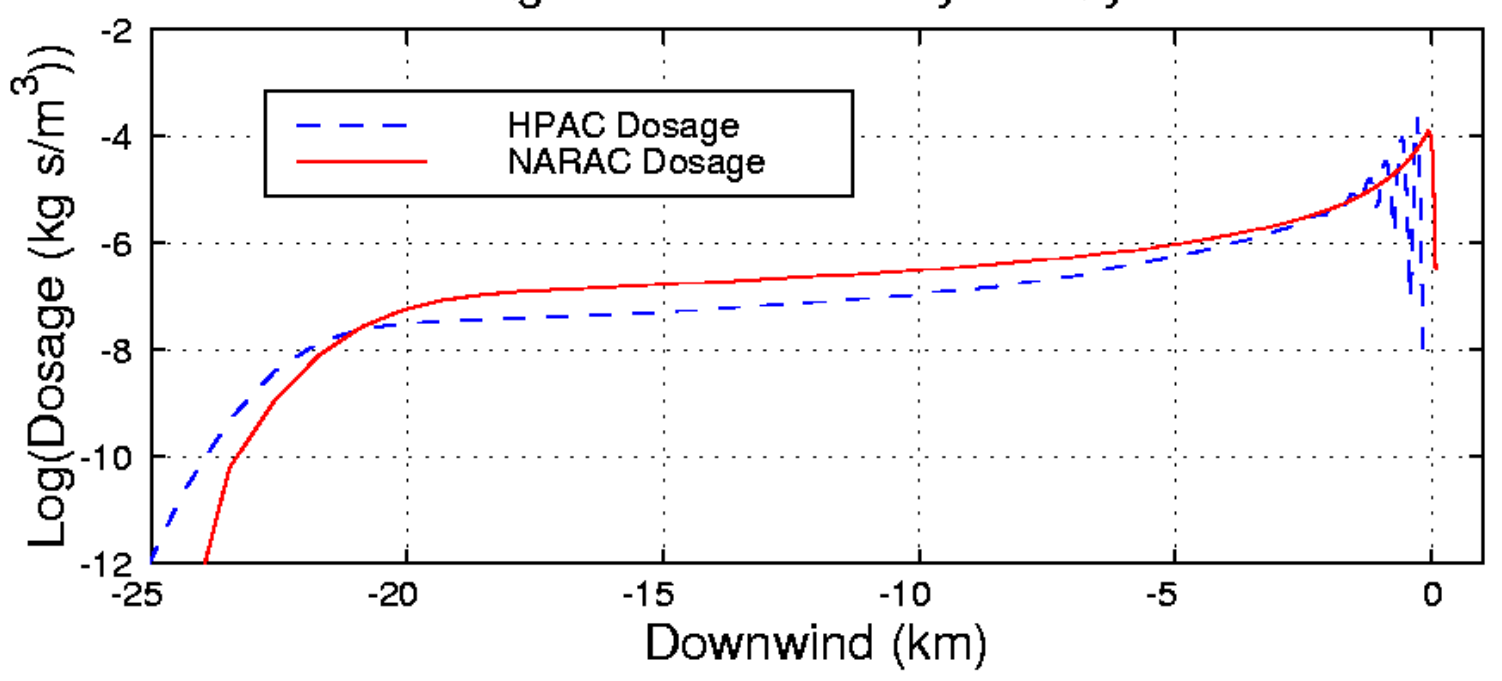

Figure D-22. MvM 13 at 60 Minutes with Upper: Dosage Contours for HPAC (BLUE - -) and NARAC (RED -); Lower: Dosage on Downwind Symmetry Axis 


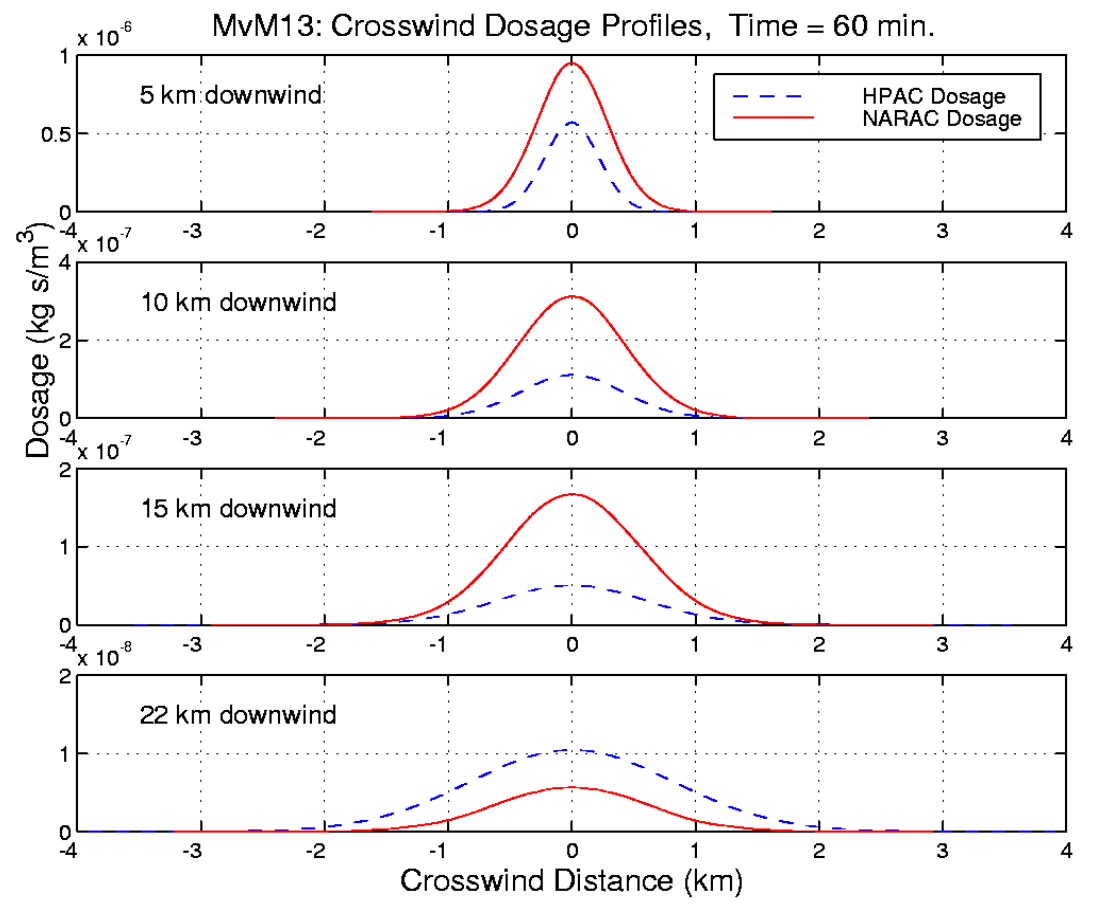

Figure D-23. MvM 13 at 60 Minutes: HPAC (BLUE - -) and NARAC (RED -) Crosswind Dosage Plumes for Various Downwind Distances

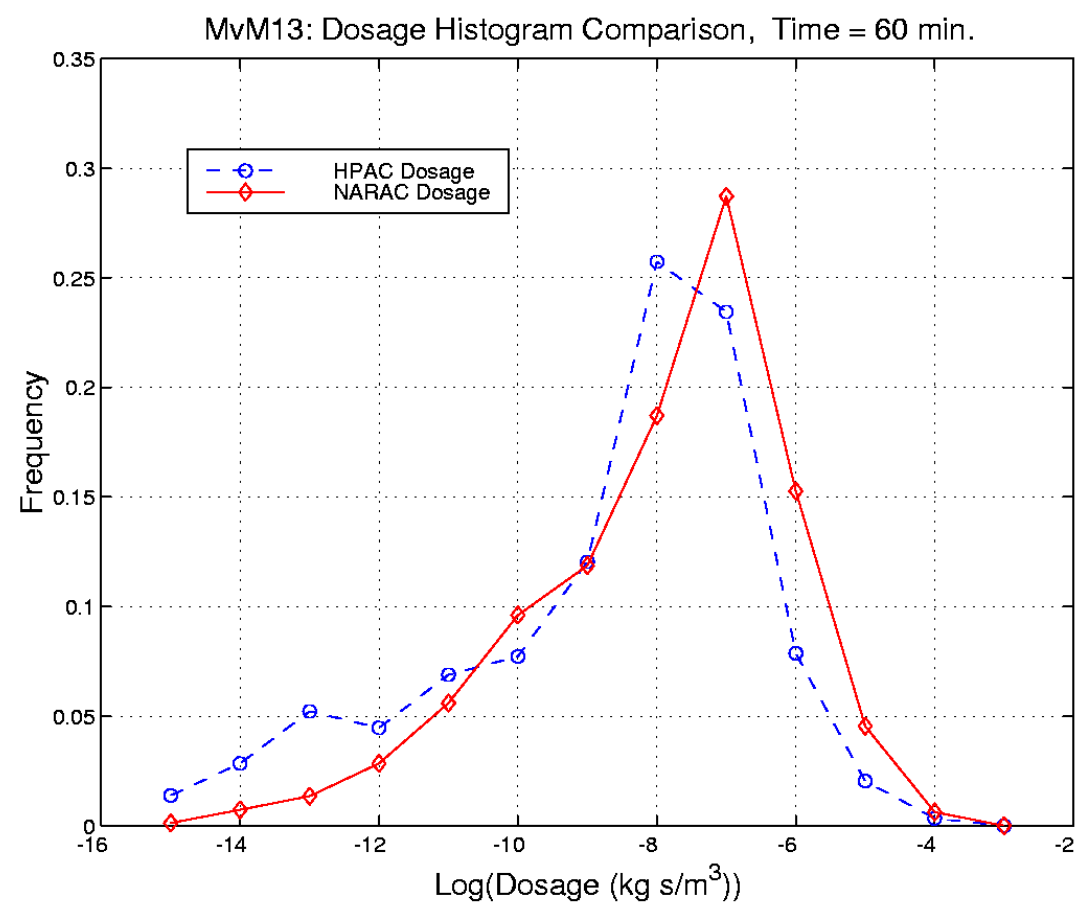


Figure D-24. MvM 13 at 60 Minutes: Dosage Histograms for HPAC (BLUE - -) and NARAC (RED -)
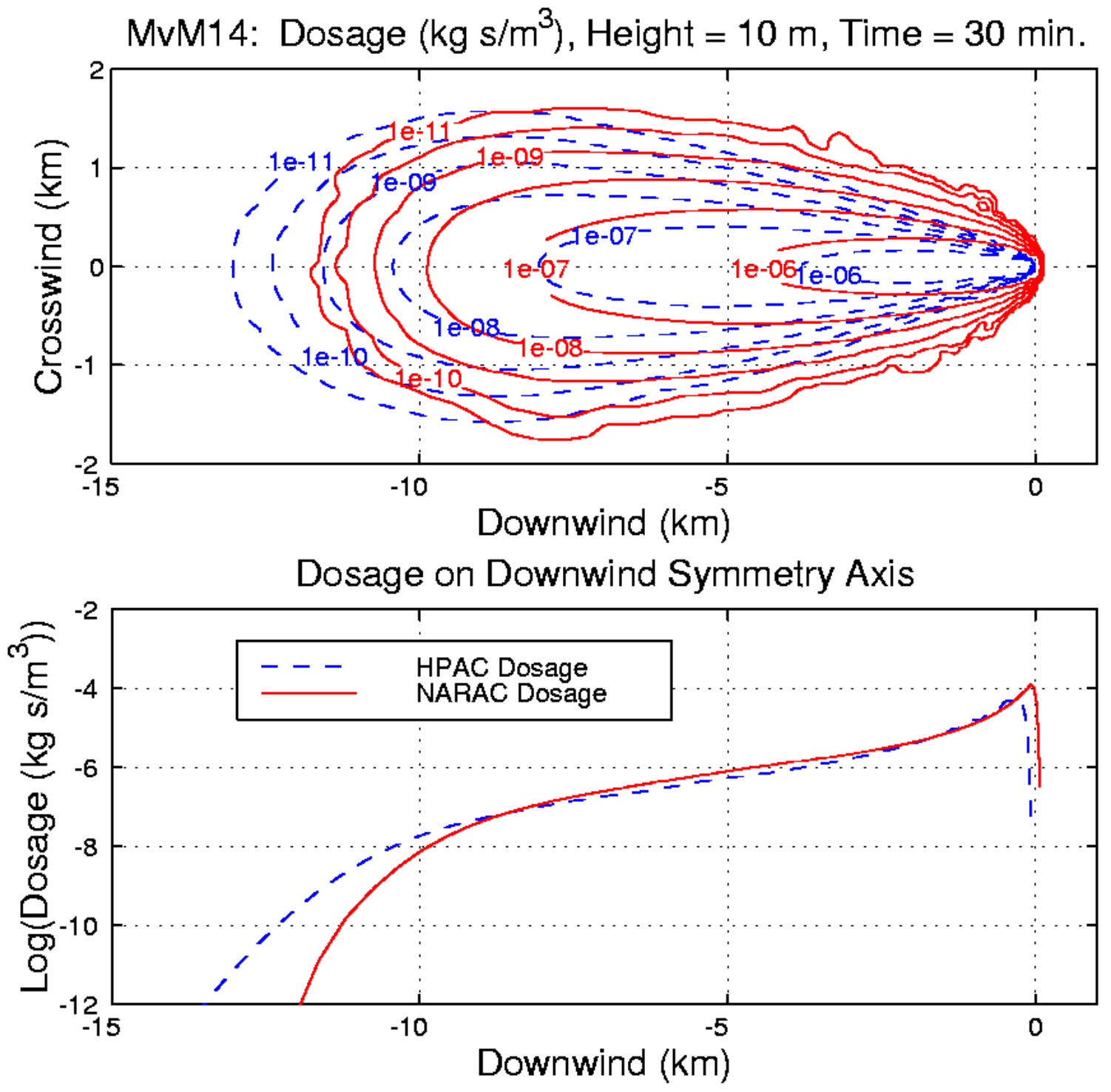

Figure D-25. MvM 14 at 30 Minutes with Upper: Dosage Contours for HPAC (BLUE - -) and NARAC (RED -); Lower: Dosage on Downwind Symmetry Axis 

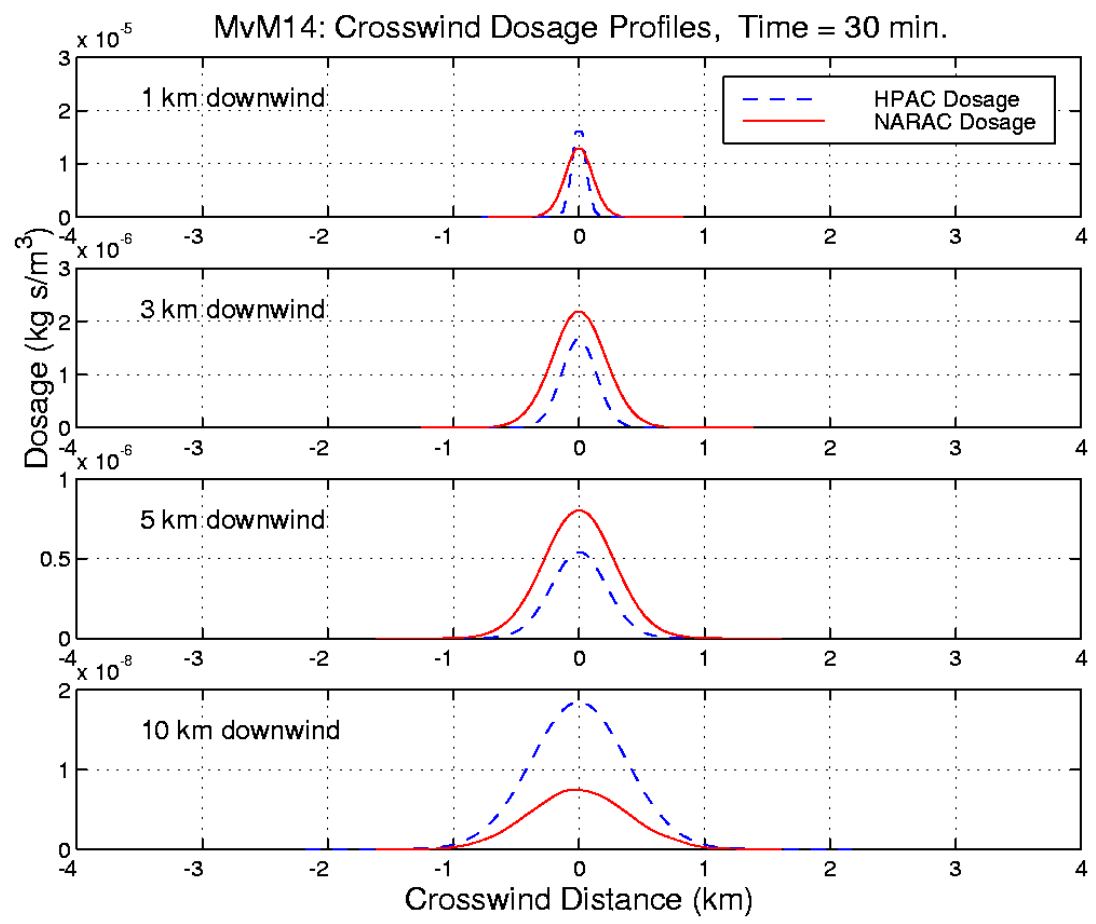

Figure D-26. MvM 14 at 30 Minutes: HPAC (BLUE - -) and NARAC (RED -) Crosswind Dosage Plumes for Various Downwind Distances

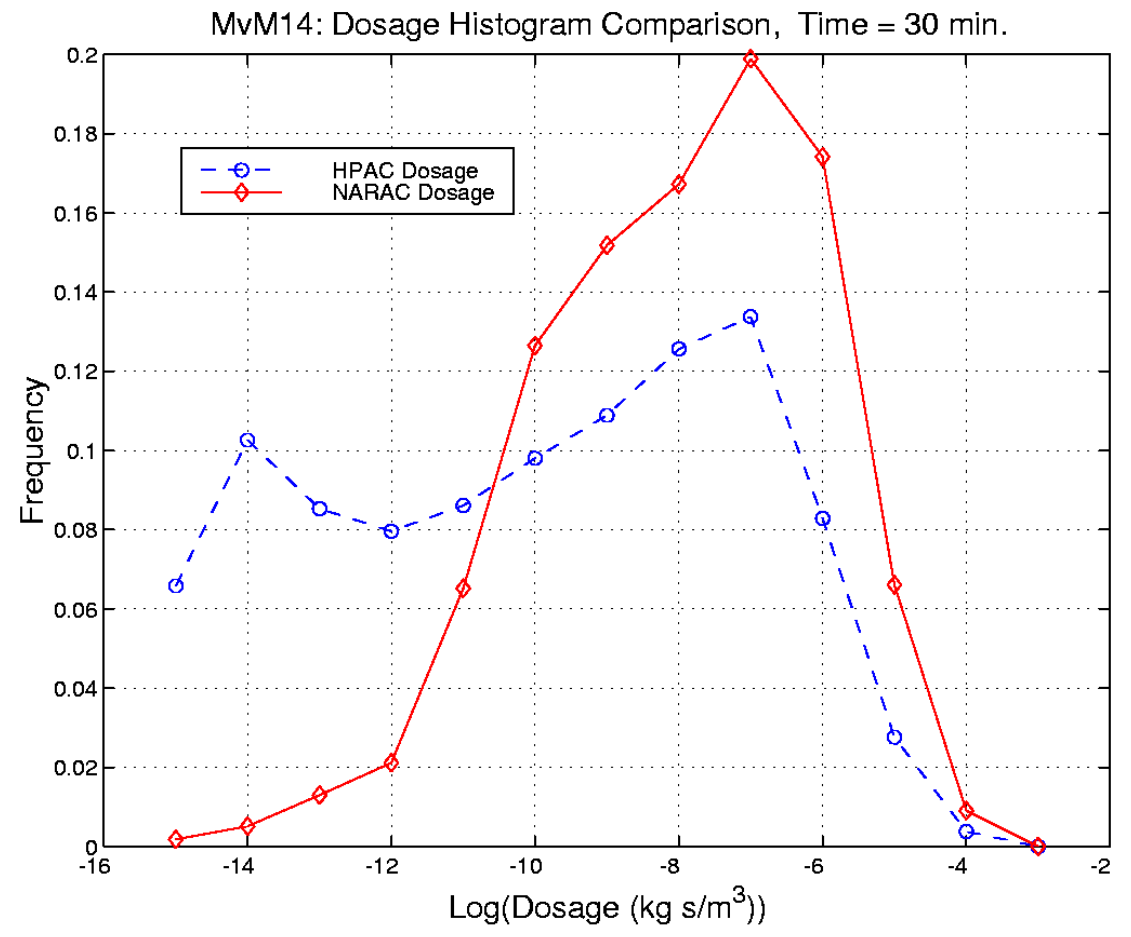

Figure D-27. MvM 14 at 30 Minutes: Dosage Histograms for HPAC (BLUE - -) and NARAC (RED -) 


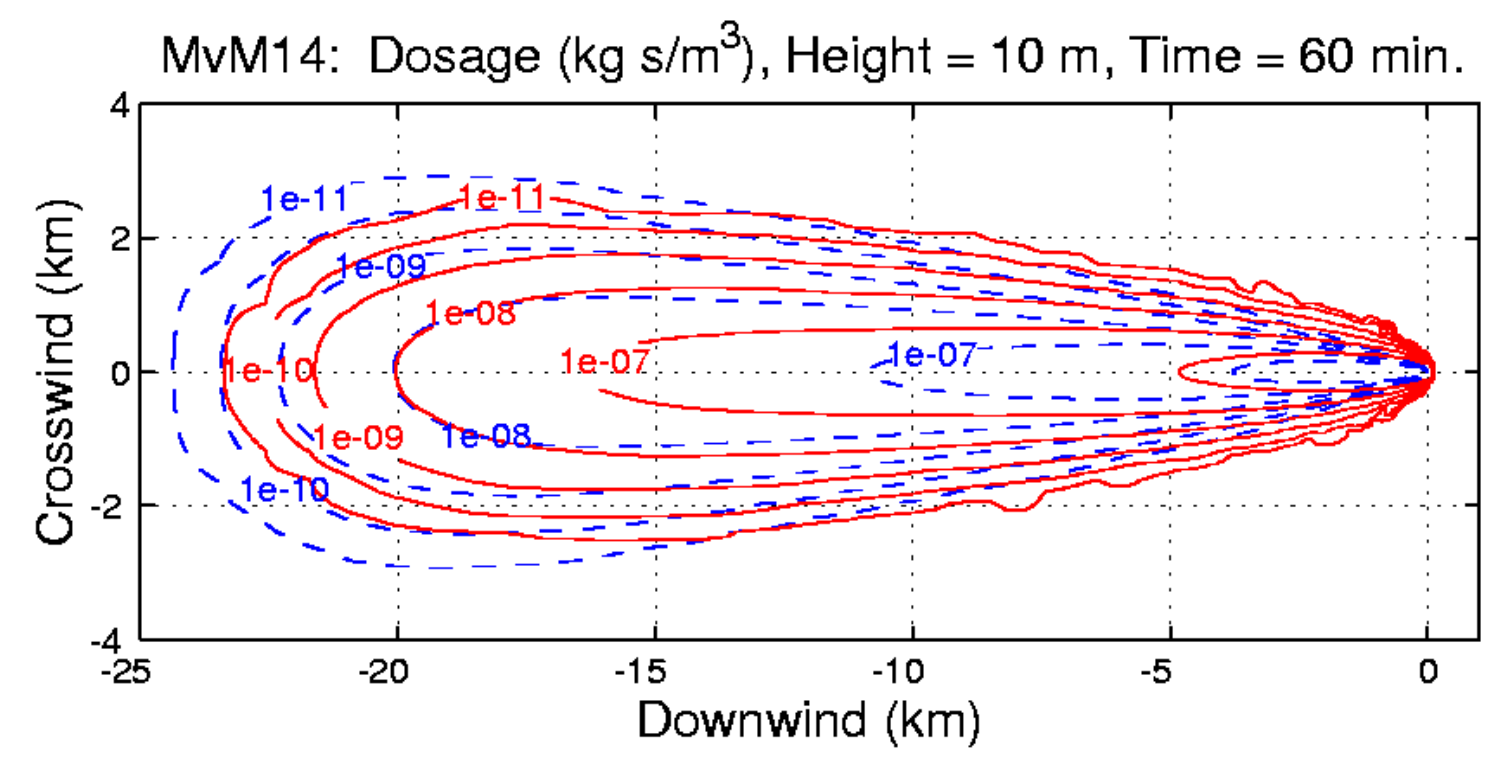

Dosage on Downwind Symmetry Axis

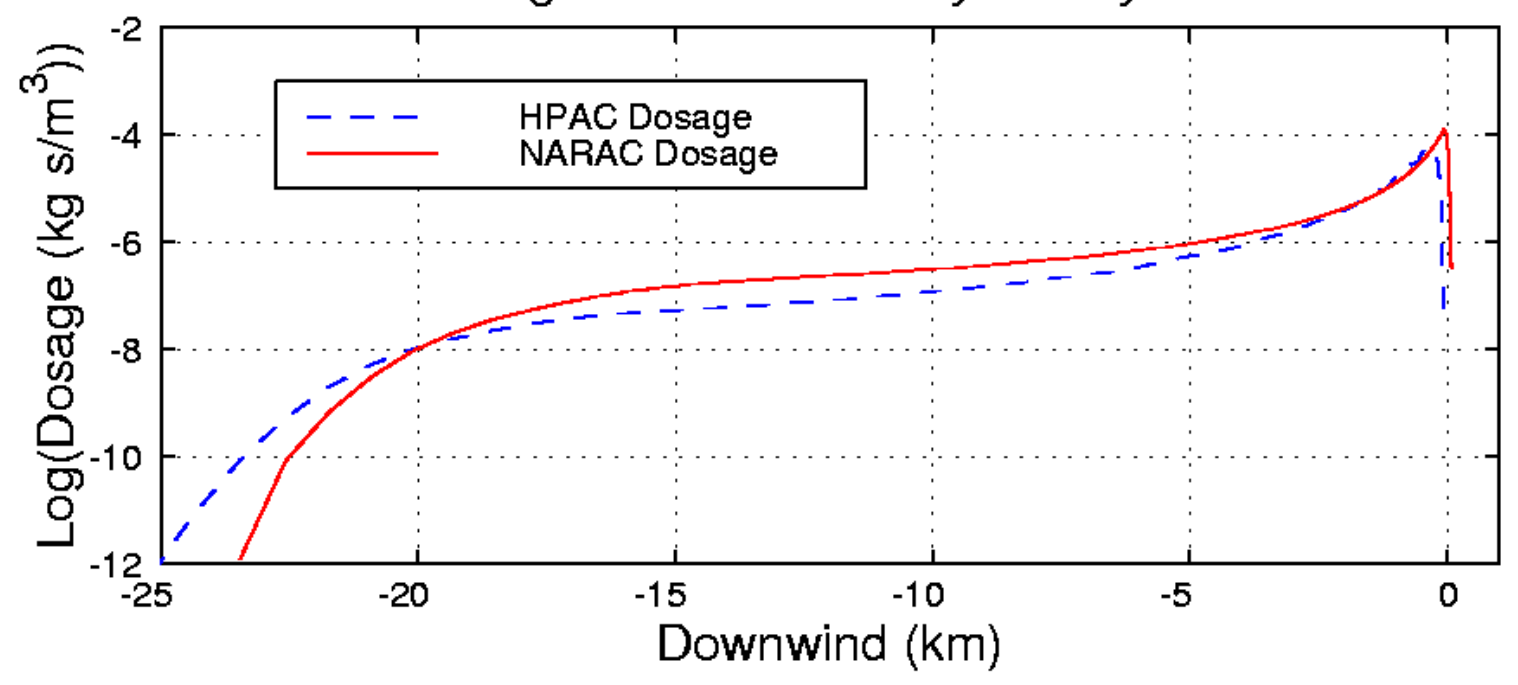

Figure D-28. MvM 14 at 60 Minutes with Upper: Dosage Contours for HPAC (BLUE - -) and NARAC (RED -); Lower: Dosage on Downwind Symmetry Axis 

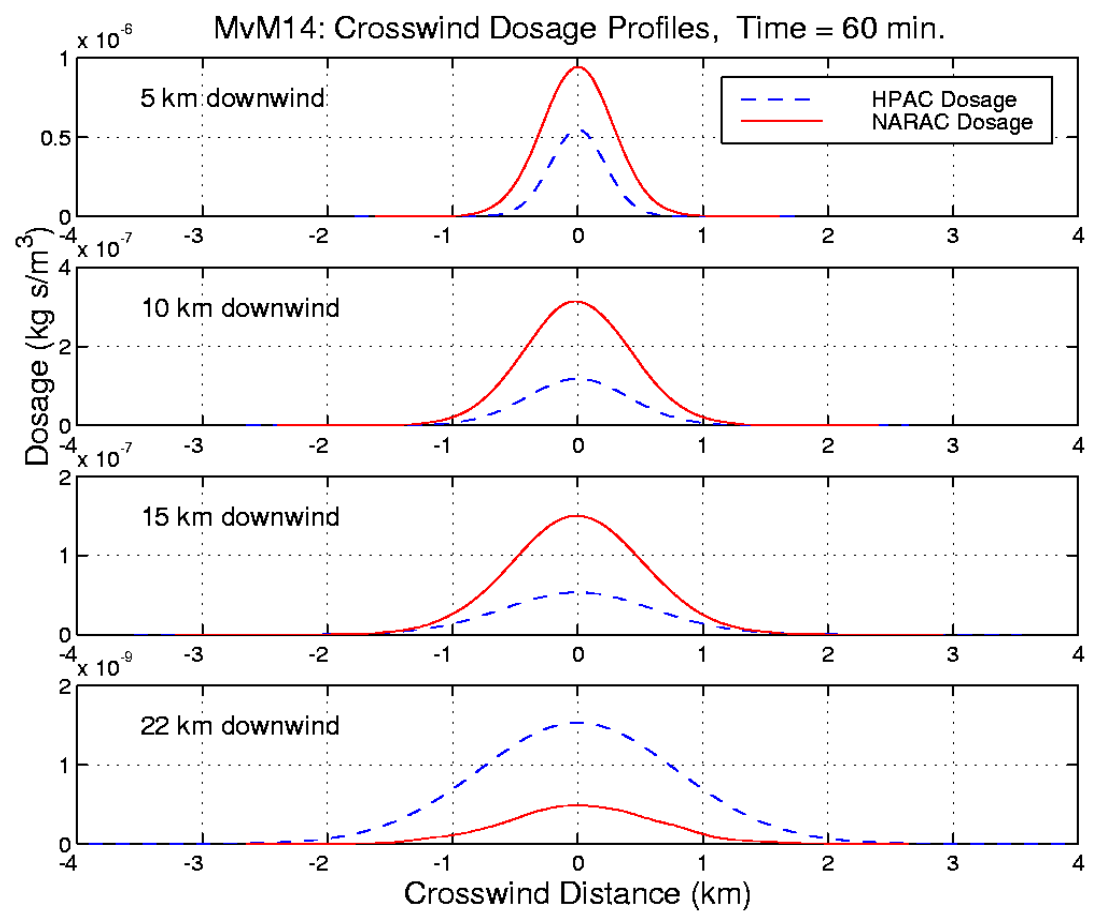

Figure D-29. MvM 14 at 60 Minutes: HPAC (BLUE - -) and NARAC (RED -) Crosswind Dosage Plumes for Various Downwind Distances

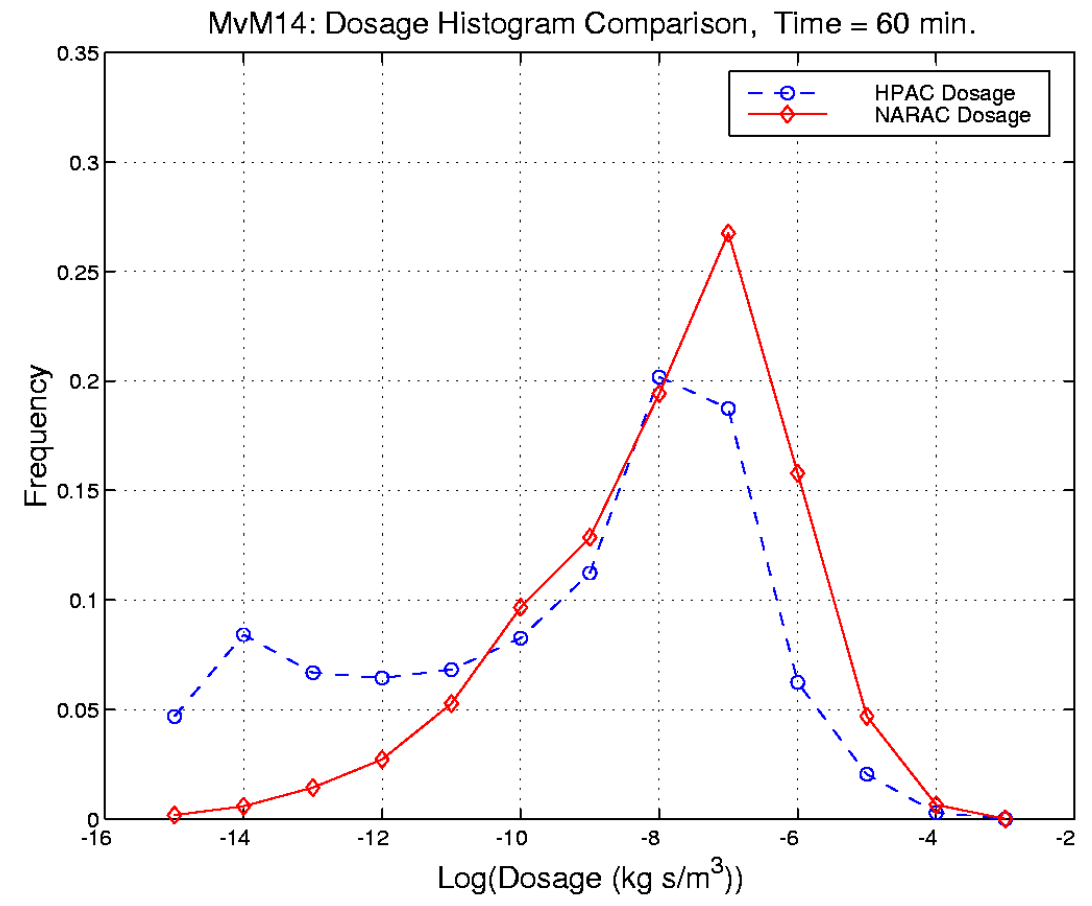

Figure D-30. MvM 14 at 60 Minutes: Dosage Histograms for HPAC (BLUE - -) and NARAC (RED -) 


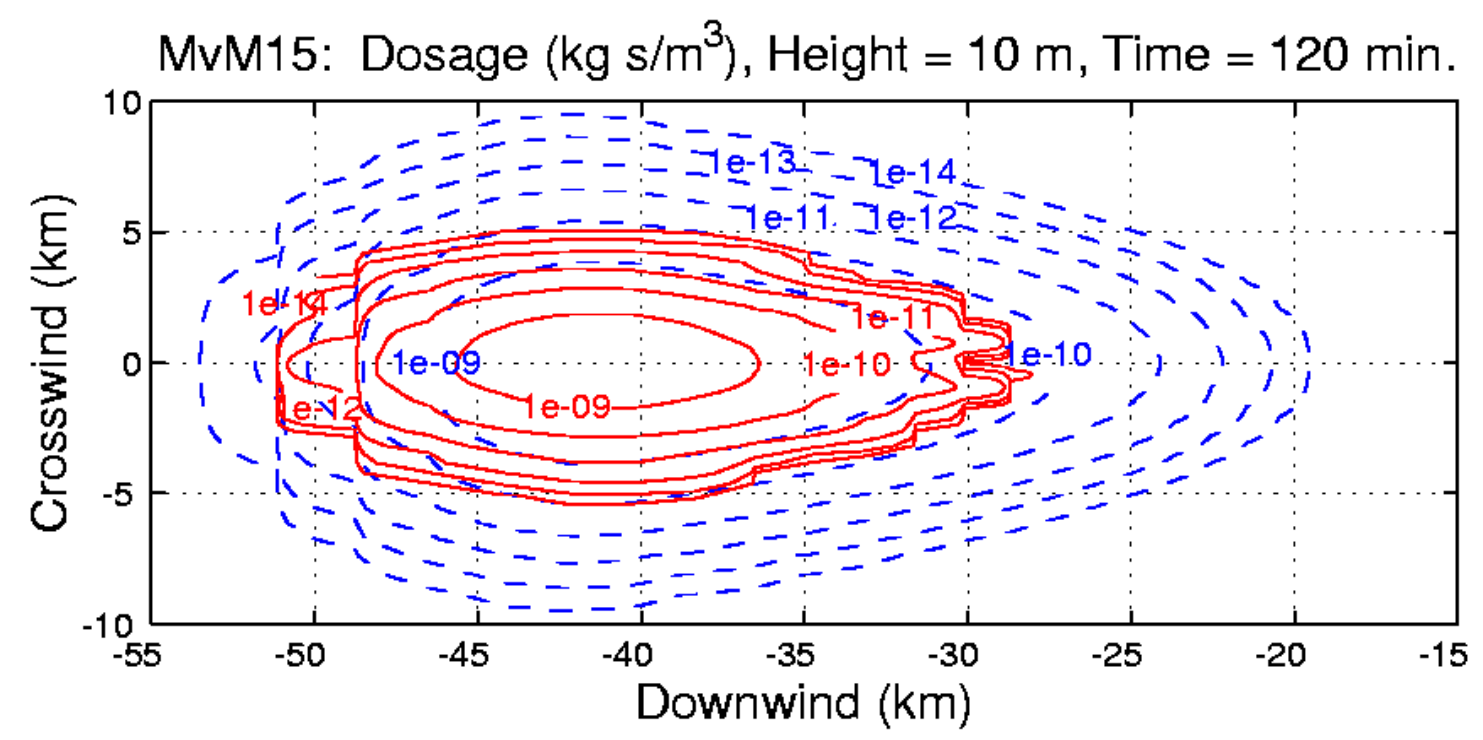

Dosage on Downwind Symmetry Axis

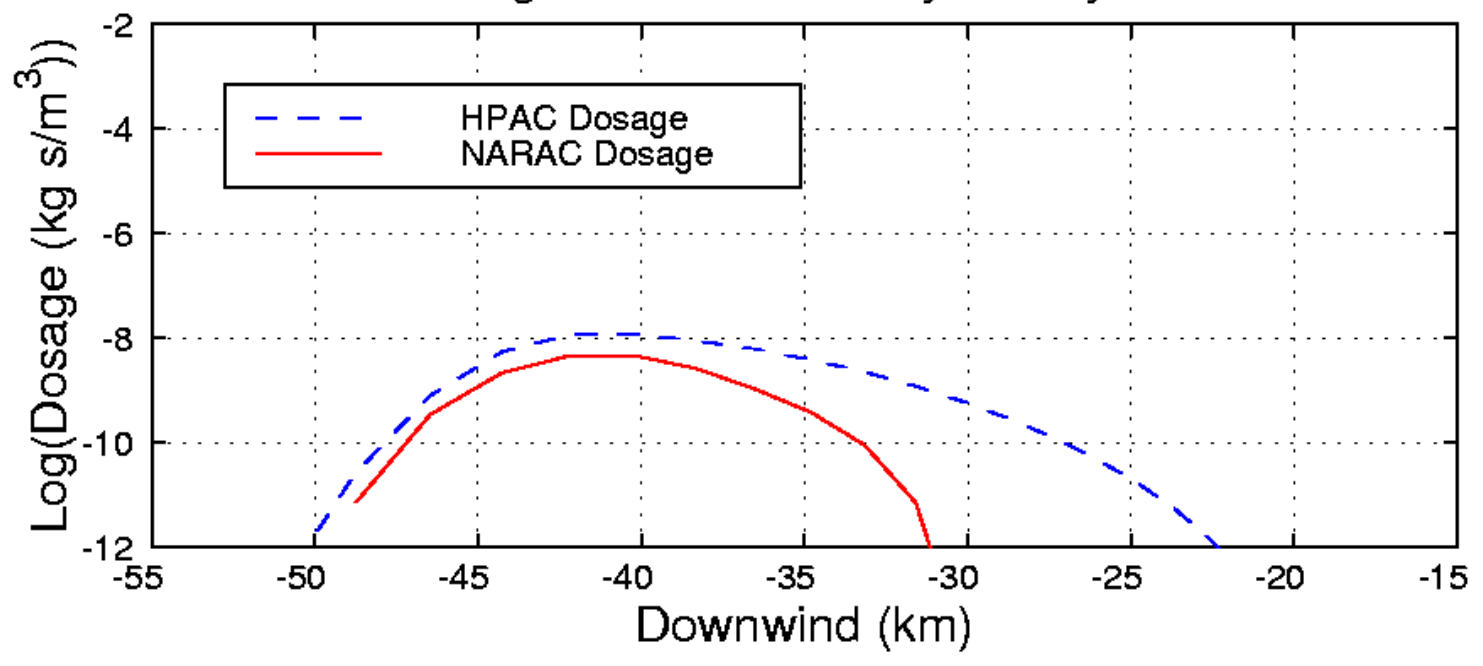

Figure D-31. MvM 15 at 120 Minutes with Upper: Dosage Contours for HPAC (BLUE - -) and NARAC (RED -); Lower: Dosage on Downwind Symmetry Axis 

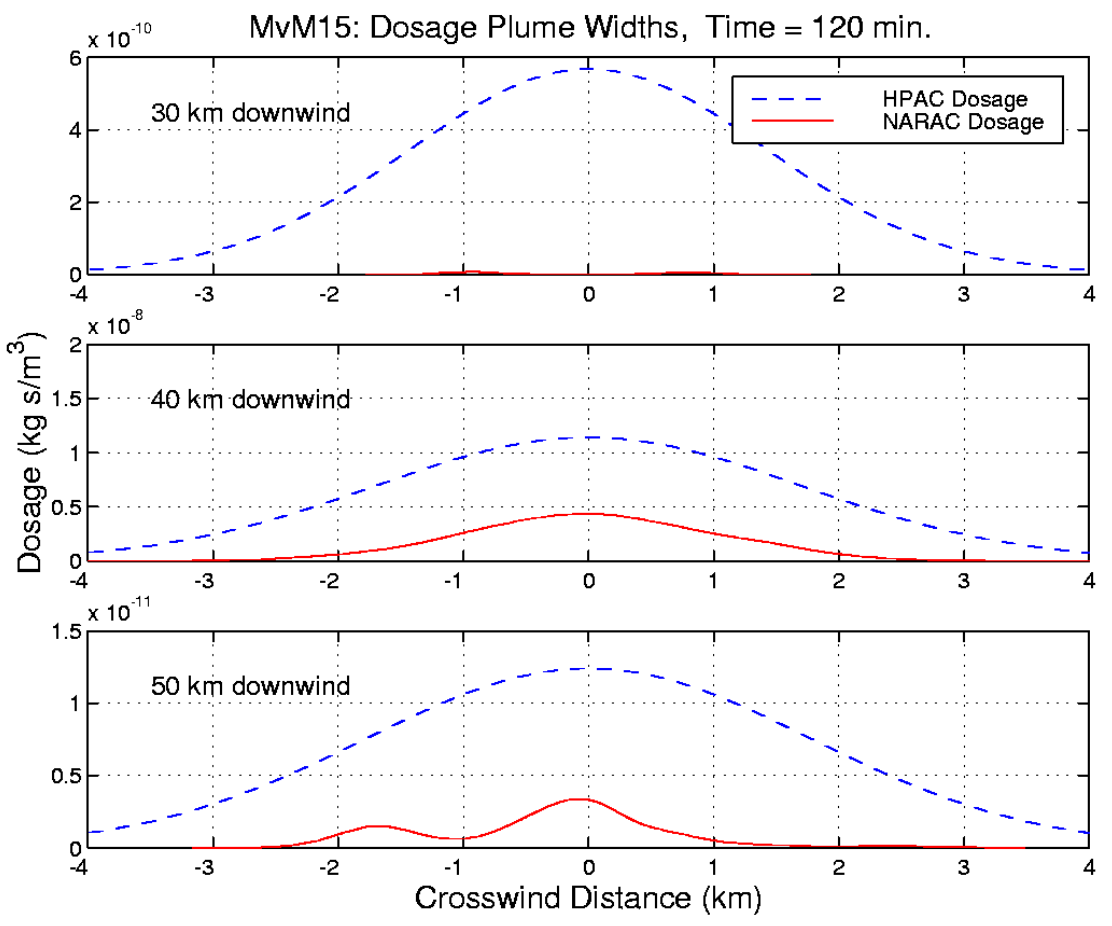

Figure D-32. MvM 15 at 120 Minutes: HPAC (BLUE - -) and NARAC (RED -) Crosswind Dosage Plumes for Various Downwind Distances

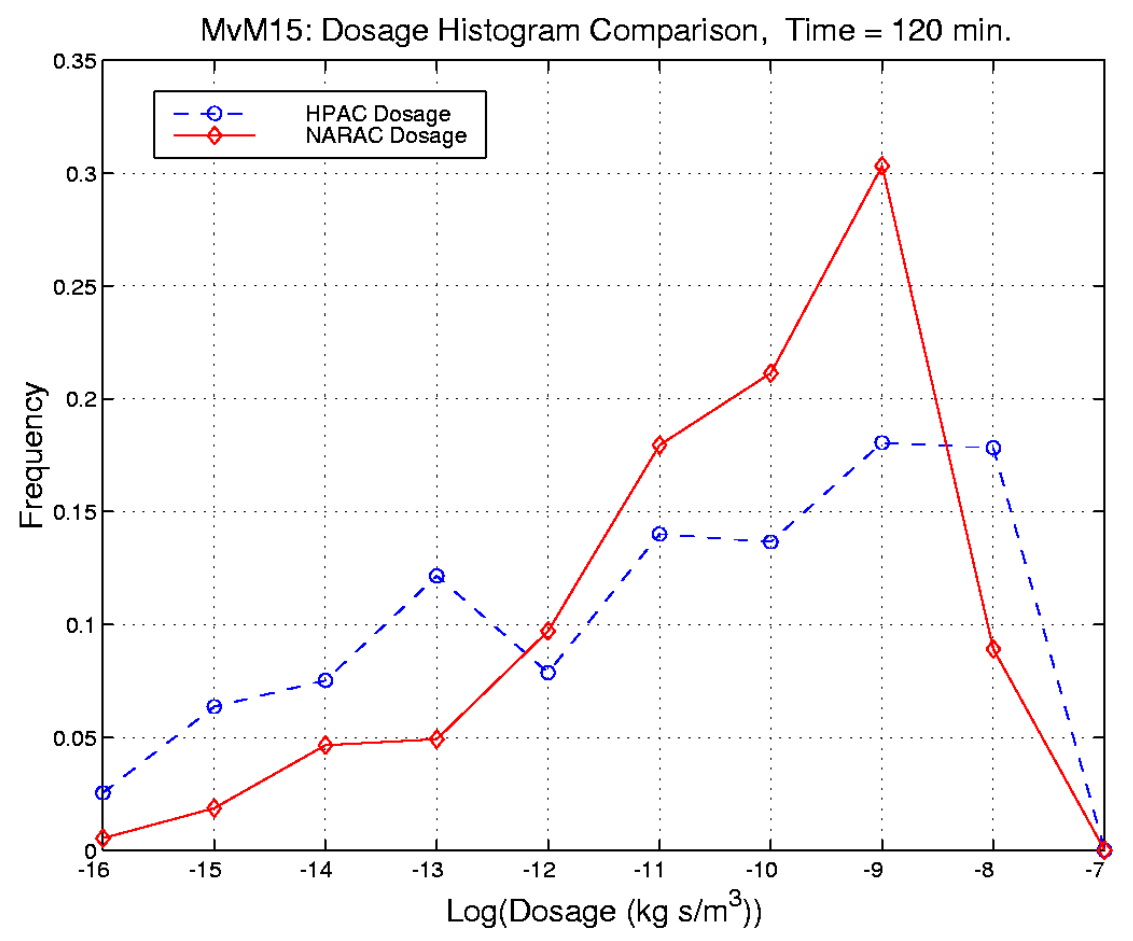

Figure D-33. MvM 15 at 120 Minutes: Dosage Histograms for HPAC (BLUE - -) and NARAC (RED -) 
MvM15: Dosage $\left(\mathrm{kg} \mathrm{s}^{\mathrm{m}} \mathrm{m}^{3}\right)$, Height $=10 \mathrm{~m}$, Time $=180 \mathrm{~min}$.

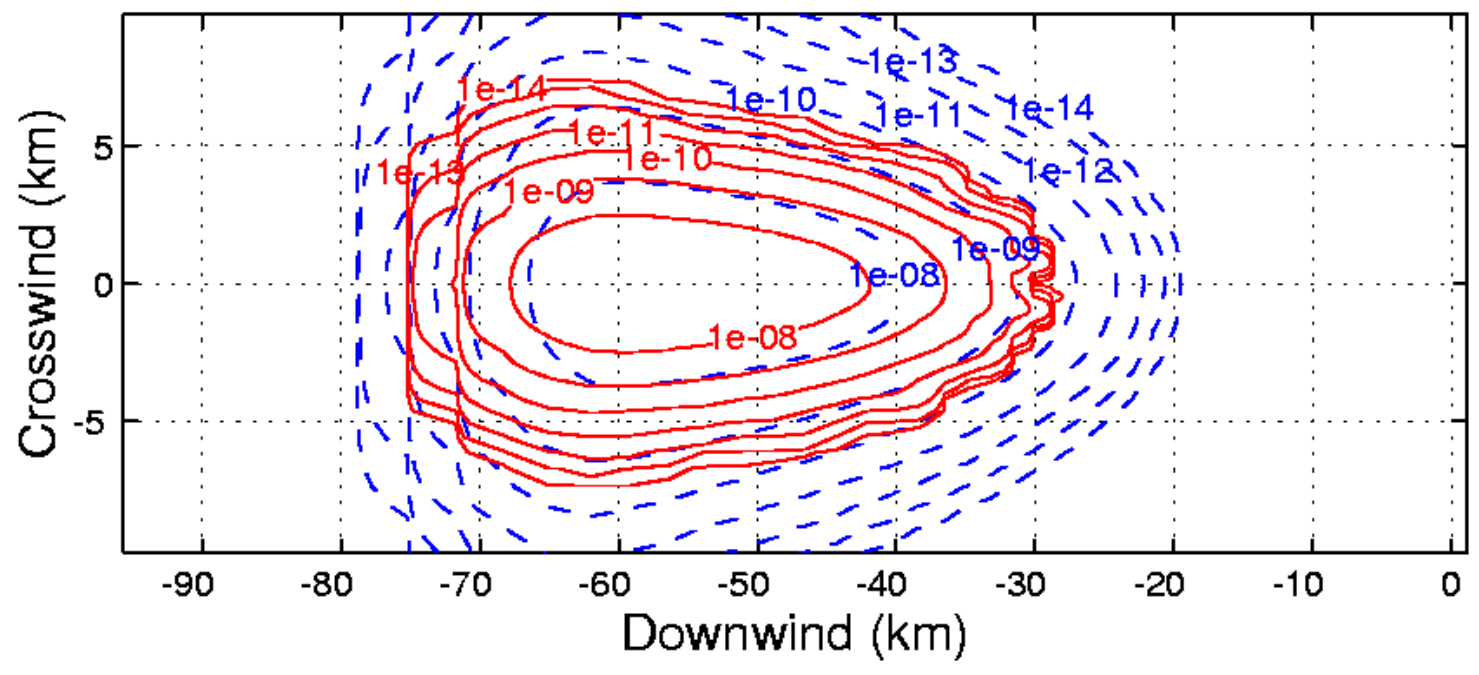

Dosage on Downwind Symmetry Axis

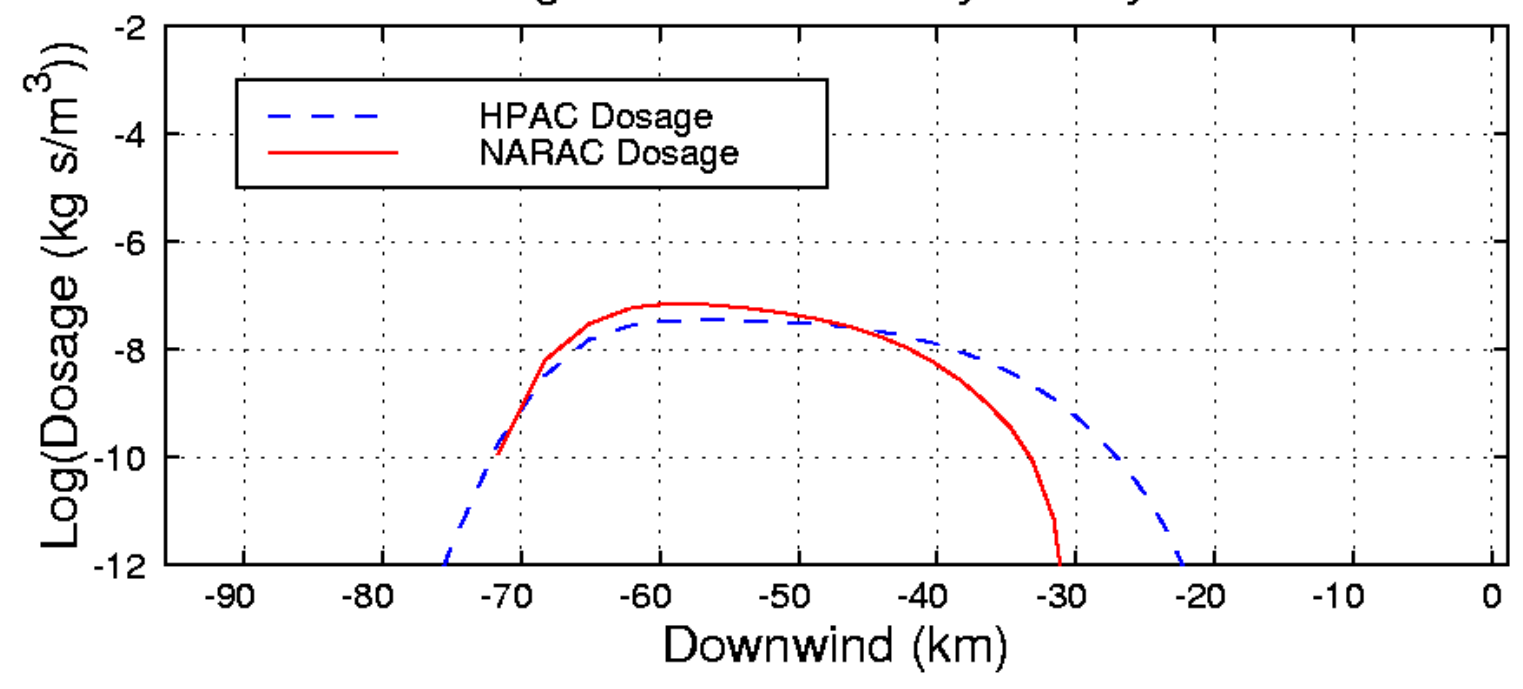

Figure D-34. MvM 15 at 180 Minutes with Upper: Dosage Contours for HPAC (BLUE - -) and NARAC (RED -); Lower: Dosage on Downwind Symmetry Axis 

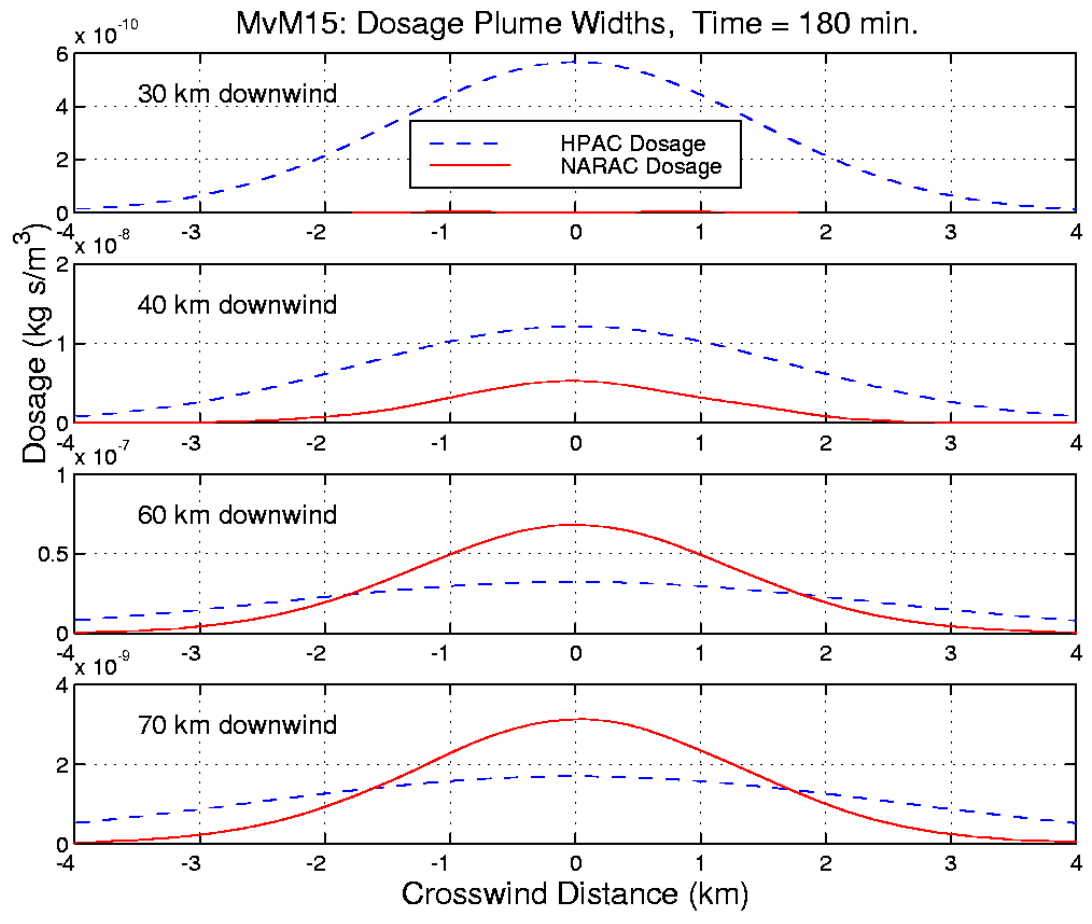

Figure D-35. MvM 15 at 180 Minutes: HPAC (BLUE - -) and NARAC (RED -) Crosswind Dosage Plumes for Various Downwind Distances

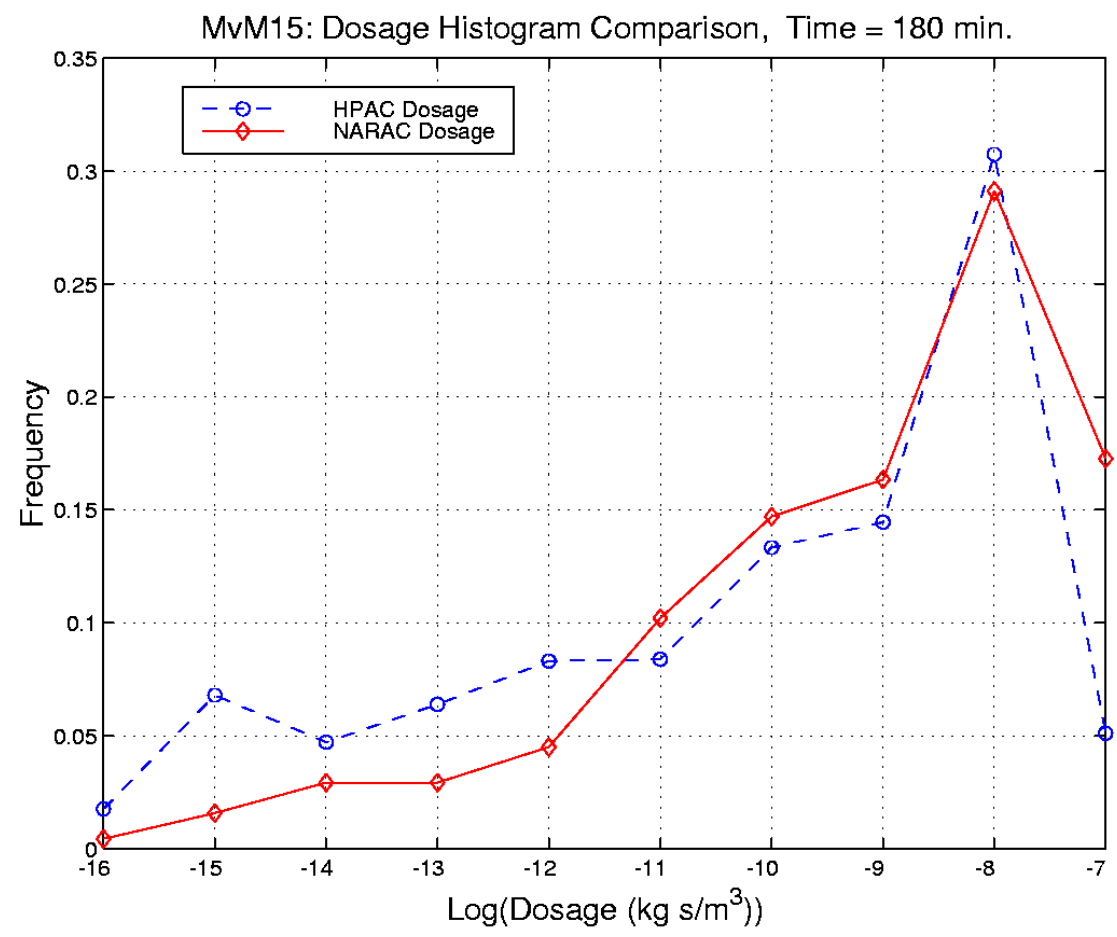

Figure D-36. MvM 15 at 180 Minutes: Dosage Histograms for HPAC (BLUE - -) and NARAC (RED -) 

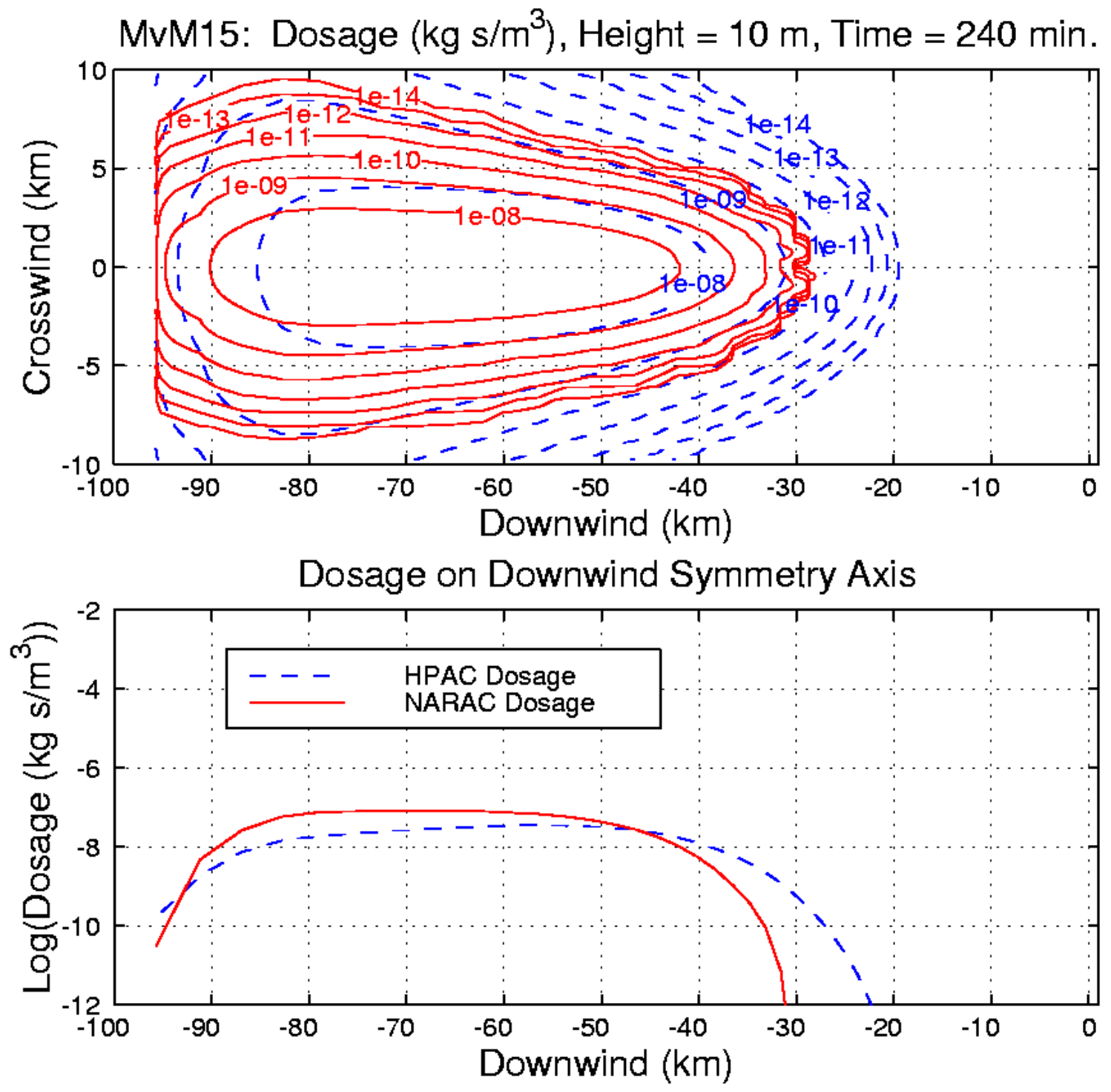

Figure D-37. MvM 15 at 240 Minutes with Upper: Dosage Contours for HPAC (BLUE - -) and NARAC (RED -); Lower: Dosage on Downwind Symmetry Axis 

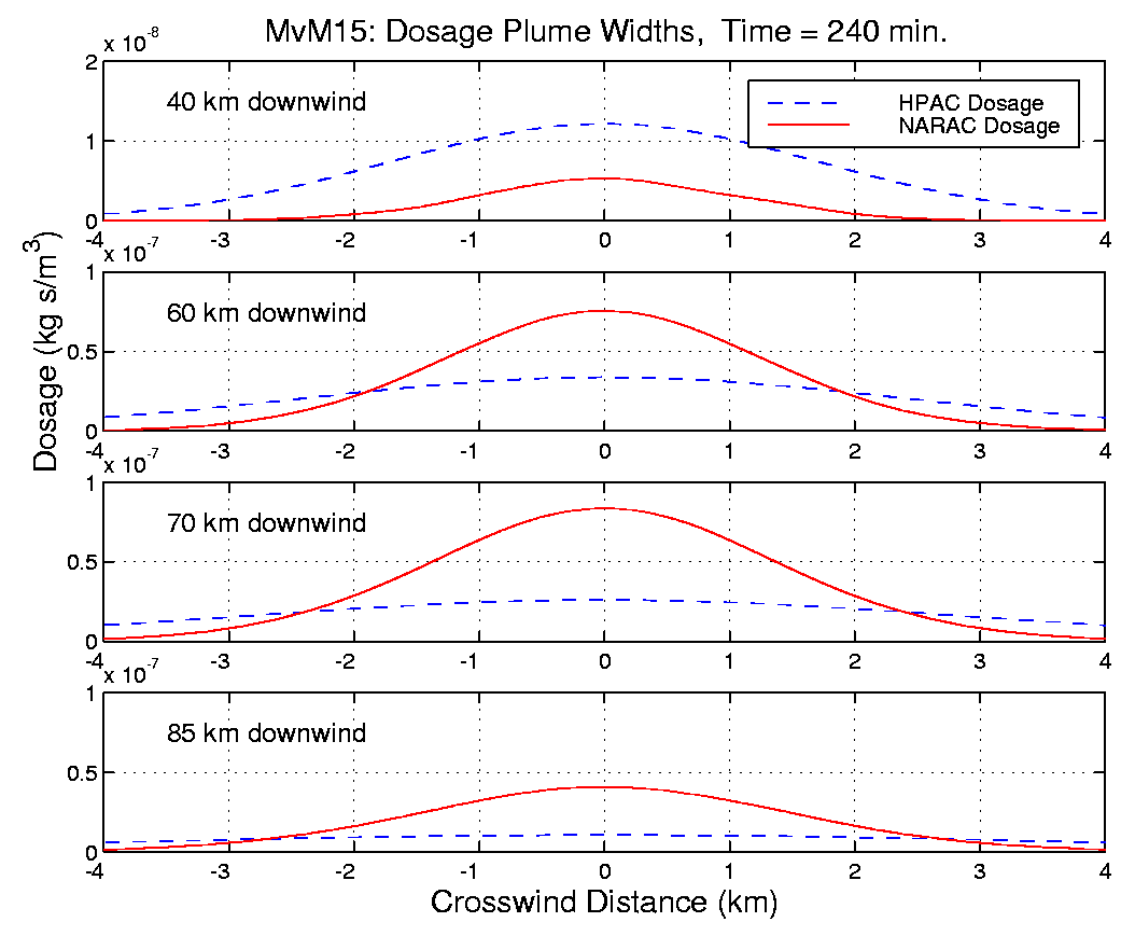

Figure D-38. MvM 15 at 240 Minutes: HPAC (BLUE - -) and NARAC (RED -) Crosswind Dosage Plumes for Various Downwind Distances

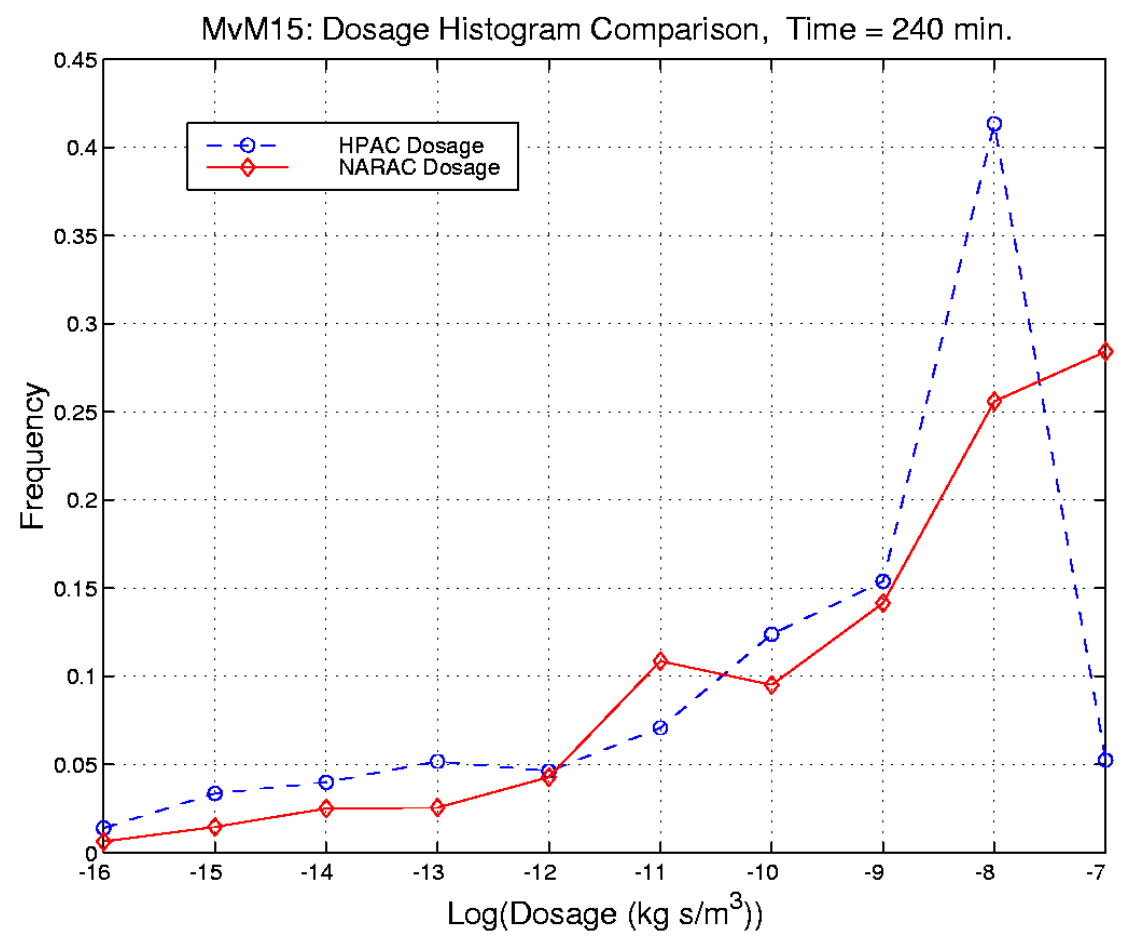

Figure D-39. MvM 15 at 240 Minutes: Dosage Histograms for HPAC (BLUE - -) and NARAC (RED -) 

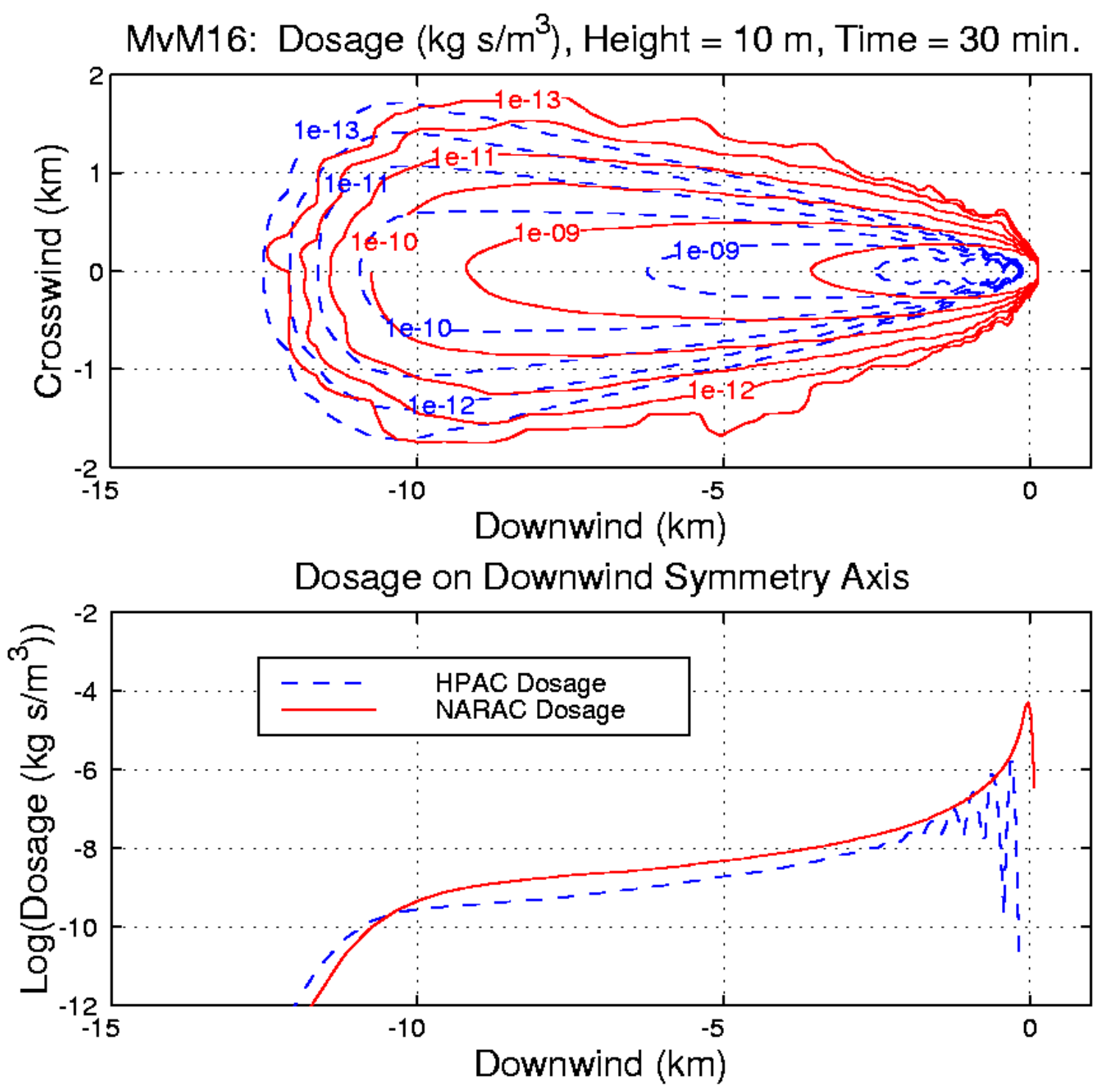

Figure D-40. MvM 16 at 30 Minutes with Upper: Dosage Contours for HPAC (BLUE - -) and NARAC (RED -); Lower: Dosage on Downwind Symmetry Axis 

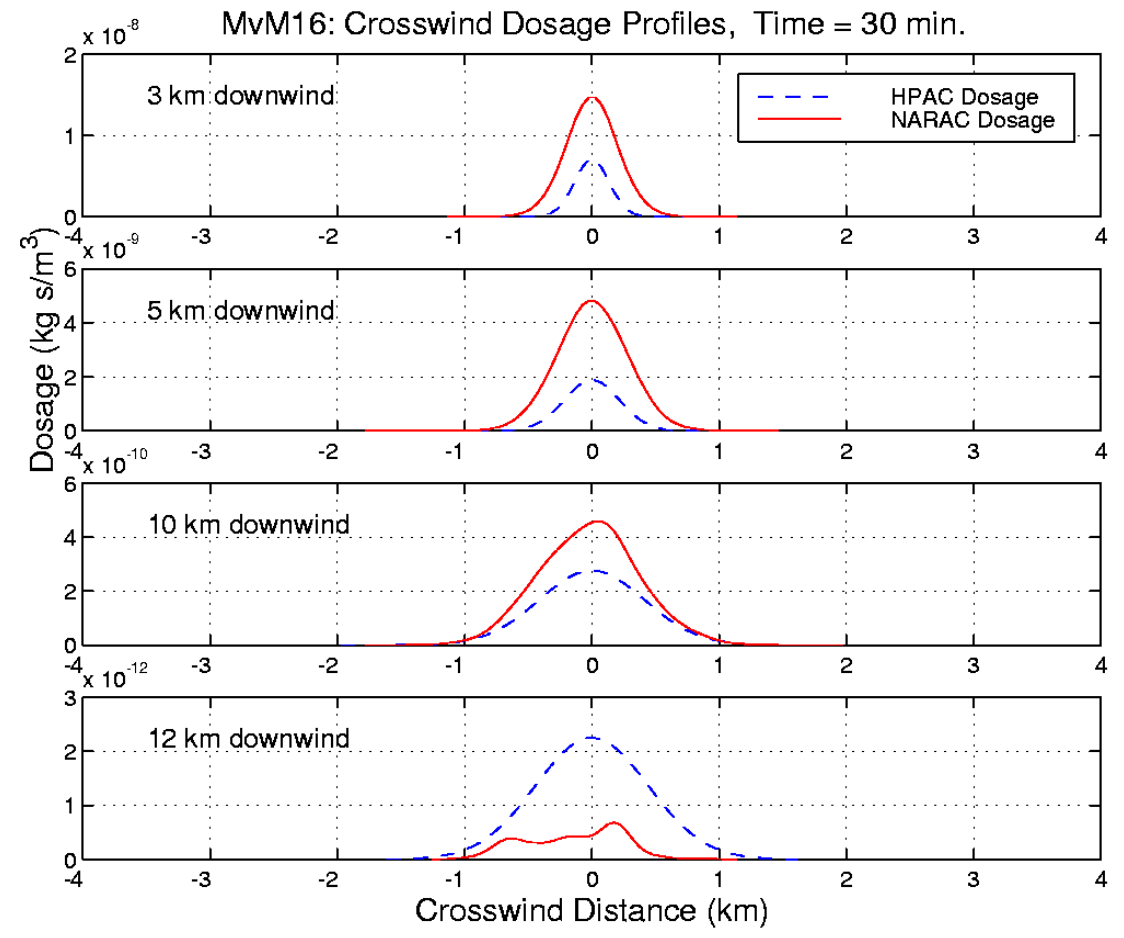

Figure D-41. MvM 16 at 30 Minutes: HPAC (BLUE - -) and NARAC (RED -) Crosswind Dosage Plumes for Various Downwind Distances

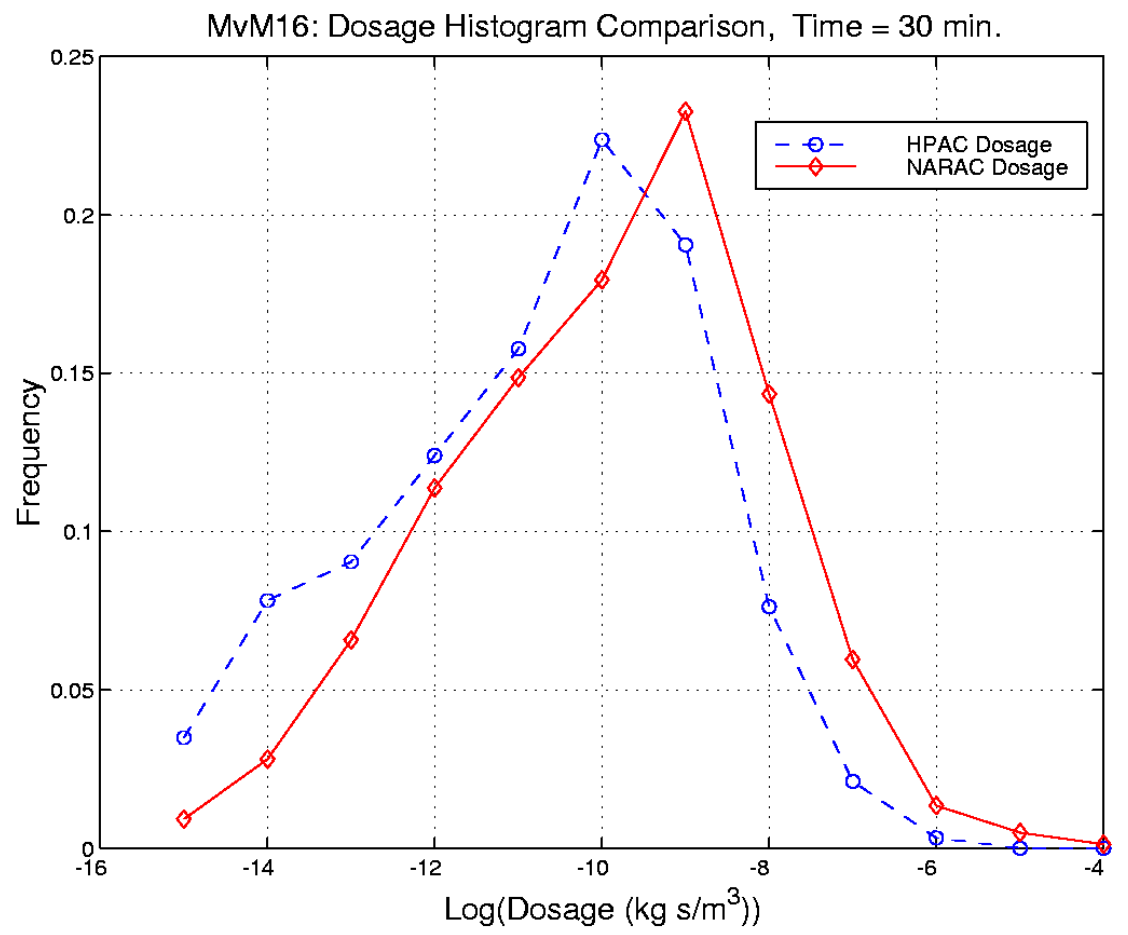

Figure D-42. MvM 16 at 30 Minutes: Dosage Histograms for HPAC (BLUE - -) and NARAC (RED -) 


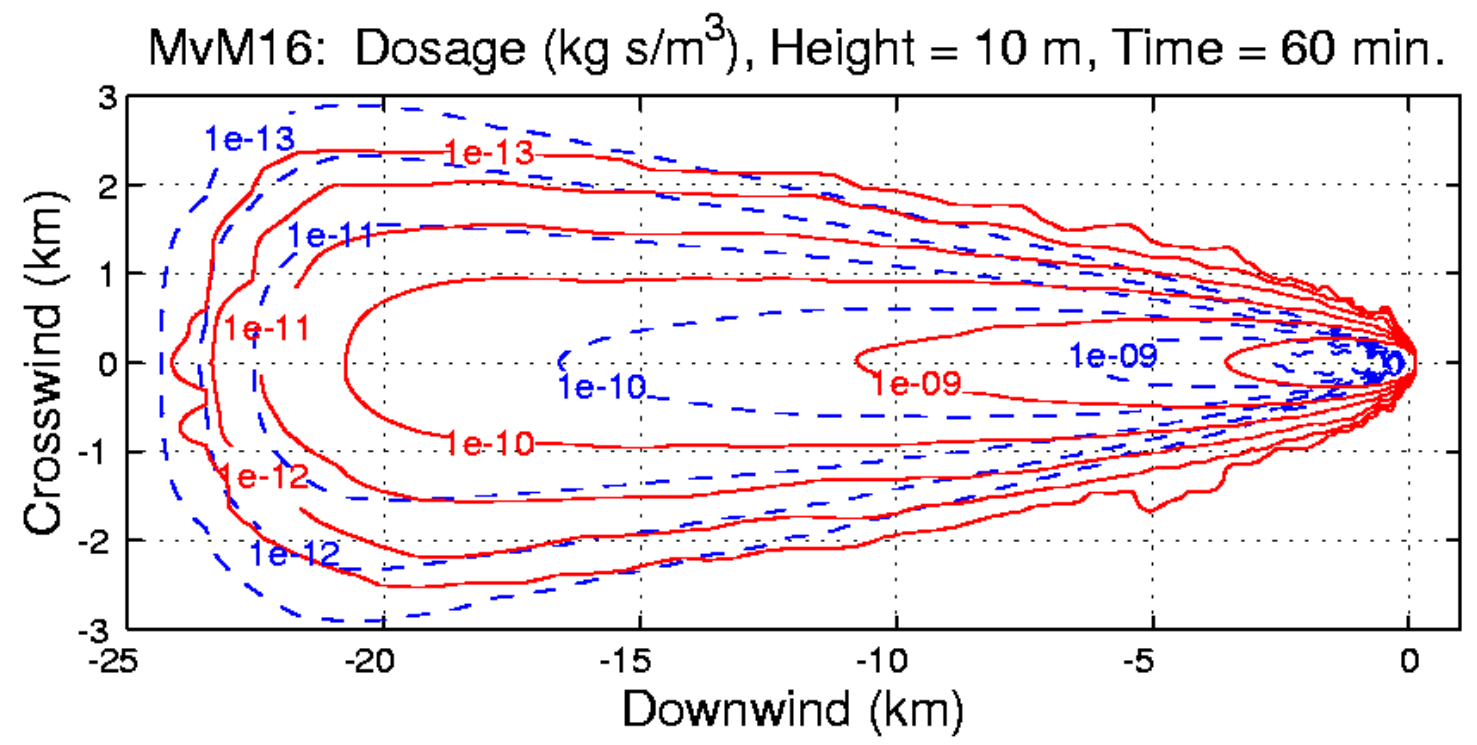

Dosage on Downwind Symmetry Axis

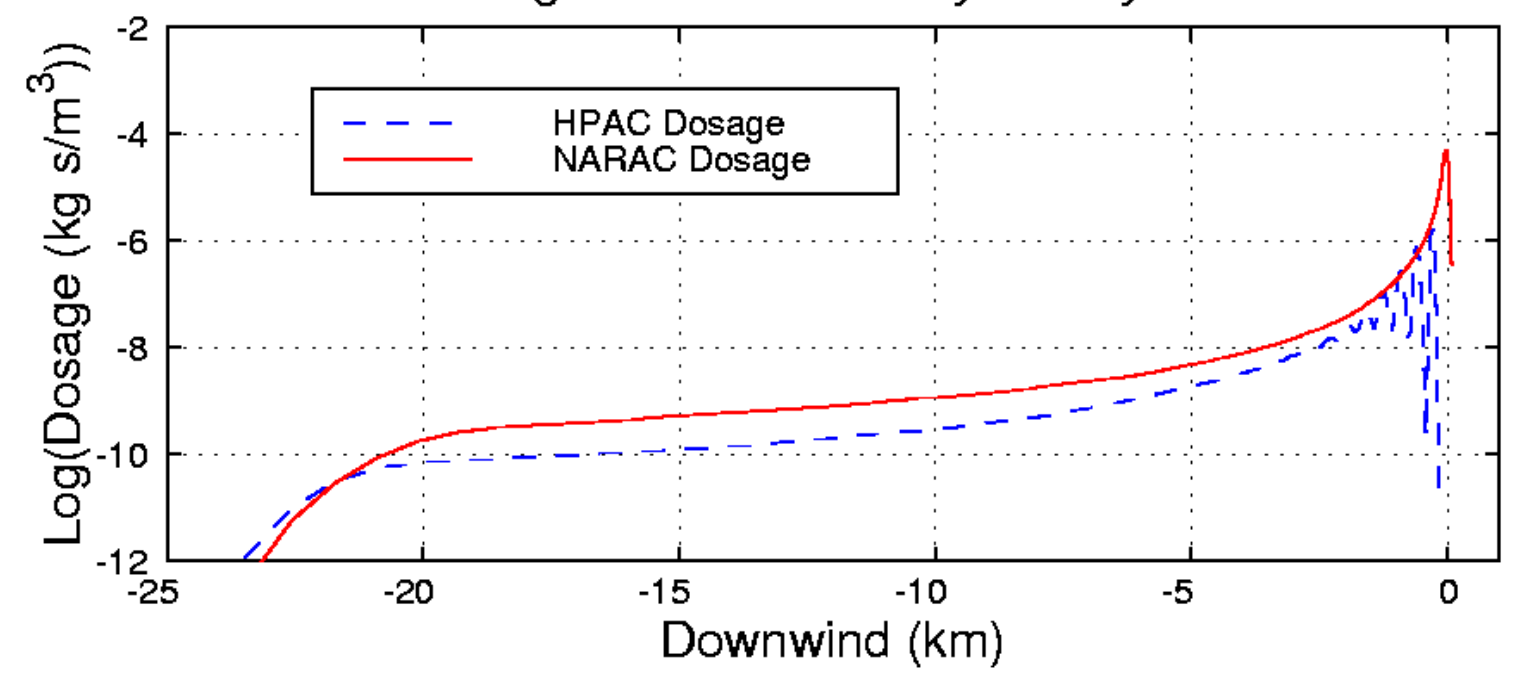

Figure D-43. MvM 16 at 60 Minutes with Upper: Dosage Contours for HPAC (BLUE - -) and NARAC (RED -); Lower: Dosage on Downwind Symmetry Axis 

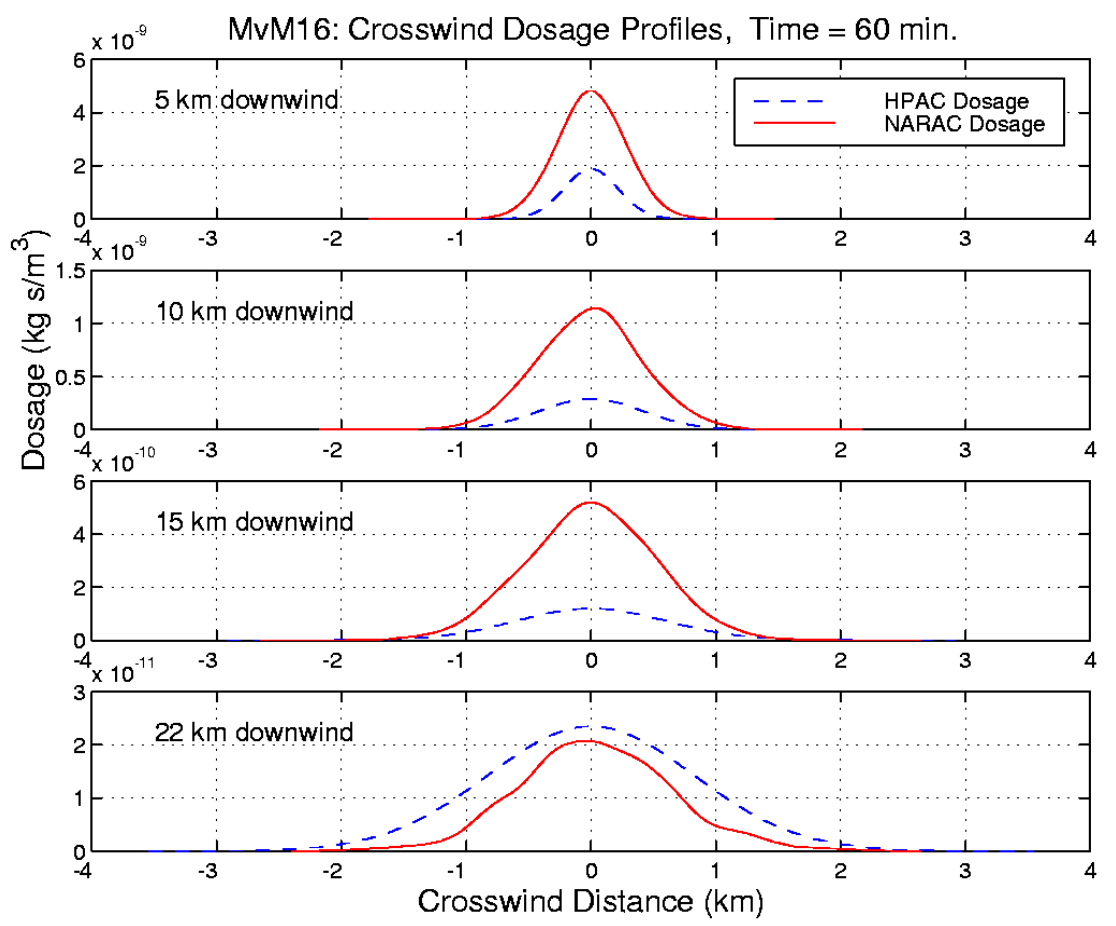

Figure D-44. MvM 16 at 60 Minutes: HPAC (BLUE - -) and NARAC (RED -) Crosswind Dosage Plumes for Various Downwind Distances

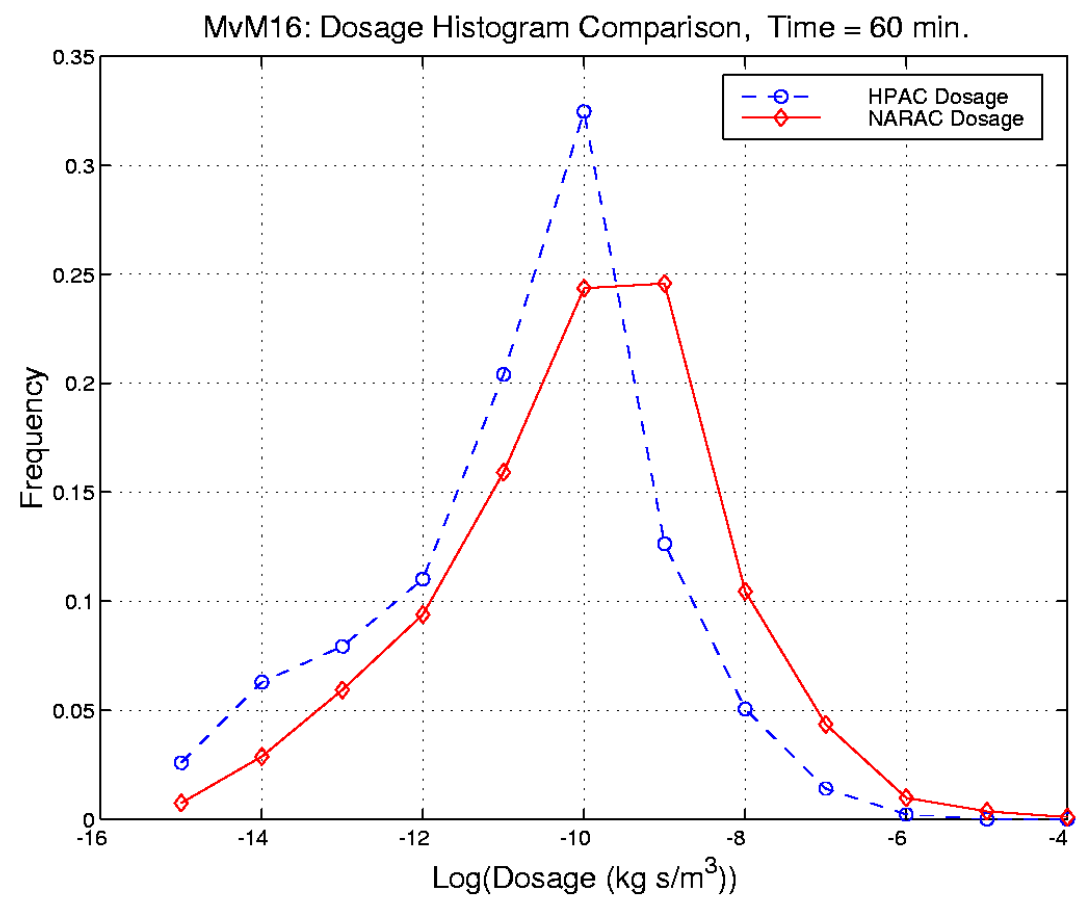

Figure D-45. MvM 16 at 60 Minutes: Dosage Histograms for HPAC (BLUE - -) and NARAC (RED -) 

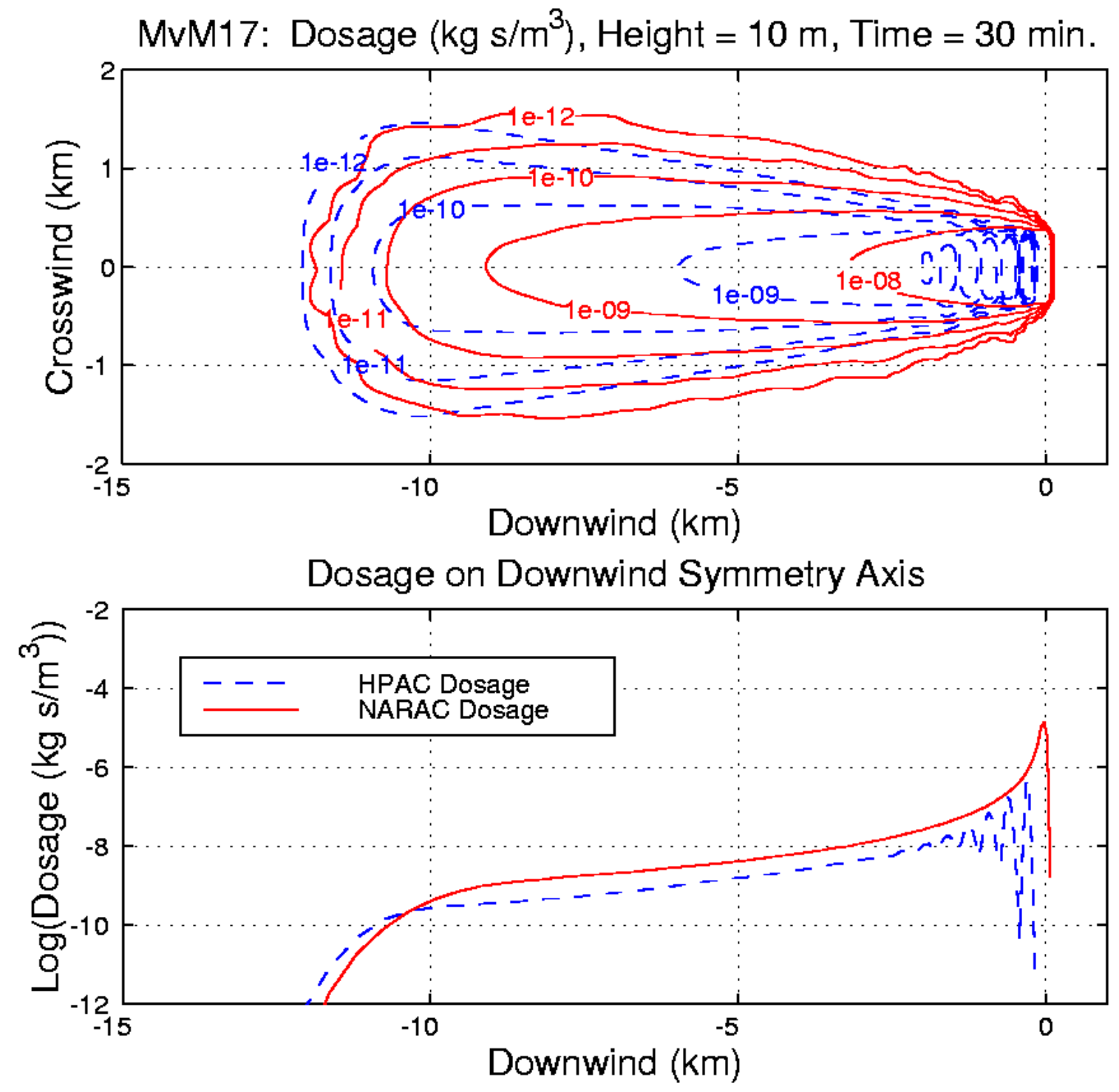

Figure D-46. MvM 17 at 30 Minutes with Upper: Dosage Contours for HPAC (BLUE - -) and NARAC (RED -); Lower: Dosage on Downwind Symmetry Axis 

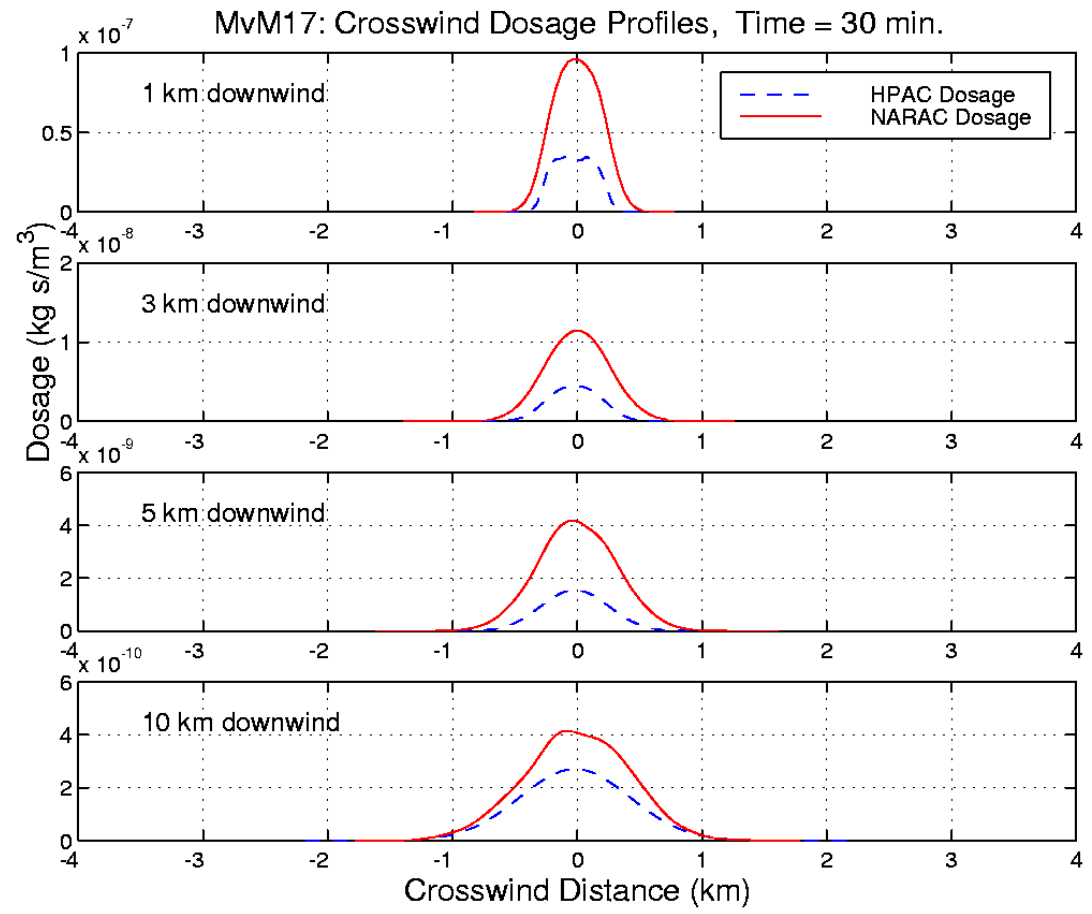

Figure D-47. MvM 17 at 30 Minutes: HPAC (BLUE - -) and NARAC (RED -) Crosswind Dosage Plumes for Various Downwind Distances

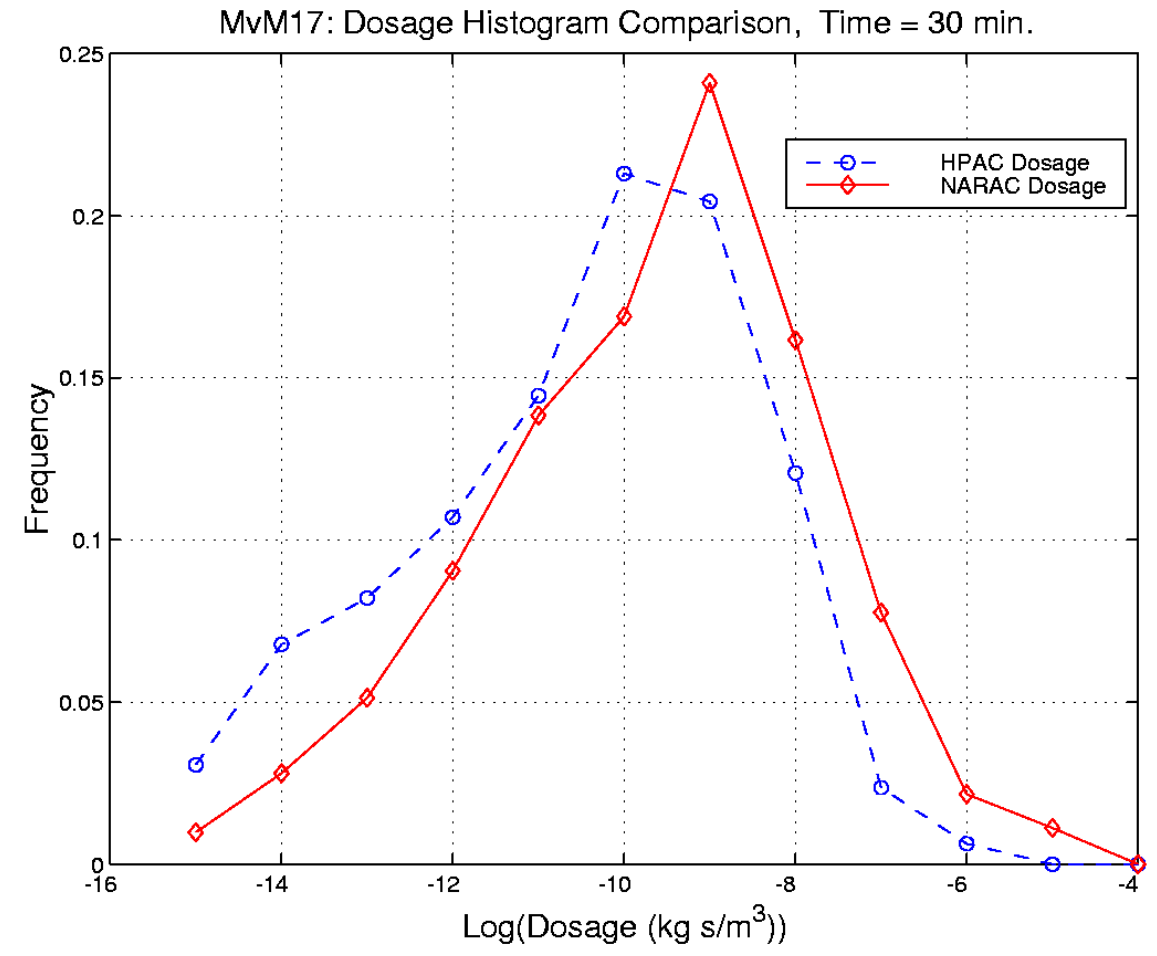

Figure D-48. MvM 17 at 30 Minutes: Dosage Histograms for HPAC (BLUE - -) and NARAC (RED -) 


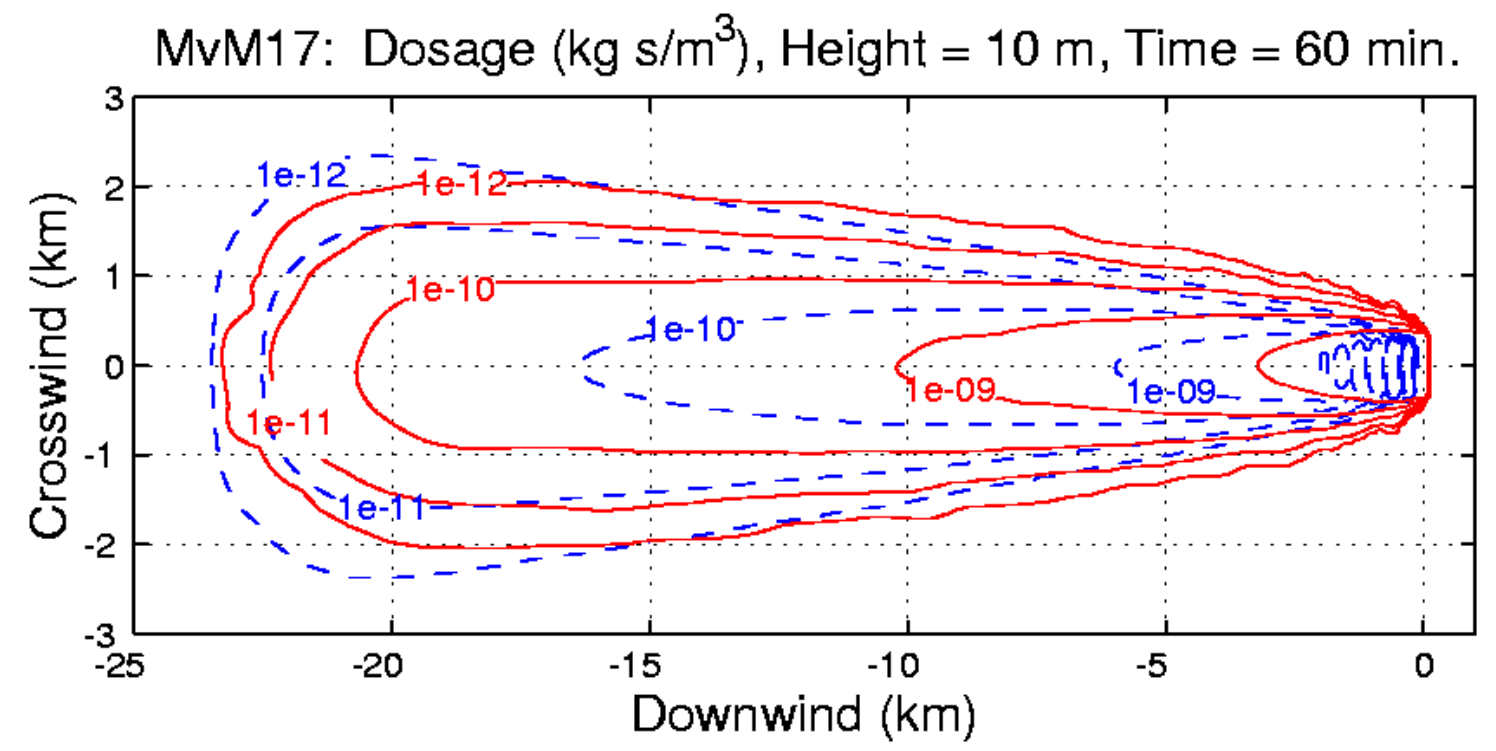

Dosage on Downwind Symmetry Axis

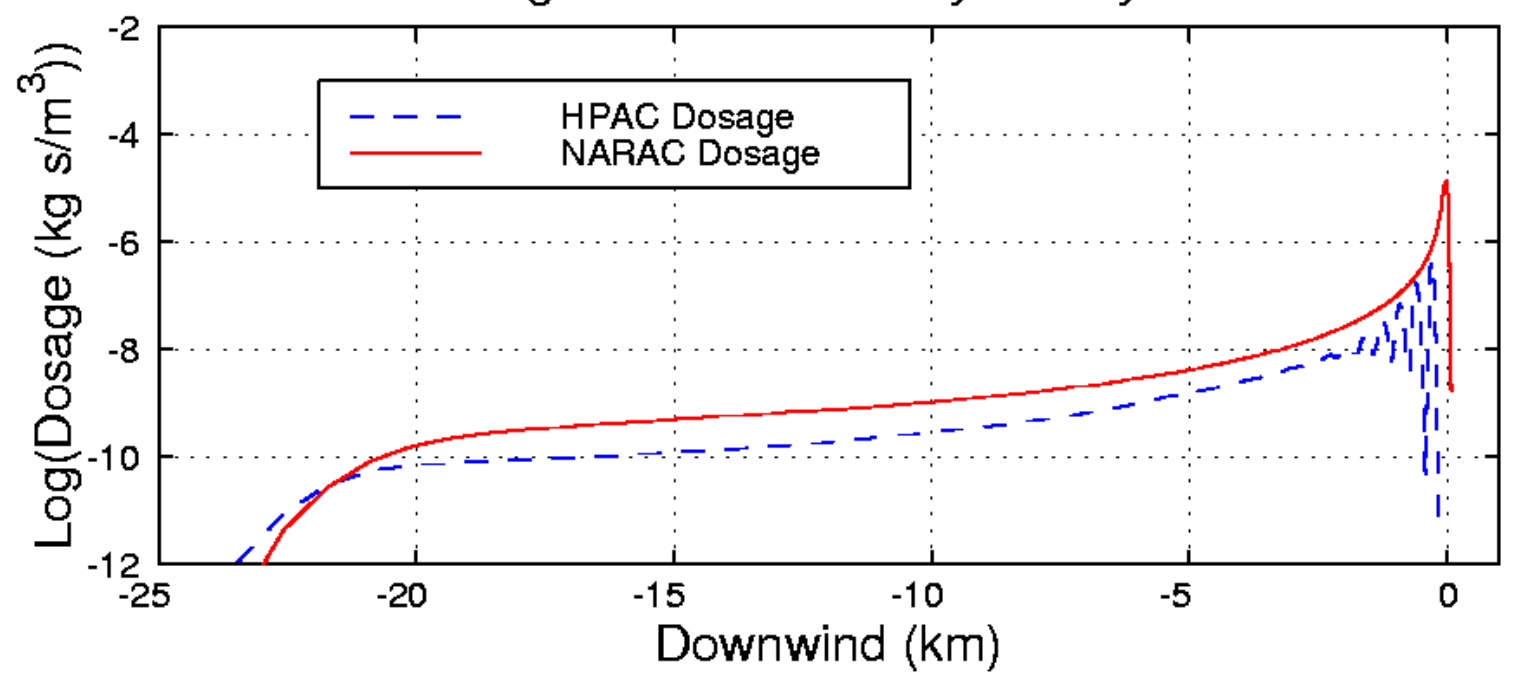

Figure D-49. MvM 17 at 60 Minutes with Upper: Dosage Contours for HPAC (BLUE - -) and NARAC (RED -); Lower: Dosage on Downwind Symmetry Axis 


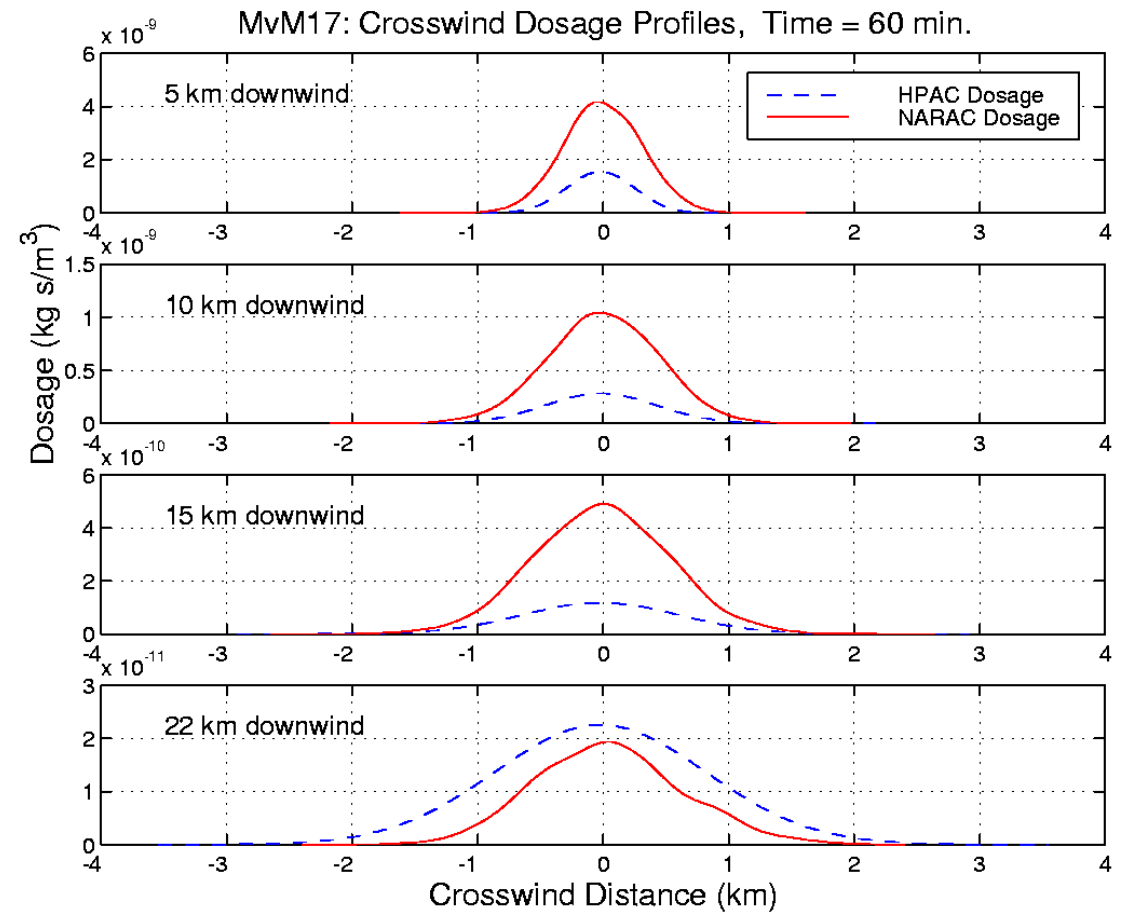

Figure D-50. MvM 17 at 60 Minutes: HPAC (BLUE - -) and NARAC (RED -) Crosswind Dosage Plumes for Various Downwind Distances

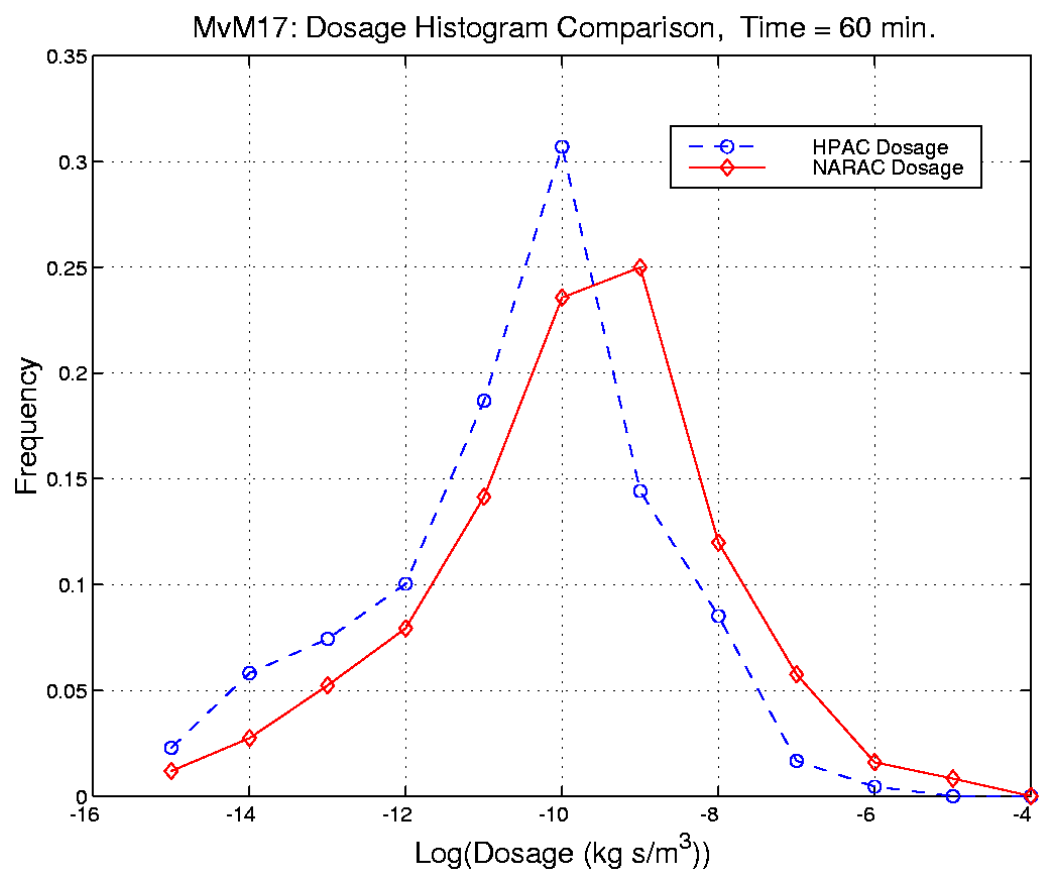

Figure D-51. MvM 17 at 60 Minutes: Dosage Histograms for HPAC (BLUE - -) and NARAC (RED -) 
APPENDIX E

TASK ORDER EXTRACT 



\section{APPENDIX E TASK ORDER EXTRACT}

DC-9-1797

TITLE: Support for DTRA and LLNL in the Validation Analysis of Hazardous Material Transport and Dispersion Prediction Models

This task order is for work to be performed by the Institute for Defense Analyses (IDA) under Contract DASW01-98-C-0067, for the Defense Threat Reduction Agency (DTRA) in the Department of Defense. This task order authorizes funding for FY 2000.

\section{BACKGROUND:}

The Hazard Prediction and Assessment Capability (HPAC) is a suite of codes that predicts the effects of hazardous material releases into the atmosphere and their impact on civilian and military populations. The software can use integrated source terms, highresolution weather forecasts, and particulate transport models to predict hazard areas produced by battlefield or terrorist use of weapons of mass destruction (WMD), by conventional counterforce attacks against WMD facilities, or by military and industrial accidents. HPAC is a forward deployable, counterproliferation and counterforce capability software tool available for government, government-related, or academic use. This tool assists warfighters in selecting weapon mixes for targets containing WMD and in emergency response to hazardous agent release. HPAC's relatively fast-running, physics-based algorithms enable users to model and predict hazard areas and human collateral effects in minutes.

The DTRA Verification and Validation (V\&V) Program represents ongoing activities performed in parallel with development of all predictive codes in support of HPAC. One element of V\&V is to perform code-on-code comparisons. In this strategy, each code receives the same input. In this manner, differences in the output predictions can lead to the identification of software bugs, or help to assess technical strengths and weaknesses of component algorithms within each code. In addition, a certain amount of credibility for both models is achieved when their predictions agree. When the inputs are simple, such as for fixed winds and simple 
terrain, the predictions tend to be dominated by the dispersion algorithms. Comparisons at this level of complexity are important to establish fundamental dispersion algorithm veracity, and to help discover software bugs. As more complex terrain and weather is included as input, the number of physical processes responsible for transport and dispersion increases and the predictions become the result of many interdependent algorithm calculations.

Code-on-code comparisons will be performed using the DTRA code HPAC, the Lawrence Livermore National Laboratory (LLNL) code Atmospheric Release Advisory Capability (ARAC), and, possibly, Sandia-developed codes. These codes represent major national investments in transport and dispersion modeling within their respective applications. The comparisons will provide information from which to validate the HPAC and ARAC models (and perhaps others), as well as provide an opportunity to advance both technologies. The code comparisons will include short, medium, and long-range transport distances. Complex terrain and weather will also be included.

It is very difficult to separate meteorological uncertainty from the transport and dispersion model accuracy when comparing predictions to field-trial validation quality or real-world data. The validation challenge is to assess whether a model performs well over different field trials, and ultimately reflects real-world phenomena. Some codes perform better under certain conditions and specific scenarios. Hazard prediction models are generally developed for a range of user communities and applications. Each user community has a different set of requirements. Thus, the corresponding hazard models tend to be optimized for specific applications. The process of accrediting a model is always couched in terms of the end-user requirements.

Various figures-of-merit (FOM) are used to express model performance relative to observed data. Most FOMs tend to use manifestations of a ratio (geometric or arithmetic) between the predicted and measured quantities. The compared quantities are usually peak, plume-centerline, and off-axis concentration or dosage, as well as crosswind and along-wind spread and area coverage. Other FOMs may include the second-moment of the dosage and concentration values at a sampler location. All these FOMs are reasonable validation performance measures, but none of them explicitly expresses an application-oriented performance measure. A "yardstick" is needed that measures application-oriented model performance. The scale on this yardstick would clearly and directly relate to specific user's concerns and needs. The pursuit of this "accreditation" performance measure is a new initiative at DTRA. 


\section{OBJECTIVE:}

IDA will conduct independent analysis and special studies associated with verification and validation of the suite of models associated with the Hazard Assessment and Prediction Capability. IDA will support development of useroriented performance measures of effectiveness (MOE) using validation quality field trial data sets; coordinate scenario definition and arbitration for code-on-code V\&V activities; and assist DTRA and the Department of Energy in identifying the $\mathrm{V} \& \mathrm{~V}$ parameter space associated with various hazard assessment and collateral effects communities.

The objectives of verification and validation analysis and coordination are: (1) to ensure that a consistent analysis approach is used when comparing model predictions, and assist DTRA in the implementation of code-on-code analysis, comparisons, and interpretation; and (2) to define measures of effectiveness in terms of user-specific objectives and applications.

The scope of this effort may be expanded to other programs as directed by DTRA.

\section{STATEMENT OF WORK:}

As required by DTRA technical representatives, IDA will perform the following tasks:

a. Support the planning, implementation, arbitration, and evaluation of code-oncode comparison activities. The purpose of these activities is to compare the transport and dispersion algorithms and corresponding output predictions between DTRA's suite of models, the DOE ARAC's suite of transport and dispersion models, and other models as called for. IDA will support code-on-code scenario definition, coordinate the identification and implementation of common performance measures, and support development of a common analysis approach. IDA will conduct independent analysis, as needed, to support the code-on-code analysis and interpretation of the results.

b. Explore validation and accreditation MOEs given a framework that includes quantification of false positive and false negative predictions. This exploration would include the computation of MOE values for various formulations based on short-range comparisons of HPAC and ARAC predictions to field trial data. A key to interpreting the results of this effort will be obtaining a sense for what are the acceptable user requirements. These requirements will differ among potential user groups (military 
targeting, passive $\mathrm{CB}$ defense, civilian first responders, military versus civilian population human effects, etc.).

\section{CORE STATEMENT:}

This research is consistent with IDA's mission in that it will support specific analytical requirements of the sponsor and will assist the sponsor with planning efforts. Accomplishment of this task order requires an organization with experience in operationally oriented issues from a joint and combined perspective, which IDA, a Federally Funded Research and Development Center, is able to provide. It draws upon IDA's core competencies in Systems Evaluations and Operational Test and Evaluation. Performance of this task order will benefit from and contribute to the long-term continuity of IDA's research program. 